\title{
TECTONICS OF THE EAST PACIFIC RISE: STUDIES OF FAULTING CHARACTERISTICS AND MAGNETIC AND GRAVITY ANOMALIES
}

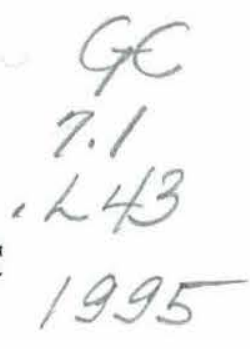

\author{
Sang-Mook Lee \\ B. S., Department of Oceanography, Seoul National University (1985) \\ Submitted in partial fulfillment of the requirements for the degree of \\ Doctor of Philosophy \\ at the \\ Massachusetts Institute of Technology \\ and the \\ Woods Hole Oceanographic Institution
}

February, 1995

(C) Sang-Mook Lee, 1995

The author hereby grants to MIT and WHOI permission to reproduce and distribute copies of this thesis document in whole or in part.

Signature of Author

U

Joint Program in Oceanography/Applied Ocean Science and Engineering Massachusetts Institute of Technology and

$\frown \frown$ Woods Hole Oceanographic Institution

Certified by

Dr. Sean C. Solomon

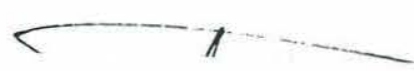

Thesis Co-Supervisor

Certified by

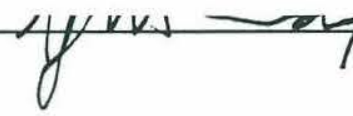

Dr. G. Michael Purdy

Thesis Co-Supervisor

Accepted by

Professor Marcia K. McNutt

Chair, Joint Committee for Marine Geology and Geophysics

Massachusetts Institute of Technology and

Woods Hole Oceanographic Institution 


\title{
TECTONICS OF THE EAST PACIFIC RISE: STUDIES OF FAULTING CHARACTERISTICS AND MAGNETIC AND GRAVITY ANOMALIES
}

\author{
by \\ Sang-Mook Lee \\ Submitted to \\ the Department of Earth, Atmospheric, and Planetary Sciences \\ Massachusetts Institute of Technology \\ and \\ the Department of Geology and Geophysics \\ Woods Hole Oceanographic Institution \\ February 1995 \\ in partial fulfillment of the requirements \\ for the degree of Doctor of Philosophy
}

\begin{abstract}
The global mid-ocean ridge system is one of the most striking geological features on the surface of the Earth. In this system, the East Pacific Rise (EPR) is the fastest spreading ridge and is thus considered as the most active magmatically among the plate boundaries. In January and February of 1988, an extensive survey by the Massachusetts Institute of Technology and the Woods Hole Oceanographic Institution was conducted along the EPR between $9^{\circ} 05^{\prime}$ and $9^{\circ} 55^{\prime} \mathrm{N}$ to study the crustal structure of the axial region.

This thesis, the result of that cruise, comprises four main topics: (1) characterization of normal faulting from Sea Beam bathymetric data, (2) application of mechanical models to explore the hypothesis that buoyancy arising from crustal magma chambers and gravitational spreading of the upper crust are the principal processes leading to the initiation and development of normal faults, (3) investigation of seafloor magnetization anomalies to constrain upper crustal structure, and (4) analysis of gravity anomalies to examine possible correlations between observed variations in seafloor manifestations of volcanism and deformation and underlying structure. Thus, each topic focuses on different levels of the mid-ocean ridge. Together with the results of seismic and other observations, the findings are woven into a better understanding of the tectonic processes and structure of fastspreading mid-ocean ridges.

First, to understand the characteristics of normal faults at fast-spreading ridges, we utilized swaths of Sea Beam bathymetry and estimated the distribution and geometry of normal fault zones using the slope of the seafloor as the criterion for a faulted surface. In
\end{abstract}


our survey area, normal fault activity begins $2-8 \mathrm{~km}$ off-axis and continues at least to $30-40$ $\mathrm{km}$ from the axis, as indicated by an increase in the total and average throws of normal fault zones versus distance from the axis. There appears to be no significant difference in the plan-view area of inward- and outward-facing normal fault zones. The distance from the rise axis to the nearest large-offset fault zone (throw $>20 \mathrm{~m}$ ) on either side of the axis is approximately symmetric to the north of $9^{\circ} 23^{\prime} \mathrm{N}$, but the midpoint between nearest largeoffset fault zones is offset $2-3 \mathrm{~km}$ to the west of the bathymetric axis to the south of $9^{\circ} 23^{\prime} \mathrm{N}$. The continued growth of normal fault zones suggests that significant extensional stress persists to greater distances from the axis than previously thought and that the rise axis possesses a finite strength. The argument that the rise axis has finite strength is consistent with recent evidence for solidified axial dikes along magmatically active portions of the EPR from near-bottom seismic refraction experiments, which suggests that, while eruption of magma at the rise axis weakens the axis, the persistence of such weak zones is short-lived and the emplacement zones at any given time are localized along the axis.

We examined how the presence of a low-density, low-strength magma chamber within the crust and gravitational spreading of a mechanically strong upper crust over an underlying substrate contribute to the formation of faults at a fast spreading mid-ocean ridge by comparing the predicted stress field with the observed pattern of normal fault zones. We employed boundary element methods to incorporate buoyancy and gravitational spreading as body forces in an elastic medium, and we determined stress and strain fields for a variety of rise axis conditions and a range of possible sets of material properties for different parts of the mid-ocean ridge.

Our results show that the strength of the rise axis is one of the most crucial factors governing the near-axis stress field. If the rise axis is mechanically weak, the maximum extensional stress from buoyancy occurs at shallow depth off the rise axis. A weak rise axis may result from recent magmatism such as the intrusion of dikes into the upper crust. On the other hand, if the rise axis is mechanically strong, which may result after solidification and cooling of the dike zone, the maximum surface extensional stress occurs on the rise axis. However, the reduction in size of a magma chamber that would accompany cessation of dike injection would lead to less buoyancy and thus a lower likelihood of stress levels sufficient for faulting. For a given set of material strengths and a given magnitude of buoyancy force, the flexural rigidity of the upper crust plays an important role in determining if a zone of extension will develop off axis and, if so, the position and horizontal extent of that zone. A thin or mechanically weak upper crust is more likely to develop a zone of extension than one that is thick or mechanically strong. The stress field resulting from gravitational spreading is similarly affected by the strength of the rise axis. While buoyancy can explain a consistent distance at which normal faults initiate off-axis, gravitational spreading can account for continued activity on normal faults to a greater distance from the axis than can buoyancy. The existence of a magma lens can play an important role in reducing the magnitude of the stress field for a weak rise axis, as the crust above the magma lens can slide and thus relieve the thickness-averaged extensional stress.

Next, we inverted surface ship measurements of the scalar magnetic field along the EPR between $9^{\circ} 10^{\prime}$ and $9^{\circ} 50^{\prime} \mathrm{N}$. We examined whether the axial magnetization high, which increases in amplitude to the south in our area, can best be explained by variations in the thickness or in the magnetization intensity of the source layer. The variation in axial 
magnetization is too large to be explained solely by the variations in the depth to the top of the axial magma chamber indicated by reflection seismology. For a magnetic source layer that is 500 or $750 \mathrm{~m}$ thick, the observed along-axis variations in $\mathrm{FeO}$ and $\mathrm{TiO}_{2}$ explain only 36 and $60 \%$, respectively, of the total variance of axial magnetization anomalies. Therefore, a combination of variations in magnetic layer thickness and in intensity of magnetization (by variations in the $\mathrm{FeO}$ and $\mathrm{TiO}_{2}$ contents of the source rock or by other mechanisms) is needed to explain the along-axis variation of axial magnetization. In addition to the increase in amplitude to the south, the axial magnetization high exhibits at least three marked changes in magnitude and offsets in its along-axis linearity ('magnetic devals') (at $9^{\circ} 25^{\prime}, 9^{\circ} 37^{\prime}$, and $9^{\circ} 45^{\prime} \mathrm{N}$ ) which appear to be related to boundaries or offsets between the segments of the axial summit caldera (ASC). Because the amplitudes of the axial magnetization anomalies are highest at the midpoints of the ASC segments, we speculate that midpoints of the ASC segments are the loci of more frequent lava eruptions, and the seafloor basalts at the midpoints are thus younger and more magnetic, than at the segment ends.

The magnetization shows distinct short-wavelength $(\sim 5 \mathrm{~km})$ banding to the north of $9^{\circ} 25^{\prime} \mathrm{N}$ over a region that does not appear to have been affected by an overlapping spreading center. Among the possible explanations for these off-axis magnetization anomalies are short geomagnetic reversal events within the Brunhes epoch, variations in the paleointensity of the Earth's field, variations in the magnetization intensity of the source rock due to variability in the magmatic supply, and variations in the degree of hydrothermal alteration at the rise axis. On the basis of comparisons of forward models and observations, short geomagnetic reversal events appear to be the most likely explanation of these anomalies.

The analysis of sea-surface gravity field measurements shows an axial residual mantle Bouguer gravity anomaly too large to be explained by the anomalous temperature of the mantle or by changes in the thickness of the crust. The broad axial residual gravity low is interpreted as a signal arising largely from the upper mantle, presumably by presence of partial melt along the rise axis. A northward increase in the width of the low implies a greater melt fraction in the region to the north than to the south, especially on the Pacific plate side. The residual gravity anomaly also shows several short-wavelength local lows along the axis (e.g., $9^{\circ} 21^{\prime}, 9^{\circ} 32^{\prime}$, and $9^{\circ} 42^{\prime} \mathrm{N}$ ) which correlate with along-axis variations in axial magnetization and tomographic images of mid-crustal seismic velocities. Along axis the local lows have an amplitude of $1.5-3 \mathrm{mGal}$ and appear at a nearly regular spacing (10$15 \mathrm{~km})$. Across the axis, however, the local lows show a greater variation (3-5 mGal), suggesting that there is an additional gravity anomaly signal arising from a low-density structure that is approximately continuous along the axis. The anomalous masses producing the local lows are interpreted as zones of relatively high melt concentration, formed within the crust by recent replenishment of magma from the upper mantle, that are surrounded by a region of lesser melt concentration corresponding to the low-velocity volume imaged by seismic tomography. If the zone of high melt concentration are modeled as circular rods of radius $1 \mathrm{~km}$, along-axis length $10 \mathrm{~km}$, and center of mass 2.25 $\mathrm{km}$ below the seafloor, density contrasts of $200-350 \mathrm{~kg} / \mathrm{m}^{3}$ are needed to match the observed anomalies. For larger anomalous mass volumes, the density contrasts would be lower. 
The findings of this study support the hypothesis that the axis of the EPR can be divided into segments $10-15 \mathrm{~km}$ in length, with each segment defined by the locus and timing of most recent emplacement of magma in the axial crust. The segments in the study area appear to be in different phases of a magmatic cycle, but the period of such a magmatic cycle is not known. By this view, the discrete emplacement of magma bodies gives rise to along-axis variations in crustal structure manifested as short-wavelength residual gravity anomalies and magnetic devals. Another consequence of a rise axis at which magma is emplaced at discrete locations is that the mechanical strength of the axial upper crust varies with position along the axis and over time. During active magmatism, the rise axis acts as a weak zone and the buoyancy of the axial magma chamber and surrounding low-velocity volume can lead to initiation of off-axis normal faulting. However, for a long segment of the rise bounded by transform faults, the axis will have sections with a solidified axial injection zone as well as sections undergoing active magmatism, and thus the rise overall may appear to have finite strength. If such a finitestrength ridge axis is subject to significant extensional stress as a result of gravitational spreading, mantle convective tractions, or differential cooling, then continued normal fault activity would extend over a broad region to distances of at least several tens of kilometers from the spreading axis.

Thesis co-supervisor: Dr. Sean C. Solomon

Department of Terrestrial Magnetism

Carnegie Institution of Washington

Washington, DC 20015-1305

Thesis co-supervisor: Dr. G. M. Purdy

Department of Geology and Geophysics

Woods Hole Oceanographic Institution

Woods Hole, MA 02543 


\section{ACKNOWLEDGEMENTS}

Many people have contributed measurably to the successful conclusion of this thesis and it is a pleasure to acknowledge them. My thesis supervisor, Professor Sean C. Solomon, now at the Carnegie Institution of Washington, has provided much of the motivation and support for this work. Our continued discussions on various topics have been very beneficial and have sharpened many issues. Most importantly, I would like to express my deep gratitude for his boundless patience during what has often seemed an endless task. I wish to thank Dr. G. Mike Purdy, my co-supervisor at the Woods Hole Oceanographic Institution and the principal investigator of the cruise to the East Pacific Rise, for his interest and guidance. I have also benefited from numerous discussions with Dr. Jian Lin and Dr. Maurice Tivey. Professors Marcia McNutt and Tom Jordan through the courses they taught during my first year as a graduate student brought me to an interest in geophysics. I also thank Dr. Brian Tucholke, Dr. Hans Schouten, Dr. Debora Smith, Dr. Peter Shaw, and Dr. Douglas Toomey. Their suggestions have improved this thesis appreciably.

I am grateful to Dr. David Aubrey and Dr. Graham Giese of the Coastal Research Center at the Woods Hole Oceanographic Institution for their support during my first two years as a graduate student studying tidal inlets at Chatham. Support through the Ocean Venture Fund by the Education Office at Woods Hole Oceanographic Institution is greatly appreciated.

My discussions with fellow students on the 5th floor have been enlightening and refreshing. I consider these to be a very important part of the "doctoral experience." I have had the pleasure of sharing ideas and problems with William Wilcock, Anne Sheehan, John Goff, Noriyuki Namiki, Pat McGovern, Mark Simon, Peter Puster, Steve Shapiro, and Jim Gaherty. I wish to thank David Krowitz and Linda Meinke for maintaining the computer system and Libby Kurten and Marie Senat for their admininstrative assistance.

None of this would have been possible but for my family. I thank my parents for their patience, encouragement and financial support. I dedicate this thesis to them. Hee-Jung, my lovely wife, has been invaluable for keeping me going on the right track. I can't express enough appreciation for her patience, dedication and understanding. Finally, I thank my daughter, Yoon-Su, and son, Won-Suk, for keeping me busy and happy during my graduate study at MIT. 
The work in this thesis was supported by the National Science Fundation under grants OCE-8615797, OCE-8615892, and OCE-9000177. 


\section{TABLE OF CONTENTS}

$\begin{array}{ll}\text { ABSTRACT } & 3\end{array}$

$\begin{array}{ll}\text { ACKNOWLEDGMENTS } & 7\end{array}$

TABLE OF CONTENTS 99

$\begin{array}{lll}\text { CHAPTER } 1 & \text { Introduction } & 13\end{array}$

$\begin{array}{ll}\text { References } & 25\end{array}$

CHAPTER 2 Constraints from Sea Beam Bathymetry on the Development of Normal Faults on the East Pacific Rise 33

Introduction $\quad 33$

Sea Beam Data $\quad 35$

$\begin{array}{ll}\text { Methods } & 38\end{array}$

Estimation of Fault-Zone Area 38

Estimation of Fault-Zone Heave and Throw 40

Effects of Mass Wasting and Sedimentation $\quad 42$

Variations in Fault Zone Characteristics 43

Discussion 46

Comparison with Other Studies $\quad 46$

Processes Controlling Initiation of Faulting 48

Along-Axis Variations $\quad 51$

Processes Controlling Continued Off-Axis Faulting 51

Conclusions $\quad 56$

References $\quad 58$

Tables $\quad 66$

$\begin{array}{ll}\text { Figures } & 68\end{array}$ 
CHAPTER 3 Mechanisms for Near-Ridge Normal Faulting at Fast-Spreading Mid-Ocean Ridges

Introduction

Model Assumptions

116

Boundary Element Models

118

Buoyancy Model

Gravitational Spreading Model

123

Special Interface Conditions

124

Model Results

126

Buoyancy Model

126

Variations in the Strength of the Rise Axis

Factors Controlling the Stress Regime

Factors Controlling the Distance to Maximum Off-Axis

Extension

Variations in the Strength of the Upper Mantle

Variations in the Axial Uplift

Effects of Adding a Sliding Interface

Gravitational Spreading Model

Strength of the Rise Axis

Variations in the Stiffness of Tangential Springs

Effect of Axial Uplift

Discussion

Buoyancy

Gravitational Spreading

Along-Axis Variations

Conclusions

References

Tables

Figures

CHAPTER 4 Crustal Magnetization Anomalies and Segmentation of the East Pacific Rise, $9^{\circ} 10^{\prime}-9^{\circ} 50^{\prime} \mathrm{N}$ 
$\begin{array}{ll}\text { Introduction } & 211\end{array}$

$\begin{array}{ll}\text { Survey Area } & 215\end{array}$

Collection of Data $\quad 217$

Reduction of Magnetic Field Data $\quad 219$

Inversion $\quad 222$

Inversion for Magnetization Intensity 223

Inversion for Magnetic Layer Thickness 226

$\begin{array}{ll}\text { Magnetization Solutions } & 227\end{array}$

$\begin{array}{ll}\text { Discussion } & 230\end{array}$

Causes of the Axial Magnetization Anomaly 230

Implications for the Characteristics of Axial Magma Bodies 234

Causes of Off-Axis Magnetization Anomalies 237

$\begin{array}{ll}\text { Conclusions } & 241\end{array}$

References 245

Tables 253

Figures 256

CHAPTER 5 Gravity Anomalies and Their Implications for the Lithospheric Structure of the East Pacific Rise 297

$\begin{array}{ll}\text { Introduction } & 297\end{array}$

Collection of Data $\quad 300$

Renavigation $\quad 302$

Reduction of Free-Air Gravity Anomalies 304

Free-Air Gravity Anomaly 304

Crustal Model 305

Gravitational Attraction from Crustal Layers 306

Mantle Bouguer Gravity Anomaly 307

Anomaly due to Lithospheric Cooling 308

Residual Gravity Anomalies $\quad 310$

Variations in Crustal Thickness 311

Comparisons with Simple Geometric Bodies 312

$\begin{array}{ll}\text { Discussion } & 315\end{array}$ 
A New Model of the EPR, $9^{\circ} 10^{\prime}-9^{\circ} 50^{\prime} \mathrm{N} \quad 322$

Conclusions $\quad 324$

References $\quad 326$

Tables $\quad 332$

$\begin{array}{ll}\text { Figures } & 334\end{array}$

$\begin{array}{lll}\text { CHAPTER } 6 & \text { Conclusions } & 373\end{array}$

Review of Primary Results 373

Discrete Emplacement Model $\quad 380$

Fault Development Model $\quad 382$

Future Work 385

References $\quad 387$

$\begin{array}{ll}\text { Figures } & 390\end{array}$

APPENDIX A Overview of Numerical Methods 397

APPENDIX B Boundary Element Formulation for Potential Field Problems 423

APPENDIX C Boundary Element Formulation for Elastostatic Problems 457

APPENDIX D Comparison Between Subregion and Spring Models of the Axial Dike Region $\quad 477$

APPENDIX E A Method for Improving Navigation Based on Sea Beam and Free-Air Gravity Anomaly at Crossovers 485

$\begin{array}{ll}\text { APPENDIX F Derivation of Matrices in Appendix E } & 509\end{array}$ 


\section{Chapter 1}

\section{Introduction}

In the theory of plate tectonics, the mid-ocean ridge is the site of creation of oceanic lithosphere by the processes of mantle upwelling, decompressional melting, magma ascent, and crustal formation. Oceanic crust created at mid-ocean ridges covers twothirds of the Earth's surface, and the heat released by the generation and cooling of oceanic lithosphere accounts for two-thirds of the total heat loss from the Earth's interior. Mid-ocean ridges regulate ocean chemistry through volcanic eruptions and hydrothermal circulation and supply the energy and nutrients which support unique deep-sea biological communities. Mid-ocean ridges are also tectonically active regions. The tectonic deformation that occurs near the ridge axes not only shapes mid-ocean ridges but also affects the morphology and relief of the seafloor as it is rafted away from the spreading axis. Abyssal hills, the most common landform on the surface of the Earth, are believed to develop from near-ridge faulting.

Despite the fundamental importance of mid-ocean ridges and the processes of oceanic lithosphere accretion to the geological evolution of the Earth's lithosphere, we lack detailed knowledge of their dynamics and structure. This is largely because mid-ocean ridges constitute a complex system which requires for its understanding information not only on the processes that operate at different depths in the Earth's interior but also on the interactions among these processes. A multidisciplinary approach is often beneficial to 
insight into any geological structure or process because, although each type of observation may be limited by spatial or temporal resolution or by inherent nonuniqueness, together these observations can provide important constraints on the detailed nature of and important processes at ridge axes.

In recent years, working models of mid-ocean ridges have evolved from twodimensional, steady-state idealizations to more complex, three-dimensional and timedependent representations. At fast-spreading ridges such as the East Pacific Rise (EPR), documentation of variations in the axial depth and cross-sectional area of the ridge [Macdonald et al., 1984; Macdonald and Fox, 1988; Scheirer and Macdonald, 1993], several scales of morphological discontinuities along-strike [Macdonald and Fox, 1983; Langmuir et al., 1986; Batiza and Margolis, 1986; Macdonald et al., 1988] and their relation to along-axis variations in the chemistry of dredged rock samples [Langmuir et al., 1986; Klein and Langmuir, 1987; Sinton et al., 1991; Reynolds et al., 1992], and the distribution of active hydrothermal vents [Haymon et al., 1991] and its relation to variations in the depth to an axial magma body along axis [Detrick et al., 1987; Harding et al., 1993] have led us to view ridges as composed of individual segments probably at different stages within a complex cycle of magmatic and tectonic activity. Although this concept of a variation of axial magmatism and deformation with time and along axis provides a powerful viewpoint for interpreting upper lithospheric phenomena, some of the fundamental aspects of the governing processes remain to be resolved. For example, it is unclear what mechanisms trigger distinct stages of a cycle or determine the cycle repeat time, and to what extent different stages of the magmatic-tectonic cycle affect the structure of the spreading axis or the properties of the lithosphere generated at each stage. With the exception of several seismic constraints [e.g., Detrick et al., 1987; Toomey et al., 1990; Harding et al., 1993; Kent et al., 1993a, b; Christeson et al., 1992; 1994a, b], most of the evidence for axial variability comes from observations of the seafloor and shallow crustal features and their interpretation in terms of volcanic, magmatic and 
hydrothermal processes. It is thus important to examine whether these interpretations of geological observations are consistent with geophysical constraints on structure and associated processes at greater depth.

Unfortunately, few direct observations have been made of the deep characteristics of mid-ocean ridges. According to models of the thermal structure and mantle flow beneath mid-ocean ridges, mantle upwelling leads to a region of melt production as much as 50 to $100 \mathrm{~km}$ in half width [Su and Buck, 1993; and references therein]. However, detailed near-bottom observations suggest that most of the magmatism and hydrothermal processes are centered within a narrow zone, the neovolcanic zone, of half width normally 1-2 km or less [Lonsdale, 1977; CYAMEX, 1981; Choukroune et al., 1984; Macdonald, 1982, 1983; Macdonald and Luyendyk, 1985; Bicknell et al., 1987]. One interpretation of this difference, by two orders of magnitudes, between the width of the zone of melt generation and the neovolcanic zone, is that the melt that accumulates within the melt production zone forms a gravitationally unstable layer beneath a depleted mantle and rises in the form of plumes to a level near the surface [Whitehead et al., 1984; Crane, 1985; Schouten et al., 1985]. Under this interpretation the observed variability and inferred episodicity along mid-ocean ridges are explained by the characteristic spacing between mantle-derived, melt-rich plumes and the timing of their ascent to the upper lithosphere. An alternative mechanism for producing a narrow neovolcanic zone is by the process of melt focusing through a porous mantle matrix. Phipps Morgan [1987], for example, suggested that, in addition to mantle flow-induced pressure gradients, straininduced anisotropic permeability leads to focusing of melt toward the axis, whereas Scott and Stevenson [1989] suggested that buoyancy due to melt segregation and depletion could lead to a narrow, rapid upwelling beneath the ridge axis.

A prerequisite in any model for the generation of oceanic crust is the presence, at least for short periods of time, of a magma chamber or shallow body of molten rock within the crust. The existence of magma chambers at oceanic spreading centers has long 
been predicted from the stratigraphy of blocks of presumed oceanic crust in ophiolite complexes [Cann, 1974; Dewey and Kidd, 1977; Casey and Karson, 1981; Pallister and Hopson, 1981; Nicolas et al., 1988]. In recent models, the magma chamber serves as a temporary, shallow-level reservoir for mantle-derived parent magmas from which crustal rocks form by chemical differentiation [Sinton and Detrick, 1992; and references therein]. The magma chamber is also believed to be the source of most of the eruptive activity as well as of the heat that drives hydrothermal circulation. However, the role of the magma chamber in the crustal generation process remains controversial, and the shape and dimensions of these magma bodies, as well as their composition, longevity, and along-strike variability, are not well constrained.

Between January and February of 1988, an intensive survey was conducted over a portion of the EPR near $9^{\circ} 30^{\prime} \mathrm{N}$ by the Massachusetts Institute of Technology and the Woods Hole Oceanographic Institution from the R/V Thomas Washington. This region of the EPR is a classic example of a fast-spreading mid-ocean ridge with an axial high and modest local relief. A previous multichannel seismic reflection investigation by Detrick et al. [1987] had discovered evidence for a strong reflection from the top of an axial magma chamber (AMC) at 1.5-2 km depth along a portion of the EPR that included the area near $9^{\circ} 30^{\prime} \mathrm{N}$.

The survey had two objectives: to perform a seismic tomography experiment using an array of ocean-bottom seismometers (OBSs) and ocean-bottom hydrophones (OBHs) to record seismic waves generated by explosives and airgun shots fired near the sea surface, and to carry out areally dense measurements of the bathymetry and the seasurface gravity and scalar magnetic fields. Bathymetry was measured using Sea Beam, a high-resolution multibeam swath-mapping system. Results of delay-time tomography were presented by Toomey et al. [1990, 1994] and those of attenuation tomography by Wilcock et al. [1992a, 1995]. In addition to our initial objectives, the deployment of OBS and $\mathrm{OBH}$ arrays provided an opportunity to monitor microearthquake activity in the axial 
and near-axial region; these microearthquake observations were reported by Wilcock et al. [1992b]. Although the gravity and magnetic fields of this area have previously been investigated by Madsen et al. [1990] and Carbotte and Macdonald [1992], respectively, the coverage of gravity and magnetic anomaly data collected during our survey is at least three times more dense than that of previous investigations. The acquisition of areally complete bathymetric data during our survey allows us to perform high-resolution threedimensional analyses of density and magnetization structure.

A number of investigations and experiments have been conducted on the EPR near $9^{\circ} 30^{\prime} \mathrm{N}$ during the time following our cruise. These include the geochemical analysis of rock samples collected by dredging [Batiza and Niu, 1992; Goldstein et al., 1994] and by a rock corer mounted on the submersible Alvin [Perfit et al., 1994; Goldstein et al., 1994], a near-bottom seismic refraction study [Christeson et al., 1992, 1994a, b], detailed investigations of axial morphology and vent distribution [Haymon et al., 1991, 1993], additional microearthquake studies [Hildebrand et al., 1992], and reprocessing of multichannel seismic reflection data [Harding et al., 1993; Kent et al., 1993a, b]. Where possible, we use the results from these studies to provide independent constraints on and tests of some of our working hypotheses.

This thesis consists of four main topics: a detailed analysis of normal fault characteristics, the modeling of stress fields capable of explaining these faulting patterns, an inversion and interpretation of magnetic anomalies, and an inversion and interpretation of gravity anomalies. Although each approach taken in this thesis focuses on different aspects of mid-ocean ridge structure and processes, they result in complementary views of a single ridge segment. Following are brief descriptions of the contents of each chapter.

Chapter 2 characterizes the distribution and geometry of normal faults from Sea Beam swaths crossing the rise axis. The acquisition of high-resolution Sea Beam data during this survey enables us to examine some of the details of seafloor morphology 
associated with normal faulting. Although normal faults may be recognized physiographically because of their sharply edged features with slopes greater than that of the adjacent seafloor, because of the limited resolution of Sea Beam, it is difficult to distinguish whether a normal fault scarp is comprised of a single dominant fault or of several closely spaced faults. In this study, closely-spaced rise-parallel fault scarps are thus referred to collectively as "fault zones." For those fault zones large enough to be resolved by Sea Beam, we were able to map their locations and distribution, determine their dimensions, and examine their variation with seafloor age.

A successful documentation of normal fault characteristics in this area provides an opportunity to better understand tectonic processes that operate near the axis of a fast spreading ridge. Although several studies have been conducted to examine seafloor morphology associated with normal faulting on the flanks of the EPR [e.g., Lonsdale, 1977; CYAMEX, 1981; Choukroune et al., 1984; Macdonald, 1982, 1983; Macdonald and Luyendyk, 1985; Bicknell et al., 1987; Malinverno and Cowie, 1993], fundamental issues such as the width of the zone of active normal faulting (i.e., the active tectonic zone) remain unresolved. One reason this is not understood is because normal fault scarps at fast-spreading ridges are generally of modest relief and thus difficult to detect. Also, each prior study used different instruments to map the seafloor and developed separate schemes to identify and measure normal faults. Unlike side-scan sonar systems, which thus far have been the most commonly used instrument for detailed seafloor mapping, Sea Beam provides accurate depth information from which the vertical dimensions of features can be measured. Thus, by measuring the density and relief of normal fault zones by a careful analyses of Sea Beam data, we hope to determine the width of the active tectonic zone and provide constraints on models of the states of stress near the axes of fast-spreading ridges.

A characteristic of normal faults on the EPR is that they begin to develop on the rise flank rather than on the axis. Moreover, contrary to previous suggestions that active 
normal faulting ceases beyond $10 \mathrm{~km}$ [Macdonald and Luyendyk, 1985; Choukroune et al., 1984; Bicknell et al., 1987; Malinverno and Cowie, 1993], we find in Chapter 2 that activity can continue to distances of $30 \mathrm{~km}$ or more from the axis. In Chapter 3 , a combination of numerical and analytical models is employed to examine several candidate sources of stress fields to see if they can explain the formation and development of normal faults. Specifically, we examine two sources of stress that we consider to be important near the axis of a fast-spreading mid-ocean ridge: the buoyant force that a low-density magma chamber exerts on an overlying crust, and extensional stress due to gravitational spreading off the axial high of the EPR. Although shear stress exerted at the base of a spreading plate by mantle flow may also be important, a recent study by Chen and Morgan [1990] suggests that the magnitude of effective shear stress is probably too small within the axial region to cause significant failure of the upper crust near fast-spreading ridges. Also, if the thickness of the mechanically strong crust varies little with distance from the axis, as suggested by Wilson et al. [1988], then thermal stress from plate cooling cannot account for the initiation of off-axis normal faulting.

In this study, we use the boundary element method to model the stress and strain fields associated with different configurations of magma chambers and mechanical properties of the axial crust in an effort to seek successful combinations of model parameter values. The boundary element method provides several significant advantages over domain methods such as finite difference and finite element methods. In essence, the boundary element method takes far less time to set up and to modify problems and produces more accurate results than domain methods in cases where fundamental solutions exist, such as potential field and linear elastic problems. Also, the boundary element method provides an effective and accurate treatment of body forces such as those arising from gravitational loading and buoyancy. A comparison of boundary element and domain methods is given in Appendix A, and the boundary element formulation for potential field and elastostatic problems is given in Appendices B and C, respectively. 
The state of stress in young oceanic lithosphere is significantly affected by boundary conditions at the ridge axis. Traditionally, the axes of fast-spreading ridges have been considered as free-surface edges [Madsen et al., 1984; Bratt et al., 1985; Chen and Morgan, 1990; Wang and Cochran, 1993]. Under this assumption, ridge axes are free to slide in the direction of plate spreading and are thus incapable of supporting any horizontal stress. However, recent detailed investigations of the rise axis [e.g., Christeson al., 1992, 1994a, b] provide evidence of solidified dikes in the uppermost axial crust which suggests that the rise axis may have finite mechanical strength. Therefore, in light of this inference, it is worthwhile to examine the relationship between the stress field and the strength of the rise axis for the various sources of stress mentioned earlier.

A simple way to consider a finite-strength rise axis when using the boundary element method is to model the axis as a set of internal springs that join both sides of the plate and then to prescribe the values for spring stiffness. Although less intuitive, this approach provides several advantages over the alternative one of modeling the rise axis as a separate subregion and then prescribing the elastic moduli of such subregion. To understand what values spring stiffness represent in relationship to an actual elastic strength of the rise axis, a comparison of two approaches involving a simple case of a dike is examined in Appendix D.

To model accurately stress and strain in a given region, it is necessary to know its material properties, especially if the range in variation of material properties is large. At a mid-ocean ridge, temperature is a major factor that influences the material properties of mid-ocean ridge rock, and yet we know that temperatures may vary widely. Unfortunately, because the structure of an axial region is complex and temperature at a given point depends on factors such as proximity to the magma chamber, convection within the magma chamber, and hydrothermal circulation, there is no universally accepted thermal model. An attempt by Wilson et al. [1988] to reconcile the misfit 
between predicted thermal fields and temperatures inferred from seismic constraints [Detrick et al., 1987] by placing sources and sinks of heat in the upper crust of the axial region is considered among one of the more realistic representations of the EPR to date, but their model extends only $10 \mathrm{~km}$ from the axis. In this study, we used a finite difference method to extend the model of Wilson et al. [1988] to a greater distance by assuming that the crust undergoes only simple conductive cooling at distances greater than $10 \mathrm{~km}$ from the axis. These results are used not only as a basis in this chapter to define the mechanically strong portion of the crust, but the model is also invoked in Chapter 5 to correct the gravity anomaly field for temperature variations across the study area.

Chapter 4 contains a study of the properties and structure of the uppermost crust from an inversion of sea-surface magnetic field anomalies for crustal magnetization. We were able to reduce the level of background noise in our magnetic field data set by correcting for the field fluctuations stemming from ionospheric activity. As a result of this correction, the root mean square (rms) misfit of total magnetic field at ship track crossovers was reduced from 26 to $15 \mathrm{nT}$. Although the information provided by magnetic anomalies is generally nonunique, useful interpretations can be made of the inversion results. For example, by assuming that the magnetization intensity is uniform, magnetization anomalies can help us to constrain the thickness of the extrusive layer, or layer 2 of the oceanic crust. However, studies have shown that magnetization intensity can also change with degree of low-temperature alteration [Honnorez, 1981] or fractionation within the magma chamber [Byerly et al., 1976; Sinton et al., 1983]. This latter possibility can be particularly useful for analyzing areas such as ours where the existence of a magma chamber is confirmed, because magnetization anomalies may then be used to place constraints on the size and replenishment rate of a chamber. Since crustal rocks can also undergo thermal demagnetization (i.e., high-temperature alteration), magnetization anomalies can be used to identify magmatic injection points in 
the upper crust and thus the relative timing of recent magmatism [e.g., Wooldridge et al., 1992, at the Trans-Atlantic Geotraverse (TAG) hydrothermal field on the Mid-Atlantic Ridge and the Sea Cliff hydrothermal fields on the Gorda Ridge].

Chapter 5 presents an analysis of gravity anomalies from the study area. A critical step in reducing the gravity measurements is to make an accurate Eötvös correction for ship's velocity, an especially important reduction step in this survey because the magnitude of the Eötvös correction increases toward the equator and the variation in the free-air gravity field across the EPR is modest compared with that at other mid-ocean ridges. Unfortunately, during the time of this survey, the Global Positioning System (GPS), a highly precise satellite navigation system capable of updating positional information almost continuously worldwide, was not fully operational and, therefore, most of the navigation during gravity and magnetic field measurements was determined using conventional Transit satellites. Therefore, as an intermediate step in reducing gravity data, we improved our navigation by reducing the misfits of Sea Beam bathymetric features at crossover points. As a result of our renavigation effort, the rms misfit of gravity at ship track crossovers was reduced from 3.9 to $1.9 \mathrm{mGal}$. The formulation of our renavigation method, which is a slight modification of that of Nishimura and Forsyth [1988] and likewise is based on a generalized inversion technique with a least squares criterion, is given in Appendices E and F.

Much of the free-air gravity field near mid-ocean ridges arises from several predictable effects, such as the attraction from the water/crust and crust/mantle interfaces, and the variation in the density of the oceanic lithosphere as it cools and moves away from the axis. Therefore, by systematically removing these predictable components from a free-air gravity field, it is possible to obtain a mantle Bouguer anomaly from which the distribution of remaining mass anomalies may be constrained. Previous investigations of gravity anomalies along the EPR [Madsen et al., 1984, 1990; Wang and Cochran, 1993] have suggested the presence of a low-density volume beneath the axial topographic high. 
However, because the gravity field alone cannot uniquely distinguish among candidate structural models, the density and depth extent of such a volume and the role it plays in the support of the axial high remain controversial. Understanding the distribution of anomalous density within the mantle is important because it provides constraints on the dynamics of mantle flow. The controversy has centered on the strength of the axial lithosphere and the melt fraction of the low-density volume.

Traditionally, the axial lithosphere was thought to have a very low flexural rigidity; by that viewpoint the axial high is produced in local isostatic response to the buoyancy of the underlying low-density volume [e.g., Cochran, 1979; McNutt, 1979; Wilson, 1992]. A contrasting view is that the axial lithosphere has a finite strength, and the axial high is explained by regional isostasy, i.e., lithospheric flexure [e.g., Madsen et al., 1984, 1990; Wang and Cochran, 1993]. The different views on the strength of the lithosphere have resulted in different estimates of the depth of isostatic compensation; according to McNutt [1979], the depth of isostatic compensation should lie at least $7 \mathrm{~km}$ below the seafloor, whereas Wang and Cochran [1993] argue that the low-density volume that explains both gravity anomalies and flexure of lithosphere should extend to depths of 25$30 \mathrm{~km}$. Using an isostatic compensation model, Wilson [1992] argued that, for a $2 \%$ melt fraction and a source volume less than $10 \mathrm{~km}$ in half width, the low-density volume should extend to at least $40 \mathrm{~km}$ beneath the seafloor. However, it is unclear whether such a small fraction of melt is consistent with large reductions in viscosity of upper mantle one would expect from focused mantle upwelling. For example, Buck and $\mathrm{Su}$ [1989] assume $20-30 \%$ melt fraction for a low-density region that extends $30 \mathrm{~km}$ below the seafloor in their mantle flow model. Such a large fraction of melt in the mantle may be gravitationally unstable [Wilson, 1992], however, and lead to the rise of magma to shallow crustal levels. If so, evidence of recently replenished crustal regions might be found through the analysis of gravity field anomalies. 
Previously, investigators have assumed that anomalous density is uniform with depth. An alternative approach is to consider that the density contrast between the low-density volume and the surrounding region is different for the shallow crust and the underlying mantle. This approach may be more realistic since recent seismic images of the crust show a distinctive low-velocity volume in the shallow to middle crust [Vera et al., 1990; Toomey et al., 1990, 1994]. In this study, we use these seismic results to place constraints on the depth and dimensions of the crustal low-density volume. By assuming that the short wavelength component of the observed gravity anomalies is caused by this crustal low-density volume, it is possible to estimate the magnitude of the density anomaly. Then, after subtracting these contributions, we can estimate the amount of gravity anomaly that is due to deeper sources. The likelihood of explaining the longwavelength variation in gravity by crustal thickness variations along the axis is also explored, but the required differences in crustal thickness are larger than permitted by seismic reflection data from the region.

In Chapter 6, conclusions drawn from this thesis are gathered, including an integration of all the different views of the EPR obtained from the diverse observations discussed in earlier chapters. In particular, we combine information gathered from observations of normal faulting, the analysis of magnetic field anomalies on the properties of the upper crust and that on the lower crust and upper mantle from the analysis of the gravity field to assemble new constraints on the governing processes along fast-spreading mid-ocean ridges. 


\section{References}

Batiza, R., and S. H. Margolis, Small non-overlapping offsets of the East Pacific Rise, Nature, 320, 439-441, 1986.

Batiza, R., and Y. Niu, Petrology and magma chamber processes at the East Pacific Rise $\sim 9^{\circ} 30^{\prime}$ N, J. Geophys. Res., 97, 6779-6797, 1992.

Bicknell, J. D., J.-C. Sempere, K. C. Macdonald, and P. J. Fox, Tectonics of a fast spreading center: A Deep-Tow and Sea Beam survey on the East Pacific Rise at 19³0'S, Mar. Geophys. Res., 9, 25-45, 1987.

Bratt, S. R., E. A. Bergman, and S. C. Solomon, Thermoelastic stress: How important as a cause of earthquakes in young oceanic lithosphere?, J. Geophys. Res., 90, 10,249$10,260,1985$.

Buck, W. R., and W. Su, Focused mantle upwelling below mid-ocean ridges due to feedback between viscosity and melting, Geophys. Res. Lett., 16, 641-644, 1989.

Byerly, G. R., W. G. Melson, and P. R. Vogt, Rhyodacites, andesites, ferro-basalts and ocean tholeiites from the Galapagos spreading center, Earth Planet. Sci. Lett., 30, 215-221, 1976.

Cann, J. R., A model for oceanic crustal structure developed, Geophys. J. R. Astron. Soc., 39, 169-187, 1974.

Carbotte, S., and K. Macdonald, East Pacific Rise $8^{\circ}-10^{\circ} 30^{\prime} \mathrm{N}$ : Evolution of ridge segments and discontinuities from SeaMARC II and three-dimensional magnetic studies, J. Geophys. Res., 97, 6959-6982, 1992.

Casey, J. F., and J. A. Karson, Magma chamber profiles from the Bay of Islands ophiolite complex, Nature, 298, 295-301, 1981.

Chen, Y., and W. J. Morgan, A nonlinear rheology model for mid-ocean ridge axis topography, J. Geophys. Res., 95, 17,583-17,604, 1990. 
Choukroune, P., J. Francheteau, and R. Hekinian, Tectonics of the East Pacific Rise near 1250'N: A submersible study, Earth Planet. Sci. Lett., 68, 115-127, 1984.

Christeson, G. L., G. M. Purdy, and G. J. Fryer, Structure of young upper crust at the East Pacific Rise near 9³0N, Geophys. Res. Lett., 19, 1045-1048, 1992.

Christeson, G. L., G. M. Purdy, and G. J. Fryer, Seismic constraints on shallow crustal emplacement processes at the fast spreading East Pacific Rise, J. Geophys. Res., 99, $17,957-17,973,1994 a$.

Christeson, G. L., G. M. Kent, G. M. Purdy, and R. S. Detrick, Extrusive thickness variability at the East Pacific Rise: Constraints from seismic techniques, submitted to J. Geophys. Res., 1994b.

Cochran, J. R., An analysis of isostasy in the world's oceans, 2. Midocean ridge crests, J. Geophys. Res., 84, 4713-4729, 1979.

Crane, K., The spacing of rift axis highs: Dependence upon diapiric processes in the underlying asthenosphere?, Earth Planet. Sci. Lett., 72, 405-414, 1985.

CYAMEX, First manned submersible dives on the East Pacific Rise at $21^{\circ} \mathrm{N}$ (project RITA): General results, Mar. Geophys. Res., 4, 345-379, 1981.

Detrick, R. S., P. Buhl, E. Vera, J. Mutter, J. Orcutt, J. Madsen, and T. Brocher, Multichannel seismic imaging of a crustal magma chamber along the East Pacific Rise, Nature, 326, 35-41, 1987.

Dewey, J. F., and W. S. F. Kidd, Geometry of plate accretion, Geol. Soc. Am. Bull., 88, 960-968, 1977.

Goldstein, S. J., M. R. Perfit, R. Batiza, D. J. Fornari, and M. T. Murrell, Off-axis volcanism at the East Pacific Rise detected by uranium-series dating of basalts, Nature, 367, 157-159, 1994.

Harding, A. J., G. M. Kent, and J. A. Orcutt, A multichannel seismic investigation of upper crustal structure at $9^{\circ} \mathrm{N}$ on the East Pacific Rise: Implications for crustal accretion, J. Geophys. Res., 98, 13,925-13,944, 1993. 
Haymon, R. M., D. J. Fornari, M. H. Edward, S. Carbotte, D. Wright, and K. C. Macdonald, Hydrothermal vent distribution along the East Pacific Rise crest $\left(9^{\circ} 09^{\prime}-\right.$ 54 'N) and its relationship to magnetic and tectonic processes on fast-spreading midocean ridges, Earth Planet. Sci. Lett., 104, 513-534, 1991.

Haymon, R. M., D. J. Fornari, K. L. Von Damm, M. D. Lilley, M. R. Perfit, J. M. Edmond, W. C. Shanks, III, R. A. Lutz, J. M. Grebmeier, S. Carbotte, D. Wright, E. McLaughlin, M. Smith, N. Beedle, and E. Olson, Volcanic eruption of the mid-ocean ridge along the East Pacific Rise crest at $9^{\circ} 45-52 ' \mathrm{~N}$ : Direct submersible observations of seafloor phenomena associated with an eruption event in April, 1991, Earth Planet. Sci. Lett., 119, 85-101, 1993.

Hildebrand, J. A., S. C. Webb, L. M. Dorman, A. E. Schreiner, M. A. McDonald, and W. C. Crawford, Microseismicity of a mid-ocean ridge volcanic eruption: The East Pacific Rise at $9^{\circ} 50 ' \mathrm{~N}$ (abstract), Eos, Trans. AGU, 73, Fall Meeting suppl., 530, 1992.

Honnorez, J., The aging of the oceanic crust at low temperature, in The Sea, vol. 7, edited by C. Emiliani, pp. 525-587, John Wiley \& Sons, New York, 1981.

Kent, G. M., A. J. Harding, and J. A. Orcutt, Distribution of magma beneath the East Pacific Rise between the Clipperton transform and the $9^{\circ} 17^{\prime} \mathrm{N}$ deval from forward modeling of common depth point data, J. Geophys. Res., 98, 13,945-13,969, 1993a.

Kent, G. M., A. J. Harding, and J. A. Orcutt, Distribution of magma beneath the East Pacific Rise near the $9^{\circ} 03^{\prime} \mathrm{N}$ overlapping spreading center from forward modeling of common depth point data, J. Geophys. Res., 98, 13,971-13,995, 1993 b.

Klein, E. M., and C. H. Langmuir, Global correlations of ocean ridge basalt chemistry with axial depth and crustal thickness, J. Geophys. Res., 92, 8089-8115, 1987.

Langmuir, C. H., J. F. Bender, and R. Batiza, Petrological and tectonic segmentation of the East Pacific Rise, 5³0'-14³0'N, Nature, 322, 422-429, 1986. 
Lonsdale, P., Structural geomorphology of a fast-spreading rise crest: The East Pacific Rise near 325'N, Mar. Geophys. Res., 3, 251-293, 1977.

Macdonald, K. C., Mid-ocean ridges: Fine scale tectonic, volcanic and hydrothermal processes within the plate boundary zone, Ann. Rev. Earth Planet. Sci., 10, 155-190, 1982.

Macdonald, K. C., and P. J. Fox, Overlapping spreading centers: A new kind of accretion geometry on the East Pacific Rise, Nature, 301, 55-58, 1983.

Macdonald, K. C., and P. J. Fox, The axial summit graben and cross-sectional shape of the East Pacific Rise as an indicators of axial magma chambers and recent volcanic eruptions, Earth Planet. Sci. Lett., 88, 119-131, 1988.

Macdonald, K. C., and B. P. Luyendyk, Investigation of faulting and abyssal hill formation on the flanks of the East Pacific Rise $\left(21^{\circ} \mathrm{N}\right)$ using ALVIN, Mar. Geophys. Res., 7, 515-535, 1985.

Macdonald, K., J.-C. Sempere, and P. J. Fox, East Pacific Rise from Siqueiros to Orozco Fracture Zones: Along-strike continuity of axial neovolcanic zones and structure and evolution of overlapping spreading centers, J. Geophys. Res., 89, 6049-6069, 1984.

Macdonald, K. C., P. J. Fox, L. J. Perram, M. F. Eisen, R. M. Haymon, S. P. Miller, S. M. Carbotte, M.-H. Cormier, and A. N. Shor, A new view of the mid-ocean ridge from the behavior of ridge-axis discontinuities, Nature, 335, 217-225, 1988.

Madsen, J. A., D. W. Forsyth, and R. S. Detrick, A new isostatic model for the East Pacific Rise crest, J. Geophys. Res., 89, 9997-10,015, 1984.

Madsen, J. A., R. S. Detrick, J. C. Mutter, P. Buhl, and J. A. Orcutt, A two- and threedimensional analysis of gravity anomalies associated with the East Pacific Rise at $9^{\circ} \mathrm{N}$ and $13^{\circ} \mathrm{N}, \mathrm{J}$. Geophys. Res., 95, 4967-4987, 1990.

Malinverno, A., and P. A. Cowie, Normal faulting and the topographic roughness of midocean ridge flanks, J. Geophys. Res., 98, 17,921-17,939, 1993. 
McNutt, M., Compensation of oceanic topography, an application of the response function technique to the Surveyor area, J. Geophys. Res., 84, 7589-7598, 1979.

Nicolas, A., I. Reuber, and K. Benn, A new magma chamber model based on structural studies in the Oman ophiolite, Tectonophysics, 151, 87-105, 1988.

Nishimura, C. E., and D. W. Forsyth, Improvements in navigation using SeaBeam crossing errors, Mar. Geophys. Res., 9, 333-352, 1988.

Pallister, J. S., and C. A. Hopson, Samail ophiolite plutonic suite: Field relations, phase variation, cryptic variation and layering, and a model of a spreading ridge magma chamber, J. Geophys. Res., 86, 2593-2644, 1981.

Perfit, M. R., D. J. Fornari, M. C. Smith, J. F. Bender, C. H. Langmuir, R. M. Haymon, Small-scale spatial and temporal variations in mid-ocean ridge crest magmatic processes, Geology, 22, 375-379, 1994.

Phipps Morgan, J., Melt migration beneath mid-ocean ridge spreading centers, Geophys. Res. Lett., 14, 1238-1241, 1987.

Reynolds, J. R., C. H. Langmuir, J. F. Bender, K. A. Kastens, and W. B. F. Ryan, Spatial and temporal variability in the geochemistry of basalts from the East Pacific Rise, Nature, 359, 493-499, 1992.

Scheirer, D. S., and K. C. Macdonald, Variation in cross-sectional area of the axial ridge along the East Pacific Rise: Evidence for the magmatic budget of a fast spreading center, J. Geophys. Res., 98, 7871-7885, 1993.

Schouten, H., K. D. Klitgord, and J. A. Whitehead, Segmentation of mid-ocean ridges, Nature, 317, 225-229, 1985.

Scott, D. R., and D. J. Stevenson, A self-consistent model of melting, magma migration and buoyancy-driven circulation beneath mid-ocean ridges, J. Geophys. Res., 94, 2973-2999, 1989.

Sinton, J. M., and R. S. Detrick, Mid-ocean ridge magma chambers, J. Geophys. Res., 97, 197-216, 1992. 
Sinton, J. M., D. S. Wilson, D. M. Christie, R. N. Hey, and J. R. Delaney, Petrologic consequences of rift propagation on oceanic spreading ridges, Earth Planet. Sci. Lett., 62, 193-207, 1983.

Sinton, J. M., S. M. Smaglik, J. J. Mahoney, and K. C. Macdonald, Magmatic processes at superfast spreading mid-ocean ridges: Glass compositional variations along the East Pacific Rise $13^{\circ}-23^{\circ} \mathrm{S}$, J. Geophys. Res., 96, 6133-6155, 1991.

$\mathrm{Su}$, W., and R. Buck, Buoyancy effects on mantle flow under mid-ocean ridges, $J$. Geophys. Res., 98, 12,191-12,205, 1993.

Toomey, D. R., G. M. Purdy, S. C. Solomon, and W. S. D. Wilcock, The threedimensional seismic velocity structure of the East Pacific Rise near latitude $9^{\circ} 30^{\prime} \mathrm{N}$, Nature, 347, 639-645, 1990.

Toomey, D. R., S. C. Solomon, and G. M. Purdy, Tomographic imaging of the shallow crustal structure of the East Pacific Rise at 9³0'N, J. Geophys. Res., 99, 24,13524,157, 1994.

Vera, E. E., J. C. Mutter, P. Buhl, J. A. Orcutt, A. J. Harding, M. E. Kappus, R. S. Detrick, and T. M. Brocher, The structure of 0 - to $0.2-\mathrm{m} . \mathrm{y}$.-old oceanic crust at $9^{\circ} \mathrm{N}$ on the East Pacific Rise from expanded spread profiles, J. Geophys. Res., 95, 15,52915,556, 1990.

Wang, X., and J. R. Cochran, Gravity anomalies, isostasy and mantle flow at the East Pacific Rise crest, J. Geophys. Res., 98, 19,505-19,531, 1993.

Whitehead, J. A., H. J. B. Dick, and H. Schouten, A mechanism for magmatic accretion under spreading centres, Nature, 312, 146-148, 1984.

Wilcock, W. S. D., S. C. Solomon, G. M. Purdy, and D. R. Toomey, The seismic attenuation structure of a fast-spreading mid-ocean ridge, Science, 258, 1470-1474, 1992a. 
Wilcock, W. S. D., G. M. Purdy, S. C. Solomon, D. L. Dubois, and D. R. Toomey, Microearthquakes on and near the East Pacific Rise, $9^{\circ}-10^{\circ} \mathrm{N}$, Geophys. Res. Lett., 19 , 2131-2134, $1992 b$.

Wilcock, W. S. D., S. C. Solomon, G. M. Purdy, and D. R. Toomey, The seismic attenuation structure of the East Pacific Rise near $9^{\circ} 30^{\prime} \mathrm{N}$, J. Geophys. Res., submitted, 1995.

Wilson, D. S., Focused mantle upwelling beneath mid-ocean ridges: Evidence from seamount formation and isostatic compensation of topography, Earth Planet. Sci. Lett., 113, 41-45, 1992.

Wilson, D. S., D. A. Clague, N. H. Sleep, and J. L. Morton, Implications of magma convection for the size and temperature of magma chambers at fast spreading ridges, J. Geophys. Res., 93, 11,974-11,984, 1988.

Wooldridge, A. L., C. G. A. Harrison, M. A. Tivey, P. A. Rona, and H. Schouten, Magnetic modeling near selected areas of hydrothermal activity on the Mid-Atlantic and Gorda Ridges, J. Geophys. Res., 97, 10,911-10,926, 1992. 


\section{Chapter 2}

\section{Constraints from Sea Beam Bathymetry on the Development of Normal Faults on the East Pacific Rise}

\section{Introduction}

Near-bottom investigations of the axial region of the East Pacific Rise (EPR) [e.g., Lonsdale, 1977; CYAMEX, 1981; Choukroune et al., 1984; Searle, 1984; Macdonald and Luyendyk, 1985; Bicknell et al., 1987] have revealed a systematic variation in the morphological characteristics of the seafloor with distance from the axis of spreading. Most recent volcanic features are confined to a narrow band, referred to as the "neovolcanic zone" [Macdonald, 1982; Macdonald and Luyendyk, 1985], which is less than 1-2 $\mathrm{km}$ wide and generally centered on the spreading axis. Except for the axial summit caldera, which is present along some sections of the EPR and is thought to result from the collapse of axial dikes which feed lava to the seafloor [Macdonald and Fox, 1988; Haymon et al., 1991], the neovolcanic zone appears to be free of large-offset normal faults. Significant normal faulting occurs only well outside the neovolcanic zone; the nearest large-offset normal faults, having throws as great as $70-150 \mathrm{~m}$, are found 2 to $12 \mathrm{~km}$ from the axis [CYAMEX, 1981; Macdonald and Luyendyk, 1985; Bicknell et al., 
1987]. The zone extending beyond these faults to the outer limits of significant off-axis fault activity on either side of the spreading axis is referred to as the "active tectonic zone" or "plate boundary zone" by Macdonald [1982] and Macdonald and Luyendyk [1985]. Macdonald [1982], for example, described the plate boundary zone as a region where newly formed seafloor is accelerated from rest on the axis to the full spreading velocity of the plate. He argued that along fast-spreading mid-ocean ridges such as the EPR, the plate boundary zone is marked by inward- and outward-facing normal faulting and block tilting that give rise to the horst-and-graben structure of Pacific abyssal hill topography. These characteristics are in contrast to those of slower spreading centers such as the Mid-Atlantic Ridge, which include a median valley having several kilometers of relief and active normal faulting that is concentrated along the inner valley walls on predominantly inward-facing normal faults.

Despite the documentation of these general characteristics in the Pacific, several aspects of normal fault development on the EPR are still not understood. For instance, there is considerable disagreement among investigators as to the width of the active tectonic zone, i.e., the distance from the axis at which near-surface normal fault activity ceases. According to Lonsdale [1977] and Searle [1984], active crustal extension extends as far as $20 \mathrm{~km}$ from the rise axis at $3^{\circ} \mathrm{S}$. In contrast, Bicknell et al. [1987] found that faulting ceases within $5-8 \mathrm{~km}$ of the rise axis at $19^{\circ} 30^{\prime} \mathrm{S}$, while Choukroune et al. [1984] argue that tectonic activity ceases within $2 \mathrm{~km}$ of the rise axis at $12^{\circ} 50^{\prime} \mathrm{S}$. Furthermore, it is not clear what processes control the initiation of normal faulting off-axis or the diminishment of fault activity at greater distances from the axis, or whether the initiation and growth of fault zones are related to along-axis variations in crustal accretion characteristics. A more comprehensive analysis of the development of normal faults near the EPR axis is necessary to improve our understanding of the state of stress and its causative processes in young oceanic crust. 
This chapter provides a set of measurements of fault-zone characteristics which addresses these questions. The results of this study also provide the basis for development of numerical models of stress and frictional failure in Chapter 3. The study area is the section of the EPR near $9^{\circ} 30^{\prime} \mathrm{N}$ (Figure 2.1), which is one of the most intensively explored sections, and serves as a classic example, of a fast-spreading ridge. Investigations in this area include the determination of seismic crustal structure (Figure 2.2) [Detrick et al., 1987; Vera et al., 1990; Toomey et al., 1990, 1994; Christeson et al., 1992, 1994a, b; Wilcock et al., 1992a, 1995; Harding et al., 1993; Kent et al., 1993a, b], near-bottom observations using the ARGO imaging system [Haymon et al., 1991], documentation of a recent volcanic eruption along the crest of the rise axis from submersible observations [Haymon et al., 1993], geochemical analyses of rock samples obtained using conventional dredges [Batiza and $\mathrm{Niu}, 1992$ ] and a rock corer mounted on a submersible [Perfit et al., 1994], and determination of microearthquake characteristics [Wilcock et al., 1992b; Hildebrand et al., 1992]. In particular, the axial magma chamber (AMC) has been identified and the depth to its top mapped along this rise section (Figure 2.2) [Detrick et al., 1987; Mutter et al., 1988; Kent et al., 1993a, b]. Given the geological and geophysical constraints provided by these studies, it is worthwhile to examine the dimensions and distribution of normal fault zones in this region and to compare them with the characteristics revealed by the other investigations.

\section{Sea Beam Data}

Information on the fine-scale morphology of the seafloor is best deduced from nearbottom bathymetric surveys made with systems such as Deep-Tow [e.g., Kleinrock and Hey, 1989] and ARGO [e.g., Haymon et al., 1991] equipped with cameras and side-scan sonars, or by deep-sea submersibles (e.g., Alvin and Cyana). While near-bottom surveys 
can resolve features along a track with relief as small as a few meters, they are limited to small areas. To cover larger areas, it is necessary to use a swath-mapping bathymetric or imaging system near the sea surface such as Sea Beam or Sea MARC II [e.g., Edwards et al., 1989; Macdonald et al., 1992; Carbotte and Macdonald, 1994]. Side-scan sonar systems such as Sea MARC II image fault scarps directly and provide information on the relative timing of fault activity, but multibeam bathymetric mapping tools such as Sea Beam offer the advantage that they provide accurate depth information from which the vertical dimensions of features can be measured and thus the variation of fault throw with distance from the axis can be addressed. Some side-scan sonar systems, including Sea MARC II, use a split-beam method, which compares phase angles to determine seafloor depth from data received by pairs of closely spaced transducers viewing the same side. However, the depth accuracy of such a system is generally poorer than multibeam systems at a similar frequency and altitude above the seafloor. Summaries of the various systems used in seafloor surveys can be found in Kleinrock [1992] and Cowie et al. [1994].

As with any bathymetric survey system, Sea Beam has finite vertical and horizontal resolution; the vertical resolution of individual beams is approximately $10 \mathrm{~m}$ [ $d e$ Moustier and Kleinrock, 1985]. From geologic, geodetic, and seismic measurements, the amount of fault slip during a single earthquake seldom exceeds a few meters [e.g., Stein et al., 1988]. Therefore, Sea Beam will not resolve the changes in seafloor morphology produced by individual seismic events. The beam width and sampling interval determine the horizontal resolution of Sea Beam and are more critical factors limiting its overall resolution. The resolution of many acoustic survey systems can be characterized by footprint dimensions. The footprint of a beam is an ellipse formed by the intersection of the cone of the beam (defined by a half-power angle) with the seafloor. In Sea Beam the beams are formed so that their outgoing angles abut, and thus the cross-track component of the footprint and the cross-track spacing are the same. In our survey, Sea Beam 
samples were taken at intervals of $4-5 \mathrm{~s}$ with 16 beams forming an angle of insonification athwartship of $\pm 21^{\circ}$. With the ship generally cruising at 10 knots over an area whose average depth is approximately $2700 \mathrm{~m}$, the corresponding sampling intervals in directions parallel and perpendicular to the ship's heading were approximately 25 and $125 \mathrm{~m}$, respectively. Therefore, in practice, the resolution of Sea Beam can range anywhere from the vertical resolution of an individual beam of $10 \mathrm{~m}$ to a footprint width of $125 \mathrm{~m}$.

The Sea Beam data used in this study were collected during a seismic tomography experiment conducted in January of 1988 onboard $R / V$ Thomas Washington. The mapping covered an area between latitude $9^{\circ} 05^{\prime} \mathrm{N}$ and $9^{\circ} 55^{\prime} \mathrm{N}$, out to a maximum distance of approximately $100 \mathrm{~km}$ to either side of the EPR axis. Figure 2.3 shows twelve straight Sea Beam tracks, selected from our bathymetric data set, which are oriented almost perpendicular to the rise axis. The spreading half-rate in this area is approximately 55 $\mathrm{mm} / \mathrm{yr}$ [Carbotte and Macdonald, 1992]; thus, a distance of $100 \mathrm{~km}$ from the axis corresponds to a crustal age of about $1.8 \mathrm{My}$.

Given information on seafloor depth from Sea Beam, the simplest way to identify a large-offset normal fault is by means of seafloor slope. Identification and characterization on the basis of seafloor slope alone, however, inevitably involves some uncertainty. Although normal faults may be recognized physiographically from their sharply edged features and slopes greater than that of adjacent seafloor, there is still no consensus on their characteristic slope, and thus it may be difficult to distinguish clearly between faults and other sloped features on the seafloor such as volcanic constructs (e.g., seamount flanks, flow margins, and caldera walls).

Despite such concerns, a rationale can be given to justify the use of slope as a criterion for identifying normal fault scarps. According to recent analyses of seamounts and submarine volcanoes on the Pacific plate [Fornari et al., 1984, 1987; Barone and Ryan, 1988; Smith, 1988], the slopes of smaller volcanic constructs average about $15^{\circ}-20^{\circ}$. 
Moreover, according to Fornari et al. [1987], seamounts are virtually absent near the spreading axis ( $<10 \mathrm{~km}$ from the axis) of the EPR, in contrast to the Mid-Atlantic Ridge, where the median valley floor is often covered with small seamounts [e.g., Batiza et al.,

1989; Smith and Cann, 1990]. Probably the most important factors that distinguish volcanic constructional features from fault structures are their horizontal dimensions and orientations. Detailed near-bottom investigation of the EPR at $19^{\circ} 30^{\prime}$ S shows that common volcanic constructional features have wavelengths much less than the long dimension of dominantly faulted structures [Bicknell et al., 1987], and they have a lesser tendency to be parallel to the rise axis.

The limited resolution of Sea Beam does not allow discrimination between a normal fault scarp composed of a single dominant fault or several closely spaced faults (Figure 2.4). In this study, in recognition of this ambiguity, narrow rise-parallel fault scarps will be referred to as "fault zones." For those fault zones large enough to be resolved by Sea Beam, we can nonetheless map their location and distribution, determine their width (heave) and height (throw), and examine their variation with seafloor age.

\section{Methods}

\section{Estimation of Fault-Zone Area}

We used two different schemes to measure the characteristics of fault zones. In the first, we gridded the individual Sea Beam swaths after the bathymetry had been renavigated so as to minimize swath misfit at crossovers [Wilcock et al., 1993]. Grid spacing was 20 and $100 \mathrm{~m}$ along and across track, respectively. The misfits between ship tracks are too large (100s of meters) for us to correlate narrow fault zones between 
swaths with confidence. Thus, we used gridded bathymetric data only to estimate the plan-view area of fault zones.

To estimate the fault zone area, slope analysis was applied to the gridded bathymetry. For each three adjacent grid points, we found the plane through them (Figure 2.5). The triangular grid surface element is regarded as part of a fault zone if the dip angle of that plane exceeds a critical value. On the basis of the previous discussion, we chose $30^{\circ}$ as the critical angle. Within the gridded data set, the fraction of grid surface elements that satisfy the slope criterion is equivalent to the fractional plan-view surface area represented by normal fault zones. By examining the dip direction for each surface element, we also determined whether the fault zones represented inward- or outwardfacing faults.

A similar technique was used by Shaw and Smith [1990] to characterize seafloor topography in Sea Beam swath data. They constructed normal vectors to small patches of the seafloor. Shaw and Smith [1990] also extended their technique to characterize the terrain from the histogram of normal vector orientations and autocovariance functions.

To present the results of our analysis, we divided the gridded data into 5-km-wide, axis-parallel isochron bins over the EPR flanks, summed the area of all fault zones within each bin, and then divided by the total gridded area in each bin. The results are shown as the percentage of seafloor area made up of inward- and outward-facing fault zones versus distance from the rise on both the Pacific and Cocos plates (Figure 2.6). Because we have only two tracks on each side of the rise that extend farther than $30-40 \mathrm{~km}$ from the axis, the results beyond $35 \mathrm{~km}$ are less certain than those within $35 \mathrm{~km}$ and are shown as dotted lines in Figure 2.6. 


\section{Estimation of Fault-Zone Heave and Throw}

In the second type of analysis, the height and width (throw and heave) of fault zones was estimated from bathymetry averaged across individual swaths. We studied twelve straight Sea Beam swaths, labeled A through L from north to south, as shown in Figure 2.3. Tracks E, F, H, and I extend more than $100 \mathrm{~km}$ from the spreading axis, while the remaining tracks extend approximately $30-40 \mathrm{~km}$ from the axis. Two tracks ( $\mathrm{K}$ and $\mathrm{L}$ ) cross areas west of the axis where large-relief features appear to be related to the southward migration of an overlapping spreading center from $9^{\circ} 20^{\prime} \mathrm{N}$ to $9^{\circ} 03^{\prime} \mathrm{N}$ during the past 0.7 My [Carbotte and Macdonald, 1992]. According to Carbotte and Macdonald [1994], who analyzed Sea MARC II images over a greater area of the EPR $\left(8^{\circ} 30^{\prime}\right.$ to $\left.10^{\circ} \mathrm{N}\right)$, discordant zones left by overlapping spreading centers exhibit low fault abundance. However, as we will show, the inclusion of those two tracks does little to change the principal conclusions of this study.

In the process of analyzing the gridded bathymetric data as discussed earlier, we determined the strike of observed fault zones (Figure 2.7). Because most fault zones in our survey area are axis-parallel, the fault-zone heave and throw are readily characterized by means of a simple automated scheme applied to profiles perpendicular to the rise axis. The details of the scheme are as follows (Figure 2.8):

(1) Topographic profiles along the spreading direction were obtained by averaging seafloor depths across the beams. During our Sea Beam bathymetric survey, the outer beams often dropped out, so we used only 13 beams that consistently provided seafloor returns. The tracks for swaths $\mathrm{E}, \mathrm{F}, \mathrm{G}, \mathrm{H}, \mathrm{I}, \mathrm{J}$ and $\mathrm{L}$ are parallel to the direction of spreading, so a simple average of the 13 beams is sufficient. However, the remainder of the tracks, A, B, C, D and $\mathrm{K}$, are along azimuths that differ from the direction of spreading by $5-10^{\circ}$. Thus, we first projected each beam profile onto a vertical plane 
perpendicular to the rise axis, and then we averaged the profile values at equal distances from the axis.

(2) Slope was calculated from this averaged topography, and values of slope were divided into bins of $10^{\circ}$ width. In practice, five bins were used: slopes less than $-20^{\circ}$ comprise group 1 , from $-20^{\circ}$ to $-10^{\circ}$ group 2 , from $-10^{\circ}$ to $10^{\circ}$ group 3 , from $10^{\circ}$ to $20^{\circ}$ group 4 , and greater than $20^{\circ}$ group 5. Positive and negative values denote seafloor dip along and opposite to the ship's direction, respectively. We identified candidate fault zones as areas in which the absolute value of the slope exceeded $20^{\circ}$, i.e., groups 1 and 5 . This threshold value is less than that used for the gridded swath bathymetry, in order to compensate for the smoothing effect of averaging across the swath. Still, as noted earlier, this value is greater than the typical $15-20^{\circ}$ slopes of volcanic constructs.

(3) A running window operation was performed to determine the along-track extent of the fault zone (Figure 2.8). We consider that we passed out of the fault zone when $75 \%$ of the points in the running window had slopes with an absolute value of less than $10^{\circ}$. This scheme ignores small changes in slope such as that midway down the scarp sketched in Figure 2.8. It also results in mapping what may be two or more closely spaced fault scarps as one fault zone.

The fault-zone dimensions determined according to this scheme are shown along illustrative swath profiles in Figure 2.9. Because of the resolution limits of Sea Beam and the smoothing effect of averaging across the swath, the widths of the fault zones measured in our scheme are greater than those of scarps determined from near-bottom surveys in other portions of the EPR [e.g., Bicknell et al., 1987]. Furthermore, the lengths of fault zones were not measured in this analysis, because many of the zones extend beyond the width of individual Sea Beam swaths. 


\section{Effects of Mass Wasting and Sedimentation}

Before describing the results of our fault-zone characterization, it is important to discuss two phenomena, fault-scarp degradation by mass wasting, and sedimentation, that may affect our quantitative analyses. At slow-spreading ridges, for instance, recent evidence shows that mass wasting plays an important role in modifying fault-scarp morphology. According to detailed near-bottom surveys performed on the flanks of the Mid-Atlantic Ridge near $26^{\circ} \mathrm{N}$ at crustal ages of 3 to 24 My [Tucholke et al., 1994], mass wasting creates canyon-like incisions and causes significant scarp retreat and scarp widening. Keith [1986] also reported that even the young rift valley floor ( 0.1 My) of slow-spreading ridges shows substantial degradation by mass wasting.

One argument that mass wasting will be ubiquitous on the seafloor is that upper crustal rocks are weak because fissures, joints, and veins develop at the time of crustal formation, and because of subsequent weathering and hydrothermal alteration. Therefore, slope failure may be common. At present, it is unclear whether there is active mass wasting on the seafloor of fast-spreading ridges. If mass wasting is prevalent, as illustrated in Figure 2.10, it could significantly increase the apparent heave of a fault zone over time. Thus, heave is not a satisfactory measure of possible growth of seafloor fault scarps with time. Throw, however, is a diagnostic measurement. Mass wasting will decrease apparent throw, so an observed increase in throw with distance from the axis is a strong indication of continued activity on normal faults off-axis.

It is uncertain to what extent sedimentation has affected the morphology of fault zones in our survey area. Lonsdale and Spiess [1980] estimated the sediment accumulation rate near $9^{\circ} \mathrm{N}$ to be approximately $18 \mathrm{~m} / \mathrm{My}$. Therefore, if sediment accumulated on the seafloor in the form of an even drape (Figure 2.11a), there may be as much as $10 \mathrm{~m}$ of sediment cover at $30 \mathrm{~km}$ from the axis. Uniform sediment cover would not change the

results of our analysis, since the apparent heave and throw would be similar to true heave 
and throw. On the other hand, if sediment were mobilized from topographic highs to lows (Figure 2.11b), as in mass wasting, the apparent throw would be reduced. The apparent heave might also be increased, depending on the slope criterion we use to define a fault zone.

\section{Variations in Fault Zone Characteristics}

By employing the analytical methods described above, we examine the characteristics of normal-fault zones and their variations in our survey area. As seen by the estimation of plan-view area of fault zones in Figure 2.6, there is no significant difference between the total area of inward- and outward-facing fault zones on either side of the rise-axis. This result contrasts with some reports based on data from other parts of the EPR that there are a greater number of inward-facing faults than outward-facing faults [e.g., Searle, 1984]. Carbotte and Macdonald [1994] argued that 60\% of all faults were inward facing. Our results do not differ significantly from those of Carbotte and Macdonald, and it appears that inward- and outward-facing faults are roughly of equal importance.

Our results also show that the plan-view area of fault zones increases with increasing distance from the axis for distances less than about $30 \mathrm{~km}$ (Figure 2.6). This trend is seen most clearly on the Pacific-plate side of the rise, but it is also evident for inward-facing fault zones on the Cocos-plate side. Fractional fault-zone area, on average, appears not to change systematically beyond approximately $30-40 \mathrm{~km}$ from the axis, but because track coverage is limited at these distances, this inference needs to be confirmed by additional investigations with wider coverage.

We examined whether discarding tracks $\mathrm{K}$ and $\mathrm{L}$ affects our observations (as noted earlier, portions of track $\mathrm{K}$ and $\mathrm{L}$ sampled seafloor where there are tectonic structures produced by an overlapping spreading center). Figure 2.12 is similar to Figure 2.6, but it 
excludes data from tracks $\mathrm{K}$ and $\mathrm{L}$. A comparison of the figures shows that there is no significant difference in the estimated plan-view area of fault zones versus distance offaxis.

While the observations shown in Figures 2.6 and 2.12 are consistent with the hypothesis that normal fault activity continues to $30 \mathrm{~km}$ or more off-axis, the plan-view area of fault zones could equally well increase with off-axis distance because of mass wasting (Figure 2.10b). As noted above, a robust indicator of continuing fault activity is given by the areally averaged fault zone throw versus distance.

The total apparent throw of fault zones within 10-km-wide isochron bins, derived from averaged swath bathymetry and normalized by the number of swaths contributing to each bin, is shown in Figure 2.13. There is clearly a systematic increase in total apparent throw of fault zones with distance from the rise axis. Because both mass wasting and sediment redeposition from topographic highs to lows would tend to decrease total apparent throw with increasing crustal age, the observed increase of throw in Figure 2.13 provides strong evidence for continued fault activity out to at least $30-40 \mathrm{~km}$ from the axis on both the Pacific and Cocos plates.

The fault zones that we mapped vary widely in size, from tens of meters to hundreds of meters in both heave and throw. However, the population of fault zones is made up principally of features of modest relief, i.e., small throw. Figure 2.14 shows a histogram of the distribution of fault zones by throw in the full gridded bathymetric data set. The upper quartile of fault zones corresponds to throws greater than $45 \mathrm{~m}$.

To determine whether the increase in total throw with distance off-axis is attributable primarily to an increase in the spatial frequency of fault zones or to continued off-axis growth of fault zones, we calculated the total throw for the upper quartile of fault zones by throw (dashed line in Figure 2.13). (In our survey area, this upper quartile accounts for more than half of the total throw for a given isochron bin). It appears that much, but not all, of the increase in total throw of fault zones within $30 \mathrm{~km}$ of the rise axis can be 
explained by increased throw on the largest-relief fault zones. However, the ratio of upper quartile throw and total throw appears to be constant with distance. This result implies that the fault activity in our survey area occurs by continuing slip on large-offset fault zones as well as from an increase in the areal density of small-offset fault zones.

As with the plan-view area of fault zones, we also examined whether removal of tracks $\mathrm{K}$ and $\mathrm{L}$ affects our results on fault throw (Figure 2.15). Even with data from these two tracks removed, we still obtain an increase in total throw within $10-\mathrm{km}$-wide isochron bins out to a distance of at least $30 \mathrm{~km}$ from the axis. Thus, the inclusion of possible tectonic features formed by an overlapping spreading center does not alter our results.

Another way to determine whether fault zones increase in throw off-axis is to examine the average throw in each bin (i.e., the total throw in each bin divided by the number of fault zones in each bin) (Figure 2.16). Average throws show an irregular but distinct increase with distance off-axis, again supporting the concept of continuing off-axis faulting over time.

On the basis of an examination of a pair of tracks on each side of the rise axis that extend beyond $40 \mathrm{~km}$ distance, fault activity appears to continue as far as $60-70 \mathrm{~km}$ off axis. Evidence for this inference can be found in the plan-view areas of fault zones on both the Pacific and Cocos plates (Figure 2.6) and, more importantly, in both the total throw (Figure 2.13) and the average throw (Figure 2.16) of identified fault zones. Because of our limited coverage, however, we are unable to assign a high confidence to this result. Further investigation with more extensive coverage will be necessary in order to determine the full width of the active tectonic zone of the EPR.

We also examined the locus of initiation of significant faulting along the spreading axis by determining the distance of the first large-offset fault zone from the axis. Only fault zones with throws greater than $20 \mathrm{~m}$ were considered. A plot of the positions of these fault zones with respect to the rise axis along each Sea Beam swath (Figure 2.17) 
shows that the total width of young seafloor free of large-offset faults is an almost uniform $7 \mathrm{~km}$ throughout our survey area. However, the distance to the first large-offset fault zone is not always symmetric across the rise axis; the midpoint between the first large-offset fault zones on either flank of the rise is offset to the west of the bathymetric axis by almost $2-3 \mathrm{~km}$ south of $9^{\circ} 23^{\prime} \mathrm{N}$.

\section{Discussion}

\section{Comparison with Other Studies}

The characteristics of normal fault zones which we documented along the section of the EPR near $9^{\circ} 30^{\prime} \mathrm{N}$ can be compared to those of other sections of the EPR reported by Lonsdale [1977] at $3^{\circ} 25^{\prime} \mathrm{S}$, Choukroune et al. [1984] at $12^{\circ} 50^{\prime} \mathrm{N}$, Macdonald and Luyendyk [1985] at $21^{\circ} \mathrm{N}$, and Bicknell et al. [1987] at $19^{\circ} 30^{\prime} \mathrm{S}$. Both at $9^{\circ} 30^{\prime} \mathrm{N}$ and along other sections of the EPR, normal faults begin to develop a few kilometers from the axis. Differences have been reported, however, for the distance to which active faulting continues (Table 2.1). Except for Lonsdale [1977], most investigators have suggested that faulting diminishes considerably within $5-10 \mathrm{~km}$ from the axis. Macdonald and Luyendyk [1985] suggested that faulting of the EPR at $21^{\circ} \mathrm{N}$ generally ceases beyond 10 $12 \mathrm{~km}$ from the axis; however, they reported fresh scarps, observed in submersible dives, which showed no indication of erosion at one location $23 \mathrm{~km}$ off-axis in their study area.

Our results, in contrast to the conclusions of most previous investigators, suggest that normal fault zones continue to be active up to distances at least $30 \mathrm{~km}$ from the axis, and perhaps as far as $60-70 \mathrm{~km}$ from the axis. This different finding may be attributed to a

number of factors, including differences in mapping systems and measures used to characterize faults. For example, studies performed with side-scan sonar systems base 
their measure of fault activity on the length of fault scarps on the seafloor. An increase in the average lengths of faults with distance from the axis is evidence for continued fault activity, but the lack of such evidence does not necessarily indicate that all activity has ceased. Unless a rigorous scaling relationship between the displacement on a fault and its length can be demonstrated, using the lengths of faults is thus an imperfect measure of fault activity. Differences in the inferred extent of fault activity between our results and those of studies that relied on deeply towed surveying systems may partly stem from differences in the amount of areal seafloor coverage. As noted earlier, most deep-tow surveys are performed on relatively small portions of the seafloor.

The locations and source mechanisms of earthquakes provide independent measures of fault activity and style of faulting. Wilcock et al. [1992b] located microearthquakes that occurred along this section of the EPR during an 8-day period. They found two events of moment $10^{20}-10^{21}$ dyne $\mathrm{cm}$ located $20-30 \mathrm{~km}$ off-axis; the event with the bestconstrained location occurred within the crust, probably within the upper $3 \mathrm{~km}$. Unfortunately, no focal mechanism study was possible for these microearthquakes, so it is unclear whether they were caused by normal faulting.

If indeed normal faulting does continue beyond $30 \mathrm{~km}$ and even as far as $60-70 \mathrm{~km}$ from the rise axis, an important question that may be asked is the distance at which normal faulting ceases. In order to have continued activity on normal faults, there must be an extensional stress field within the upper crust. Investigations of large ridge-flank earthquakes in lithosphere 3-35 My in age (160 km or more off-axis at this portion of the EPR) suggest that normal-faulting mechanisms are common, but body waveform inversion indicates that most such normal-faulting events have centroid depths beneath the crust [Bergman and Solomon, 1984; Wiens and Stein, 1984]. In contrast, thrust or reverse faulting events typically have centroid depths within the crust at these ages. Therefore, from these earthquake studies and our observations of fault patterns, it seems likely that normal faulting within the upper crust of fast-spreading ridges should cease 
somewhere beyond $30 \mathrm{~km}$ from the axis $(0.6 \mathrm{My})$ but at a seafloor age less than $3 \mathrm{My}$. At present, the relationship between large ridge-flank earthquakes, plausibly attributable to differential thermoelastic stress associated with plate cooling [Bergman and Solomon, 1984; Bratt et al., 1985], and the active tectonic zone of the EPR is not clear.

In terms of relative abundance of inward versus outward facing normal faults, our results differ slightly from those of Carbotte and Macdonald [1994]. According to Carbotte and Macdonald [1994], inward-facing faults are more numerous and have greater vertical offset and length on average than outward-facing faults. They also found that outward-facing faults tend to appear as clusters of short, closely-spaced antithetic faults subsidiary to long master inward-facing faults. In our data, there appear to be no significant differences between the plan-view areas of inward- and outward-facing normal fault scarps. Assuming that fault zone widening by mass wasting is equally effective on inward- and outward-facing fault zones, our results suggest that in total, approximately equal areas of the seafloor are covered by inward- and outward-facing normal faults.

\section{Processes Controlling Initiation of Faulting}

Our observations and those of others (Table 2.1) confirm that large-offset normal faulting begins several kilometers from the axis at the EPR. A possible explanation for the first formation of large-offset normal faults at such distances is that replenishment of the magma chamber heats and weakens the overlying material within a few kilometers of the axis to such an extent that no large-offset faults can form. However, an argument against this hypothesis is that the upper crust tends to be well cooled by hydrothermal circulation. A more likely explanation of this off-axis initiation of normal faulting is that frequent volcanic eruptions create a zone of weakness along the axial magmatic 
emplacement zone. Unlike the first hypothesis, this explanation does not invoke changes in material properties over a large portion of the upper crust but, rather, only over a narrow zone $(\sim 100 \mathrm{~m})$ along the axis. Given a far-field extensional stress, a zone surrounding the weak axis would have a lower level of deviatoric stress. Lachenbruch [1961] derived an analytical solution to the problem of the stress field in the vicinity of a vertical crack in a half-space in which pressure is applied to the crack walls. His study showed that in the case of uniform pressure applied to the walls of the crack, the pressure decays to $10 \%$ of its peak value at a distance approximately equivalent to 5 times the depth extent of the crack. In Chapter 3, we develop numerical models to examine the effects that mechanical strength has on the near-ridge stress field for candidate sources of stress, and we conclude that the process most likely responsible for the initiation of normal fault formation is buoyancy of the axial magma chamber and the surrounding low-velocity volume.

Buoyancy arising from low-density material beneath fast-spreading ridges has long been regarded as a viable source of tectonic stress and deformation near the axis, yet few studies have examined buoyancy quantitatively as a possible cause of near-ridge normal faulting. Madsen et al. [1984] considered the axial high of the EPR to be a result of a buoyant force bending the free edges of a plate upwards. They used a model that consisted of an elastic plate of uniform thickness $(6 \mathrm{~km})$, and they assumed that the buoyant force is balanced by the flexural rigidity of the plate and a hydrostatic restoring force created when crustal rock effectively replaces denser mantle rock in the vertical column. However, there are two principal difficulties with the treatment of buoyancy in their model. First, their depth for the source of buoyancy is inconsistent with the depth of the AMC observed seismically [Detrick et al., 1987], information not available at the time of their study. Second, the base of the lithosphere was assumed to be free of shear stress as if it were lying over an inviscid fluid. This implies that the buoyant source itself is an inviscid fluid, and the possible transmission of shear stresses between the buoyant 
source and the surrounding mantle or the crust is ignored. Furthermore, given this assumption, the plate on each side of the spreading axis deflects upwards in a concave manner. As a result, the top half of the plate is under compression while the bottom half is under extension, which is contrary to the stress regime implied by normal faults on the seafloor. A more realistic model of the crust near the axis, including different assumptions about boundary conditions, produces a buoyancy model that can explain the initiation of normal faulting in agreement with observations, as discussed in Chapter 3.

A different explanation for why few normal faults are found very near the axis is that tectonic features form at such distance but are masked by lava flow from the neovolcanic zone [Bicknell et al., 1987]. Under this explanation, faults may actually form on the rise axis, but because the brittle layer of upper crust on the axis is very thin, fault offsets may be quite small. As a result, frequent volcanic eruptions may cover the features. Recent geochemical analyses [Perfit et al., 1994] and uranium-series dating [Goldstein et al., 1994] conducted on rock-core samples collected from a suite of closely spaced lava flows within the axial summit caldera and on the crestal plateau of the EPR near $9^{\circ} 31^{\prime} \mathrm{N}$ suggest that eruptions occur throughout the crestal region and are not restricted to the axis. Support for the emplacement of lavas outside the axial summit region is given by the evidence for significant thickening of layer $2 \mathrm{~A}$ within $2 \mathrm{~km}$ of the EPR axis near $9^{\circ} 30^{\prime} \mathrm{N}$ [Christeson et al., 1992, 1994a]. Two arguments, however, can be made against this explanation. First, the off-axis onset of large-throw normal faults often occurs at distances ( $8 \mathrm{~km}$ or more) too large to be explained by this mechanism. Second, off-axis faults generally display relief too large to be completely covered by lava flows. For instance, detailed near-bottom investigations of the axial region of the EPR often reveal features such as faults and graben embayed but not fully covered by lava flows [W. B. F. Ryan, personal communication, 1994]. 


\section{Along-Axis Variations}

Along-axis variability in the characteristics of the EPR is well documented near $9^{\circ} 30^{\prime} \mathrm{N}$. We can compare the near-axis pattern of fault development (Figure 2.17) with results of other investigations conducted in this area to look for relations indicative of the processes controlling the onset of faulting. As noted previously, the cross-axis separation between first-appearing large-offset fault zones appears almost uniform throughout the survey area; however, the midpoint between these fault zones is nearly centered on the axis north of $9^{\circ} 23^{\prime} \mathrm{N}$, but to the south of $9^{\circ} 23^{\prime} \mathrm{N}$ it is offset to the west by $2-3 \mathrm{~km}$. This offset is at about the same location as a westward offset in the axial magma chamber reflector (by 2-3 km) near 9 $20^{\prime} \mathrm{N}$ [Mutter et al., 1988; Kent et al., 1993a] (see Figure 2.2). The approximate coincidence of the midpoint between large-offset fault zones flanking the rise axis and the locus of magmatic emplacement as indicted by the AMC reflector supports the hypothesis that the upper crust is thermomechanically weakened at the axis of most recent crustal accretion.

\section{Processes Controlling Continued Off-Axis Faulting}

As noted above, thermoelastic stress caused by the differential cooling of the oceanic lithosphere provides a likely mechanism for the generation of ridge-flank earthquakes in lithosphere 3-35 My old, so it is worth considering whether thermal stress could also be responsible for a zone of active extension at least $60 \mathrm{~km}$ wide centered on the axis of the EPR. Because crustal rocks in general have fairly high coefficients of thermal expansion, depending on the boundary conditions a small change in differential temperature can produce a large stress, and an accumulation of such stresses may ultimately lead to brittle failure. On the other hand, if rocks are at a sufficiently high temperature, the thermal stress is relieved by flow on time scales short compared with those leading to brittle 
failure of the upper crust. This behavior is sometimes parameterized in terms of an elastic "blocking temperature" [Turcotte, 1983]; this is the temperature marking the base of the elastic or mechanical lithosphere, above which thermal stress can be assumed to be rapidly relieved by flow. For crustal and mantle materials, these temperatures are thought be $250-450^{\circ} \mathrm{C}$ and $600-800^{\circ} \mathrm{C}$, respectively [Chen and Molnar, 1983]. Since we are dealing with normal faulting within the upper crust, we may assume, for example, $400^{\circ} \mathrm{C}$ as the elastic blocking temperature for our problem. Unfortunately, the depth of the $400^{\circ} \mathrm{C}$ isotherm near the axis of a fast-spreading ridge is poorly constrained, because it is strongly dependent on the assumed thermal model.

A comparison of two models illustrates this dependence (Figure 2.18). Lin and Parmentier [1989] assumed that crustal accretion occurs within a narrow zone along the axis, and they simulated hydrothermal convection by increasing the thermal conductivity in a surficial crustal layer. Wilson et al. [1988], in contrast, modeled a narrow zone $( \pm 10$ $\mathrm{km}$ ) around the axis and incorporated a magma chamber of finite size; they utilized point sources and sinks of heat to simulate latent heat release, hydrothermal circulation, and convection within and near the magma chamber. Their model was also constrained to match the depth of the axial magma chamber reflection present in the multichannel seismic reflection data of Detrick et al. [1987], and thus may be a better representation of the thermal structure of the EPR near $9^{\circ} 30^{\prime} \mathrm{N}$ than that of Lin and Parmentier [1989]. In the thermal model of Wilson et al. [1988], the depth of the $400^{\circ} \mathrm{C}$ isotherm is almost uniform (1.0-1.5 km) within $10 \mathrm{~km}$ of the spreading axis. This result leads us to conclude that crustal cooling is not a major source of stress at distances of $10 \mathrm{~km}$ or less from the axis. However, beyond $10 \mathrm{~km}$, the thermal model of Lin and Parmentier [1989] suggests that the extensional stress arising from cooling of the crust might be an important mechanism that affects the development or growth of normal faults.

Another source of stress is the mantle flow field. This subject has been studied by Chen and Morgan [1990a, b]. They argue on the basis of finite element models that 
anomalously high temperature leads to a broad zone of low viscosity beneath the axial crust of a fast-spreading mid-ocean ridge (Figure 2.19a). This low-viscosity zone causes sufficient reduction in the magnitude of stress induced by mantle flow that frictional failure will not occur in the brittle upper crust near the rise axis. Without such a lowviscosity zone, the shear stress induced by mantle flow tractions on the base of the mechanical lithosphere is a maximum at the spreading axis and can result in a broad region of frictional failure in the upper crust (Figure 2.19b).

A number of factors can affect the outcome of finite element modeling, including material parameters in the flow law

$$
\dot{\varepsilon}=A\left(\sigma_{1}-\sigma_{3}\right)^{n} \exp \left(-\frac{Q}{R T}\right)
$$

where $\dot{\varepsilon}$ is the uniaxial strain rate, $\sigma_{1}-\sigma_{3}$ is the differential stress, $R$ the gas constant, $T$ the absolute temperature, and $n, Q$, and $A$ are material constants. In the model of Chen and Morgan [1990b], values for the rheological parameters $n$ and $Q$ for crust and mantle are based on laboratory measurements of diabase [Ranalli, 1982] and olivine [Goetze, 1978], respectively. However, Chen and Morgan chose values for $A$, the least constrained among material parameters, in such a way that the model matches observations. For instance, the value of $A$ for the crust was chosen so that results of the model match the width of the axial valley at slow-spreading rates. The value of $A$ for the mantle was selected from a mantle-only half-space model. The choice was made in such a manner that the transition between two domains, one at which the failure zone is wider than the decoupling zone and vice versa, take place at a spreading rate of $35 \mathrm{~mm} / \mathrm{yr}$; this value, according to Small and Sandwell [1989], represents the spreading rate at which an abrupt transition in the smoothness of gravity and geoid anomalies occurs. Despite these uncertainties in material parameters, the models of Chen and Morgan [1990] appear to 
present a reasonable argument that mantle flow does not explain the initiation or development of normal faults near the EPR axis.

As noted earlier, Macdonald [1982] argued that a zone of active faulting of finite width may occur along a spreading axis simply because newly formed crust accelerates to the full spreading velocity over such a zone. While this hypothesis is purely kinematic, such a zone of acceleration would be expected to give rise to extensional stress and, if sufficiently wide, might account for the observed steady increase in fault throw to distances of at least $30 \mathrm{~km}$ from the rise. This issue can be examined from the model results of Chen and Morgan [1990b]. They investigated the horizontal velocity of the seafloor under the assumptions that the viscosity of the mantle is either uniform or dependent on temperature and stress, and that horizontal velocity increases from zero at the spreading axis to the plate spreading velocity at some distance off axis. According to their calculations, the zone of acceleration is very narrow for cases with temperature- and stress-dependent viscosity; for example, the half-widths of the acceleration zone are 4.5, 2 , and $1.5 \mathrm{~km}$ for spreading half-rates of 10,30 , and $60 \mathrm{~mm} / \mathrm{yr}$, respectively (Figure 2.20). Therefore, it is unlikely that the acceleration of newly emplaced crust would explain active normal faulting to distances of $30 \mathrm{~km}$ from the rise axis.

A final possible mechanism of extension is gravitational spreading off the axial high of the EPR. Under the assumption that the oceanic lithosphere is in local isostatic equilibrium and is underlain by region of inviscid fluid, Dahlen [1981] argued that deviatoric stress necessary to support the topography of a mid-ocean ridge is compressive in the direction perpendicular to the axis. However, the study of Dahlen [1981] represents a particular case in which the boundaries of the spreading axis and the base of the lithosphere are considered to be free surfaces. While such an assumption may be valid for considerations of the platewide stress field, for near-ridge regions the stress field may be sensitive to the boundary conditions at the axis. Therefore, one needs to explore different boundary conditions for the spreading axis. 
The first-order effects of gravitational spreading on stress can be illustrated by schematic models involving an upper crust resting on a sloping detachment (Figure 2.21). For the sake of simplicity, we assume that plane strain applies. If the top of the slope is pinned, the upper portion of the slope will experience extensional stress while the base of the slope will be subjected to compressional stress (Figure 2.21a). On the other hand, if the top of the slope is free, there is no resistance to downslope motion and the expected stress will be compressional throughout, with the magnitude of compression increasing downslope (Figure 2.21b). Also, if gravitational spreading occurs because a mechanically strong lithosphere slides over a weaker asthenosphere, then the shape of the base of the lithosphere and the ease of sliding may be important factors. These topics are explored at greater length in Chapter 3. 


\section{Conclusions}

From an analysis of Sea Beam bathymetry, we determined the distribution, plan-view area, and throw of normal fault zones out to $30-60 \mathrm{~km}$ from the axis of the East Pacific Rise (EPR). From gridded bathymetry produced from twelve Sea Beam swaths extending across the axis of the EPR, we identified fault zones, determined their strike and dip directions, and measured their plan-view area. One-dimensional profiles perpendicular to the axis also were produced by averaging along-strike across individual Sea Beam swaths. Along these averaged profiles, an automated scheme based on seafloor slope was used to identify and measure the heaves and throws of fault zones.

Our study yielded the following conclusions:

(1) The immediate axis of the EPR generally appears to lack large-offset fault zones (i.e., throw greater than $20 \mathrm{~m}$ ). While fissures, cracks, and an axial summit caldera may be present, as near-bottom investigations [e.g., Haymon et al., 1991] have shown, fault zones with significant offsets generally do not form within $2-3 \mathrm{~km}$ of the axis.

(2) The plan-view area of fault zones increases steadily out to a distance of at least $30 \mathrm{~km}$ from the axis. However, because mass wasting may significantly increase the apparent widths of fault zones with age, such an increase is not uniquely diagnostic of continuing off-axis fault activity. On the basis of plan-view area, there appears to be no significant difference in the density of inward- and outward-facing faults.

(3) The total throw and average throw of fault zones also show steady increases with distance from the spreading axis out to at least $30-40 \mathrm{~km}$, indicating that fault activity continues at least this far off axis. It is difficult to determine if fault activity continues to distances greater than $30-40 \mathrm{~km}$ from the axis because of our limited bathymetric coverage. Measurements of fault-zone throw along a few long tracks on both sides of the plate, however, suggest that the normal fault activity may continue as far as $60-70 \mathrm{~km}$ 
from the spreading axis. Large fault zones (the upper quartile of the population of fault throws) account for more than half of the total fault throw in our survey area. Fault activity occurs both through repeated slip on existing faults and by the formation of new faults.

(4) The midpoint between the nearest large-offset fault zones on either side of the axis generally coincides with the bathymetric axis north of $9^{\circ} 23^{\prime} \mathrm{N}$. However, south of $9^{\circ} 23^{\prime} \mathrm{N}$, the midpoint is offset to the west of the bathymetric axis by $2-3 \mathrm{~km}$. This offset is similar to that of the AMC reflector [Mutter et al., 1988; Kent et al., 1993a], suggesting that magmatic emplacement is offset to the west of the bathymetric axis in this region. The pattern of fault zone development is thus influenced more by the position of the most recent axis of magmatic accretion and shallow thermal structure than by the position of the bathymetric rise axis. 


\section{References}

Barone, A. M., and W. R. F. Ryan, Along-axis variations within the plate boundary zone of the southern segment of the Endeavor Ridge, J. Geophys. Res., 93, 7856-7868, 1988.

Batiza, R., and Y. Niu, Petrology and magma chamber processes at the East Pacific Rise $\sim 9^{\circ} 30^{\prime N}$, J. Geophys. Res., 97, 6779-6797, 1992.

Batiza, R., P. J. Fox, P. R. Vogt, S. C. Cande, N. R. Grindlay, W. G. Melson, and T. O'Hearn, Morphology, abundance, and chemistry of near-ridge seamounts in the vicinity of the Mid-Atlantic Ridge $\sim 26^{\circ}$ S, J. Geol., 97, 209-220, 1989.

Bergman, E. A., and S. C. Solomon, Source mechanisms of earthquakes near mid-ocean ridges from body waveform inversion: Implications for the early evolution of oceanic lithosphere, J. Geophys. Res., 89, 11,415-11,441, 1984.

Bicknell, J. D., J.-C. Sempéré, K. C. Macdonald, and P. J. Fox, Tectonics of a fast spreading center: A deep-tow and Sea Beam survey on the East Pacific Rise at 19³0'S, Mar. Geophys. Res., 9, 25-45, 1987.

Bratt, S. R., E. A. Bergman, and S. C. Solomon, Thermoelastic stress: How important as a cause of earthquakes in young oceanic lithosphere?, J. Geophys. Res., 90, 10,249$10,260,1985$.

Carbotte, S., and K. Macdonald, East Pacific Rise $8^{\circ}-10^{\circ} 30^{\prime} \mathrm{N}$ : Evolution of ridge segments and discontinuities from SeaMARC II and three-dimensional magnetic studies, J. Geophys. Res., 97, 6,959-6,982, 1992.

Carbotte, S., and K. C. Macdonald, Comparison of seafloor tectonic fabric at intermediate, fast, and super fast spreading ridges: Influence of spreading rate, plate motions, and ridge segmentation on fault patterns, J. Geophys. Res., 99, 13,60913,631, 1994. 
Chen, W. P., and P. Molnar, Focal depths of intracontinental and intraplate earthquakes and their implications for the thermal and mechanical properties of the lithosphere, $J$. Geophys. Res., 88, 4183-4214, 1983.

Chen, Y., and W. J. Morgan, Rift valley/no rift valley transition at mid-ocean ridges, J. Geophys. Res., 95, 17,571-17,581, 1990a.

Chen, Y., and W. J. Morgan, A nonlinear rheology model for mid-ocean ridge axis topography, J. Geophys. Res., 95, 17,583-17,604, 1990 b.

Choukroune, P., J. Francheteau, and R. Hekinian, Tectonics of the East Pacific Rise near 1250'N: A submersible study, Earth Planet. Sci. Lett., 68, 115-127, 1984.

Christeson, G. L., G. M. Purdy, and G. J. Fryer, Structure of young upper crust at the East Pacific Rise near 9³0N, Geophys. Res. Lett., 19, 1045-1048, 1992.

Christeson, G. L., G. M. Purdy, and G. J. Fryer, Seismic constraints on shallow crustal emplacement processes at the fast spreading East Pacific Rise, J. Geophys. Res., 99, 17,957-17,973, 1994a.

Christeson, G. L., G. M. Kent, G. M. Purdy, and R. S. Detrick, Extrusive thickness variability at the East Pacific Rise: Constraints from seismic techniques, J. Geophys. Res., submitted, 1994b.

Cowie P. A., A. Malinverno, W. B. F. Ryan, and M. H. Edwards, Quantitative fault studies on the East Pacific Rise: A comparison of sonar imaging techniques, $J$. Geophys. Res., 99, 15,205-15,218, 1994.

CYAMEX, First manned submersible dives on the East Pacific Rise at $21^{\circ} \mathrm{N}$ (project RITA): General results, Mar. Geophys. Res., 4, 345-379, 1981.

Dahlen, F. A., Isostasy and the ambient state of stress in the oceanic lithosphere, $J$. Geophys. Res., 86, 7801-7807, 1981.

de Moustier, C., and M. C. Kleinrock, Bathymetric artifacts in Sea Beam data: How to recognize them and what causes them, J. Geophys. Res., 91, 3407-3424, 1986. 
Detrick, R. S., P. Buhl, E. Vera, J. C. Mutter, J. Orcutt, J. Madsen, and T. Brocher, Multichannel seismic imaging of a crustal magma chamber along the East Pacific Rise, Nature, 326, 35-41, 1987.

Edwards, M. H., D. J. Fornari, A. Malinverno, W. B. F. Ryan, J. A. Madsen, D. G. Gallo, M. R. Perfit, and A. N. Shor, High resolution swath mapping using Sea MARC II over an intermediate to fast spreading segment of the East Pacific Rise from $13^{\circ} \mathrm{N}$ to $15^{\circ} \mathrm{N}$ : Quantitative structural data and implications for the fine-scale tectonic evolution of the mid-ocean ridge crest and flank, IGARSS 89, Proceedings of the 12th Canadian Symposium on Remote Sensing, Part III, pp. 1435-1438, Institute of Electrical and Electronic Engineers, Piscataway, N.J., 1989.

Fornari, D. J., W. B. F. Ryan, and P. J. Fox, The evolution of craters and calderas on young seamounts: Insights from Sea MARC I and Sea Beam sonar surveys of a small seamount group near the axis of the East Pacific Rise at $10^{\circ} \mathrm{N}, J$. Geophys. Res., 89 , 11,069-11,083, 1984.

Fornari, D. J., R. Batiza, and M. A. Luckman, Seamount abundances and distribution near the East Pacific Rise $0^{\circ}-24^{\circ} \mathrm{N}$ based on Sea Beam data, in Seamounts, Islands and Atolls, Geophys. Mongr., 43, edited by B. H. Keating, P. Fryer, R. Batiza, and G. W. Boehlert, pp. 13-21, AGU, Washington, D. C., 1987.

Goetze, C., The mechanisms of creep in olivine, Phil. Trans. R. Soc. Lond., Ser. A., 288, 99-119, 1978.

Goldstein, S. J., M. R. Perfit, R. Batiza, D. J. Fornari, and M. T. Murrell, Off-axis volcanism at the East Pacific Rise detected by uranium-series dating of basalts, Nature, 367, 157-159, 1994.

Harding, A. J., G. M. Kent, and J. A. Orcutt, A multichannel seismic investigation of upper crustal structure at $9^{\circ} \mathrm{N}$ on the East Pacific Rise: Implications for crustal accretion, J. Geophys. Res., 98, 13,925-13,944, 1993. 
Haymon, R. M., D. J. Fornari, M. Edwards, S. Carbotte, D. Wright, and K. Macdonald, Hydrothermal vent distribution along the East Pacific Rise crest $\left(9^{\circ} 09^{\prime}-54^{\prime} \mathrm{N}\right)$ and its relationship to magmatic and tectonic processes on fast-spreading mid-ocean ridges, Earth Planet. Sci. Lett., 104, 513-534, 1991.

Haymon, R. M., D. J. Fornari, K. L. Von Damm, M. D. Lilley, M. R. Perfit, J. M. Edmond, W. C. Shanks, III, R. A. Lutz, J. M. Grebmeier, S. Carbotte, D. Wright, E. McLaughlin, M. Smith, N. Beedle, and E. Olson, Volcanic eruption of the mid-ocean ridge along the East Pacific Rise crest at $9^{\circ} 45-52^{\prime} \mathrm{N}$ : Direct submersible observations of seafloor phenomena associated with an eruption event in April, 1991, Earth Planet. Sci. Lett., 119, 85-101, 1993.

Hildebrand, J. A., S. C. Webb, L. M. Dorman, A. E. Schreiner, M. A. McDonald, and W. C. Crawford, Microseismicity of a mid-ocean ridge volcanic eruption: The East Pacific Rise at $9^{\circ} 50^{\prime} \mathrm{N}$ (abstract), Eos, Trans. AGU, 73, Fall Meeting suppl., 530, 1992.

Keith, D. J., The role of mass wasting in the evolution of seafloor topography along slowly-accreting plate boundaries and adjoining transforms, M. S. thesis, Univ. Rhode Island, Narragansett, 65 pp., 1986.

Kent, G. M., A. J. Harding, and J. A. Orcutt, Distribution of magma beneath the East Pacific Rise between the Clipperton transform and the $9^{\circ} 17^{\prime} \mathrm{N}$ deval from forward modeling of common depth point data, J. Geophys. Res., 98, 13,945-13,969, 1993a.

Kent, G. M., A. J. Harding, and J. A. Orcutt, Distribution of magma beneath the East Pacific Rise near the $9^{\circ} 03^{\prime} \mathrm{N}$ overlapping spreading center from forward modeling of common depth point data, J. Geophys. Res., 98, 13,971-13,995, 1993 b.

Kleinrock, M. C., Capabilities of some systems used to survey the deep-sea floor, in $C R C$ Handbook of Geophysical Exploration at Sea, 2nd Edition, edited by R. A. Geyer, pp. 35-86, CRC Press, Boca Raton, Fla., 1992. 
Kleinrock, M. C., and R. N. Hey, Detailed tectonics near the tip of the Galapagos $95.5^{\circ} \mathrm{W}$ propagator: How the lithosphere tears and a spreading axis develops, J. Geophys. Res., 94, 13,801-13,838, 1989.

Lachenbrunch, A. H., Depth and spacing of tension cracks, J. Geophys. Res., 66, 42734292, 1961.

Lin, J., and E. M. Parmentier, Mechanisms of lithospheric extension at mid-ocean ridges, Geophys. J. R. Astron. Soc., 96, 1-22, 1989.

Lonsdale, P., Structural geomorphology of a fast-spreading rise crest: The East Pacific Rise near 325'N, Mar. Geophys. Res., 3, 251-293, 1977.

Lonsdale, P., and F. N. Spiess, Deep-tow observations at the East Pacific Rise, $8^{\circ} 45^{\prime}$ N, and some interpretations, in Initial Reports of the Deep Sea Drilling Project, Vol. 54, edited by B. R. Rosendahl, R. Hekinian, et al., pp. 43-62, U. S. Government Printing Office, Washington D.C., 1980.

Macdonald, K. C., Mid-ocean ridges: Fine scale tectonic, volcanic and hydrothermal processes within the plate boundary zone, Ann. Rev. Earth Planet. Sci., 10, 155-190, 1982.

Macdonald, K. C., and P. J. Fox, The axial summit graben and cross-sectional shape of the East Pacific Rise as an indicator of axial magma chamber and recent volcanic eruptions, Earth Planet. Sci. Lett., 88, 119-131, 1988.

Macdonald, K. C., and B. P. Luyendyk, Investigation of faulting and abyssal hill formation on the flanks of the East Pacific Rise $\left(21^{\circ} \mathrm{N}\right)$ using ALVIN, Mar. Geophys. Res., 7, 515-535, 1985.

Macdonald, K. C., P. J. Fox, S. Miller, S. C. Carbotte, M. H. Edwards, M. Eisen, D. J. Fornari, L. Perram, R. Pockalny, D. Scheirer, S. Tighe, C. Weiland, and D. Wilson, The East Pacific Rise and its flanks $8-18^{\circ} \mathrm{N}$ : History of segmentation, propagation and spreading direction based on SeaMarc II and Sea Beam studies, Mar. Geophys. Res., 14, 299-344, 1992. 
Madsen, J. A., D. W. Forsyth, and R. S. Detrick, A new isostatic model for the East Pacific Rise crest, J. Geophys. Res., 89, 9997-10,015, 1984.

Mutter, J. C., G. A. Barth, P. Buhl, R. S. Detrick, J. C. Orcutt, and A. Harding, Magma distribution across ridge-axis discontinuities on the East Pacific Rise from multichannel seismic imaging, Nature, 336, 156-158, 1988.

Perfit, M. R., D. J. Fornari, M. C. Smith, J. F. Bender, C. H. Langmuir, R. M. Haymon, Small-scale spatial and temporal variations in mid-ocean ridge crest magmatic processes, Geology, 22, 375-379, 1994.

Ranalli, G., Deformation maps in grain-size-stress space as a tool to investigate mantle rheology, Phys. Earth Planet. Inter., 29, 42-59, 1982.

Searle, R. C., GLORIA survey of the East Pacific Rise near $3.5^{\circ}$ S: Tectonic and volcanic characteristics of a fast spreading mid-ocean rise, Tectonophysics, 101, 319-344, 1984.

Shaw, P., and D. K. Smith, Robust description of statistically heterogeneous seafloor topography through its slope distribution, J. Geophys. Res., 95, 8705-8722, 1990.

Small, C., and D. T. Sandwell, An abrupt change in ridge axis gravity with spreading rate, J. Geophys. Res., 94, 17,383-17,392, 1989.

Smith, D. K., Shape analysis of Pacific seamounts, Earth Planet. Sci. Lett., 90, 457-466, 1988.

Smith, D. K., and J. R. Cann, Hundreds of small volcanoes on the median valley floor of the Mid-Atlantic Ridge at 24-30 ${ }^{\circ}$, Nature, 348, 152-155, 1990.

Stein, R. S., G. C. P. King, and J. B. Rundle, The growth of geological structures by repeated earthquakes: 2. Field examples of continental dip-slip faults, J. Geophys. Res., 93, 13,319-13,331, 1988.

Toomey, D. R., G. M. Purdy, S. C. Solomon, and W. S. D. Wilcock, The threedimensional seismic velocity structure of the East Pacific Rise near latitude $9^{\circ} 30^{\prime} \mathrm{N}$, Nature, 347, 639-645, 1990. 
Toomey, D. R., S. C. Solomon, and G. M. Purdy, Tomographic imaging of the shallow crustal structure of the East Pacific Rise at 9³0'N, J. Geophys. Res., 99, 24,13524,157, 1994.

Tucholke, B. E., W. K. Stewart, and M. C. Kleinrock, Dissection and degeneration of fault scarps observed by fine-scale survey of slow-spreading ocean crust (abstract), Eos, Trans. AGU, 75, Fall Meeting suppl., 649, 1994.

Turcotte, D. L., Thermal stresses in planetary elastic lithospheres, Proc. Lunar Planet. Sci. Conf. 13th, Part 2, J. Geophys. Res., 88, suppl., A585-A587, 1983.

Vera, E. E., J. C. Mutter, P. Buhl, J. A. Orcutt, A. J. Harding, M. E. Kappus, R. S. Detrick, and T. M. Brocher, The structure of 0- to 0.2-m.y.-old oceanic crust at $9^{\circ} \mathrm{N}$ on the East Pacific Rise from expanding spread profiles, J. Geophys. Res., 95, 15,52915,556, 1990.

Wiens, D. A., and S. Stein, Intraplate seismicity and stresses in young oceanic lithosphere, J. Geophys. Res., 89, 11,442-11,464, 1984.

Wilcock, W. S. D., G. M. Purdy, S. C. Solomon, D. L. DuBois, and D. R. Toomey, Microearthquakes on and near the East Pacific Rise, $9^{\circ}-10^{\circ} \mathrm{N}$, Geophys. Res. Lett., 19, 2131-2134, 1992a.

Wilcock, W. S. D., S. C. Solomon, G. M. Purdy, and D. R. Toomey, The seismic attentuation structure of a fast-spreading mid-ocean ridge, Science, 258, 1470-1474, $1992 b$.

Wilcock, W. S. D., D. R. Toomey, G. M. Purdy, and S. C. Solomon, The renavigation of Sea Beam bathymetric data between $9^{\circ} \mathrm{N}$ and $10^{\circ} \mathrm{N}$ on the East Pacific Rise, Mar. Geophys. Res., 15, 1-12, 1993.

Wilcock, W. S. D., S. C. Solomon, G. M. Purdy, and D. R. Toomey, The seismic attenuation structure of the East Pacific Rise near $9^{\circ} 30^{\prime}$ N, J. Geophys. Res., submitted, 1995. 
Wilson, D. S., D. A. Clague, N. H. Sleep, and J. L. Morton, Implications of magma convection for the size and temperature of magma chambers at fast spreading ridges, J. Geophys. Res., 93, 11,974-11,984, 1988. 
Table 2.1. Half-widths of active tectonic zones inferred along various portions of the EPR.

\begin{tabular}{cccc}
\hline Location & $\begin{array}{c}\text { Spreading half-rate, } \\
\text { mm/yr }\end{array}$ & $\begin{array}{c}\text { Half-width of active } \\
\text { tectonic zone, } \\
\mathrm{km}\end{array}$ & Reference \\
\hline $21^{\circ} \mathrm{N}$ & 36 & $10-12$ & Macdonald and Luyendyk \\
[1985]
\end{tabular}


Figure 2.1. Schematic map of the East Pacific Rise showing our Sea Beam survey area near $9^{\circ} 30^{\prime} \mathrm{N}$. The Sea Beam data were collected as part of a seismic tomography experiment in 1988. 


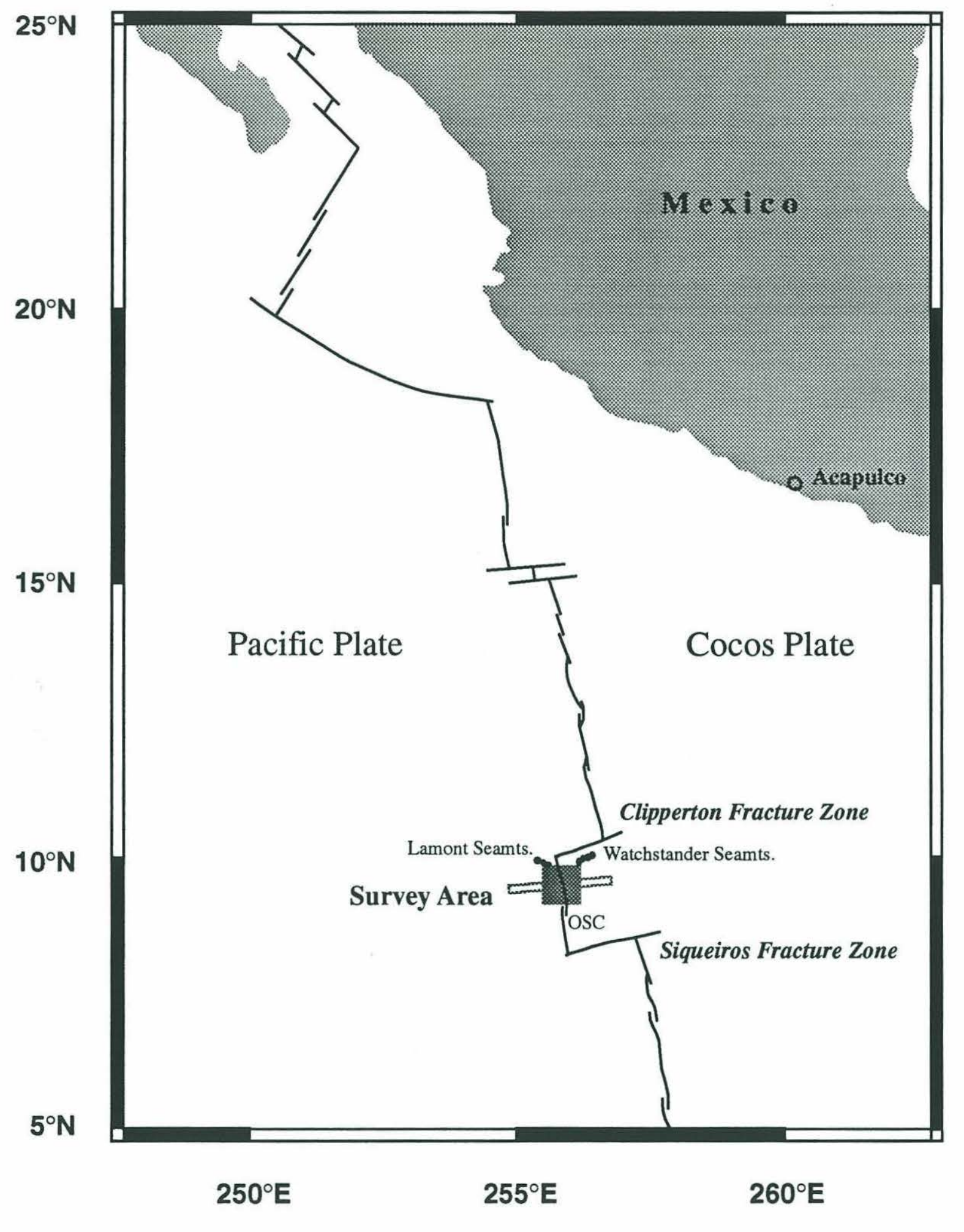


Figure 2.2. Diagrams from Kent et al. [1993a], showing three-dimensional character of the EPR in our study area. (a) Cross-sectional view of along-axis variations of layer $2 \mathrm{~A}$ and axial magma chamber (AMC) reflections. (b) Plan view of along-axis variation in the width of the AMC reflector superimposed on bathymetry (in meters); bold black lines show where the AMC reflector was detected in multichannel reflection profiles. (c) Cross-sectional interpretation of upper crustal structure at $9^{\circ} 19^{\prime} \mathrm{N}$ (Line CDP 33 in b). (d) Depth-migrated solution to the data of (c) showing an offset of the AMC reflector toward the west. 
(a)

Line Drawing: LINE CDP 41

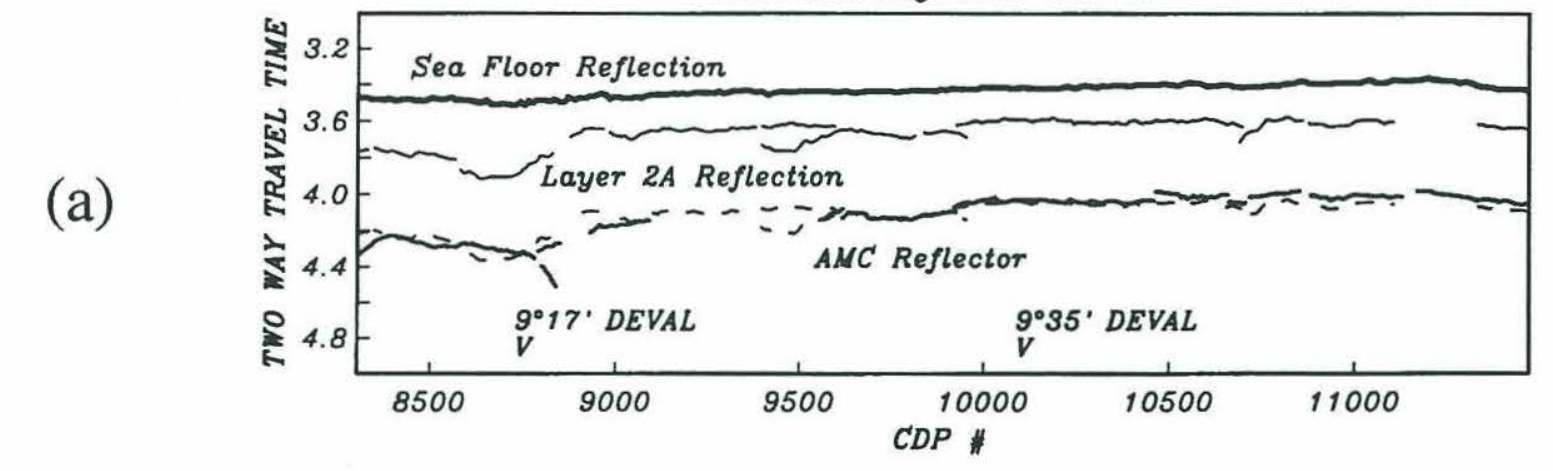

Wandering of Ship Track: LINE CDP 41

(b)

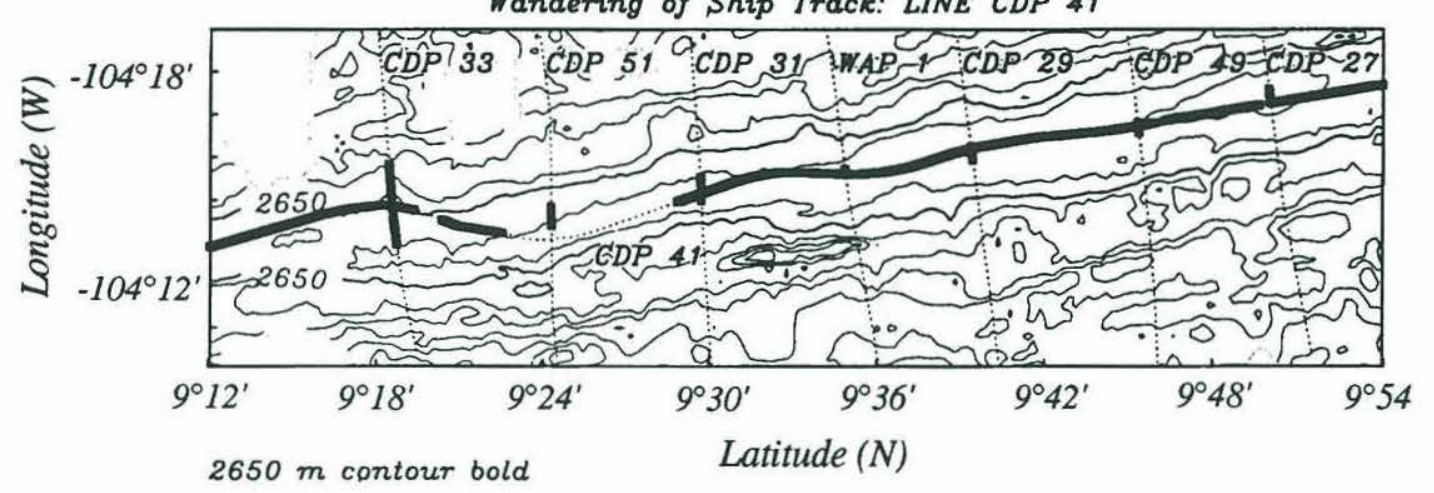

(c)

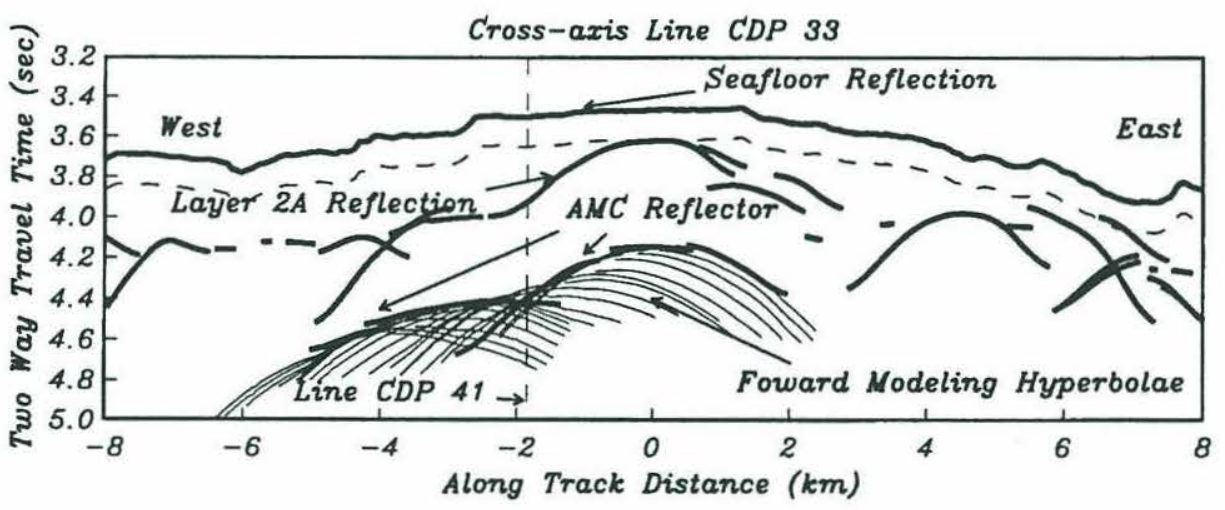

(d)

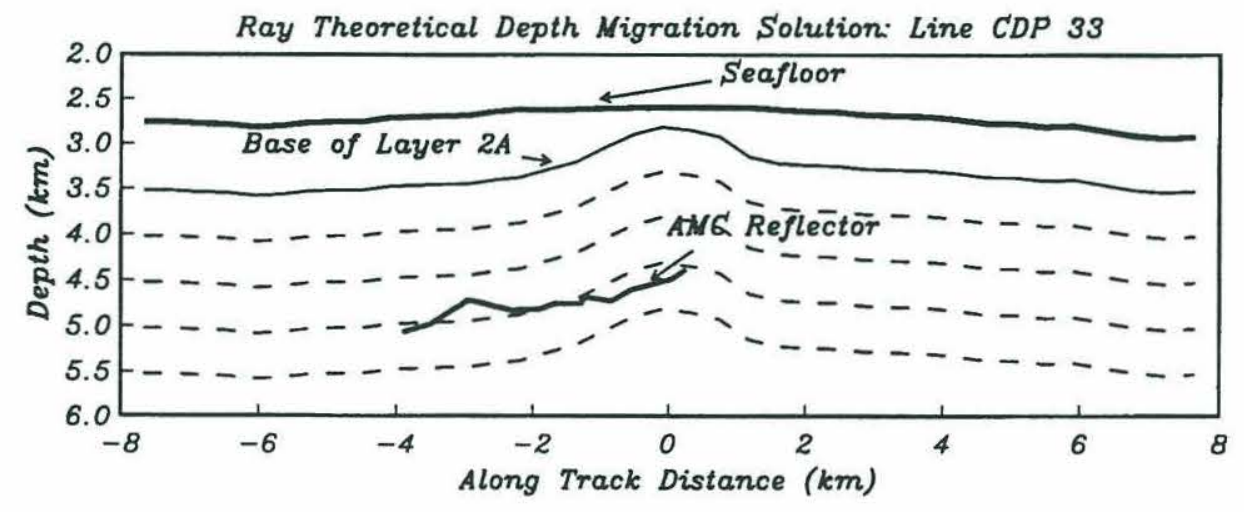

Kent et al. [1993a] 
Figure 2.3. Location of the 12 ship tracks whose Sea Beam swaths were used in this study to map the distribution of fault zones and determine their characteristics. The ship tracks are labeled from A to L; the axis of the EPR is shown as a dashed line. 


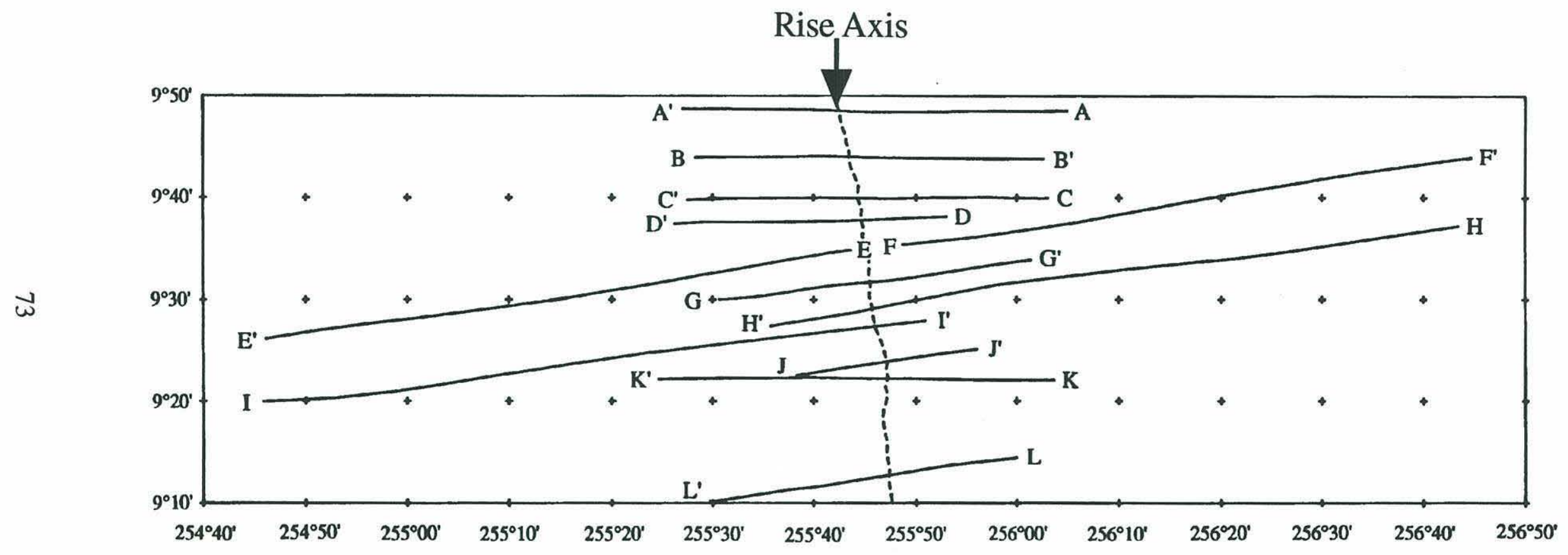

氶 
Figure 2.4. Schematic illustration of two types of normal fault zones, one in which offset occurs principally on a single fault (top) and one with closely spaced, multiple faults (bottom). A thick solid line denotes the exposed fault scarp, and dashed lines illustrate possible continuation of fault planes at depth. Because of limitations in the resolution of Sea Beam, these two types of fault zones may not be distinguishable from one another. 


\section{Types of Fault Zone}

A fault zone with a single fault

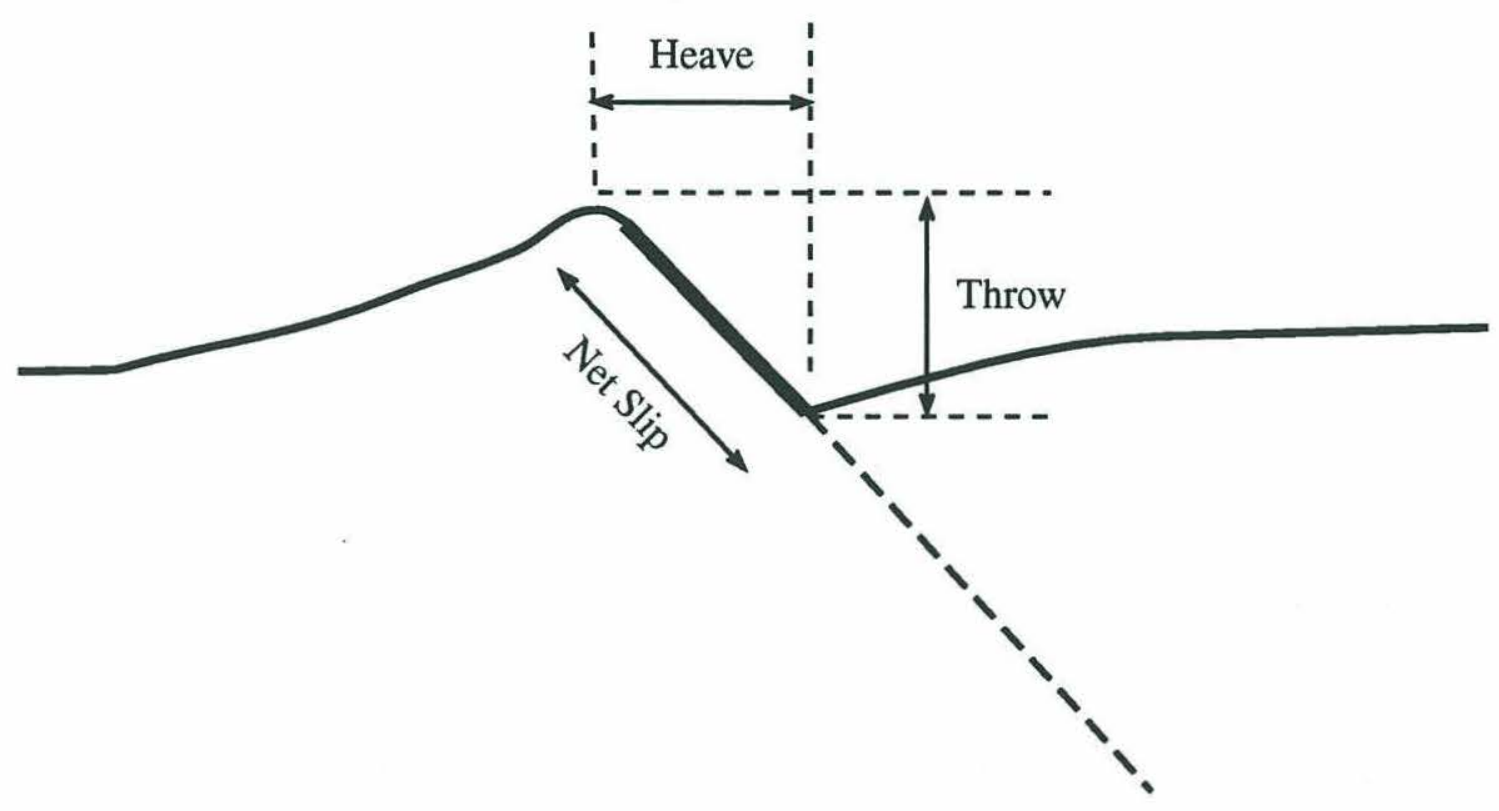

A fault zone with multiple faults

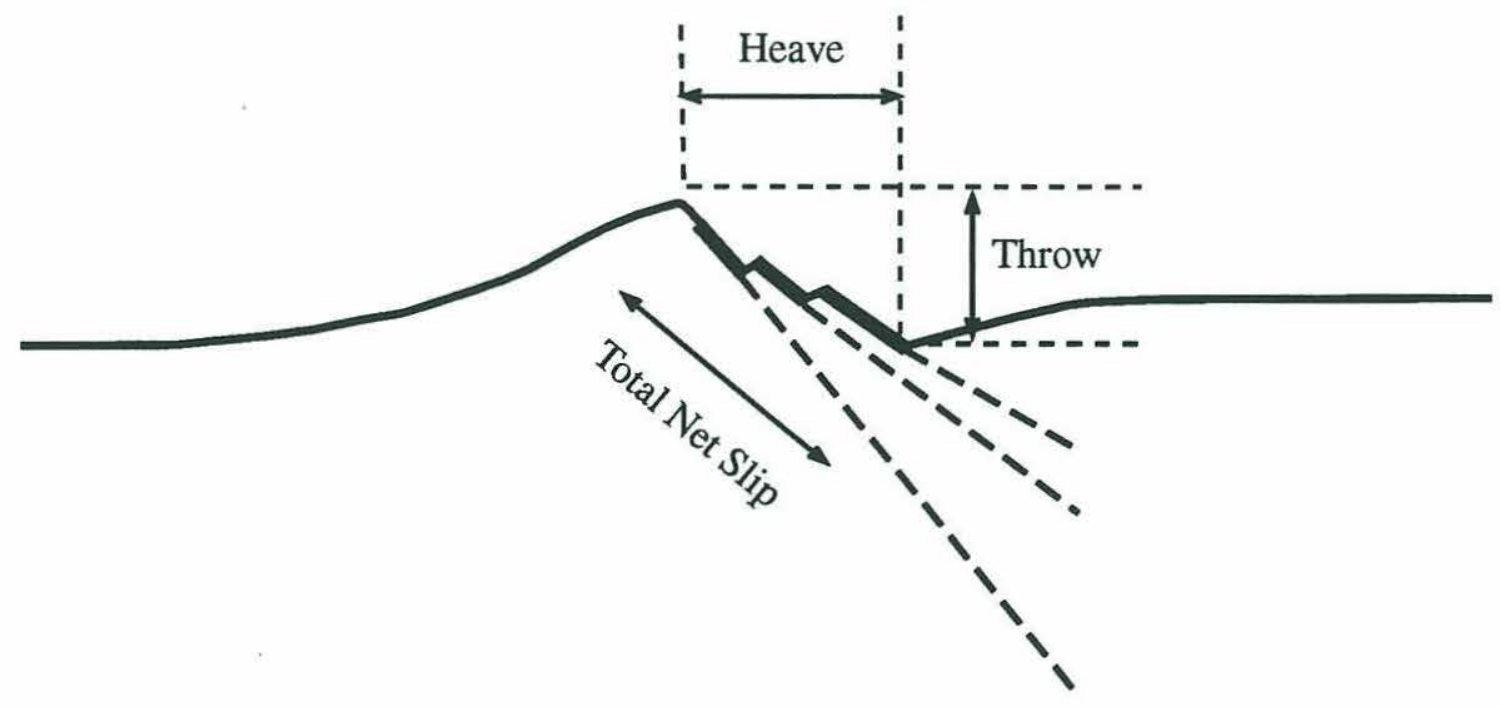


Figure 2.5. An illustration of the scheme used for identifying a fault zone from gridded Sea Beam data. A plane is constructed from three adjacent grid points. The magnitude of the dip angle $\alpha$ is used as a criterion for whether the grid surface element represents a portion of a fault zone. 


\section{Gridded Sea Beam Swath}
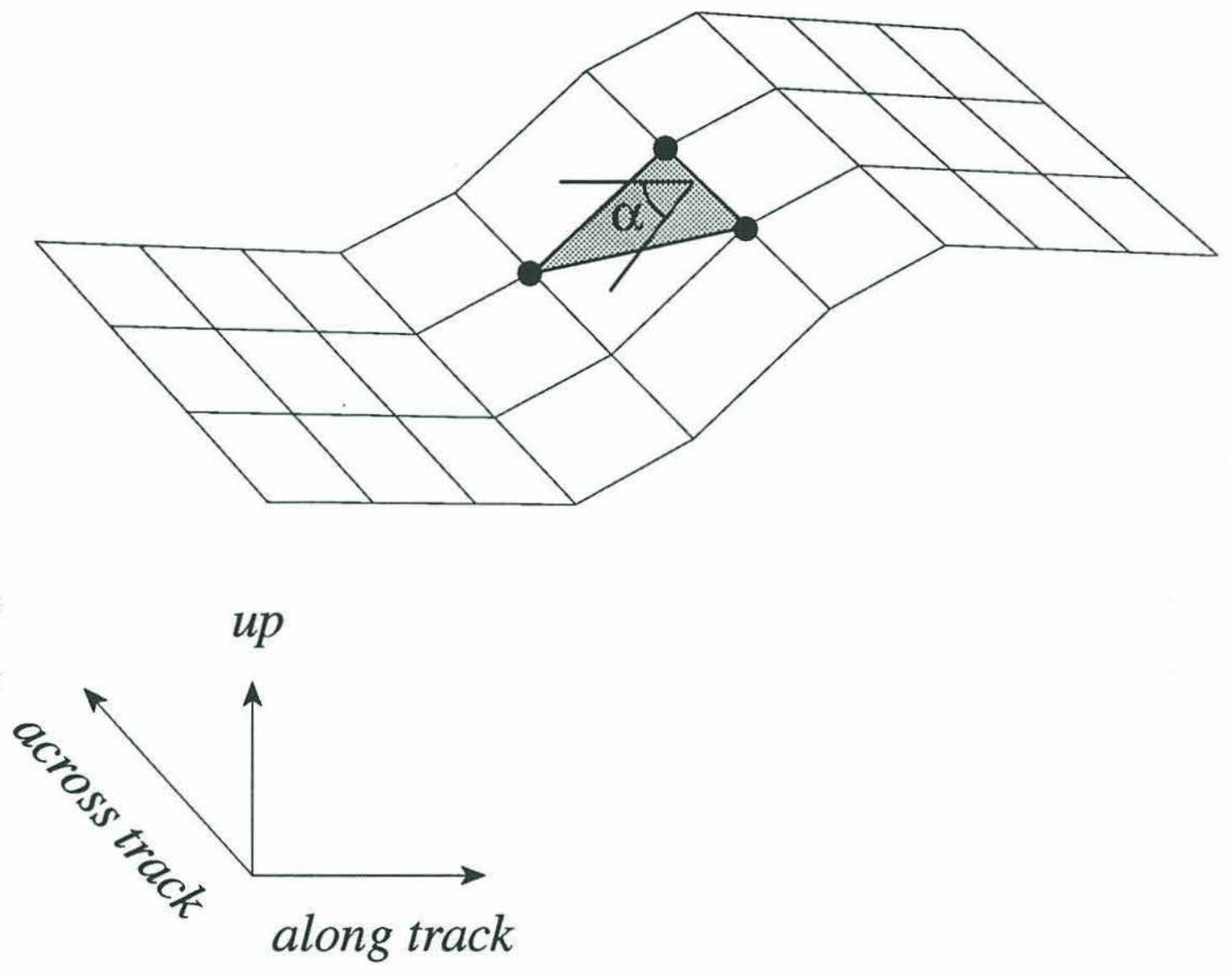
Figure 2.6. Percent of plan-view seafloor area composed of fault zones (dip $>30^{\circ}$ ) versus distance from the spreading axis: (a) inward-facing and (b) outward-facing fault zones on the Pacific plate; (c) inward-facing and (d) outward-facing fault zones on the Cocos plate. Dip calculations were made with gridded Sea Beam data. The data have been grouped into $5-\mathrm{km}$-wide bins parallel to the spreading axis. Because of limited coverage, the results beyond $30 \mathrm{~km}$ are more uncertain than those closer to the axis and are plotted as dotted lines. Distance from the axis can be converted to age by the rule that 1 My corresponds to approximately $55 \mathrm{~km}$. 


\section{Plan-View Area of Fault Zones Using All Gridded Data}

(a) Inward-facing fault zones on Pacific plate

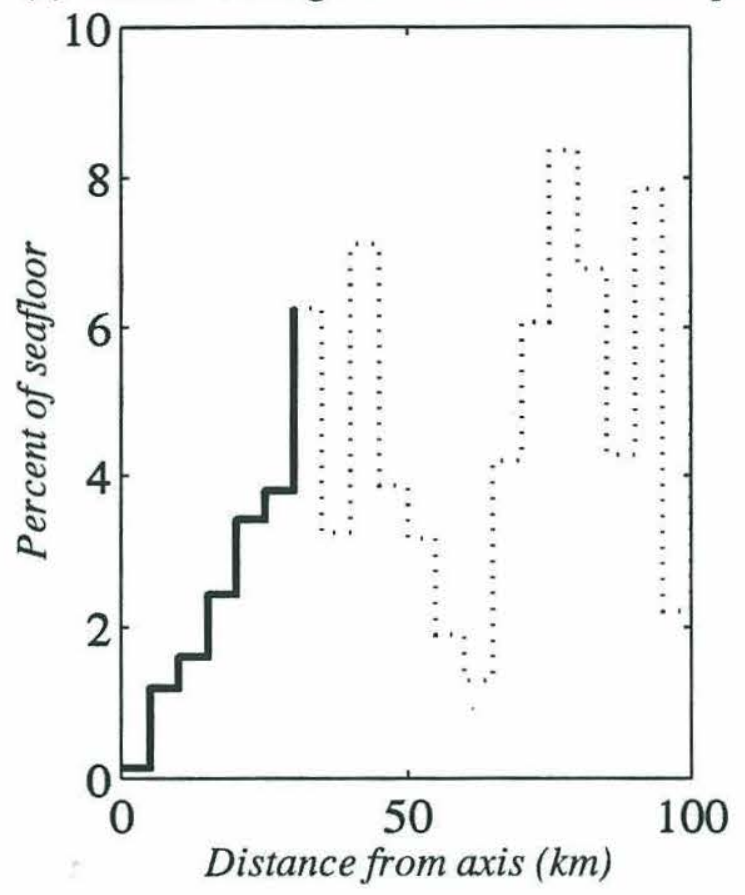

(c) Outward-facing fault zones on Pacific plate

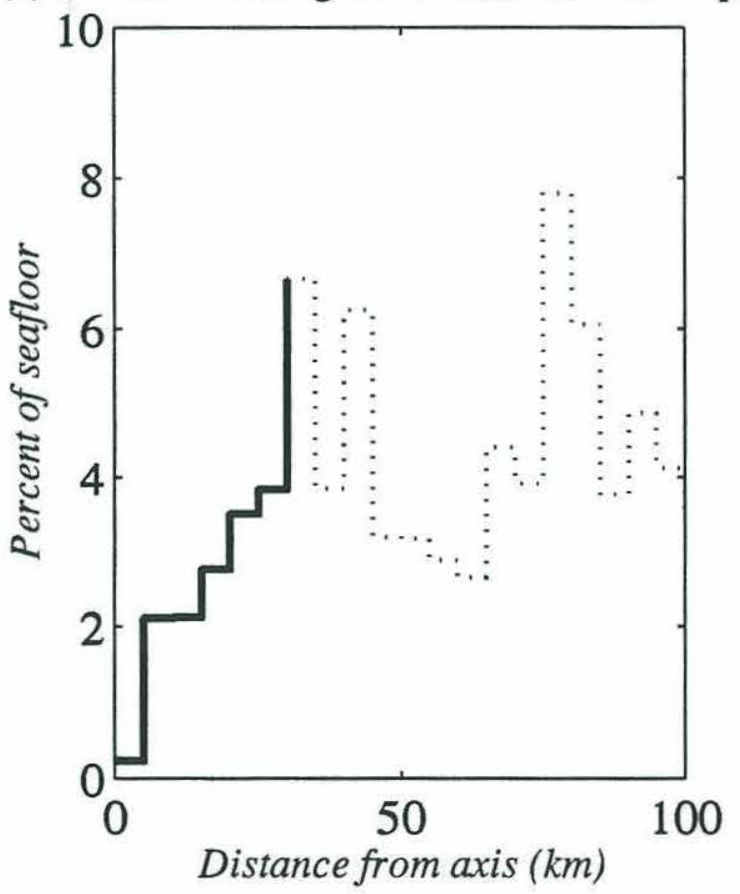

(b) Inward-facing fault zones on Cocos plate

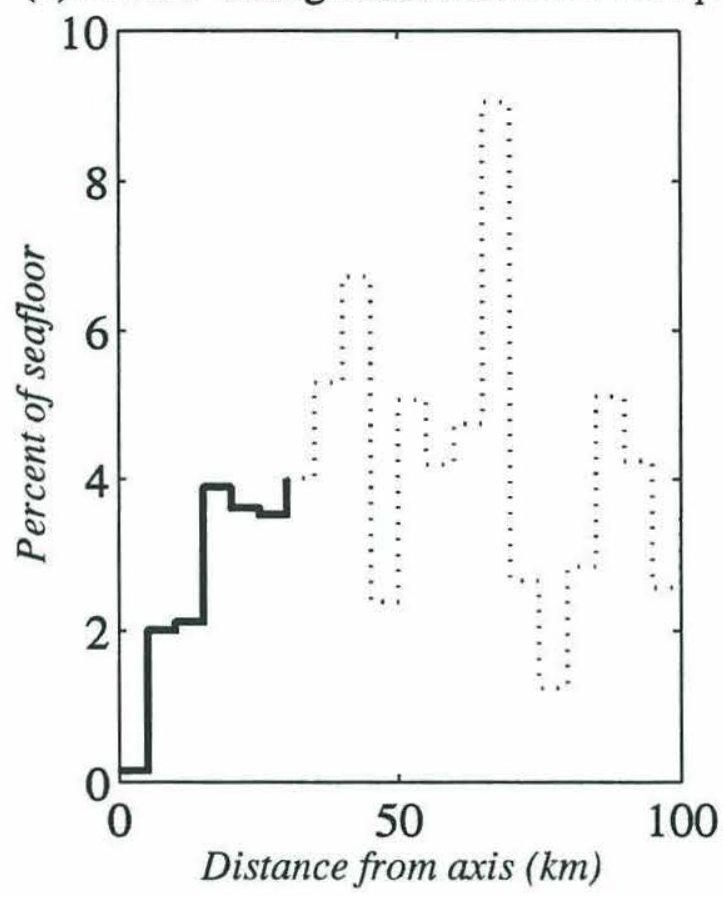

(d) Outward-facing fault zones on Cocos plate

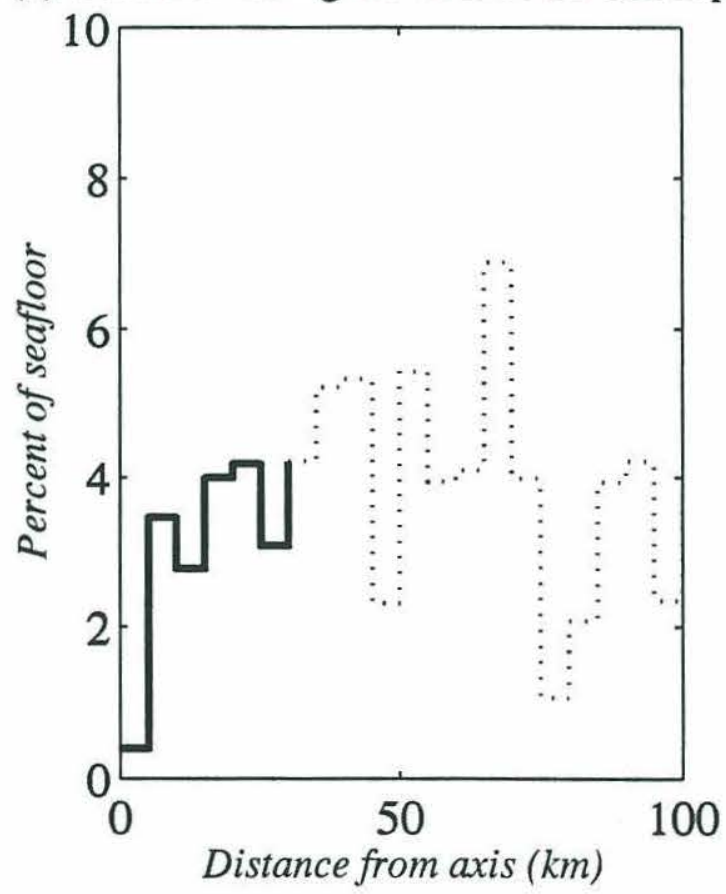


Figure 2.7. Rose diagram of the strike directions of fault zones, obtained from gridded bathymetry in swath A (Figure 2.3) using the grid element method noted in Figure 2.5. The dominant strike direction is parallel to the rise axis. 


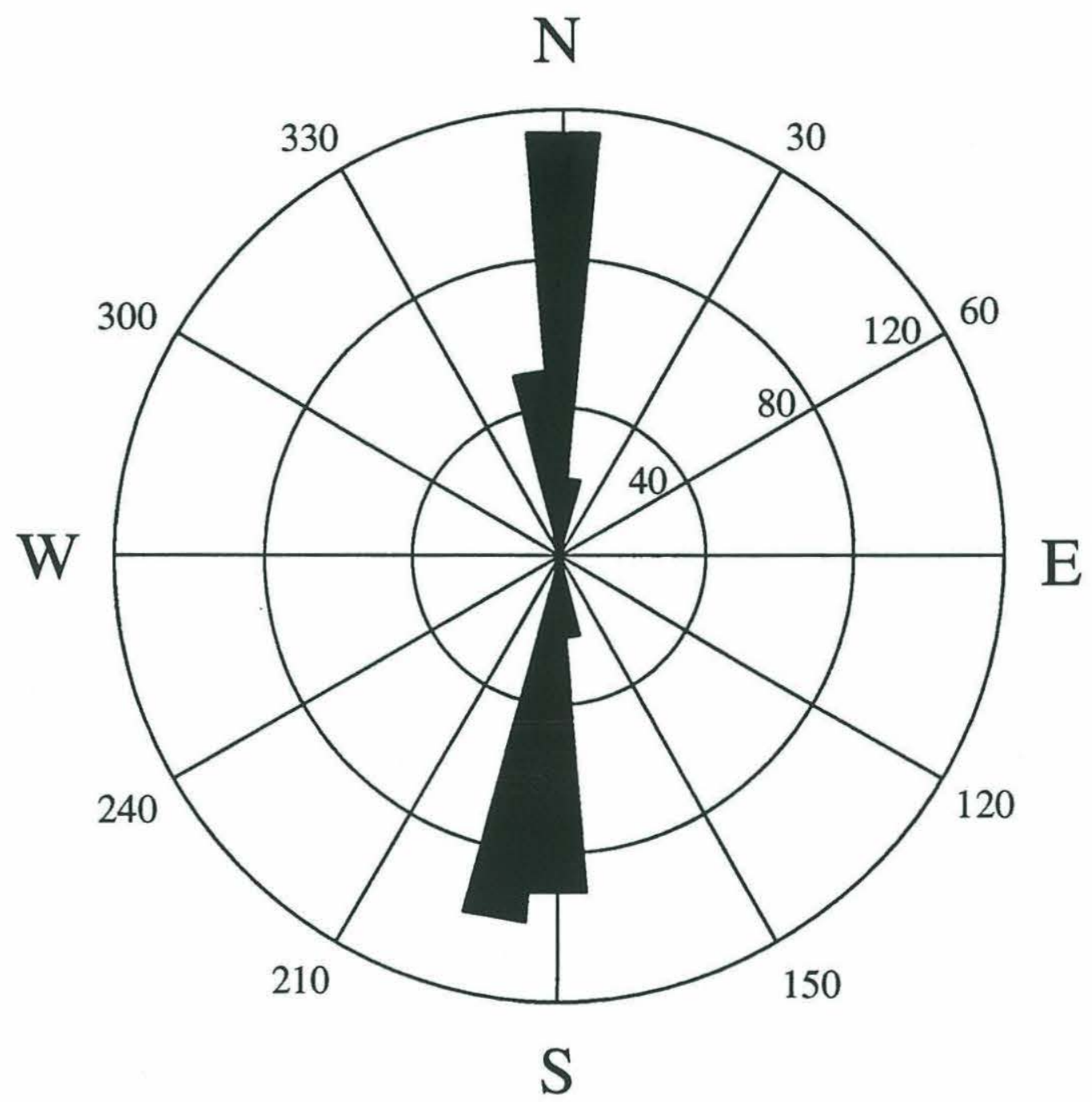

(Figure 2.7) 
Figure 2.8. An illustration of the scheme for identifying and characterizing fault zones from Sea Beam swath data. (Top) A schematic bathymetric profile obtained by averaging the beams perpendicular to the spreading direction. (Bottom) Slopes (filled circles) calculated from the bathymetric profile and classified into five bins (greater than $20^{\circ}$, between $10^{\circ}$ and $20^{\circ}$, between $-10^{\circ}$ and $10^{\circ}$, between $-20^{\circ}$ and $-10^{\circ}$, and less than $20^{\circ}$ ). A running window operation is performed with 6 windows, each $25 \mathrm{~m}$ along track. A fault zone is considered to be present when the absolute magnitude of the dip in a window exceeds $20^{\circ}$, and the edge of the zone to have been passed when $75 \%$ of the slope values in the running window have an absolute magnitude of dip less than $10^{\circ}$. 


\section{Stacked Sea Beam Profile}

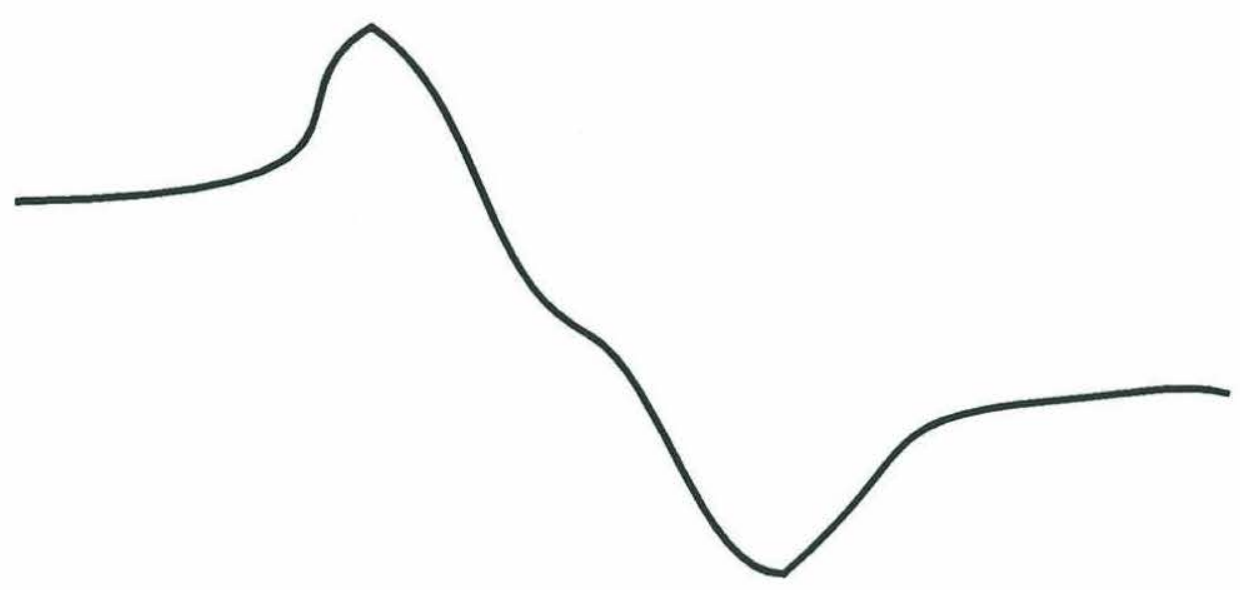

running window

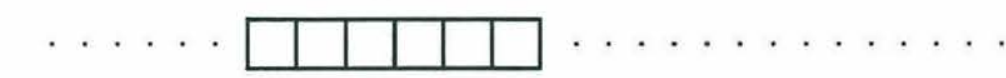

\begin{tabular}{|c|}
\hline 品 \\
\hline 品 \\
\hline 品 \\
\hline 品 \\
\hline 品 \\
\hline
\end{tabular}

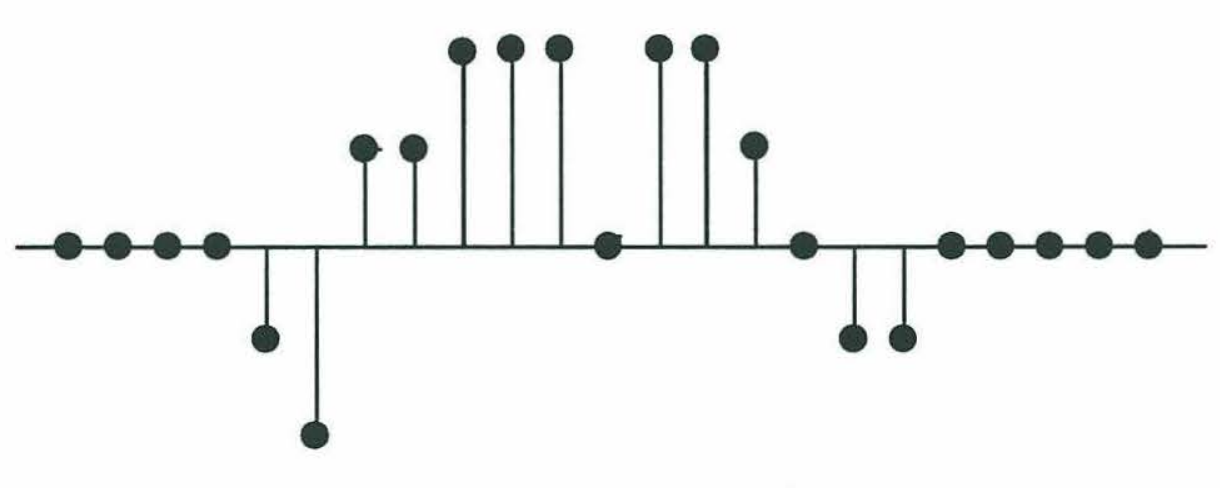


Figure 2.9. Two examples of fault zones identified from Sea Beam swath data (tracks A and G). Shown here are traces of only 13 of the 16 beams, because there often are no seafloor returns in outer beams. For each plot, crosses beneath the trace denote the apparent heave and throw of fault zones as determined in Figure 2.8. The top and bottom rows of crosses represent positive and negative polarities of fault-zone dip direction. The position of the spreading axis is indicated by the arrows. 


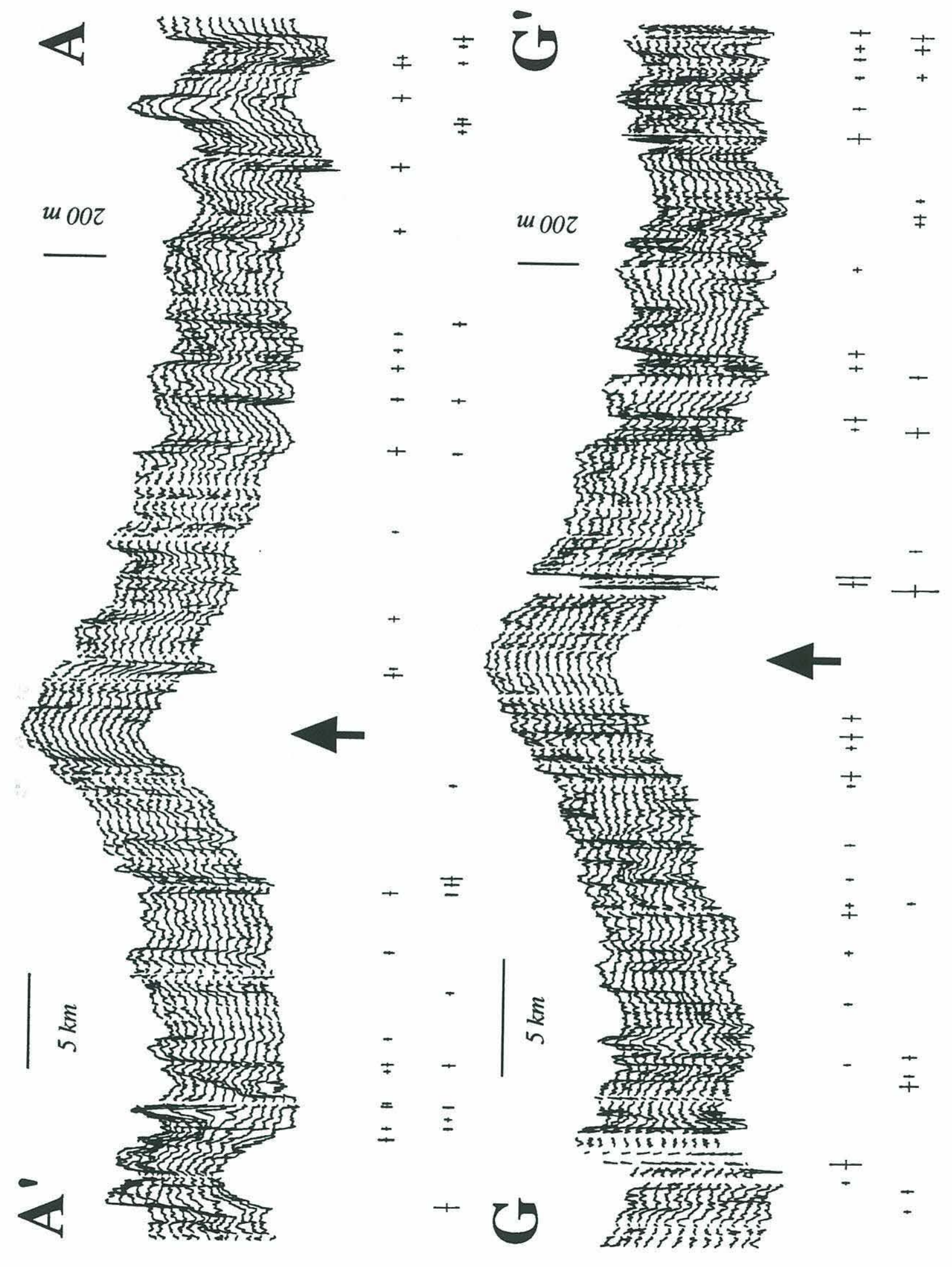


Figure 2.10. Schematic illustration of the effects of mass wasting. (a) The heave and throw are the horizontal and vertical components, respectively, of displacement on a single normal fault. (b) Despite no further fault movement, mass wasting can cause the apparent heave to become greater than the heave of the original fault. On the other hand, the apparent throw will be reduced because of deposition at the base of the fault zone. 


\section{Effects of Mass Wasting}

(a) Original Fault

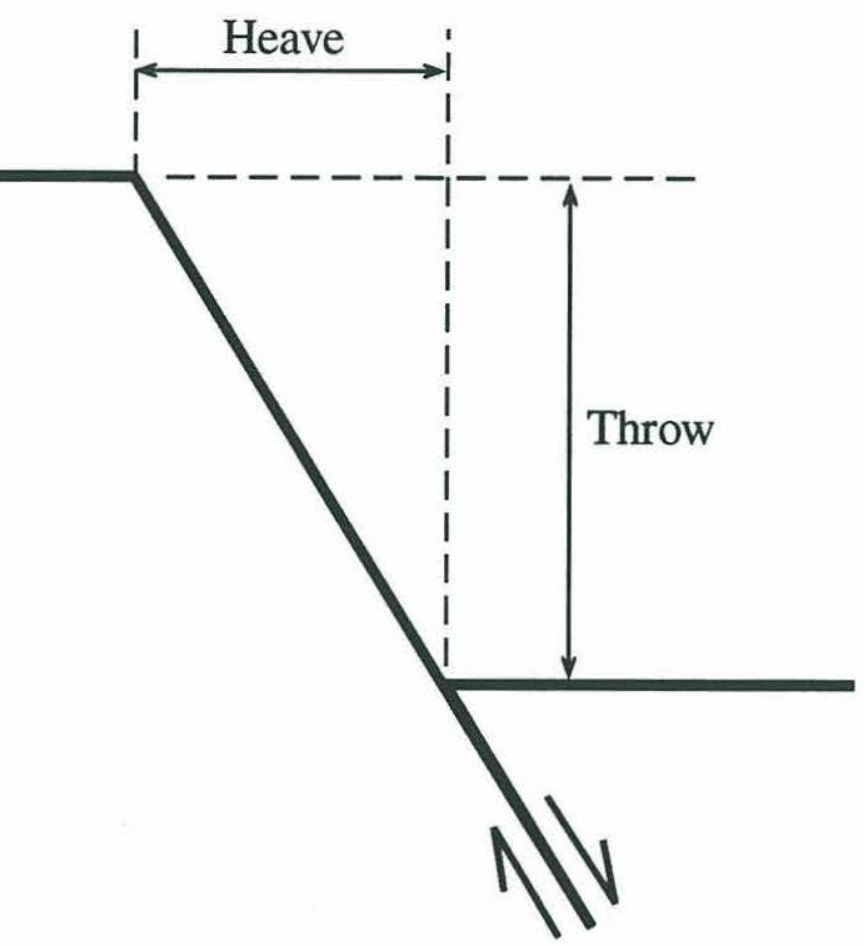

(b) Mass Wasting with No Further

Fault Movement

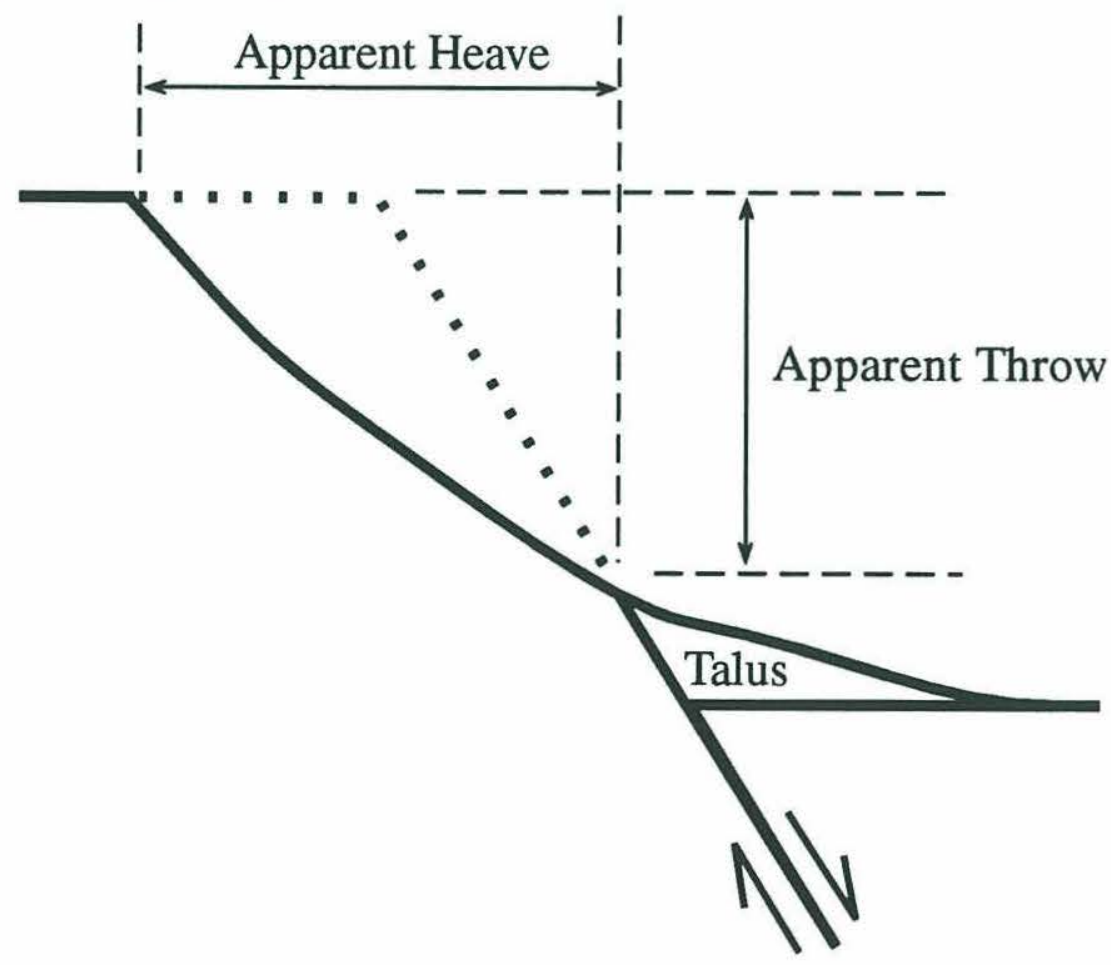


Figure 2.11. Schematic illustration of the effects of sedimentation. (a) In the case where sediment accumulation occurs in the form of a uniform drape, heave and throw will replicate true heave and throw. (b) However, if there is remobilization of sediment from topographic highs to lows, it will reduce the apparent throw. Apparent heave may be increased. 


\section{Effects of Sedimentation}

(a) Even Drape

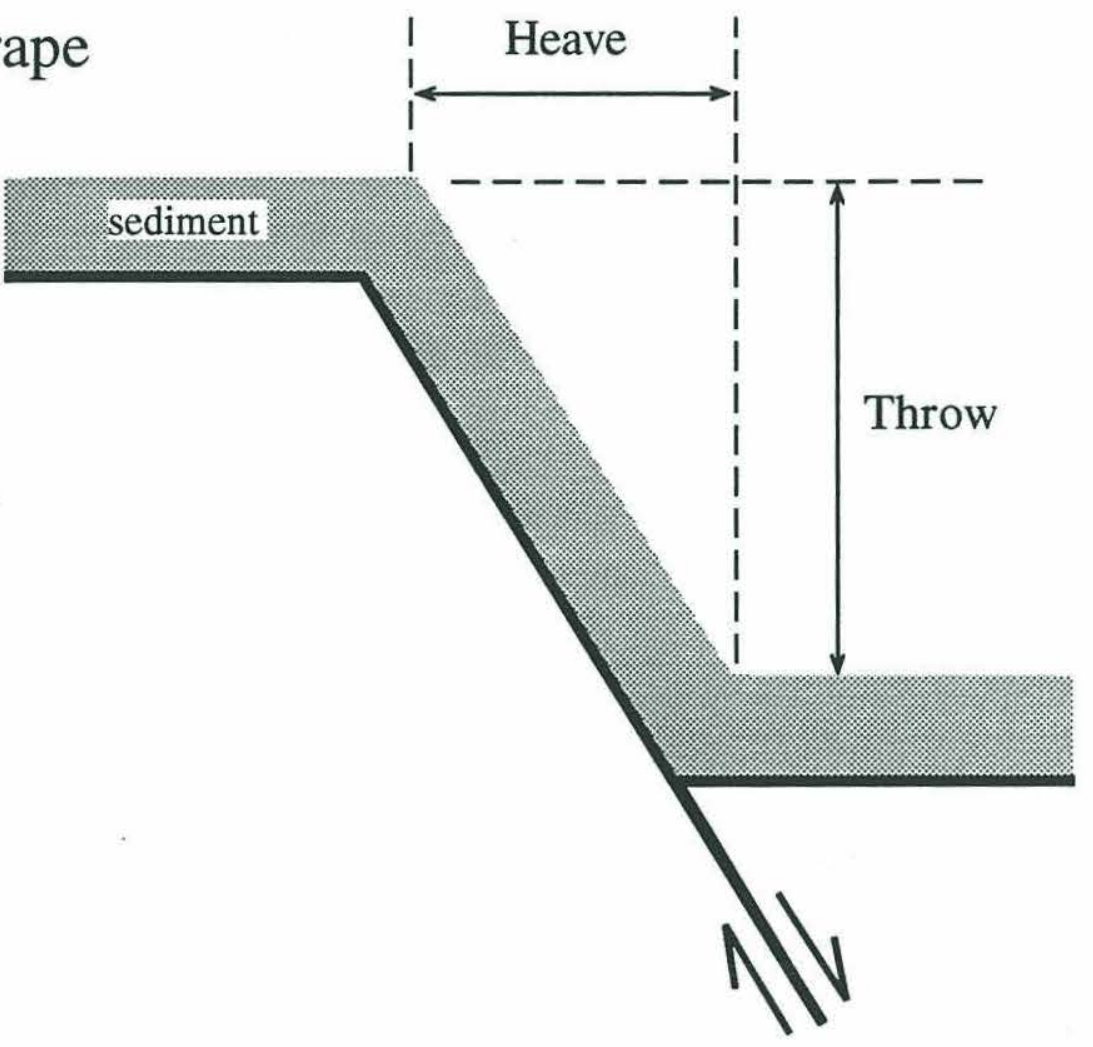

(b) After Remobilization of Sediment from Topographic Highs to Lows

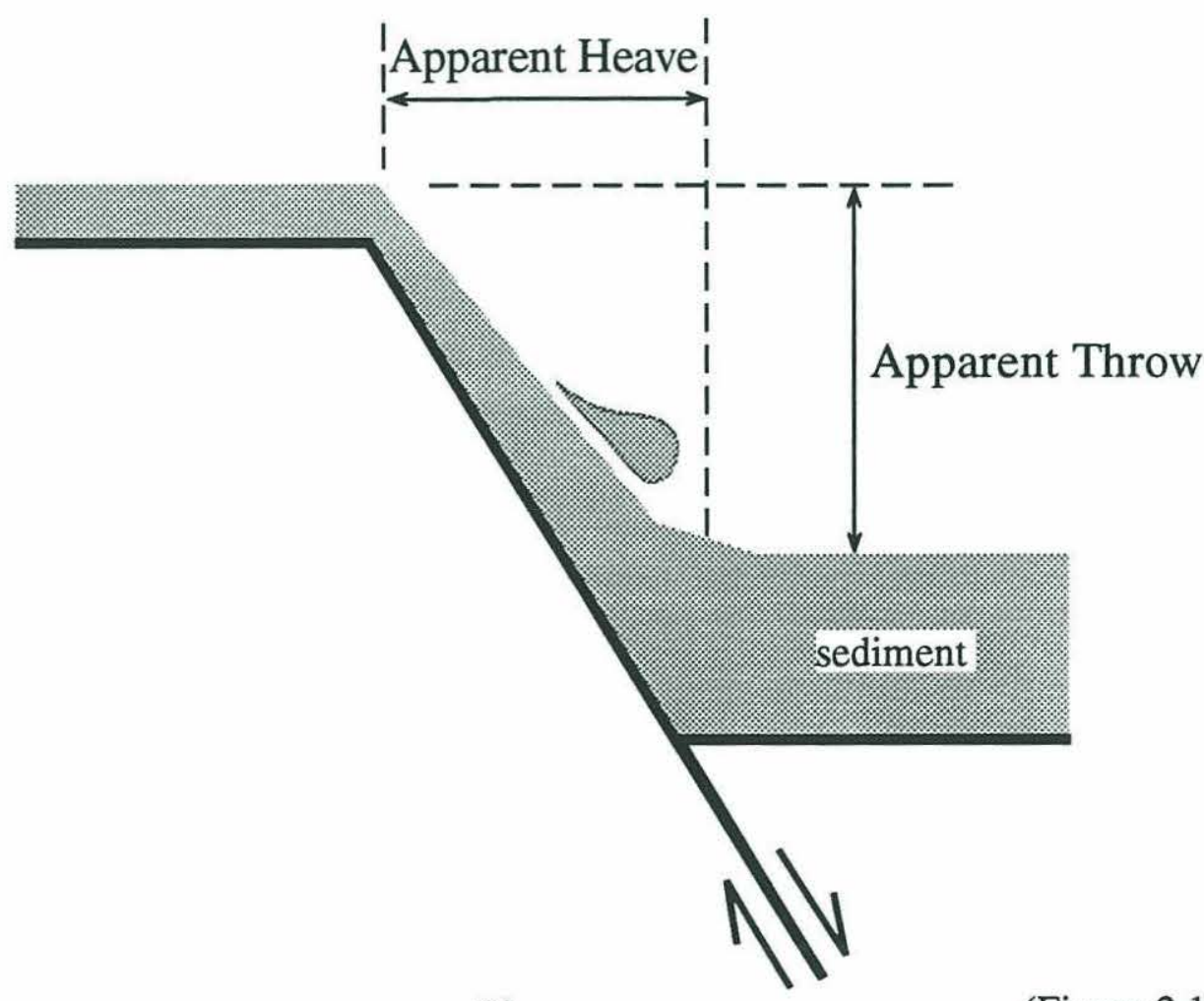


Figure 2.12. Percent of plan-view seafloor area (within a 5-km-wide isochron bins) composed of fault zones (dip $>30^{\circ}$ ) versus distance from the spreading axis, but without the data from tracks $\mathrm{K}$ and L (Figure 2.3): (a) inward-facing and (b) outward-facing fault zones on the Pacific plate; (c) inward-facing and (d) outward-facing fault zones on the Cocos plate. The removal of data from tracks $\mathrm{K}$ and $\mathrm{L}$ does not significantly affect the pattern of increasing fault-zone area with distance from the spreading axis observed in Figure 2.6. 


\section{Plan-View Area of Fault Zones Excluding K \& L from Gridded Data}

(a) Inward-facing fault zones on Pacific plate

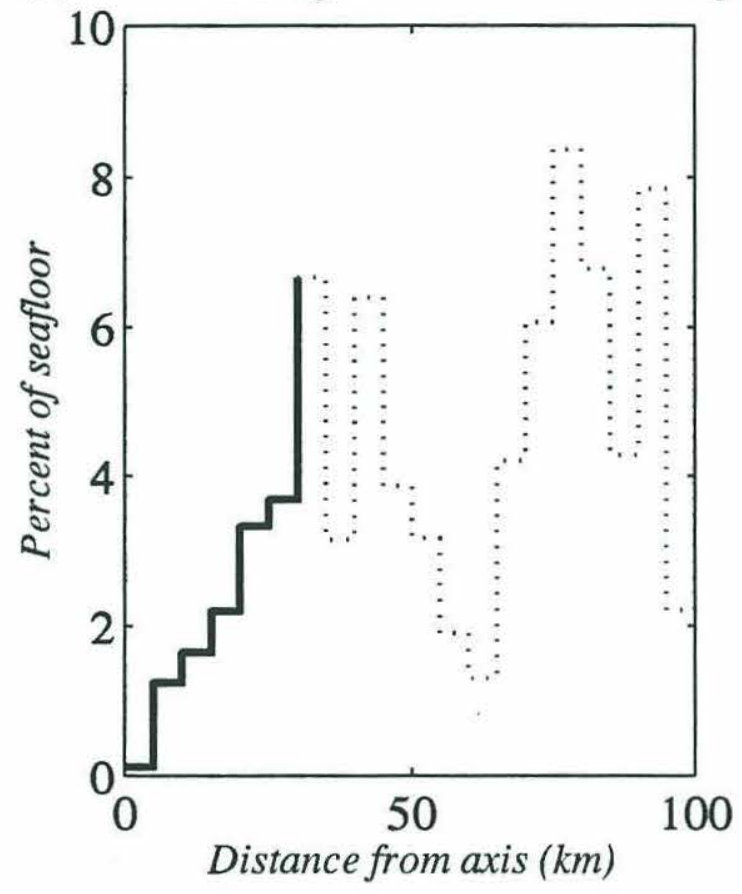

(c) Outward-facing fault zones on Pacific plate

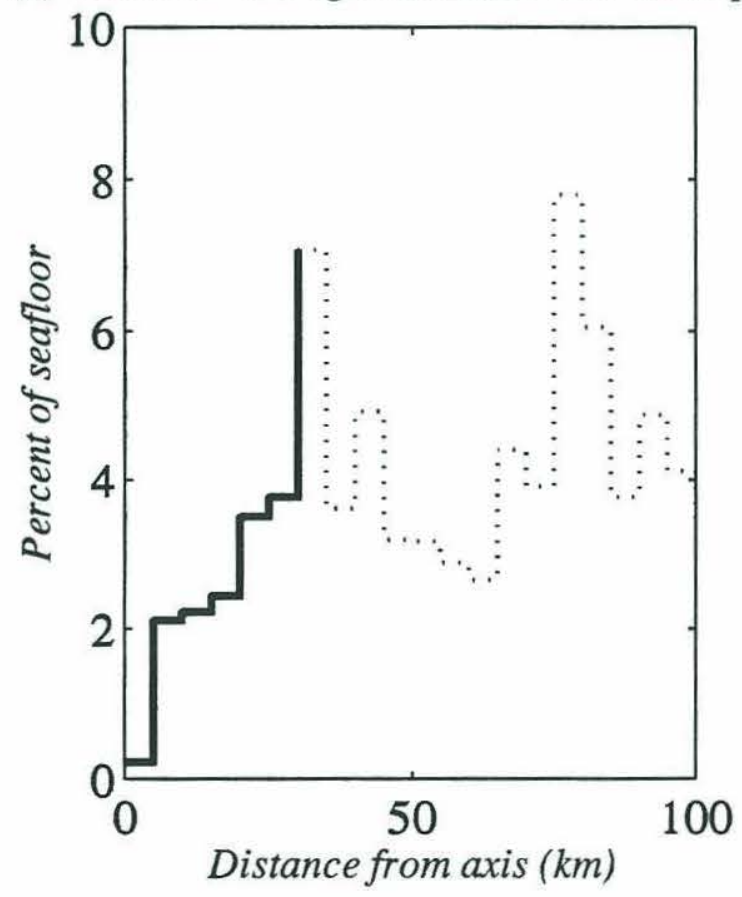

(b) Inward-facing fault zones on Cocos plate

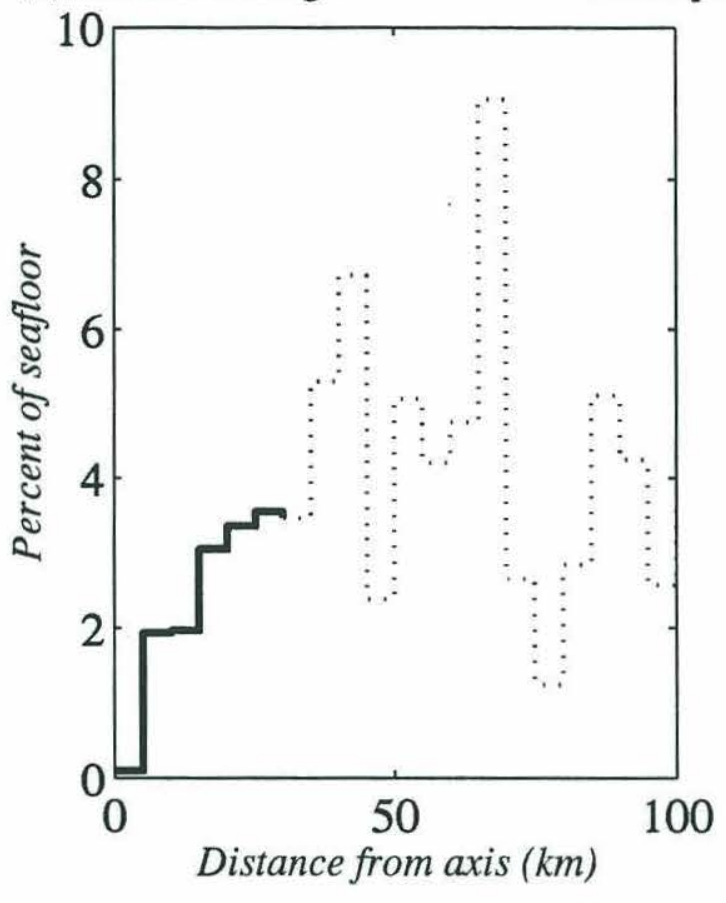

(d) Outward-facing fault zones on Cocos plate

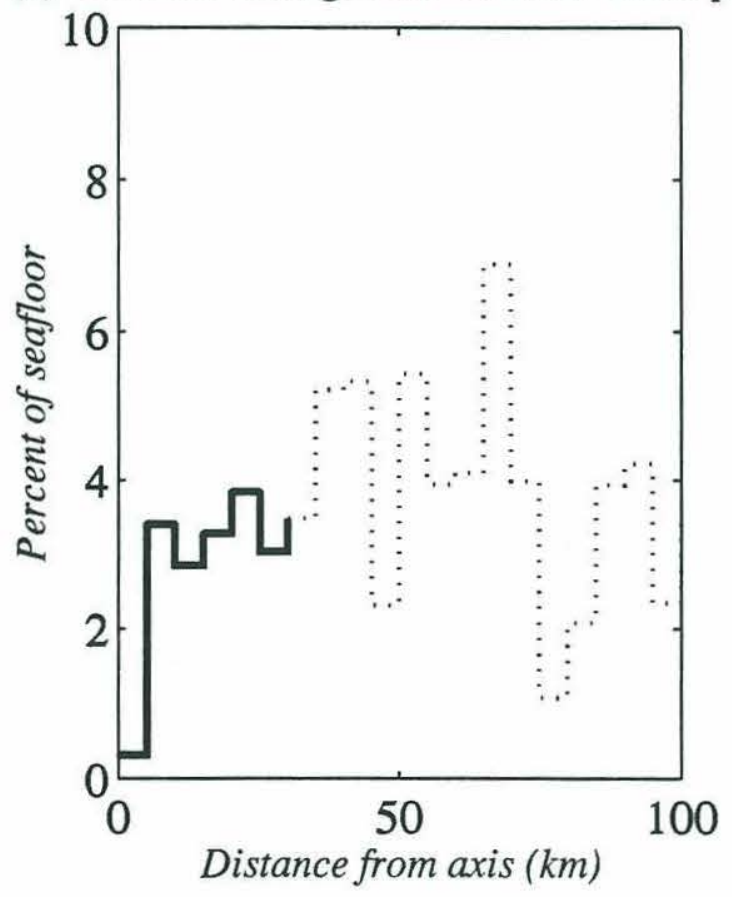


Figure 2.13. The total apparent throw of fault zones within successive $10-\mathrm{km}$-wide isochron bins versus distance from the EPR axis. Calculations were based on Sea Beam swath data. The solid line is based on all fault zones within each 10-km-wide isochron bin. The dashed line is based only on fault zones that comprise the top quartile by throw (Figure 2.14). This upper quartile accounts for more than half of the total throw for all fault zones. The results are normalized by the number of swaths contributing to each bin. Again, due to limited coverage, the results beyond $35 \mathrm{~km}$ are plotted as dotted lines (note that we have 4-5 tracks covering each side of the rise axis out to $35 \mathrm{~km}$ from the axis). 


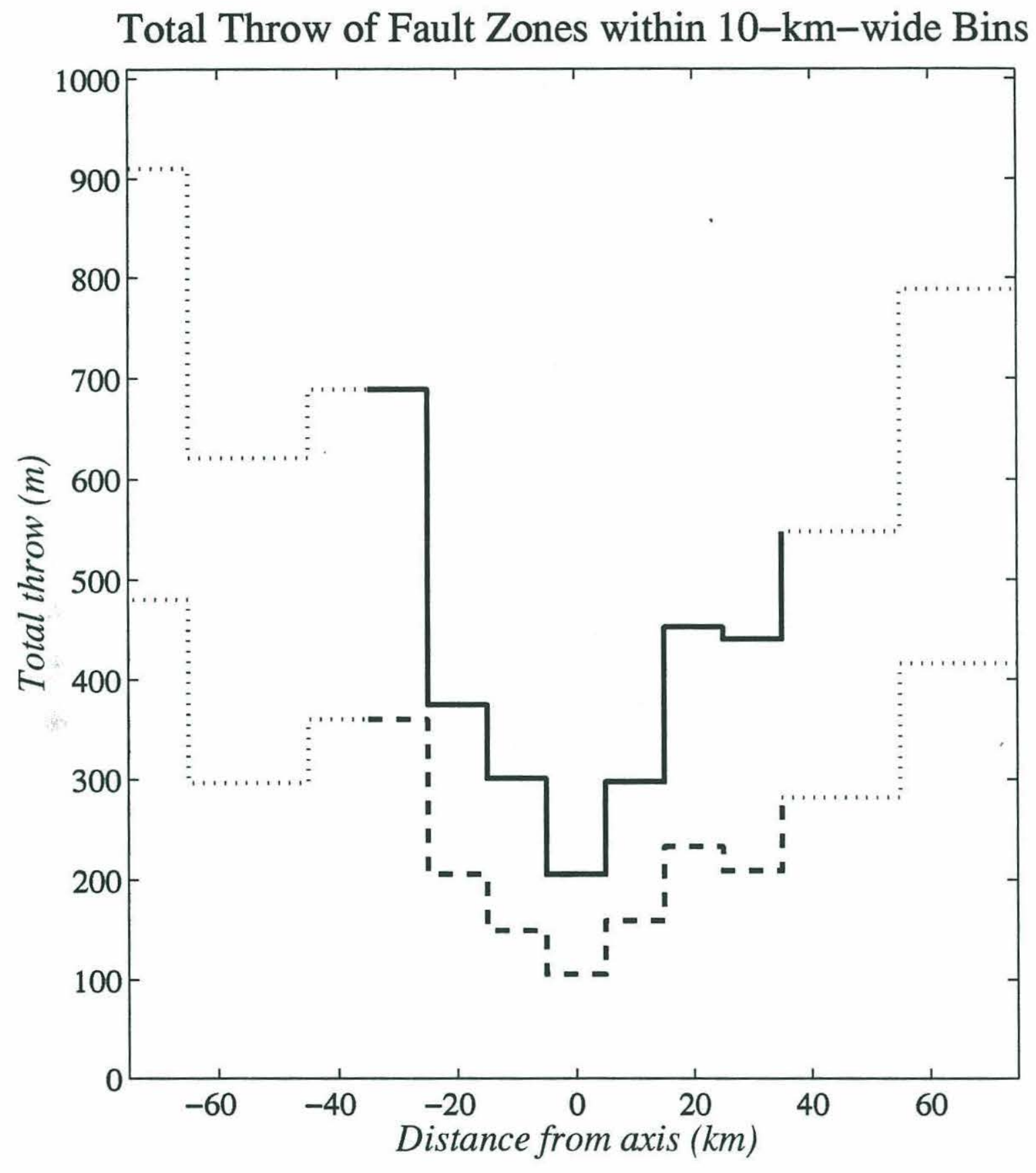


Figure 2.14. The distribution of fault zones by apparent throw. Fault zones with small apparent throw show the highest frequency of occurrence. The upper quartile of fault zones corresponds to apparent throws greater than $45 \mathrm{~m}$. 


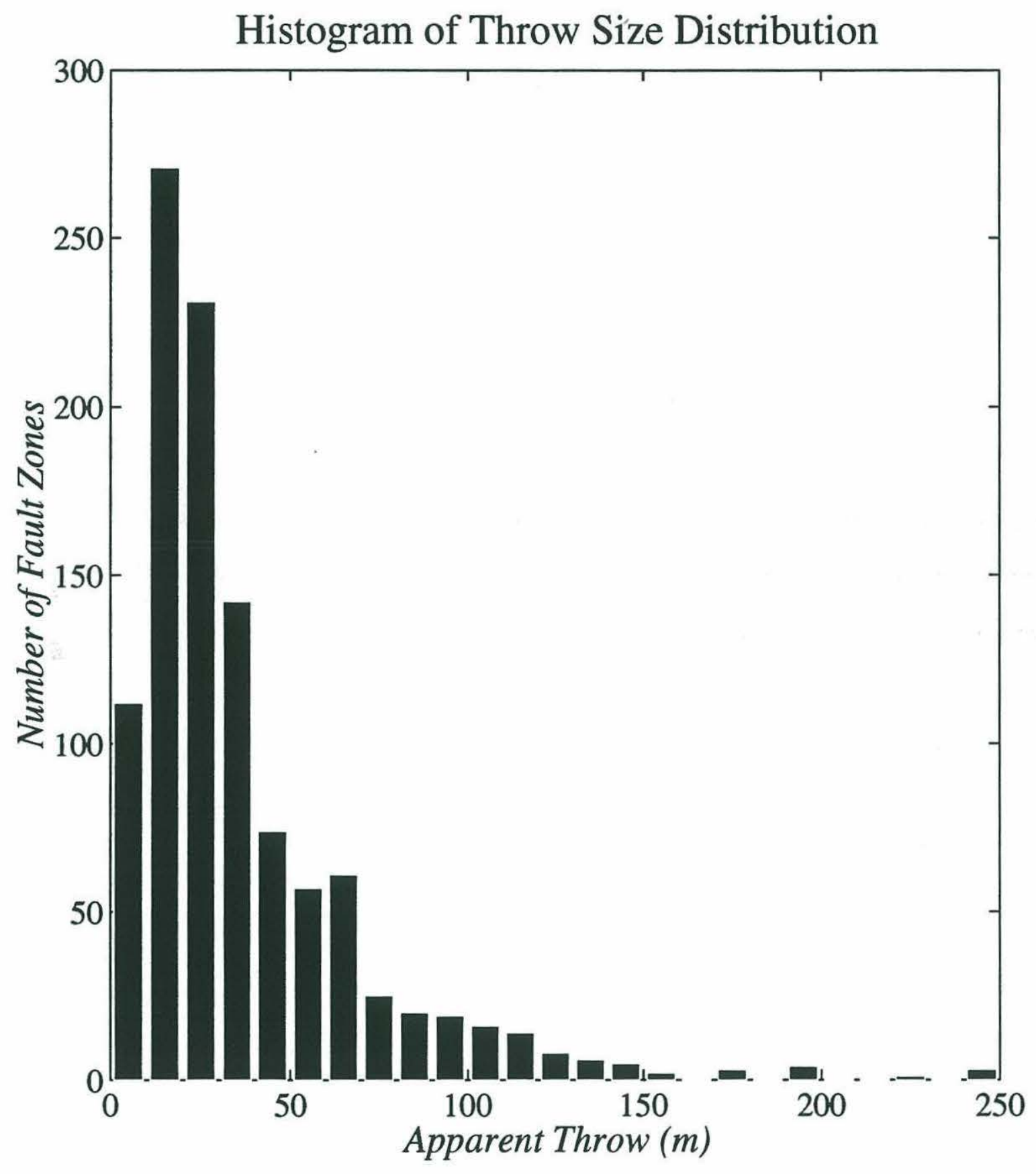


Figure 2.15. The total apparent throw of fault zones within 10-km-wide isochron bins versus distance from the EPR axis with data from tracks $\mathrm{K}$ and $\mathrm{L}$ excluded. The results beyond $35 \mathrm{~km}$ are plotted as dotted lines. 


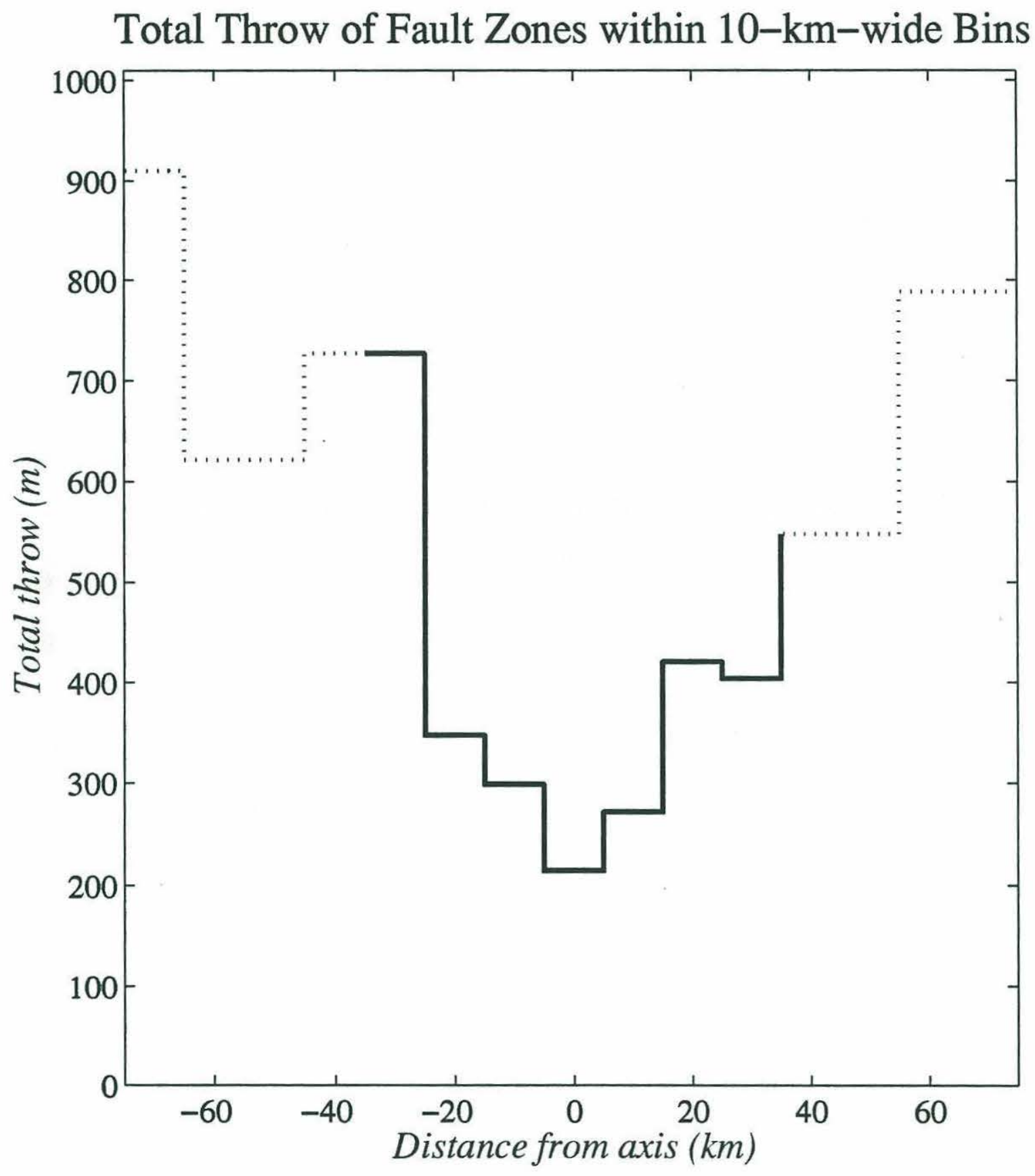


Figure 2.16. The average apparent throw of fault zones within 10-km-wide isochron bins versus distance from the EPR axis. The results beyond $35 \mathrm{~km}$ are plotted as dotted lines. 


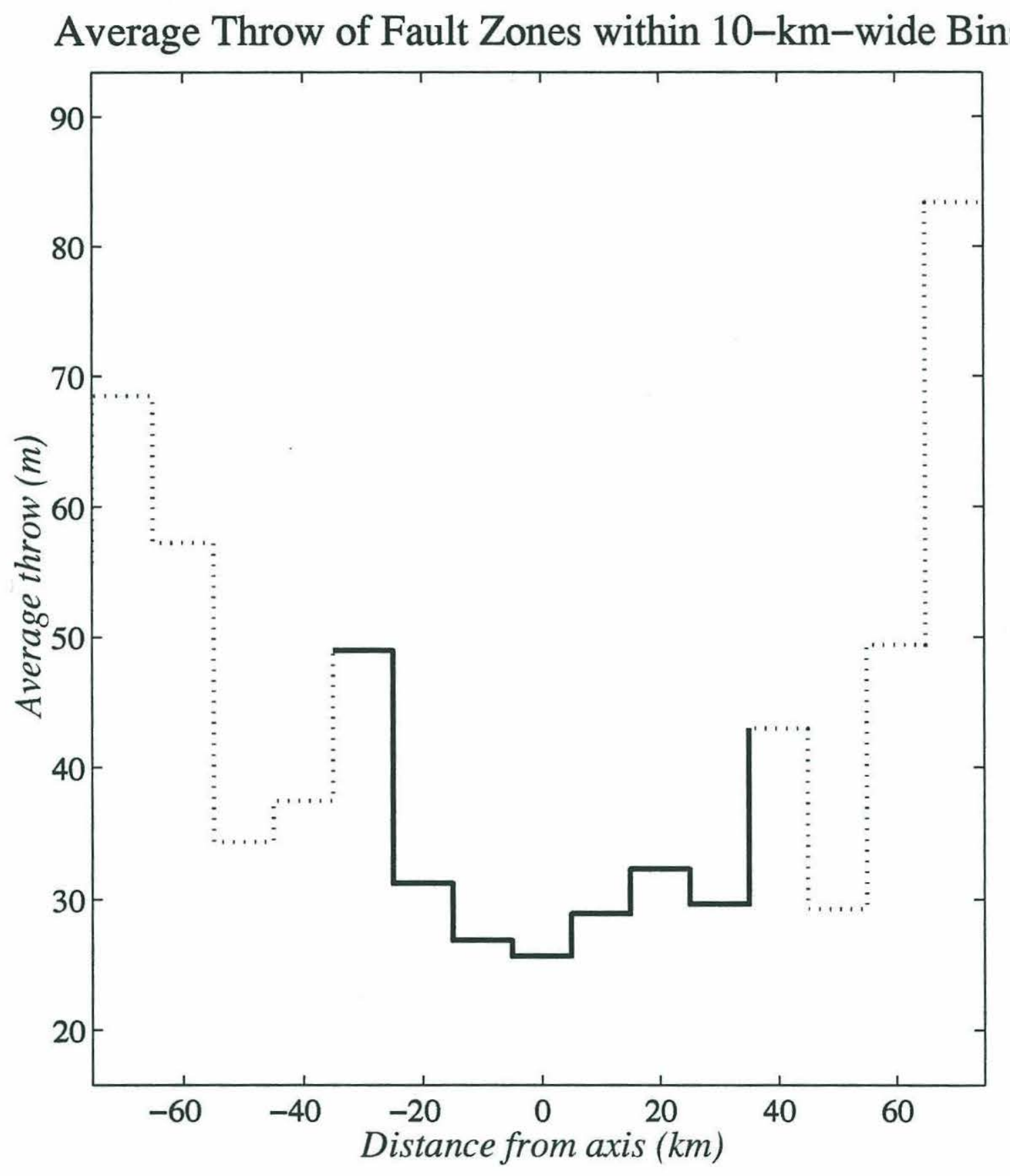


Figure 2.17. Variation in distance from the spreading axis to the first large-offset fault zone (apparent throw greater than $20 \mathrm{~m}$ ), coded by profile (Figure 2.3). The EPR axis is shown as a dashed line. 


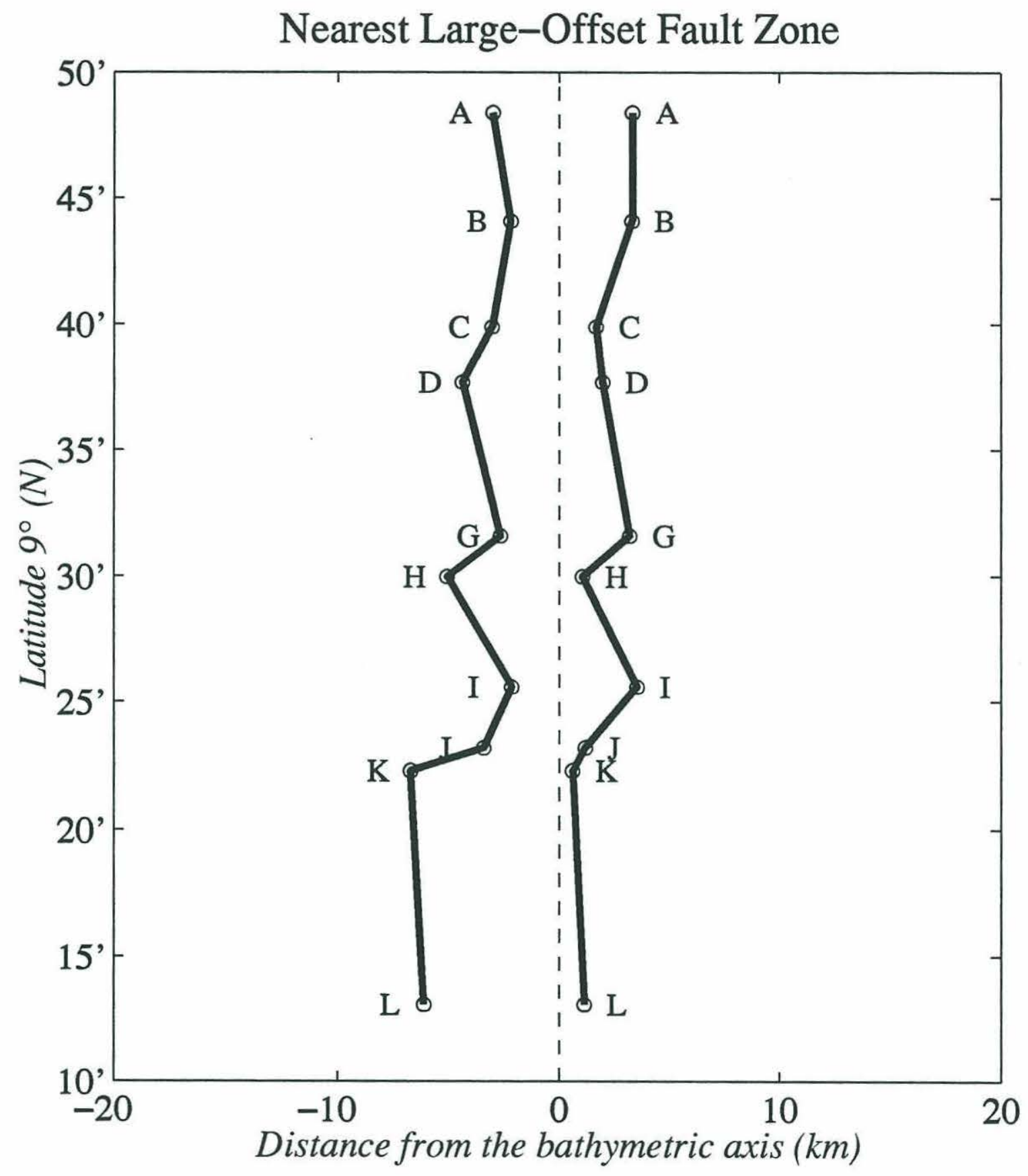


Figure 2.18. Two models of the temperature distribution at a fast-spreading mid-ocean ridge. (a) Isotherms (in ${ }^{\circ} \mathrm{C}$ ) for the thermal model of Lin and Parmentier [1989], which include the effects of lithospheric thickening on mantle flow, the latent heat of magmatic solidification at the ridge axis, and hydrothermal circulation in the crust. In this particular model, the Nusselt number in a permeable layer of $6 \mathrm{~km}$ thickness is 10 and the spreading half-rate is $50 \mathrm{~mm} / \mathrm{yr}$. The dashed line represents the base of the crust at a depth of $6 \mathrm{~km}$, and material at a temperature less than $400^{\circ} \mathrm{C}$ is shown as shaded. (b) The near-axis thermal model of Wilson et al. [1988] for a slab spreading at a constant velocity (61 mm/yr spreading half-rate) from a narrow, continuously intruding, vertical dike. The lightly shaded area represents material at a temperature of $1150^{\circ} \mathrm{C}$, and upper crust at temperatures less than $400^{\circ} \mathrm{C}$ is shown by darker shading. Plus and minus symbols indicate discrete sources and sinks of heat used as input to the model. 
(a) Lin and Parmentier [1989]

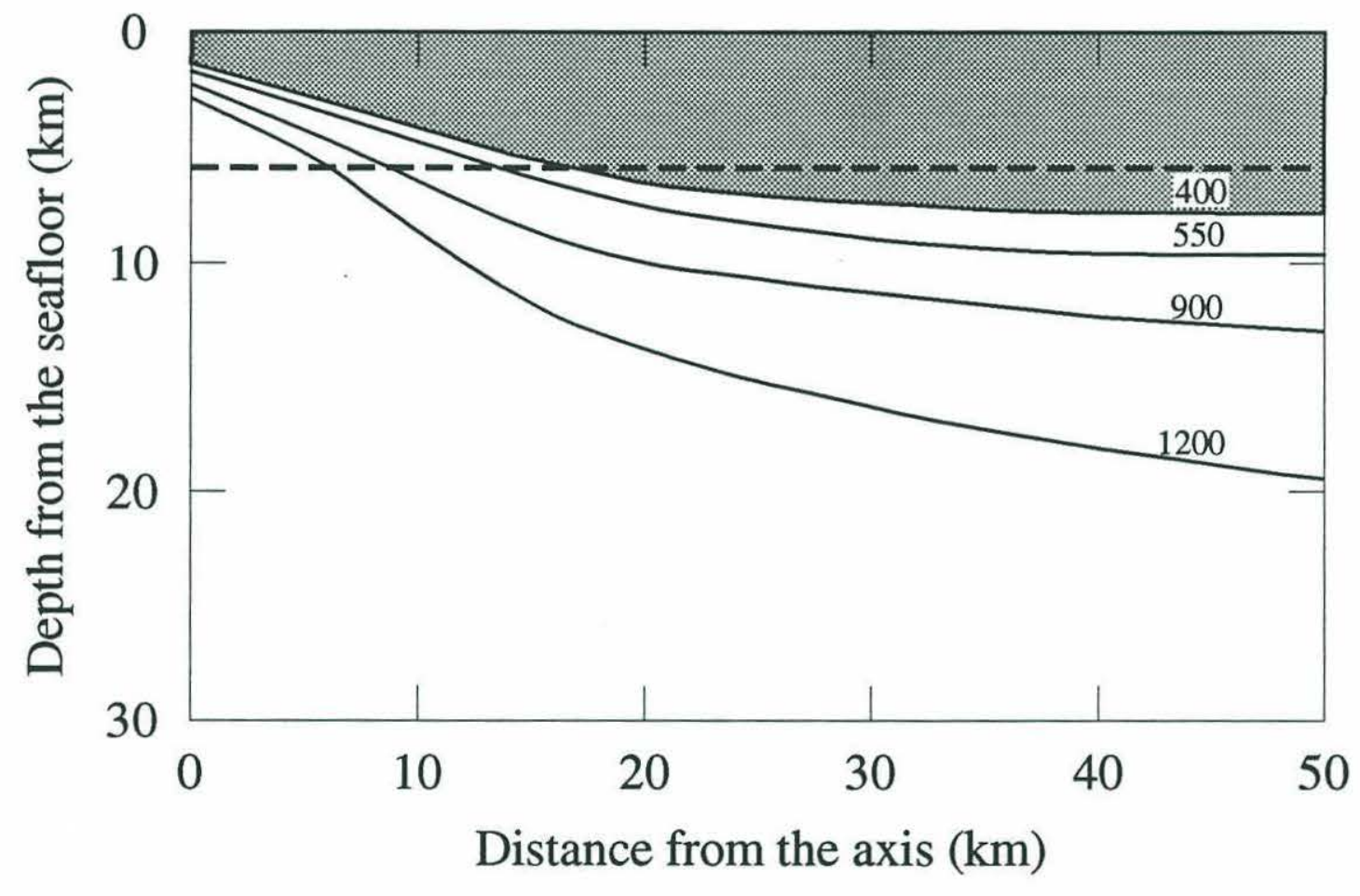


(b) Wilson et al. [1988]

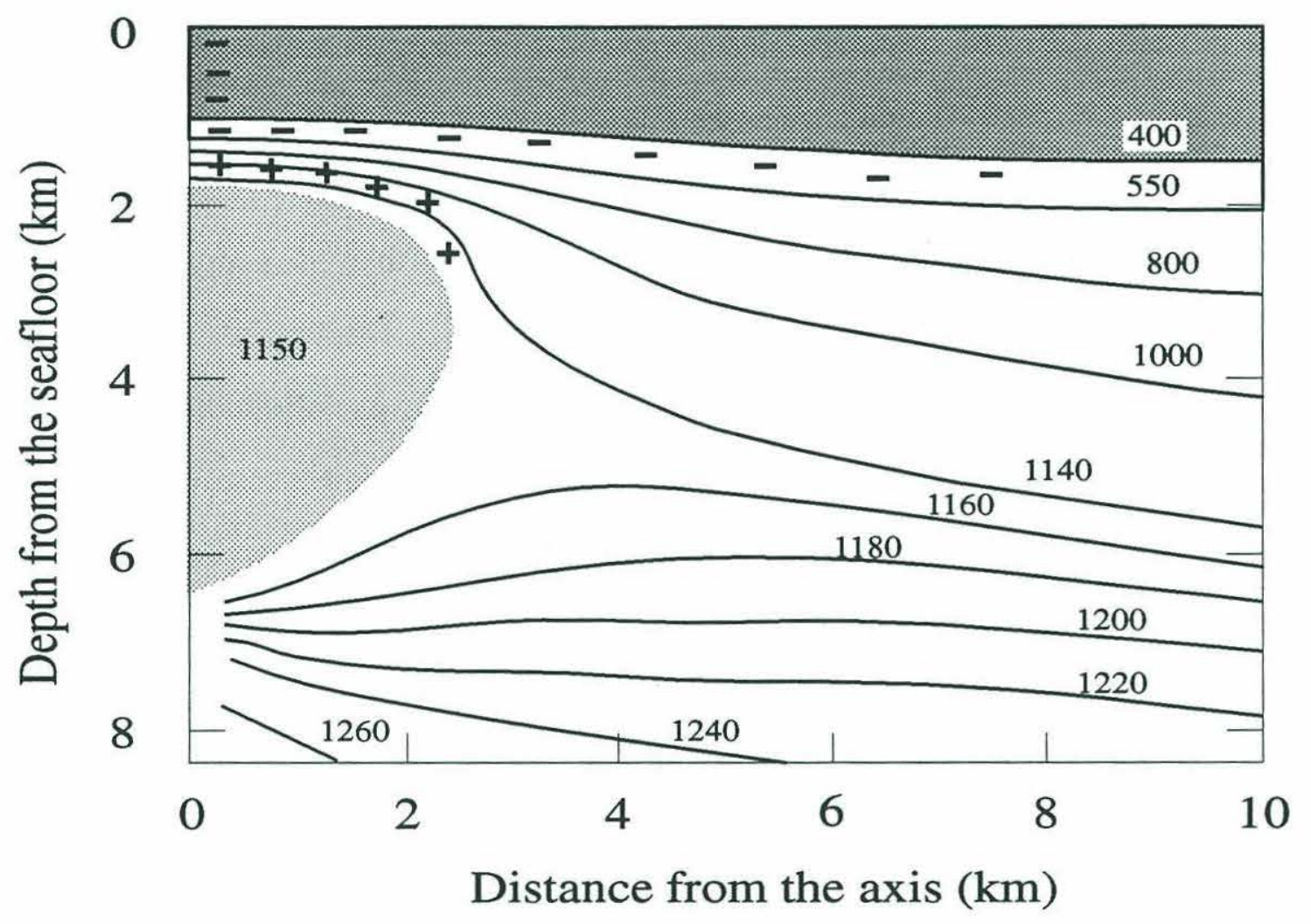


Figure 2.19. Schematic diagram showing two different stress regimes predicted for passive mantle flow, drawn from modeling results of Chen and Morgan [1990a, b]: (a) fast-spreading mid-ocean ridges (spreading half-rate greater than $35 \mathrm{~mm} / \mathrm{yr}$ ), and (b) slow-spreading (spreading half-rate less than $35 \mathrm{~mm} / \mathrm{yr}$ ). In case (b), the shear stress $(\tau)$ induced by mantle flow is maximized at the axis and decays rapidly with increasing distance $(x)$. In case (a), however, due to higher temperature and lower viscosity beneath the rise axis, a zone of decoupling (shown by the shaded area) develops and the shear stress is reduced significantly in the axial region. $\tau_{c}$ represents the magnitude of the critical shear stress for frictional failure, and $x_{c}$ is the distance from the axis at which $\tau=$ $\tau_{c}$. The variation in lithosphere thickness is greater at a slow-spreading than a fastspreading ridge. 
(a) Fast-Spreading Ridge

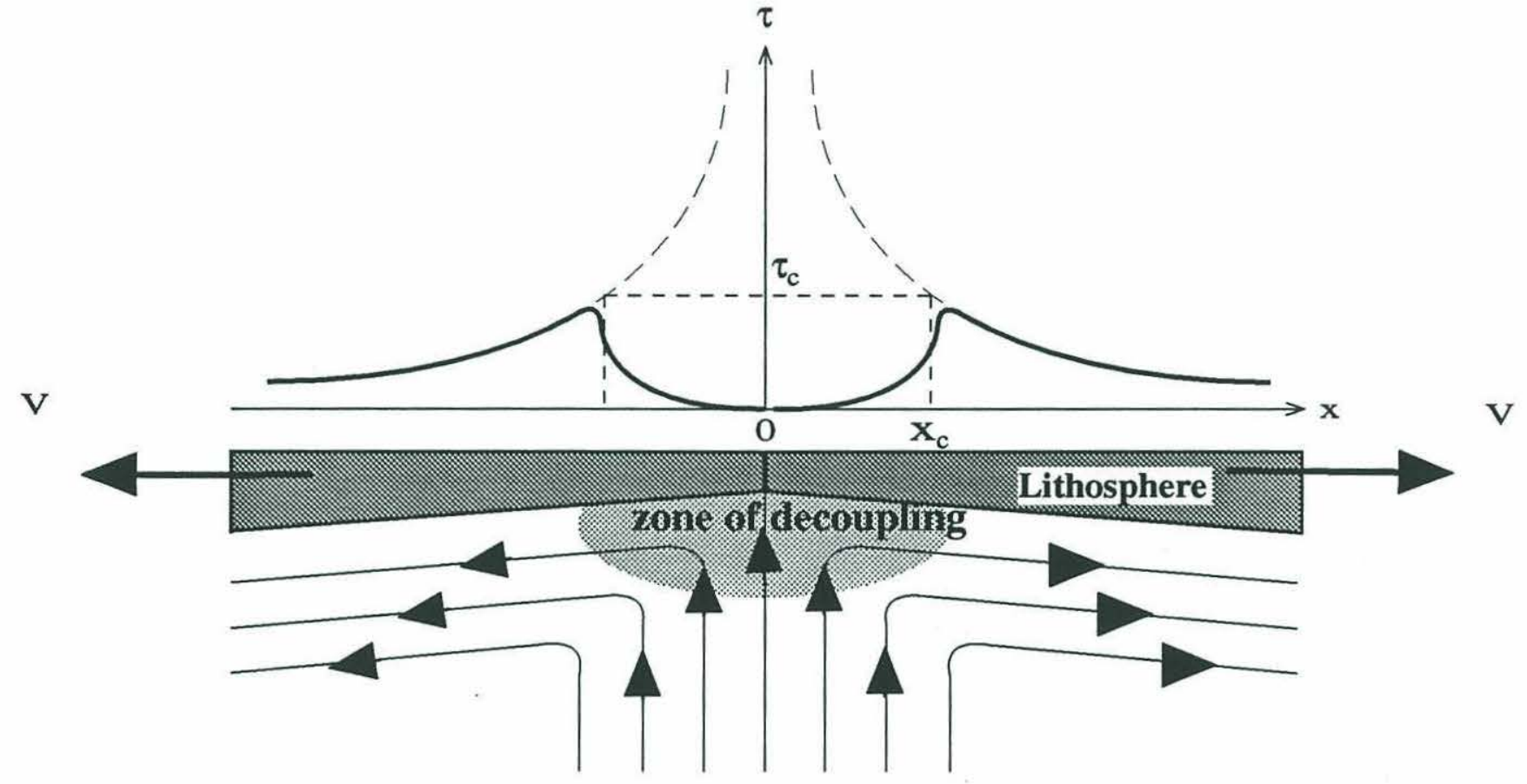

(b) Slow-Spreading Ridge

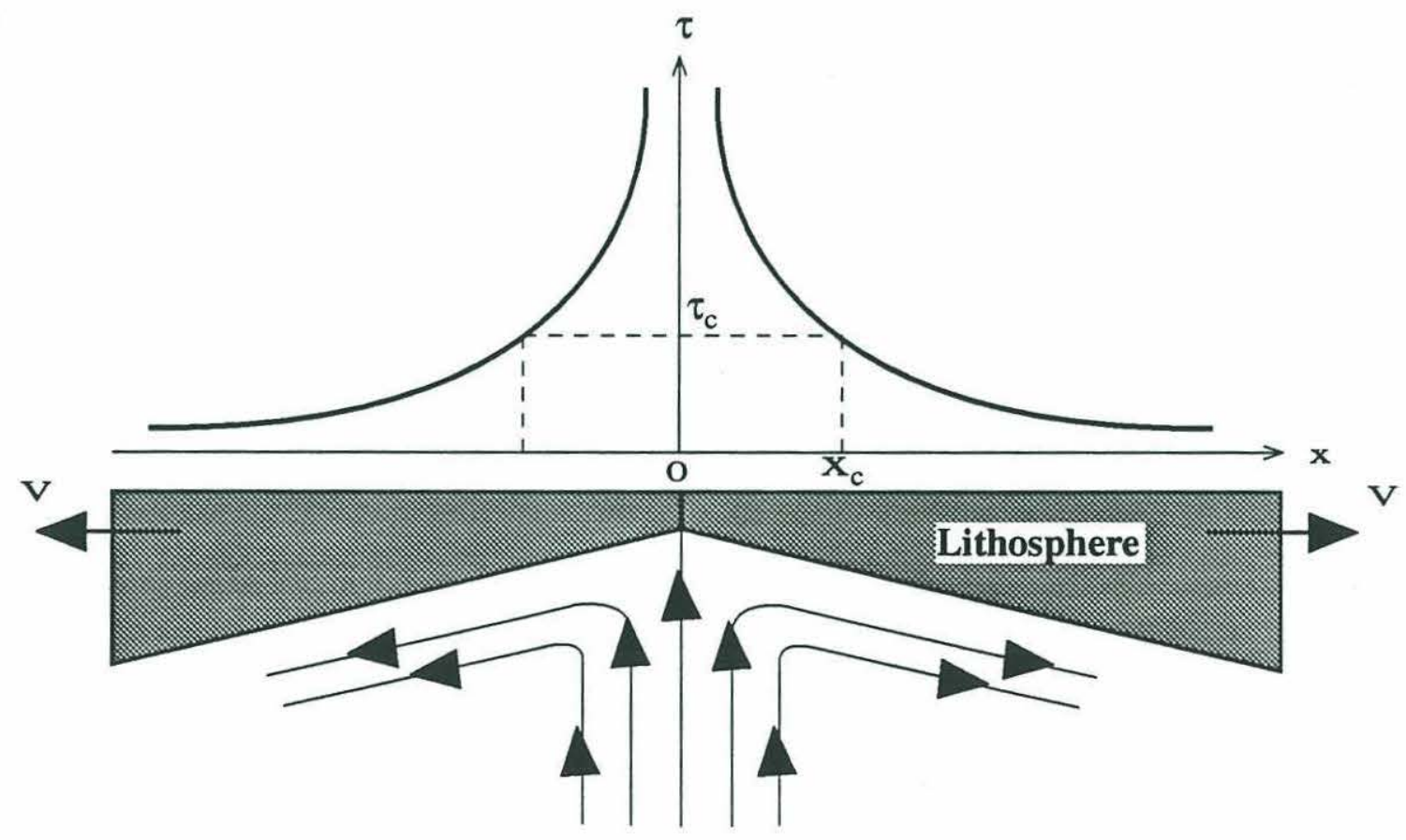


Figure 2.20. Horizontal velocity of the seafloor, according to models of Chen and Morgan [1990b], for three spreading half-rates: (a) $10 \mathrm{~mm} / \mathrm{yr}$, (b) $30 \mathrm{~mm} / \mathrm{yr}$, and (c) 60 $\mathrm{mm} / \mathrm{yr}$. The solid curves represent the results with a mantle viscosity that is stress- and temperature-dependent, while the dashed curves are based on a uniform-viscosity mantle. Numerals 1,2 , and 3 represent three cases $L=20,50$, and $80 \mathrm{~km}$, respectively, where $\mathrm{L}$ is the location beyond which horizontal velocity of the seafloor equals the plate velocity. For a uniform-viscosity fluid mantle, the flow depends critically on the choice of L. However, for a temperature-dependent nonlinear mantle rheology, the solutions are independent of the boundary conditions. 


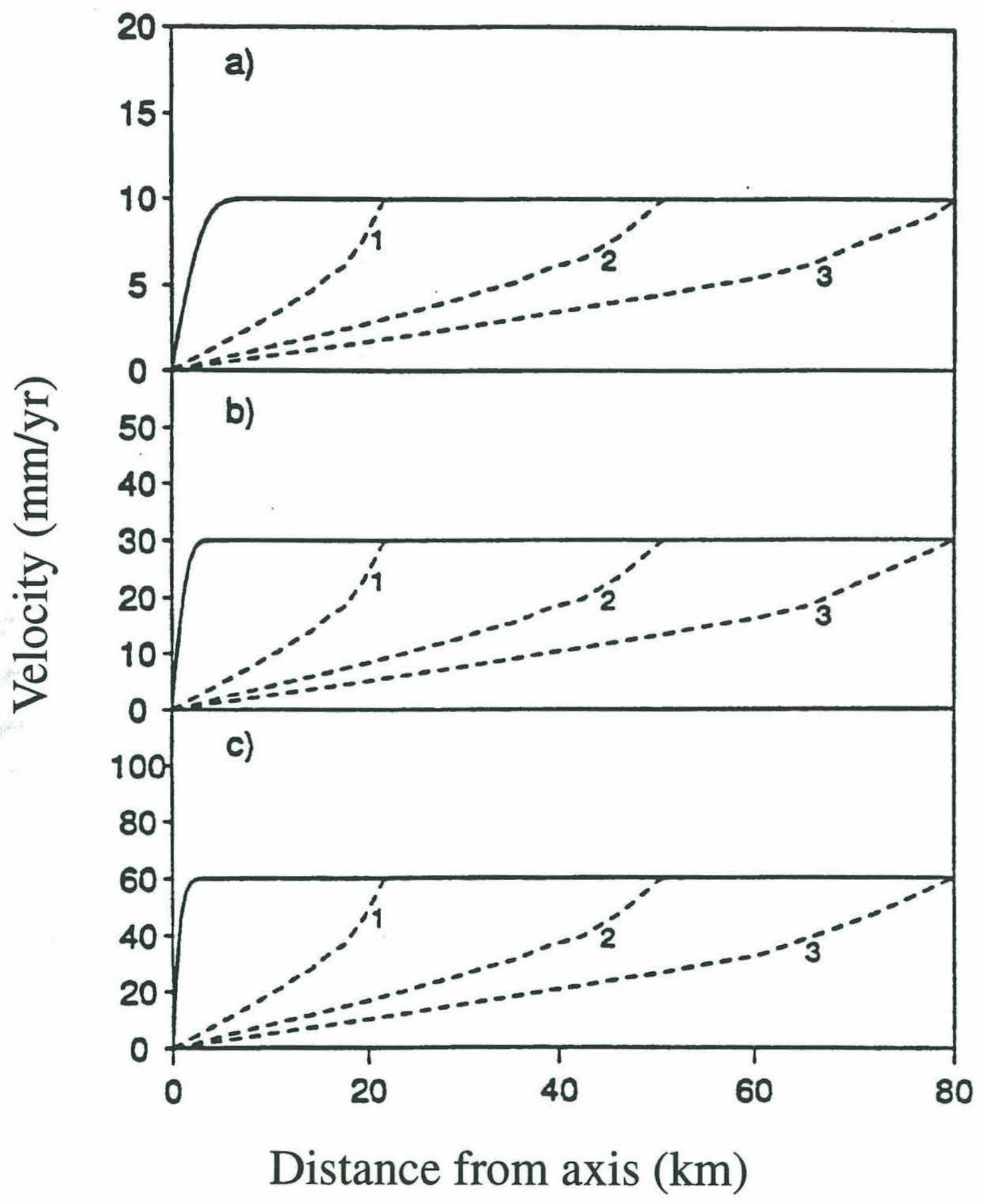


Figure 2.21. Schematic diagram illustrating stress associated with gravitational spreading of an upper crustal layer resting on a sloping detachment. Dashed lines denote the shape of the crustal layer prior to gravitational spreading. (a) In a case where the top is pinned, the upper part of the slope will experience extensional stress while the lower part will be under compression. (b) If the top is free to slide, stress arising from gravitational spreading will be compressional throughout and will increase in magnitude downslope. 


\section{(a) Pinned Axis}

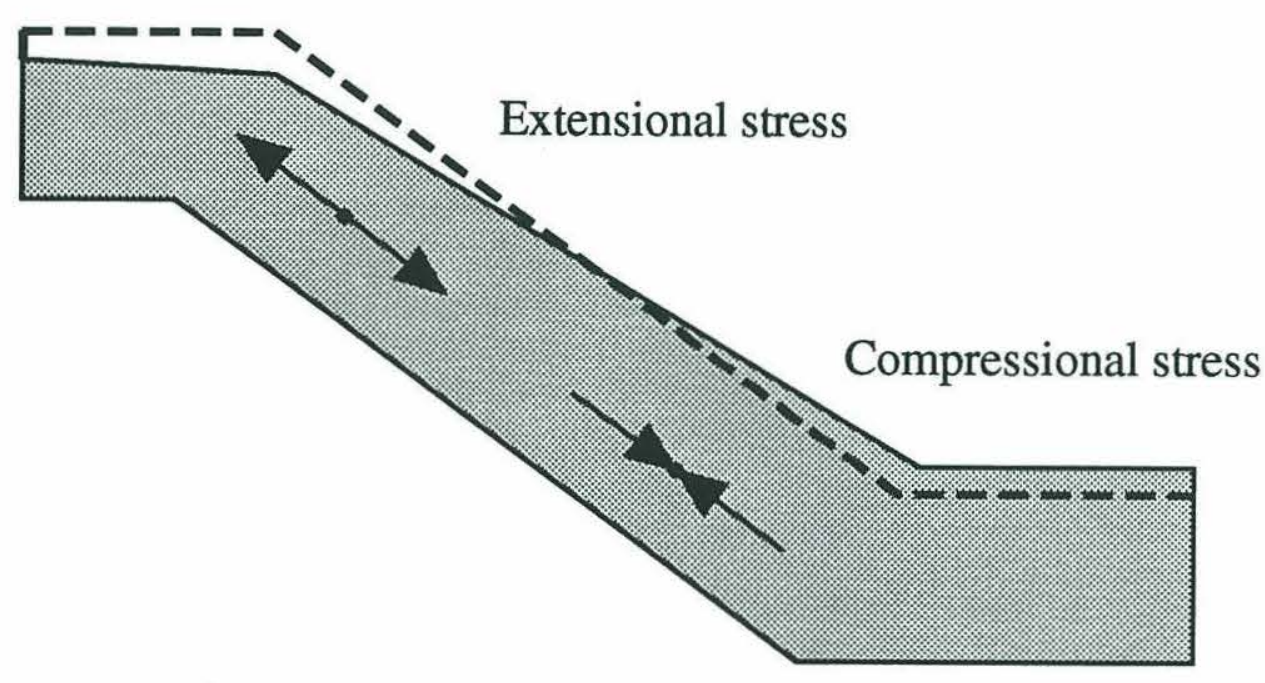

(b) Free Axis

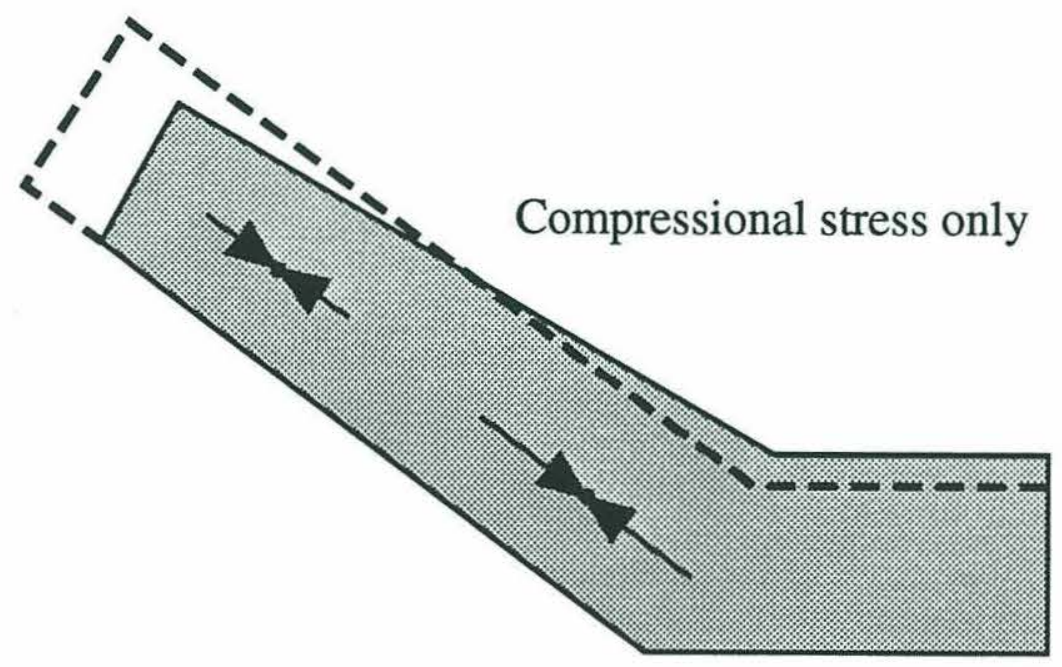




\section{Chapter 3}

\section{Mechanisms for Near-Ridge Normal Faulting at Fast-Spreading Mid-Ocean Ridges}

\section{Introduction}

Normal faults are nearly ubiquitous along mid-ocean ridges. Such faults not only provide constraints on the state of stress and mechanical properties of the oceanic crust, but they are also a primary structural component of abyssal hills, the most common landform on the surface of the Earth. Despite their widespread occurrence, the causes of near-ridge faulting at fast-spreading mid-ocean ridges are not well understood. One reason for this lack of understanding is the intrinsically complex nature of faulting. For instance, laboratory experiments on rock specimens suggest that the path of fracture propagation is more likely to be determined by material inhomogeneities or preexisting zones of weaknesses than by the directions of principal stresses, and that the onset of fracture propagation is also affected by processes that occur within the zone of plasticity that develops at the tip of a fracture [e.g., Atkinson, 1987]. In addition to the inherent complexity of faulting, the fact that normal faulting at fast-spreading ridges generally produces small features further compounds efforts to map and characterize these features. Despite great improvements during the last decade in our capability to map large areas of 
seafloor accurately, it is still difficult to detect normal fault scarps and measure their relief with certainty at fast-spreading ridges.

Although it is difficult to predict the formation of individual faults in a tectonic setting, in situations where a number of faults have formed under similar material and stress conditions, the characteristics of such a group of faults can often be explained by simple principles. One such principle is based on the premise that faulting occurs when differential stress exceeds the critical fracture strength of the material and, once the material is fractured, a frictional law (also known as Byerlee's law) governs continued displacement along the fracture plane. Given this principle, one useful approach in trying to understand the formation of normal faults is to model the near-ridge stress and strain fields that arise under candidate tectonic forces and compare model predictions to the observed pattern of normal faulting.

Detailed investigations of the morphology of the East Pacific Rise (EPR) have provided a number of observational constraints that a stress-strain model of a fastspreading ridge must address. One constraint is the distance to the first appearance of large-offset normal faults, which generally is between 2 and $10 \mathrm{~km}$ from the ridge axis [Lonsdale, 1977; Choukroune et al., 1984; Macdonald and Luyendyk, 1985; Bicknell et al., 1987; Carbotte and Macdonald, 1994]. Another observational constraint that remains to be resolved by a stress-strain model is the possibility of further slip on a normal fault after it has formed. There are at least two different views on this issue. According to Macdonald and Luyendyk [1985], Choukroune et al. [1984], and Bicknell et al. [1987], most of the active faulting at the EPR is confined to a narrow zone extending no more than 5-10 km from the axis. An alternative view for the continued development of normal fault zones to distances of at least $30 \mathrm{~km}$ from the axis is motivated by the evidence described in Chapter 2.

Any explanation regarding continued normal faulting activity at large distances from the axis must also be consistent with the body of evidence from near-ridge earthquakes. 
Investigations of large near-ridge earthquakes in lithosphere 3-35 My in age have found that normal faulting mechanisms are common, but waveform inversions indicate that most such normal faulting events have centroid depths beneath the crust, whereas nearridge events with centroid depths of less than $6 \mathrm{~km}$ typically have thrust or reverse faulting mechanisms [Bergman and Solomon, 1984; Wiens and Stein, 1984]. At present, however, the relationship between large near-ridge earthquakes, plausibly attributable to thermoelastic stress associated with plate cooling [Bergman and Solomon, 1984; Bratt et al., 1985], and the active tectonic zone of the EPR is not clear.

Although no formal assessment has been performed to determine the principal sources of tectonic stress in the lithosphere of a young fast-spreading ridge, sources generally thought to be important include shear stress exerted at the base of the lithosphere by mantle flow [Chen and Morgan, 1990a, b], buoyancy of low-density material beneath the spreading axis [Madsen et al., 1984], gravitational spreading off the axial topographic high [Lister, 1975; Dahlen, 1981], and differential cooling of the lithosphere [Bratt et al., 1985; Haxby and Parmentier, 1988]. However, there are several difficulties with these previous models as explanations for the initiation and development of normal faulting near the axis of the EPR. For one, previous models of buoyancy, gravitational spreading, and differential cooling all predict that axis of greatest compressional tectonic stress within the shallow crust is normal to the ridge. Although mantle-flow-induced shear stress gives rise to extensional stress at fast-spreading ridges, because of the likelihood of a low-viscosity region in the uppermost asthenosphere, such extensional stress is not likely to be large enough to cause brittle failure [Chen and Morgan, 1990a, b].

Another difficulty with previous models is that they generally lack sufficient detail to predict the specific characteristics of near-ridge stress and strain fields. For instance, the state of stress of a near-ridge region can be strongly affected by a variation with depth of the mechanical conditions at the spreading axis. However, the axial boundary condition 
generally adopted in previous models has been either zero shear stress or zero displacement with no depth variation [e.g., Chen and Morgan, 1990a, b]. Also, because these models were aimed at explaining features of relatively large scale or examining processes averaged over a relatively long time ( $>$ several thousand years), the near-ridge lithosphere was idealized either as a uniformly thick plate overlying an inviscid fluid [e.g., Madsen et al., 1984], in a state of local isostatic equilibrium [e.g., Dahlen, 1981], or as a plate with a stress-free base defined by a half-space conductive cooling model [e.g., Haxby and Parmentier, 1988].

This study examines the near-ridge stress and strain fields at a fast-spreading ridge caused by the separate and combined effects of (1) the buoyancy of low-density material within the crust and (2) the gravitational spreading of a mechanically strong upper crust over an underlying substrate. The model uses a boundary element method (BEM) based on linear elastostatic theory, and explicit consideration is given to a range of possible heterogeneities in mechanical properties The resulting stress fields are compared with the observed pattern of normal faulting at the EPR as a step toward understanding the processes of the initiation and development of normal faulting at fast-spreading ridges.

\section{Model Assumptions}

One of the primary difficulties in applying a mechanical model for the investigation of ocean ridge tectonics is the representation of material properties. From studies of crustal deformation [e.g., Forsyth, 1980], earthquake sources [e.g., Chen and Molnar, 1983], and rock mechanics [e.g., Ashby and Verrall, 1977], we know that the mechanical properties of rocks depend on composition and temperature as well as the stress magnitude and strain rate. Figure 3.1 is a schematic diagram of rheological stratification that may be expected in a relatively cold or low-stress regime versus that in a hot or high- 
stress regime. It illustrates that, while the upper crust can be modeled as linear elastic medium, the lower crust and perhaps all of the upper mantle may be modeled as viscoelastic or viscous media, since nonlinear mechanisms such as ductile flow may dominate the mode of deformation in those regions. While the strength of some regions near ridges may be well represented simply as a function of depth as shown in Figure 3.1, the distribution of material strength near the ridge axis may be more complex because of additional factors such as the presence of melt. Also, the reference state of stress is uncertain near the ridge axis, since a variety of forces may act on a variety of length and time scales.

When trying to explain tectonic features in the shallow crust, it is worthwhile to see if the simple assumption of linear elasticity is adequate. The BEM can accommodate compositional changes and structural heterogeneity in a linear elastic model to some extent by dividing the modeling region into a number of subregions of uniform properties. In general, for linear problems, the BEM is more convenient and yields more accurate results than finite difference or finite element methods. For instance, the BEM reduces the dimension of the problem by one, i.e., a volume integration can be reduced to a surface integration and a surface integration to an integration along a path (see Appendices A, B and C for an extensive discussion of these subjects).

The accuracy of the calculated stress and strain fields are only as good as the degree to which the structure of the mid-ocean ridge is represented by our models. Thanks to numerous investigations of the structure of the EPR carried out over the last decade, a much more realistic model can now be developed than was heretofore possible for the structure of fast-spreading ridges. For instance, seismic experiments on the EPR near $9^{\circ} \mathrm{N}$ [Detrick et al., 1987; Vera et al., 1990; Toomey et al., 1990, 1994; Wilcock et al., 1992, 1995; Harding et al., 1993; Kent et al., 1993a, b] suggest a structure in which the upper crust near the rise axis consists of a thin lid overlying a small magma lens of extremely low seismic velocity and a surrounding zone of low melt volume which 
extends approximately $5 \mathrm{~km}$ from the rise axis (Figure 3.2). In this study, we incorporate these features in our models and, through suitable parameterization, we seek the set of model parameters that best explains the observed patterns of normal faulting.

\section{Boundary Element Models}

This section describes the boundary element models used to investigate stress resulting from the buoyancy of a crustal magma chamber and the gravitational spreading of a relatively strong upper crust over an underlying substrate. A two-dimensional crosssection of the mid-ocean ridge is taken as the basis of our models, and linear elastostatic and plane-strain assumptions are made throughout this study. As mentioned earlier, the BEM can accommodate changes in material properties through a division of the modeling region into several homogeneous subregions. Three special interface conditions explored for boundaries between different subregions, including (1) an internal-spring interface, used to understand the effect of rise-axis mechanical strength; (2) a tangential spring, used to model the ease with which the mechanically strong upper crust can slide over an underlying substrate; and (3) a sliding interface at the base of the mechanically strong upper crust, used to understand the effects of the presence of mid-crustal zones of high melt concentration. In this study, we used the Boundary Element Analysis SYstem (BEASY), a code developed by Computational Mechanics, Inc. One unique feature of BEASY when compared with other boundary element codes is that it allows for the prescription of body forces over an entire region or any subregion. This capability of BEASY makes it possible to model phenomena such as buoyancy and gravitational spreading. 


\section{Buoyancy Model}

The configuration of the buoyancy model is based on constraints provided by recent seismic experiments [Detrick et al., 1987; Toomey et al., 1990; 1994; Vera et al., 1990; Wilcock et al., 1992, 1995], which characterize the crustal structure near the rise axis of a fast-spreading ridge (Figure 3.2). These studies consistently point toward a low-velocity volume in the shallow to middle crust. The mid-ocean ridge is therefore divided into five subregions of different properties in our model: the mechanically strong upper crust, the weak lower crust, the axial magma chamber (AMC), the low-velocity volume (LVV) that surrounds the AMC, and the upper mantle (Figure 3.3). Both the AMC and the LVV act as potential sources of buoyancy. The modeling region extends $30 \mathrm{~km}$ from the axis on both sides. The mechanically strong portion of the crust thickens as it moves away from the rise axis. We assume that all the subregions are fully bounded except for the upper mantle that extends downward as an infinite half-space.

The mechanically strong upper crust is defined as that portion of the crust at temperatures less than $400^{\circ} \mathrm{C}$, which is the approximate elastic blocking temperature [Turcotte, 1993], that is, the temperature below which crustal rock has long-term mechanical strength [Chen and Molnar, 1983]. To determine the position of the $400^{\circ} \mathrm{C}$ isotherm, we extended the thermal model of Wilson et al. [1988] to distances greater than $10 \mathrm{~km}$ (see Chapter 5 for a detailed discussion of the thermal model).

The general shape of each subregion of our buoyancy model agrees with the shape of the different zones defined in the composite magma chamber model of Sinton and Detrick [1992]. However, because our model is simplified, there are minor differences from seismic models, such as that of Vera et al. [1990]. For example, in the model of Vera et al. [1990] (Figure 3.2), the P-wave velocity varies significantly with depth in the crust above the AMC. In particular, a large change in P-wave velocity, from 2.5 to 5.0 $\mathrm{km} / \mathrm{sec}$, occurs within the uppermost $300 \mathrm{~m}$ on axis and $500 \mathrm{~m}$ off axis. This depth 
interval is interpreted as a layer of extrusive basalts. In our model, such vertical changes in the material properties of the upper crust are ignored in order to keep the model as simple as possible and because the boundary element technique is generally not well suited to incorporating regions of high aspect ratios. Also, in the seismic velocity models, the region of extremely low-velocity $(<2 \mathrm{~km} / \mathrm{sec})$, interpreted as a region of significant magma fraction, is actually very small (Figure 3.2). Sinton and Detrick [1992] refer to this region as a magma lens to distinguish it from a surrounding region of lower magma concentration, the crystalline mush. The AMC in our buoyancy model includes both the magma lens and the zone of crystalline mush. The AMC is modeled in cross-section as circular body with a radius of $1 \mathrm{~km}$. According to seismic reflection profiles along the northern EPR [Detrick et al., 1987], the depth to the top of the magma lens varies, but on average it is located at about $1.6 \mathrm{~km}$ below the seafloor. The LVV in our buoyancy model extends laterally to approximately $5 \mathrm{~km}$ from the rise axis. The interface between the LVV and the upper crust is $2 \mathrm{~km}$ in half width. We later consider a case where this interface is $5 \mathrm{~km}$ in half width.

Determining the appropriate elastic strength values of those subregions that lie below the upper crust involves a rather large uncertainty. Even for the upper crust there is considerable discrepancy between the estimates of Young's modulus from laboratory experiments and those from studies of long-term crustal deformation. Laboratory measurements indicate that Young's modulus for oceanic basalt and gabbro ranges from 50 to $70 \mathrm{GPa}$ [e.g., Jaeger and Cook, 1979]. On the other hand, the effective Young's modulus used in crustal deformation studies is generally at most $50-70 \%$ of these values [Kirby, 1983]. In some modeling studies, the effective Young's moduli were even lower. For instance, King and Ellis [1990] had to reduce the effective elastic thickness of the crust by a factor of 4 from the observed seismogenic thickness to match the observed deformation in the case of a high-angle normal faulting of an elastic upper crust overlying 
an inviscid lower crust, which is equivalent to the reduction of Young's modulus by a factor of 64 from given by laboratory measurement.

In this study, we first estimate the dynamic modulus of the each subregion from the seismic velocity structure. The dynamic Young's modulus $E_{D}$ can be obtained from the relationship

$$
G_{D}=\frac{E_{D}}{2(1+v)}=V_{P}^{2} \rho \frac{1-2 v}{2(1-v)}
$$

where $G_{D}$ is the dynamic shear modulus, $V_{P}$ is average P-wave velocity, $\rho$ is the density, and $v$ is Poisson's ratio. Table 3.1 summarizes the values of parameters used for estimating the dynamic moduli of the subregions. With the dynamic moduli of the subregions as a reference, we then uniformly lower the strength of those subregions below the mechanically strong upper crust. Since the compositional difference between the crust and mantle can play an important role, we also consider cases where the strength of the upper mantle is much higher or much lower than that given by the uniform reduction of dynamic modulus. Poisson's ratios of 0.28 and 0.32 are assumed for the upper and lower crust, respectively [Hyndman, 1979]. Using $4.0 \mathrm{~km} / \mathrm{sec}$ as the S-wave velocity of the upper mantle beneath the EPR [Zhang and Tanimoto, 1992] and $8 \mathrm{~km} / \mathrm{sec}$ as the P-wave velocity, we estimate 0.32 as the Poisson's ratio for the upper mantle. For the LVV, we also use a Poisson's ratio of 0.32 , which is consistent with that determined by Bratt and Solomon [1984] for the region between 1.2 and $3.7 \mathrm{~km}$ depth beneath the axis of the EPR at $11^{\circ} 20^{\prime} \mathrm{N}$. While a Poisson's ratio of 0.5 may seem appropriate for a region of high melt concentration such as a magma lens, we assumed 0.41 as the Poisson's ratio for the AMC for two reasons. First, the AMC in our model includes not only the magma lens but also the surrounding crystalline mush, which probably has a much lesser melt fraction than the magma lens. Second, a Poisson's ratio of 0.5 would 
result in zero elastic strength under the assumption of linear elasticity, so that even a small stress within the AMC would give rise to unbounded strain.

We assumed density contrasts of 300 and $100 \mathrm{~kg} / \mathrm{m}^{3}$ for the AMC and LVV, respectively. These density contrasts are consistent with the assumption that the AMC and LVV provide the necessary buoyant forces to balance isostatically the increase in the thickness of layer 2 with distance from the EPR axis near $9^{\circ} 30^{\prime} \mathrm{N}$ [Christeson et al., 1994]. A density contrast of $300 \mathrm{~kg} / \mathrm{m}^{3}$ for the AMC is also consistent with that estimated from the local short-wavelength gravity low if the causative mass anomaly is a cylindrical body approximately $1 \mathrm{~km}$ in radius, $10 \mathrm{~km}$ in length, and buried $1.25 \mathrm{~km}$ beneath the seafloor [see Chapter 5].

In boundary element analysis, boundary conditions are imposed by pairs of stress or displacement or by combinations of stress and displacement in the normal and tangential directions for each element. The relationships between those quantities are imposed at the interface between two subregions. To avoid rigid-body motion of the whole region, it is important that at least one displacement condition be imposed in each orthogonal direction. Since the upper mantle is modeled as a semi-infinite region, zero vertical displacement in the far-field is implicitly assumed. We also assume zero displacement in the horizontal direction at the far left $(x=-30 \mathrm{~km})$ and far right $(x=30 \mathrm{~km})$ side of the upper crust (Figure 3.3). The length of our modeling region is sufficient so that details of the manner in which these boundary conditions are imposed do not affect the results near the rise axis. The seafloor is prescribed as a stress-free surface. Except along those interfaces where special interface conditions are prescribed, the interface conditions between subregions are required to satisfy continuous stress and displacement in both normal and tangential directions, i.e., as if there were no physical discontinuity except for changes in material properties across the interfaces.

As shown in Figure 3.3, boundary elements are spaced more densely near the rise axis. Elements are spaced every $250 \mathrm{~m}$ along the seafloor within $10 \mathrm{~km}$ of the rise axis 
but only every $500 \mathrm{~m}$ at distances greater than $10 \mathrm{~km}$ from the rise axis. The resulting stress and strain fields are thus more accurate near the axis.

\section{Gravitational Spreading Model}

Many elements of the gravitational spreading model are similar to those of the buoyancy model. However, the gravitational spreading model has only the mechanically strong upper crust, which is defined in the same manner as in the buoyancy model. In our models, the mechanically strong crust thickens less rapidly within $10 \mathrm{~km}$ of the axis than beyond this distance (Figure 3.4).

There is a problem with modeling gravitational spreading as a mechanically strong crust overlying a mechanically weak substrate as in the case of buoyancy. Because the upper crust thickens with distance from the axis, a greater vertical pressure will be applied to the underlying substrate with increasing distance from the axis. Such a pressure may unevenly deform the prescribed interface between the upper crust and underlying substrate, unless one assumes an unrealistically high modulus for the underlying substrate. To circumvent this problem, we assumed no normal displacement at the base of the mechanically strong crust in our gravitational spreading model (or, equivalently, that the substrate is infinitely rigid). The resistance that the underlying substrate provides to the upper crust (or the ease with which the upper crust can slide over the underlying substrate) is parameterized by the stiffness of tangential springs that connect the base of the upper crust to the underlying substrate. Although it is unclear how values of spring stiffness in this case relate to material properties such as Young's modulus or viscosity, we can still examine qualitatively the stress field arising from gravitational spreading. 
In our model, gravitational spreading can occur because the upper crust is resting on a sloping surface of an underlying substrate, presumably weaker than the upper crust, and because the upper crust itself has an axial uplift. To examine the significance of the axial uplift, we shall consider the amount of axial uplift as a variable. As with the buoyancy model, we assume zero displacement in the horizontal direction at the far left $(x=-30$ $\mathrm{km})$ and far right $(x=30 \mathrm{~km})$ sides of the upper crust to avoid rigid-body motion. We assume $2700 \mathrm{~kg} / \mathrm{m}^{3}$ as the density of the upper crust. Aside from the gravitational body force provided by this layer, a $2.5-\mathrm{km}$ column of water exerts additional weight on the lithosphere. Thus, a pressure of $25 \mathrm{MPa}$ is assumed to act on the seafloor. As with the buoyancy model, the boundary elements are spaced more densely over the axial region (Figure 3.4).

\section{Special Interface Conditions}

The mechanical strength of the rise axis may differ depending on whether the shallowest zone of axial intrusion is solidified or molten (Figure 3.5a). By modeling the rise axis as an interface between the two sides of the mechanically strong upper crust bound together by pairs of internal springs in normal and tangential directions, one can examine systematically how rise-axis strength affects the stress field. Then the strength of the rise axis, that is, the ease with which the two plates can be pulled apart, can be represented by the stiffnesses of these springs (Figure $3.5 \mathrm{~b}$ ).

The internal spring conditions can be expressed as

$$
T_{i 1}=k_{i}\left(u_{i 2}-u_{i 1}\right)
$$


where $T_{i 1}$ is the traction in the $i$ th direction acting on one side of the upper crust, $k_{i}$ is the spring stiffness in the $i$ th direction, and the displacements $u_{i 1}$ and $u_{2}$ represent the displacements of the two sides of the upper crust.

The above equation also describes the tangential spring interface condition that we used along the base of the upper crust in the gravitational spreading model. In this case, the tangential displacement corresponding to the substrate is taken to be zero.

There are two important advantages in considering the axial dike zone as pairs of internal springs rather than as a separate subregion. One advantage is that considering the axial dike zone as an interface with springs reduces the number of parameters. For instance, even if one assumes that the subregion has a Poisson's ratio of 0.28 as in other subregions and that the depth extent of the subregion is known, one still has to explore two other parameters, the width and the Young's modulus of the subregion, in contrast to a single parameter, internal spring stiffness, required in a spring-type model. The other advantage, as mentioned earlier, is that the boundary element method is generally not suitable for handling regions with high aspect ratios such as a dike zone.

Fortunately, one can generally relate the internal spring stiffness to the width and material strength of the axial dike zone. This relationship can be expressed as

$$
k \approx \frac{E_{d}}{W_{o}}
$$

where $k$ is the internal spring stiffness, $E_{d}$ is the Young's modulus of the axial dike region, and $W_{o}$ is the width of the axial dike region. Appendix D provides a comparison of two approaches, an internal-spring approach and a separate-subregion approach for the simple case of a dike.

A second type of special interface conditions is a sliding interface condition, for which only normal stress and normal displacements are continuous across the border between two subregions (Figure 3.5c). This condition is useful for modeling stress and 
strain in areas where solid and liquid come into contact. In this study, we use a sliding interface to understand how the presence of a zone of highly concentrated melt such as a magma lens (Figure 3.5a) may affect the stress and strain in the upper crust.

\section{Model Results}

The buoyancy and gravitational spreading models contain several variables that have significant geological implications and can affect the stress and strain fields near the surface. For the buoyancy model, these include the elastic moduli of the subregions, the mechanical strength of the rise axis, the source of buoyancy, the magnitude of the buoyancy force, and the interface conditions between the mechanically strong upper crust and underlying subregions. For the gravitational spreading model, the strength of the rise axis and the interface condition between the mechanically strong upper crust and the underlying substrate are the important variables. In this section, we explore these variables systematically by prescribing different values to one or more variables while fixing the rest and examining the resulting stress and strain fields.

\section{Buoyancy Model}

For the study of the effect of buoyancy, we shall consider the following sets of material strengths of the subregions (Table 3.2). Set I represents a case where the Young's moduli of the subregions equal the dynamic Young's moduli. Set II and III are cases in which the strengths of the subregions below the mechanically strong crust are uniformly reduced from their dynamic strengths by factors of 10 and 100 , respectively. We also consider cases in which the reduction in material strength of the upper mantle 
differs from that of other subregions below the upper crust (Table 3.3). Set IIa and IIIa, for example, represent cases where the upper mantle is reduced by a factor half that of the lower crust. The cases where the upper mantle is 10 times weaker than the lower crust are represented as sets IIb and IIIb. In this study, we limit the strength reductions to a factor of 1000 . Although the boundary element method can accommodate large strength contrasts among subregions, too large a strength contrast was found to produce numerical errors in the results. To consider situations with very large strength contrasts (e.g., a mechanically strong upper crust underlain by an extremely weak substrate), it is often beneficial to model the weak side of the interface as a stress-free surface.

\section{Variations in the Strength of the Rise Axis}

The mechanical strength of the rise axis appears to be one of the most important factors that affect the stress field within the upper crust. We examine two extreme cases, one where both sides of the upper crust are connected at the axis as if there were no physical boundary across the axis, and another where zero stiffness was prescribed for the internal springs at the axis. In the latter case, the walls of the rise axis act almost as stress-free surfaces. For convenience, we shall refer to the former case as a "strong axis" and the latter case as a "weak axis." Figures 3.6 and 3.7 show the differential stresses for strength set I, and sets II and III, respectively. The results show that the stress fields for the strong and weak axis cases differ near the axis. In the cases of a strong axis, the maximum differential stresses occur on the rise axis (Figure 3.6a). The basic pattern of stress is the same for all strong-axis cases, and thus we shall not show results for other strength sets. In contrast, for the cases of a weak axis, the maximum differential stress occurs off axis (Figures 3.6b, and 3.7a and b). The principal stress orientations and the distance from the axis of maximum differential stress differ depending on the strengths of 
the underlying subregions. For strength set I, for instance, the horizontal stress at the point of maximum surface differential stress is extensional (Figure 3.6b), whereas for strength sets II and III, the highest surface differential stresses occur over broad zones farther off-axis in which the horizontal stresses are compressional (Figure 3.7a and b).

One can infer the type of faulting from these stress fields. In particular, the stress fields resulting from strong axis cases are not consistent with the observed pattern of normal faulting at fast-spreading ridges because they predict a maximum stress too close to the rise axis. For some cases of a weak axis, however, the occurrence of a zone of large horizontal extensional stress off-axis as in Figure 3.6b may explain the development of normal faulting off-axis. Further examination is warranted to explore this possibility.

\section{Factors Controlling the Stress Regime}

To see whether a variation in the width of the interface between the upper crust and the LVV might change the stress field in the upper crust, we modified the buoyancy model so that this interface is $5 \mathrm{~km}$ in half width. We assume that the total buoyancy force is the same as in the previous models. The differential stresses for this case are shown in Figures 3.8a and b for strength sets I and II, respectively. Overall, the differential stress fields for 2- and 5-km-interface half widths do not appear to differ much, except that surface extensional stresses occur over a broader area for the 5-km half width.

A useful way to compare stress fields is to look at the horizontal stress $\sigma_{x x}$ at the surface (Figure 3.9). For strength sets I and II, cases with both $2-\mathrm{km}$ and $5-\mathrm{km}$ interface half widths develop an off-axis zone of extensional (positive) $\sigma_{x x}$ In the case of the 5-km half width, this zone is broader (set I) and the magnitude of extensional stress is greater (set II) than for a $2-\mathrm{km}$ half width. Therefore, the width of the interface between the 
mechanically strong crust and the LVV appears to be one of the factors controlling the characteristics of the off-axis zone of normal faulting.

Next, we examined how a variation in the thickness of the mechanically strong upper crust affects the stress field. For a weak axis with a $5-\mathrm{km}$ interface half width between the upper crust and the LVV, we increased the thickness of the upper crust uniformly at increments of $250 \mathrm{~m}$. The resulting surface horizontal stresses are shown in Figures $3.10 \mathrm{a}$ and $3.10 \mathrm{~b}$ for strength sets I and II, respectively. The figures show that the magnitude of extensional stress decreases with an increase in the thickness of the upper crust. Therefore, a thin upper crust is more likely to develop normal faults off-axis than a thick one. In addition, there appears to be some difference between the two strength sets in the variation in the distance from the axis of maximum surface extensional stress with increasing upper crustal thickness. This difference is discussed later in this section.

To examine how a variation in the material strength of the upper crust affects the stress field, we lowered the mechanical strength of the upper crust. We considered two cases of a weak axis with a 5-km interface half width: one with a Young's modulus of 10 $\mathrm{GPa}$ for the upper crust and one with a modulus of $5 \mathrm{GPa}$. For the subregions below the upper crust, we assumed strength set II for the former case and strength set III for the latter case. From the resulting horizontal stresses at the surface (Figure 3.11), we conclude that an off-axis zone of extensional stress is more likely to occur for an upper crust that is mechanically weak than for one that is strong.

Thus far we have examined the stress field only for two extreme types of rise axis, weak and strong. For a given set of strengths and a given half width of the interface between the upper crust and the LVV, we need to determine the spring stiffness where the transition occurs in near-axial stress field from that of a strong-axis, where the maximum differential stress occurs on-axis, to that of a weak-axis, where the maximum differential stress occurs off-axis. Knowledge of the spring stiffness corresponding to such a transition constrains the width or material strength of the axial dike zone. 
Figure 3.12 shows the surface horizontal stress for different spring stiffness values applied along the axis, for cases with a 5-km interface half width between the LVV and the upper crust and strength set II. The transition between strong-axis and weak-axis behavior occurs at a stiffness of about $5 \mathrm{MPa} / \mathrm{m}$. We found that the transition generally occurred at about the same stiffness for other strength sets as long as the strength of the upper crust remained at $53 \mathrm{GPa}$. This result leads us to conclude the transition in nearaxial stress field from strong-axis to weak-axis behavior appears to be governed primarily by the material strength of the upper crust.

\section{Factors Controlling the Distance to Off-Axial Extension}

For those weak axis cases in which extensional stresses develop off-axis, it is important to determine those factors that control the distance to the point of maximum extensional surface stress. From our earlier analysis, we already know that one such factor is the width of the interface between the upper crust and the LVV. In general, as the width of the interface between the upper crust and the LVV increases, the distance from the axis to the maximum extensional surface stress also increases (Figure 3.9). Another factor that may determine the distance to the maximum extensional stress is the vertical extent of the axial weak zone. For example, theoretical models of tension cracks in a semi-infinite solid suggest that the vertical length of the cracks is an important factor that determines the distance to which stress is relieved [Lachenbruch, 1961]. From the previous examples of a 5-km interface half width, we can examine the horizontal stress at the surface as a function of the thickness of the upper crust (Figure 3.10). For strength set I, the figure shows that the distance from the axis to the maximum extensional stress at the surface increases with thickening upper crust or, equivalently, with an increase in the vertical extent of the axial weak zone (Figure 3.10a). For strength set II, on the other 
hand, increasing the thickness of the upper crust does not increase the distance to the maximum extensional surface stress (Figure 3.10b). The reason that we obtain results similar to those for a semi-infinite solid only for strength set I is probably because its upper crust and underlying subregions have the more modest contrast in material strength among subregions than set II.

\section{Variations in the Strength of the Upper Mantle}

In our model, the buoyancy force is balanced by the tractions applied by surrounding to the boundaries of the LVV. Therefore, for a given density contrast, the total vertical traction will be the same regardless of the material strength. On the other hand, the distribution of vertical tractions may differ with respect to the material strengths of the surrounding subregions. For example, if the lower crust or the upper mantle is relatively strong, it will be difficult to deform those regions and thus less traction will be applied to the upper crust. For a weak lower crust or upper mantle, on the other hand, the opposite will be true. Figure 3.13a and b illustrate the vertical traction $\mathrm{T}_{\mathrm{y}}$ along the boundaries of the LVV for strong and weak axes, respectively, for different strength sets. Again, in all cases, the sum of all vertical tractions along the LVV and AMC is uniform. However, a reduction in the strength of the lower crust and upper mantle allows a greater fraction of the total vertical traction to be applied to the upper crust. The reason that a large positive vertical traction occurs at the axis for a weak-axis condition (Figure 3.13b) can be attributed to the fact that the LVV is least constrained just below the weak axis.

Since the difference in the composition of crustal and upper mantle materials can produce a large difference in strength, we need to examine how the relative strength of the upper mantle affects the stress field in the upper crust. The horizontal surface stress and the vertical traction along the LVV are shown in Figures 3.14a and b, respectively, 
for strength sets IIa, IIb, IIIa, and IIIb. For a fixed set of material strengths of the crustal subregions, a weak upper mantle is generally more likely to develop a zone of extension off-axis than a strong upper mantle (Figure 3.14a). This can be explained by the fact that a weak upper mantle applies more traction to the upper crust than a strong one (Figure 3.14b).

\section{Variations in Axial Uplift}

The axial uplift produced by low-density volumes within the crust was examined for various sets of material strengths (Figure 3.15). The magnitude of the axial uplift show a large dependence on the strengths of the subregions. For example, for the same buoyancy force, strength set Ia produces the least axial uplift $(\sim 10 \mathrm{~m})$, and set IIIb produces the largest axial uplift $(\sim 270 \mathrm{~m})$.

We also examined a case where the AMC alone acts as source of buoyancy and compared the axial uplift with a case where both the AMC and LVV act as sources of buoyancy. The results show that the axial uplift caused by the AMC alone is small, less than $5 \mathrm{~m}$ or $10 \%$ of that caused by the AMC and LVV combined for strength sets I and II. Also, the differential stresses produced by the buoyancy of the AMC appear to be too small to cause significant frictional failure in the upper crust.

\section{Effects of Adding a Sliding Interface}

We have thus far assumed that stress and displacement in both the normal and tangential directions are continuous across interfaces between subregions. However, if a zone of highly concentrated melt is present within the sources of buoyancy, there may be a discontinuity in tangential stress and displacement across the interface between that 
region and other regions. Here we examine how a sliding interface affects stress and strain due to buoyancy near the axis. First, we assumed that the upper half of the interface between the AMC and the LVV acts as a sliding interface. The resulting differential stress fields show that the case of a sliding interface produces less extensional stress in the axial region than without a sliding interface; however, the difference is small. Next, we assumed that the full length of contact between the upper crust and the LVV acts as a sliding interface. Figure 3.16 shows the differential stress and the directions of principal stresses for a $2-\mathrm{km}$ and $5-\mathrm{km}$ interface half width. The case with no sliding interface is also shown for comparison. The figure shows that the amount of stress will generally be reduced over a sliding interface. Therefore, the addition of a sliding interface to a weak axis makes failure less likely to occur.

\section{Gravitational Spreading Model}

In our gravitational spreading model, the interaction between the mechanically strong upper crust and the underlying substrate is modeled by tangential springs at the base of the upper crust. A greater stiffness means that it is harder for the upper crust to slide over the underlying substrate. Unlike previous cases where the rise axis is modeled as a set of internal springs, the relationship between the spring stiffness and the Young's modulus of the substrate is not straightforward. We found, however, that the stress and strain fields are became similar to those for a fixed base with no tangential displacement when the spring stiffness reachs $10^{8} \mathrm{~Pa} / \mathrm{m}$. In this study, we consider four spring stiffnesses: $10^{2}$, $10^{4}, 10^{6}$, and $10^{8} \mathrm{~Pa} / \mathrm{m}$. 
Strength of the Rise Axis

For gravitational spreading as well as for the buoyancy model, the maximum differential stress develops on axis in the case of a strong axis and off-axis in the case of a weak axis. In this study, we examined at what spring stiffness of the rise axis does the stress field change from strong-axis to weak-axis in character. As with the buoyancy model, we found that the transition occurs at an axial spring stiffness of approximately 5 $\mathrm{MPa} / \mathrm{m}$.

\section{Variation in the Stiffness of Tangential Springs}

We examined the surface horizontal stress for the four tangential spring stiffnesses (Figure 3.17) for both strong and weak axes. For a spring stiffness of $10^{8} \mathrm{~Pa} / \mathrm{m}$, there is virtually no difference in the stress field between a strong and a weak axis. A small extensional stress develops off axis over the region where the base of the upper crust shows the largest depth gradient. Since we assumed no horizontal displacement at $30 \mathrm{~km}$ distance, a zone of compressional stress occurs beyond the zone extension. Such a variation in the surface horizontal stress tends to diminish as we increase the material strength of the upper crust. With a reduction in the spring stiffness from $10^{8} \mathrm{~Pa} / \mathrm{m}$, the stress field starts to differentiate between strong- and weak-axis cases. For a strong axis, a reduction in the tangential spring stiffness causes a greater extensional stress at the axis. For weak axis cases, a large extensional stress develops at $10 \mathrm{~km}$ from the axis for a spring stiffness of $10^{6} \mathrm{~Pa} / \mathrm{m}$. A further reduction in the tangential spring stiffness diminishes the amplitude of the off-axis extensional stress, and beyond about $10 \mathrm{~km}$ distance the horizontal stress becomes increasingly compressive with greater axial distance. 


\section{Effect of Axial Uplift}

We have thus far considered situations where there is no axial uplift at the surface and all the spreading is caused by the sloping base of the upper crust. We need to examine how important the axial uplift is to the total stress field. To do so, we modified the shape of the upper crust such that there is $200 \mathrm{~m}$ of axial uplift in addition to the sloping base. The resulting stress field can be compared to that obtained without axial uplift. Figure 3.18 shows the comparison of two cases for both strong and weak axes. There is only a small difference in the stress field between the two cases. Therefore, axial uplift is not a major source of stress in gravitational spreading.

\section{Discussion}

The two most important characteristics of normal faulting that need to be addressed by a stress model of a fast-spreading mid-ocean ridge are the off-axial initiation of normal faulting, which generally occurs at $2-12 \mathrm{~km}$ distance, and the continued development of normal fault zones to distances at least $30 \mathrm{~km}$ from the axis. As we noted in Chapter 2 and earlier in this chapter, previous models of sources of stress and strain along fast-spreading ridges provide little insight on the explanation of such patterns of normal faulting. Unlike previous models of plate-wide stress and strain fields, our buoyancy and gravitational spreading models focus on regional stress and strain fields produced by processes and structure near the ridge axis. We incorporated constraints provided by recent seismic investigations of the EPR near $9^{\circ} 30^{\prime} \mathrm{N}$ and set up the models so that they can handle a variety of mechanical and material conditions. This section summarizes the results of our modeling and compares them with the observed pattern of normal faulting. In particular, we hypothesize that buoyancy may contribute to the 
initiation of normal faulting, while gravitational spreading may explain the continued development of normal fault zones. We also discuss how the boundary condition at the rise axis might affect other sources of stress, including the thermal stress from plate cooling and the stress induced by mantle flow. Finally, on the basis of the results of our modeling and other studies, a new model of faulting at fast-spreading ridges is presented.

Among several factors that could affect the pattern of stress in near-ridge oceanic lithosphere, the mechanical strength of the rise axis appears to be the most important factor. The results of buoyancy and gravitational spreading modeling consistently show that for a strong axis a zone of extension is centered on the axis. On the other hand, if the rise axis is weak, since it cannot support large stresses, the maximum differential stress at the surface due to buoyancy and gravitational spreading occurs off-axis. The argument that a strong axis would develop extensional stress on-axis can be easily foreseen from a consideration of a continuous plate under vertical loading from the base or a thickening plate that is extended in the horizontal direction by a far-field stress. In the former case, the loading will cause the region above the loading point to deform such that the upper half of the plate is extended while the lower half is compressed; and in the latter case, because the plate is thinnest at the axis, the greatest concentration of stress will occur at the axis. This leads us to conclude that for a strong axis normal faulting will initiate onaxis rather than off-axis.

At fast-spreading ridges, there may be temporal variations in the strength of the axis arising as a result of different phases in the evolution of an axial dike zone, with a strong axis corresponding to a solidified stage and a weak axis to a molten stage. In our models, the transition from strong to weak axis occurs when the stiffness of the spring used to model the rise axis is approximately $5 \mathrm{MPa} / \mathrm{m}$ for an upper crust with a Young's modulus of $53 \mathrm{GPa}$. On the basis of the relationship between the width of the dike, its Young's modulus, and the spring stiffness of the axis, we can estimate the width of the axial injection zone or its Young's modulus relative to normal upper crust in order for the rise 
axis to be considered weak. For example, for two cases of dike zone width of 10 and 100 $\mathrm{m}$, the strength of such a zone has to be at least 200 and 20 times less than that of normal upper crust, respectively. The width of the axial summit caldera may provide a constraint on the width of such an active dike zone. According to Haymon et al. [1991], the width of axial summit caldera ranges from $40-150 \mathrm{~m}$ along the axis of the EPR.

\section{Buoyancy}

For a weak rise axis under a buoyancy force, the type of stress that occurs near the surface depends on the structure and material properties of the mid-ocean ridge. However, since the material properties of mid-ocean ridge are not well known and difficult to represent by elastic moduli, in this study, we considered a range of possible variations in moduli among model subregions. For a weak axis and relatively strong subregions below the upper crust, we found that the near-axial stress field is analogous to that of a pressurized vertical crack in a semi-infinite solid [Lachenbruch, 1961] in that a zone develops around the axis where stress is generally relieved. As with the case of a pressurized vertical crack, the vertical extent of the weak axis is a crucial factor determining the size of the area of stress relief and thus the distance from the axis to the maximum surface extensional stress. The reason that this case resembles that of a pressurized vertical crack is understandable, considering the fact that the subregions beneath the upper crust are relatively strong, and thus the whole region may behave as a semi-infinite solid. However, a weak axis with relatively strong subregions below the upper crust may not be representative of fast-spreading ridges over the time scale of most geologic deformation. One consequence of having a high modulus LVV is the development of a zone of stress concentration at the lower tip of the weak axial injection zone. 
For a weak axis and relatively weak subregions below the upper crust, a number of factors control whether a zone of extensional stress will develop or not, and if so, the stress magnitude and the locus of such a zone. Without a knowledge of some of these factors, such as the material properties, it is difficult to determine which mechanism will dominate the process of normal faulting. For a given buoyancy force, a zone of extensional stress is more likely to develop if the upper crust is thin or weak than if it is thick or strong. Therefore, the flexural rigidity of the upper crust appears to be one of the parameters that determines if normal faulting will develop off-axis or not.

Another important factor is the way in which traction is applied to the upper crust by the buoyancy sources. In the models of Madsen et al. [1984] and Wang and Cochran [1993], by assuming that the lithosphere is underlain by a region of inviscid fluid, the buoyancy force was simply considered as a normal traction applied along the base of the lithosphere. This is conceptually different from the way we have modeled buoyancy. In our case, buoyancy forces are modeled as body forces in the source regions and therefore can exert shear as well as normal tractions along the base of the upper crust as the source regions themselves deform not only vertically but also laterally.

For those cases with a weak axis where a zone of extensional stress develops off-axis, a greater buoyancy force will increase the size of this extensional zone and thus promote the development of normal faulting off-axis. Another way to increase the buoyancy force applied to the upper crust is by lowering the strength of the underlying subregions. However, simply lowering the strength of the subregions below the upper crust will not guarantee that a greater extensional stress will develop off-axis. This is because as one reduces the strength of the LVV, the shear traction that the LVV exerts at the base of the upper crust is also reduced. In our buoyancy model, this shear traction provides the necessary mechanism for extension in the upper crust. This effect was demonstrated earlier; we showed that a systematic reduction in the strengths of the subregions underlying the upper crust leads to greater axial uplift (Figure 3.15a) but also results in 
the development of a greater compressional stress off-axis (Figures 3.6 and 3.7). One way to promote the development of normal faulting off-axis would be to have a relatively strong LVV while having a relatively weak upper mantle. A weak mantle will allow a greater fraction of total buoyancy to be applied to the upper crust, and the strong LVV will allow a greater shear traction to be applied along the base of the upper crust. However, such conditions may not be realistic, for the reasons discussed below. Another way to facilitate the development of normal faulting off-axis is to have a wide interface between the LVV and the upper crust. In this study, we considered two configurations of the LVV, one where the interface is $2-\mathrm{km}$ in half width and the other where it is $5-\mathrm{km}$ in half width. For a given set of material properties for the subregions underlying the upper crust and a given magnitude of the buoyancy force, the 5-km half width allows more shear traction to be applied directly along the base of the upper crust than the 2-km half width and thus increases the likelihood of normal faulting (Figure 3.9).

Thus far we have assumed that displacements and tractions in both the normal and tangential directions are continuous across the interfaces between the buoyancy sources and surrounding subregions. However, a recent seismic investigation by Kent et al. [1993a] suggests that the AMC reflector may not be the roof top of the AMC, but instead the path of melt migration just below an impermeable upper crustal layer. If so, it may not be valid to assume that tangential displacements and tractions are continuous across this interface. Our results show that adding a sliding interface between the upper crust and the LVV, for a weak rise axis, virtually eliminates stress within upper crust above the sliding interface. Although extensional stresses do develop in the upper crust beyond the sliding interface, the magnitude of those stresses are small relative to those in cases without the sliding interface. Nonetheless, we cannot preclude the possibility that offaxial development of normal faulting may be controlled by the dimensions of the path of melt migration within the crust. 
Based on our discussion thus far, we have developed three possible mechanisms for normal faulting to initiate off-axis due to sources of buoyancy within the crust (Figure 3.19). However, the extensional stresses resulting from buoyancy forces, for reasonable material parameters, do not extend far enough from the axis to explain the continued development of normal fault zones. In Chapter 2, we noted that the midpoint between the nearest large offset normal fault zones on either side of the axis follows the inferred axis of magmatism rather than large-scale bathymetry. We examine each of the three mechanisms to see if it is consistent with the observed distribution of normal fault zones along the EPR.

For cases involving strong subregions beneath the upper crust (Figure 3.19, top), an offset in the buoyancy source produces a greater magnitude of extensional stress on the same side of the upper crust, but the distance from the bathymetric axis to the peak extensional stress remains virtually unchanged, and thus would not explain the observed variation in the distance to the nearest large-offset normal fault zone along axis. This may be understandable considering the earlier argument that the vertical extent of the weak axial zone controls the size of the area of stress relief for strong subregions. For cases with weak subregions beneath the upper crust (Figure 3.19, middle) or with a sliding interface (Figure 3.19, bottom), on the other hand, the distance to the peak extensional stress is asymmetric in a manner consistent with the observed pattern of normal fault zones along the EPR.

\section{Gravitational Spreading}

For a strong axis, reduction of the tangential spring stiffness at the base of the upper crust results in a greater extensional stress at the axis (Figure 3.17a). In general, the magnitude of such stress diminishes with distance from the axis and eventually becomes 
compressional. Obviously, the total extent of the zone of extension at the surface may have an important influence on the width of the zone of normal faulting. However, according to our analysis, the width of such a zone appears to be controlled by the configuration of the base of the upper crust and the boundary condition at the far ends of the modeling region. For example, because we assume no horizontal displacement at the ends of our model (i.e., at $x= \pm 30 \mathrm{~km}$ ), the transition from horizontal extension to compression at the surface in most cases occurs halfway along the total length of the modeled region. Because of such a dependence of horizontal stress on the length of the modeling region, a direct comparison between the distal end of the zone of extension at the surface and the distance of normal fault activity is not meaningful.

Two distinct stress fields result from weak-axis cases. In cases where the base of the upper crust has extremely low stiffness because the upper crust is allowed to move virtually freely in the horizontal direction, the horizontal stress is predominantly compressional and increases in magnitude with distance from the axis. This type of stress field is thus similar to that obtained by Dahlen [1981] using an isostatic model of the lithosphere. For an upper crust whose base deepens with distance from the axis, surface extensional stresses are nowhere predicted. With increasing stiffness at the base of the upper crust, however, a zone of extensional stress develops in the near-axis region. The stress fields are virtually indistinguishable between weak- and strong-axis cases except for the region very near the axis. Therefore, as with strong-axis cases, the shape of the base of the mechanically strong upper crust and the boundary condition at the far end of the modeling region determine the general stress field. For a moderate stiffness, both weak and strong axes can account for continued fault activity. 


\section{Along-Axis Variations}

Mid-ocean ridges at all spreading rates are segmented into individual spreading cells bounded by ridge-axis offsets. A segment of the mid-ocean ridge may undergo cycles of active and inactive phases of magmatism or extension. During such a cycle, the strength of the rise axis and the boundary conditions at the base of the upper crust can change, allowing the stress field in the upper crust to vary as well.

An active phase of magmatism may be characterized as a stage in which the rise axis is mechanically weak compared with other parts of the crust (Figure 3.20). When the magma chamber may is replenished by hot magma, a sequence of dike intrusions and surface eruptions may follow. The buoyancy force that the magma chamber exerts on the overlying upper crust is then at its maximum. The place where normal faulting is most likely to occur is then predicted by our models to be on an off-axis region (for example, between 2 and $10 \mathrm{~km}$ from the axis). Furthermore, if a zone with a high concentration of melt is present at the top of AMC, it will allow the upper crust to slide and thus the thickness-averaged component of extensional stress to be relieved to a greater extent in the region near the axis. In contrast, when the supply of magma diminishes in the magma chamber, the frequency of eruptions will lessen and the shallow structure of the neovolcanic zone may become comparatively cool and strong. During this phase, faulting due to buoyancy could develop on-axis. However, the chances of failure on-axis during this phase may decrease if the magnitude of buoyancy force decreases or if the magma chamber retreats deeper into the crust.

Once normal faults that initiated near the axis are transported far from the axis, the buoyancy of the axial magma chamber and surrounding low-velocity volume is no longer able to drive further activity on these faults. With increasing distance from the axis, the local boundary condition at the axis is expected to become less important. Thus, sources such as gravitational spreading, plate cooling, and mantle-induced stress must play more 
important roles in the continued slip on normal faults beyond the zone of initial fault formation (Figure 3.20). At present, however, it is unclear which of the above mechanism is the dominant source of continued fault activity.

The argument that the rise axis possesses some strength does not contradict the evidence from near-ridge earthquakes. Studies of near-ridge earthquake have suggested that the source mechanism of earthquakes in 3-35-My-old lithosphere is consistent with thermoelastic stress arising from a weak axis under plate cooling [Bergman and Solomon, 1984; Bratt et al., 1985]. Figure 3.21 shows two situtations where there could be characteristic stress field as a result of plate cooling (i.e., compressional stress at the top of the lithosphere and extensional stress at mid to bottom of the lithosphere). Obviously, one is to have a weak axis (Figure 3.21a). However, if there exists a finite width plate boundary zone, where most of the deformation takes place, then the plate outside this zone can still act in the same way as if the axis was weak even if the rise axis has significant strength (Figure 3.21b). For instance, consider an extensional stress applied in the horizontal direction by sources outside this zone of active tectonic deformation. In response to such stress, deformation will probably occur by normal faulting throughout this zone rather than only at the rise axis itself.

An important element of our model that we may be able to test is that the initiation of normal faulting by buoyancy should occur preferentially at portions of the ridge axis where independent geological evidenc indicates a weak boundary (Figure 3.22). Here the dotted line represents the portion of the rise axis that is mechanically weak, and the surrounding shaded area represents an area where stress is generally relieved by the presence of the weak rise axis, and I and I' denote the initiation of normal faults predicted for weak and strong rise axes, respectively. If normal faults do form as a result of buoyancy during a period of a weak rise axis, one could further predict that the normal faults will appear closer to the rise axis in regions where the rise axis has been most recently weak. 
This idea can be tested using the results of Sea MARC II side scan sonar survey of the EPR between $8^{\circ} 30^{\prime}$ and $10^{\circ} \mathrm{N}$ [Carbotte and Macdonald, 1994] (Figure 3.23). Although there is no direct way to tell which portions of the rise axis have been most recently weak, we may deduce from the residual gravity anomalies [Chapter 5] that local gravity lows near $9^{\circ} 21^{\prime}, 9^{\circ} 32^{\prime}$, and $9^{\circ} 42^{\prime} \mathrm{N}$ represent regions of high magmatic flux and therefore places where the rise axis has been recently weakened by volcanic eruptions (dark shades in Figure 3.23). There appears to be a qualitative correlation between regions where normal faults occur close to the rise axis and the loci of gravity lows, which is consistent with our hypothesis.

The continued growth of normal faults beyond the zone of stress relief (denoted as II and III in Figure 3.22) may depend on a number of factors, such as the effect of mechanisms such as gravitational spreading, mantle flow-induced stress, and thermoelastic stress. It appears that the average fault length is greater beyond $10-15 \mathrm{~km}$ from the rise axis than at closer distances (Figure 3.23). Such a pattern would favor the initiation of new faults, with geometry influenced by the thicker mechanical lithosphere (Figure 3.20), rather than only continued slip on previously formed faults. A careful comparison of fault populations versus distance, however, awaits a future, more quantitative analysis. 


\section{Conclusions}

We have examined the stress and strain fields that result from two different types of sources that we consider to be important at fast-spreading mid-ocean ridges: the buoyancy forces exerted on the lithosphere by low-density regions in the lower crust, and gravitational spreading. Recent seismic studies along the northern EPR [Detrick et al, 1987; Vera et al., 1990; Toomey et al., 1990] and thermal models [Wilson et al., 1988] provide us with an opportunity to constrain the shapes of low density regions and of the overlying mechanically strong upper crust. We employed boundary element methods to incorporate buoyancy and gravitational spreading as body forces in a linear elastic medium, and we determined stress and strain fields for a variety of rise axis conditions.

On the basis of our modeling results, the following conclusions may be drawn:

(1) The mechanical strength of the rise axis is the most important factor affecting the stress field in the upper crust near the axis. If the rise axis is mechanically weak, buoyancy and gravitational spreading produce a stress field in which a zone of extensional stress develops off-axis. On the other hand, if the rise axis is mechanically strong, buoyancy and gravitational spreading produce a stress field in which the zone of extensional stress is centered on the axis. While buoyancy can explain a consistent distance at which normal faults initiate off-axis, gravitational spreading can account for continued activity on normal faults to a greater distance from the axis than can with buoyancy. The existence of a magma lens can play an important role in reducing the magnitude of the stress field for a weak rise axis, as the crust above the magma lens can slide and thus relieve the thickness-averaged extensional stress.

(2) For a given set of material strengths and a given magnitude of buoyancy force, the flexural rigidity of the upper crust plays an important role in determining if a zone of extension will develop off axis and, if so, the size of that zone. A thin or mechanically 
weak upper crust is more likely to develop a zone of extension than one that is thick or mechanically strong.

(3) A number of factors control the distance from the axis of the maximum surface extensional stress for a weak-axis case, including the vertical extent of the axial weak zone and the horizontal extent of the magma chamber and magma lens.

(4) The rise axis can be considered as weak locally at sites of recent magmatic activity but of a finite strength when viewed at a sufficient distance from the axis. The initiation of normal faulting near a weak axis can be the result of buoyancy, while continued normal faulting activity farther from the axis may be maintained by an extensional stress field produced over a wide region by such other tectonic processes as gravitational spreading, mantle-convective tractions, and lithospheric cooling. 


\section{References}

Ashby, M. F., and R. A. Verrall, Micromechanisms of flow and fracture, and their relevance to the rheology of the upper mantle, Phil. Trans. R. Soc. Lond., Ser. A, 288, 59-95, 1977.

Atkinson, B. K., Fracture Mechanics of Rock, Academic Press, London, 534 pp., 1987.

Bergman, E. A., and S. C. Solomon, Source mechanisms of earthquakes near mid-ocean ridges from body waveform inversion: Implications for the early evolution of oceanic lithosphere, J. Geophys. Res., 89, 11,415-11,441, 1984.

Bicknell, J. D., J.-C. Sempéré, K. C. Macdonald, and P. J. Fox, Tectonics of a fast spreading center: A Deep-Tow and Sea Beam survey on the East Pacific Rise at 19³0'S, J. Geophys. Res., 9, 25-45, 1987.

Bratt, S. R., and S. C. Solomon, Compressional and shear wave structure of the East Pacific Rise at $11^{\circ} 20^{\prime} \mathrm{N}$ : Contraints from three-component ocean bottom seismometer data, J. Geophys. Res., 89, 6095-6110, 1984.

Bratt, S. R., E. A. Bergman, and S. C. Solomon, Thermoelastic stress: How important as a cause of earthquakes in young oceanic lithosphere?, J. Geophys. Res., 90, 10,249$10,260,1985$.

Carbotte, S. M., and K. C. Macdonald, Comparison of seafloor tectonic fabrics at intermediate, fast, and superfast spreading ridges: Influence of spreading rate, plate motions, and ridge segmentation on fault patterns, J. Geophys. Res., 99, 13,60913,631, 1994.

Chen, W. P., and P. Molnar, Focal depths of intracontinental and intraplate earthquakes and their implications for the thermal and mechanical properties of the lithosphere, $J$. Geophys. Res., 88, 4183-4214, 1983. 
Chen, Y., and W. J. Morgan, Rift valley/no rift valley transition at mid-ocean ridges, $J$. Geophys. Res., 95, 17,571-17,581, 1990a.

Chen, Y., and W. J. Morgan, A nonlinear rheology model for mid-ocean ridge axis topography, J. Geophys. Res., 95, 17,583-17,604, 1990b.

Choukroune, P., J. Francheteau, and R. Heikinian, Tectonics of the East Pacific Rise near 1250'N: A submersible study, Earth Planet. Sci. Lett., 68, 115-127, 1984.

Christeson, G. L., G. M. Kent, G. M. Purdy, and R. S. Detrick, Extrusive thickness variability at the East Pacific Rise: Constraints from seismic techniques, J. Geophys. Res., submitted, 1994.

Dahlen, F. A., Isostasy and the ambient state of stress in the oceanic lithosphere, $J$. Geophys. Res., 86, 7801-7807, 1981.

Detrick, R. S., P. Buhl, E. Vera, J. C. Mutter, J. Orcutt, J. Madsen, and T. Brocher, Multichannel seismic imaging of a crustal magma chamber along the East Pacific Rise, Nature, 326, 35-41, 1987.

Forsyth, D. W., Comparison of mechanical models of the oceanic lithosphere, $J$. Geophys. Res., 85, 6364-6368, 1980.

Harding, A. J., G. M. Kent, and J. A. Orcutt, A multichannel seismic investigation of upper crustal structure at $9^{\circ} \mathrm{N}$ on the East Pacific Rise: Implications for crustal accretion, J. Geophys. Res., 98, 13,925-13,944, 1993.

Haxby, W. F., and E. M. Parmentier, Thermal contraction and the state of stress in the oceanic lithosphere, J. Geophys. Res., 93, 6419-6429, 1988.

Haymon, R. M., D. J. Fornari, M. Edwards, S. Carbotte, D. Wright, and K. Macdonald, Hydrothermal vent distribution along the East Pacific Rise crest $\left(9^{\circ} 09^{\prime}-54^{\prime} \mathrm{N}\right)$ and its relationship to magmatic and tectonic processes on fast-spreading mid-ocean ridges, Earth Planet. Sci. Lett., 104, 513-534, 1991.

Hyndman, R. D., Poisson's ratio in the oceanic crust - A review, Tectonophysics, 59, 321-333, 1979. 
Jaeger, J. C., and N. G. W. Cook, Fundamentals of Rock Mechanics, 3rd ed., Chapman and Hall, London, 593 pp., 1979.

Kent, G. M., A. J. Harding, and J. A. Orcutt, Distribution of magma beneath the East Pacific Rise between the Clipperton Transform and the $9^{\circ} 17^{\prime} \mathrm{N}$ deval from forward modeling of common depth point data, J. Geophys. Res., 98, 13,945-13,969, 1993a.

Kent, G. M., A. J. Harding, and J. A. Orcutt, Distribution of magma beneath the East Pacific Rise near the $9^{\circ} 03^{\prime} \mathrm{N}$ overlapping spreading center from forward modeling of common depth point data, J. Geophys. Res., 98, 13,971-13,995, 1993b.

King, G., and M. Ellis, The origin of large local uplift in extensional regions, Nature, 348, 689-693, 1990.

Kirby, S. H., Rheology of the lithosphere, Rev. Geophys. Space Phys., 21, 1458-1487, 1983.

Lachenbrunch, A. H., Depth and spacing of tension cracks, J. Geophys. Res., 66, 42734292, 1961.

Lister, C. R. B., Gravitational drive on oceanic plates caused by thermal contraction, Nature, 257, 663-665, 1975.

Lonsdale, P., Structural geomorphology of a fast-spreading rise crest: The East Pacific Rise near $3^{\circ} 25^{\prime}$ N, Mar. Geophys. Res., 3, 251-293, 1977.

Macdonald, K. C., and B. P. Luyendyk, Investigation of faulting and abyssal hill formation on the flanks of the East Pacific Rise $\left(21^{\circ} \mathrm{N}\right)$ using ALVIN, Mar. Geophys. Res., 7, 515-535, 1985.

Madsen, J. A., D. W. Forsyth, and R. S. Detrick, A new isostatic model for the East Pacific Rise crest, J. Geophys. Res., 89, 9,997-10,015, 1984.

Sinton, J. M., and R. S. Detrick, Mid-ocean ridge magma chambers, J. Geophys. Res., 97, 197-216, 1992. 
Toomey. D. R., G. M. Purdy, S. C. Solomon and W. S. D. Wilcock, The threedimensional seismic velocity structure of the East Pacific Rise near latitude $9^{\circ} 30^{\prime} \mathrm{N}$, Nature, 347, 639-645, 1990.

Toomey, D. R., S. C. Solomon, and G. M. Purdy, Tomographic imaging of the shallow crustal structure of the East Pacific Rise at $9^{\circ} 30^{\prime} \mathrm{N}$, J. Geophys. Res., 99, 24,13524,157, 1994.

Turcotte, D. L., Thermal stresses in planetary elastic lithospheres, Proc. 13th Lunar Planet. Sci. Conf., Part 2, J. Geophys. Res., 88, Suppl., A585-A587, 1983.

Vera, E. E., J. C. Mutter, P. Buhl, J. A. Orcutt, A. J. Harding, M. E. Kappus, R. S. Detrick, and T. M. Brocher, The structure of 0- to $0.2-\mathrm{m} . \mathrm{y}$.-old oceanic crust at $9^{\circ} \mathrm{N}$ on the East Pacific Rise from expanded spread profiles, J. Geophys. Res., 95, 15,52915,556, 1990.

Wang, X., and J. R. Cochran, Gravity anomalies, isostasy, and mantle flow at the East Pacific Rise crest, J. Geophys. Res., 98, 19,505-19,531, 1993.

Wiens, D. A., and S. Stein, Intraplate seismicity and stresses in young oceanic lithosphere, J. Geophys. Res., 89, 11,442-11,464, 1984.

Wilcock, W. S. D., S. C. Solomon, G. M. Purdy, and D. R. Toomey, The seismic attentuation structure of a fast-spreading mid-ocean ridge, Science, 258, 1470-1474, 1992.

Wilcock, W. S. D., S. C. Solomon, G. M. Purdy, and D. R. Toomey, The seismic attenuation structure of the East Pacific Rise near $9^{\circ} 30^{\prime} \mathrm{N}$, J. Geophys. Res., submitted, 1995.

Wilson, D. S., D. A. Clague, N. H. Sleep, and J. L. Morton, Implications of magma convection for the size and temperature of magma chambers at fast spreading ridges, J. Geophys. Res., 93, 11,974-11,984, 1988.

Zhang, Y.-S., and T. Tanimoto, Ridges, hotspots and their interaction as observed in seismic velocity maps, Nature, 355, 45-49, 1992. 
Table 3.1 Values of parameters used to determine dynamic moduli of subregions in our modeling region.

\begin{tabular}{lcccc}
\hline & $\begin{array}{c}\text { P-wave velocity } \\
(\mathrm{km} / \mathrm{s})\end{array}$ & $\begin{array}{c}\text { Density } \\
\left(\mathrm{kg} / \mathrm{m}^{3}\right)\end{array}$ & Poisson's Ratio & $\begin{array}{c}\text { Young's } \\
\text { modulus (GPa) }\end{array}$ \\
\hline Upper Crust & 5 & 2700 & 0.28 & 53 \\
AMC & 3.5 & 2500 & 0.41 & 13 \\
LVV & 6 & 2600 & 0.32 & 65 \\
Lower Crust & 7 & & & 100 \\
& & 2900 & 0.32 & 160 \\
Upper Mantle & 8 & 3300 & 0.32 & \\
\hline
\end{tabular}


Table 3.2. Sets of material strengths considered in this study.

\begin{tabular}{|c|c|c|c|}
\hline \multirow[b]{2}{*}{ Set } & \multicolumn{3}{|c|}{ Young's Modulus (GPa) } \\
\hline & I & II & III \\
\hline Upper Crust & 53 & 53 & 53 \\
\hline $\mathrm{AMC}$ & 13 & 1.3 & 0.13 \\
\hline LVV & 65 & 6.5 & 0.65 \\
\hline Lower Crust & 100 & 10 & 1 \\
\hline Upper Mantle & 160 & 16 & 1.6 \\
\hline
\end{tabular}


Table 3.3. Sets of material strengths used to study the effect of variations in mantle strength.

\begin{tabular}{lcccc}
\hline \multicolumn{1}{c}{ Set } & \multicolumn{4}{c}{ Young's Modulus (GPa) } \\
IIa & IIb & IIIa & IIIb \\
\hline Upper Crust & 53 & 53 & 53 & 53 \\
AMC & 1.3 & 1.3 & 0.13 & 0.13 \\
LVV & 6.5 & 6.5 & 0.65 & 0.65 \\
Lower Crust & 10 & 10 & 1 & 1 \\
Upper Mantle & 80 & 1.6 & 8 & 0.16 \\
\hline
\end{tabular}


Figure 3.1. Schematic diagram of strength and mode of deformation in oceanic crust and upper mantle. The upper crust can be modeled as an elastic-brittle medium and thus a zone where brittle failure can occur. Ductile flow dominates the deformation in the lower crust. Depending on the temperature and stress, the uppermost part of the mantle may behave as elastic. 


\section{Material Strength}

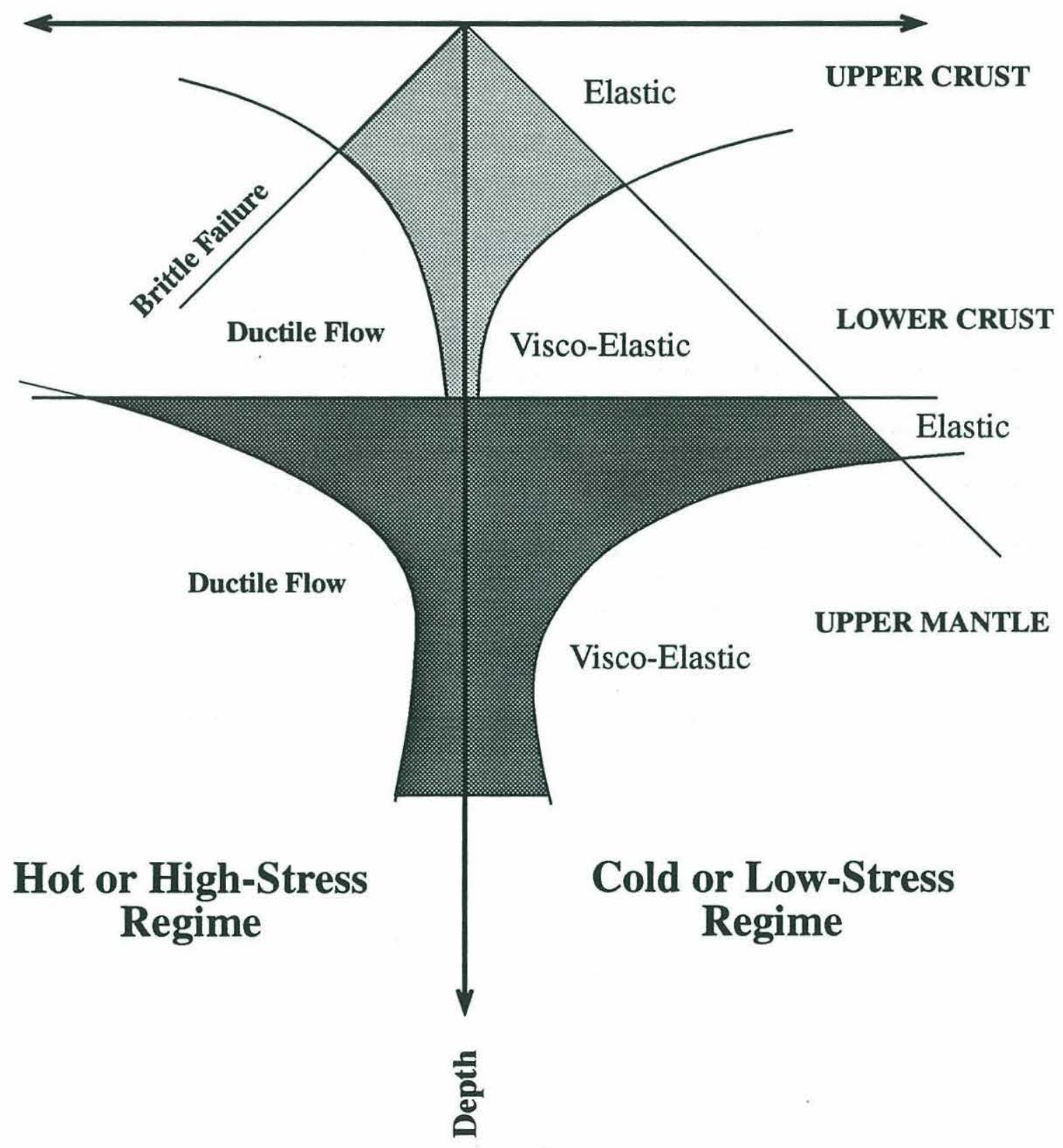


Figure 3.2. P-wave velocity structure (in $\mathrm{km} / \mathrm{s}$ ) of the EPR derived from expandingspread-profile and common-depth-point reflection data [Vera et al., 1990]. Although the roof of the axial magma chamber appears as a narrow reflector whose total width is only about $2 \mathrm{~km}$ [Detrick et al., 1987; Kent et al., 1993a, b], the seismic low-velocity volume extends to $5 \mathrm{~km}$ from the rise axis. The arrows represent schematically the extent of hydrothermal circulation near the axis. According to Sinton and Detrick [1992], the lowvelocity zone comprises a narrow, sill-like body of melt 1-2 km below the rise axis that grades downward into a partially solidified crystal mush zone which is, in turn, surrounded by a transition zone of solidified but still hot, surrounding rock. 


\section{Seismic Velocity Structure of the East Pacific Rise near $9^{\circ} 30^{\prime} \mathrm{N}$}

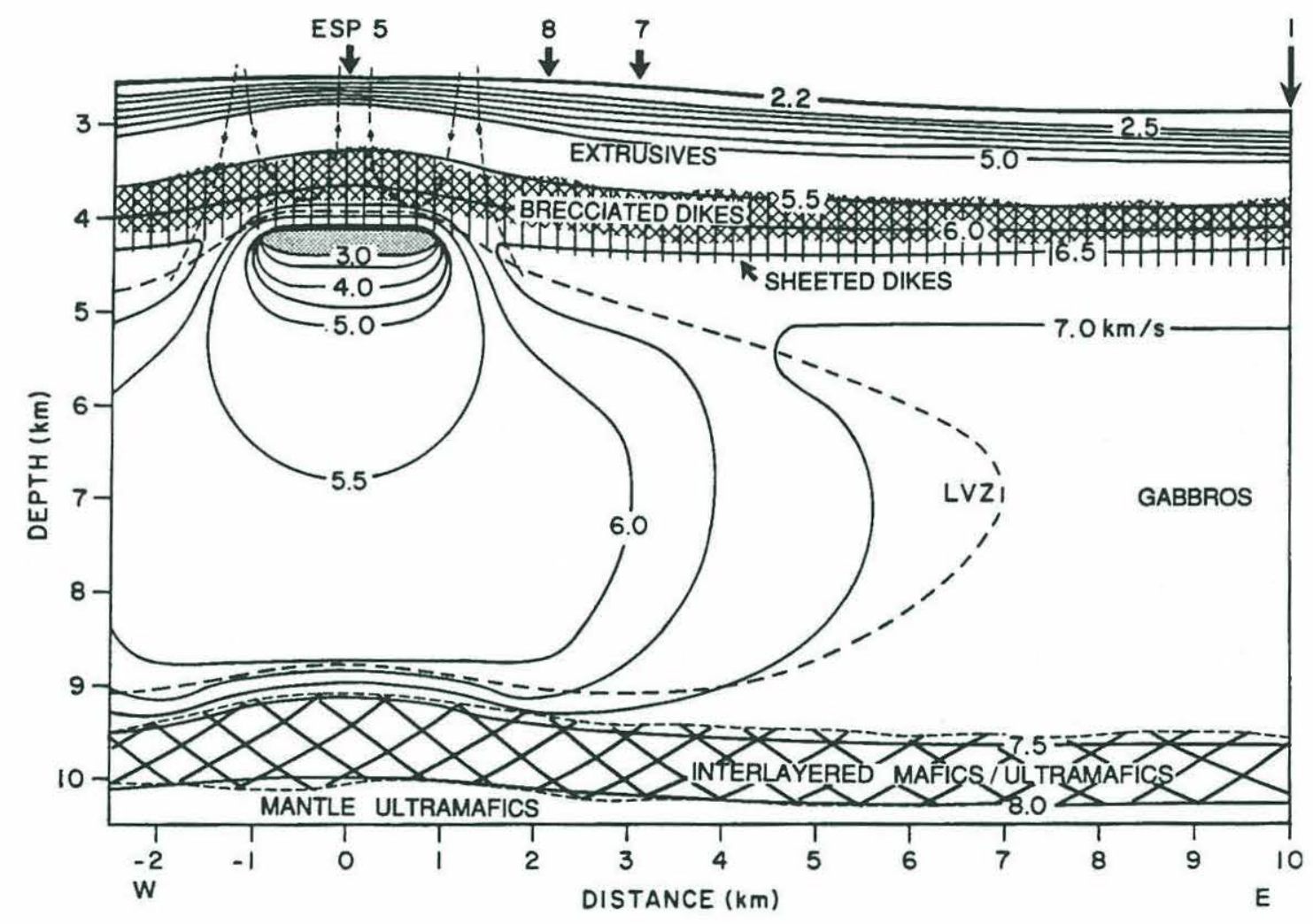

Vera et al. [1990] 
Figure 3.3. Schematic diagram showing the configuration of the buoyancy model developed and used in this study. The region of modeling, extending $30 \mathrm{~km}$ to each side of the rise axis, is divided into five subregions: the axial magma chamber (AMC), the low-velocity volume (LVV), the mechanically strong upper crust, the weak lower crust, and the upper mantle. In this study, we assume a fixed Young's modulus of $53 \mathrm{GPa}$ for the upper crust. The Poisson's ratios of the subregions are given in Table 3.1. The axial magma chamber and the low-velocity volume, lower in density than the lithosphere because of high temperatures, act as potential sources of buoyancy. To avoid rigid-body motion of the modeling region, we prescribe zero displacement in the horizontal direction for three elements at the far end of the upper crust. Elements are prescribed more densely in the upper crust near the rise axis. 


\section{Configuration of Buoyancy Model}

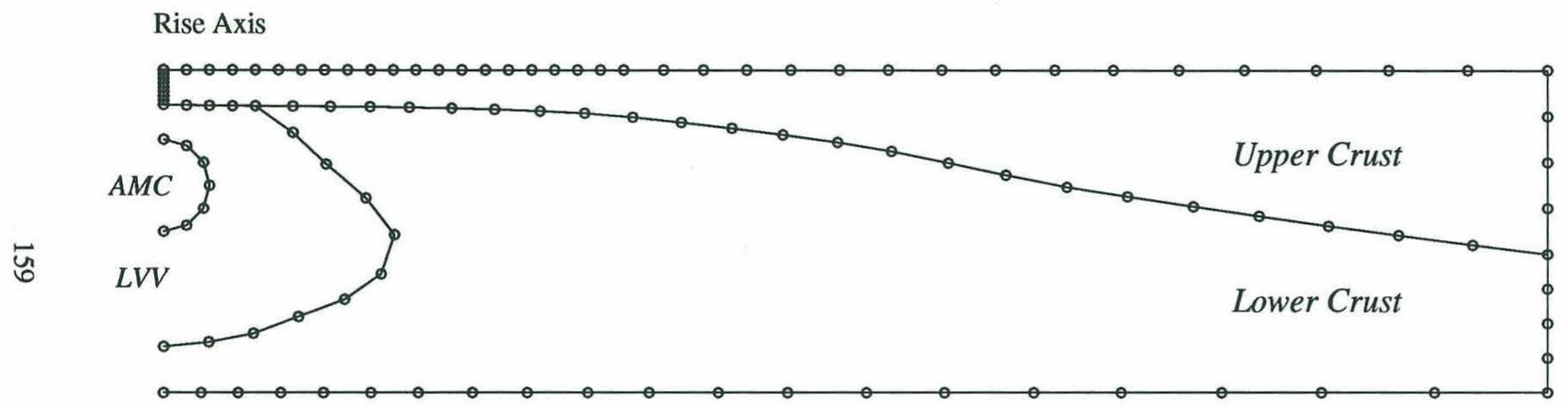

Upper Mantle

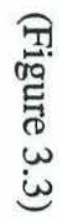

Semi-infinite half-space 
Figure 3.4. Schematic diagram showing the configuration of the gravitational spreading model used in this study. The region of modeling extends to $30 \mathrm{~km}$ on each side of the rise axis. The amount of axial uplift is treated as a variable. The elevation lessens with increasing distance from the axis and becomes zero at approximately $30 \mathrm{~km}$ from the axis. The base of the mechanically strong upper crust is defined in the same manner as with the buoyancy model. The elevation at the rise axis and the fact that the upper crust sits on the sloping substrate provide the component of gravitational body force that drives the lithosphere away from the axis. To avoid rigid-body motion of the modeling region, we prescribe zero displacement in the horizontal direction for three elements at the far end of the upper crust. Elements are prescribed more densely in the upper crust near the rise axis. 


\section{Configuration of Gravitational Spreading Model}

Rise Axis

六

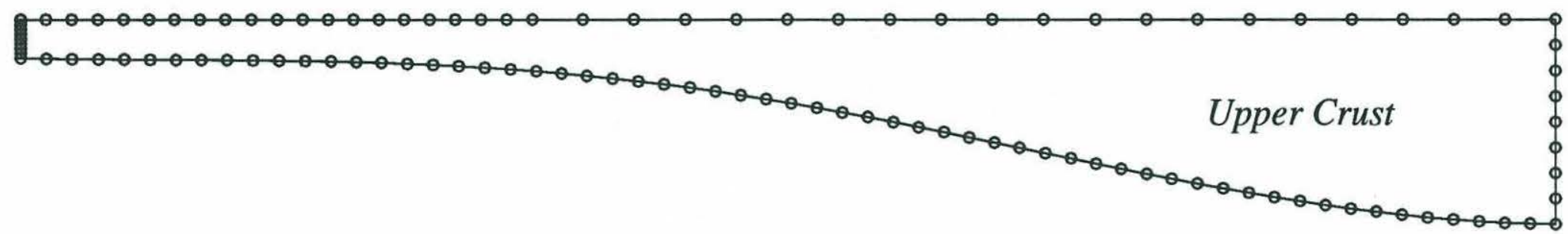

Underlying Substrate

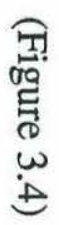


Figure 3.5. (a) Locations of internal spring and sliding interface conditions. In our models, the axial dike zone is modeled as an internal spring interface and the magma lens as a sliding interface. (b) and (c) are enlarged illustrations of internal spring and sliding interface conditions, respectively. The internal spring interface is specified in terms of a spring stiffness in a given direction. In the case of the sliding interface, the two zones are free to slip past each other frictionlessly in the tangential direction. Normal stress $\sigma_{\mathrm{n}}$ and normal displacement $u_{\mathrm{n}}$ are continuous across the interface. 
(a) Locations of Special Interfaces

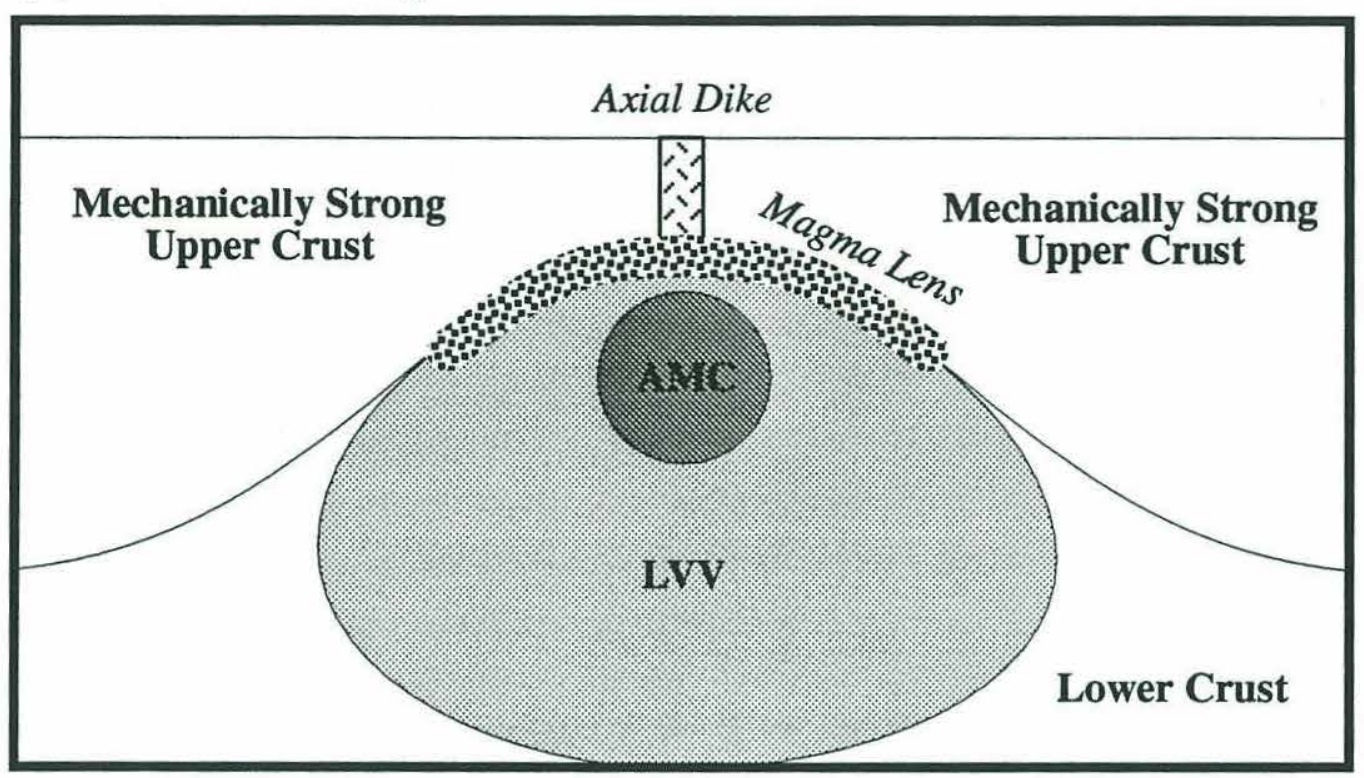

(b) Internal Spring Interface

(c) Sliding Interface
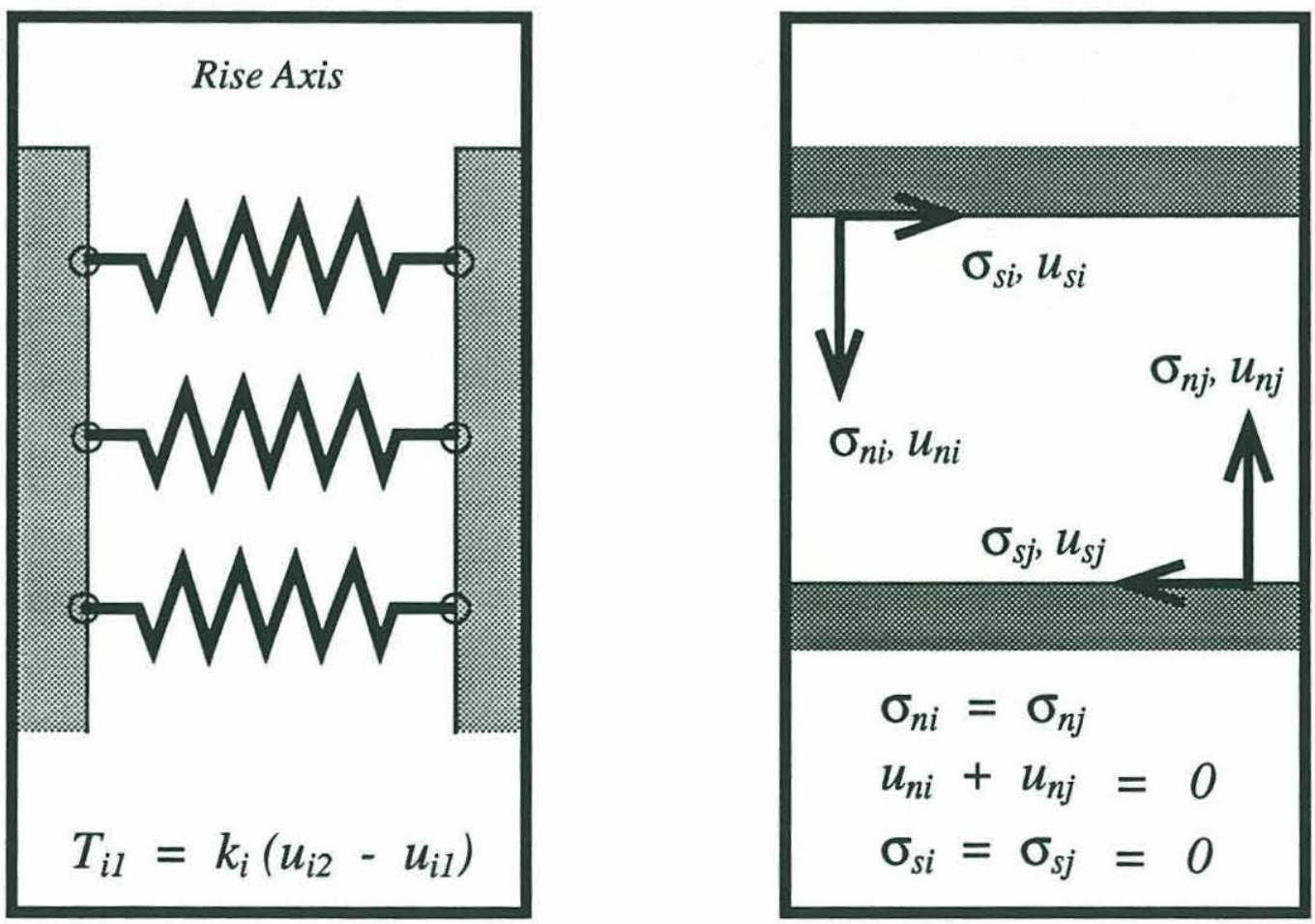
Figure 3.6. Differential stresses for (a) strong- and (b) weak-axis cases for strength set I. The two pairs of arrows depict the polarity direction of the two principal stresses; the relative absolute magnitudes of the principal stress are represented only approximately. For the strong rise axis case the lithosphere is continuous across the axis, while for the weak rise axis case the axis has zero internal spring stiffness and thus acts as a stress-free surface. Both the AMC and the LVV act as sources of buoyancy. The stress fields are almost identical except in the axial region. In the case of a strong axis, the maximum differential stress at the surface occurs on-axis. This is true for all other strong-axis cases. On the other hand, for a weak axis the maximum differential stress occurs offaxis, approximately $2 \mathrm{~km}$ from the axis in this particular case. 


\section{Difference between a Strong and a Weak Axis For strength set I}

(a) Strong Axis
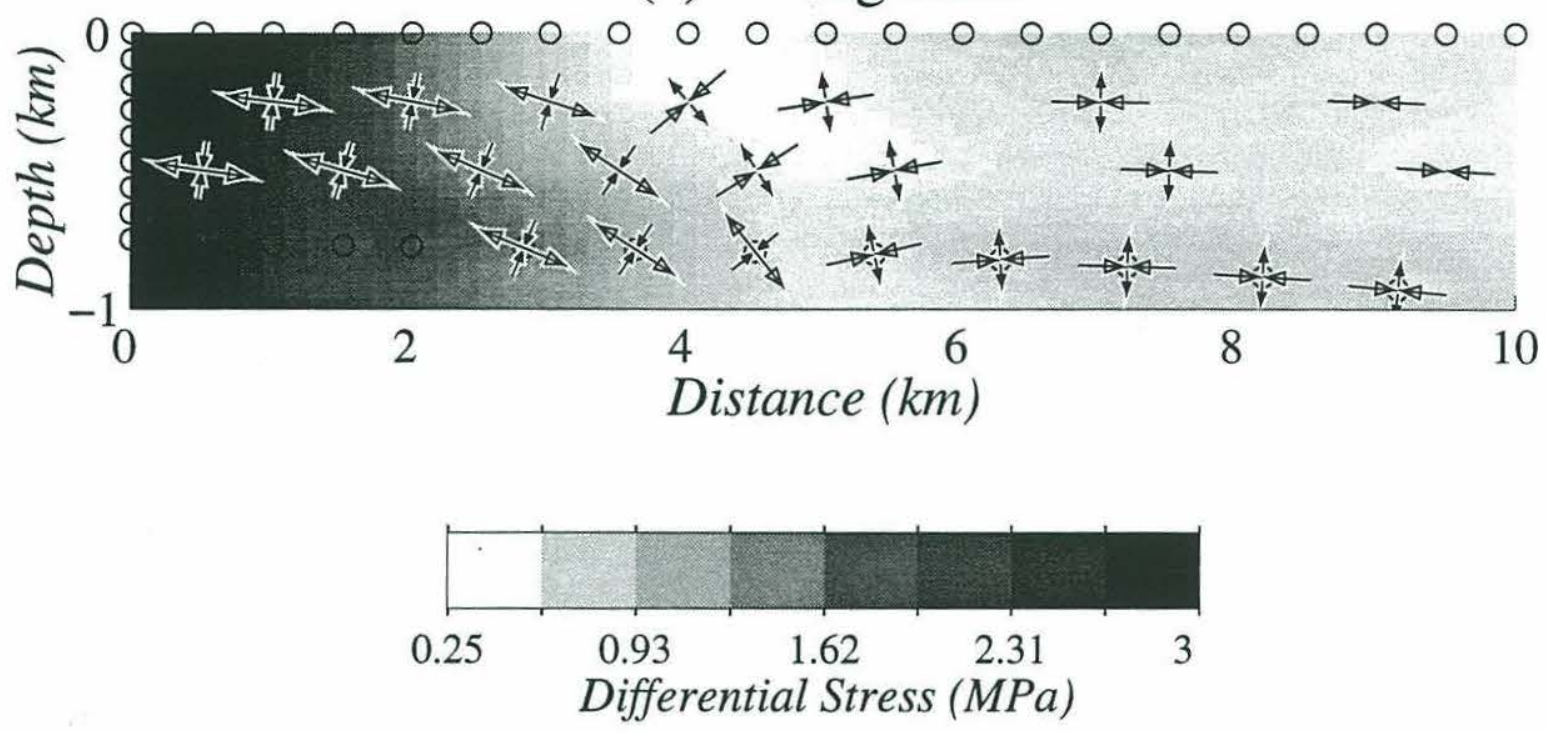

(b) Weak Axis
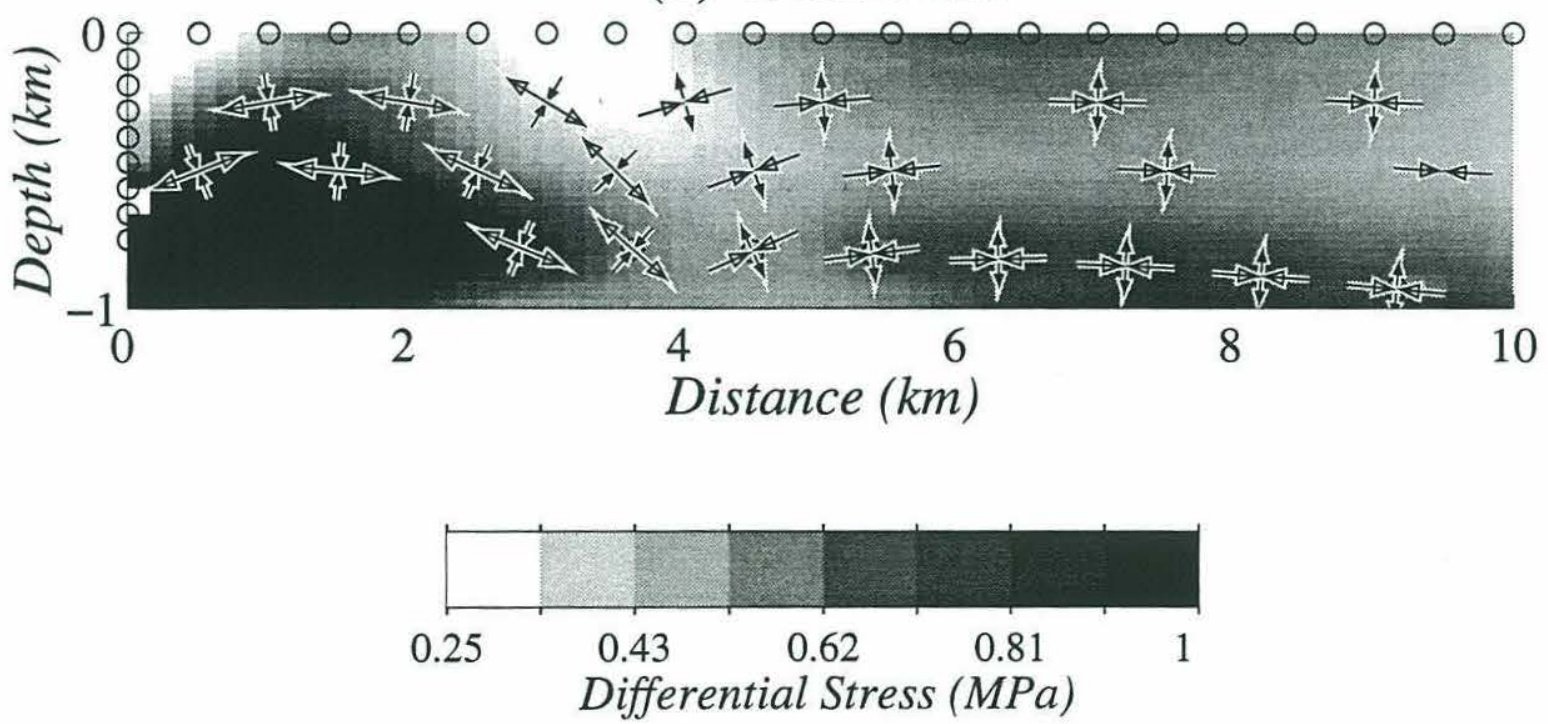
Figure 3.7. Differential stresses for a weak axis (a) for strength set II and (b) for strength set III. In (a), the surface horizontal stress is extensional within $2-3 \mathrm{~km}$ of the axis, but this stress is of low magnitude. In (b), the surface horizontal stress is compressional throughout. 


\section{Effect of Low Strengths below Upper Crust}

For weak-axis cases

\section{(a) Strength Set II}
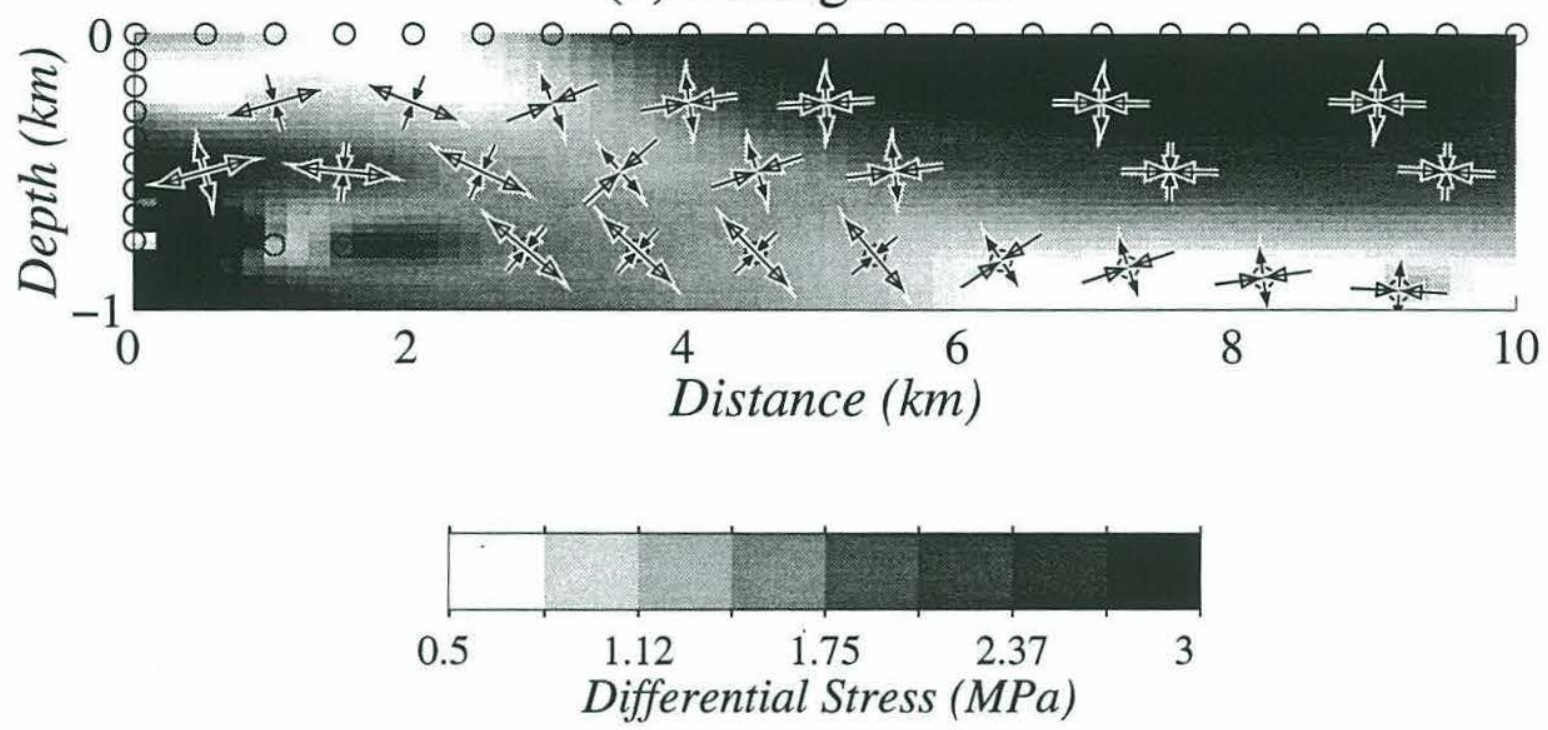

(b) Strength Set III
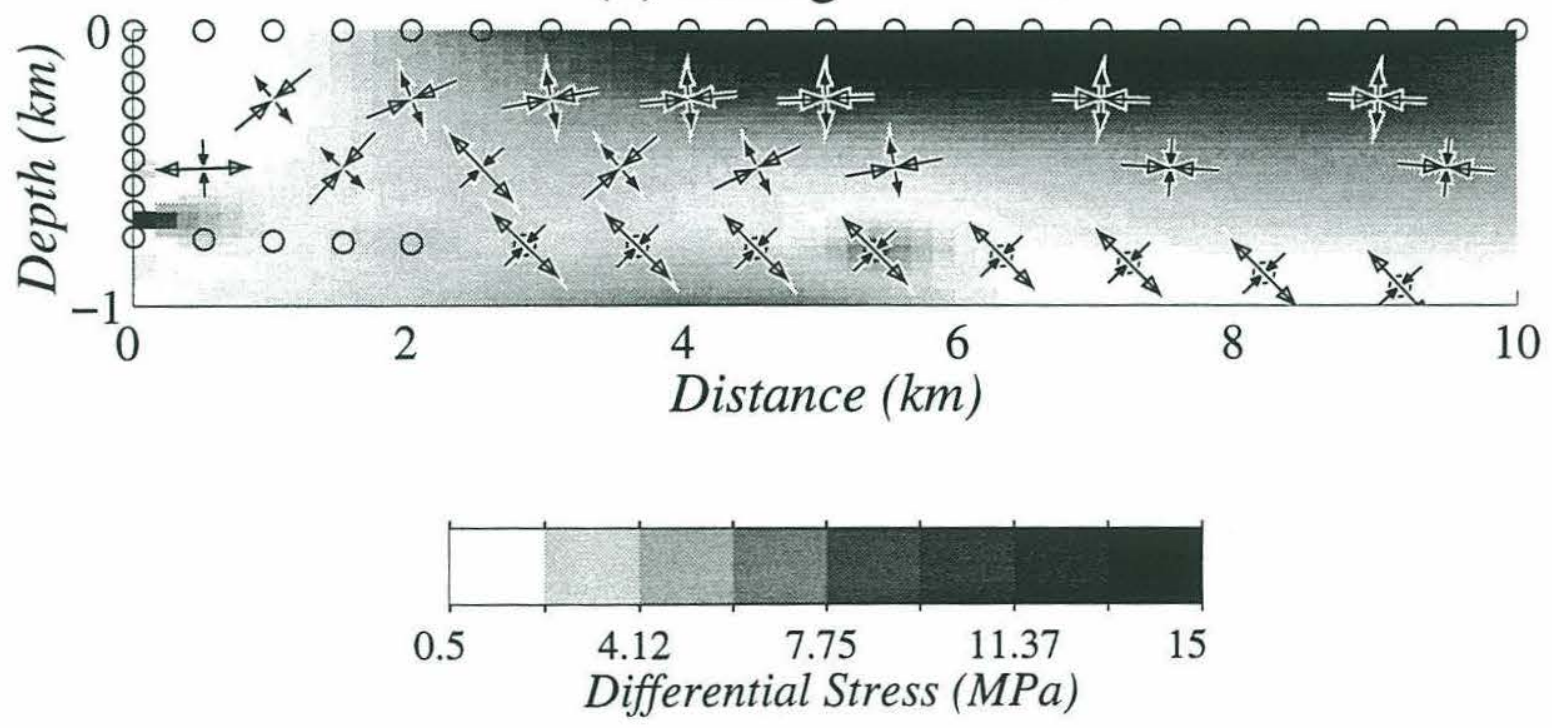
Figure 3.8. Differential stresses for a weak-axis (a) for strength set I and (b) for strength set II. In both of these cases, the interface between the LVV and the upper is 5 $\mathrm{km}$ in half width, in contrast to the half width of $2 \mathrm{~km}$ in the cases shown in Figures 3.6 and 3.7. Therefore, the top plot may be compared with Figure 3.6b and the bottom plot with Figure 3.7a. Both comparisons show that the zone of extensional stress at the surface is wider for the greater interface width. 


\section{Wide Upper Crust/LVV Interface}

For weak-axis cases

(a) Strength Set I
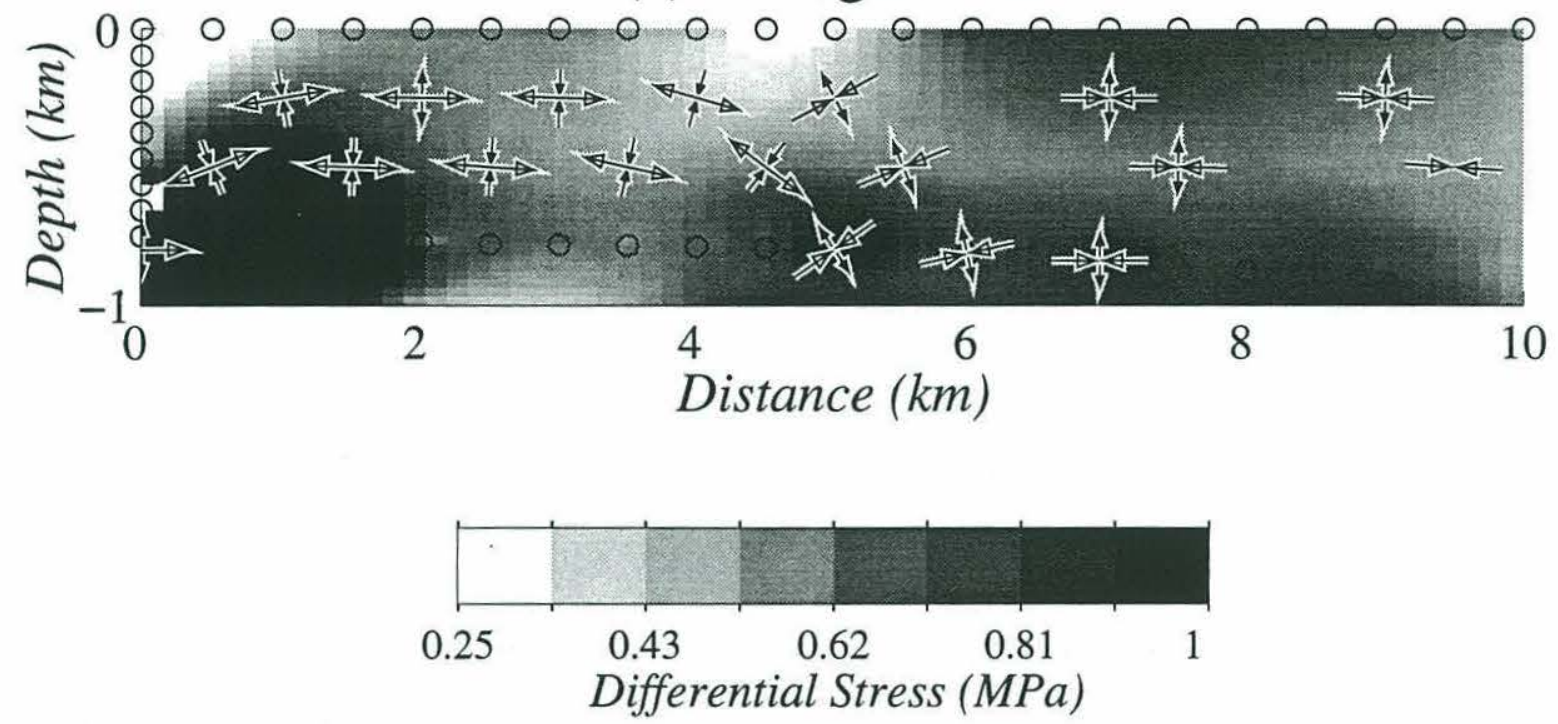

(b) Strength Set II
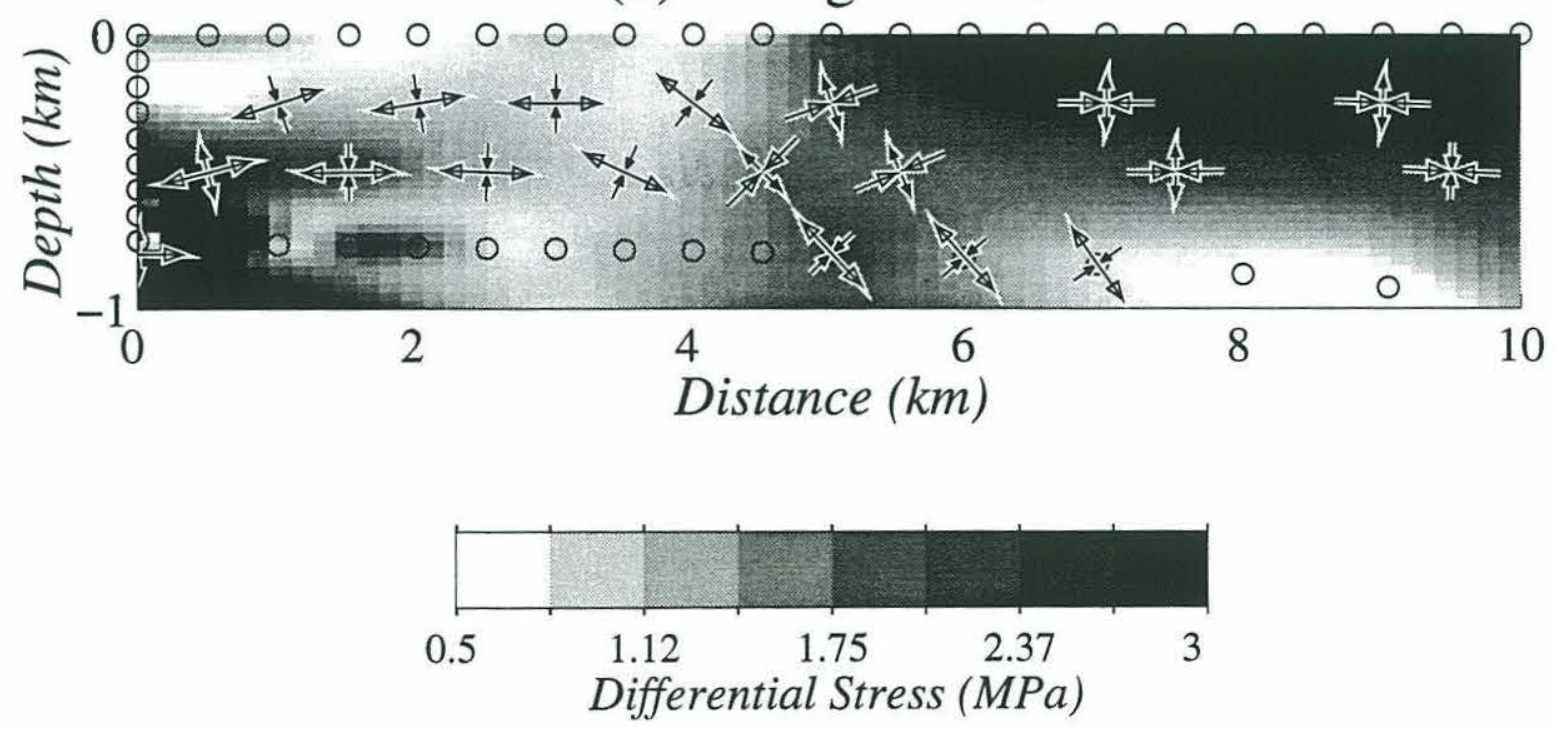
Figure 3.9. Surface horizontal stresses for cases involving different strength sets and different half widths of the interface between the LVV and the upper crust. All cases include a weak axis. Thick lines are used for cases with a 5-km interface half width. For a given strength set, a broader interface produces a wider zone of extension at the surface or a greater magnitude of stress in that zone. Also, an increase in the width of the interface allows the maximum extensional stress at the surface to occur farther from the axis. 


\section{As Functions of Upper Crust/LVV Contact Half Width \& Strength Sets}

For weak-axis cases

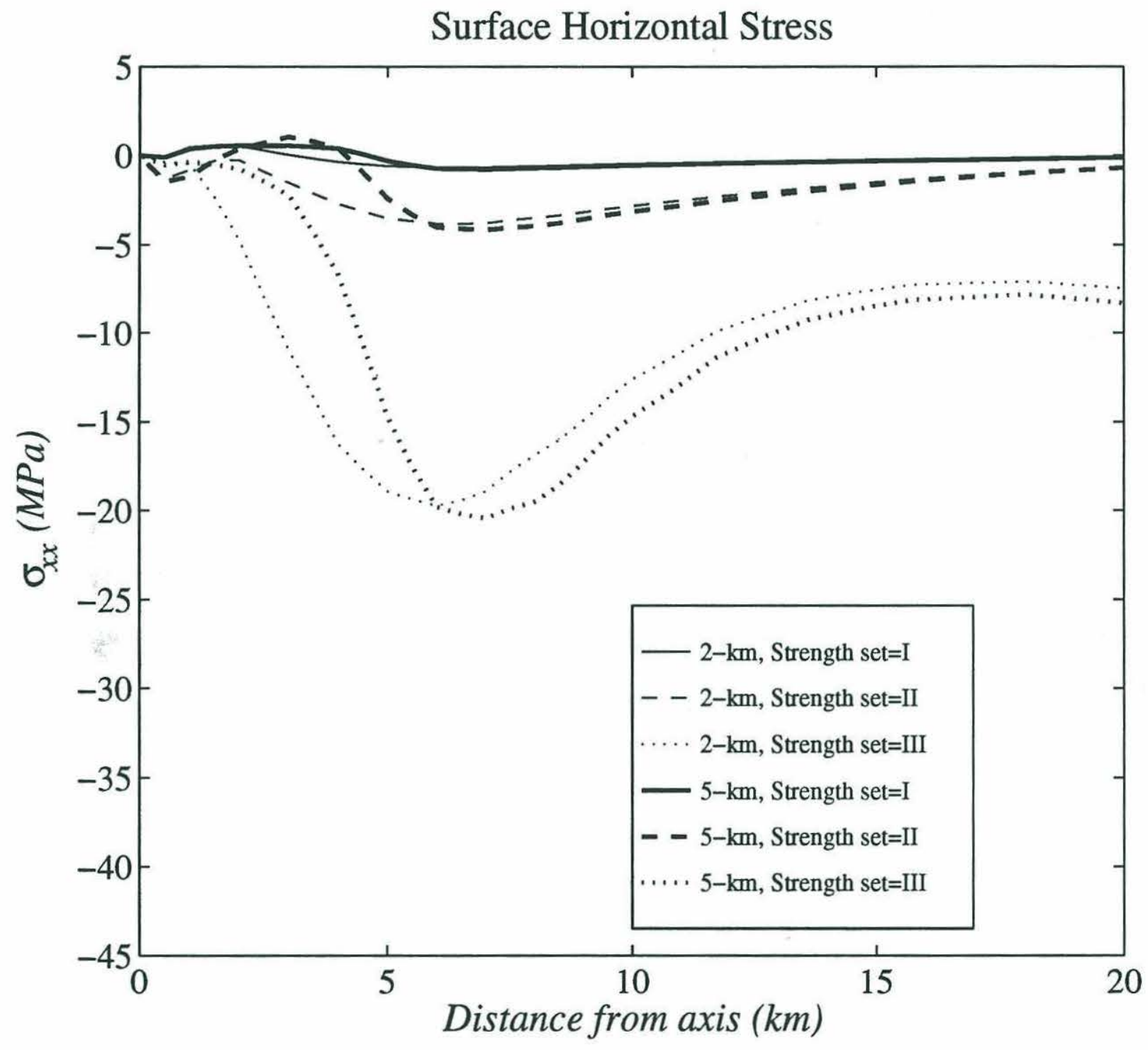


Figure 3.10. Variation in surface horizontal stresses with upper crustal thickness for (a) strength set I and (b) strength set II. In both cases, we assumed that the rise axis is weak and the interface between the LVV and the upper crust is $5 \mathrm{~km}$ in half width. The magnitude of extensional stress decreases with increasing upper crustal thickness. For strength set I, where the contrasts in strength between the upper crust and the underlying subregions are relatively small, the distance from the axis to the maximum surface extensional stress increases with upper crustal thickeness. On the other hand, this distance is virtually constant for strength set II, where contrasts in the strength between the upper crust and underlying subregions are relatively large. 


\section{As a Function of Upper Crustal Thickness}

For 5-km interface half width \& strength set=I

(a) Surface Horizontal Stress

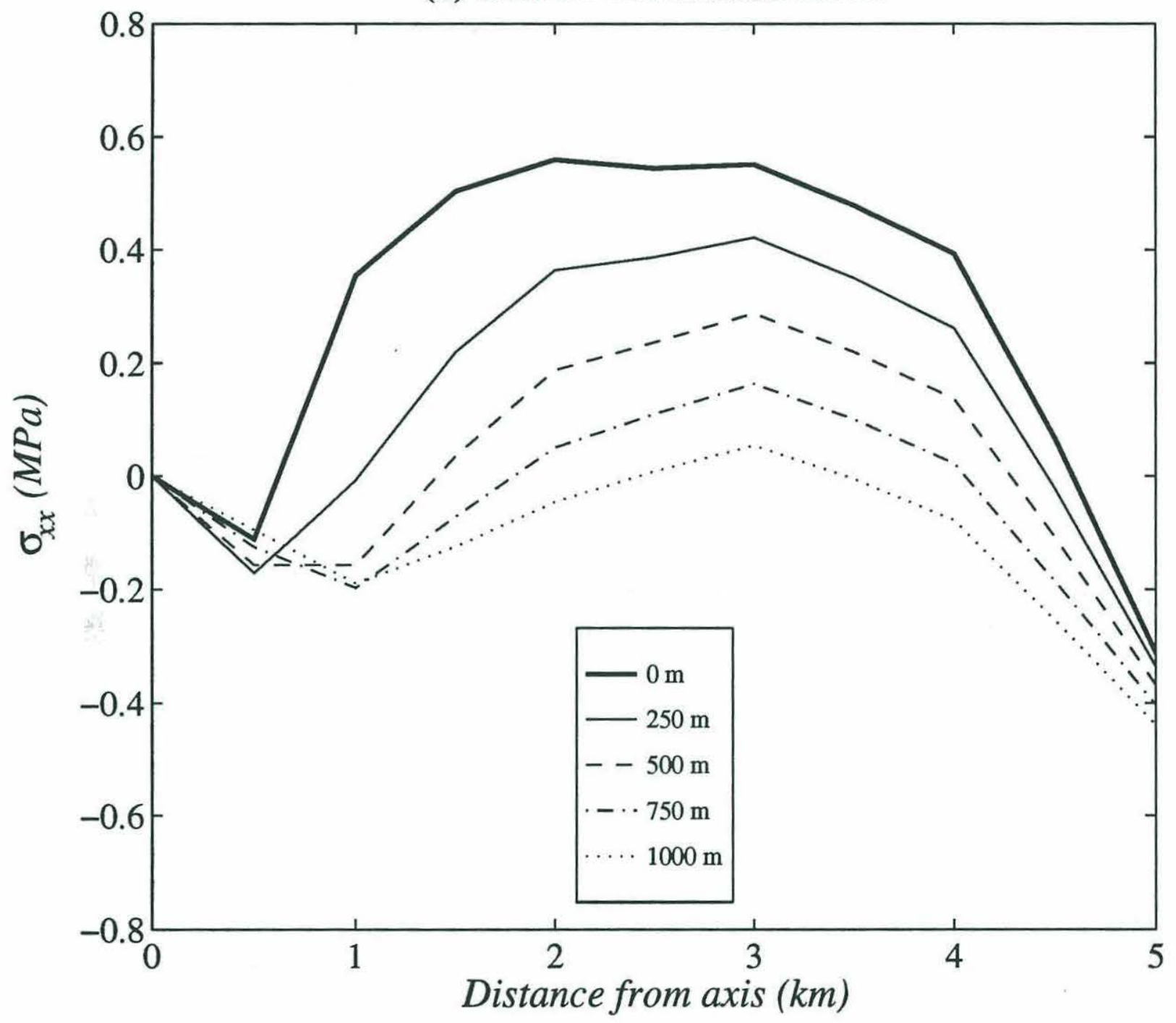




\section{As a Function of Upper Crustal Thickness}

For 5-km interface half width \& strength set=II

(b) Surface Horizontal Stress

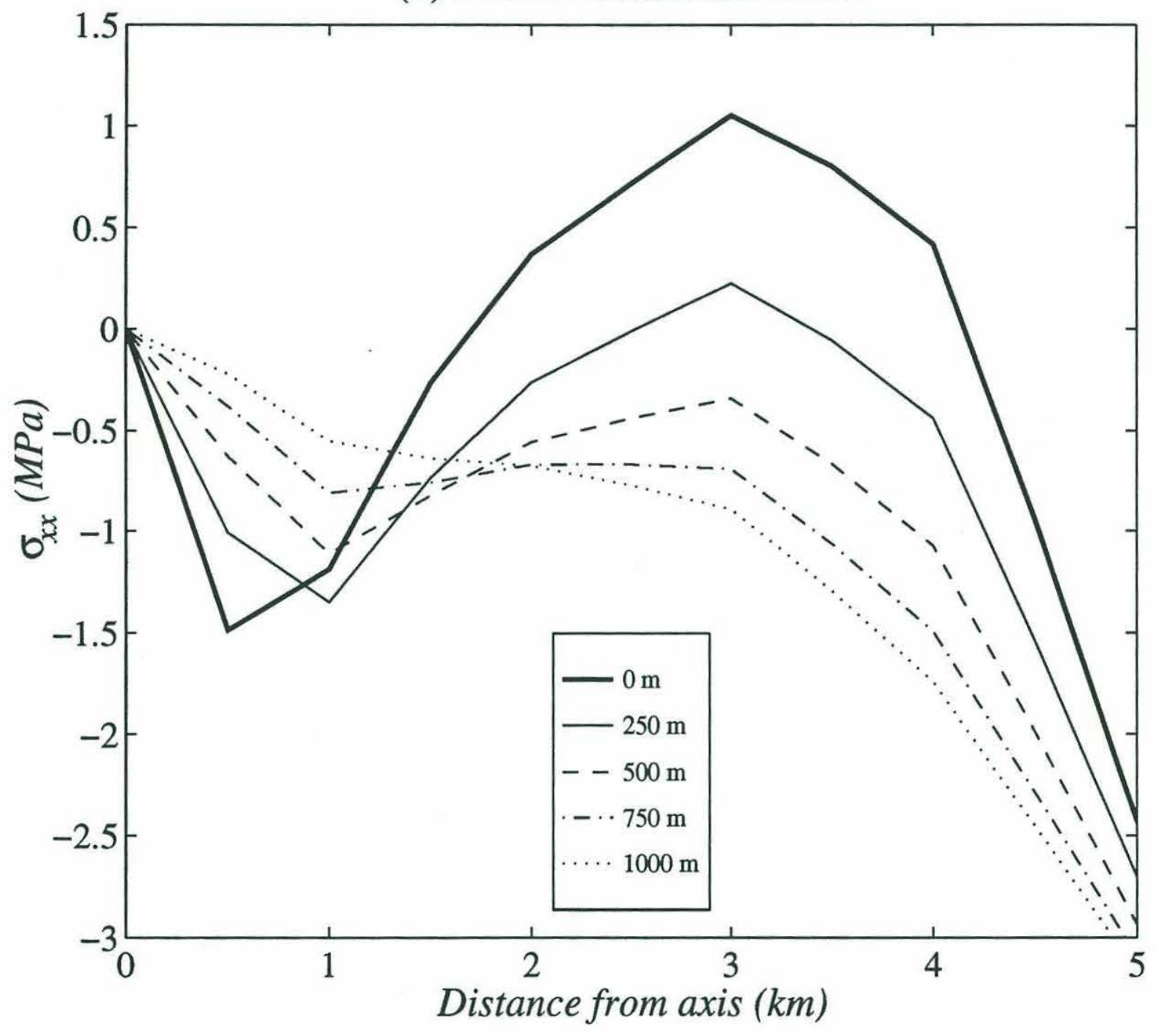


Figure 3.11. Surface horizontal stress as a function of upper crustal strength. The case with strength set II and an upper crustal Young's modulus of $53 \mathrm{GPa}$ (solid line) is shown for reference. This case can be compared with that where the upper crustal Young's modulus is $10 \mathrm{GPa}$ but underlying subregions have unchanged strengths (dashed line). A case with strength set III and an upper crustal Young's modulus of $5 \mathrm{GPa}$ (dotted line) can be compared with the case shown as a thin dotted line in Figure 3.9, where the upper crustal Young's modulus was $53 \mathrm{GPa}$ but the strengths of underlying subregions were the same. For a given set of strengths for the underlying subregions and a given magnitude of the buoyancy force, a zone of extension off-axis is more likely to develop for a weak than for a strong upper crustal layer. 


\section{As a Function of Upper Crustal Strength}

For weak axis \& 2-km interface half width

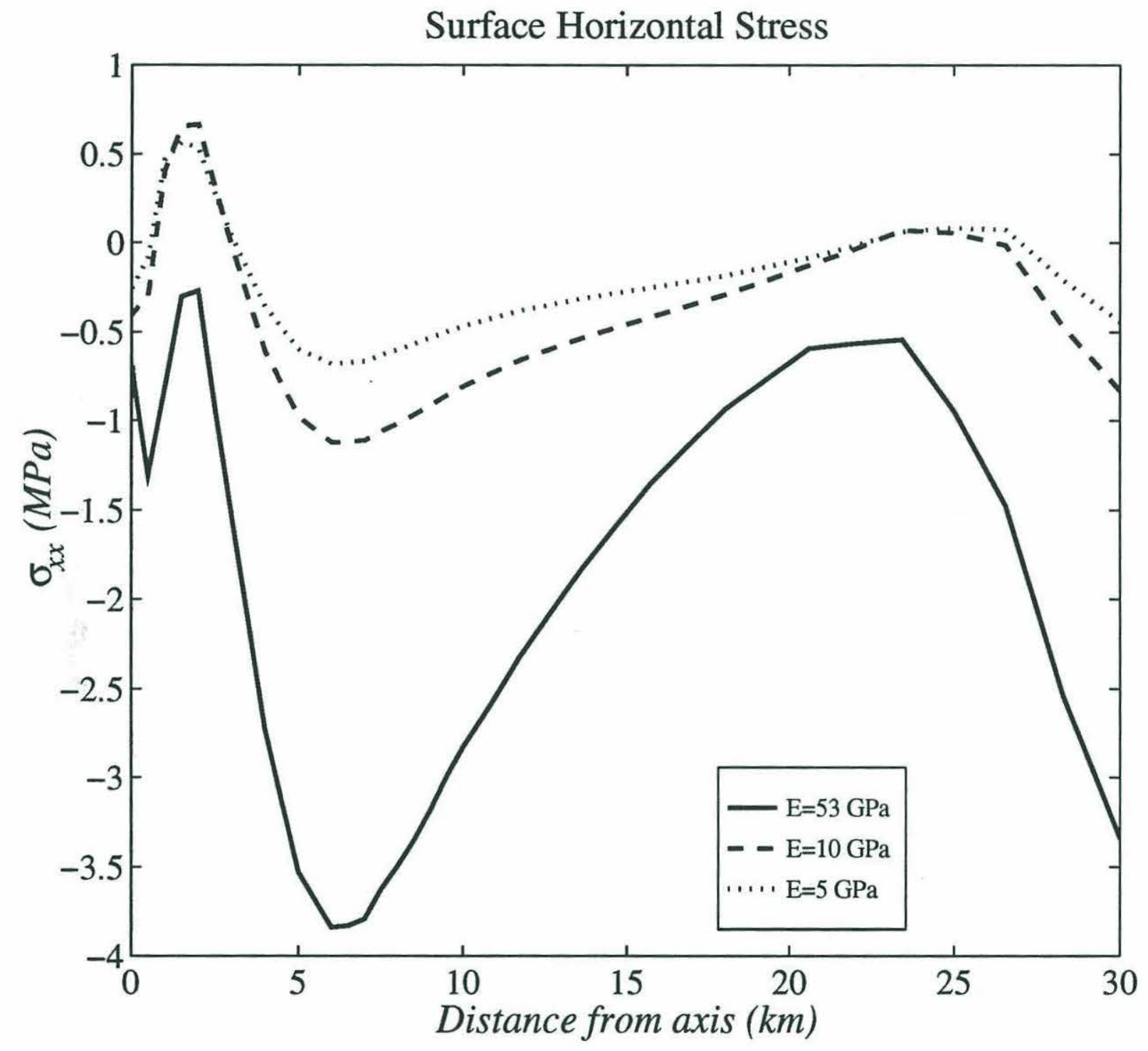


Figure 3.12. Variations in the surface horizontal stresses as a function of spring stiffness at the rise axis. For an upper crust with a strength of $53 \mathrm{GPa}$, the transition from weak-axis to strong-axis behavior occurs at a spring stiffness of about $5 \mathrm{MPa} / \mathrm{m}$. 


\section{As a Function of Axis Strength}

For 5-km interface half width \& strength set II

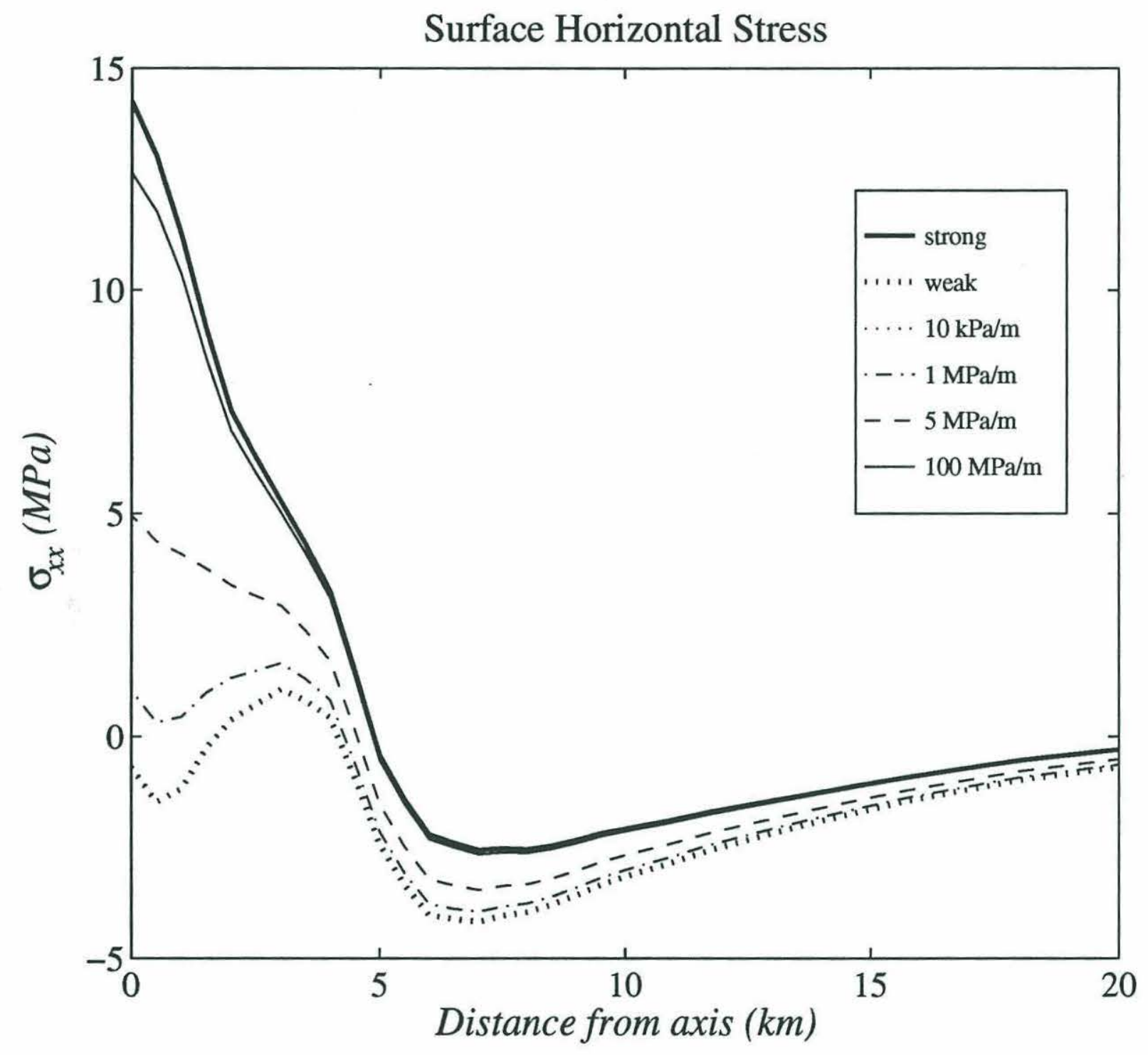


Figure 3.13. Vertical tractions along the outer boundary of the LVV for (a) strong- and (b) weak-axis cases, for different strength sets. For the upper half of the plot, negative values represent compression on the LVV whereas, for the lower half of the plot, they represent extension of the LVV. For strong-axis cases, the greatest compression occurs at the axis. However, for weak-axis cases, because the LVV is least constrained at the axis, a large extension develops near the axis. 


\section{As a Function of Material Strengths}

For strong axis \& 2-km interface half width

(a) Vertical Traction along the LVV

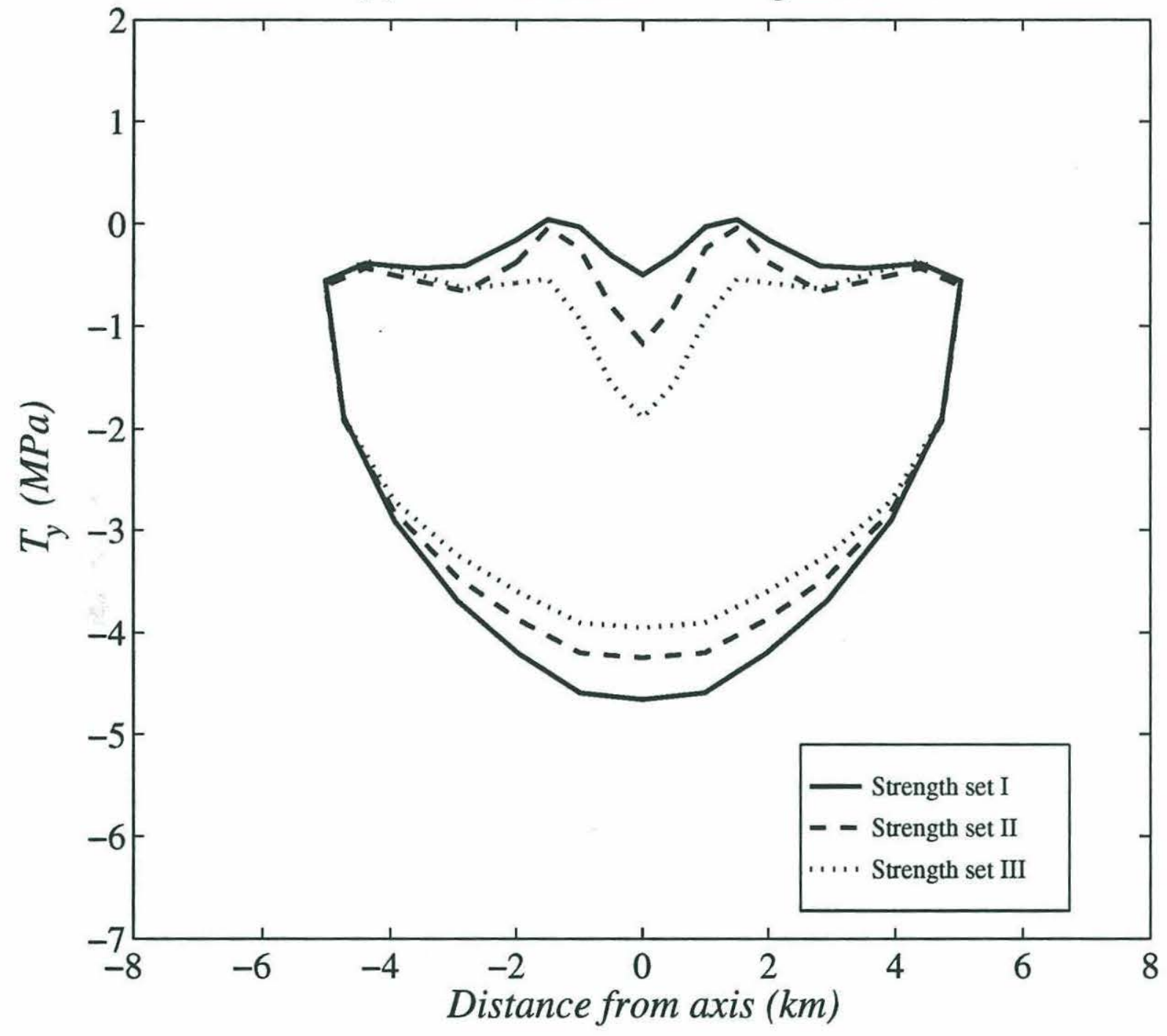




\section{As a Function of Material Strengths}

For weak axis \& 2-km interface half width

(b) Vertical Traction along the LVV

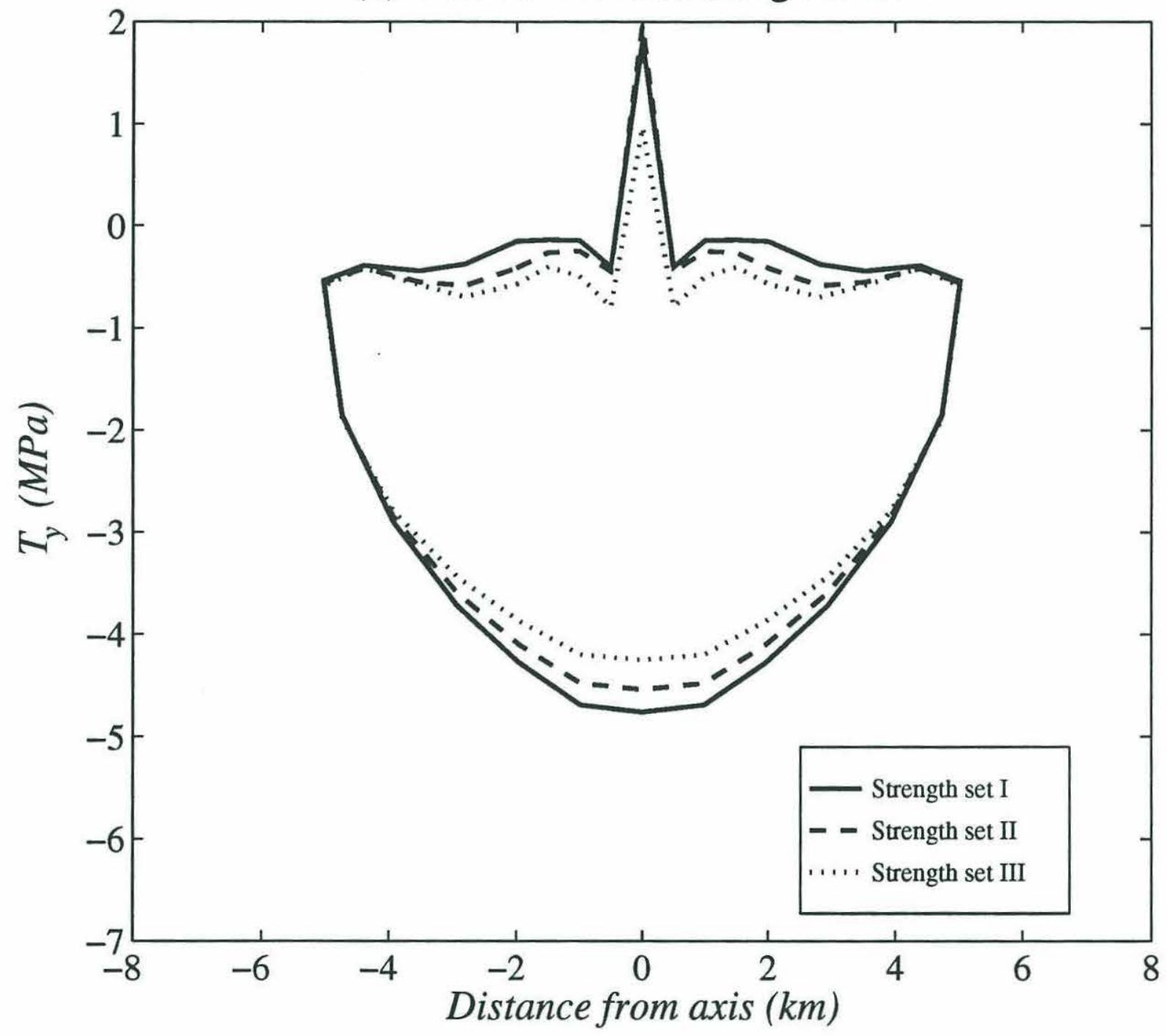


Figure 3.14. (a) Surface horizontal stresses and (b) vertical tractions along the LVV for different relative strengths between crust and upper mantle. 


\section{As a Function of Upper Mantle Strength}

For weak axis \& 2-km interface half width

(a) Surface Horizontal Stress

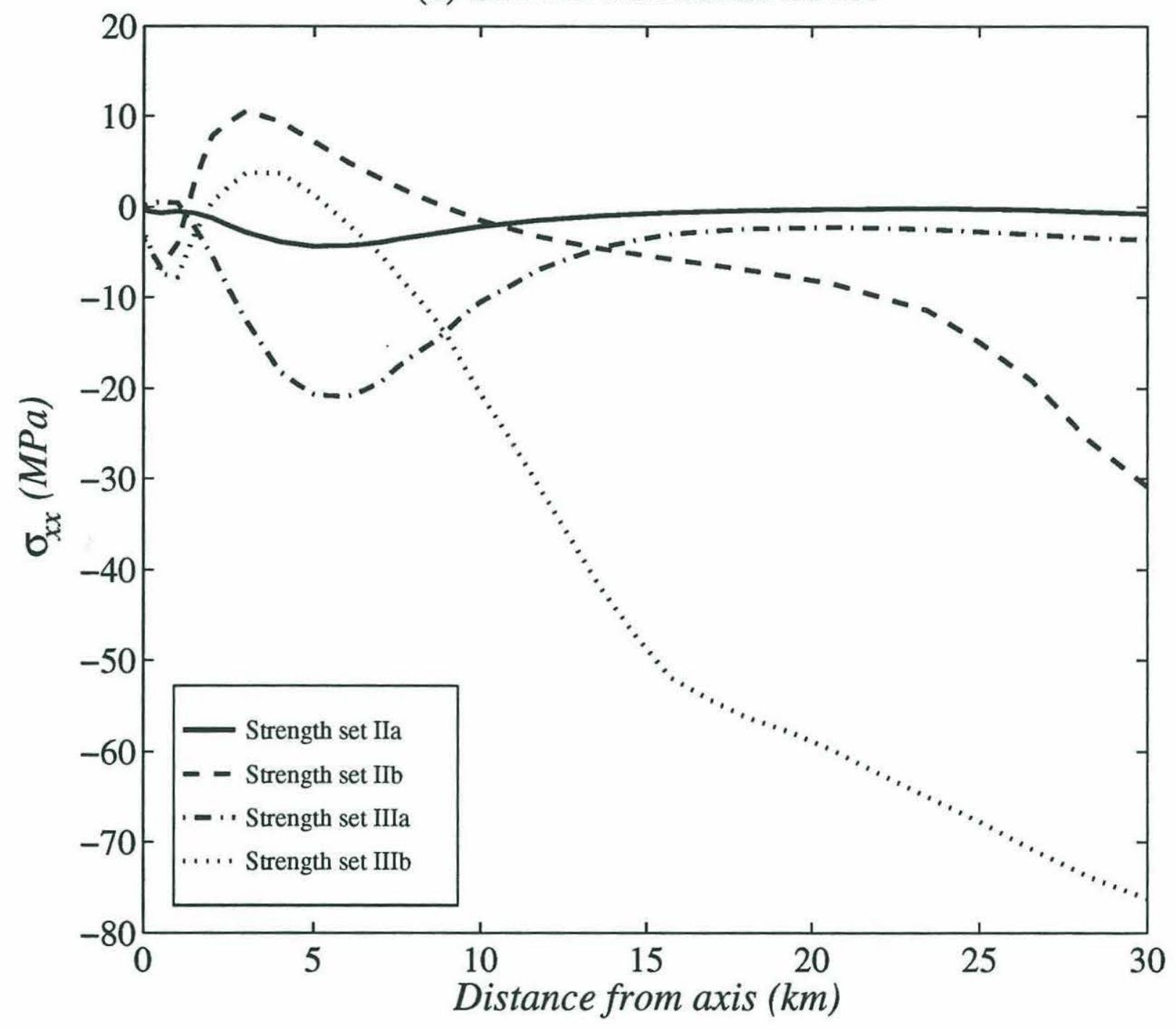




\section{As a Function of Upper Mantle Strength}

For weak axis \& 2-km interface half width

(b) Vertical Traction along the LVV

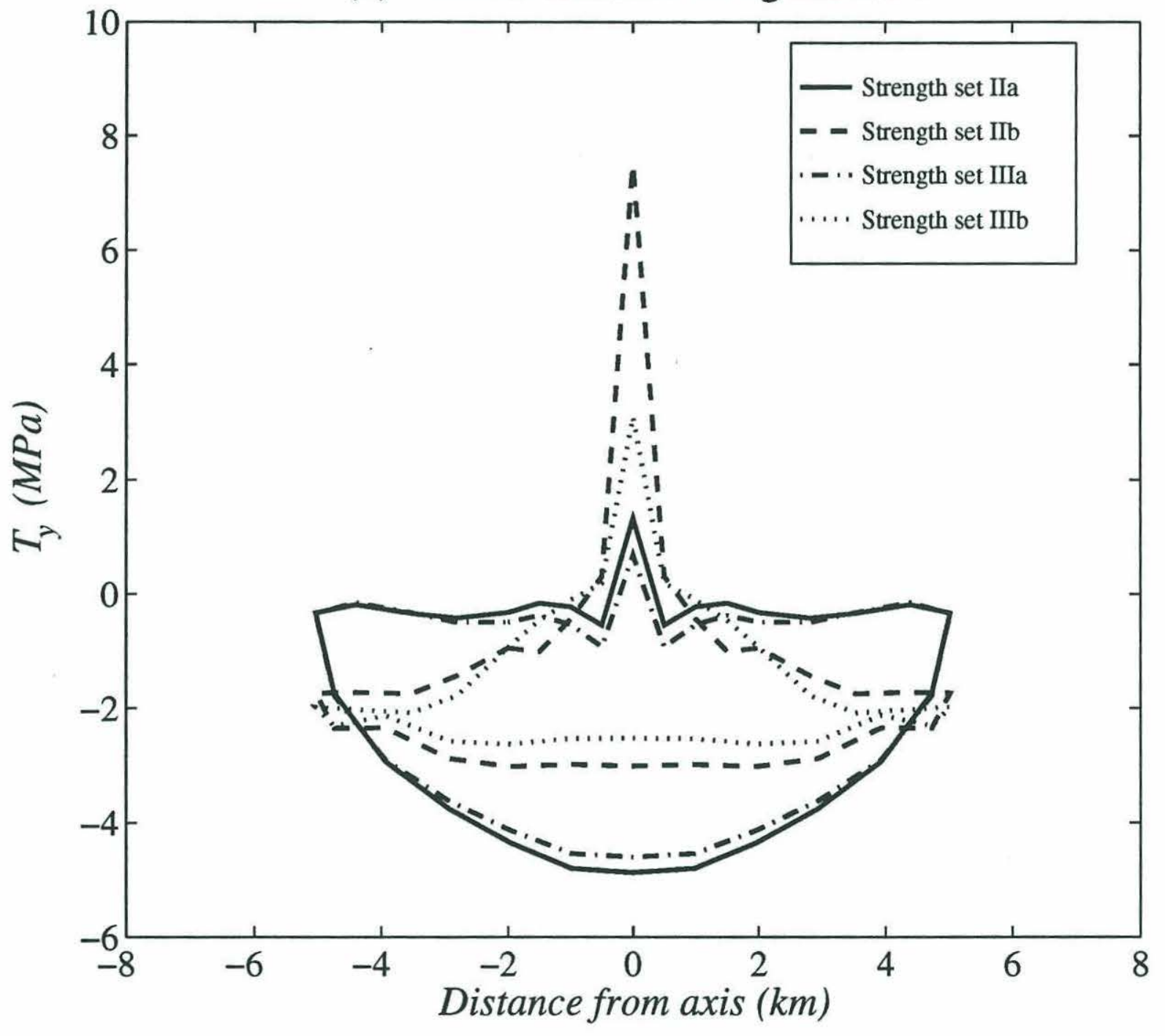


Figure 3.15. Axial uplift for (a) strength sets I, II, and III, and (b) strength sets IIa, IIb, IIIa, and IIIb. 


\section{Axial Uplift as a Function of Strengths}

For weak-axis cases

(a) Surface Vertical Displacement

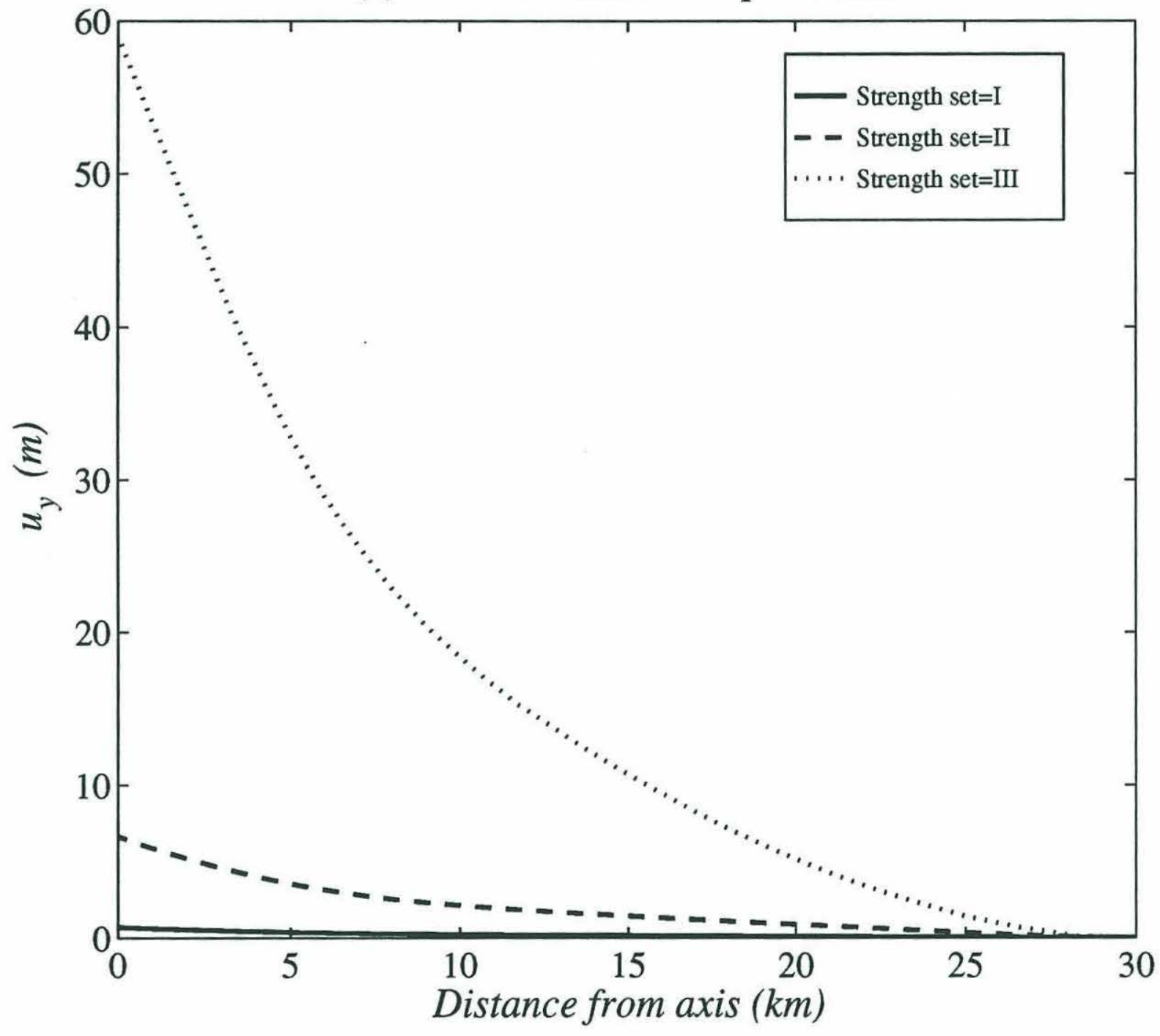




\section{Axial Uplift as a Function of Strengths}

For weak-axis cases

(b) Surface Vertical Displacement

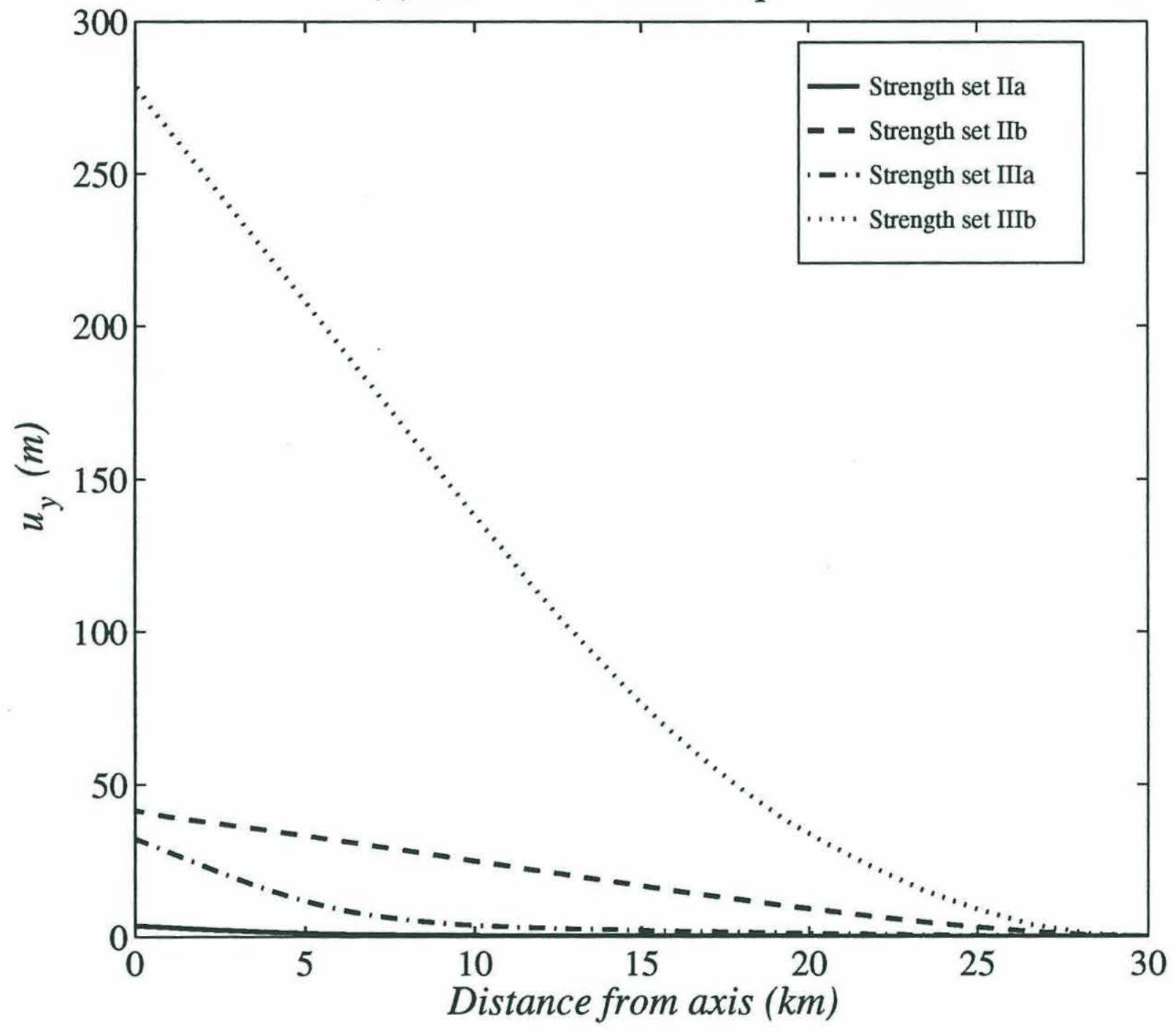


Figure 3.16. Surface horizontal stresses for two cases with a sliding interface between the LVV and the strong upper crust, one where the interface extends $5 \mathrm{~km}$ from the axis and the other $2 \mathrm{~km}$. The case without a sliding interface is shown for comparison. A sliding interface has the effect of reducing the amount of the stress in the overlying crust for weak-axis cases. 


\section{Effect of Sliding Interface}

For 5-km interface half width \& strength set II

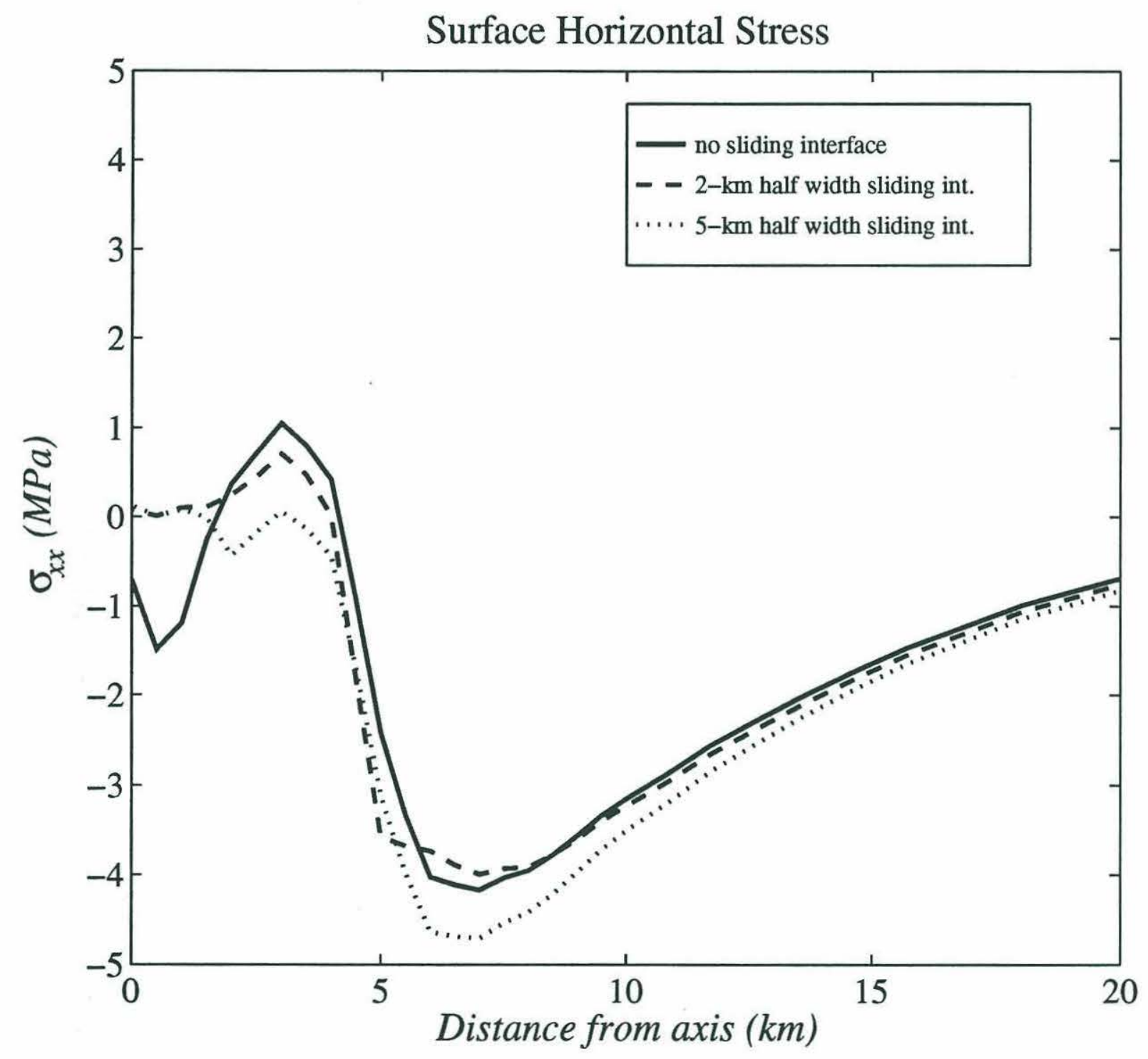


Figure 3.17. Surface horizontal stresses resulting from gravitational spreading as a function of tangential spring stiffness for (a) a strong axis and (b) a weak axis. 


\section{As a Function of Spring Stiffness at Base}

For strong-axis cases

(a) Surface Horizontal Stress

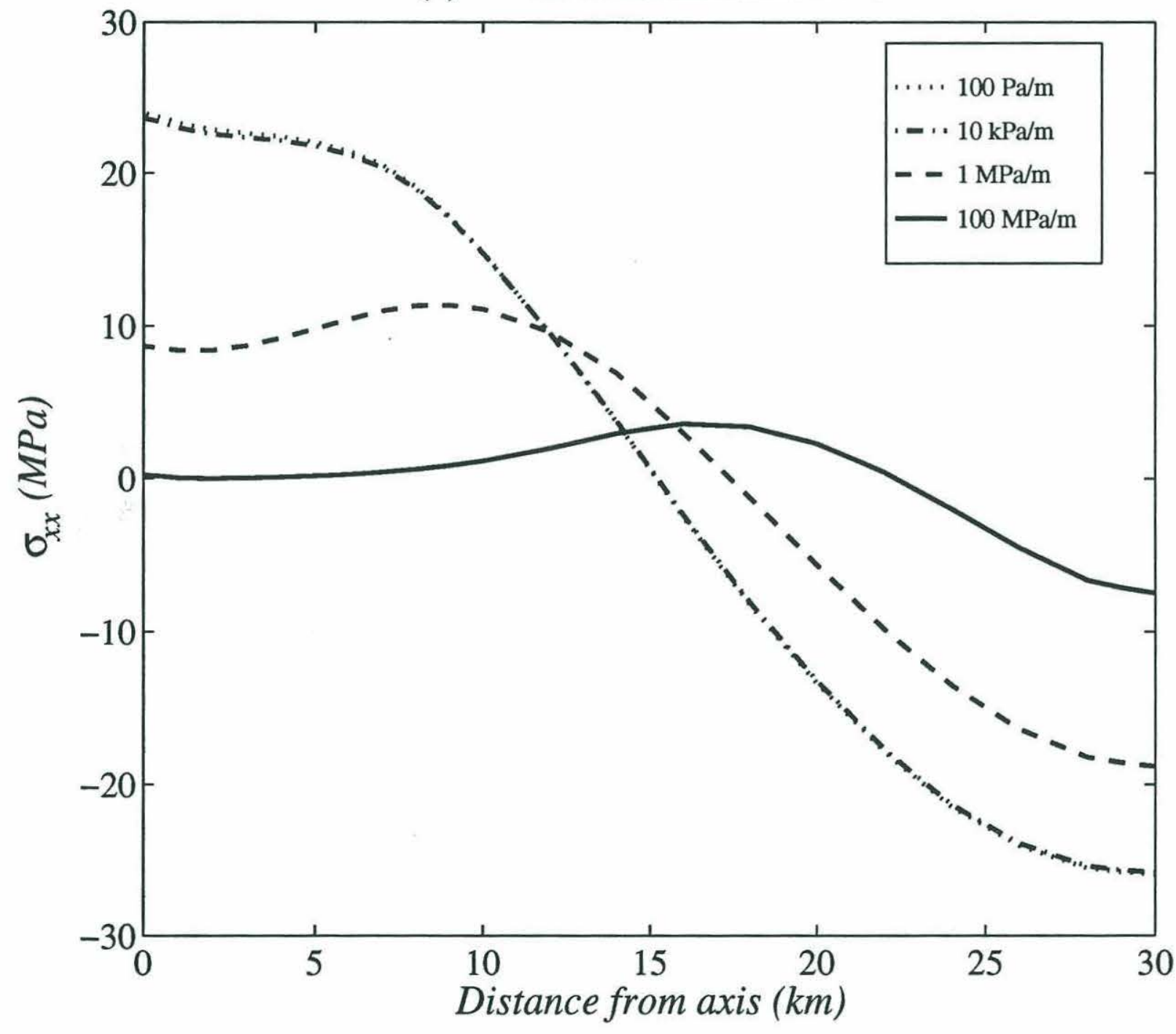




\section{As a Function of Spring Stiffness at Base}

For weak-axis cases

(b) Surface Horizontal Stress

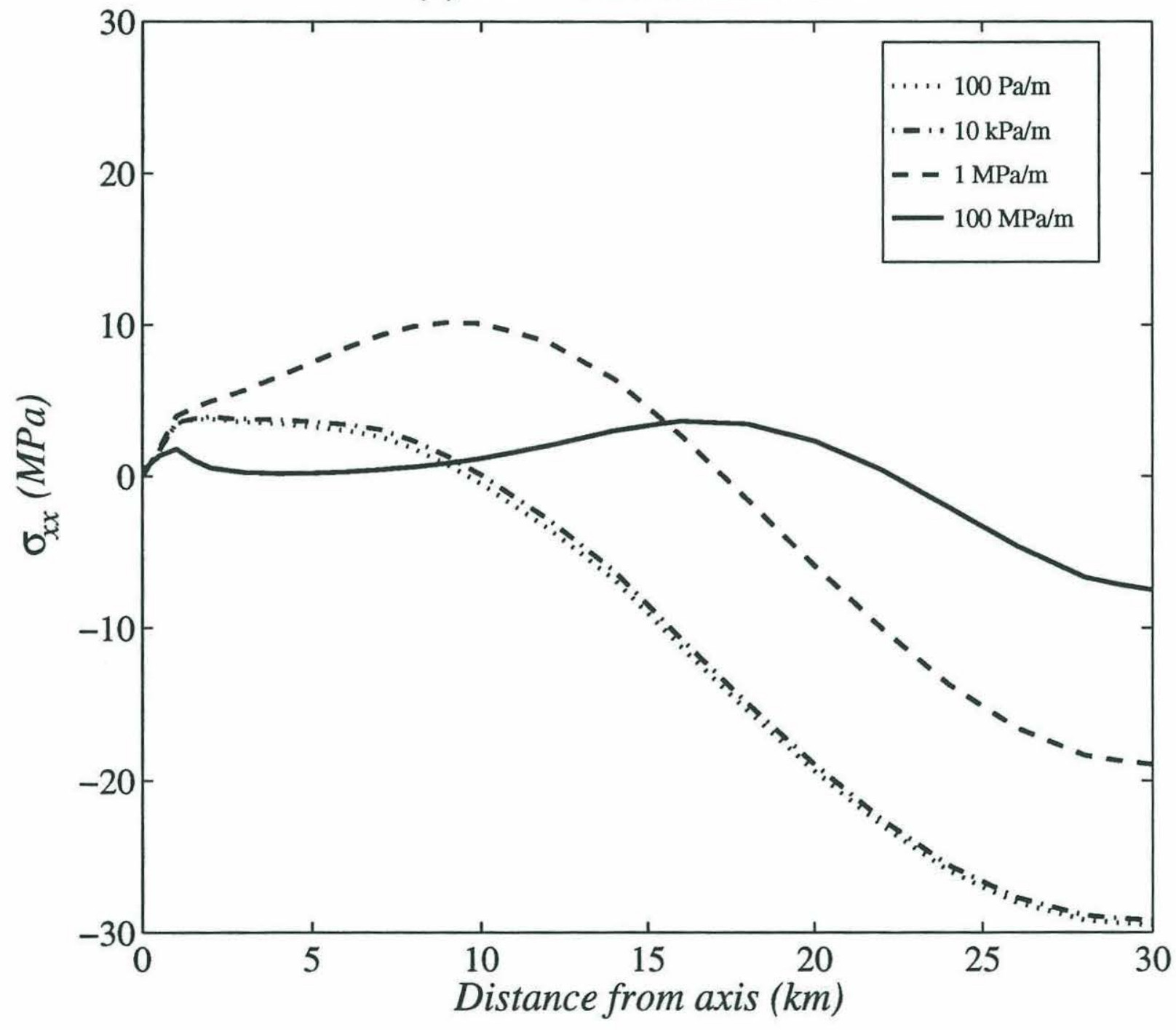


Figure 3.18. Comparison of surface horizontal stresses for two cases, one where an axial uplift of $200 \mathrm{~m}$ was prescribed and the other where no axial uplift was prescribed. Both weak- and strong-axis cases are shown. 


\section{With and Without Axial Uplift}

For spring stiffness of $10 \mathrm{kPa} / \mathrm{m}$ at base

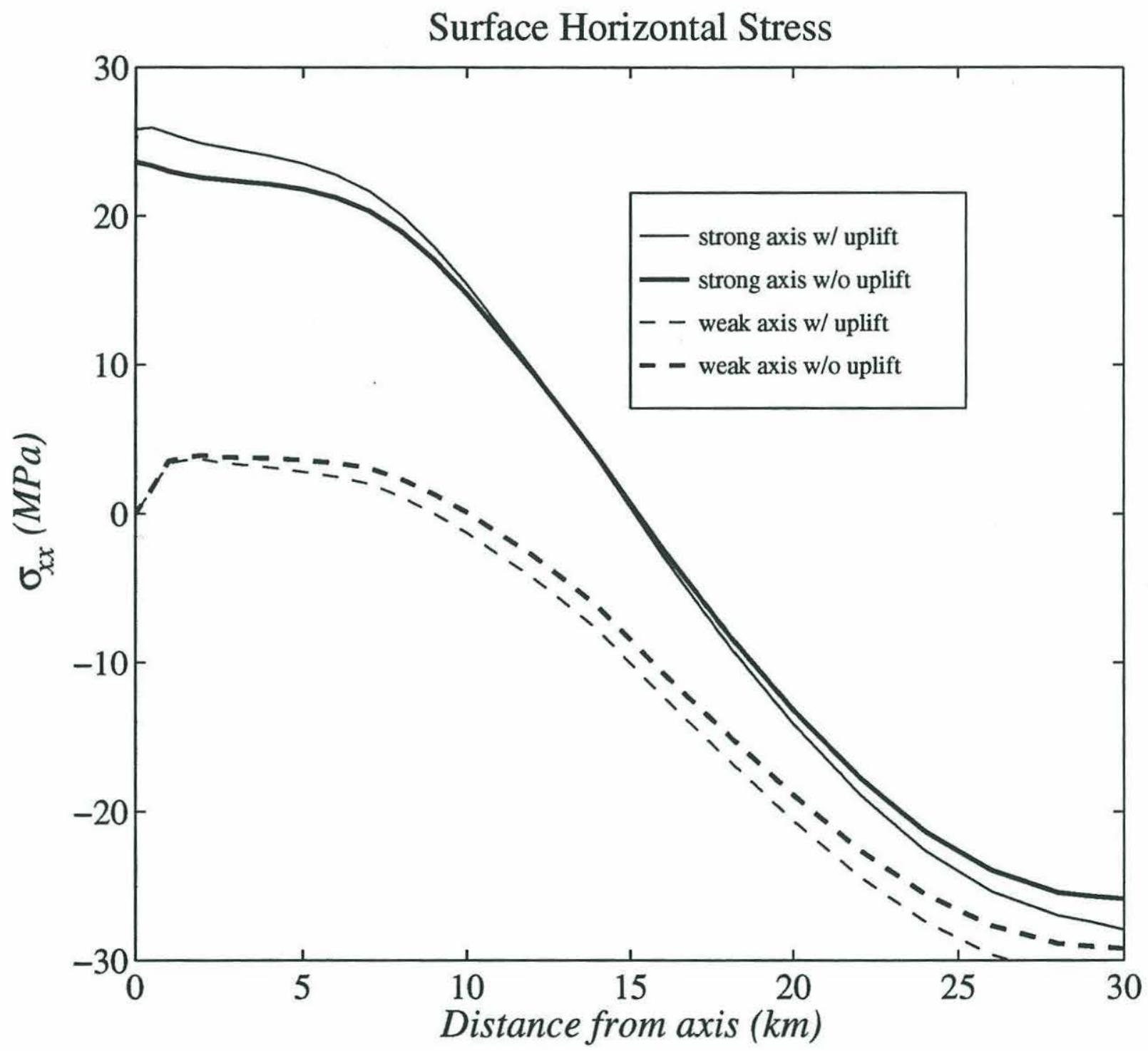


Figure 3.19. Schematic diagram of three mechanisms by which a zone of normal faulting can initiate off-axis from the buoyancy of an underlying low-density region. All three mechanisms require a mechanically weak axis. (a) In the case where the magma chamber volume is relatively strong, the development of extensional stress off-axis is similar to that produced by a vertical crack in a semi-infinite solid. A zone develops around the axis, in which stress is generally relieved. Even for a magma chamber that is offset from the bathymetric axis, the normal faulting should develop symmetrically with respect to the axis, because the vertical extent of the axial weak zone is the most important factor determining the size of the stress-relief volume. (b) For a relatively lowstrength magma chamber, the deformation of the magma chamber itself may provide the necessary traction at the base of the upper crust for the initiation of off-axis normal faulting. In this case, the largest vertical displacement along the interface between the magma chamber and the upper crust may occur just below the weak axis. With vertical displacement of the weak axis, the upper crust off-axis may be extended horizontally, which may result in a zone of normal faulting. An offset in the magma chamber can change the distribution of tractions under the upper crust and thus can affect the distance from the axis at which normal faulting occurs. (c) If a region of high melt concentration such as a magma lens is present under the mechanically strong upper crust, it would allow the upper crust above it to displace freely in the horizontal direction. This would make extensional stress less likely to develop near the axis. The width of the magma lens can be a crucial factor determining the distance to off-axis normal faulting. 


\section{(a) Stress Relief Around Crack}

Zone of Normal Faulting

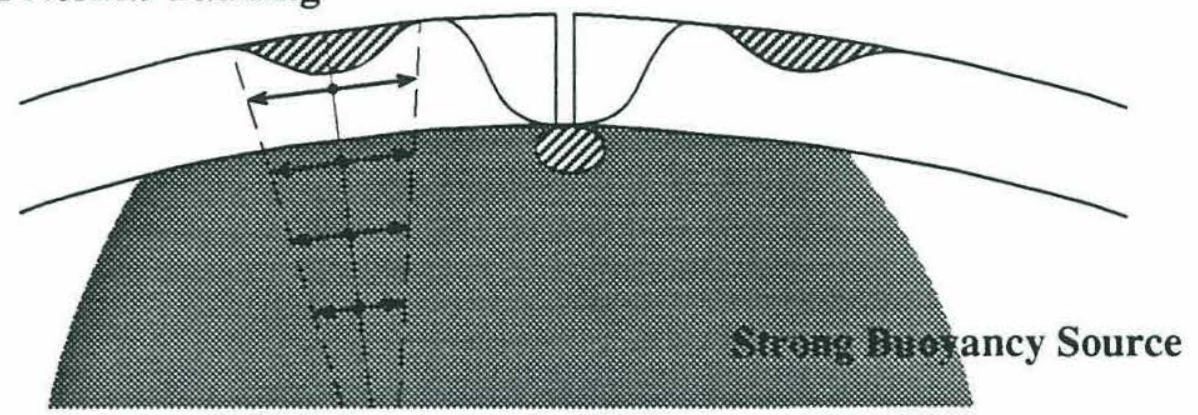

(b) Deforming Magma Chamber

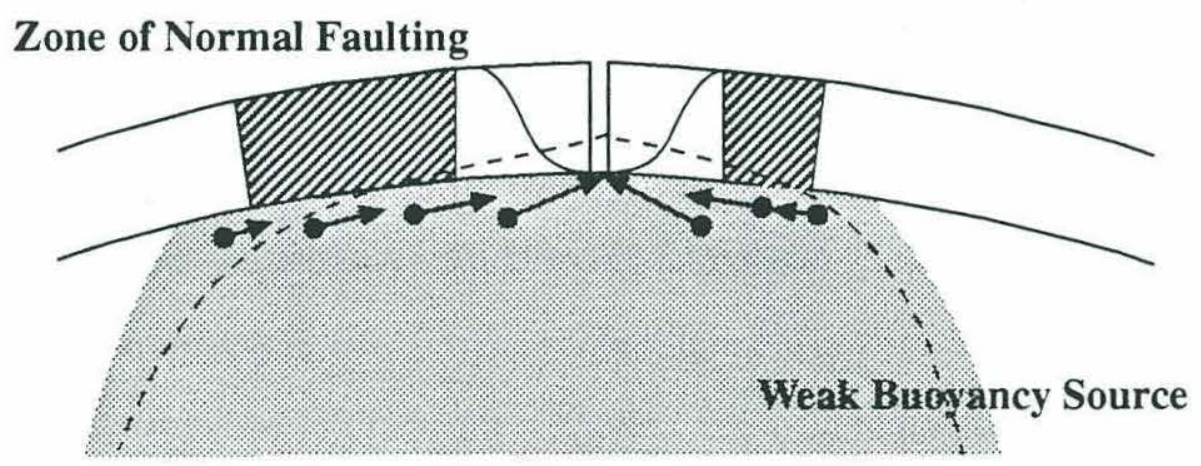

(c) Sliding Interface

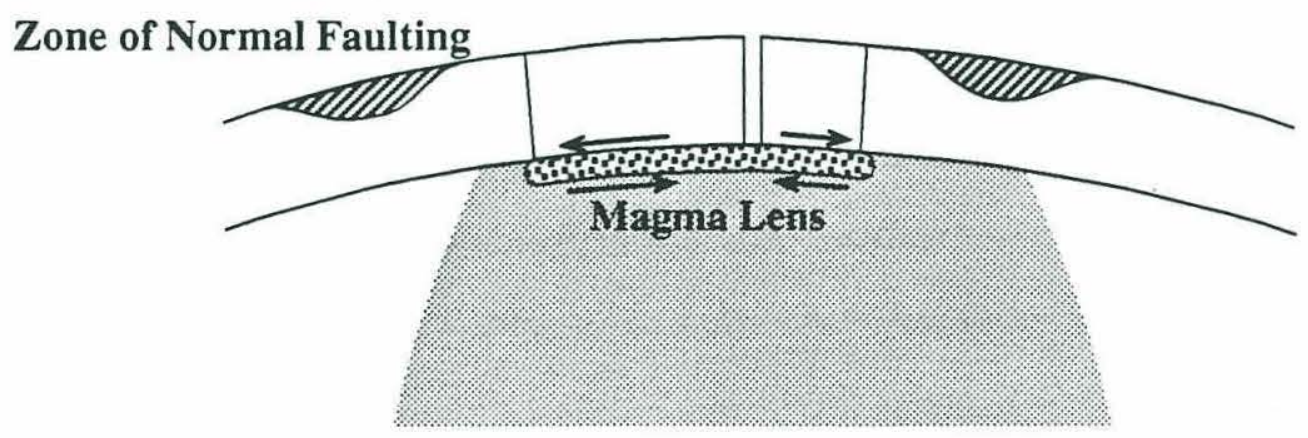


Figure 3.20. A schematic diagram illustrating the basic characteristics of faulting observed at fast-spreading mid-ocean ridges, which can be grouped into three stages of differing seafloor age: the initiation of normal faulting, which generally occurs $2-12 \mathrm{~km}$ from the axis, continued activity on normal faults to distances of $30 \mathrm{~km}$ or more, and the transformation in the state of stress in the upper lithosphere so that shallow thrust faulting occurs (ages of $3 \mathrm{My}$ and greater). Shown here is a segment of mid-ocean ridge bounded by major transform faults, which in turn is composed of smaller segments with mechanically weak axes. Pairs of parallel lines denote fault zones on the seafloor. The outward- and inward-facing pairs of arrows depict extensional and compressional states of stress, respectively. The probable causes of faulting at each stage are also depicted. At the initiation of normal faulting, the local boundary condition at the axis can be important. For example, our study has shown that off-axis initiation of normal faulting can occur only if the rise axis is weak. With increasing distance from the axis, the local boundary condition becomes less important, and the condition of the ridge as a whole may govern the continuation of normal faulting. Even though the rise axis may become weakened by an increase in magmatic activity, if the phase of active magmatism is short relative to that of inactive magmatism or if the axial region affected by magmatism is localized, the strength of the rise axis as a whole may be higher than that inferred locally. In that case, several mechanisms, including gravitational spreading, may favor continued normal fault activity to a considerable distance from the axis. If deformation is distributed across a zone several tens of kilometers in half width (i.e., if the plate boundary zone has a finite width), then from the perspective of the entire plate, the ridge can be perceived to act as a free surface. This may explain why thermoelastic stress from plate cooling under a weak-axis assumption is consistent with the observed characteristics of near-ridge earthquakes. 


\section{Stages of Fault Development at a Fast-Spreading Ridge}
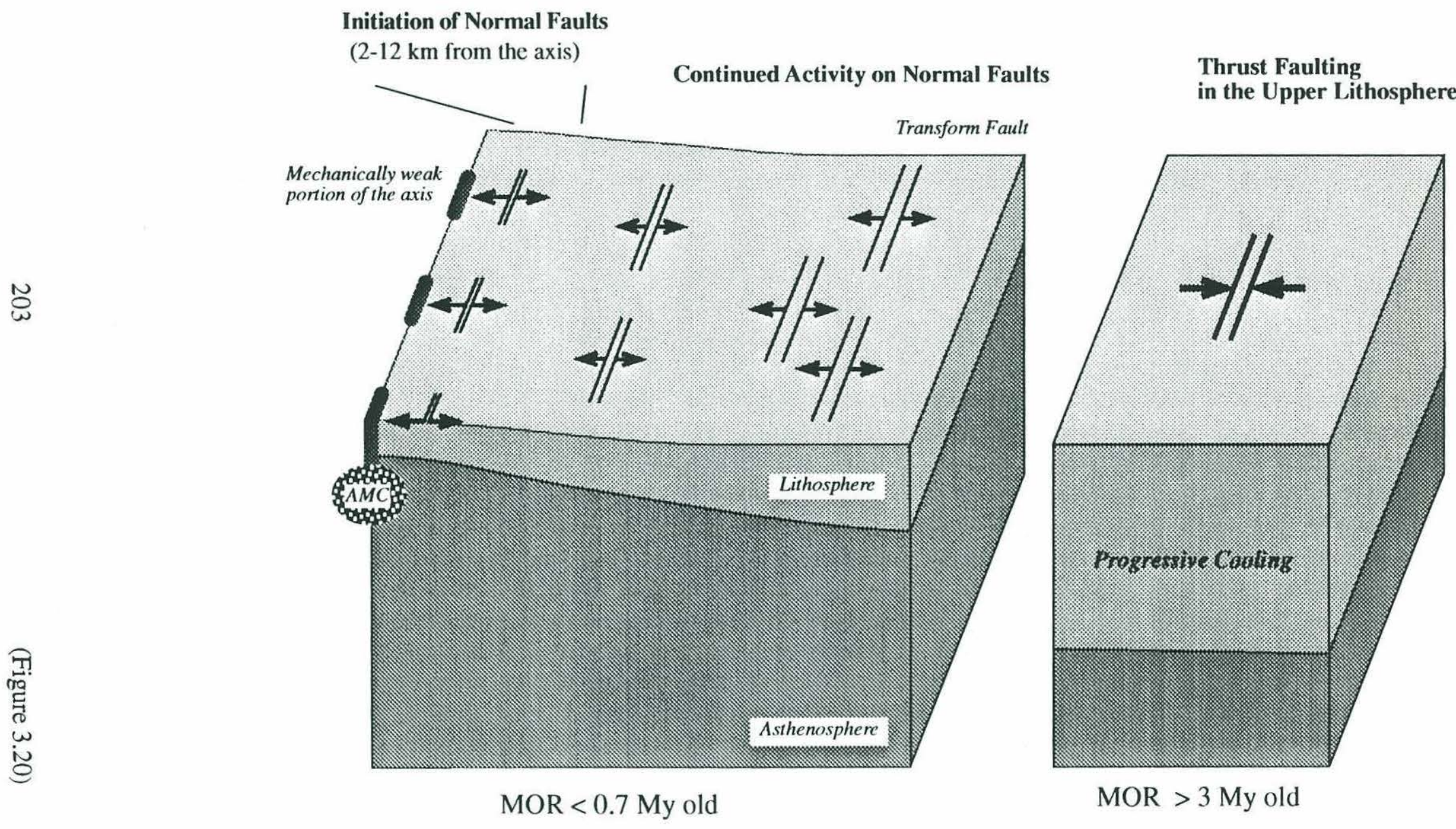

Thrust Faulting in the Upper Lithosphere

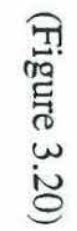

ד?

MOR > 3 My old 
Figure 3.21. Two situtations yielding the same characteristic stress field of compressional stress at the top and extension at the bottom by plate cooling in lithosphere 3-35 My in age [Bratt et al., 1985]: (a) a weak rise axis; and (b) a rise axis with a finite strength within a zone of distributed deformation extending at least several tens of kilometers off axis but to ages less than $3 \mathrm{My}$. Here $\mathrm{V}$ and $\mathrm{F}$ denote the horizontal displacement and total force exerted on the young lithosphere by plate cooling beyond 3 My, respectively, and the lithosphere is assumed to overlie an inviscid fluid. In the former case, all deformation takes place at the axis essentially at the time of generation of new crust. Thus, the lithosphere may be assumed to be rigid and moving everywhere at the rate of plate spreading. However, in the latter case, deformation occurs over a finitewidth zone. When viewed from lithosphere older than $3 \mathrm{My}$, both cases would appear similar. 
(a) Weak Rise Axis

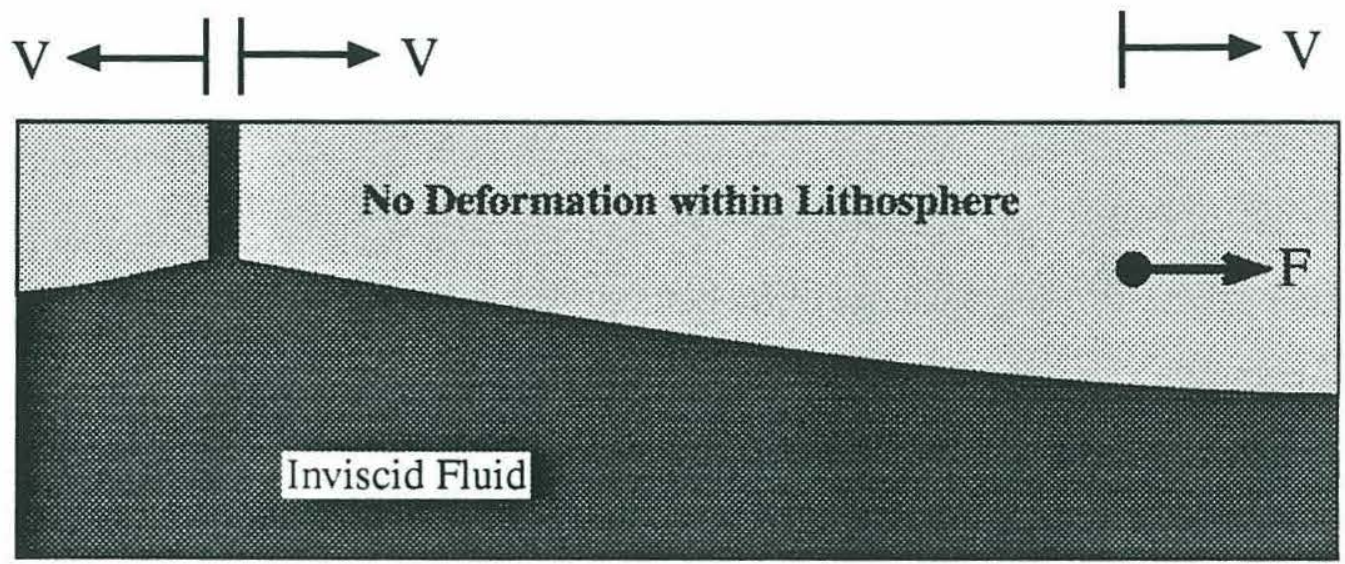

(b) Finite-Strength Rise Axis with Zone of Deformation Rise Axis Zone of Deformation

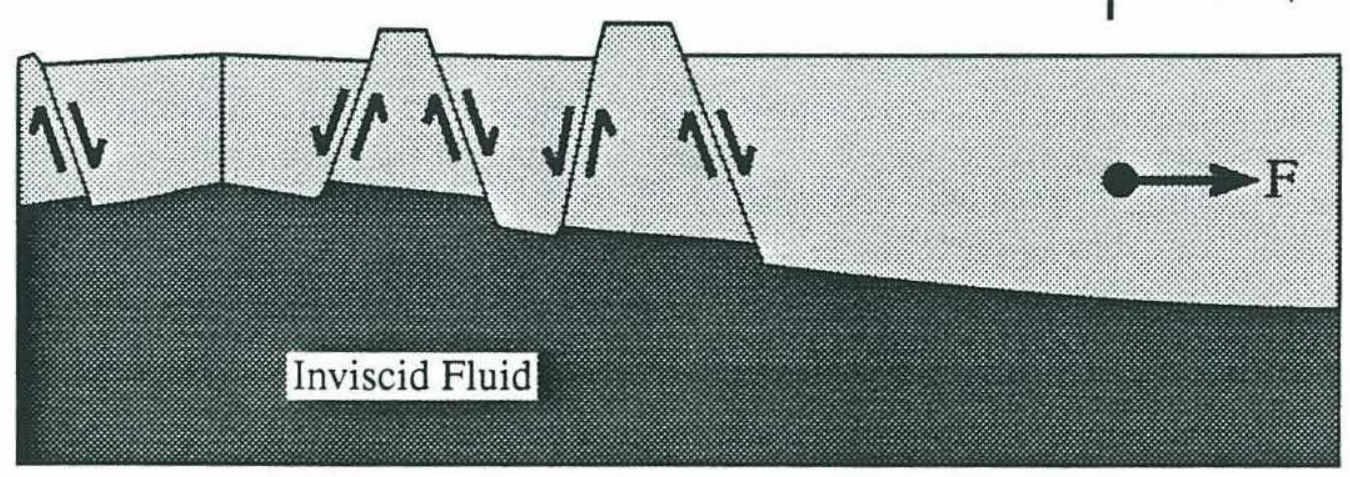


Figure 3.22. Predicted pattern of fault development for a rise axis that is composed of mechanically strong (shown as solid lines) and weak portions (shown as the dotted line). The shaded area around the weak rise axis represents an area where stress is generally relieved by the weak axis. Normal faulting is initiated by a bending moment that arises from the buoyancy of a low-density magma chamber during a weak-axis condition. Such a fault, denoted by I, forms close to the rise axis ( $2-3 \mathrm{~km}$ from the axis). If magmatic activity is cyclic, then portions of rise axis which appear strong may have been weak in the past. Because normal faults that formed during the weak axis period must have been transported off-axis by plate motion, such faults (denoted by I') should appear farther from the axis than in an area which is currently undergoing active magmatism. Farther off-axis (e.g., > 10-15 km from the axis), the rise axis will be seen by the faults as having a finite strength and thus will continue to grow (denoted by II and III) provided that there is an extensional stress field produced by gravitational spreading or another mechanism. 


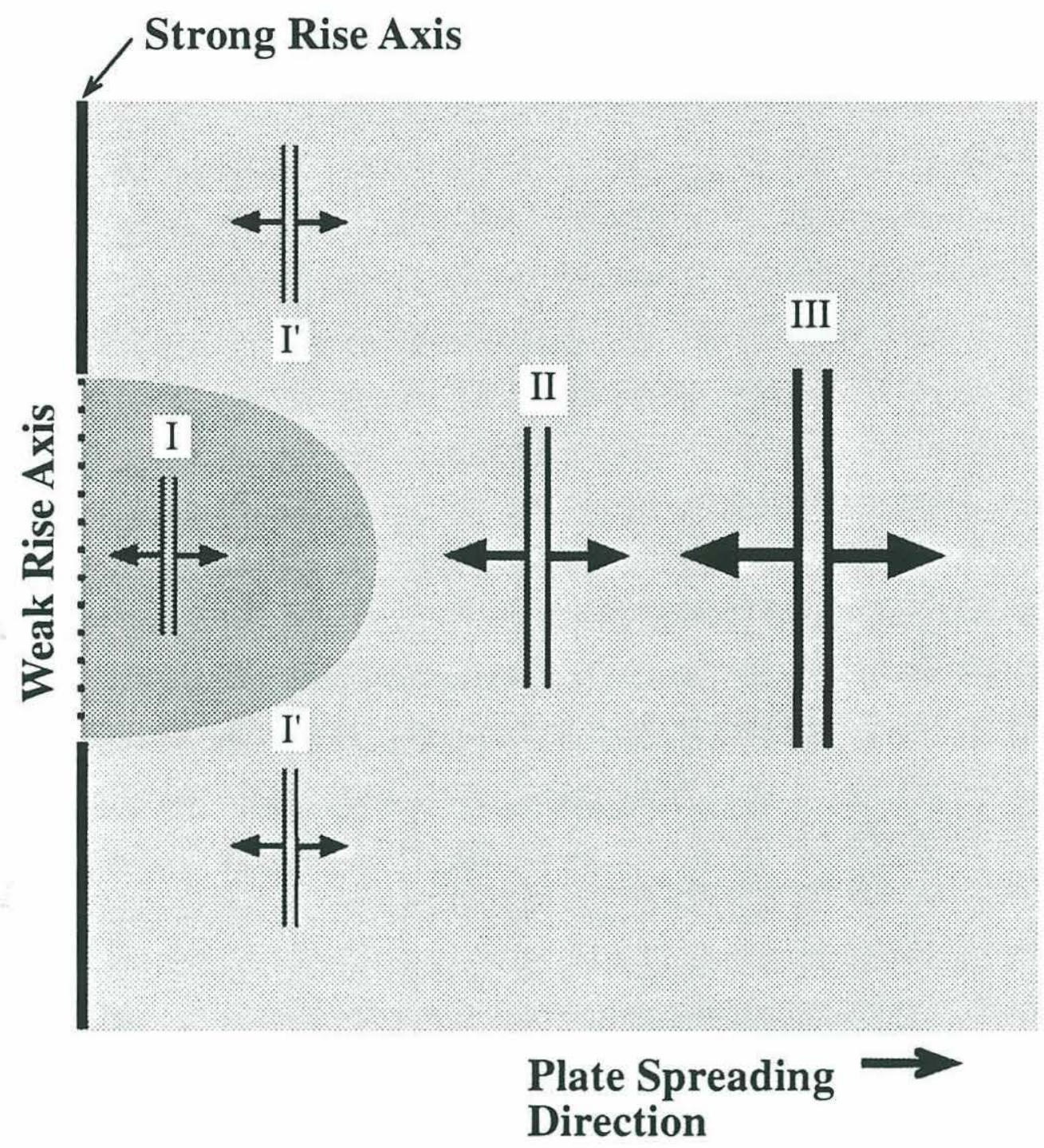


Figure 3.23. A map of fault distribution derived from Sea MARC II data for the EPR between $8^{\circ} 30^{\prime}-10^{\circ} \mathrm{N}$ (after Carbotte and Macdonald [1994]), shown together with local gravity lows identified from the short-wavelength residual gravity anomaly [Chapter 5]. The local gravity lows, which are centered at $9^{\circ} 21^{\prime}, 9^{\circ} 32^{\prime}$, and $9^{\circ} 42^{\prime} \mathrm{N}$, are shown as dark shaded areas. The light shaded area is the $2700 \mathrm{~m}$ contour enclosing the rise axis. 


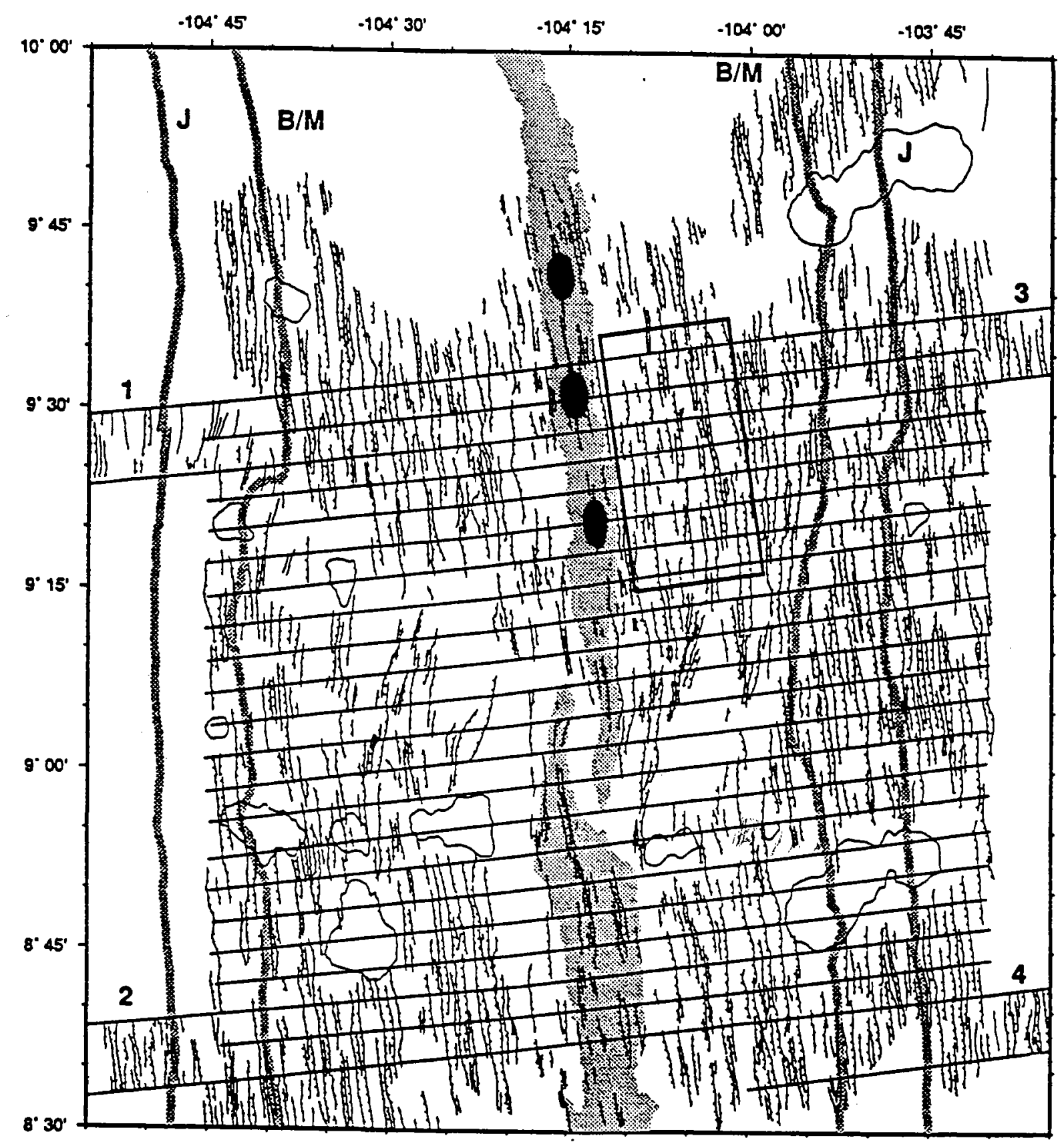

Carbotte and Macdonald [1994] 


\section{Chapter 4}

\section{Crustal Magnetization Anomalies and Segmentation of the East Pacific Rise, $9^{\circ} 10^{\prime}-9^{\circ} 50^{\prime} \mathrm{N}$}

\section{Introduction}

Since the establishment of the seafloor spreading theory in the early 1960s, magnetic surveys have become a standard method for investigating the evolution of tectonic plates. In the last two decades, along with improvements in our capability to map fine-scale features on the seafloor, new attention has been given to relatively short $(<10 \mathrm{~km})$ wavelength magnetic anomalies that lie within a single polarity interval. Investigations of such short-wavelength magnetic field anomalies at mid-ocean ridges have provided detailed information on the properties and structure of the upper crust and have played an important role in transforming the working models of mid-ocean ridges from twodimensional, steady-state idealizations into more complex, three-dimensional, timedependent representations [e.g., Hey et al., 1980; Sempéré et al., 1984; Tivey and Johnson, 1987; Gee and Kent, 1994]. Although mid-ocean ridge basalts acquire their magnetic properties after cooling below their Curie temperatures, a variety of complex processes can lead to changes in the magnetization intensity and the thickness of the magnetic source layer. Thus, determining the process responsible for a magnetic anomaly can be difficult. 
Moreover, this difficulty in interpreting magnetic results is compounded by a fundamental ambiguity of all potential field problems, since the magnetization anomalies that we deduce from the total magnetic field is a product of the magnetization intensity of the source layer and its thickness.

Several factors can cause variations in the magnetization intensity of the source rock. One important factor to consider when examining the magnetization of a young mid-ocean ridge is hydrothermal alteration or oxidation, whereby, through reaction with seawater, magnetite and titanomagnetite in basalt are altered to less magnetic hematite and titanomaghemite. Such changes may be divided into rapid high-temperature hydrothermal alteration [Thompson and Humphris, 1977; Mottl, 1983; Alt et al., 1986; Johnson and Pariso, 1987] and gradual low-temperature alteration or weathering, which normally occurs on rock surfaces during the first few tens of thousands of years following their emplacement [Irving et al., 1970; Marshall and Cox, 1972; Johnson and Merrill, 1973; Johnson and Atwater, 1977; Marshall, 1978; Honnorez, 1981]. Fissures and cracks at the seafloor can also affect the extent of low-temperature hydrothermal alteration, since they facilitate the penetration of seawater and thus increase the depth to which low-temperature oxidation can occur. Mineral grain size is another factor that can affect the magnetization intensity. For instance, dikes are considered to be less magnetic than surface pillow basalts because they generally have larger grains as a result of slower cooling. Finally, the composition of ferromagnetic minerals within the source rock can greatly affect the magnetization intensity. For instance, evolved magmas enriched in $\mathrm{Fe}$ and $\mathrm{Ti}$ can form basalts with higher intrinsic magnetization [Vogt and Johnson, 1973; Byerly et al., 1976; Sinton et al., 1983]. Recent investigations of magnetic anomalies along propagating rift systems and overlapping spreading centers [e.g., Hey et al., 1980; Sempéré et al., 1984] have suggested that a smaller magma body, in general, has less chance of becoming wellmixed and thus is more likely to become highly evolved. 
Variations in the thickness of the magnetic source layer can be caused by a number of factors. One important factor that can affect the processes of magnetization and demagnetization is temperature. Understanding the thermal structure can provide important information on the structure of a magnetic source layer. For example, local negative magnetic anomalies on or very near ridge axes have been associated with an anomalous thermal source, such as a hydrothermal vent field [e.g., McGregor and Rona, 1975; McGregor et al., 1977; Wooldridge et al., 1992; Tivey et al., 1993]. The Curie temperature of unaltered basalt is estimated to be approximately $150-200^{\circ} \mathrm{C}$ [Carmichael, 1970; Irving et al., 1970; Marshall and Cox, 1972; Marshall, 1978], which is well within the range of temperatures encountered in hydrothermal discharge zones, so that large heat sources are potentially capable of erasing the magnetization of oceanic crust. The thickness of the magnetic extrusive layer can also vary locally through variations in volcanic flux.

This chapter examines measurements of the scalar magnetic field taken near the sea surface during a cruise on board $R / V$ Thomas Washington to the East Pacific Rise (EPR) in January-February of 1988 . The magnetic survey covered the area between $9^{\circ} 10^{\prime} \mathrm{N}$ and $9^{\circ} 50^{\prime} \mathrm{N}$ and $255^{\circ} 27^{\prime}$ and $256^{\circ} 02^{\prime} \mathrm{E}$ (Figure 4.1). The magnetic anomalies are analyzed with the aim of improving our understanding of the structure and governing processes of this fast-spreading mid-ocean ridge. In this study, we perform three-dimensional inversions of the magnetic field anomaly to obtain the distribution of magnetization over of the survey area as well as two-dimensional inversions to obtain the thickness of the magnetic source layer along selected profiles. Since seafloor topography can have a significant effect on the resulting magnetization anomalies, the correction of the contribution for topography is an important task, especially when examining short-wavelength anomalies. For the threedimensional inversions, we assume and that the magnetic source layer is of uniform thickness. For two-dimensional inversions, we assume that the upper boundary of the magnetic source layer is the seafloor, and we try to determine the lower boundary that best satisfies the observed scalar magnetic field. 
Although the source of magnetization of normal oceanic crust is generally considered to be fairly uniform in thickness, there is a continuing debate on the thickness value (see Johnson [1979], Banerjee [1984], and Harrison [1987] for detailed discussions of this issue). Some models define the extrusive layer as the source layer, whereas other models suggest a significant contribution from deeper intrusive dike and gabbro layers. According to DSDP 504B results [Smith and Banerjee, 1986] from 5.9-My-old crust, substantial magnetization was measured from a dike complex at $1000 \mathrm{~m}$ depth, although a difference was noted in the dominant magnetic carrier between the pillow basalt layer $(\sim 500 \mathrm{~m}$ depth) and the dike complex. Miller and Hey [1986] estimated that the thickness of the magnetic layer at the Galapagos Propagating Rift is $900 \mathrm{~m}$ on the basis of a comparison of inversion results with the magnetization of dredged rock samples [Anderson et al., 1975; Vogt and de Boer, 1976].

One beneficial approach to resolving the ambiguity in the interpretation of magnetic results is to use independent observations and models. Fortunately, the section of the EPR which includes our survey area is one of the most intensively explored sections of a fastspreading mid-ocean ridge. Investigations in this area include the determination of seismic crustal structure [Detrick et al., 1987; Vera et al., 1990; Toomey et al., 1990, 1994; Christeson et al., 1992, 1994; Wilcock et al., 1992a; Harding et al., 1993; Kent et al., 1993a, b], near-bottom observations using the ARGO imaging system [Haymon et al., 1991], geochemical analyses of rock samples obtained with conventional dredges [Batiza and Niu, 1992] and with a rock corer mounted on submersible [Perfit et al., 1994], and the determination of microearthquake characteristics [Wilcock et al., 1992b; Hildebrand et al., 1992]. Therefore, whenever possible, we compare the structures and properties of the crust inferred from our investigation of the magnetization to those obtained from other studies such as gravity [Chapter 5] and seismic imaging [Vera et al., 1990; Toomey et al., 1990, 1994; Harding et al., 1993; Kent et al., 1993a, b] conducted over the same region. 


\section{Survey Area}

The magnetic survey area, covering the EPR from $9^{\circ} 10^{\prime}$ to $9^{\circ} 50^{\prime} \mathrm{N}$ and $255^{\circ} 27^{\prime}$ to $256^{\circ} 02^{\prime} \mathrm{E}$, corresponds to the upper portion of a long segment of the ridge-axis bounded by two major transform faults: the Clipperton Fracture Zone at $10^{\circ} 05^{\prime} \mathrm{N}$ to the north and the Siqueiros Fracture Zone at $8^{\circ} 20^{\prime} \mathrm{N}$ far to the south (Figure 4.1). This portion of the EPR forms a boundary between the Pacific plate to the west and the Cocos plate to the east. Directly south of the survey area at $9^{\circ} 03^{\prime} \mathrm{N}$ lies an overlapping spreading center (OSC) which has migrated episodically but at an average rate of $52 \mathrm{~km} / \mathrm{My}$ to the south over the past 0.7 My [Carbotte and Macdonald, 1992]. Numerous deviations from linearity (devals) of along-axis bathymetry have been identified along this portion of the EPR [Langmuir et al., 1986; Toomey et al., 1990; Haymon et al., 1991]. Such devals are thought to represent the topographic expression of variability in magma supply to the ridge crest. This portion of the EPR shows a slight degree of asymmetrical spreading. The half spreading rate has been approximately 53 to $55 \mathrm{~mm} / \mathrm{yr}$ on the Cocos plate and 58 to 59 $\mathrm{mm} / \mathrm{yr}$ on the Pacific plate during the past 0.7 My [Carbotte and Macdonald, 1992].

Morphologically, the EPR near $9^{\circ} 30^{\prime} \mathrm{N}$ is a classic example of a fast spreading midocean ridge; along-strike the ridge axis is fairly straight and continuous, and across-strike it is characterized by a smooth axial high of approximately $500 \mathrm{~m}$ in relief and $20 \mathrm{~km}$ in width (Figure 4.2). However, a closer observation shows some deviations from this simple description both along-strike and across-strike. First, the height of the rise summit decreases steadily to the south, from $9^{\circ} 50^{\prime} \mathrm{N}$ to $9^{\circ} 10^{\prime} \mathrm{N}$, by approximately $50 \mathrm{~m}$. Second, the cross-axis profile of the ridge broadens to the north. Variations in breadth are larger on the Pacific plate than on the Cocos plate. To the north of the survey area on the Pacific plate side lies a series of seamounts known as the Lamont Seamount Chain. Another chain of seamounts, the Watchstander Seamount Chain, is located to the northeast of our survey 
area but at a greater distance from the axis than the Lamont Seamount Chain. Several depressions 100-200 $\mathrm{m}$ deep are found at the south end of the survey area. These depressions are long and narrow, and appear to be bounded by pairs of normal faults, suggesting that they were formed by extension. The depressions and the small highs which appear between them have been identified as the relicts of overlapping basins and ridges which became extinct and were transported off-axis as the overlapping spreading center migrated to the south [Carbotte and Macdonald, 1992].

A critical constraint on the structure of the EPR is provided by multichannel seismic reflection profiles. A reflection from the top of an axial magma chamber (AMC) was detected and traced almost continuously along the rise axis [Detrick et al., 1987]. The presence of an AMC at a fast spreading center is an important element of current geological models for the formation of oceanic crust. The width of the AMC is quite narrow $(<4-6$ $\mathrm{km}$ ), with the top located $1.2-2.4 \mathrm{~km}$ below the seafloor. Although it was thought initially that the depth to the top of the AMC from the seafloor increases as much as $500 \mathrm{~m}$ from $9^{\circ} 50^{\prime}$ to $9^{\circ} 10^{\prime} \mathrm{N}$ in our survey area, after reprocessing the multichannel seismic reflection data, Kent et al. [1993a] suggested that much of this apparent increase may be due to ship wandering off the rise crest. In three-dimensional images obtained by travel-time tomography, the upper crustal structure of the EPR shows pronounced heterogeneity over distances of a few kilometers [Toomey et al., 1990, 1994]. Much of the variation in the velocity structure of the upper crust is considered to reflect evolution over the first few tens of thousands of years of age.

Geochemical analyses of dredged rock samples along the EPR between $5^{\circ} 30^{\prime}$ and $14^{\circ} 30^{\prime} \mathrm{N}$ by Langmuir et al. [1986] indicate a relatively high content of $\mathrm{MgO}$ along this portion of the ridge, which has been interpreted as suggesting a high quenching temperature of the basalts. In a more recent and detailed analysis between $9^{\circ} 17^{\prime}$ and $9^{\circ} 42^{\prime} \mathrm{N}$, Batiza and Niu [1992] noted an increase in the $\mathrm{MgO}$ content and decreases in the $\mathrm{FeO}$ and $\mathrm{TiO}_{2}$ contents by approximately $15 \%$ from south to the north in our survey area. 
From the geochemical analysis of closely spaced lava flow near the axis at $9^{\circ} 31^{\prime} \mathrm{N}$, Perfit et al. [1994] suggested that eruptions on this portion of the EPR occur throughout the crestal region and are not restricted to the axial summit caldera (ASC). A similar conclusion was reached on the basis of uranium-series dating by Goldstein et al. [1994].

In a recent survey using ARGO Optical/Acoustical Survey System equipped with sidelooking sonar, video, 35-mm and electronic still cameras, Haymon et al. [1991] were able to map the distribution of hydrothermal vents and sulfide deposits and image the surface morphology of a narrow axial zone, 40 to $200 \mathrm{~m}$ wide, from $9^{\circ} 09^{\prime}$ to $9^{\circ} 54^{\prime} \mathrm{N}$. Their results show a systematic variation in both the morphology of the ASC, which is $50-100 \mathrm{~m}$ wide and $10 \mathrm{~m}$ deep, and the distribution of hydrothermal vents field along the axis. Between $9^{\circ} 09^{\prime}$ and $9^{\circ} 27^{\prime} \mathrm{N}$, no well-developed ASC or evidence of hydrothermal vents were found. Extremely fresh, largely unfissured lobate and pillowed lavas were found from $9^{\circ} 13^{\prime}$ to $9^{\circ} 17^{\prime} \mathrm{N}$. However, between $9^{\circ} 27^{\prime}$ and $9^{\circ} 54^{\prime} \mathrm{N}$, a well-developed ASC, hydrothermal vents, and sulfide deposits are all present along-axis. The ASC becomes especially narrow between $9^{\circ} 44^{\prime}$ and $9^{\circ} 54^{\prime} \mathrm{N}$, which coincides with the location where most of the active hydrothermal vents were found, and where a volcanic eruption as recent as April of 1991 has been documented [Haymon et al., 1993].

\section{Collection of Data}

During a 21-day survey period, we were able to obtain dense coverage of Sea Beam bathymetric and magnetic data within our survey area. The magnetic data consist of total scalar magnetic field measurements recorded near the sea surface by a ship-towed proton precession magnetometer. The magnetic field data, initially sampled every $6 \mathrm{~s}$ by the magnetometer, were averaged to produce observations at one-minute intervals. Except for the times during which explosives or airguns were fired or instruments were being 
deployed and recovered, the magnetometer was operating continuously. In this study, we used only data taken on long, straight ship tracks. Magnetic field measurements within 15 minutes of major speed or course changes were removed from the data set, since it takes some time for the magnetometer to stabilize after changes in course or speed. The coverage of the magnetic field measurements used in this study is shown in Figure 4.3. The cumulative duration of measurement is approximately 200 hours, corresponding to $50 \%$ of the total time span of the survey. Most of the measurements were taken within the Brunhes normal epoch, except for four excursions approximately $100 \mathrm{~km}$ long that were made to the east and west from the main survey area to cross the Brunhes/Matuyama reversal boundary.

Though not as critical as for gravity field analysis or seismic tomography, obtaining accurate navigation is also important for magnetic field analysis. The navigation for the magnetic survey was performed using the Global Positioning System (GPS) and conventional Transit satellites. Although GPS yields much more precise navigation than Transit satellites, its coverage was limited to 8 hours a day at the time of this survey. Moreover, even when GPS navigation became available, seismic tomography was given a higher priority than magnetic and gravity field measurements. Therefore, our initial navigation contained substantial errors which were manifested by misfits in Sea Beam bathymetry at expected crossover points.

In this study, we used the reprocessed navigation of Wilcock et al. [1993]. The renavigation is based on the technique of Nishimura and Forsyth [1988], which minimizes misfit errors of Sea Beam swaths at track crossing points. According to Wilcock et al. [1993], the average Sea Beam misfit error was reduced from several kilometers to several hundreds of meters as a result of their inversion.

Magnetograms from land-based geomagnetic observatories during the period of the survey, obtained through the World Data Center at Boulder, Colorado, were used to extract information on low-frequency ionospheric activity. Although proximity to our survey area 
was an important criterion for selecting the land-based stations, not all the stations around our survey area had useable magnetic field data. In this study, we used digital magnetograms from stations at Honolulu (HON), Hawaii; Fresno (FRN), California; and Del Rio (DLR), Texas. The geographic and geomagnetic locations of these observatories are summarized in Table 4.1.

\section{Reduction of Magnetic Field Data}

The presence of background noise can pose a serious problem, especially for magnetic surveys conducted in near-equatorial regions where the signal-to-noise-ratio is low. This is because subsequent analysis of the magnetic field anomalies involves downward continuation, which tends to amplify short-wavelength signals, such as those attributable to noise, relative to long-wavelength ones. Several sources have been recognized as potential contributors to background noise, including errors in navigation, ship-induced magnetic fields, unstable motions of the magnetometer, and ionospheric activity [Miller, 1977]. A simple way to estimate the background noise level in our magnetic field record is to calculate the crossover error. The following describes the series of steps that were taken to reduce the level of noise in our magnetic data.

First, we examined whether renavigation had reduced crossover error. We compared the crossover errors before and after renavigation. The result showed a slight reduction in the rms of crossover error from 28.2 to $26.0 \mathrm{nT}$ after the new navigational information was applied (Figure 4.4a).

Next, we corrected for the magnetic field that arises from ionospheric activity. We divided the magnetic field that arises from the ionosphere into a diurnal component and a low-frequency component (periods greater than one day). This distinction was necessary because the diurnal field corrections were derived from the WDCA/SQ1 global model 
[Campbell et al., 1989], whereas the low-frequency field correction was calculated from the digital magnetograms gathered from land-based geomagnetic observatories.

The global model of solar quiet day field variation (WDCA/SQ1) is based on a spherical harmonic analysis of digital magnetograms obtained from a worldwide distribution of observatories in 1965 , a year of sunspot minimum in the 22-year solar-cycle and with the highest percentage of geomagnetic quiet days (i.e., the activity index, $\mathrm{K}_{\mathrm{P}}$, is less than 3). This model does not contain a solar-cycle adjustment and includes only a yearly adjustment of geomagnetic coordinates calculated according to the International Geomagnetic Reference Field (IGRF). Nevertheless, it is considered to be a fairly accurate representation for a sunspot-minimum period with reliable predictions of the 24-, 12-, 8-, and 6-hour period components at mid- and low-latitude regions. Comparison of diurnal variations predicted by WDCA/SQ1 and magnetic fields observed at the geomagnetic observatories used in this study showed that the rms discrepancies are less than $10 \mathrm{nT}$ during normal atmospheric conditions. Figure 4.5 is an illustration of the diurnal variation in the scalar field predicted for the EPR at $9^{\circ} 30^{\prime} \mathrm{N}$ on January 25,1990 . The diurnal variation is approximately $30 \mathrm{nT}$; most of the activity occurs around local noon. By subsequently correcting for the diurnal field, we were able to reduce the rms crossover error to $21.8 \mathrm{nT}$ (Figure $4.4 \mathrm{~b}$ ).

Unlike diurnal variations of a magnetic field, there is no model for predicting lowfrequency variations in the magnetic field because such variations are too irregular. For land-based stations, low-frequency field variations can be derived simply by averaging 24hour-long records of the magnetograms. Figure 4.6 shows the low-frequency field variations at three land-based stations (Table 4.1). Despite the large distances between stations, the low-frequency field signals show strong similarities. We assumed that the low-frequency field variation can be characterized as a long-wavelength signal, and we took a simple average of the three observed low-frequency field variations as a first-order 
representation of the low-frequency field variation at $9^{\circ} 30^{\prime} \mathrm{N}$. After correcting for the lowfrequency field variation, the rms crossover error was reduced to $17.4 \mathrm{nT}$ (Figure 4.4c).

Finally, we examined carefully the residual crossover errors to see if they show a correlation with the heading direction of the ship. If so, it could mean that there is an induced magnetic field affecting our measurements, which were taken $200 \mathrm{~m}$ behind the ship. Bullard and Mason [1961] proposed a simple model for correcting for a shipinduced magnetic field. According to this model, the amplitude of the ship's field is zero at magnetic poles and maximum at the magnetic equator. Also, the ship's field is represented as a negative cosine function with respect to the heading direction. With this model, we estimated the amplitude of the ship's field to be approximately $8.4 \mathrm{nT}$. After correcting for this ship effect, the rms crossover error was further reduced to $15.1 \mathrm{nT}$ (Figure 4.4d).

As shown in Figure 4.4, we were able to improve the quality of magnetic data significantly. Our improvement corresponds to a 70\% reduction in the variance of the crossover error. Considering that the fit of WDCA/SQ1 to data from land-based geomagnetic observatories was only slightly better than $10 \mathrm{nT}$, the overall reduction of crossover error that we achieved appears to be quite remarkable. In magnetic surveys conducted at on the EPR at $11^{\circ} 45^{\prime} \mathrm{N}$ by Perram and Macdonald [1990], the rms crossover error was 28-29 nT, even after shifting the field values of individual track lines by a constant amount to minimize the overall crossover error in a least squares sense [Prince and Forsyth, 1984]. Carbotte and Macdonald [1992] also report an rms crossover error of $33 \mathrm{nT}$ in their study of magnetic anomalies of the EPR at $8^{\circ}-10^{\circ} 30^{\prime} \mathrm{N}$.

Once the background noise from various sources was corrected, the long-wavelength field variations of the IGRF [IAGA Division I, 1986] were removed from the observed magnetic field. IGRF provides spherical harmonic coefficients up to degree and order 10, which is equivalent to a wavelength of approximately $1000 \mathrm{~km}$. Because our survey area is small, the IGRF correction has a negligible effect, except to reduce all values by a constant. The reduced magnetic field data were then gridded using a minimum curvature 
scheme [Briggs, 1974] on a 64 by 64 grid with sampling intervals corresponding to 1.16 and $1.0 \mathrm{~km}$ in latitude and longitude, respectively. This procedure is analogous to the bending of a thin elastic sheet by forces at fixed points in such a manner that the displacement at those points equals the observed values. The resulting magnetic field anomaly map is shown in Figure 4.7. To minimize boundary edge effects the gridded field and bathymetric data sets were mirrored along the edges to produce a grid of 128 by 128 for inversion.

The magnetic field anomaly within our survey area shows a notable north-south variation, with higher anomalies occuring to the north (Figure 4.7). That this trend is real, and not an artifact of an erroneous reference field, is demonstrable because a similar longwavelength variation can also be seen in the magnetic field map of Carbotte and Macdonald [1992], which covered a much larger area of the EPR (from $8^{\circ} 30^{\prime}$ to $10^{\circ} 40^{\prime} \mathrm{N}$ and from $254^{\circ} 30^{\prime}$ to $257^{\circ} 15^{\prime} \mathrm{E}$ ). Some of the north-south variation in the magnetic field in our area appears to have been accentuated by the presence of the Lamont Seamount Chain just to the northwest and overlapping spreading center basins to the south of our survey area.

\section{Inversion}

In this study, we performed two types of inversion: one to invert for the distribution of magnetization intensity from the observed magnetic field anomaly assuming that the magnetic source layer has a uniform thickness and that the direction of magnetization is known, and the other to invert for the thickness of the magnetic source layer from the observed magnetic field anomaly assuming that both the magnetization intensity and the direction of magnetization are known. Both cases involve the solution of an integral equation which can be expressed as 


$$
A(\mathrm{x})=\int_{-\infty}^{+\infty} J(\xi) \cdot K\left(\mathrm{x}-\xi, \zeta_{1}, \zeta_{2}\right) d \xi
$$

where $A(\mathrm{x})$ is the observed magnetic field anomaly at point $\mathrm{x}, J(\xi)$ is magnetization intensity at point $\xi, K$ is a kernel defining the shape of the magnetized body and is a function of the upper boundary $\zeta_{1}(\xi)$ and lower boundary $\zeta_{2}(\xi)$ of the source layer. Both $\mathrm{x}$ and $\xi$ are coordinates defined in the horizontal level of observation, and $\zeta_{1}$ and $\zeta_{2}$ are defined in the vertical direction.

There is an important difference between the two types of inversion. As is clear from equation (4.1), the problem of determining magnetization intensity distribution $(J)$ is linear, whereas that of determining layer thickness $(\zeta)$ is nonlinear. In the following sections, we examine the basic characteristics and assumptions made in the course of each inversion method in detail.

\section{Inversion for Magnetization Intensity}

The inversion for magnetization intensity of a magnetic source layer of uniform thickness that follows the undulations of surface topography was developed by Parker and Huestis [1974] and later extended to incorporate three-dimensional cases by Macdonald et al. [1980]. The method is based on a Fourier domain representation of magnetic fields and a search for the solution that best fits the observed magnetic field in a least squares sense through Taylor series expansion. It is more efficient and yields more accurate results than direct matrix inversions such as that employed by Bott [1967].

The forward solution for the magnetic field anomaly resulting from a magnetic source layer located at depth shows that it inherently involves a bandpass filter, also known as an 
"earth filter," in which the low- and high-wavenumber components are attenuated [Schouten, 1971; Schouten and McCamy, 1972]. Upon inversion, high and low wavenumber components are amplified so that, it is common practice to apply a bandpass filter to the computed magnetization after each iteration to ensure that convergence and stability are achieved throughout the inversion. In this study, we employed a bandpass filter in which a higher cutoff wavenumber was set at $2 \pi / 4 \mathrm{~km}^{-1}$, with cosine tapering between $2 \pi / 4$ and $2 \pi / 8 \mathrm{~km}^{-1}$, and a lower cutoff wavenumber at $2 \pi / 148 \mathrm{~km}^{-1}$, with cosine tapering between $2 \pi / 74$ and $2 \pi / 148 \mathrm{~km}^{-1}$. The higher cutoff wavenumber was set at $2 \pi / 4$ $\mathrm{km}^{-1}$ because our measurements were taken near the sea surface, and the inversion will not resolve wavelengths shorter than the average depth to the seafloor (i.e., approximately 2.8 $\mathrm{km})$. Also, because of the earth filter, a common practice is to choose the lower cutoff wavelength such that it is less than the shortest dimension of the inversion area. The lower cutoff wavelength of $148 \mathrm{~km}$ corresponds to the horizontal length of our mirrored inversion area. One consequence of such bandpass filtering is that the resulting solution will be much smoother than the true magnetization and the long wavelength variations will be subdued.

A parameter that we need to prescribe is the direction of magnetization of the magnetic source layer. According to the IGRF [IAGA Division I, 1986], the present-day magnetic field direction in our survey area corresponds to a declination of $8^{\circ}$ and an inclination of $31^{\circ}$. However, it is thought that over periods of time in excess of $10^{4}$ years the average direction of the Earth's magnetic field is believed to be close to that of an axial, centered dipole field aligned with the rotation axis. Therefore, we assumed $0^{\circ}$ declination and $18^{\circ}$ inclination as the direction of magnetization.

An important factor that one needs to consider when estimating the distribution of magnetization intensity of a body from a field measurement external to the body is the existence of an "annihilator," a particular magnetization solution that produces zero magnetic field anomalies [Parker and Huestis, 1974]. The general solution which satisfies 
the observed magnetic field is nonunique, since it is the sum of an initial magnetization solution obtained from an inversion of the magnetic field plus an arbitrary amount of the annihilator. The correct amount of annihilator to be added to the initial solution, however, can often be deduced from an independent piece of information. One commonly used technique is to assume that the magnetization intensity is equal but opposite in sign across reversal boundaries, such as Brunhes/Matuyama boundary. During our survey, we made four transects across the Brunhes/Matuyama reversal boundary (Figure 4.3). On the basis of two-dimensional inversions performed along these four ship tracks, we found the scaling for the annihilator needed to balance the magnetization on the eastern Brunhes/Matuyama reversal boundary. We used the eastern reversal boundary because the western reversal boundary appeared to be less well defined, presumably due to large variations in seafloor topography. Figure 4.8 shows two examples of these inversions. In the first example (Figure 4.8a-c), we first combined the two long northern tracks (i.e., tracks 056 and 066 ) and then inverted for the magnetization intensity, assuming a $500-\mathrm{m}$ thick magnetic source layer. In the second example (Figure 4.8d-f), the result was obtained after combining the two long southern tracks (i.e., tracks 058 and 068). We will discuss the choice of magnetic layer thickness later. In our problem, however, the annihilator solution has a very small variance compared with that of the initial solution, and thus the addition of annihilator does little to affect changes in the pattern of magnetization anomalies other than shifting the overall value by a constant amount.

We conducted a simple test to see how closely this magnetization intensity solution reproduces the observed magnetic field. The rms difference between the observed bandpass-filtered magnetic field and the recomputed total magnetic field, obtained by a forward calculation from the magnetization intensity solution, is approximately $4 \mathrm{nT}$, or less than $1 \%$ of the total variance of the magnetic field. 


\section{Inversion for Magnetic Layer Thickness}

The problem of determining the thickness of the magnetic layer is solved iteratively with successive adjustments to the starting layer model. Since we assume the seafloor to be the upper boundary $\left(\zeta_{1}\right)$ of the magnetic source layer, the problem reduces to that of determining the lower boundary $\left(\zeta_{2}\right)$. As with the inversion for magnetization intensity, we assumed that the direction of magnetization corresponds to that of the axial dipole field of the Earth (i.e., $0^{\circ}$ declination and $18^{\circ}$ inclination). The resulting solution depends on the prescribed value of magnetization intensity, since one can not resolve both the intensity and the thickness from only the observed magnetic field.

The method is in many ways similar to that described by Tanner [1967] for analyzing gravity anomalies. However, unlike the case of gravity, the pattern of the total scalar magnetic field varies with the angle between the local magnetic dipole source and the Earth's field. As a result, even if a discrepancy between the observed and estimated magnetic fields is found, deciding where to adjust the thickness of the magnetic source layer can be quite complicated. Fortunately, our survey was conducted near the magnetic equator, and therefore, we can simply adjust the thickness of the magnetic source layer directly below the point of discrepancy. To illustrate, consider the oceanic crust as a horizontal slab whose magnetic lineations strike north-south. Assume that the direction of magnetization has zero declination. If the seafloor is at the magnetic pole, increasing the layer thickness locally acts to increase the total magnetic field at the overlying sea surface. On the other hand, if the seafloor lies at magnetic equator, increasing the layer thickness locally acts to decrease the total magnetic field. The following describes the steps taken for the two-dimensional inversion for layer thickness.

First, we gridded the observed magnetic field anomaly and the source layer thickness into $\mathrm{m}$ points equally spaced in a horizontal direction (i.e., $A\left(\mathrm{x}_{\mathrm{i}}\right)$ and $\left.\zeta_{2}\left(\mathrm{x}_{\mathrm{i}}\right), \mathrm{i}=1 \ldots \mathrm{m}\right)$. We began by taking as the starting model a uniformly thick magnetic source layer that is 
uniformly magnetized. At each step, a comparison is made between the observed magnetic anomaly and the estimated anomaly for the $\mathrm{N}$-th update of the layered model at points $\mathrm{x}_{\mathrm{i}}, \mathrm{i}=1 \ldots \mathrm{m}$,

$$
A\left(\mathrm{x}_{\mathrm{i}}\right)-\widehat{A}^{\mathrm{N}}\left(\mathrm{x}_{\mathrm{i}}\right)
$$

The latter term is simply a forward solution for a non-uniform layer, which can be readily computed using the method of Parker [1972]. If the grid interval, $\Delta \mathrm{x}=\mathrm{x}_{\mathrm{p}+1}-\mathrm{x}_{\mathrm{p}}$, is sufficiently larger than the depth to the base of the layer, the difference between the observed field and the estimated field at a point $x_{p}$ can be reduced by adjusting the lower interface at that point $x_{p}$ :

$$
\zeta_{2}^{N+1}\left(x_{p}\right)=\zeta_{2}^{N}\left(x_{p}\right) \pm \Delta \zeta .
$$

This process is repeated until a satisfactory fit is achieved between the observed and estimated fields.

\section{Magnetization Solutions}

The three-dimensional solution for magnetization intensity of an upper crustal layer of uniform thickness is shown in Figure 4.9. In this study, we assumed $500 \mathrm{~m}$ as the thickness of the magnetic source layer. This thickness estimate was chosen on the basis of the multichannel seismic results from the EPR [Detrick et al., 1987] and thermal models of Wilson et al. [1988]. In the thermal models of Wilson et al. [1988], point sources and sinks of heat were used to simulate latent heat release, hydrothermal circulation, and convection within a magma chamber, and the isotherms were constrained to match 
multichannel seismic results from the EPR [Detrick et al., 1987]. According to those thermal models, the depth of the $150-200^{\circ} \mathrm{C}$ isotherms, which correspond to the approximate Curie temperature of unaltered basalt, ranges from 300 to $600 \mathrm{~m}$ beneath the seafloor near the axis. However, as mentioned earlier, the source and the thickness of magnetic layer for oceanic crust remain debatable, and therefore it is worthwhile to examine the consequences of assuming other thickness estimates. Figure 4.10 shows three profiles of the axial magnetization anomaly obtained by inversions of the full magnetic anomaly data set under different assumptions for the thickness of the magnetic source layer (i.e., 500,750 , and $1000 \mathrm{~m}$ ). Although the total variance of the magnetization anomaly is a function of the assumed magnetic layer thickness, we found that the basic patterns were insensitive to layer thickness.

A well-defined magnetization high can be traced along the rise axis throughout most of the survey area (Figure 4.9). Such an axial magnetization high, often referred to as the central anomaly magnetic high (CAMH), has been found along many other mid-ocean ridges [e.g., Klitgord, 1976; Tivey and Johnson, 1987; Gee and Kent, 1994] and is considered to be the result of the most recent acquisition of permanent magnetization by fresh basalts.

The axial magnetization high shows considerable along-axis variation, both in its magnitude and its linearity. In general, the magnitude of the axial magnetization decreases to the north (Figure 4.10). Several marked reductions in the axial magnetization intensity occur along the axis at $9^{\circ} 25^{\prime}, 9^{\circ} 37^{\prime}$, and $9^{\circ} 45^{\prime} \mathrm{N}$. These marked changes in the axial magnetization intensity are often accompanied by an offset in the along-axis linearity. For example, a major offset in the linearity of the axial magnetization anomaly can be seen at $9^{\circ} 45^{\prime} \mathrm{N}$ (Figure 4.9); and smaller offsets can be discerned at $9^{\circ} 25^{\prime}$ and $9^{\circ} 37^{\prime} \mathrm{N}$. We refer to such offsets as "magnetic devals" to distinguish them from conventional bathymetric devals. We also compare the center of the axial magnetization high with the bathymetric axis. Shown in Figure 4.9 by white crosses are the locations of the rise summit 
(bathymetric axis) in our survey area. Although the axis of the axial magnetization high does not always coincide precisely with this bathymetric axis, the discrepancy does not appear to be significant, except from $9^{\circ} 42^{\prime}$ to $9^{\circ} 45^{\prime} \mathrm{N}$ where the bathymetric axis appears 2 $3 \mathrm{~km}$ to the west of the axis of the axial magnetization high.

The magnetization anomalies also show several notable features off the rise axis. One such feature appears to the south of $9^{\circ} 25^{\prime} \mathrm{N}$ as a series of magnetization highs and lows occurring off the rise axis. These features have been identified as relict ridges and basins of an overlapping spreading center by Carbotte and Macdonald [1992]. Some asymmetry in the magnitude of magnetization with respect to the rise axis is evident to the north of $9^{\circ} 30^{\prime} \mathrm{N}$, an area not known to have been influenced by an overlapping spreading center. Our calculation shows that the average magnetization of the crust of the Cocos plate is almost twice that of the crust of the Pacific plate between $9^{\circ} 30^{\prime}$ and $9^{\circ} 45^{\prime} \mathrm{N}$. This lower magnetization appears to correlate with a lower gravity anomaly seen over the Pacific plate to the north of $9^{\circ} 30^{\prime} \mathrm{N}$ [Chapter 5]. We performed simple tests to see if an error in our estimate of the declination of the magnetization direction may have contributed to the asymmetry in magnetization anomaly. We varied the assumed declination over the range $\pm 10^{\circ}$ in the inversion and examined the magnetization anomalies resulting from a suite of inversions. The results showed that the asymmetry in magnetization can not be solely the result of uncertainty in the assumed magnetization direction.

As noted earlier, a number of processes can cause the thickness of the magnetic source layer to vary. We performed two-dimensional inversions to examine how much of a variation in the thickness along axis can explain the observed axial magnetic anomalies. The inversions were performed using starting models with different magnetization intensity. Results show that a magnetic layer that thickens to the south, with a minimum thickness near $9^{\circ} 40^{\prime} \mathrm{N}$, would fit the observed axial magnetic field. Figure 4.11 is an example of a variable-thickness layer solution with a magnetization intensity of $10 \mathrm{~A} / \mathrm{m}$. Although a uniform thickness of $500 \mathrm{~m}$ was the starting model for the inversion, results 
indicate that the final solutions are insensitive to the initial thickness. Results for other magnetization intensities are summarized in Figure 4.12, where the difference in the magnetic layer thickness between $9^{\circ} 40^{\prime}$ and $9^{\circ} 15^{\prime} \mathrm{N}$ serves as a measure of overall thickness variation. As expected, the variance in the layer thickness increases with decreasing magnetization intensity.

\section{Discussion}

\section{Causes of the Axial Magnetization Anomaly}

One of the prominent features in the map of magnetization anomalies (Figure 4.9) is the along axis variation of the magnetization at the rise axis. An examination of the cause of the axial magnetization anomaly may reveal new insight into rise processes and structure. One hypothesis is that the variation of axial magnetization anomaly along the rise axis represents an along-axis variation in the thickness of the magnetic source layer. The results of two-dimensional inversion for thickness variation (Figure 4.11) showed that the magnetic layer has to thicken from $9^{\circ} 40^{\prime}$ to $9^{\circ} 15^{\prime} \mathrm{N}$ by $150-400 \mathrm{~m}$ depending on the assumed magnetization intensity (Figure 4.12).

These estimates of the variation in the magnetic layer thickness can be compared with structural constraints obtained by other methods. One useful constraint may be the variation in the depth to the $\mathrm{AMC}$ along the axis. To make this comparison, however, we first need to consider a simple model of the mid-ocean ridge in which the thickness of the magnetic layer at the rise axis is controlled by the depth to the AMC. In such a model, we can assume that both the top of the AMC and the seafloor represent fixed-temperature boundaries, and the magnetic layer is simply a region whose temperature is less than the Curie temperature $\left(150-200^{\circ} \mathrm{C}\right)$. We assume that the seafloor is at $0^{\circ} \mathrm{C}$. Usselman and 
Hodge [1978] and Sleep [1978] suggested that the zone of partial melt marking the AMC reflectors may correspond to a temperature of $1185^{\circ} \mathrm{C}$, the temperature at which mid-ocean ridge basalt melt is $70 \%$ solid. For a locally uniform gradient of temperature with depth above the AMC reflector, a thicker magnetic source layer would be expected in regions where the AMC lies at greater depth. Detrick et al. [1987] have suggested that the AMC reflector deepens by approximately $500 \mathrm{~m}$ from north to south in our survey area. Recently, however, Kent et al. [1993a] suggested that this estimate may have been exaggerated by an error in navigation during the 1987 seismic reflection survey when the ship wandered off-axis. The amount of any southward increase in the depth to the top of the AMC reflector is therefore unclear. However, one speculation is that it should be comparable to the southward increase in the off-axis thickness of layer $2 \mathrm{~A}$, which is approximately 100-200 m [G. M. Kent, personal communication, 1994]. Table 4.2 summarizes the average thicknesses of layer $2 \mathrm{~A}$ on each side of the rise axis estimated along three cross-axis common depth point (CDP) seismic reflection lines that transected our survey area. The locations of these cross-axis CDP lines are shown as white dashed lines in Figure 4.9. If the depth to the top of the AMC deepens by only $100-200 \mathrm{~m}$, it is unlikely that the magnetic source layer itself would thicken by more than this amount. If the magnetic layer does thicken southward by $100-200 \mathrm{~m}$ in our survey area, the magnetization intensity must be at least $25 \mathrm{~A} / \mathrm{m}$ in order to explain the observed variation in the axial magnetic field anomaly Although there is no direct measurement of the magnetization intensity of surface rocks for this portion of the EPR, according to measurements of magnetic properties of young basalt recovered from other parts of the EPR [Sempéré et al., 1988; H. P. Johnson, personal communication, 1995], a magnetization intensity of $25 \mathrm{~A} / \mathrm{m}$ or greater is not uncommon for young mid-ocean ridge basalts. However, if the temperature gradient above the AMC reflector is indeed uniform, then an increase in the depth to the top of the AMC of $100-200 \mathrm{~m}$ along axis would only give rise to a $15-30 \mathrm{~m}$ increase in the thickness of the magnetic source layer, and the 
magnetization intensity would have to exceed $70 \mathrm{~A} / \mathrm{m}$ in order to explain the observed variation in axial anomaly.

Another argument against a variation in the thickness of the magnetic source layer as the principle cause of the variation in the axial magnetic anomaly derives from estimates of layer 2A thickness at the axis of the three CDP lines (Figure 4.13). Although the average thickness of layer 2A is the greatest along CDP line 33 (Table 4.2), much of this difference is due to a thicker layer $2 \mathrm{~A}$ off axis. If one compares the thickness at the rise axis, CDP line 29 shows the greatest thickness among the three profile lines, followed by CDP line 33 and then by CDP line 31 (Figure 4.13). These thicknesses do not correlate with the axial magnetization at the same locations.

An alternative explanation for the variation in the axial magnetization anomaly is that it is caused by along-axis variation in magnetization intensity. As a test of this idea, we may ask whether the observed variations in $\mathrm{FeO}$ and $\mathrm{TiO}_{2}$ content in our survey area match the inferred variations in the magnetization intensity. The measured composition of glasses found in dredged rock samples at the rise axis indicate that the content of $\mathrm{FeO}$ and $\mathrm{TiO}_{2}$ increases to the south from 9 to $11 \%$ and 1.2 to $1.9 \%$, respectively, in our survey area [Batiza and Niu, 1992]. We compared these variations against an empirical relationship between $\mathrm{FeO}$ and $\mathrm{TiO}_{2}$ contents and magnetization intensity of surface rock derived by Vogt and de Boer [1976] from samples from several mid-ocean ridges (Figure 4.14). The variation predicted for magnetization intensity from basalt chemistry is consistent with the inversion solution, but only if we assume a 1-km-thick magnetic source layer. If the assumed magnetic layer thickness is 500 or $750 \mathrm{~m}$, the predicted variation in magnetization explains only 36 or $60 \%$ of the total variance of axial magnetization intensity, respectively. Thus, additional causes, such as a variation in the thickness of the magnetic layer or postemplacement hydrothermal alteration, are needed to explain the observed magnetic field completely. For a magnetic source layer less than $700 \mathrm{~m}$ thick, such causes can be equally 
or more important than the variation in magnetization caused by the variation in $\mathrm{FeO}$ and $\mathrm{TiO}_{2}$.

In addition to the increase in amplitude to the south, the axial magnetization high exhibits short-wavelength variability that appears to be related to boundaries or offsets between the segments of the ASC (Figure 4.15a). On the basis of the distribution of ASCs [Haymon et al., 1991], the rise axis in our survey area may be divided into four segments (Figure 4.15b): The first segment is the axial region to the south of the $9^{\circ} 25^{\prime} \mathrm{N}$. Although an ASC exists between $9^{\circ} 21^{\prime}$ and $9^{\circ} 25^{\prime} \mathrm{N}$, it is very narrow $(<50 \mathrm{~m})$, and the remainder of the segment is without an ASC. The magnitude of the axial magnetization anomaly is the highest along this segment. The second segment can be placed between $9^{\circ} 25^{\prime}$ and $9^{\circ} 37^{\prime} \mathrm{N}$. The ASCs along this segment are generally the widest, and the magnitude of axial magnetization anomaly is moderate. The third segment can be defined between $9^{\circ} 37^{\prime}$ and $9^{\circ} 43^{\prime} \mathrm{N}$, and the fourth segment to the north of $9^{\circ} 43^{\prime} \mathrm{N}$. In this fourth segment, ASCs are present, but again they are narrower than on the second and third segment. On the basis of such correlations between axial magnetization and ASCs, we speculate that a reduction of the original magnetization intensity in the magnetic source layer by cracks around the ASCs and the subsequent enhancement of low-temperature oxidation along those cracks may have played a role in the along-axis variation of magnetization.

The degree of weathering of surface rock is likely to be affected by the development of an ASC. The faults forming the bounding walls of the ASC may facilitate the penetration of seawater and thus increase the depth to which low-temperature oxidation can occur. The permeability of such faults, as well as secondary fissures and cracks, may be most pronounced at the midpoint of an ASC segment where the ASC typically shows the largest relief. If so, the greatest degree of weathering may be found at the midpoint of an ASC. However, if the ASC has also been the locus of repeated volcanic eruptions, the bulk of the most recently extruded and most magnetic basalts would appear near the midpoint. On the basis of the correlation between the boundaries of ASCs and the loci of marked decreases 
in axial magnetization (Figure 4.15a), the effect of recent eruptions appears to override any tendency for enhanced rates of weathering near ASC segment centers.

\section{Implications for the Characteristics of Axial Magma Bodies}

It has been argued that the variation in $\mathrm{FeO}$ and $\mathrm{TiO}_{2}$ in dredged rock samples and the corresponding variation in magnetization provide important insight into the characteristics of the magma bodies from which the rocks of the magnetic source layer were derived. Basalts originating from highly evolved magma tend to be more enriched in $\mathrm{Ti}$ and $\mathrm{Fe}$ than those originating from less evolved magmas [Sinton et al., 1983]. The size of crustal magma bodies may be a critical factor affecting the degree of magma evolution. This is because small magma bodies are less prone to mixing and, since mixing can impede crystallization and fractionation, less mixing will allow the magma to become more evolved. Previous investigations to the south of our survey area [Sempéré et al., 1984; Carbotte and Macdonald, 1992] have found extremely high magnetization near the tips of the overlapping spreading center at $9^{\circ} 03^{\prime} \mathrm{N}$ and have interpreted such anomalies as evidence for magmatic bodies that are small relative to normal sections of the ridge.

We have examined whether the occurrence of a high axial magnetization anomaly in the south of our survey area can be related to the extremely high magnetization anomalies near the tips of the OSC at $9^{\circ} 03^{\prime} \mathrm{N}$. Since our coverage does not extend to the overlapping spreading center, we combined our results with those from previous investigations [Sempéré et al., 1984; Carbotte and Macdonald, 1992]. We found that the high axial magnetization anomaly that occurs to the south of $9^{\circ} 25^{\prime} \mathrm{N}$ in our survey area can be traced farther southward to the tip of an OSC at $9^{\circ} 03^{\prime} \mathrm{N}$. If, indeed, the high magnetization anomalies near the tips of the OSC were produced by relatively small magma bodies, the 
northward continuity of the axial magnetization anomaly implies that the axial magma body has not fully recovered to its normal dimensions until $40 \mathrm{~km}$ from the OSC.

Our investigation of gravity anomalies [Chapter 5] may provide additional information on the cause of the higher axial magnetization to the south. According to our analysis, the long-wavelength component of the residual gravity anomaly (Figure 5.10) shows a positive correlation with the axial magnetization anomaly (Figure 4.9, 4.10), i.e., regions of low residual gravity anomaly coincide with regions where the axis appears as a magnetization high, and regions of high residual gravity anomaly with regions where the axis appears as a magnetization low. Although gravity anomalies alone can not resolve the distribution of anomalous density, the most plausible interpretation of the long-wavelength component of the residual gravity anomalies is that they represent unmodeled temperature heterogeneity or variations in melt content [Chapter 5]. Under this interpretation, the lower residual gravity to the north of our area suggests that the mantle or crust is hotter or has a greater fraction of retained melt to the north than to the south.

On the other hand, the short-wavelength component of the residual gravity anomaly along axis reveals a quite different pattern. In our survey area, the short-wavelength residual gravity anomalies [Chapter 5] along axis are characterized by a series of local gravity lows which may mark the locations of larger than average crustal magma chambers or crustal magma chambers with greater melt content. Unlike the long-wavelength component of the residual gravity anomaly, however, these gravity lows do not show a systematic variation along axis in terms of their wavelength or amplitude, which suggests that the size of the largest crustal magma chambers does not vary substantially along axis. According to Phipps Morgan and Chen [1993], the width of a crustal magma chamber is limited by hydrothermal cooling. If indeed the sizes of the largest crustal magma chambers are more or less the constant along the rise axis as in our area, then an enhanced rate of melt production (due to hotter mantle) would have to be accommodated by an increased frequency of replenishment of crustal magma chambers. A more frequent 
replenishment of magma will lead to a magma chamber that is better mixed and to the eruption of basalts that are, on average, less evolved and lower in magnetization intensity.

According to Batiza and Niu [1992], a higher $\mathrm{MgO}$ content is observed toward the north in our survey area, which suggests that the basalts may have been quenched from higher temperatures. A more frequent replenishment will also enable the crustal magma chamber to maintain its temperature more effectively than a less frequently replenished one. Using an empirical relationship obtained from studies of the Kilauea Iki lava lake in Hawaii [Helz and Thornber, 1987], we estimate a $15^{\circ}-20^{\circ} \mathrm{C}$ increase in the quenching temperature from $9^{\circ} 20^{\prime}$ to $9^{\circ} 40^{\prime} \mathrm{N}$. The distribution of the ASC is also consistent with the argument that crustal magma chambers are replenished more frequently to the north of $9^{\circ} 25^{\prime} \mathrm{N}$. According to Haymon et al. [1991], the ASC is found only to the north of $9^{\circ} 21^{\prime} \mathrm{N}$ in our survey area (Figure 4.15b). The presence of an ASC on the rise summit was originally interpreted as the result of a waxing and waning in the magma supply to the AMC [Macdonald and Fox, 1988]. If the magma chambers to the north of our survey area are indeed replenished more frequently than those to the south, it would cause the magma chamber to wax and wane more often which, in turn, increases the chance of producing an ASC.

Although we argue, on the basis of short-wavelength residual gravity anomalies along axis, that the largest crustal magma chambers in our survey area appear to be approximately uniform in size, it is still possible that magma in the southern part of our survey area originated from comparatively small sources. The bulk of the lava that is extruded on the seafloor may, just prior to eruption, lie within only a small section of the crustal magma chamber, such as the magma lens. Sea surface gravity measurements may not be able to detect changes along axis in the characteristics of such a late-stage reservoir. According to Kent et al. [1993a], almost a fourfold increase in the width of the AMC reflector can be observed between $9^{\circ} 30^{\prime}$ and $9^{\circ} 19^{\prime} \mathrm{N}$. Kent et al. [1993a, b] argued that the AMC reflectors may represent migration paths of melt instead of the frozen roofs of 
AMCs, as previously thought. If so, a wider $\mathrm{AMC}$ reflector at $9^{\circ} 19^{\prime} \mathrm{N}$ may mean that the melt migration path is longer at $9^{\circ} 19^{\prime} \mathrm{N}$ than at other locations. A longer migration path, in turn, may have led the melt to become more evolved and thus produce basalts that are relatively highly magnetized.

\section{Causes of Off-Axis Magnetization Anomalies}

The magnetization anomaly maps exhibit several large-amplitude features off the rise axis. Many of the off-axis features exhibit some degree of asymmetry with respect to the rise. For instance, to the north of $9^{\circ} 30^{\prime} \mathrm{N}$, the average magnetization on the Pacific plate is lower than on the Cocos plate, whereas to the south of $9^{\circ} 20^{\prime} \mathrm{N}$, it is considerably higher on the Pacific side. To the south of $9^{\circ} 25^{\prime} \mathrm{N}$ on the Pacific plate, the magnetization anomaly is also characterized by a series of distinctive highs and lows. On the basis of an analysis of magnetic anomalies obtained over a larger area, Carbotte and Macdonald [1992] showed that some of these local lows and highs correspond to deformed basins and ridges marking the path of an OSC which migrated episodically to the south over the last $0.7 \mathrm{My}$.

Before discussing the exact of cause of short-wavelength features in our magnetization anomaly map, it is important to address whether they are artifacts caused by combining data from adjacent north-south ship tracks such that intertrack noise was not adequately removed. This issue is particularly important because many of these short-wavelength features in the magnetization map (Figure 4.9) are aligned parallel to the axis. Since our survey area is near the equator, we need to be cautious because there is a tendency for the east-west component to become amplified during the inversion. A simple way to check for this possibility is to compare our three-dimensional inversion solution, which is

obtained using all ship tracks, with the two-dimensional inversion solutions obtained along east-west tracks that continue out to the Brunhes/Matuyama reversal boundary (see Figure 
4.3 and Figure 4.9). In Figure 4.16, we show comparisons between two-dimensional inversions and the three-dimensional inversion solution sampled along the same tracks. There is a strong correlation between the two solutions, confirming that the shortwavelength features in our magnetization anomaly map are not ship track artifacts.

A number of possibilities may explain such short-wavelength variations in the magnetization anomaly in our area. These include short geomagnetic reversal events within the Brunhes epoch [Champion et al., 1988], variations in the magnetic source layer thickness [Tivey and Johnson, 1993; Gee and Kent, 1994], variations in the paleointensity of the Earth's field [Valet and Meynadier, 1993; Schneider and Mello, 1994], variations in the magnetization intensity of the source rock due to variability in the magmatic supply [Sinton et al., 1983], and variations in the degree of hydrothermal alteration at the rise axis [Tivey and Johnson, 1987]. To examine whether short reversal events might have caused the variations in magnetization intensity, we plotted the times of documented short reversal events at the bottom of Figure 4.16. If short geomagnetic reversals were the cause of cross-axis variations in the short-wavelength magnetization, they should correlate with the magnetization anomaly signal on east-west tracks. Figure 4.16 shows that both twodimensional and three-dimensional magnetization solutions show symmetry with respect to the rise axis in their short-wavelength variations. If we take the short-timescale reversal signal and impose a 1-km-wide Gaussian emplacement filter [Schouten and Denham, 1979], we generate a magnetization anomaly that is similar to the observed magnetization anomaly (see thick solid lines in Figure 4.17). Thus, while the amplitudes of the off-axis magnetization anomalies may be quite small, they may represent short reversals within the Brunhes epoch.

Variation in the paleointensity of the Earth's field is also a viable explanation. We took the available paleointensity history [Valet and Meynadier, 1993] and subjected it to the same 1-km-wide Gaussian emplacement filter (see dashed lines in Figure 4.17). While the resulting profile does not fit the peaks and troughs of the observed magnetization anomaly 
well, the variation of paleointensity of the Earth's field is still a matter of debate [Valet and Meynadier, 1993; Schneider and Mello, 1994].

Recently, Tivey and Johnson [1993] found from deep-towed magnetometer data that the thickness of the seismically-defined layer $2 \mathrm{~A}$ correlates positively with the thickness of the magnetic source layer on the Endeavour Segment of the northern Juan de Fuca Ridge. Although there is evidence for a significant increase in the thickness of layer $2 \mathrm{~A}$ within 1-2 $\mathrm{km}$ of the axis in our area [Christeson et al, 1992, 1994; Harding et al., 1993], because our measurements were taken near the sea surface, the resulting magnetization intensity anomalies are at too long a wavelength to resolve a change in layer thickness over so short a scale. However, we can still compare the magnitudes of off-axis magnetization anomalies with estimates of layer 2A thickness made by Harding et al. [1993] along CDP seismic reflection profile lines. Comparisons of magnetization anomalies with estimates of layer $2 \mathrm{~A}$ thickness along three $\mathrm{CDP}$ lines that transected our survey area are shown in Figure 4.13. On the basis of these three lines, there does not appear to be a positive correlation between the magnetization anomaly and layer 2A thickness. For CDP line 29, which transects the rise axis at approximately $9^{\circ} 40^{\prime} \mathrm{N}$, the average thickness of layer $2 \mathrm{~A}$ on the Pacific plate:is only slightly $(\sim 10 \mathrm{~m})$ thinner than that on the Cocos plate, although the Pacific plate shows a significantly lower magnetization. For CDP line 31, which transects the rise axis at approximately $9^{\circ} 30^{\prime} \mathrm{N}$, despite a layer $2 \mathrm{~A}$ that is $90 \mathrm{~m}$ thicker beneath the Pacific plate than on the Cocos plate, the magnetization on the Pacific plate is lower than that on the Cocos plate. For CDP line 33, the region of thickest layer 2A on the Pacific plate appears as an area of low magnetization.

We discussed in the previous section how a variation in magmatic supply and alteration can lead to a variation in the magnetization intensity of the source layer. For the magnetization anomalies to the south of $9^{\circ} 25^{\prime} \mathrm{N}$, an episodically migrating overlapping spreading center probably played an important role in causing the magnetization intensity of the source layer to vary [Carbotte and Macdonald, 1992]. However, to the north of 
$9^{\circ} 25^{\prime} \mathrm{N}$, there are few independent constraints to examine how much of a contribution the variation in the magnetization intensity of the source layer played in generating the off-axis magnetization anomalies.

In summary, short reversal events appear to be the primary cause of the shortwavelength off-axis magnetization anomalies to the north of $9^{\circ} 25^{\prime} \mathrm{N}$. Neither a variation in the thickness of the magnetic source layer nor a variation in the paleointensity of Earth's field predict convincing matches to observed magnetization anomalies. 


\section{Conclusions}

We have measured the total scalar magnetic field at the sea surface over the East Pacific Rise between $9^{\circ} 10^{\prime}-9^{\circ} 50^{\prime} \mathrm{N}$ and $255^{\circ} 27^{\prime}-256^{\circ} 02^{\prime} \mathrm{E}$. Through renavigation, and corrections for magnetic field fluctuations due to ionospheric activity and the ship-induced magnetic field, we were able to improve the quality of the magnetic data. The rms misfit of the measured magnetic field misfit at track crossovers was reduced significantly from 28 to 15 nT. Complete coverage of the bathymetry from Sea Beam and dense magnetic field coverage allowed us to perform a three-dimensional inversion to obtain a map of magnetization anomalies within a magnetic source layer assumed to be of uniform thickness $(1 \mathrm{~km})$. We also performed two-dimensional inversions for the thickness of the magnetic source layer along the rise axis under the assumption of uniform magnetization intensity $(10-25 \mathrm{~A} / \mathrm{m})$. Throughout this study, we assumed that the direction of magnetization is that of an axial dipole field about the Earth's rotation axis (i.e., $0^{\circ}$ declination and $18^{\circ}$ inclination).

On the basis of our analyses of the magnetic field data, we have drawn the following conclusions:

(1) The axial magnetization high appears well defined and continuous over almost the entire survey area. However, the axial magnetization shows a significant variation along axis. The magnitude of the axial magnetization anomaly increases to the south, with the sharpest increase at about $9^{\circ} 25^{\prime} \mathrm{N}$. When combined with the results from previous magnetic surveys [Sempéré et al., 1984; Carbotte and Macdonald, 1992], the enhanced axial magnetization high can be traced $40 \mathrm{~km}$ southward to the tip of the overlapping spreading center at $9^{\circ} 03^{\prime} \mathrm{N}$.

(2) The increase in the amplitude of the axial magnetization high toward the south may be caused by a number of factors, which can be classified as either variations in the 
thickness or in the magnetization intensity of the source layer. Because of the suggestion that the axial magma chamber reflector may deepen by as much as $100-200 \mathrm{~m}$ to the south in our survey area, we examined whether a similar increase in the thickness of the magnetic source could explain the increase in the axial magnetization anomaly. Such an explanation requires that the magnetization intensity of the source layer be at least $25 \mathrm{~A} / \mathrm{m}$, which is not uncommon for young basalts. However, it is more likely that the actual increase in the thickness of the magnetic layer resulting from a 100-200 m deepening of the axial magma chamber would be much smaller $(<30 \mathrm{~m})$, in which case one would require unreasonably high $(>70 \mathrm{~A} / \mathrm{m})$ magnetization. Furthermore, estimates of layer $2 \mathrm{~A}$ thickness on the rise axis from cross-axis multichannel seismic reflection profiles [Kent et al., 1993a] do not show a systematic north-south variation. Therefore, a southward increase in the thickness of the magnetic source layer in our area does not appear to be the major cause of the alongaxis variation in the axial magnetization.

The empirical relationship between $\mathrm{FeO}$ and $\mathrm{TiO}_{2}$ contents and magnetization intensity was employed to test whether variations in $\mathrm{FeO}$ and $\mathrm{TiO}_{2}$ along axis could explain the southward increase in magnetization. The concentrations of $\mathrm{FeO}$ and $\mathrm{TiO}_{2}$ are known to increase to the south [Batiza and Niu, 1992], but in order for this effect to increase the magnetization by the required amount the magnetic source layer has to be $1000 \mathrm{~m}$ thick. On the basis of multichannel seismic data [Detrick et al., 1987] and thermal models [Wilson et al., 1988], the thickness of the magnetic source layer is unlikely to be this great. For a magnetic source layer that is 500 or $750 \mathrm{~m}$ thick, the observed along-axis variations in $\mathrm{FeO}$ and $\mathrm{TiO}_{2}$ contents explain only 36 and $60 \%$, respectively, of the total variance of axial magnetization anomalies. Therefore, a variation in magnetic layer thickness or a variation in magnetization unrelated to bulk chemistry must accompany the magnetization variation caused by variations in the $\mathrm{FeO}$ and $\mathrm{TiO}_{2}$ contents of the extrusive layer.

(3) We also observed short-wavelength variability in the axial magnetization high. Two effects may contribute to this variability. On the basis of correlations between the 
location of the axial summit caldera (ASC) and the magnitude of the axial magnetization anomaly, we speculate that the faults bounding the ASC and the subsequent enhancement of low-temperature oxidation along those faults and associated secondary cracks and fissures may have varied along individual ASC segments. In addition, if the midpoint of an ASC segment is the locus of more frequent lava eruptions than the ends, then basalts near an ASC midpoint will tend to be younger and more magnetic. The addition of new lava along ASCs appears to have a greater affect on the magnetization anomaly than lowtemperature oxidation.

(4) We found distinct bands of short-wavelength $(\sim 5 \mathrm{~km})$ variations in the magnetization anomaly. These features are not artifacts caused by intertrack errors. Possible explanations of these off-axis variations in magnetization anomalies include short geomagnetic reversal events within the Brunhes epoch, variations in the magnetic source layer thickness, variations in the paleointensity of the Earth's dipole field, variations in the magnetization intensity of the source rock due to a variability in magma supply, and variations in degree of hydrothermal alteration at the rise axis. We compared the magnetization anomalies with estimates of layer 2A thickness [Harding et al., 1993] along several cross-axis multichannel seismic profiles, since layer $2 \mathrm{~A}$ can be an important contributor to the magnetic source layer. No clear evidence was found for a positive correlation between the magnetization anomaly and layer $2 \mathrm{~A}$ thickness. Also, a comparison between the observed magnetization anomaly and that derived from available information on the history of Earth's field strength did not show a good correlation. An application of 1-km-wide Gaussian emplacement filter to the short-timescale reversal signal shows a good correlation with the positions of the observed magnetization anomalies. On the basis of this argument, the most likely explanation for the off-axis magnetization anomalies is that they result from short reversal events within the Brunhes epoch. 
(5) There are two possible explanations for the along-axis variation in the magnetization intensity of the magnetic source layer. Although it is commonly thought that small crustal magma chambers are more likely to produce basalts enriched in $\mathrm{Fe}$ and Ti, the short-wavelength residual gravity anomalies along axis [Chapter 5] show no evidence of substantial variation in the size of the largest crustal magma chambers in our survey area. On the basis of the along-axis variation in the long-wavelength component of the residual gravity anomaly, however, there is evidence that the crust or upper mantle in the north of our survey is hotter or more melt-rich than that to the south [Chapter 5], which would in turn favor a more frequent replenishment of crustal magma chambers, less evolved magmas, lower Fe and Ti contents, and less magnetization. A second explanation, based largely on recent observations of the width of axial magma chamber reflections [Kent et al., 1993a, b] along the rise axis, is that melt follows a longer migration path or takes more time to reach the seafloor in the south of our survey area than in the north. A longer migration path or increased migration time can yield more evolved magmas and thus basalts with greater magnetization intensity. 


\section{References}

Alt, J. C., J. Honnorez, C. Laverne, and R. Emmermann, Hydrothermal alteration of a 1 $\mathrm{km}$ section through the upper oceanic crust, deep sea drilling project hole 504B: Mineralogy, chemistry, and evolution of seawater-basalt interactions, J. Geophys. Res., 91, 10,309-10,335, 1986.

Anderson, R. N., D. A. Clague, K. D. Klitgord, M. Marshall and R. K. Nishimori, Magnetic and petrologic variations along the Galapagos spreading center and their relation to the Galapagos melting anomaly, Geol. Soc. Am. Bull., 86, 683-694. 1975.

Banerjee, S. K., The magnetic layer of the oceanic crust - How thick is it?, Tectonophysics, 105, 15-27, 1984.

Batiza, R., and Y. Niu, Petrology and magma chamber processes at the East Pacific Rise -9³0'N, J. Geophys. Res, 97, 6779-6797, 1992.

Bott, M. H. P., Solution of the linear inverse problem in magnetic interpretation with application to oceanic magnetic anomalies, Geophys. J. R. Astron. Soc., 13, 313-323, 1967.

Briggs, I. C., Machine contouring using minimum curvature, Geophysics, 39, 39-48, 1974.

Bullard, E. C., and R. G. Mason, The magnetic field astern of a ship, Deep-Sea Res., 8, 20-27, 1961.

Byerly, G. R., W. G. Melson, and P. R. Vogt, Rhyodacites, andesites, ferro-basalts and ocean tholeiites from the Galapagos spreading center, Earth Planet. Sci. Lett., 30, 215 $221,1976$.

Campbell, W. H., E. R. Schiffmacher, and H. W. Kroehl, Global quiet day field variation model WDCA/SQ1, Eos, Trans. AGU, 70, 73-74, 1989. 
Carbotte, S., and K. Macdonald, East Pacific Rise $8^{\circ}-10^{\circ} 30^{\prime} \mathrm{N}$ : Evolution of ridge segments and discontinuities from SeaMARC II and three-dimensional magnetic studies, J. Geophys. Res, 97, 6959-6982, 1992.

Carmichael, C. M., The Mid-Atlantic Ridge near $45^{\circ} \mathrm{N}$, VII, Magnetic properties and opaque mineralogy of dredged samples, Can. J. Earth Sci., 7, 239-256, 1970.

Champion, D. E., M. A. Lanphere, and M. A. Kuntz, Evidence for a new geomagnetic reversal from lava flows in Idaho: Discussion of short polarity reversals in the Brunhes and late Matuyama polarity chrons, J. Geophys. Res., 93, 11,667-11,680, 1988.

Christeson, G. L., G. M. Purdy, and G. J. Fryer, Structure of young upper crust at the East Pacific Rise near 9³0N, Geophys. Res. Lett., 19, 1045-1048, 1992.

Christeson, G. L., G. M. Purdy, and G. J. Fryer, Seismic constraints on shallow crustal emplacement processes at the fast spreading East Pacific Rise, J. Geophys. Res., 99, 17,957-17,973, 1994.

Detrick, R. S., P. Buhl, E. Vera, J. C. Mutter, J. Orcutt, J. Madsen, and T. Brocher, Multichannel seismic imaging of a crustal magma chamber along the East Pacific Rise, Nature, 326, 35-41, 1987.

Gee, J., and D. V. Kent, Variations in layer 2A thickness and the origin of the central anomaly magnetic high, Geophys. Res. Lett., 21, 297-300, 1994.

Goldstein, S. J., M. R. Perfit, R. Batiza, D. J. Fornari, and M. T. Murrell, Off-axis volcanism at the East Pacific Rise detected by uranium-series dating of basalts, Nature, 367, 157-159, 1994.

Harding, A. J., G. M. Kent, and J. A. Orcutt, A multichannel seismic investigation of upper crustal structure at $9^{\circ} \mathrm{N}$ on the East Pacific Rise: Implications for crustal accretion, J. Geophys. Res., 98, 13,925-13,944, 1993.

Harrison, C. G. A., Marine magnetic anomalies: The origin of the stripes, Ann. Rev. Earth Planet. Sci., 15, 505-543, 1987. 
Haymon, R. M., D. J. Fornari, M. Edwards, S. Carbotte, D. Wright, and K. Macdonald, Hydrothermal vent distribution along the East Pacific Rise crest $\left(9^{\circ} 09^{\prime}-54^{\prime} \mathrm{N}\right)$ and its relationship to magmatic and tectonic processes on fast-spreading mid-ocean ridges, Earth Planet. Sci. Lett., 104, 513-534, 1991.

Haymon, R. M., D. J. Fornari, K. L. Von Damm, M. D. Lilley, M. R. Perfit, J. M. Edmond, W. C. Shanks, III, R. A. Lutz, J. M. Grebmeier, S. Carbotte, D. Wright, E. McLaughlin, M. Smith, N. Beedle, and E. Olson, Volcanic eruption of the mid-ocean ridge along the East Pacific Rise crest at $9^{\circ} 45-52$ 'N: Direct submersible observations of seafloor phenomena associated with an eruption event in April, 1991, Earth Planet. Sci. Lett., 119, 85-101, 1993.

Helz, R. T., and C. R. Thornber, Geothermometry of Kilauea Iki lava lake, Hawaii, Bull. Volcanol., 49, 651-668, 1987.

Hey, R. N., F. K. Duennebier, and W. J. Morgan, Propagating rifts on mid-ocean ridges, J. Geophys. Res., 84, 3647-3658, 1980.

Hildebrand, J. A., S. C. Webb, L. M. Dorman, A. E. Schreiner, M. A. McDonald, and W. C. Crawford, Microseismicity of a mid-ocean ridge volcanic eruption: The East Pacific Rise at 9 ${ }^{\circ} 50^{\prime} \mathrm{N}$ (abstract), Eos, Trans. AGU, 73, Fall Meeting suppl., 530, 1992.

Honnorez, J., The aging of the oceanic crust at low temperature, in The Sea, vol. 7, edited by C. Emiliani, John Wiley \& Sons, New York, pp. 525, 1981.

IAGA Division I, Working Group 1, International Geomagnetic Reference Field revision 1985, Eos, Trans. AGU, 67, 523-524, 1986.

Irving, E., W. A. Robertson, and F. Aumento, The Mid-Atlantic Ridge near $45^{\circ} \mathrm{N}$, VI, Remanent intensity, susceptibility and iron content of dredge sample, Can. J. Earth Sci., 7, 226-238, 1970.

Johnson, H. P., Magnetization of the oceanic crust, Rev. Geophys., 17, 215-226, 1979.

Johnson, H. P., and T. Atwater, Magnetic study of basalts from the Mid-Atlantic Ridge, lat. $37^{\circ}$ N, Geol. Soc. Am. Bull., 88, 637-647, 1977. 
Johnson, H. P., and R. Merrill, Low temperature oxidation of a titanomagnetite and the implications for paleomagnetism, J. Geophys. Res., 78, 4938-4949, 1973.

Johnson, H. P., and J. E. Pariso, The effects of hydrothermal alteration on the magnetic properties of oceanic crust: Results from drill holes CY-2 and CY-2a, Cyprus Crustal Study Project, in Cyprus Crustal Study Project: Initial Reports, Holes CY2 and 2a, edited by P. T. Robinson, I. L. Gibson, and A. Panayiotou, Geol. Surv. Can. Pap. 8529, pp. 283-293, 1987.

Kent, G. M., A. J. Harding, and J. A. Orcutt, Distribution of magma beneath the East Pacific Rise between the Clipperton Transform and the $9^{\circ} 17^{\prime} \mathrm{N}$ deval from forward modeling of common depth point data, J. Geophys. Res., 98, 13,945-13,969, 1993a.

Kent, G. M., A. J. Harding, and J. A. Orcutt, Distribution of magma beneath the East Pacific Rise near the $9^{\circ} 03^{\prime} \mathrm{N}$ overlapping spreading center from forward modeling of common depth point data, J. Geophys. Res., 98, 13,971-13,995, 1993 b.

Klitgord, K. D., Sea-floor spreading: The central anomaly magnetization high, Earth Planet. Sci. Lett., 29, 201-209, 1976.

Langmuir, C. H., J. F. Bender, and R. Batiza, Petrological and tectonic segmentation of the East Pacific Rise, 5³0'-14³0'N, Nature, 322, 422-429, 1986.

Macdonald, K. C., and P. J. Fox, The axial summit graben and cross-sectional shape of the East Pacific Rise as indicators of axial magma chambers and recent volcanic eruptions, Earth Planet. Sci. Lett., 88, 119-131, 1988.

Macdonald, K. C., S. P. Miller, S. P. Heustis, and F. N. Spiess, Three-dimensional modeling of a magnetic reversal boundary from inversion of deep-tow measurements, J. Geophys. Res., 85, 3670-3680, 1980.

Marshall, M., The magnetic properties of some DSDP basalts from the North Pacific and inferences for Pacific plate tectonics, J. Geophys. Res., 83, 289-308, 1978.

Marshall, M., and A. Cox, Magnetic changes in pillow basalt due to sea floor weathering, J. Geophys. Res., 77, 6459-6469, 1972. 
McGregor, B. A., C. G. A. Harrison, J. W. Lavelle, and P. A. Rona, Magnetic anomaly pattern on Mid-Atlantic Ridge crest at 26 N, J. Geophys. Res., 82, 231-238, 1977.

McGregor, B. A., and P. A. Rona, Crest of the Mid-Atlantic Ridge at $26^{\circ} \mathrm{N}, J$. Geophys. Res., 80, 3307-3314, 1975.

Miller, S. P., The validity of the geological interpretations of marine magnetic anomalies, Geophys. J. R. Astron. Soc., 50, 1-21, 1977.

Miller, S. P., and R. N. Hey, Three-dimensional magnetic modeling of a propagating rift, Galapagos 95³0'W, J. Geophys. Res., 91, 3395-3406, 1986.

Mottl, M. J., Hydrothermal processes at seafloor spreading centers: Application of basaltseawater experimental results, in Hydrothermal Processes at Seafloor Spreading Centers, NATO Conf. Ser. IV, 12, pp. 199, edited by P. A. Rona, K. Boström, L. Laubier, and K. L. Smith, Plenum Press, New York, 1983.

Nishimura, C. E., and D. W. Forsyth, Improvements in navigation using SeaBeam crossing errors, Mar. Geophys. Res., 9, 333-352, 1988.

Parker, R. L., The rapid calculation of potential anomalies, Geophys. J. R. Astron. Soc., 31, 447-455, 1972.

Parker, R. L., and S. P. Huestis, The inversion of magnetic anomalies in the presence of topography, J. Geophys. Res., 79, 1587-1593, 1974.

Perfit, M. R., D. J. Fornari, M. C. Smith, J. F. Bender, C. H. Langmuir, R. M. Haymon, Small-scale spatial and temporal variations in mid-ocean ridge crest magmatic processes, Geology, 22, 375-379, 1994.

Perram, L. J., and K. C. Macdonald, A one-million-year history of the $11^{\circ} 45^{\prime} \mathrm{N}$ East Pacific Rise discontinuity, J. Geophys. Res., 95, 21,363-21,381, 1990.

Phipps Morgan, J., and Y. J. Chen, The genesis of oceanic crust: Magma injection, hydrothermal circulation, and crustal flow, J. Geophys. Res., 98, 6283-6297, 1993.

Prince, R. A., and D. W. Forsyth, A simple objective method for minimizing crossover errors in marine gravity data, Geophysics, 49, 1070-1083, 1984. 
Schneider, D. A., and G. A. Mello, Pleistocene geomagnetic intensity variation from Sulu Sea sediments (abstract), Eos, Trans. AGU, 75, Fall Meeting suppl., 193, 1994.

Schouten, J. A., A fundamental analysis of magnetic anomalies over oceanic ridges, Mar. Geophys. Res., 1, 111-144, 1971.

Schouten, H., and C. R. Denham, Modeling the oceanic magnetic source layer, in DSDP Results in the Atlantic Ocean: Ocean Crust, Maurice Ewing Ser., 2, edited by M. Talwani, C. G. A. Harrison, and D. E. Hayes, pp. 151-159, AGU, Washington, D.C., 1979.

Schouten, H., and K. McCamy, Filtering marine magnetic anomalies, J. Geophys. Res., 77, 7089-7099, 1972.

Sempéré, J., K. C. Macdonald, and S. P. Miller, Overlapping spreading centres: 3-D inversion of the magnetic field at $9^{\circ} 03^{\prime} \mathrm{N}$ on the East Pacific Rise, Geophys. J. $R$. Astron. Soc., 79, 799-811, 1984.

Sempéré, J.-C., A. Meshkov, M. Thommeret, and K. Macdonald, Magnetic properties of some young basalts from the East Pacific Rise, Mar. Geophys. Res., 9, 131-146, 1988.

Shackleton, N. J., A. Berger, and W. R. Peltier, An alternative astronomical calibration of the lower Pleistocene timescale based on ODP Site 677, Trans. R. Soc. Edinburgh Earth Sci., 81, 251-261, 1990.

Sinton, J. M., D. S. Wilson, D. M. Christie, R. N. Hey, and J. R. Delaney, Petrologic consequences of rift propagation on oceanic spreading ridges, Earth Planet. Sci. Lett., 62, 193-207, 1983.

Sleep, N. H., Thermal structure and kinematics of mid-ocean ridge axis, Some implications to basaltic volcanism, Geophys. Res. Lett., 5, 426-428, 1978.

Smith, G. M., and S. K. Banerjee, Magnetic structure of the upper kilometer of the marine crust at Deep Sea Drilling Project hole 504B, Eastern Pacific Ocean, J. Geophys. Res., 91, 10,337-10,354, 1986. 
Stewart, W. K., A model-based approach to 3-d imaging and mapping underwater, in Proc. 7th Int. Conf. Offshore Mechanics Arctic Eng., Vol. 6, edited by J. S. Chung, and D. C. Angelides, pp. 61-71, Am. Soc. Mech. Eng., New York, 1988.

Tanner, J. G., An automated method of gravity interpretation, Geophys. J. R. Astron. Soc. 13, 339-347, 1967.

Thompson, G., and S. E. Humphris, Seawater-rock interaction in the oceanic basement, in Proc. 2nd Int. Symp. Water-Rock Interact., Vol. 3, edited by H. Pacquet and Y. Tardy, pp. 3-8, Univ. Louis Pasteur, Strasbourg, France, 1977.

Tivey, M. A., and H. P. Johnson, The central anomaly magnetic high: Implications for ocean crust construction and evolution, J. Geophys. Res., 92, 12,685-12,694, 1987.

Tivey, M. A., and H. P. Johnson, Variations in oceanic crustal structure and implications for the fine-scale magnetic anomaly signal, Geophys. Res. Lett., 20, 1879-1882, 1993.

Toomey, D. R., G. M. Purdy, S. C. Solomon and W. S. D. Wilcock, The threedimensional seismic velocity structure of the East Pacific Rise near latitude $9^{\circ} 30^{\prime} \mathrm{N}$, Nature, 347, 639-645, 1990.

Toomey, D. R., S. C. Solomon, and G. M. Purdy, Tomographic imaging of the shallow crustal structure of the East Pacific Rise at $9^{\circ} 30^{\prime}$ N, J. Geophys. Res., 99, 24,13524,157, 1994.

Usselman, T. M., and D. S. Hodge, Thermal control of low-pressure fractionation processes, J. Volcanol. Geotherm. Res., 4, 265-281, 1978.

Valet, J.-P., and L. Meynadier, Geomagnetic field intensity and reversals during the past four million years, Nature, 366, 234-238, 1993.

Vera, E. E., J. C. Mutter, P. Buhl, J. A. Orcutt, A. J. Harding, M. E. Kappus, R. S. Detrick, and T. M. Brocher, The structure of 0- to 0.2 -m.y.-old oceanic crust at $9^{\circ} \mathrm{N}$ on the East Pacific Rise from expanded spread profiles, J. Geophys. Res., 95, 15,52915,556, 1990. 
Vogt, P. R., and J. de Boer, Morphology, magnetic anomalies and basalt magnetization at the ends of the Galapagos high-amplitude zone, Earth Planet. Sci. Lett., 33, 145-164, 1976.

Vogt, P. R., and G. L. Johnson, Magnetic telechemistry of oceanic crust, Nature, 245, 373$375,1973$.

Wilcock, W. S. D., S. C. Solomon, G. M. Purdy, and D. R. Toomey, The seismic attenuation structure of a fast-spreading mid-ocean ridge, Science, 258, 1470-1474, 1992a.

Wilcock, W. S. D., G. M. Purdy, S. C. Solomon, D. L. Dubois, and D. R. Toomey, Microearthquakes on and near the East Pacific Rise, $9^{\circ}-10^{\circ} \mathrm{N}$, Geophys. Res. Lett., 19 , 2131-2134, 1992b.

Wilcock, W. S. D., D. R. Toomey, G. M. Purdy, and S. C. Solomon, The renavigation of Sea Beam bathymetric data between $9^{\circ} \mathrm{N}$ and $10^{\circ} \mathrm{N}$ on the East Pacific Rise, Mar. Geophys. Res., 15, 1-12, 1993.

Wilson, D. S., D. A. Clague, N. H. Sleep, and J. L. Morton, Implications of magma convection for the size and temperature of magma chambers at fast spreading ridges, $J$. Geophys. Res., 93, 11,974-11,984, 1988.

Wooldridge, A. L., C. G. A. Harrison, M. A. Tivey, P. A. Rona, and H. Schouten, Magnetic modeling near selected areas of hydrothermal activity on the Mid-Atlantic and Gorda Ridges, J. Geophys. Res., 97, 10,911-10,926, 1992. 
Table 4.1. Land-based geomagnetic observatories used to deduce the low-frequency variation of the total magnetic field at the EPR near $9^{\circ} 30^{\prime} \mathrm{N}$.

\begin{tabular}{lccc}
\hline & $\begin{array}{c}\text { Honolulu } \\
(\text { HON })\end{array}$ & $\begin{array}{c}\text { Fresno } \\
(\text { FRN })\end{array}$ & $\begin{array}{c}\text { Del Rio } \\
\text { (DLR) }\end{array}$ \\
\hline & & & \\
Geographic & & 36.8 & 29.4 \\
Latitude $\left({ }^{\circ} \mathrm{N}\right)$ & 21.3 & 240.3 & 258.8 \\
Longitude $\left({ }^{\circ} \mathrm{E}\right)$ & 202.0 & & \\
& & & \\
Geomagnetic & & 43.5 & 38.6 \\
Latitude $\left({ }^{\circ} \mathrm{N}\right)$ & 21.5 & 304.0 & 325.8 \\
Longitude $\left({ }^{\circ} \mathrm{E}\right)$ & 268.7 & & \\
& & & \\
Field Direction & & 61.4 & 8.3 \\
Inclination $\left({ }^{\circ}\right)$ & 38.8 & 15.2 & \\
Declination $\left({ }^{\circ}\right)$ & 11.1 & & \\
\hline
\end{tabular}


Table 4.2. Average thickness of seismically-defined layer 2A along CDP lines, based on data from Harding et al. [1993].

\begin{tabular}{|c|c|c|c|}
\hline CDP line & Pacific plate (m) & Cocos plate $(\mathrm{m})$ & Both (m) \\
\hline 29 & 440 & 450 & 440 \\
\hline 31 & 490 & 400 & 450 \\
\hline 33 & 580 & 450 & 510 \\
\hline
\end{tabular}


Figure 4.1. Sketch map of the East Pacific Rise showing the survey area near $9^{\circ} 30^{\prime} \mathrm{N}$ where the magnetic survey was conducted as part of a seismic tomography experiment in 1988. 


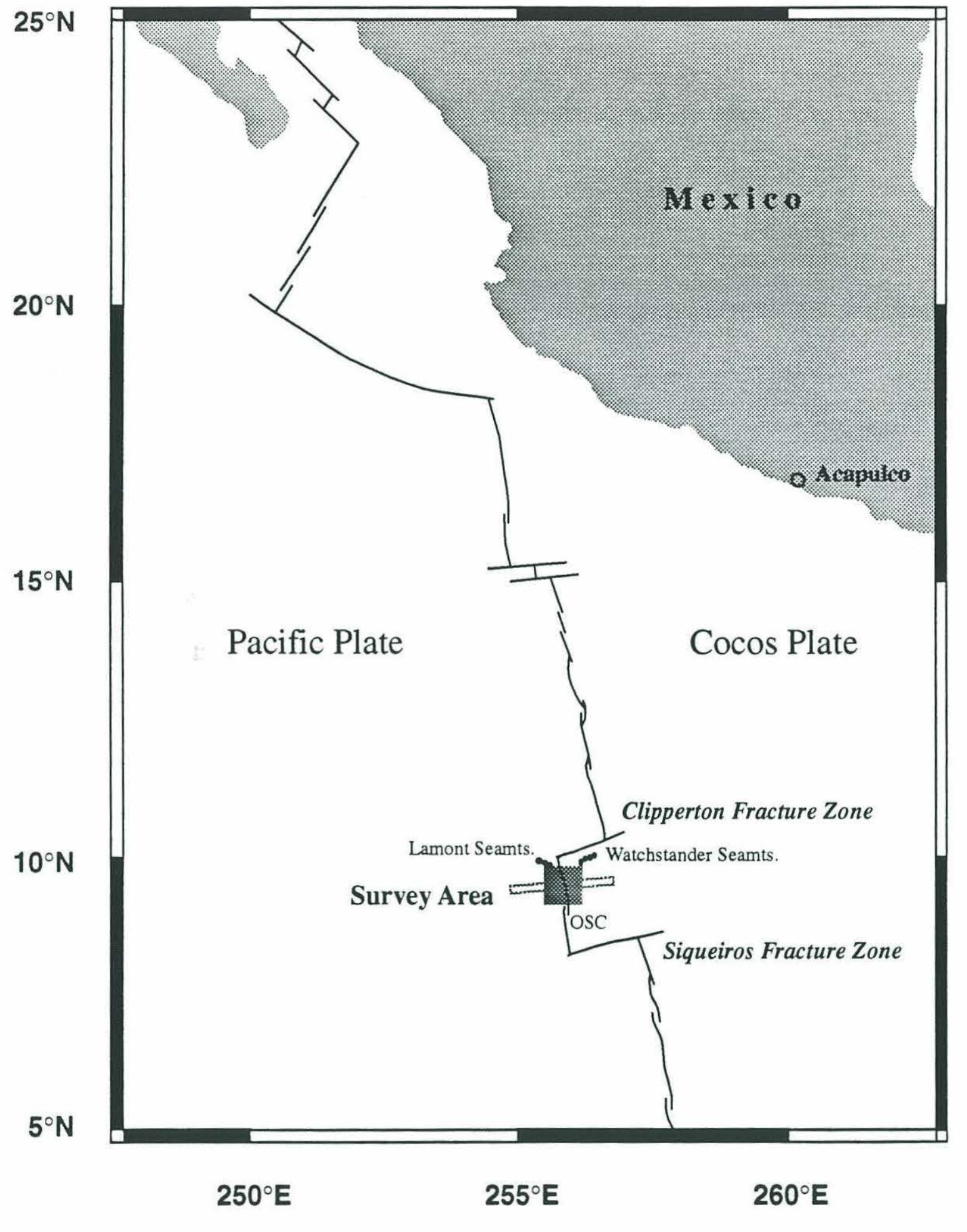


Figure 4.2. Bathymetic map of the survey area. The map was constructed with backprojection gridding [Stewart, 1988] and new navigation information provided by Wilcock et al. [1993]. The yellow circles in the middle of the survey area represent the locations of seismic instruments (OBSs and OBHs) deployed for the seismic tomography experiment and are shown here for reference. 

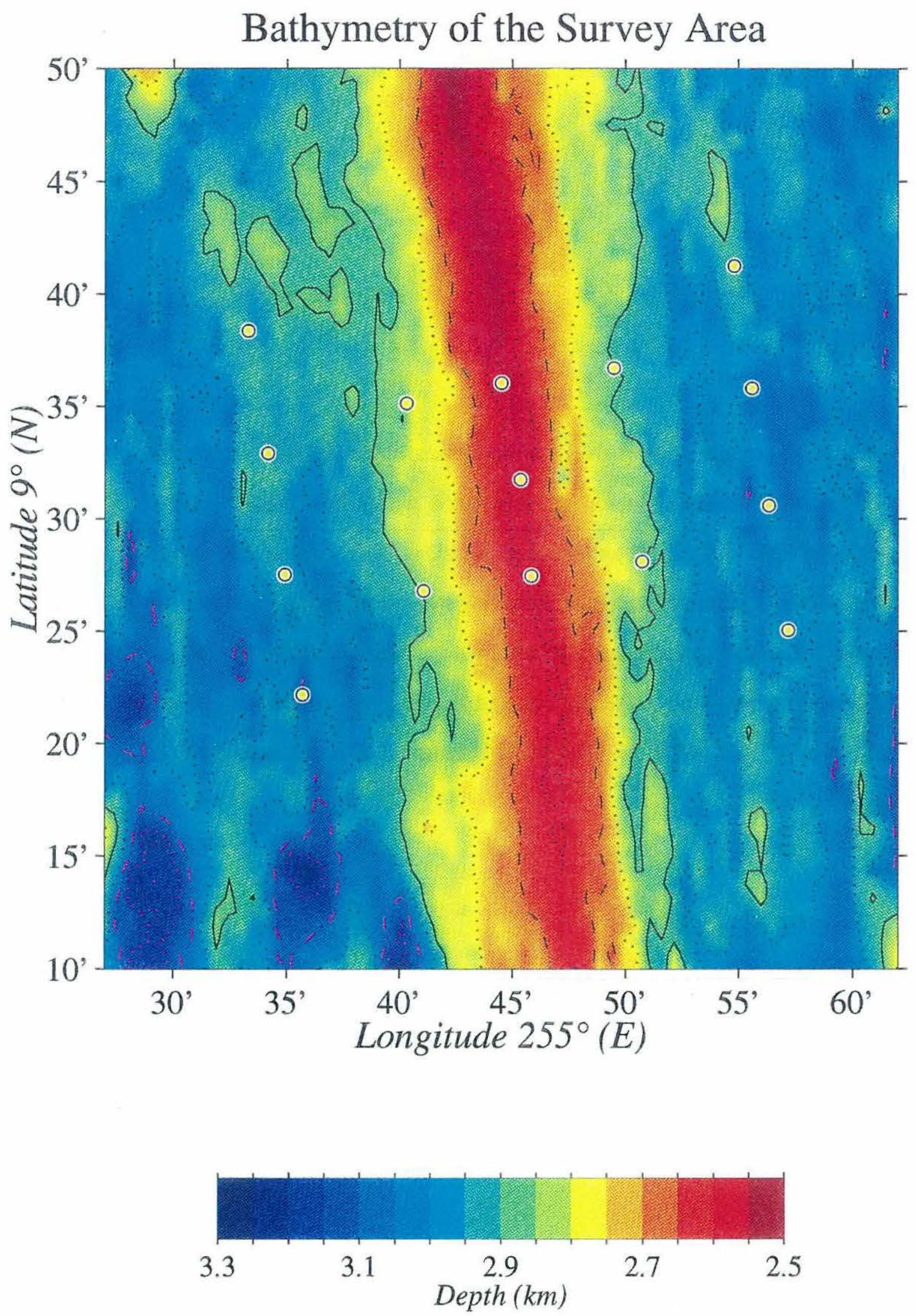
Figure 4.3. Coverage of ship tracks along which magnetic field measurements were taken. Most of the field measurements were taken within the Brunhes central anomaly. The two dotted lines indicate the approximate locations of the Brunhes/Matuyama reversal boundaries, estimated according to half spreading rates of $59 \mathrm{~mm} / \mathrm{yr}$ and $54 \mathrm{~mm} / \mathrm{yr}$ on the Pacific and Cocos plates, respectively [Carbotte and Macdonald, 1992]. The numbers 056 and 058 denote the two long tracks that traveled across the reversal boundary on the Pacific plate side, and 066 and 068 those that traveled across the reversal boundary on the Cocos plate side. 
Plot of Ship Tracks

๙

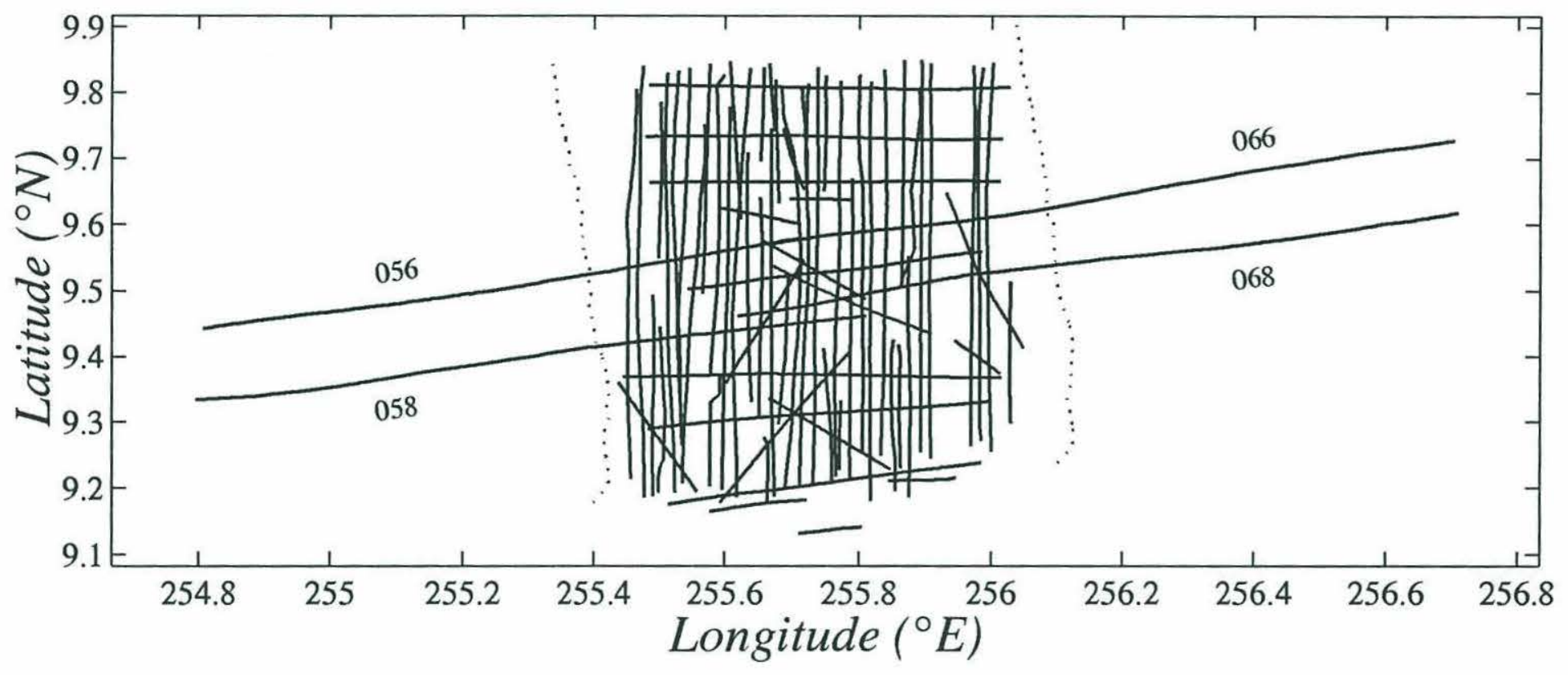

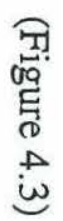


Figure 4.4. Histograms of misfit errors following each correction step: (a) renavigation, (b) diurnal fluctuation of the magnetic field, (c) low-frequency variation, and (d) ship-induced field. 

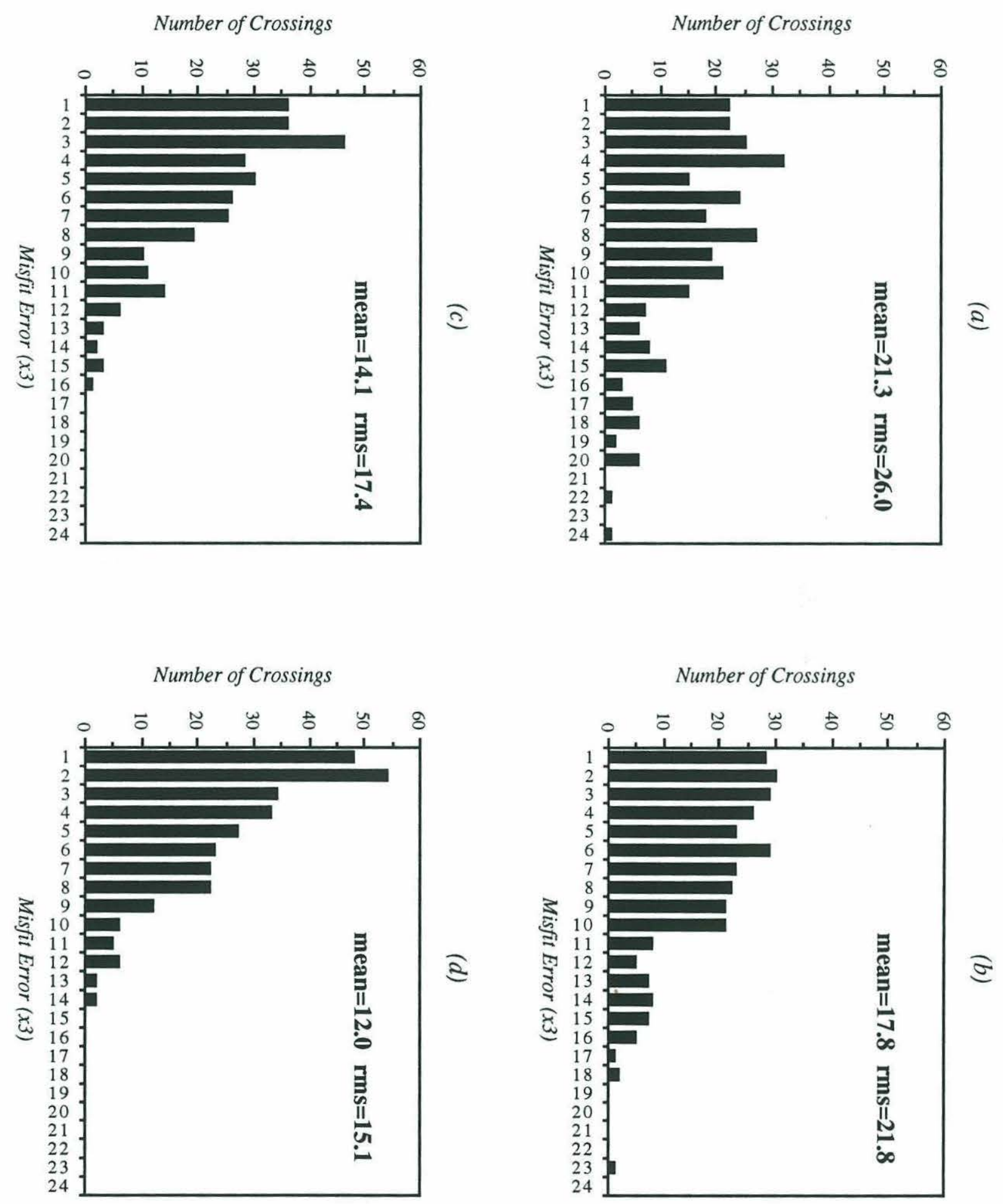
Figure 4.5. Diurnal variations in the scalar magnetic field predicted by the WDCA/SQ1 global model for a solar-quiet day [Campbell et al., 1989] on January 25, 1988 at 9³0' $\mathrm{N}$, $255^{\circ} 45^{\prime} \mathrm{E}$. Note the high activity which occurs around local noon. 


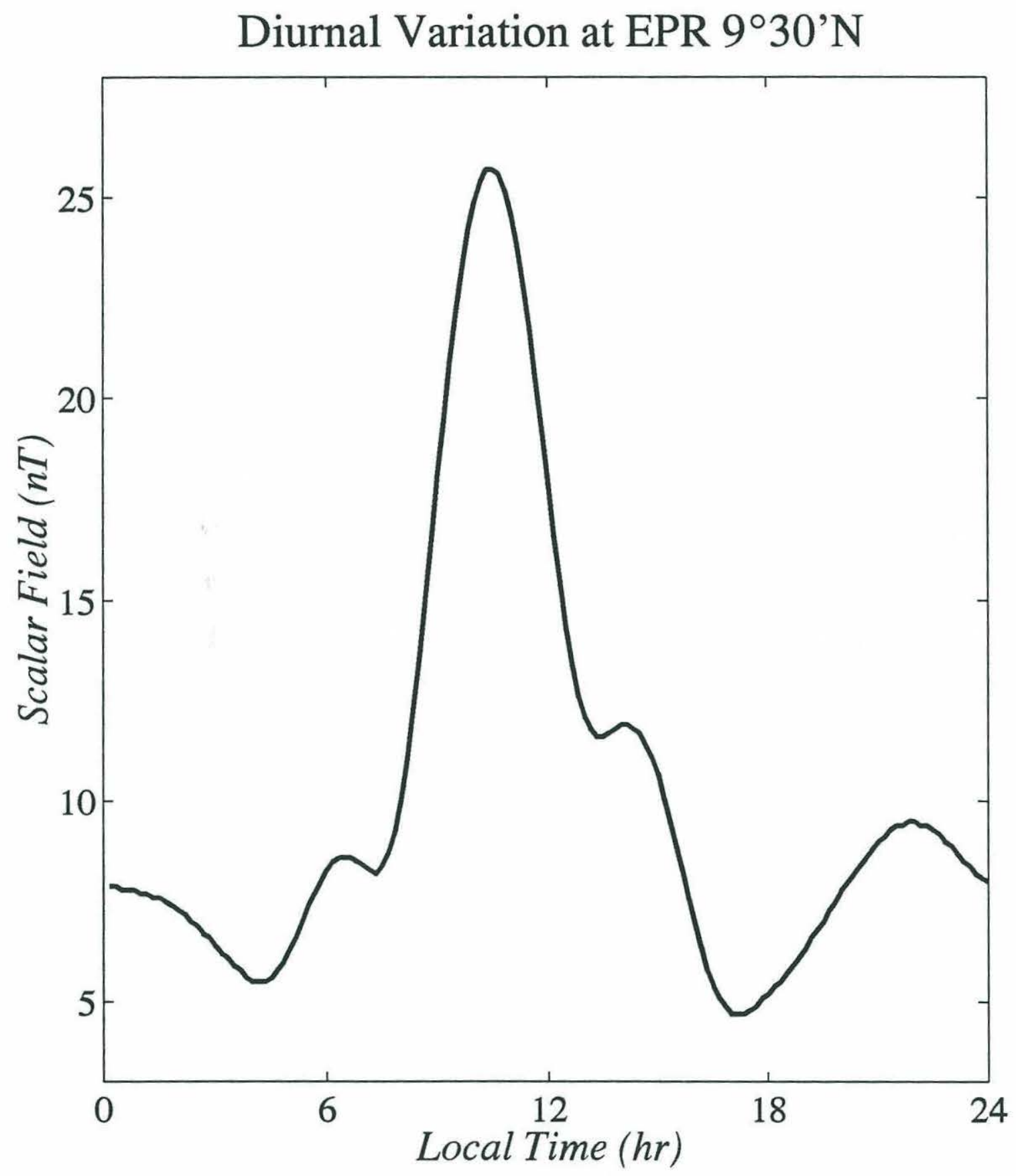


Figure 4.6. Low-frequency variations in the total magnetic field at land-based geomagnetic observatories in Hawaii, California, and Texas (Table 4.1). Most of the variations at the beginning of the survey appear related to a magnetic storm which occurred on January 15 , followed by a recovery period which lasted for several days. Another magnetic storm occurred on February 5, near the end of the survey. 


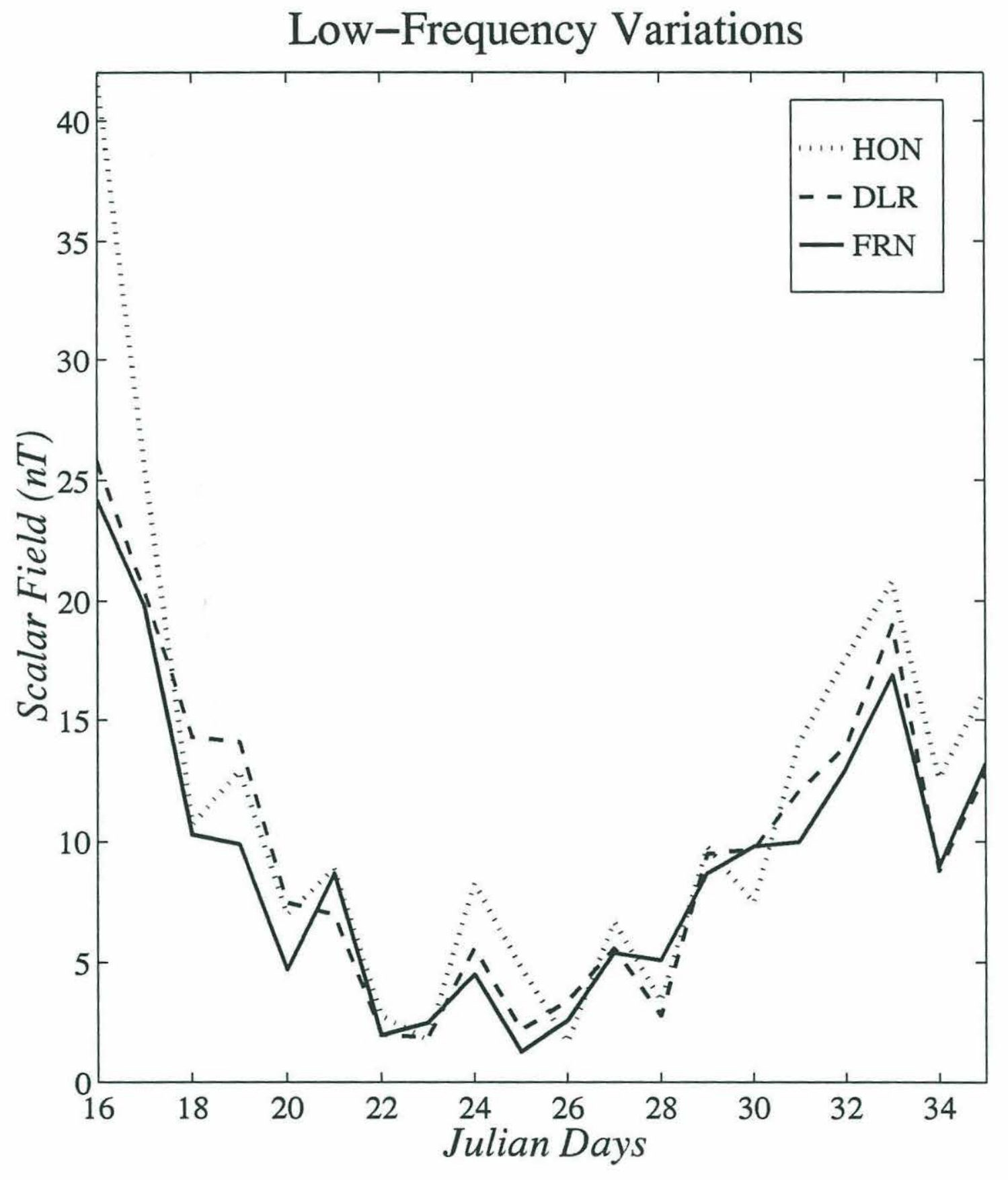


Figure 4.7. Gridded magnetic field anomaly map after corrections. The grid spacing is to 1.16 and $1.0 \mathrm{~km}$ in latitude and longitude, respectively. Although much of the background noise along tracks has been reduced by our correction effort, some artifacts appear to remain. However, in our inversion, we apply a bandpass filter with lower stopband and lower passband cutoff wavenumbers set at $2 \pi / 4$ and $2 \pi / 8 \mathrm{~km}^{-1}$, respectively. Therefore, the magnetic field actually inverted is much smoother than the field shown in this map. 

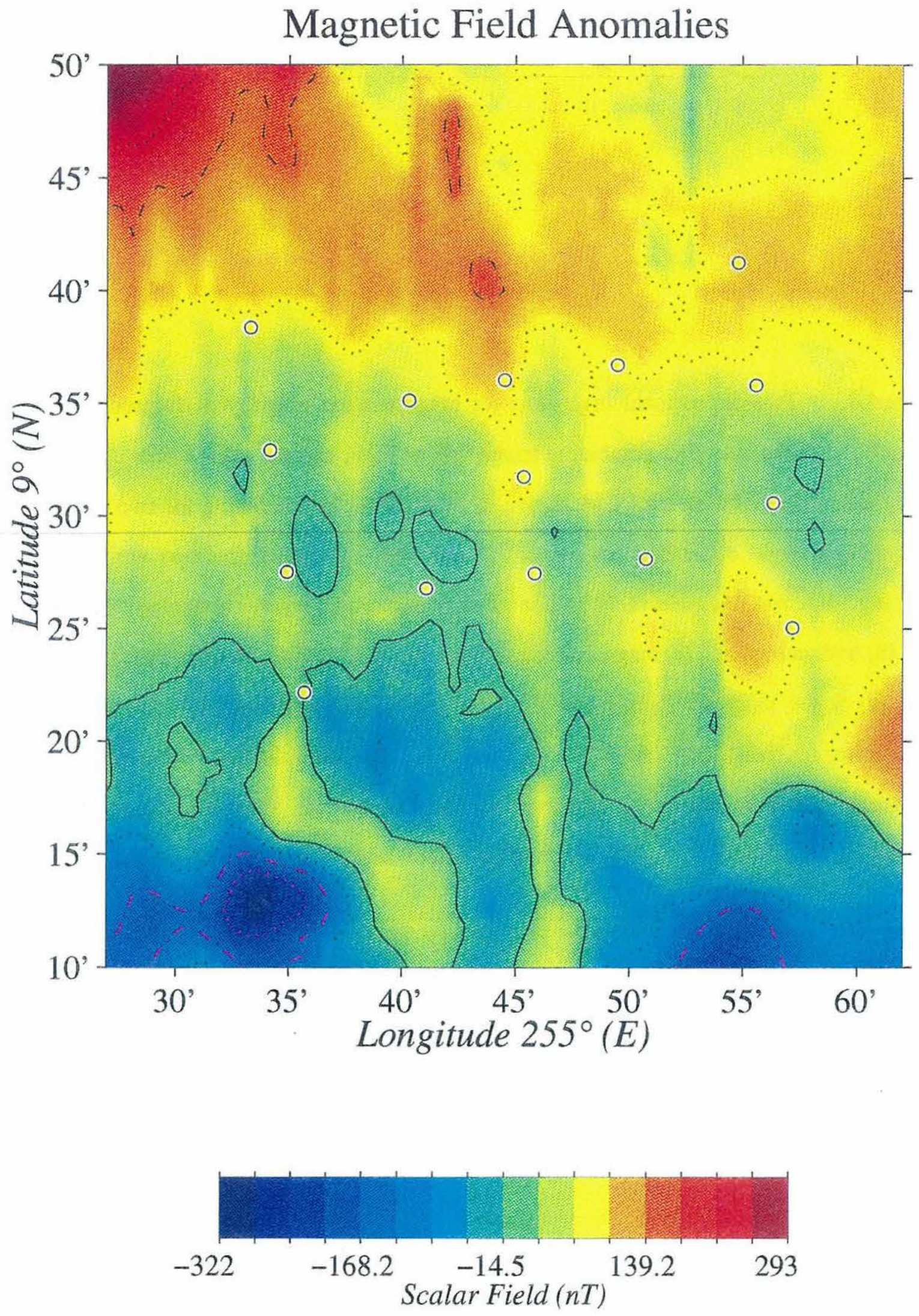
Figure 4.8. Two-dimensional inversions for magnetization intensity performed along the two long tracks, one after combining tracks 056 and 066 and the other tracks 058 and 068. The locations of these tracks are shown in Figure 4.3. In combining the two tracks, we ignored a slight offset between tracks 058 and 068 . The inversion was performed assuming a uniform thickness of $500 \mathrm{~m}$ for the magnetic source layer. (a) Scalar magnetic field, (b) bathymetry, and (c) magnetization solution for the combination of tracks 056 and 066. (d) Scalar magnetic field, (e) bathymetry, and (f) magnetization solution for the combination of tracks 058 and 068 . In both magnetization solutions, we scaled the annihilator relative to the initial solutions so that the average absolute magnetization intensity would be the same on either side of the Brunhes/Matuyama reversal boundary. 


\section{2-D Inversion for Magnetization along 056 \& 066}

(a) Magnetic Field

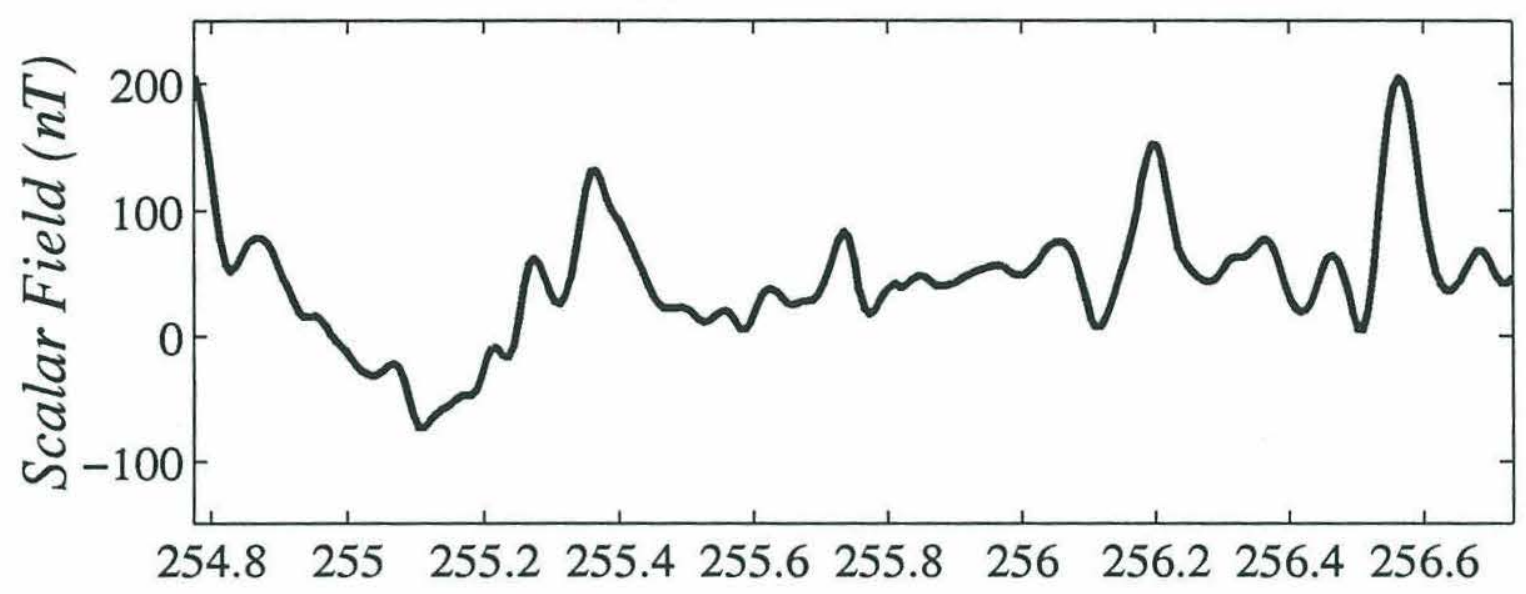

(b) Bathymetry

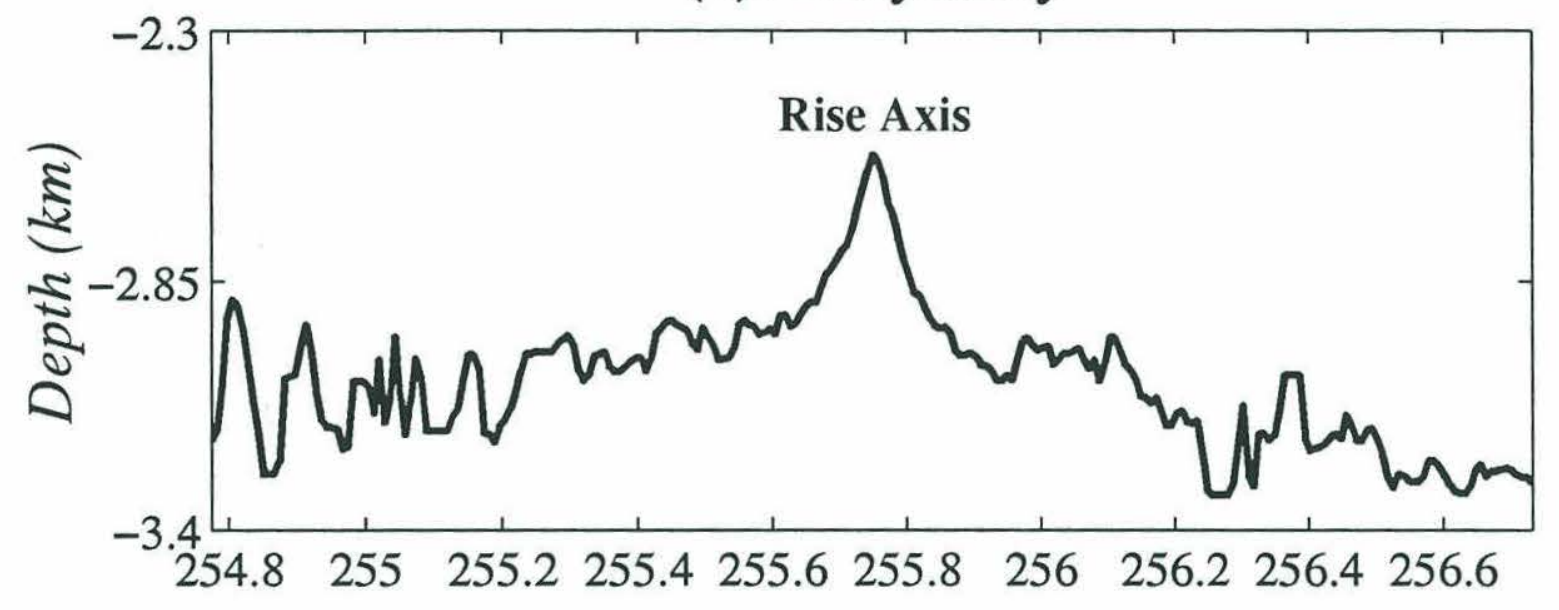

(c) Magnetization

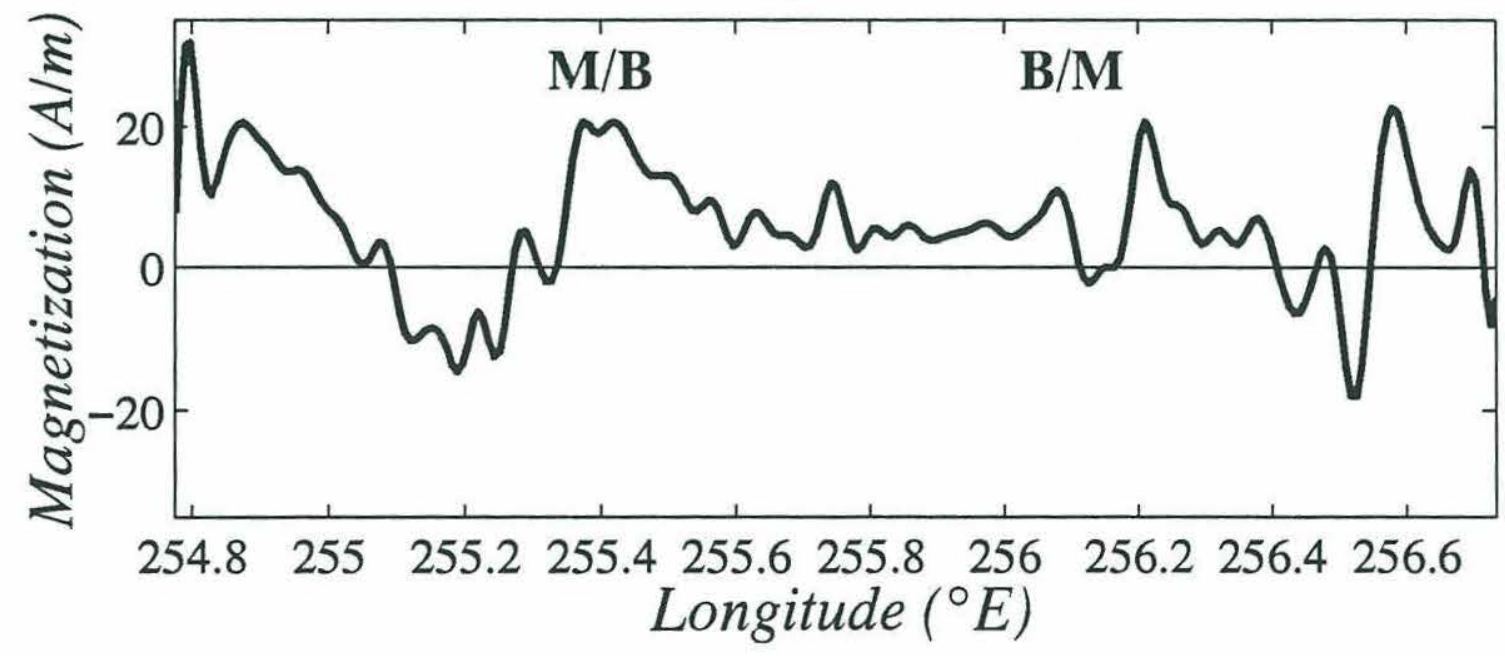


2-D Inversion for Magnetization along $058 \& 068$

(d) Magnetic Field

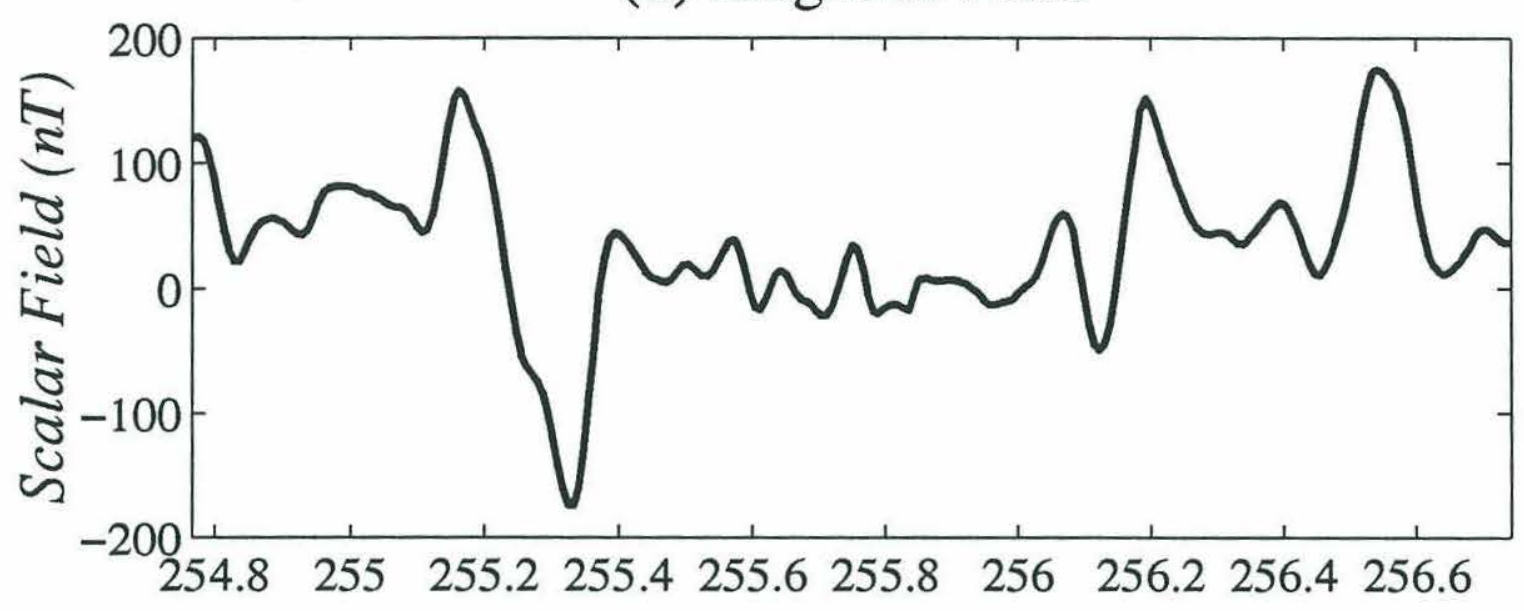

(e) Bathymetry

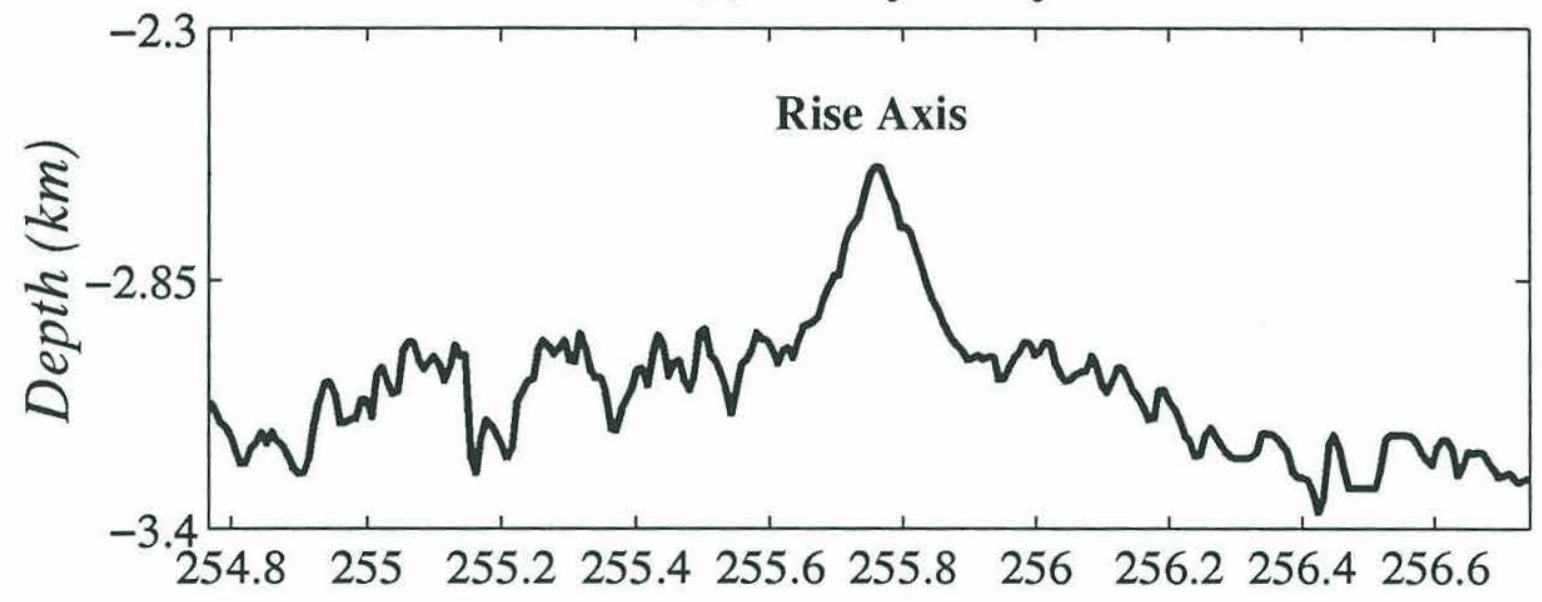

(f) Magnetization

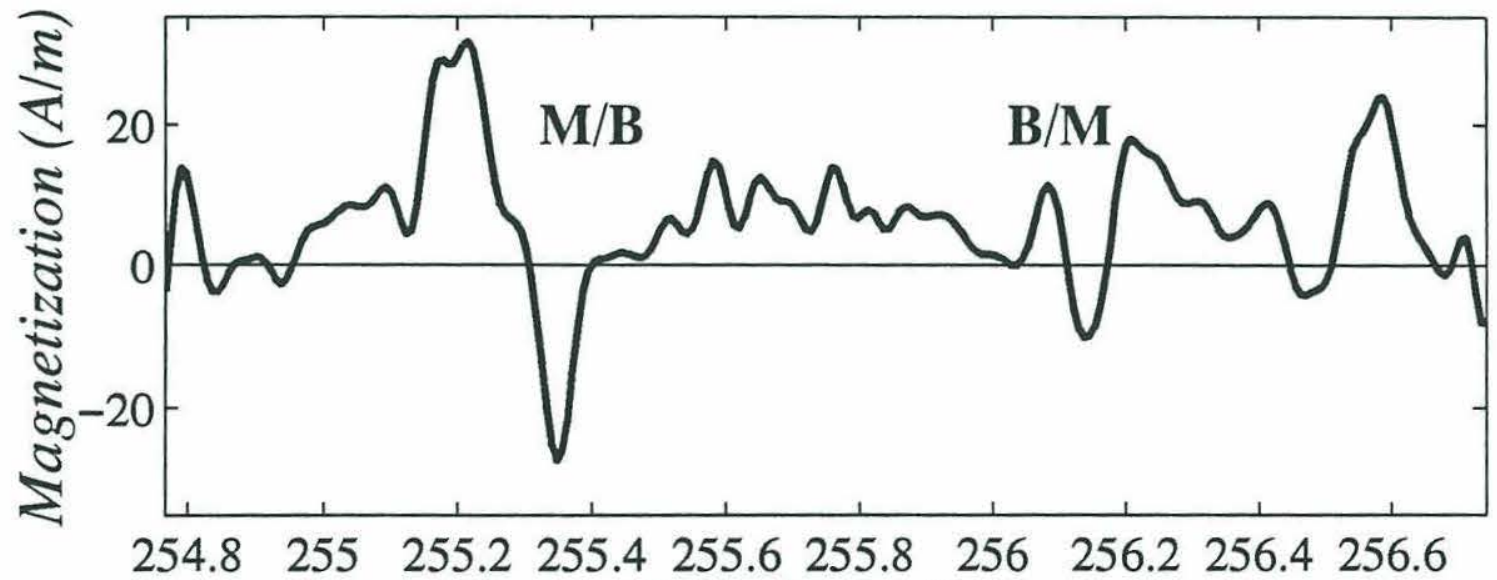

Longitude $\left({ }^{\circ} \mathrm{E}\right)$ 
Figure 4.9. Magnetization intensity map obtained by inversion of magnetic anomaly data assuming a uniform magnetic layer thickness of $500 \mathrm{~m}$ and adding an annihilator as determined by fitting the observed field across the Brunhes/Matuyama reversal boundary (see Figure $4.8 \mathrm{c}$ and $\mathrm{f}$ ). The white crosses represent the bathymetric rise axis. Circles represent instrument locations during the seismic tomography experiment [Toomey et al., 1990]. Plus symbols represent three magnetic devals (at $9^{\circ} 25^{\prime}, 9^{\circ} 37^{\prime}$, and $9^{\circ} 45^{\prime} \mathrm{N}$ ), i.e., major breaks in the axial magnetization anomaly defined by changes in magnitude and offsets in anomaly linearity. White dashed lines indicate the locations of three commondepth-point (CDP) seismic reflection lines conducted across the axis [Harding et al., 1993]. White dotted lines represent the two combined long tracks (i.e., tracks 056 and 066 , and tracks 058 and 068). 

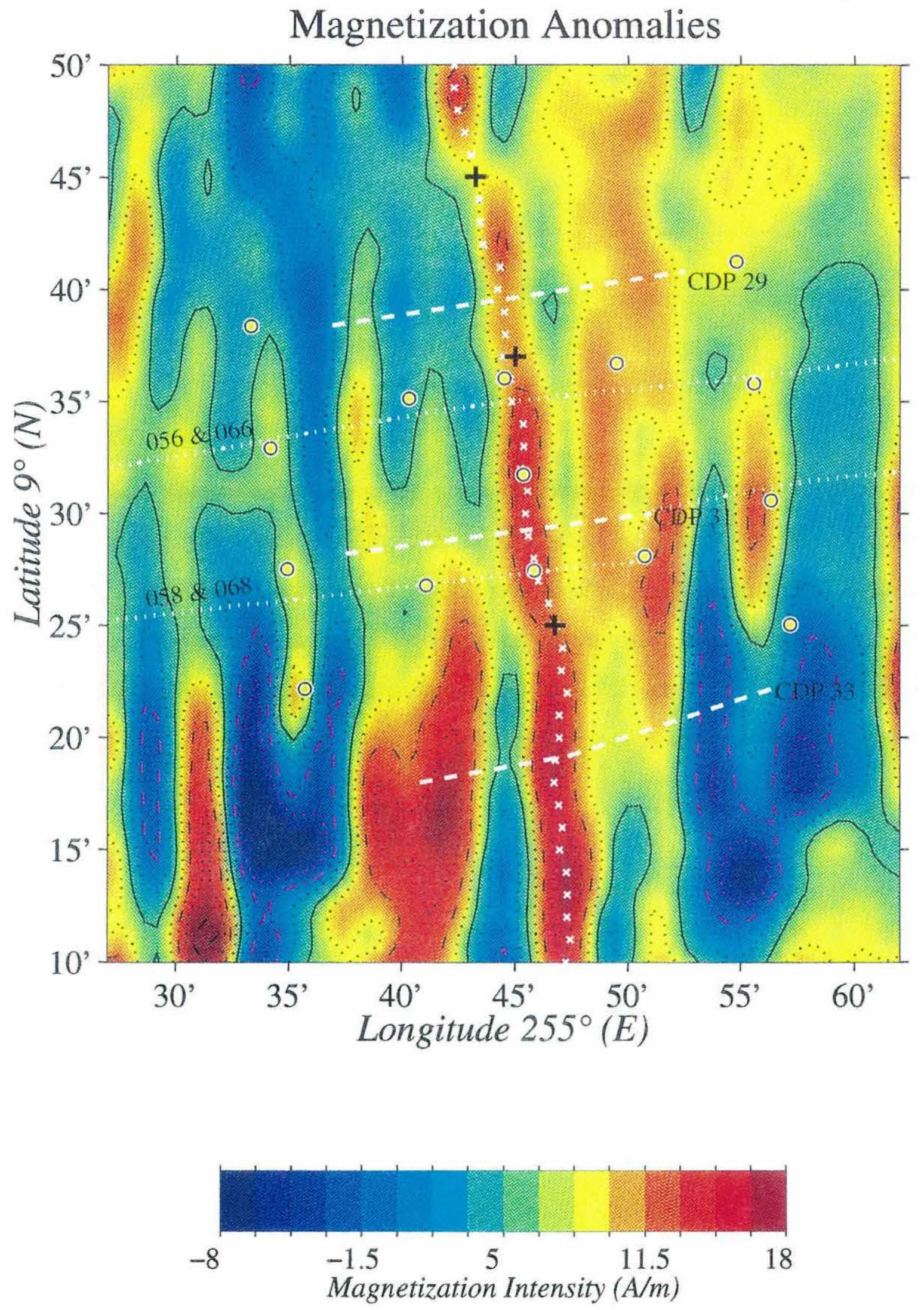
Figure 4.10. Profiles of magnetization anomaly along the magnetization axis from inversions of the full magnetic anomaly data for different fixed values of magnetic layer thickness. The profiles were obtained after adding the appropriate annihilator to the particular solution so as to satisfy the anomaly profiles that cross the Brunhes/Matuyama reversal boundary. The overall level and the total variance of the magnetization anomaly decrease with increasing magnetic layer thickness. 


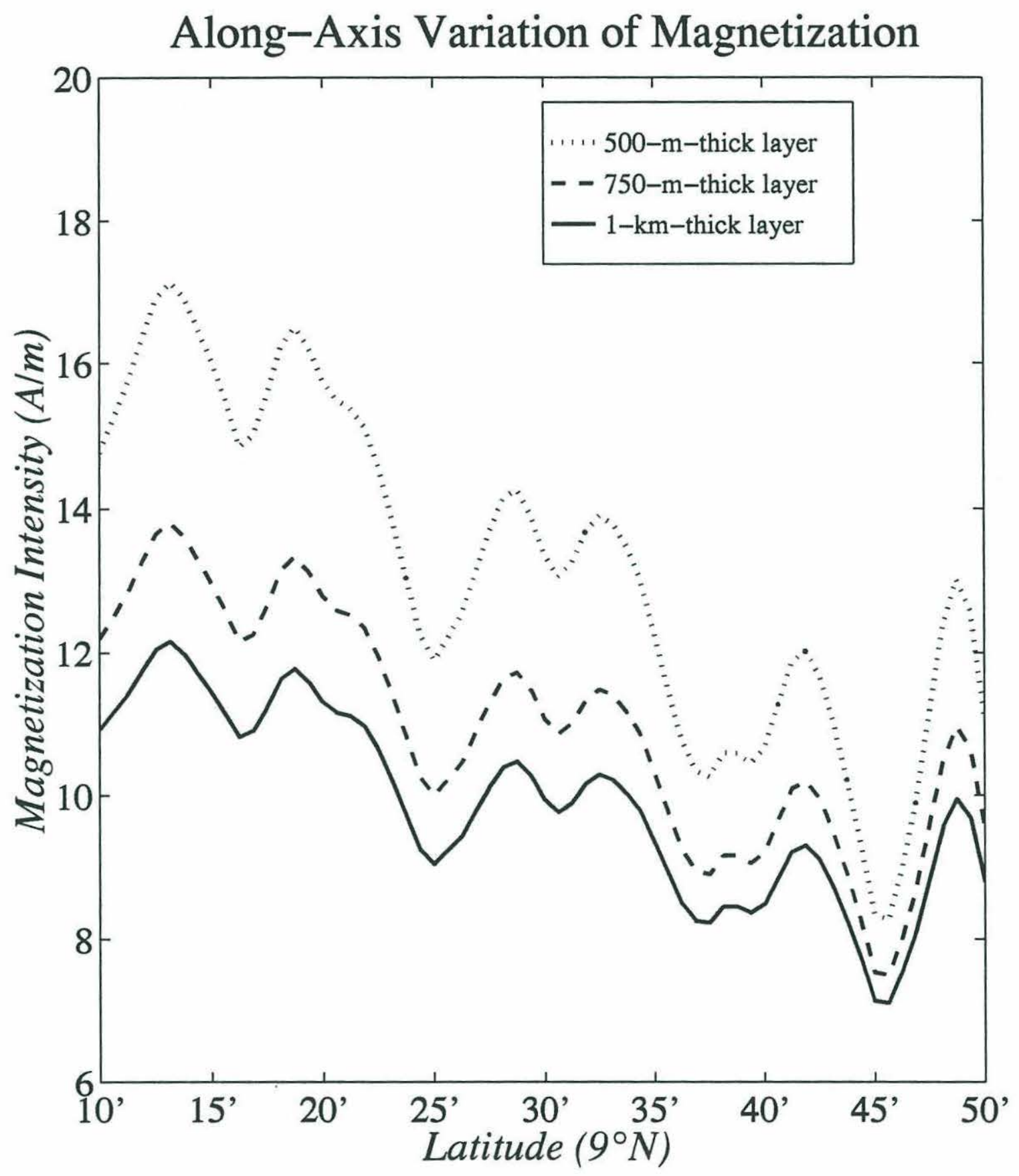


Figure 4.11. (a) Observed and modeled magnetic field anomaly along-axis for a uniformly magnetized upper crustal layer of variable thickness. (b) Magnetic layer thickness along-axis, assuming a $10 \mathrm{~A} / \mathrm{m}$ magnetization intensity. The lower boundary (dashed) was obtained by successive inversions starting from a uniform thickness of 500 $\mathrm{m}$. 


\section{2-D Inversion for Magnetic Layer Thickness}

(a) Magnetic Field at Sea Surface

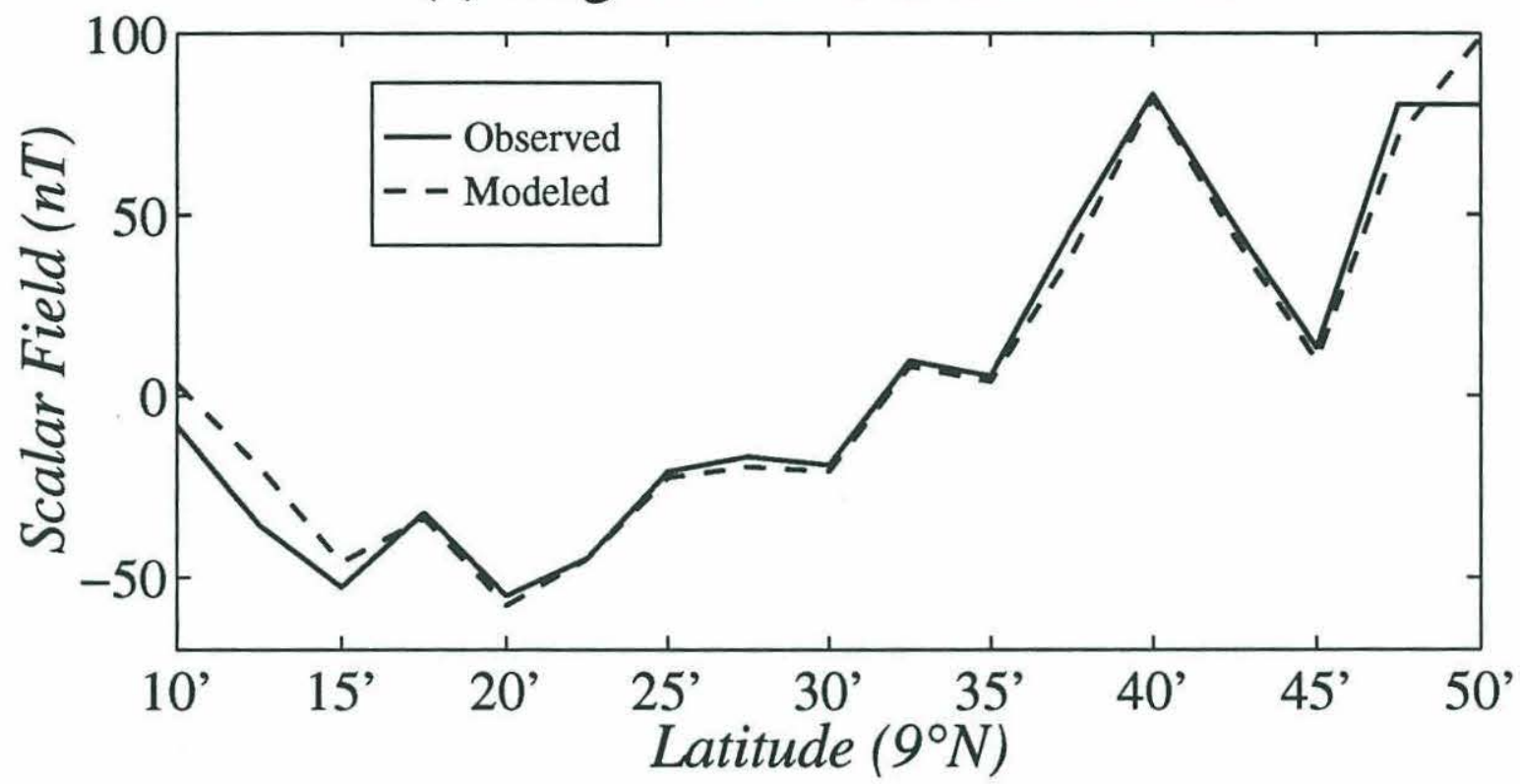

(b) Along-Axis Variation in Thickness

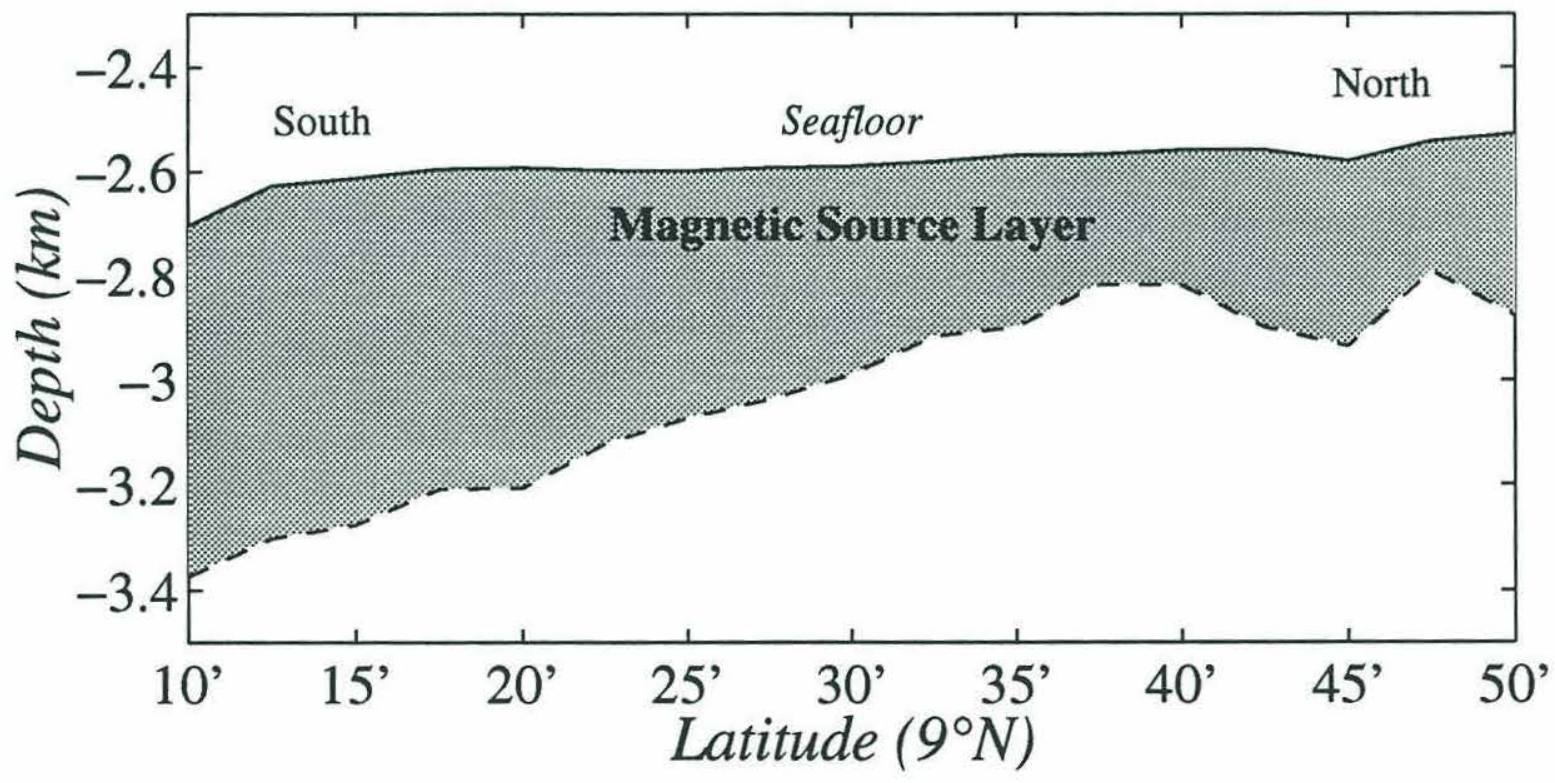


Figure 4.12. The difference in magnetic layer thickness, between $9^{\circ} 40^{\prime}$ and $9^{\circ} 15^{\prime} \mathrm{N}$, as a function of the assumed magnetization intensity. A uniform thickness of $500 \mathrm{~m}$ was the starting model for the inversion, but the final solutions are insensitive to the initial thickness. 


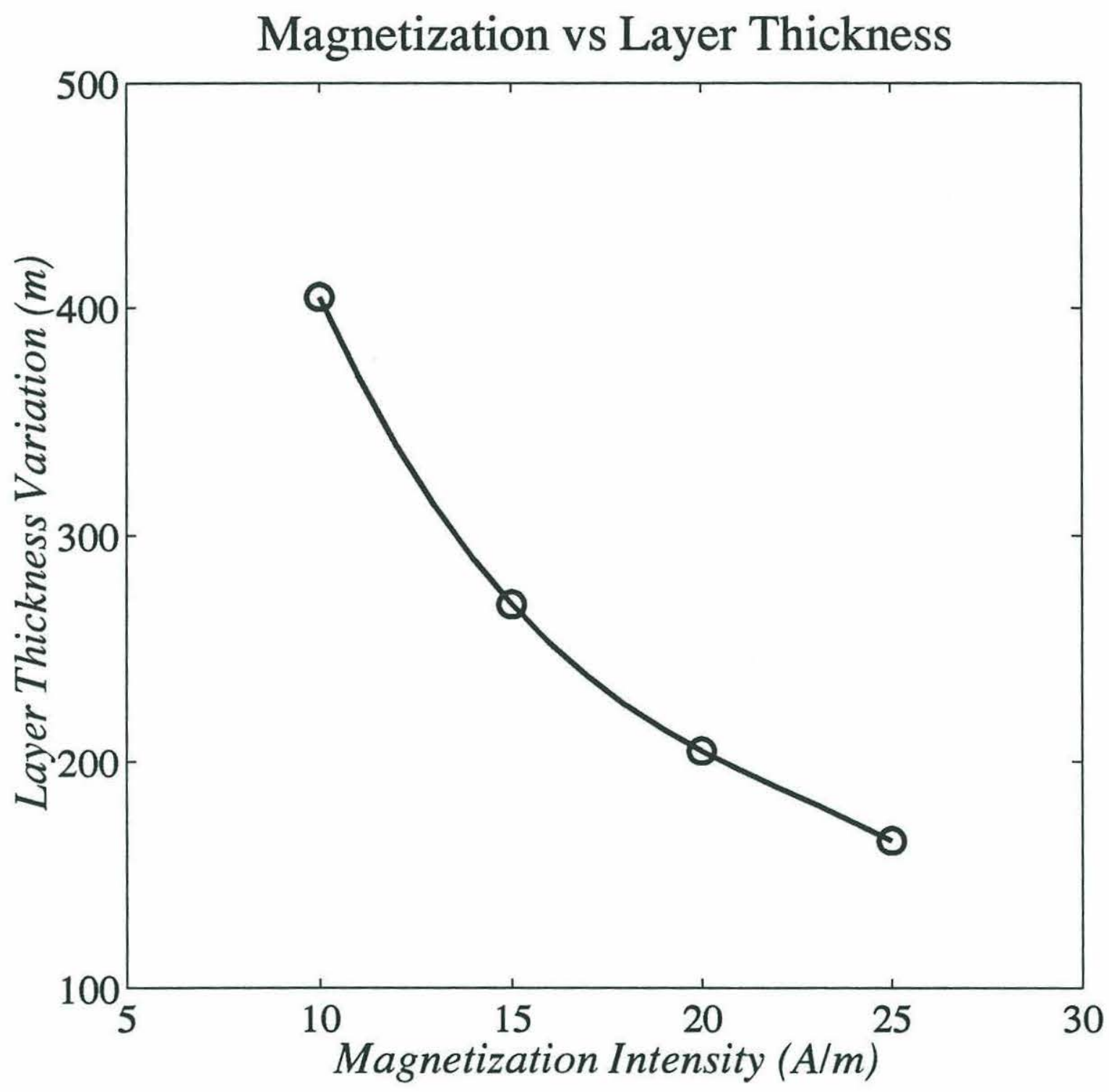


Figure 4.13. Comparisons between the magnetization anomaly (solid line) and the estimated layer 2A thickness [Harding et al, 1993] along three CDP lines, whose locations are shown in Figure 4.9. Notice that at the axis the thickness of layer $2 \mathrm{~A}$ is the smallest for CDP line 031. 
(a) CDP 29

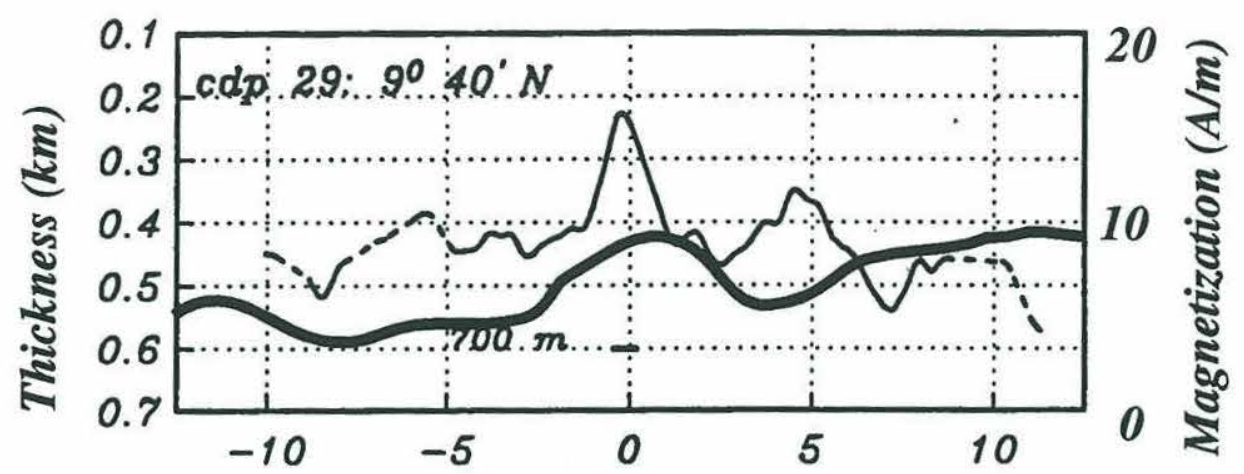

(b) CDP 31

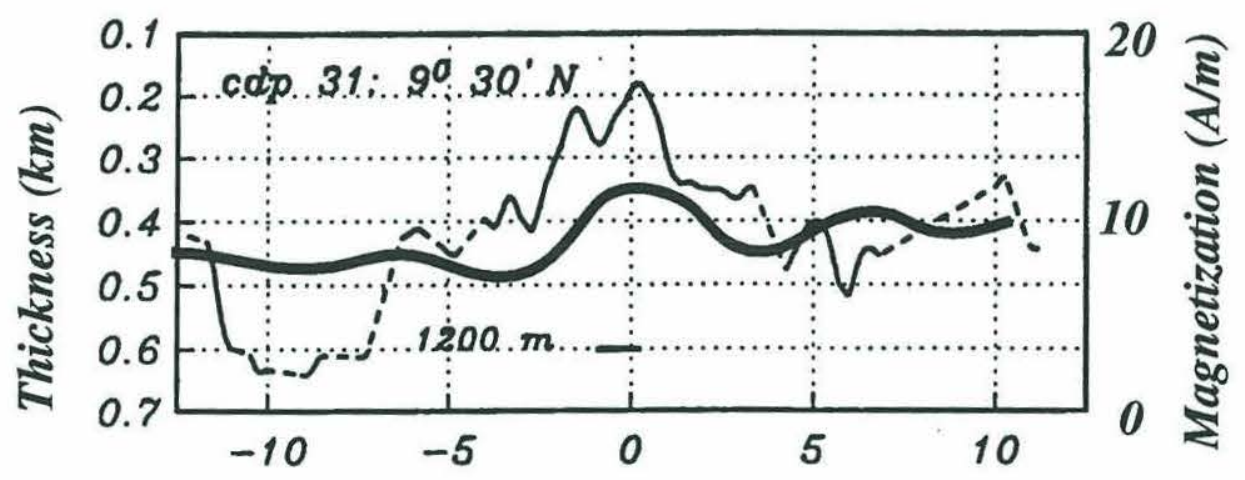

(c) CDP 33

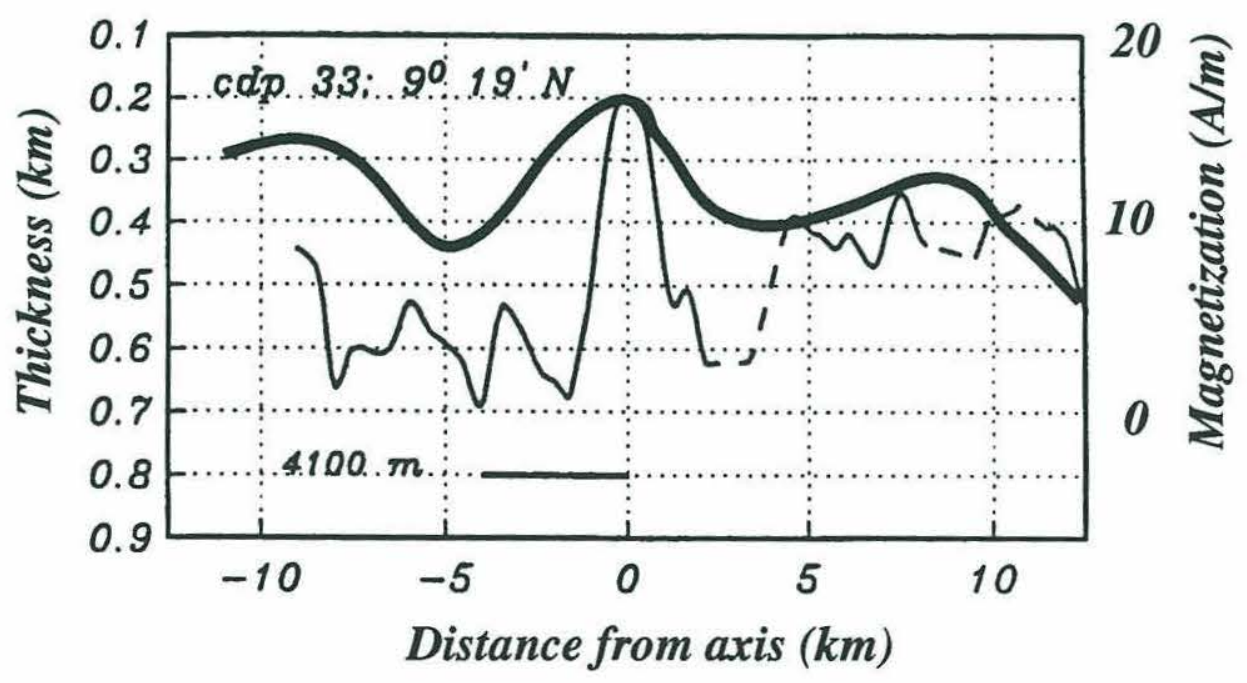


Figure 4.14. Empirical relationship between (a) $\mathrm{FeO}$ and (b) $\mathrm{TiO}_{2}$ contents and remanent magnetization intensity (modified from Vogt and de Boer [1976]). 
(a)

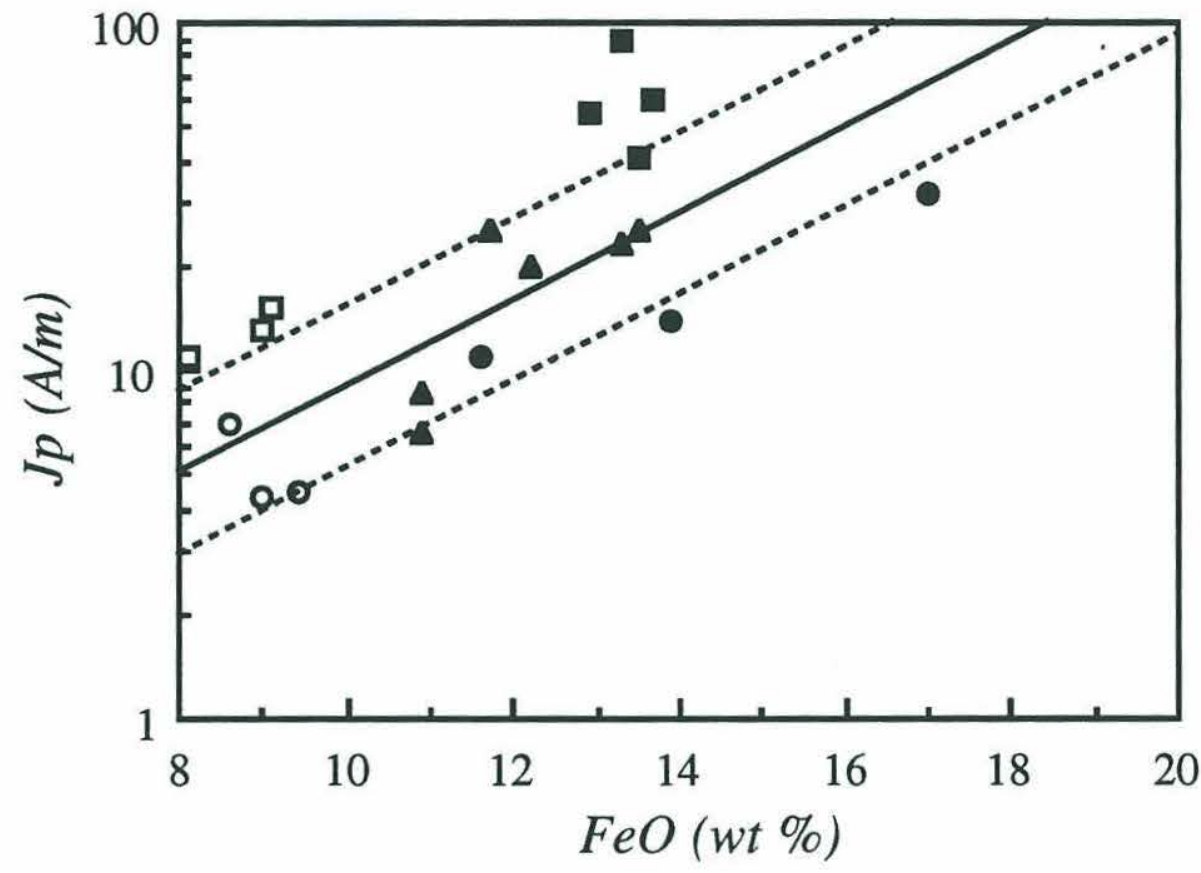

- Galapagos I

- Galapagos I (H-type)

D Galapagos II

- Galapagos II (H-type)

A Juan de Fuca \& Carlsberg R.

— data fit

-.- field fluctuation

- - - field fluctuation

(b)

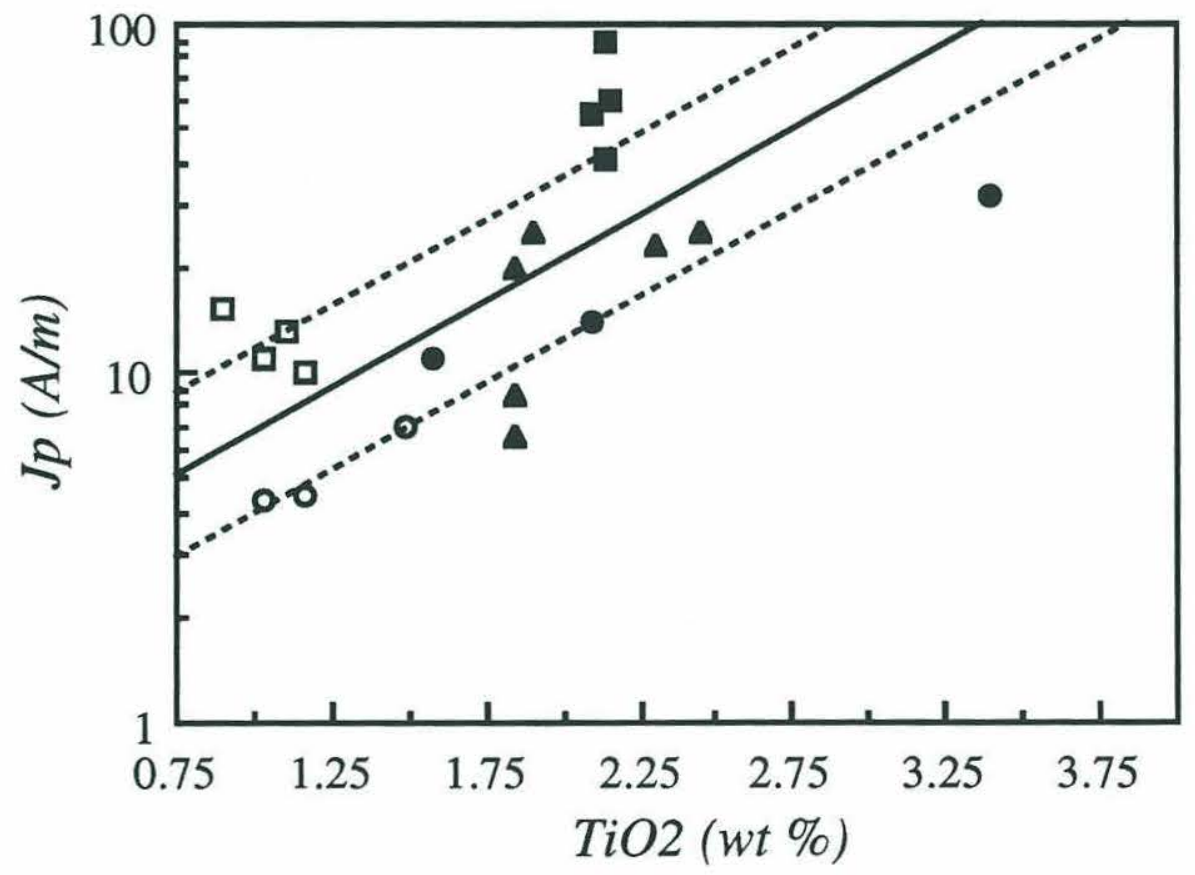

- Galapagos I

- Galapagos I (H-type)

D Galapagos II

- Galapagos II (H-type)

- Juan de Fuca \& Carlsberg R.

- data fit

- - field fluctuation

-.- field fluctuation 
Figure 4.15. (a) Along axis variation of the axial magnetization anomaly. The circles represent the loci of boundaries and breaks in the ASCs, and the plus symbols the magnetic devals $\left(9^{\circ} 25^{\prime}, 9^{\circ} 37^{\prime}\right.$, and $\left.9^{\circ} 45^{\prime} \mathrm{N}\right)$. Notice that the boundaries and the breaks in the ASCs in many cases coincide with the magnetic devals. (b) Distribution of the ASC. Notice that no ASC is found to the south of $9^{\circ} 21^{\prime} \mathrm{N}$. 


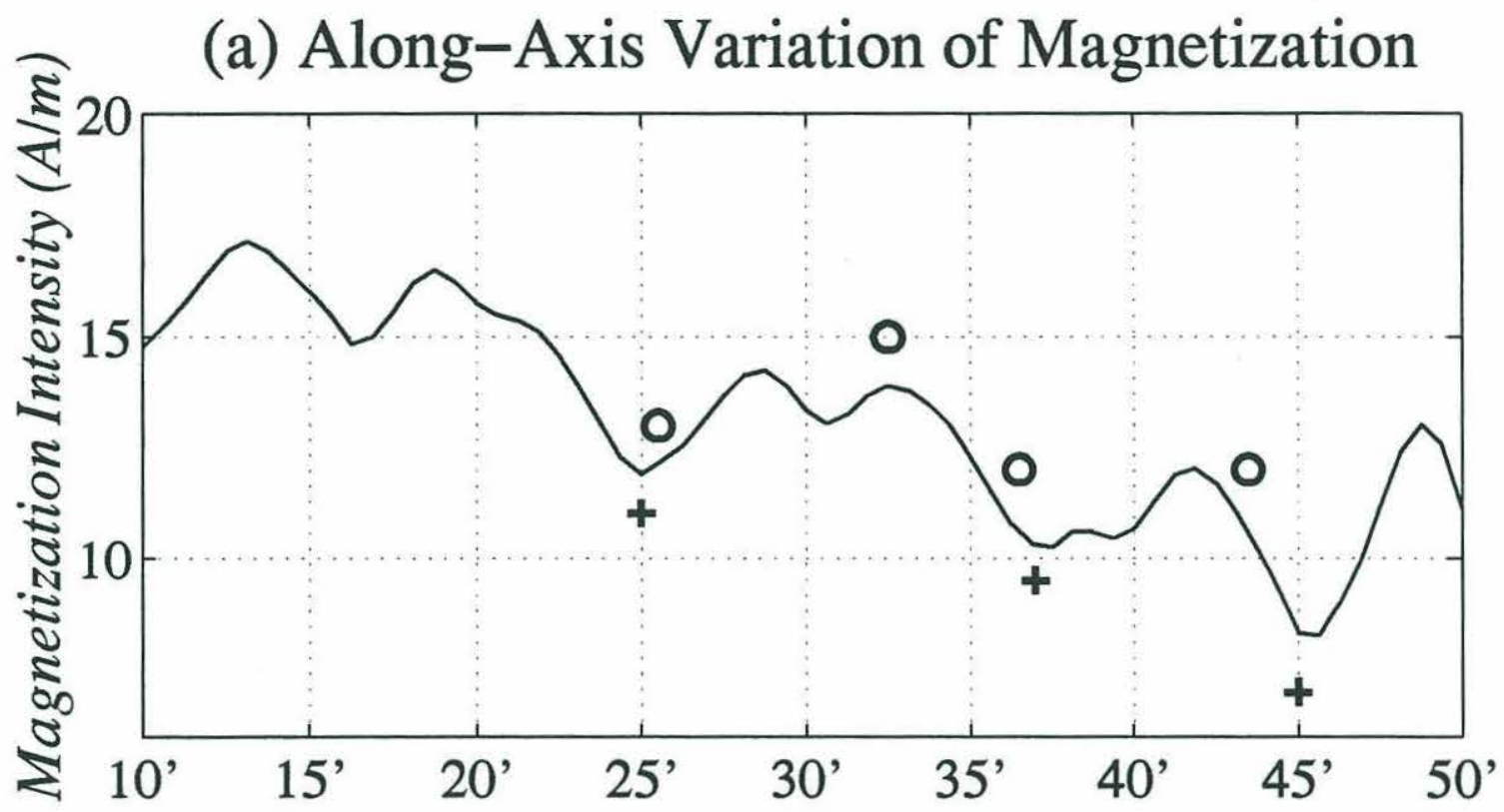

(b) Distribution of ASC

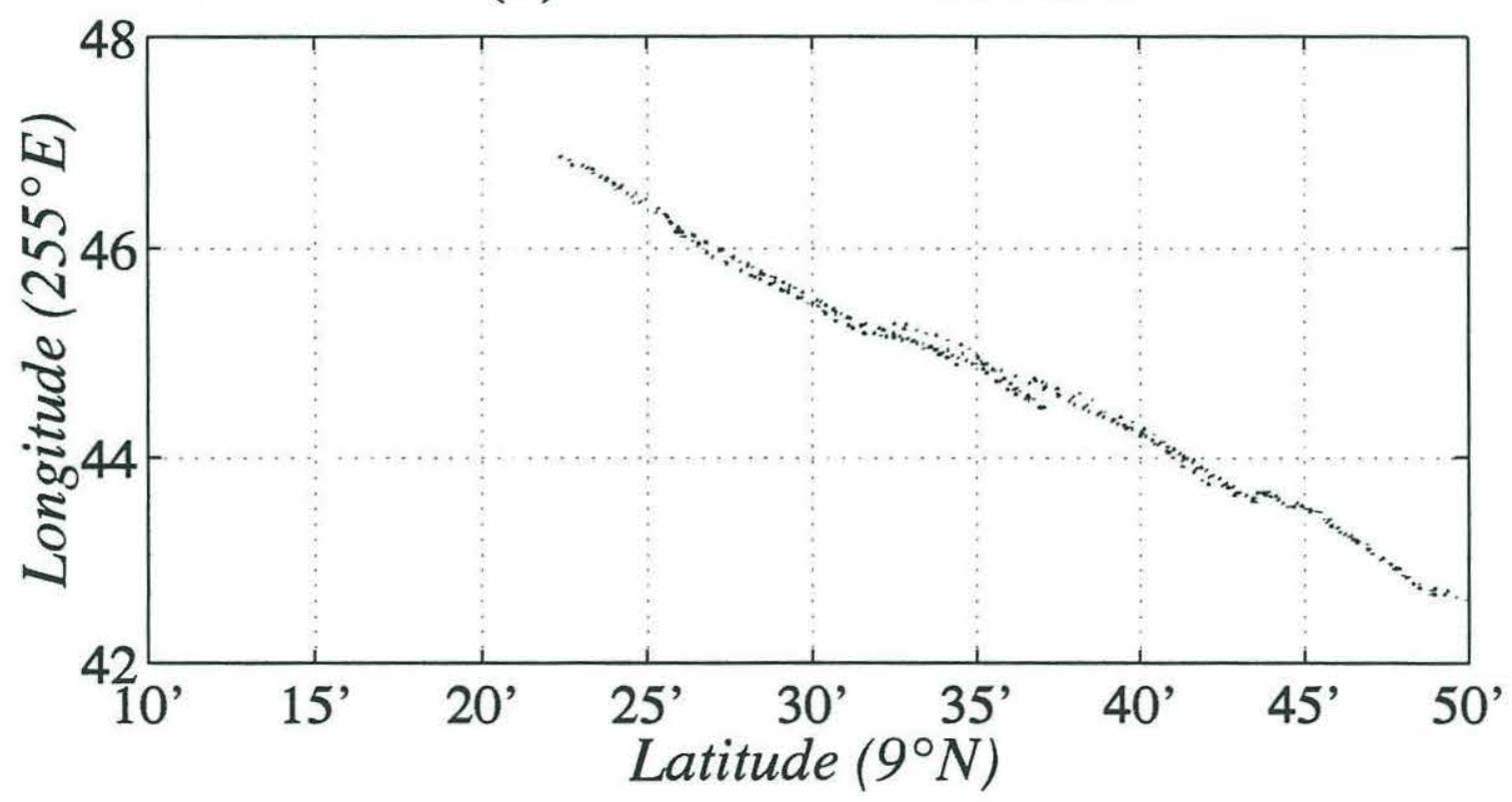


Figure 4.16. Comparisons of two-dimensional and three-dimensional inversions for magnetization anomaly along the two combined tracks; (a) 056 and 066, and (b) 058 and 068. The comparisons show that highs and lows of the two solutions match quite well, confirming that the short-wavelength variations in the magnetization anomaly in the 3-D inversion are not caused by errors between adjacent N-S ship tracks. We assumed 59 and $54 \mathrm{~mm} / \mathrm{yr}$ as the spreading half-rates on the Pacific and Cocos plates, respectively. The gray shaded scale at the bottom of each figure indicates short reversal events within the Brunhes central anomaly (e.g., 1 = Laschamp, 2 = Blake, 3 = Jamaica, $4=$ Levantin, $5=$ Biwa III, $6=$ Emperor, and 7 = Big Lost). The timing of these reversal events, originally from Champion et al. [1988], was recalibrated to match the new estimate of the time of the Brunhes/Matuyama reversal boundary (0.78 My) [Shackleton et al., 1990]. 
(a) Combined tracks $056 \& 066$

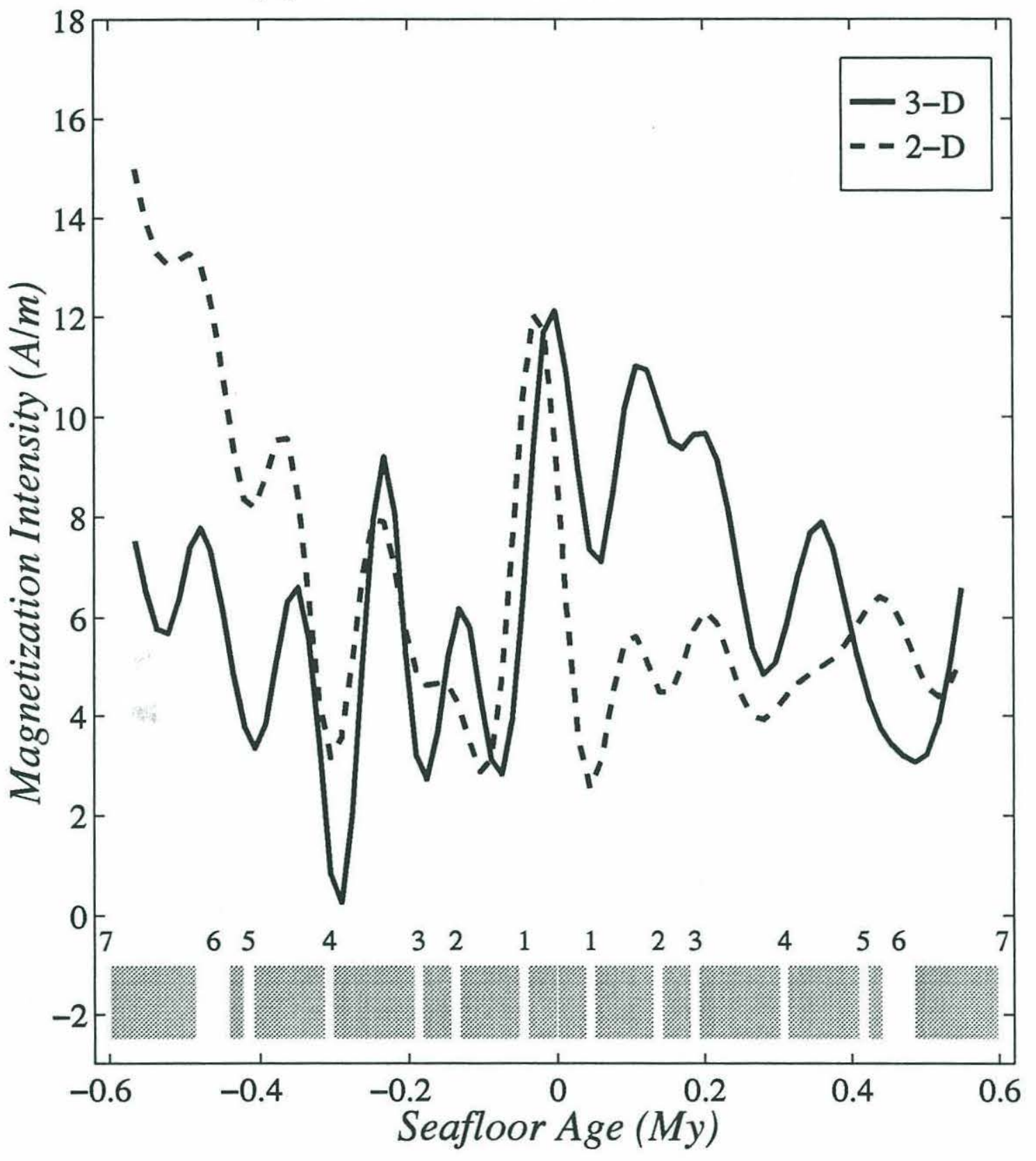


(b) Combined tracks $058 \& 068$

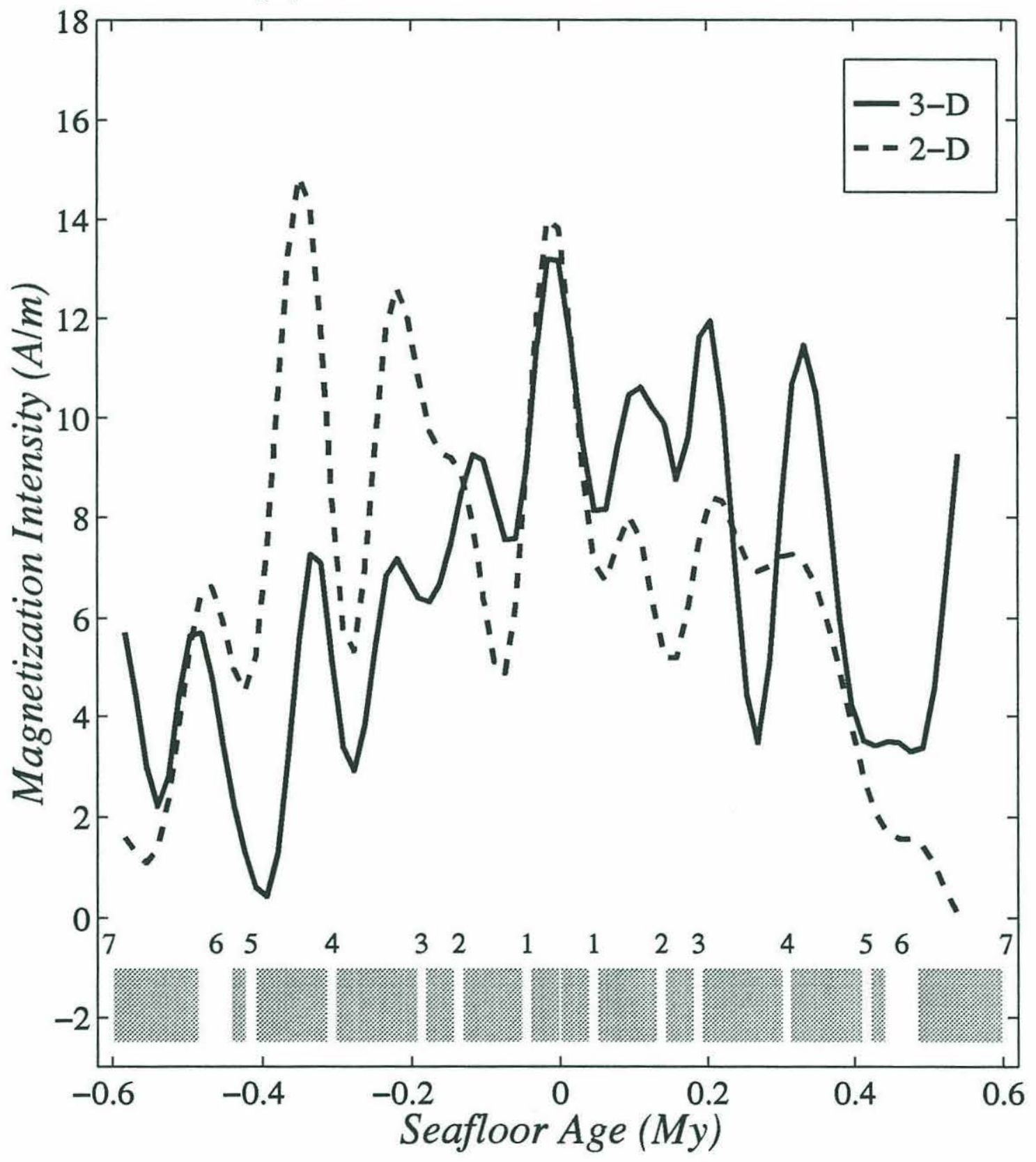


Figure 4.17. Predicted magnetization anomalies resulting from short-timescale reversals (thick solid lines) and paleointensity variations (dashed lines) compared with the anomalies obtained by three-dimensional inversions along the two long ship tracks (thin solid line): (a) tracks 056 and 066, and (b) tracks 058 and 068. The predicted anomalies from reversals and paleointensity variations were applied with a 1-km-wide Gaussian emplacement filter [Schouten and Denham, 1979]. The gray shaded bars at the bottom of the figures show the times of short reversal events as in Figure 4.16. 
(a) Combined tracks $056 \& 066$

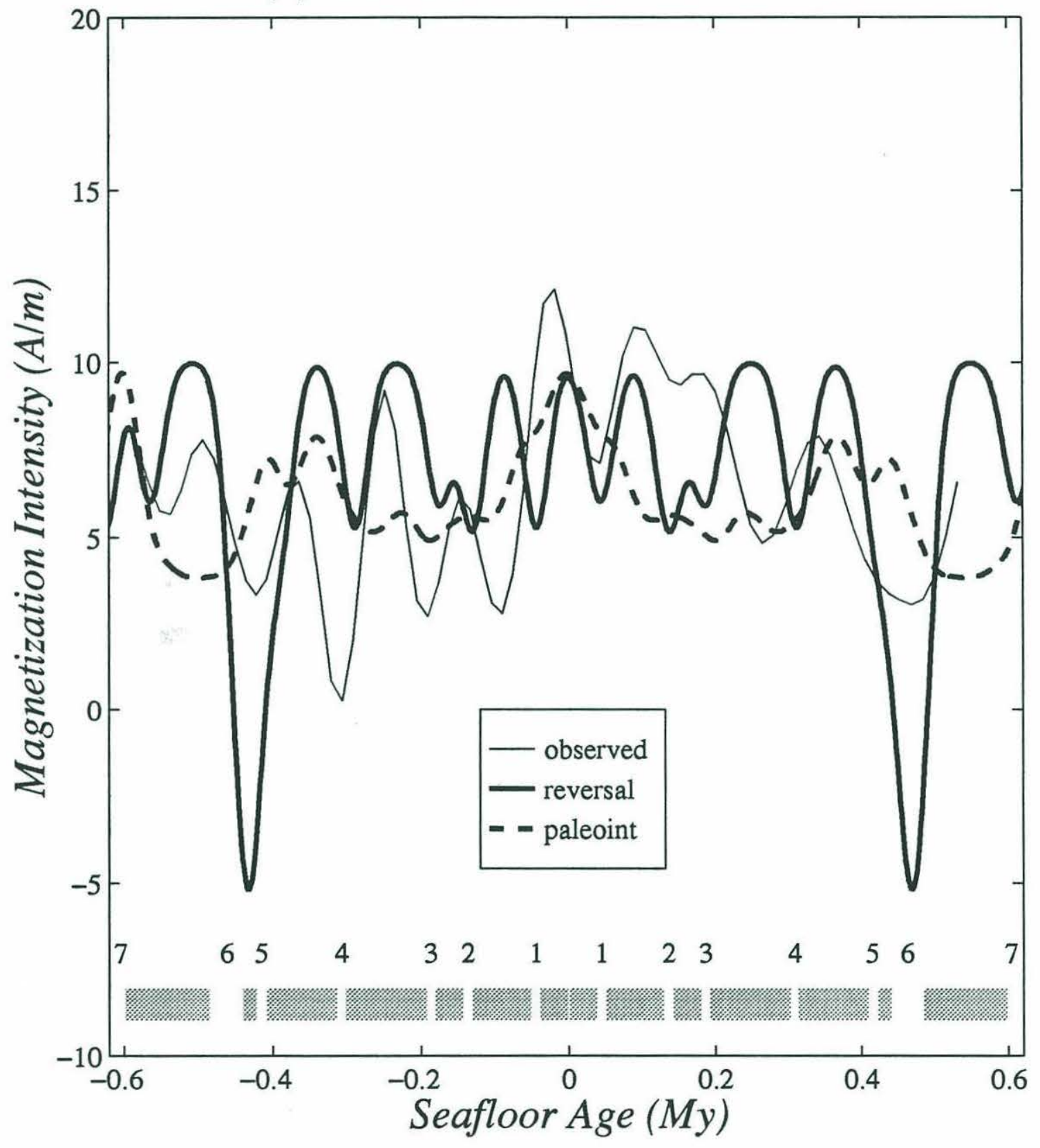


(b) Combined tracks $058 \& 068$

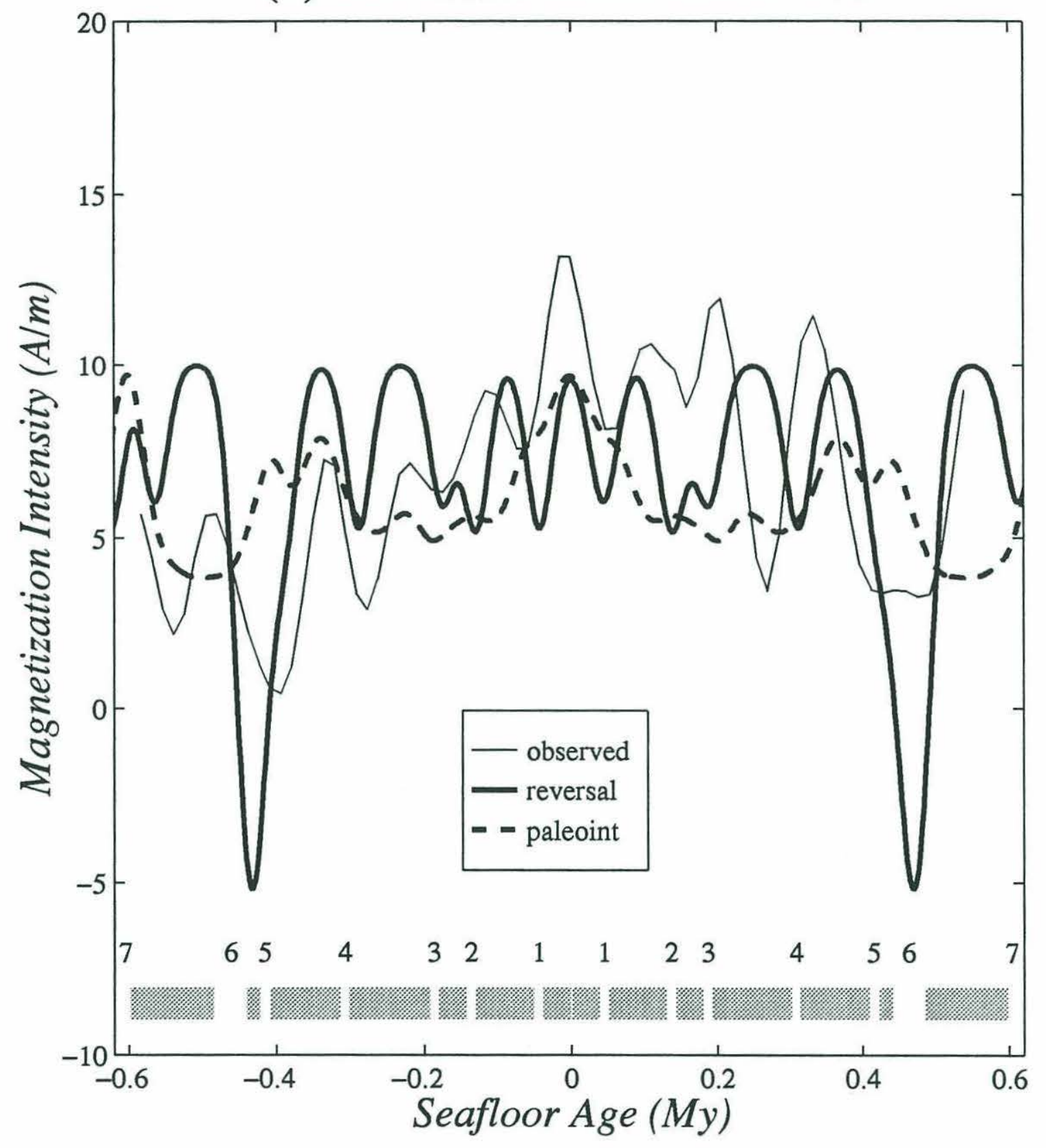




\section{Chapter 5}

\section{Gravity Anomalies and Their Implications for the Lithospheric Structure of the East Pacific Rise}

\section{Introduction}

Our knowledge of the structure of fast-spreading mid-ocean ridges has improved greatly during the last decade because of a number of surveys performed over the East Pacific Rise (EPR). A series of active seismic investigations, including multichannel seismic reflection [Detrick et al., 1987; Mutter et al., 1988; Harding et al., 1989, 1993; Kent et al., 1990, 1993a, b], seismic refraction [Harding et al., 1989; Vera et al., 1990; Christeson et al., 1992, 1994a, b], and travel-time [Burnett et al., 1989; Toomey et al., 1990, 1994; Caress et al., 1992] and attenuation [Wilcock et al., 1992b] tomography along portions of the EPR have led to the discovery of an axial magma chamber (AMC) and structures related to it within the crust. However, because these investigations were performed on relatively small volumes within the crust, they generally provide us with little information on structures that may lie below the crust.

The analysis of gravity field measurements at the sea surface is complementary to seismic information and can provide information on relatively long-wavelength density 
structures such as those associated with the thermal structure of the mid-ocean ridge or systematic variations in crustal thicknesses. Since a large part of the near-ridge gravity field can be attributed to undulations in topography and changes in the density structure associated with cooling and progressive thickening of the lithosphere, by removing these effects from the observed gravity field systematically, we can isolate residual gravity anomalies. These residual gravity anomalies can then be used to place bounds on the size and along-axis variability of any anomalous mass associated with a crustal magma chamber or unmodeled anomalous density structures that lie below the crust [e.g., Kuo and Forsyth, 1988; Lin et al., 1990; Madsen et al., 1984, 1990; Wang and Cochran, 1993; Neumann and Forsyth, 1993].

Previous investigations of gravity anomalies along the EPR [Madsen et al., 1984, 1990; Wang and Cochran, 1993] have suggested that a low-density volume is present along the axis and that the axial topographic high is a consequence of such a low-density volume. However, because the investigation of gravity fields alone can not uniquely distinguish among probable structural models of the EPR, the density and depth of such a volume and the role it plays in the generation of the axial topographic high remain controversial. One of the questions that remains to be resolved is how much of the axial gravity anomaly is due to sources within the crust and how much is due to those in the upper mantle. Recently, Magde et al. [1994] argued that approximately $70 \%$ of mantle Bouguer anomaly low of the southern EPR $\left(14^{\circ} \mathrm{S}\right.$ and $\left.17^{\circ} \mathrm{S}\right)$ can be explained by a crustal region of partial melt and elevated temperature and that the remaining gravity signal is contributed by a narrow ( $10 \mathrm{~km}$ wide) partial melt conduit that extends to depths of 50-70 $\mathrm{km}$ with melt fraction up to $2 \%$ higher than the surrounding mantle. However, it is unclear whether such a small fraction of melt is consistent with the large reductions in the viscosity of upper mantle one would expect from focused mantle upwelling. For instance, Buck and Su [1989] assume 20-30\% melt fraction for a low-density region that extends $30 \mathrm{~km}$ below the seafloor in their mantle flow model. If indeed a large portion of the axial gravity 
anomaly is cuased by sources within the crust, then understanding the amount of this contribution is crucial for unraveling upper mantle structure.

In this chapter, we examine the sea surface gravity field measurements taken during a cruise of the $R / V$ Thomas Washington to the EPR in January of 1988. The area surveyed lies between $9^{\circ} 05^{\prime}$ and $9^{\circ} 55^{\prime} \mathrm{N}$ and $255^{\circ} 25^{\prime}$ and $256^{\circ} 05^{\prime} \mathrm{E}$, which corresponds to the upper portion of a long segment of the ridge-axis bounded by two major transform faults: the Clipperton Fracture Zone at $10^{\circ} 05^{\prime} \mathrm{N}$ to the north and the Siqueiros Fracture Zone at $8^{\circ} 20^{\prime} \mathrm{N}$ far to the south (Figure 5.1). By taking advantage of information on crustal structure gathered by previous seismic investigations [Detrick et al., 1987; Harding et al., 1993; Kent et al., 1993a], we attempt to distinguish those portions of the low-density volume that can be associated with sources within the crust and those below it. We also explore whether the gravity anomalies of the EPR can be interpreted as systematic variations in the thickness of crustal layers. Since the density contrast between the lower crust and upper mantle is greater than that expected to arise from temperature variations or melt content, a change in crustal thickness is an effective way to induce gravity anomalies. A number of recent developments in the study of mid-ocean ridges make this a worthwhile exercise, including recent evidence for thicker crust at the midpoint of several segments of the Mid-Atlantic Ridge [e.g., Tolstoy et al., 1993] and a global compilation of seismic velocity structure data reprocessed by Mutter and Mutter [1993] which suggests that a thicker crust is produced mainly through increases in the thickness of layer 3. Although the travel time between the seafloor and the Moho appears to be almost constant in several seismic reflection profiles across the EPR near our study area [Detrick et al., 1987], these data do not constrain crustal thickness variations within $2-3 \mathrm{~km}$ of the axis. Further, it is possible that some variation in crustal thickness is still permitted by the variation in vertical travel times. Although the gravity field in this area has previously been investigated by Madsen et al. [1990], the coverage of gravity anomaly data collected during our survey is at least five times more dense than that of the previous investigation, and areally complete 
bathymetric data of the area was acquired during our survey, allowing us to perform highresolution three-dimensional analyses of the gravity field. An accurate analysis of gravity field anomalies may help us to examine the nature of those variations which are believed to be associated with processes that occur at shallow levels beneath the rise axis. For instance, some of the deviations from linearity of along-axis bathymetry (devals) or axial summit calderas (ASCs) have long been thought to represent the topographic expression of variability in magma supply to the ridge crest. By comparing the gravity anomalies with such fine-scale bathymetric features, we may be able to better understand their origin.

The section of the EPR which includes our survey area is one of the most intensively explored sections of a fast-spreading ridge (see Chapter 4 for a detailed description of this area). Investigations in this area include the determination of seismic crustal structure [Detrick et al., 1987; Vera et al., 1990; Toomey et al., 1990, 1994; Christeson et al., 1992, 1994a, b; Wilcock et al., 1992b; Harding et al., 1993; Kent et al., 1990, 1993a, b], nearbottom observations using the ARGO imaging system [Haymon et al., 1991], geochemical analyses of dredged rock samples [Batiza and Niu, 1992], and determination

of microearthquake characteristics [Wilcock et al., 1992a; Hildebrand et al., 1992]. Therefore, whenever possible, we compared the structures inferred from the gravity field to those obtained from magnetic [Chapter 4] and seismic data [Vera et al., 1990; Toomey et al., 1994, 1990; Harding et al., 1993; Kent et al., 1993a, b] conducted over the same portion of the EPR.

\section{Collection of Data}

The sea surface gravity field was measured using a Bell BGM-3 gravimeter, which measures the total acceleration field. BGM-3, which has an accuracy of approximately \pm 1 
$\mathrm{mGal}$ [Bell and Watts, 1986], is a significant improvement over the conventional beamtype gravimeters which had a cross-coupling error of $10-20 \mathrm{mGal}$.

One of the important steps in the reduction of ship-borne gravity measurements is to apply an optimal lowpass filter so that high frequency noise from wave motion is suppressed and geological signals are recovered with the least amount of distortion. In this study, we used a 25-pole recursive filter designed by Bell Aerospace. After applying the Bell filter, the original data from the gravimeter, which came as pulse counts every second, were reduced to a record with a 3-minute sampling interval. The gravimeter had negligible drift; on the basis of gravity ties made at the start (San Diego) and the end (Acapulco) of our cruise, we estimated a drift of $-0.064 \mathrm{mGal} /$ day.

In addition to measuring the sea-surface gravity field and bathymetry, other objectives of our investigation were to measure the sea-surface scalar magnetic field and to perform a seismic tomography experiment using an array of ocean-bottom seismometers (OBSs) and ocean-bottom hydrophones (OBHs) to record seismic waves generated by explosives and airgun shots fired near the sea surface. The measurement of scalar magnetic field was performed simultaneously with the measurement of gravity and bathymetry. However, the seismic tomography had to be conducted during the time of the day when Global Positioning System (GPS) navigation was available (about 8 hours per at the time of this survey). Given such a restriction, we covered areas outside the tomography experiment as much as we could during times of the day when GPS navigation was not available but then returned to the central portion of our survey area for the seismic tomography experiment when three or more GPS satellites were in view. As a result, many speed and course changes were made during this survey. Such changes can adversely affect the overall quality of gravity measurements, because it takes some time for the gravimeter to stabilize after changes in course or speed. Therefore, in this study, we restrict our analysis only to straight, long track lines with few speed changes (Figure 5.2). This restriction resulted in the omission of gravity data collected during the seismic shooting when changes in course 
and speed occurred frequently. Also, three minutes of record at the beginning and end of each straight long line of track were eliminated to ensure that the transient effects of course and speed changes were not included in our data set. The total duration of measurements used in our analysis is approximately 200 hours, corresponding to $50 \%$ of the total duration of the survey, or approximately $3800 \mathrm{~km}$ of track length.

\section{Renavigation}

The gravity field that we measured is the sum of the gravitational acceleration and centrifugal force of the Earth's rotation. A change in the velocity of the ship with respect to the Earth's rotating coordinate frame perturbs the centrifugal force field and thus changes our gravity measurements. The ability to compensate accurately for this phenomenon, known as the Eötvös effect, is one of the most critical steps in marine gravity field investigation. Correction for the Eötvös effect is especially important, because our survey area is near the equator and the EPR generally has only a small variance in its gravity anomaly signal. For instance, a miscalculation of the east-west component of the ship speed by 1 knot results in a $7 \mathrm{mGal}$ error, whereas the largest variation of free-air gravity anomaly signal across the EPR is only $20-30 \mathrm{mGal}$.

A technique for renavigating ship tracks based on the principle of minimizing misfit errors of Sea Beam swaths at crossovers was initially investigated by Nishimura and Forsyth [1988]. In their method, the navigation and the constraints, including the positional fixes provided by satellites and amount of shift required to fit Sea Beam swaths at crossovers, were first represented as random variables, and then a generalized inversion technique was used to update navigation. A major difficulty in implementing this technique on a computer for most surveys, however, is that the number of parameters in the inversion is too large. To address this difficulty, instead of representing a misfit as a 
difference between the positional parameters of each track, Nishimura and Forsyth [1988] attributed half of the positional difference to each of the tracks at a crossover. Making this assumption allowed them to avoid placing off-diagonal elements in the matrices and thus having to store and invert full matrices. Applications of this technique to surveys conducted along the southern Mid-Atlantic Ridge [Nishimura and Forsyth, 1988] and the East Pacific Rise (EPR) near $9^{\circ} 30^{\prime} \mathrm{N}$ [Wilcock et al., 1993] showed a reduction in the overall misfit of Sea Beam at crossovers to within a few hundred meters. However, since matching Sea Beam at crossovers was built into the inverse problem as a constraint, the overall reduction of Sea Beam misfit is not an objective measure of whether navigation was improved. In fact, when independent measurements such as the free-air gravity anomalies were compared at crossovers, the errors increased as a result of renavigation [C. E. Nishimura, personal communication, 1988; Wilcock et al., 1993].

The free-air gravity anomaly is an especially important criterion for examining the plausibility of an inversion solution, since it is sensitive to ship speed changes in the eastwest directions through the Eötvös correction. Thus, unless free-air gravity anomaly misfits are also reduced at crossovers, one cannot be confident that an optimal solution is obtained simply because the Sea Beam crossover misfits are reduced. Although the reduction of free-air gravity anomaly misfit itself may be used as a direct constraint in the formulation of a renavigation inversion, ship-borne gravity field measurements often contain spurious data and are generally difficult to implement into the inversion problem.

Our approach instead has been to use the reduction of free-air gravity anomaly misfit as a criterion with which to assess a family of inversions of Sea Beam misfit data. Unlike Nishimura and Forsyth [1988], we represent the Sea Beam crossover misfits as positional differences between two tracks. Further, by taking advantage of sparse matrix algorithms, we are able to explore a large range of inversion parameters. The navigation solution to the Sea Beam crossover misfit problem that minimize the rms free-air gravity anomaly misfit yields a $75 \%$ reduction in the variance of the gravity misfit, or a reduction in the gravity 
misfit from 3.9 to $1.9 \mathrm{mGal}$. Details of our renavigation inversion scheme are given in Appendix E to this thesis.

\section{Reduction of Free-Air Gravity Anomalies}

\section{Free-Air Gravity Anomaly}

The along-track free-air anomaly was obtained by applying the Eötvös correction and a latitude correction to our gravity measurements; both corrections were based on our new navigation. The along-track free-air gravity anomaly data was then projected onto a surface using a minimum curvature scheme [Briggs, 1974]. Although many of the artifacts due to errors in navigation were corrected by renavigation, we applied a two-dimensional lowpass filter with cosine tapering with a bandpass cutoff wavenumber of $2 \pi / 10 \mathrm{~km}^{-1}$ and a stopband cutoff wavenumber of $2 \pi / 5 \mathrm{~km}^{-1}$ to ensure that remaining artifacts were not included in our free-air gravity anomaly map (Figure 5.3).

The dominant features in the free-air anomaly map are those related to seafloor topography. For instance, the highs in the free-air gravity anomaly map correlate with the topographic highs of the seafloor and the lows with bathymetric depressions such as those resulting from relicts of an overlapping spreading center that appear on the Pacific plate side. In addition to the close correspondence between free-air gravity and bathymetry, freeair gravity anomalies show a notable variation along the rise axis. Despite the fact that, in our survey area, the ridge crest is shallower to the north (Figure 5.2), some of the peak values of free-air gravity anomaly are found along the southern portion of the rise axis.

The free-air gravity anomaly is a sum of gravitational attractions that arise from a variety of sources. The sources can be divided conceptually into well-known and less wellknown ones. Well-known sources include undulations in interfaces between two regions 
of differing density, such as water/crust and crust/mantle, and the systematic increase in the density of the lithosphere as it cools and moves away from the axis (Figure 5.4). Some of the less well-known sources in this study include those that arise from the AMC and structures related to it within the crust, as well as crustal thickness variations and anomalous density structures that may lie below the crust. A common procedure used in analyzing a gravity field is to use simple models of crustal structure and temperature to calculate the gravitational attraction from the well-known sources. Then by systematically removing the effects of well-known sources from free-air gravity anomalies, one can obtain a residual gravity anomaly which represents contributions from less well-known sources.

\section{Crustal Model}

The initial model that we used for calculating the gravitational attraction arising from the undulation of various interfaces consists of a crust whose thickness and densities within layers are uniform (illustration on the left side of Figure 5.4). The mid-ocean ridge is modeled as four layers of differing density, that is layer 2A (extrusive section), layer 2B (dike complex), layer 3 (gabbro), and the mantle. Each layer is assumed to have a constant thickness across-axis, except for layer 2A, which thickens by almost a factor of 2 within 1$2 \mathrm{~km}$ of the rise axis [Harding et al., 1993]. Average seismic velocities for the extrusive section and dike complex were converted to densities using the relationship of Christensen and Shaw [1970], $\rho=1850+0.165 V_{p}$ (for velocities in $\mathrm{m} / \mathrm{s}$ and density in $\mathrm{kg} / \mathrm{m}^{3}$ ), which was obtained by comparing the compressional wave velocities and bulk density of dredged rock samples in the laboratory. The measurements were performed at room temperature and at pressures ranging up to $100 \mathrm{MPa}$. The rock specimens were wrapped with copper foil so that the pressure medium does not enter the pore spaces of the rock. For an average 
layer $2 \mathrm{~A}$ velocity of $3500 \mathrm{~m} / \mathrm{s}$ and layer $2 \mathrm{~B}$ velocity of $5500 \mathrm{~m} / \mathrm{s}$, the resulting densities are roughly $2400 \mathrm{~kg} / \mathrm{m}^{3}$ and $2700 \mathrm{~kg} / \mathrm{m}^{3}$, respectively. Near-bottom gravity measurements determined a density $2630 \pm 50 \mathrm{~kg} / \mathrm{m}^{3}$ for the upper $2 \mathrm{~km}$ of young crust on the southern Juan de Fuca Ridge [Stevenson et al., 1994], which is consistent with our estimate of densities. For layer 3, we assumed an average velocity of $6750 \mathrm{~m} / \mathrm{s}$ [Vera et al., 1990], which results in a density of roughly $2900 \mathrm{~kg} / \mathrm{m}^{3}$. We assumed a density of $3300 \mathrm{~kg} / \mathrm{m}^{3}$ for the mantle. Table 5.1 summarizes the parameters used for the forward calculation of gravitational attraction from the crustal model.

A recent detailed analysis of multichannel seismic data suggests several along-axis variations. For instance, according to Harding et al. [1993], reexamination of multichannel seismic data taken in 1987 showed a slight thickening of layer 2A (50-100 m) which may occur towards the south of our survey area.

In most of the multichannel seismic profiles taken across the rise axis, reflections from the Moho can be traced almost continuously, except within a few kilometers of the axis [Detrick et al., 1987]. Figure 5.5 shows Moho reflections on several common-depth-point (CDP) profiles which cross the rise axis in our survey area. Although a detailed examination shows that there may be slight variations in the travel time (one way travel time differences are less than $150 \mathrm{~ms}$ ) from the seafloor to Moho among CDP lines [Barth, 1991], it is unclear which layer or layers is the source of such a travel-time anomaly. Therefore, in our initial model, we assume that the crust has a uniform thickness of $7 \mathrm{~km}$.

\section{Gravitational Attraction from Crustal Layers}

The calculation of the gravitational attraction arising from an undulating interface with a density contrast is based on the method developed by Parker [1972]. This method uses a 
Taylor series expansion to represent the Fourier transform of the gravity anomaly as an infinite sum of discrete Fourier transforms of powers of the relief of a density interface. In most cases, Taylor series expansion terms up to and including the third power are sufficient to account for the nonlinearity associated with roughness on the density interfaces.

To minimize edge effects, we began with a larger map of the survey area $\left(9^{\circ} 05^{\prime}\right.$ $\left.9^{\circ} 55^{\prime} \mathrm{N}, 255^{\circ} 25^{\prime}-256^{\circ} 05^{\prime} \mathrm{E}\right)$. Since the Fourier transform assumes that the structure is periodic, the input grids were mirrored along the boundaries to prevent discontinuities.

The contributions to the gravitational attractions from each layer within an area defined by $9^{\circ} 10^{\prime}-9^{\circ} 50^{\prime} \mathrm{N}$ and $255^{\circ} 30^{\prime}-256^{\circ} \mathrm{E}$ are shown in Figure 5.6. Due to the upward continuation of the gravity signal from the source level to the sea surface, most of the highfrequency components of the gravity signals are damped. The total variance due to the interfaces water/layer $2 \mathrm{~A}$, layer $2 \mathrm{~A} /$ layer $2 \mathrm{~B}$, layer $2 \mathrm{~B} /$ layer 3 , and layer $3 /$ mantle is approximately $32,6.6,3.6$, and $4.3 \mathrm{mGal}$, respectively.

\section{Mantle Bouguer Gravity Anomaly}

The mantle Bouguer anomaly (Figure 5.7) is obtained after removing the gravitational attraction of the different crustal layers (Figure 5.6) from the free-air anomaly (Figure 5.3). On a broad scale, the mantle Bouguer anomaly is low along the rise axis and increases offaxis. Much of this long-wavelength variation, as shown below, can be attributed to changes in the density structure of the plate as it cools and moves away from the axis. The mantle Bouguer anomaly also shows significant along-axis as well as cross-axis variations. The width of the cross-axis low of the mantle Bouguer anomaly generally increases to the north, especially on the Pacific plate side. On average, the mantle Bouguer anomaly to the north of $9^{\circ} 35^{\prime} \mathrm{N}$ is lower by approximately $2 \mathrm{mGal}$ on the Pacific plate than on the Cocos 
plate. In addition, the asymmetry in mantle Bouguer to the north of $9^{\circ} 35^{\prime} \mathrm{N}$ appears to correlate well with the asymmetry in bathymetry in the same general area (Figure 5.2); the seafloor is elevated by approximately $25 \mathrm{~m}$ on the Pacific plate compared with that on the Cocos plate. This apparent asymmetry in mantle Bouguer anomaly might be due to an anomalous mantle structure, thickness variations among sublayers, or an error in our density estimate of one or more sublayers. The mantle Bouguer anomaly map also shows several short-wavelength features: several distinctive local gravity lows are centered alongaxis at around $9^{\circ} 21^{\prime}, 9^{\circ} 26^{\prime}, 9^{\circ} 32^{\prime}, 9^{\circ} 42^{\prime}$, and $9^{\circ} 50^{\prime} \mathrm{N}$ (Figure 5.7).

\section{Anomaly due to Lithospheric Cooling}

In addition to density differences due to variations in the lithology of the crust, changes in temperature also give rise to variations in density structure. Our knowledge of the thermal structure of the mid-ocean ridge is largely based on analytical and numerical models. However, for lithosphere ages of a few million years and less, because of complex and transient processes such as those involved with hydrothermal cooling and magmatic injection in addition to conductive cooling, there are considerable differences among existing thermal models [Stein and Stein, 1994; Chapter 2] and, therefore, the gravitational field contributed from plate cooling remains uncertain. In this study, we extend the thermal model of Wilson et al. [1988], which covers a region extending $10 \mathrm{~km}$ from the axis and to $7 \mathrm{~km}$ depth, to greater distances from the axis. The thermal model of Wilson et al. [1988] is for a horizontal, uniform slab spreading at a constant rate away from a narrow, continuously intruding vertical dike (illustration on the right side of Figure 5.4). Point sources and sinks of heat were used to simulate latent heat release, hydrothermal circulation, and convection within a magma chamber, and the isotherms were constrained 
to match multichannel seismic results from the EPR near our survey area [Detrick et al., 1987].

In this study, we assume that most active hydrothermal cooling occurs within $10 \mathrm{~km}$ of the axis as described by Wilson et al. [1988]. Less active, but significant hydrothermal cooling beyond $10 \mathrm{~km}$ is considered in our model by enhancing the thermal conductivity. In deriving a new thermal model, we took the temperature profile at $10 \mathrm{~km}$ distance from the model of Wilson et al. [1988] and used it as a boundary condition for our modeling region. Within $10 \mathrm{~km}$ from the axis and for depths greater than $7 \mathrm{~km}$, we assumed a temperature gradient of $0.8^{\circ} \mathrm{C} / \mathrm{km}$. Figure 5.8 shows the configuration of our thermal model and the rest of the boundary conditions used to set up a steady-state twodimensional heat flow problem. Table 5.2 summarizes the parameters that were used.

The problem was solved using a finite difference method based on a successive overrelaxation technique [Smith, 1985]. Convergence was obtained easily after several iterations. The resulting temperature distributions for distances beyond $10 \mathrm{~km}$ from the axis were then combined with the thermal model of Wilson et al. [1988] at closer axial distances (Figure 5.9). At first, we considered four values of thermal diffusivity ( $\mathrm{\kappa})$ : 0.25 , 1,5 , and $10 \mathrm{~mm}^{2} / \mathrm{s}$. A thermal diffusivity of $0.25 \mathrm{~mm}^{2} / \mathrm{s}$, for instance, corresponds to the value adopted by Wilson et al. [1988], although the detailed features of their thermal models appear to be controlled by the placement and magnitudes of heat sources and sinks rather than their value of thermal diffusivity. A more typical estimate of the average thermal diffusivity of the oceanic lithosphere is $1 \mathrm{~mm}^{2} / \mathrm{s}$ [e.g., Phipps Morgan et al., 1987; Lin and Parmentier, 1989]. Thermal diffusivities of 5 and $10 \mathrm{~mm}^{2} / \mathrm{s}$ can thus be considered as enhancements in thermal conduction by factors of 5 and 10, respectively, as a result of hydrothermal circulation. We prefer the thermal model result with $\kappa=5 \mathrm{~mm}^{2} / \mathrm{s}$ (Figure 5.9c), because it appears to match the estimates of average total heat flow for $0-1$ My old seafloor $\left(\sim 2 \mathrm{~W} / \mathrm{m}^{2}\right)$ [Stein and Stein, 1994]. 
Unlike the situation for discrete layers, there is no efficient way to estimate the gravitational effects of a three-dimensional temperature structure. In this study, we first divided the crust into subblocks of equal dimensions, and then for each point at the sea surface we calculated the contribution from subblocks around the point. In our model, the distance from the sea surface (i.e., the level of measurement) to the center of mass of each subblock is determined by bathymetry. Fortunately, because the distances from each measurement point to the subblocks are sufficiently large, the dimensions of the subblocks did not have to be very small. For example, in this study, we used subblocks that were 1$\mathrm{km}$ cubes. The resulting gravitational field from our thermal model (i.e., $\mathrm{\kappa}=5 \mathrm{~mm}^{2} / \mathrm{s}$ ) has a total variance of less than $3 \mathrm{mGal}$ within our survey area.

\section{Residual Gravity Anomalies}

By removing the effects of plate cooling from the mantle Bouguer anomaly, we obtain the residual gravity anomaly (Figure 5.10). Since the contribution of plate cooling can be represented as a variation in the gravity anomaly predominantly in the cross-axis direction, the residual gravity anomaly maps still show many of the same features that were observed in the mantle Bouguer anomaly map. For example, the broad low-gravity signal along the axis is present in both the residual gravity anomaly and mantle Bouguer anomaly maps, and the short-wavelength gravity lows along the axis are present in the residual gravity anomaly for all four thermal models.

In the absence of independent constraints, it is impossible to determine the depth and the density contrast of an anomalous structure from gravity anomaly information alone. However, one can separate the residual gravity anomalies into long- and short-wavelength components and assume that, while the former can be caused by sources that are either deep or shallow, the latter must stem from relatively shallow sources, such as density 
anomalies within the crust. In this study, we take two approaches, each looking at different wavelengths of the residual gravity anomaly. First, we examine if the long-wavelength residual gravity anomaly can be explained by variations in the crustal thickness. The outcome of this examination, in turn, can help us validate another hypothesis, namely that the long-wavelength residual gravity anomalies are caused by sources in the mantle. Next, by systematically filtering the long-wavelength components from the residual gravity anomaly, we obtain the map of short-wavelength anomalies. From the along-axis variation of short-wavelength gravity anomaly, we then explore the nature of the anomalous mass within the crust needed to explain the short-wavelength gravity anomaly signal.

\section{Variations in Crustal Thickness}

As a possible cause of variations in crustal thickness, we consider variations in the thickness of layer 3. We should note that all of the features in the residual gravity map cannot be explained by such variations. This is because the base of layer 3 (i.e., the Moho) lies approximately $10 \mathrm{~km}$ below the sea surface and thus will only contribute to residual gravity anomaly features that are much greater than $10 \mathrm{~km}$ in horizontal wavelength unless unreasonable thickness variations are invoked. For residual anomaly features with wavelengths of a few tens of kilometers or less, we examine below alternative explanations such as density anomalies within the middle to upper crust.

To convert residual gravity anomalies to crustal thickness variations, we need to perform a downward continuation of the gravity anomalies. A problem with such a downward continuation is that it is inherently unstable; short-wavelength signals are amplified relative to long-wavelength ones. As a result, a lowpass filter must first be applied to the gravity anomalies to ensure a stable downward continuation. Even with lowpass filtering there still can be some problems, however; if the filter is designed on the 
basis of an empirically determined cutoff wavenumber, for instance [e.g., Blackman and Forsyth, 1991], filtering may eliminate a significant geological signal.

In this study, we used the downward continuation scheme proposed by Phipps Morgan and Blackman [1993]. The scheme differs from previous methods in which filters with empirically determined cutoff wavenumbers were used in that the downward continuation filter can be tailored to find the crustal thickness solution that satisfies a criterion of minimum slope, or maximal smoothness, or a weighted combination of these desired solution features. The resulting variation in layer 3 thickness is shown in Figure 5.11b. For comparison, we also show the crustal thickness variation that was determined after the application of a lowpass filter given by a cosine taper between a passband cutoff wavenumber of $2 \pi / 30 \mathrm{~km}^{-1}$ and a stopband cutoff wavenumber of $2 \pi / 15 \mathrm{~km}^{-1}$ (Figure 5.11a). The result shown in Figure 5.11b is based on a maximal smoothness criterion and was obtained from an inversion of residual gravity anomalies where the effects of plate cooling were removed with the thermal model given by a thermal diffusivity of $5 \mathrm{~mm}^{2} / \mathrm{s}$ for regions beyond $10 \mathrm{~km}$ from the axis. (Because the magnitude of the gravity anomalies and the size of the survey area were small, a minimum slope criterion yielded a solution with virtually no variation in thickness.) The result shows a significant change in crustal thickness; as much as 1-1.2 km greater thickness of crust is needed beneath the rise axis to explain the broad gravity lows in the residual gravity anomaly. Also, in terms of an alongaxis variation in layer 3 thickness, the crust must increase its thickness by as much as 400 $\mathrm{m}$ to the north of the survey area. We comment on the plausibility of this solution below.

\section{Comparisons with Simple Geometric Bodies}

The residual gravity anomaly that we observe is a sum of contributions arising from sources in the crust as well as from those in the mantle and, therefore, without knowing 
how much of any given anomaly is from crustal sources, estimating density contrasts of crustal sources can be misleading. In this study, as a way of partitioning the residual gravity anomaly into crustal and mantle contributions, we use a highpass filter. We adopt a cosine taper between passband and stopband cutoff wavenumbers, and we take the former as twice than the latter. For example, Figure 5.12 is a map of short-wavelength gravity anomalies that was obtained after applying a two-dimensional highpass filter to the residual gravity anomaly (Figure 5.10) with cosine tapering between a stopband cutoff wavenumber of $2 \pi / 40 \mathrm{~km}^{-1}$ and a passband cutoff wavenumber of $2 \pi / 20 \mathrm{~km}^{-1}$. We refer to such a gravity anomaly as "local residual gravity anomaly" to distinguish it from a residual gravity anomaly which contains both long- and short-wavelength components. In the ideal sitiuation, the highpass filter will cut out features arising from the mantle, while retaining the short-wavelength features arising from sources within the crust. Of course, long-wavelength anomalies may also arise from crustal sources.

The variation of local residual gravity anomaly clearly depends on the highpass filter. Figure 5.13 shows along-axis variations of local short-wavelength residual gravity anomalies that were obtained using three different stopband cutoff wavenumbers $(2 \pi / 20$, $2 \pi / 40$, and $2 \pi / 60 \mathrm{~km}^{-1}$ ). Also shown in the figure (solid line) is a residual gravity anomaly obtained by removing a linear trend from the unfiltered residual gravity anomaly (Figure 5.10). This representation is equivalent to the admittedly ad hoc assumption that the mantle contribution to the residual gravity anomaly is represented by a linear trend alongaxis. We use this line as a reference for selecting the filter. The local residual gravity anomaly obtained with a stopband cutoff wavenumber of $2 \pi / 40 \mathrm{~km}^{-1}$ provides a best match to the detrended anomaly. We choose this filter parameter for determining a local residual gravity anomaly from crustal sources. Had we chosen the local residual gravity anomaly obtained with a stopband cutoff wavenumber of $2 \pi / 60 \mathrm{~km}^{-1}$, it would mean that we were more likely to incoporate some long-wavelength mantle contribution, and thus we would overestimate the anomalous mass in the crust. On the other hand, had we chosen 
the local residual gravity anomaly obtained with a stopband cutoff wavenumber of $2 \pi / 20$ $\mathrm{km}^{-1}$, then we would have likely removed components that are from crustal sources, and thus we would underestimate the anomalous mass in the crust. .

Three local gravity lows, centered at $9^{\circ} 21^{\prime}, 9^{\circ} 32^{\prime}$, and $9^{\circ} 42^{\prime} \mathrm{N}$, can be seen in the alongaxis profiles of short-wavelength residual gravity anomaly in Figure 5.13. The anomaly at $9^{\circ} 21^{\prime} \mathrm{N}$ shows the largest amplitude. The magnitudes of these anomalies depend on the parameters of the highpass filter chosen. For the filter used in Figure 5.12, the anomalies have amplitudes of 1.5-3 mGal along axis and 3-5 mGal across axis.

That these short-wavelength residual gravity anomalies are real, despite having magnitudes comparable to or only slightly larger than the rms gravity anomaly misfit at crossovers, is supported by their strong correlation with other documented variations in crustal properties. For example, the box in Figure 5.12 delineates the area where images of crustal velocity structure were obtained by delay-time tomography [Toomey et al., 1990]. The local gravity low at $9^{\circ} 32^{\prime} \mathrm{N}$ appears to be consistent with the tomographic image [Toomey et al., 1990] in terms of its location and dimensions. Figure 5.15 shows horizontal cross-sections of the tomographic images at the seafloor and at $2 \mathrm{~km}$ depth. Both the mid-crustal velocity low imaged by delay-time tomography and the local gravity low appear approximately midway between the two devals at $9^{\circ} 28^{\prime} \mathrm{N}$ and $9^{\circ} 35^{\prime} \mathrm{N}$. As with the tomographic images, the local gravity low at $9^{\circ} 32^{\prime} \mathrm{N}$ is slightly offset to the west of the bathymetric rise axis.

We next compared the local residual gravity anomaly with the gravitational attraction arising from anomalous masses of specified geometry. Specifically, we assume that the anomalous masses are cylindrical bodies of circular cross-section buried beneath the seafloor. We further assumed that there are three cylindrical bodies of equal dimensions and depths beneath the seafloor and that their centers coincide with the troughs of the gravity lows at $9^{\circ} 21^{\prime}, 9^{\circ} 32^{\prime}$, and $9^{\circ} 42^{\prime} \mathrm{N}$. We also fixed the radius at $1 \mathrm{~km}$, the along-axis length at $10 \mathrm{~km}$, and the depth to the top of the anomalous body at $1.25 \mathrm{~km}$ beneath the 
seafloor. The density contrasts of the cylindrical bodies, however, were considered as variables. In comparing the observed short-wavelength gravity anomalies to predicted gravity anomalies, details of the shape of the anomalous body are not important since the distance between the point of measurement and the source is large compared with the dimensions of the anomalous body. Once the predicted gravity anomaly was calculated, it was then convolved with the same highpass filter as the observed local residual gravity anomaly.

The predicted and observed local residual gravity anomalies along and across the axis are compared in Figure 5.14. In this particular example, density contrasts of 350, 200, and $200 \mathrm{~kg} / \mathrm{m}^{3}$ for the anomalous cylindrical bodies at $9^{\circ} 21^{\prime}, 9^{\circ} 32^{\prime}$, and $9^{\circ} 42^{\prime} \mathrm{N}$, respectively, provide the best match to the observed local residual gravity anomaly along the axis (Figure 5.14a). However, the same models for the anomalous mass predict only about half the observed magnitude of the local residual gravity anomalies in cross-axis profiles (Figure 5.15b). We infer that in addition to the along-axis variations arising from discrete bodies of anomalous mass there is also an additional signal arising from a structure that is approximately continuous along the rise. It is important to note that these estimates represent the amounts of reduction in density caused by effects other than the average axial temperature at mid-crustal depths as given by the thermal model of Wilson et al. [1988]. The magma chamber in that thermal model is considered to have a temperature greater than $1150^{\circ} \mathrm{C}$.

\section{Discussion}

Before focusing on the causes of the observed residual gravity anomalies, we review some of the important aspects of the models used in this study to correct for various sources of gravitational attraction. In obtaining the residual gravity anomaly, we used two 
models, one to correct for the gravitational attraction arising from changes in lithology with depth, and the other to correct for the gradual variation in the density structure of the plate with cooling. Although there is evidence that layer $2 \mathrm{~A}$ may thicken to the south of our survey area by approximately $200 \mathrm{~m}$ [Harding et al., 1993], the total contribution of such thickening would be very small, less than $0.5 \mathrm{mGal}$. As mentioned earlier, the thermal structure of a fast-spreading rise at ages of less than a few million years is not well known because of the lack of measurements that can validate the thermal models, except for near axial regions where seismic observations [e.g., Detrick et al., 1987] provide some constraints on the distribution of temperatures. In this study, we employed a simple model where the thermal diffusivity of the modeling region beyond $10 \mathrm{~km}$ from the axis was considered as a variable. After comparing the average heat fluxes of various thermal model results with the predicted average total heat flow for 0-1 My old seafloor [Stein and Stein, 1994], we chose a thermal model which assumes an 5-fold enhancement in the effective thermal conductivity due to additional hydrothermal cooling (i.e., $\kappa=5 \mathrm{~mm}^{2} / \mathrm{s}$ ).

The residual gravity anomaly map, obtained by correcting for crustal layering and plate cooling, shows several notable patterns. For instance, it shows that the area near the rise axis is characterized by a broad residual gravity low (Figure 5.10). Although there are indications that the AMC at this portion of the EPR is surrounded by a wider zone of low velocities [Vera et al., 1990; Toomey et al., 1990], such a low-velocity volume extends only about $5 \mathrm{~km}$ from the axis. Therefore, the width of the residual gravity low is too large to be explained by a body of anomalous density coinciding with the low-velocity volume.

We tested whether this anomaly can be explained by a variation in the thickness of the crust, specifically in the thickness of layer 3 [Mutter and Mutter, 1993]. If the axial residual gravity low is to be attributed to crustal thickness variations, then the crust must be thickest on axis and thin by as much as $1-1.2 \mathrm{~km}$ over a distance of $10-20 \mathrm{~km}$ from the axis (Figure 5.11). Also, to explain the broadening of the residual gravity low to the north, layer 3 must increase its thickness systematically by approximately $400 \mathrm{~m}$ along the axis. 
Such large variations can be excluded on the basis of seismic reflection profiles conducted along this portion of the EPR [Detrick et al., 1987], which show no sign of crustal thinning with axial distance or of crustal thickening of that magnitude to the north. To the contrary, a detailed examination of seismic reflection profiles show a slightly lesser travel-time between the seafloor and Moho to the north than to the south of our survey area [Barth and Mutter, 1994]. However, it should be noted that seismic reflection from the Moho is absent within several kilometers of the axis. Also, it is unclear what portions of the crust are contributing to these travel-time anomalies. Since compressional wave velocity differs among oceanic crustal layers, there can be different estimates for the variation in crustal thickness for the same magnitude of travel-time anomaly. For example, assuming that the travel-time anomalies not explained by variations in layer 2A thickness [Harding et al., 1993] occur within layer 3, Barth and Mutter [1994] estimate that the crust thins by as much as $1.5 \mathrm{~km}$ from $9^{\circ} 19^{\prime}$ to $9^{\circ} 40^{\prime} \mathrm{N}$ (Figure 5.16). However, since layer 3 is normally the fastest $(\sim 7.2 \mathrm{~km} / \mathrm{s})$ section of the crust, their estimate should be interpreted as an upper bound. Regardless of the magnitude of the crustal thickness variation, a variation in crustal thickness does not appear to the principal cause of residual gravity anomaly in our survey area.

The most probable explanation of the broad residual gravity low is that it is caused by a low-density volume that lies beneath the crust. Low density in the upper mantle beneath a ridge can be caused by changes in the composition of the residual mantle as melting occurs and by presence of melt in the solid matrix, as well as by elevated temperature. For instance, one could imagine a region beneath the crust that serves as the source of magma supply to one or more crustal magma chambers. Many models of mid-ocean ridges view the generation of magma and upward ascent as a hierarchical system where the magma becomes more spatially focused as it is derived from a larger and deeper magmatic source [e.g., Crane, 1985; Schouten et al., 1985; Macdonald et al., 1988]. 
Although there is no other direct measurement made to date that can constrain the lateral distribution or depth extent of the low-density volume, a simple analysis still permits us to examine some of the characteristics of the anomalous mass accounting for the long wavelength variation in gravity anomaly. The gravity anomaly for a vertical cylinder with an infinitely large radius and temperature anomaly $\Delta T$ is

$$
\Delta g \approx 2 \pi G \rho_{s} \alpha_{v} \Delta T \Delta h
$$

where $G$ is the universal gravitational constant, $\rho_{\mathrm{s}}$ is the density of the mantle, $\alpha_{v}$ is the volumetric thermal expansion coefficient, and $\Delta h$ is the height of the source volume. For example, the residual gravity anomaly map (Figure 5.10) shows a decrease of approximately $10 \mathrm{mGal}$ to the north. If the decrease is caused by an increase in the temperature of the mantle by $100^{\circ} \mathrm{C}$, the temperature anomaly should extend from the seafloor to approximately 25 kilometers below. However, such a temperature increase should be accompanied by an increase in melt production, which in turn should produce a thicker crust to the north. Since there is no observed increase in the crustal thickness in our survey area from the multichannel seismic survey [Detrick et al., 1987], a preferred argument would be that the long-wavelength gravity anomaly is caused by a lesser temperature variation and sources extending deeper into the mantle. For $\Delta T=50^{\circ} \mathrm{C}$ sources extending down to $50 \mathrm{~km}$ are required; according to Wilson [1992], the lowdensity volume at fast-spreading ridges should extend down to at least $40 \mathrm{~km}$ of depth in order to be consistent with evidence for the geochemical diversity of seamount lavas.

The cause of such along-axis variations as the broadening of the residual anomaly low, particularly on the Pacific plate side to the north of $9^{\circ} 35^{\prime} \mathrm{N}$, is also unclear. As mentioned earlier, the pattern of low residual anomaly appears to correlate with an area of the seafloor that is slightly more elevated than elsewhere at a given age. One possible explanation is that the crust may be thicker in the area of elevated seafloor. For a seafloor that is elevated 
by $50 \mathrm{~m}$ on Pacific plate relative to that of the Cocos plate, the amount of thickening predicted for layer 3 is approximately $170 \mathrm{~m}$. According to the map of crustal thickness estimates [Barth and Mutter, 1994] (Figure 5.16), there is not a noticeable difference in crustal thickness across $9^{\circ} 35^{\prime} \mathrm{N}$. However, a difference in crustal thickness of $170 \mathrm{~m}$ across the rise axis may be within the uncertainty in seismic reflection measurements. An alternative explanation is that the area on the Pacific plate to the north of $9^{\circ} 35^{\prime} \mathrm{N}$ may be receiving a greater than average heat flux from the upper mantle, and therefore it is elevated by greater thermal expansion compared with other regions at the same distance from the axis.

The observation that the region to the north exhibits a lower residual gravity anomaly appears to be consistent with the results of several previous investigations. According to a geochemical analysis of dredged rock samples along the axis [Batiza and Niu, 1992], there are indications that seafloor basalts were quenched from a higher temperature to the north of our survey area than to the south. Also, magnetic anomalies along axis show an abrupt increase in the magnitude of magnetization to the south of $9^{\circ} 25^{\prime} \mathrm{N}$ [Chapter 4]. This increase in magnetization is interpreted as evidence that lava to the south of $9^{\circ} 25^{\prime} \mathrm{N}$ was derived from more highly differentiated magma chambers. If the upper mantle to the north has a higher temperature than that toward the south, it also should be capable of a greater magma generation rate. This could lead in turn to a more frequent replenishment of magma in crustal magma chambers, which may explain why seafloor basalts appear quenched at higher temperatures. Also, a more frequently replenished magma chamber is more likely to be well mixed and thus produce a less differentiated magma than less frequently replenished one.

Several characteristics of the broad residual anomaly low of the EPR may be compared and contrasted with those of the Mid-Atlantic Ridge. At the Mid-Atlantic Ridge, the gravity lows generally form concentric patterns and tend to be centered at midpoints of ridge segments [e.g., Kuo and Forsyth, 1989; Lin et al., 1990, Blackman and Forsyth, 
1989; Neumann and Forsyth, 1993], leading to the so-called "bull's eye" pattern. Although our coverage is somewhat limited, the pattern of residual anomaly lows at this portion of the EPR does not appear to be distinctly as concentric as over the Mid-Atlantic Ridge, nor are anomalies centered at midpoints of ridge segments. For the residual anomaly low to be situated midway between the Clipperton Fracture Zone at $10^{\circ} 05^{\prime} \mathrm{N}$ and an OSC at $9^{\circ} 03^{\prime} \mathrm{N}$, the center of the low would have to be at $9^{\circ} 31^{\prime} \mathrm{N}$. Instead, the lowest residual anomaly lies at $9^{\circ} 45^{\prime} \mathrm{N}$ or farther north. The residual anomaly north of $9^{\circ} 35^{\prime} \mathrm{N}$ is only about $5 \mathrm{mGal}$ lower than that to the south, whereas at the Mid-Atlantic Ridge the along-axis difference can be as high as $20-30 \mathrm{mGal}$.

The local residual anomaly shows several lows along the axis which are interpreted as magmatically robust regions within the crust. Distinct lows are centered at $9^{\circ} 21^{\prime}, 9^{\circ} 32^{\prime}$ and $9^{\circ} 42^{\prime} \mathrm{N}$. From the apparent wavelengths of these lows, it is clear that the anomalies are due to sources in the crust. We have modeled the anomalous masses giving rise to these lows as circular rods of radius $1 \mathrm{~km}$, along-axis lengths $10 \mathrm{~km}$, and tops $1.25 \mathrm{~km}$ below the seafloor. With such a geometry, the required density contrasts are approximately 200-350 $\mathrm{kg} / \mathrm{m}^{3}$. Such contrasts are far too large to be due to unmodeled thermal anomalies, and they are also higher than can be plausibly be explained by melt fraction given that the density change associated with complete melting of typical crustal rock is less than 300 $\mathrm{kg} / \mathrm{m}^{3}$. Of course, lesser contrasts would be obtained for anomalous masses of greater volume.

Although the magnitudes of the crustal density anomalies trade off with the geometry of the anomalous masses, the positions and spacing of gravity lows correlate well with other known crustal variations. For instance, the local gravity low at $9^{\circ} 32^{\prime} \mathrm{N}$ coincides with the low-velocity volume imaged by delay-time tomography [Toomey et al., 1990] in terms of its location and dimensions. Unfortunately, for other local gravity lows, there are no similar seismic constraints. However, we can compare the distribution of the local gravity anomaly with that of ASCs mapped by Haymon et al. [1991]. Except for the local gravity 
low at $9^{\circ} 21^{\prime} \mathrm{N}$ which appears at the terminus of an ASC, the local gravity lows are generally centered over segments of the ASC, but not necessarily at their midpoints. Compared to ASCs, devals show a slightly better correlation with the loci of local gravity lows. None of the devels appear near the centers of the local gravity lows; instead, most of them occur along the portions of the rise axis where gravity anomalies are relatively high. The local gravity lows show some correlation with the distribution of reflectors from the top of the AMC mapped by Kent et al. [1993a]. For instance, there is a large gap between $9^{\circ} 29^{\prime}$ and $9^{\circ} 22^{\prime} \mathrm{N}$ where the AMC reflector is absent, according to a seismic reflection profile conducted along the axis (i.e., CDP line 41), and it coincides with an along-axis region where the residual gravity anomaly lacks a prominent low.

In our survey area, the AMC reflector is the widest at around $9^{\circ} 18^{\prime} \mathrm{N}$ but is offset to the west by approximately $2-3 \mathrm{~km}$ [Kent et al., 1993a]. The residual gravity anomaly low does not show an offset of such a magnitude, but shows some sign of bifurcation to the south of $9^{\circ} 15^{\prime} \mathrm{N}$, with the gravity low to the west appearing as slightly more pronounced in magnitude than that on the east. One possible scenario that may explain this pattern of residual gravity anomaly is that, the eastern limb of the OSC at $9^{\circ} 03^{\prime} \mathrm{N}$ is being overtaken by the western limb [Sempéré et al., 1984], with the consequence that the crust beneath the western limb is being more frequently replenished with magmatic material. Unfortunately, because our gravity survey does not cover the region of the OSC, we are not able to examine the southward extension of the residual anomaly pattern in detail to test this idea.

The local gravity low centered at $9^{\circ} 21^{\prime} \mathrm{N}$ is the largest in magnitude of the axial lows. Since there is no evidence that a magma chamber is unusually shallow at this location, we speculate that the AMC at $9^{\circ} 21^{\prime} \mathrm{N}$ may have been the axial region most recently replenished with new magma. The absence of an ASC over the local gravity low at $9^{\circ} 21^{\prime} \mathrm{N}$ may be another indication that the region has only recently undergone lava eruption, so that preexisting ASCs would have become filled with sheet flows and pillow lavas. According 
to Haymon et al. [1991], some of the freshest basalts and an active hydrothermal vents were found at $9^{\circ} 17^{\prime} \mathrm{N}$.

The residual gravity anomaly in our area shows greater cross-axis variation than alongaxis. A plausible explanation to a greater cross-axis variation is that axial regions that are magmatically robust are surrounded by a region of lower than normal density that is approximately continous along the axis. Such a region may correspond to the low-velocity volume surrounding the magma chamber imaged by seismic tomography. Although no further quantitative analysis is carried out here, on the basis of a comparison between the amplitudes of the observed cross-axis residual gravity anomaly and those predicted by our cylinderical models, the surrounding low-velocity volume appears to have a mass anomaly comparable to that of the magmatically robust regions.

\section{A New Model of the EPR, $9^{\circ} 10^{\prime}-9^{\circ} 50^{\prime} \mathrm{N}$}

Based on the information gathered through gravity analysis, we suggest the following description of the EPR between $9^{\circ} 10^{\prime}$ and $9^{\circ} 50^{\prime} \mathrm{N}$ (Figure 5.17). The temperature of the upper mantle is probably higher, and thus the melt flux is higher, in the upper mantle to the north than to the south. A greater presence of melt in the upper mantle in turn reduces the density. (Regions of lower density are represented by darker shades in the bottom figure.) In addition to an along-axis variation of density, the density structure of the upper mantle shows a slight asymmetry with respect to the bathymetric axis, which is illustrated by the white dashed line in the bottom figure. The gray arrows represent the loci of magma upwelling from the mantle to the crust, each marked by a short-wavelength residual gravity anomaly low. Because the rate of upper mantle magma production is greater to the north, magma chambers to the north are being replenished with new magma more frequently. 
To a large extent, the structure of the crust near the axis appears to reflect magmatic processes that occur in the upper mantle. The axial crust along the axis can be characterized by a series of approximately regularly spaced bodies of high melt concentration surrounded by a region of lesser melt concentration. The actual transition between regions of high and low melt concentration, of course, may be more gradual. The regions of low melt concentration may correspond to the seismically-defined low-velocity volume (LVV) [Vera et al., 1990]. Although shown as uniform, the width of the LVV may vary along the rise axis. There are at least five distinct regions of high melt concentration in our survey area. As mentioned earlier, the dimensions and the densities of these regions of high melt concentration are not derivable from gravity information alone. However, if the shape of the region of high melt concentration is a circular rod whose radius is $1 \mathrm{~km}$, along-axis length is $10 \mathrm{~km}$, and center of mass is $2.25 \mathrm{~km}$ beneath the seafloor, the density contrast of such a region of high melt concentration with the surrounding region may range from 200 to $350 \mathrm{~kg} / \mathrm{m}^{3}$ on the basis of a fit to along-axis residual gravity anomaly profiles. Near the southern limit of our survey area, the region of high melt concentration appears to be divided into two sections, with the one to the west more pronounced and perhaps receiving magma at greater rate than the one to the east. Consequently, the magmatic axis may deviate to the west of the bathymetric axis southward of $9^{\circ} 21^{\prime} \mathrm{N}$. 


\section{Conclusions}

We have examined sea surface gravity field measurements gathered over the East Pacific Rise between $9^{\circ} 10^{\prime}-9^{\circ} 50^{\prime} \mathrm{N}$ and $255^{\circ} 30^{\prime}-256^{\circ} \mathrm{E}$. Complete coverage of bathymetry from Sea Beam and dense coverage of gravity allowed us to perform a three-dimensional analysis of this area. By reducing the misfit of Sea Beam bathymetry at track crossovers, rms free-air gravity misfit after renavigation was reduced from 3.9 to $1.9 \mathrm{mGal}$.

A residual gravity anomaly map was obtained by removing from the free-air anomaly the effects of crustal layering and plate cooling. We modeled the crust as having three distinct layers of constant density: layers $2 \mathrm{~A}, 2 \mathrm{~B}$, and 3 . The layers were assumed to have uniform thickness, except for layer $2 \mathrm{~A}$, which thickened approximately twofold within 2 $\mathrm{km}$ of the axis. The thermal model used to correct for cooling was extended from that of Wilson et al. [1988] to distances greater than $10 \mathrm{~km}$ from the axis. A variable thermal diffusivity permitted the examination of a range of thermal models.

The residual gravity anomaly map shows that the EPR is underlain by a wide region of low density that is not explained by plate cooling or modeled density structures within the crust. The broad residual gravity anomaly cannot be explained solely by crustal thickness variations, because the crust would have to decrease by as much as $1 \mathrm{~km}$ in thickness over a distance of $10-20 \mathrm{~km}$ off axis, a change too large to be compatible with multichannel seismic observations [Detrick et al., 1987]. The broad residual gravity low, therefore, is interpreted as a signal arising from the upper mantle, presumably caused by the presence of partial melt along the rise axis.

The width of the broad residual gravity pattern varies considerably along-axis, with greater values occurring to the north. To the north of $9^{\circ} 35^{\prime} \mathrm{N}$, the broad low is slightly more prominent on the Pacific than on the Cocos plate side. The increase in the width of the broad low is interpreted as evidence for a greater presence of melts in the mantle to the 
north than to the south, especially on the Pacific plate side. A greater melt productivity in the upper mantle may lead to more frequent replenishment of the AMC and more frequent axial eruptions.

The residual gravity anomaly shows several short-wavelength lows approximately regularly spaced along the axis (e.g., $9^{\circ} 21^{\prime}, 9^{\circ} 32^{\prime}$, and $9^{\circ} 42^{\prime} \mathrm{N}$ ) which correlate with variations in seismic structure and other characteristics. The local lows have an along -axis amplitude of $1.5-3 \mathrm{mGal}$ and appear at almost regular distances $(10-15 \mathrm{~km})$ along the axis. They are interpreted as regions of relatively high melt concentration in the crust, presumably sites of recent replenishment of magma from the upper mantle. Furthermore, because the local lows show a greater variation (3-5 mGal) across the axis, an additional low-density structure that is approximately continous along the axis is thought to surround the regions of high melt concentration. If this view is valid, one can deduce information on the state of axial magma chambers during comparatively active and inactive phases of a magmatic cycle from the along-axis variation of the gravity field. For a simple model of the anomalous density structures, density contrasts of approximately $200-350 \mathrm{~kg} / \mathrm{m}^{3}$ can account for the observed along-axis variations. 


\section{References}

Barth, G. A., A marine seismic study of the East Pacific Rise, $8^{\circ} 50^{\prime} \mathrm{N}$ to $13^{\circ} 30^{\prime} \mathrm{N}, \mathrm{Ph}$. D. thesis, Columbia University, New York, 237 pp., 1991.

Barth, G. A., and J. C. Mutter, Multichannel seismic reflection results from the East Pacific Rise: Spatial and temporal variability in oceanic crustal structure, J. Geophys. Res., submitted, 1994.

Batiza, R., and Y. Niu, Petrology and magma chamber processes at the East Pacific Rise 9³0'N, J. Geophys. Res., 97, 6779-6797, 1992.

Bell, R. E., and A. B. Watts, Evaluation of the BGM-3 sea gravity meter system onboard R/V Conrad, Geophysics, 51 , 1480-1493, 1986.

Blackman, D. K., and D. W. Forsyth, Isostatic compensation of tectonic features of the Mid-Atlantic Ridge: 25-27³0'S, J. Geophys. Res., 96, 11,741-11,758, 1991.

Briggs, I. C., Machine contouring using minimum curvature, Geophysics, 39, 39-48, 1974.

Buck, W. R., and W. Su, Focused mantle upwelling below mid-ocean ridges due to feedback between viscosity and melting, Geophys. Res. Lett., 16, 641-644, 1989.

Burnett, M. S., D. W. Caress, and J. A. Orcutt, Tomographic image of the magma chamber at $12^{\circ} 50^{\prime} \mathrm{N}$ on the East Pacific Rise, Nature, 339, 206-208, 1989.

Caress, D. W., M. S. Burnett, and J. A. Orcutt, Tomographic images of the axial lowvelocity zone at $12^{\circ} 50^{\prime} \mathrm{N}$ on the East Pacific Rise, J. Geophys. Res., 97, 9243-9263, 1992.

Christensen, N. I., and G. H. Shaw, Elasticity of mafic rocks from the Mid-Atlantic Ridge, Geophy. J. R. Astron. Soc., 20, 271-284, 1970.

Christeson, G. L., G. M. Purdy, and G. J. Fryer, Structure of young upper crust at the East Pacific Rise near 9³0N, Geophys. Res. Lett., 19, 1045-1048, 1992. 
Christeson, G. L., G. M. Purdy, and G. J. Fryer, Seismic constraints on shallow crustal emplacement processes at the fast spreading East Pacific Rise, J. Geophys. Res., 99, 17,957-17,973, 1994a.

Christeson, G. L., G. M. Kent, G. M. Purdy, and R. S. Detrick, Extrusive thickness variability at the East Pacific Rise: Constraints from seismic techniques, J. Geophys. Res., submitted, 1994b.

Crane, K., The spacing of rift axis highs: Dependence upon diapiric processes in the underlying asthenosphere?, Earth Planet. Sci. Lett., 72, 405-414, 1985.

Detrick, R. S., P. Buhl, E. Vera, J. Mutter, J. Orcutt, J. Madsen, and T. Brocher, Multichannel seismic imaging of a crustal magma chamber along the East Pacific Rise, Nature, 326, 35-41, 1987.

Harding, A. J., J. A. Orcutt, M. Kappus, E. E. Vera, J. C. Mutter, P. Buhl, R. S. Detrick, and T. M. Brocher, Structure of young oceanic crust at $13^{\circ} \mathrm{N}$ on the East Pacific Rise from expanding spread profiles, J. Geophys. Res., 94, 12,163-12,193, 1989.

Harding, A. J., G. M. Kent, and J. A. Orcutt, A multichannel seismic investigation of upper crustal structure at $9^{\circ} \mathrm{N}$ on the East Pacific Rise: Implications for crustal accretion, J. Geophys. Res., 98, 13,925-13,944, 1993.

Haymon, R. M., D. J. Fornari, M. H. Edward, S. Carbotte, D. Wright, and K. C. Macdonald, Hydrothermal vent distribution along the East Pacific Rise crest $\left(9^{\circ} 09^{\prime}-\right.$ 54 ' $\mathrm{N}$ ) and its relationship to magnetic and tectonic processes on fast-spreading midocean ridges, Earth Planet. Sci. Lett., 104, 513-534, 1991.

Hildebrand, J. A., S. C. Webb, L. M. Dorman, A. E. Schreiner, M. A. McDonald, and W. C. Crawford, Microseismicity of a mid-ocean ridge volcanic eruption: The East Pacific Rise at 9 ${ }^{\circ} 50^{\prime} \mathrm{N}$ (abstract), Eos, Trans. AGU, 73, Fall Meeting suppl., 530, 1992.

Kent, G. M., A. J. Harding, and J. A. Orcutt, Evidence for a smaller magma chamber beneath the East Pacific Rise at 9³0'N, Nature, 344, 650-653, 1990. 
Kent, G. M., A. J. Harding, and J. A. Orcutt, Distribution of magma beneath the East Pacific Rise between the Clipperton Transform and the $9^{\circ} 17^{\prime} \mathrm{N}$ deval from forward modeling of common depth point data, J. Geophys. Res., 98, 13,945-13,969, 1993 a.

Kent, G. M., A. J. Harding, and J. A. Orcutt, Distribution of magma beneath the East Pacific Rise near the $9^{\circ} 03^{\prime} \mathrm{N}$ overlapping spreading center from forward modeling of common depth point data, J. Geophys. Res., 98, 13,971-13,995, 1993 b.

Kuo, B.-Y., and D. W. Forsyth, Gravity anomalies of the ridge-transform system in the South Atlantic between 31 and $34.5^{\circ} \mathrm{S}$ : Upwelling centers and variations in crustal thickness, Mar. Geophys. Res., 10, 205-232, 1989.

Lin, J., and E. M. Parmentier, Mechanisms of lithospheric extension at mid-ocean ridges, Geophys. J., 96, 1-22, 1989.

Lin, J., G. M. Purdy, H. Schouten, J.-C. Sempéré, and C. Zervas, Evidence from gravity data for focused magmatic accretion along the Mid-Atlantic Ridge, Nature, 344, 627$632,1990$.

Macdonald, K. C., P. J. Fox, L. J. Perram, M. F. Eisen, R. M. Haymon, S. P. Miller, S. M. Carbotte, M.-H. Cormier, and A. N. Shor, A new view of the mid-ocean ridge from the behavior of ridge-axis discontinuities, Nature, 335, 217-225, 1988.

Madsen, J. A., D. W. Forsyth, and R. S. Detrick, A new isostatic model for the East Pacific Rise crest, J. Geophys. Res., 89, 9997-10,015, 1984.

Madsen, J. A., R. S. Detrick, J. C. Mutter, P. Buhl, and J. A. Orcutt, A two- and threedimensional analysis of gravity anomalies associated with the East Pacific Rise at $9^{\circ} \mathrm{N}$ and $13^{\circ}$ N, J. Geophys. Res., 95, 4967-4987, 1990.

Magde, L. S., R. S. Detrick, G. M. Kent, A. J. Harding, J. A. Orcutt, J. C. Mutter, and P. Buhl, The crustal and upper mantle contribution to the axial gravity anomaly at the southern East Pacific Rise, J. Geophys. Res., submitted, 1994.

Mutter, C. Z., and J. C. Mutter, Variation in thickness of layer 3 dominate oceanic crustal structure, Earth Planet. Sci. Lett., 117, 295-317, 1993. 
Mutter, J. C., G. A. Barth, P. Buhl, R. S. Detrick, J. Orcutt, and A. Harding, Magma distribution across ridge-axis discontinuities on the East Pacific Rise from multichannel seismic images, Nature, 336, 156-158, 1988.

Neumann, G. A., and D. W. Forsyth, The paradox of the axial profile: Isostatic compensation along the axis of the Mid-Atlantic Ridge?, J. Geophys. Res., 98, 17,89117,910, 1993.

Nishimura, C. E., and D. W. Forsyth, Improvements in navigation using SeaBeam crossing errors, Mar. Geophys. Res., 9, 333-352, 1988.

Parker, R. L., The rapid calculation of potential anomalies, Geophys. J. R. Astron. Soc., 31, 447-455, 1972.

Phipps Morgan, J., and D. K. Blackman, Inversion of combined gravity and bathymetry data for crustal structure: A prescription for downward continuation, Earth Planet. Sci. Lett., 119, 167-179, 1993.

Phipps Morgan, J., E. M. Parmentier, and J. Lin, Mechanisms for the origin of mid-ocean ridge axial topography: Implications for the thermal and mechanical structure of accreting plate boundaries, J. Geophys. Res., 92, 12,823-12,836, 1987.

Schouten, H., K. D. Klitgord, and J. A. Whitehead, Segmentation of mid-ocean ridges, Nature, 317, 225-229, 1985.

Sempéré, J., K. C. Macdonald, and S. P. Miller, Overlapping spreading centres: 3-D inversion of the magnetic field at $9^{\circ} 03^{\prime} \mathrm{N}$ on the East Pacific Rise, Geophys. $J . R$. Astron. Soc., 79, 799-811, 1984.

Smith, G. D., Numerical Solution of Partial Differential Equations: Finite Difference Methods, 337 pp., Oxford University Press, New York, 1985.

Stein, C. A., and S. Stein, Constraints on hydrothermal heat flux through the oceanic lithopshere from global heat flow, J. Geophys. Res., 99, 3081-3095, 1994.

Stevenson, J. M., J. A. Hilderbrand, and M. Zumberge, An ocean bottom gravity study of the southern Juan de Fuca Ridge, J. Geophys. Res., 99, 4875-4888, 1994. 
Tolstoy, M., A. J. Harding, and J. A. Orcutt, Crustal thickness on the Mid-Atlantic Ridge: Bull's-eye gravity anomalies and focused accretion, Science, 262, 726-729, 1993.

Toomey, D. R., G. M. Purdy, S. C. Solomon, and W. S. D. Wilcock, The threedimensional seismic velocity structure of the East Pacific Rise near latitude $9^{\circ} 30^{\prime} \mathrm{N}$, Nature, 347, 639-645, 1990.

Toomey, D. R., S. C. Solomon, and G. M. Purdy, Tomographic imaging of the shallow crustal structure of the East Pacific Rise at $9^{\circ} 30^{\prime N}$, J. Geophys. Res., 99, 24,13524,157, 1994.

Vera, E. E., J. C. Mutter, P. Buhl, J. A. Orcutt, A. J. Harding, M. E. Kappus, R. S. Detrick, and T. M. Brocher, The structure of 0- to 0.2-m.y.-old oceanic crust at $9^{\circ} \mathrm{N}$ on the East Pacific Rise from expanded spread profiles, J. Geophys. Res., 95, 15,529$15,556,1990$.

Wang, X., and J. R. Cochran, Gravity anomalies, isostasy and mantle flow at the East Pacific Rise crest, J. Geophys. Res., 98, 19,505-19,531, 1993.

Wilcock, W. S. D., G. M. Purdy, S. C. Solomon, D. L. Dubois, and D. R. Toomey, Microearthquakes on and near the East Pacific Rise, $9^{\circ}-10^{\circ} \mathrm{N}$, Geophys. Res. Lett., 19 , 2131-2134, 1992a.

Wilcock, W. S. D., S. C. Solomon, G. M. Purdy, and D. R. Toomey, The seismic attenuation structure of a fast-spreading mid-ocean ridge, Science, 258, 1470-1474, 1992b.

Wilcock, W. S. D., D. R. Toomey, G. M. Purdy, and S. C. Solomon, The renavigation of Sea Beam bathymetric data between $9^{\circ} \mathrm{N}$ and $10^{\circ} \mathrm{N}$ on the East Pacific Rise, Mar. Geophys. Res., 15, 1-15, 1993.

Wilson, D. S., Focused mantle upwelling beneath mid-ocean ridges: Evidence from seamount formation and isostatic compensation of topography, Earth Planet. Sci. Lett., $113,41-45,1992$. 
Wilson, D. S., D. A. Clague, N. H. Sleep, and J. L. Morton, Implications of magma convection for the size and temperature of magma chambers at fast spreading ridges, $J$. Geophys. Res., 93, 11,974-11,984, 1988. 
Table 5.1. Thicknesses and densities of layers used for the calculation of gravitational attraction.

\begin{tabular}{ccc}
\hline Layer & Density $\left(\mathrm{kg} / \mathrm{m}^{3}\right)$ & Thickness $(\mathrm{m})$ \\
\hline Seawater & 1000 & \\
Layer 2A & 2400 & 400 \\
Layer 2B & 2700 & 1350 \\
Layer 3 & 2900 & 5250 \\
Mantle & 3300 & \\
\hline
\end{tabular}


Table 5.2 Parameter values used for the thermal model.

\begin{tabular}{lll}
\hline Variable & Meaning & Value Used \\
\hline$T_{m}$ & Temperature of the mantle (i.e., $100 \mathrm{~km})$ & $1300^{\circ} \mathrm{C}$ \\
$T_{o}$ & Temperature of the seafloor & $0^{\circ} \mathrm{C}$ \\
$\alpha_{v}$ & Volumetric thermal expansion coefficient & $3 \times 10^{-5} \mathrm{C}$ \\
$\kappa$ & Thermal diffusivity & variable \\
$\mathrm{V}$ & Half spreading rate & $55 \mathrm{~mm} / \mathrm{yr}$ \\
\hline
\end{tabular}


Figure 5.1. Schematic map of the East Pacific Rise showing the survey area near $9^{\circ} 30^{\prime} \mathrm{N}$ where the gravity field survey was conducted as part of a seismic tomography experiment in 1988. The survey area corresponds to the upper portion of a long segment of the ridge-axis bounded by two major transform faults: the Clipperton Fracture Zone at $10^{\circ} 05^{\prime} \mathrm{N}$ to the north and the Siqueiros Fracture Zone at $8^{\circ} 20^{\prime} \mathrm{N}$ far to the south. An overlapping spreading center (OSC) lies just south of the survey area at $9^{\circ} 03^{\prime} \mathrm{N}$. Two seamount chains appear just outside of our survey area to the north, the Lamont and Watchstander Seamount Chains located on the Pacific and Cocos plates, respectively. 


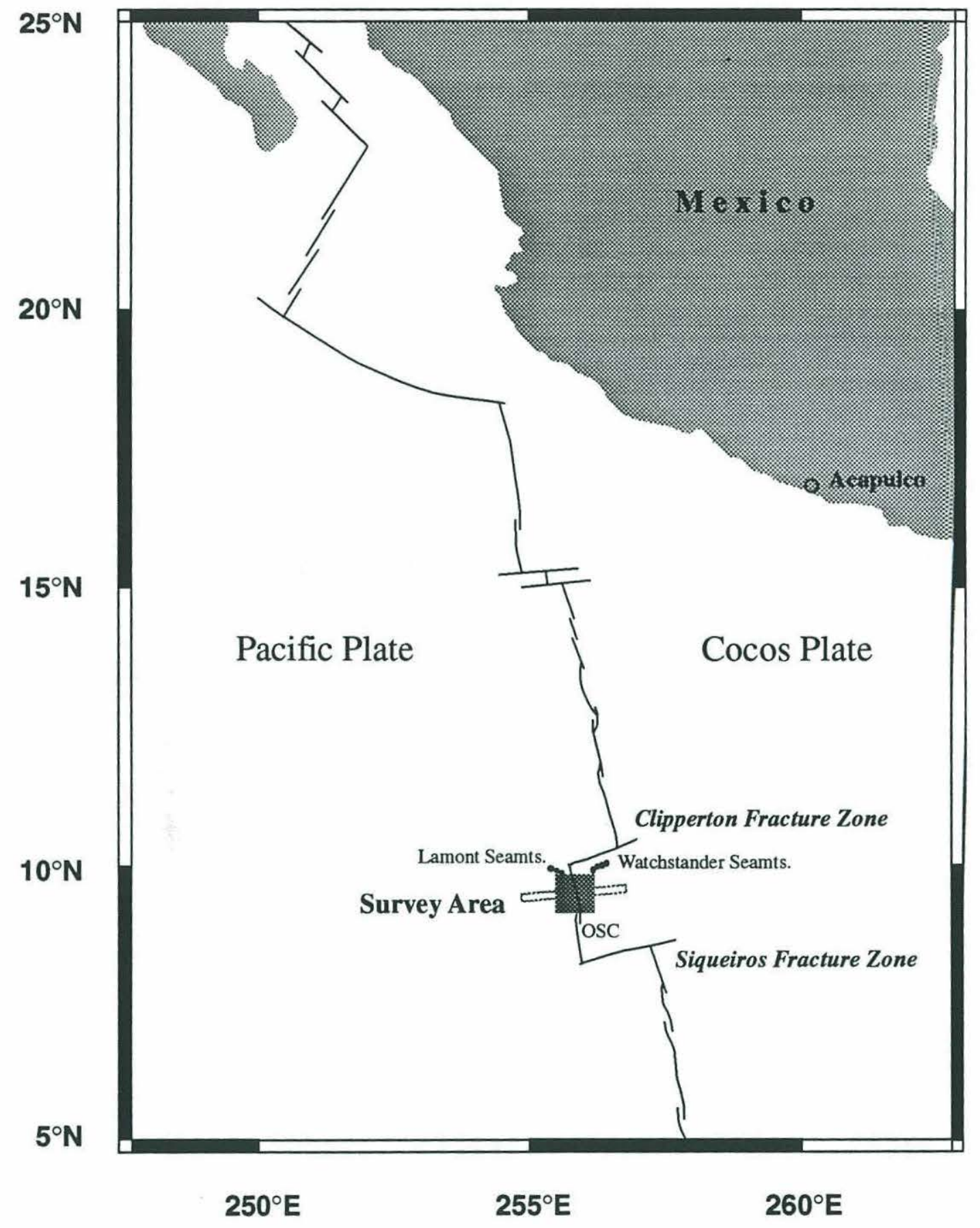


Figure 5.2. Bathymetic map of the survey area, from $9^{\circ} 05^{\prime}$ to $9^{\circ} 55^{\prime} \mathrm{N}$ and $255^{\circ} 25^{\prime}$ to $256^{\circ} 05^{\prime} \mathrm{E}$, compiled from Sea Beam after renavigation [Wilcock et al., 1993]. The depth of the seafloor ranges from approximately 2500 to $3400 \mathrm{~m}$. The purple dashed and dotted contour lines represent the depths of 3000 and $3200 \mathrm{~m}$, respectively. The yellow circles represent the locations of OBSs and OBHs that were deployed in the central portion of the survey area for the seismic tomography experiment. The white lines are ship tracks used for the gravity field analysis. 

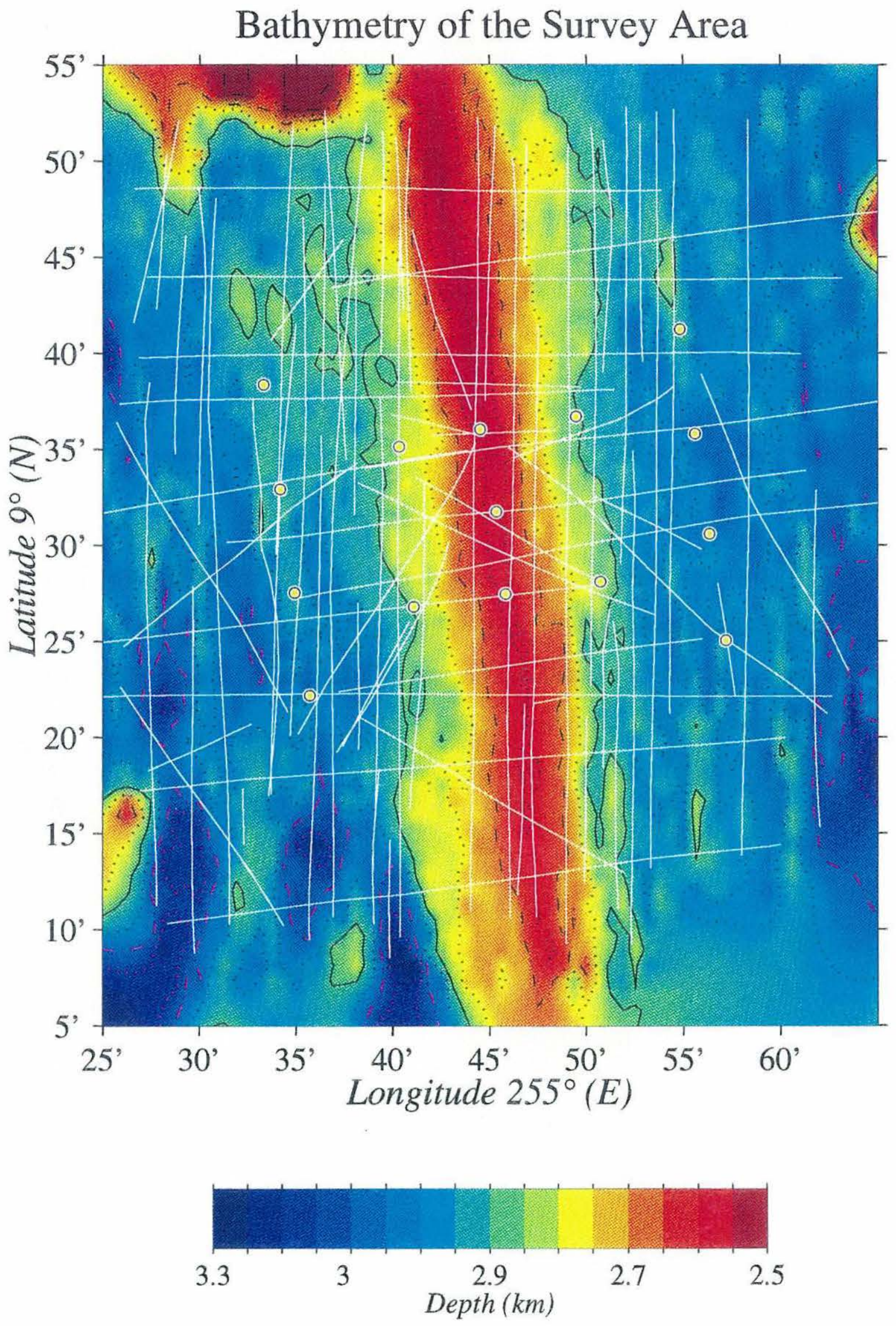
Figure 5.3. Free-air anomaly map of the survey area, from $9^{\circ} 10^{\prime}$ to $9^{\circ} 50^{\prime} \mathrm{N}$ and $255^{\circ} 30^{\prime}$ to $256^{\circ} \mathrm{E}$. The circles, shown here as reference points, represent the locations of OBSs and OBHs that were deployed for the seismic tomography experiment. The white crosses represent the bathymetric axis. 
Free-Air Anomalies
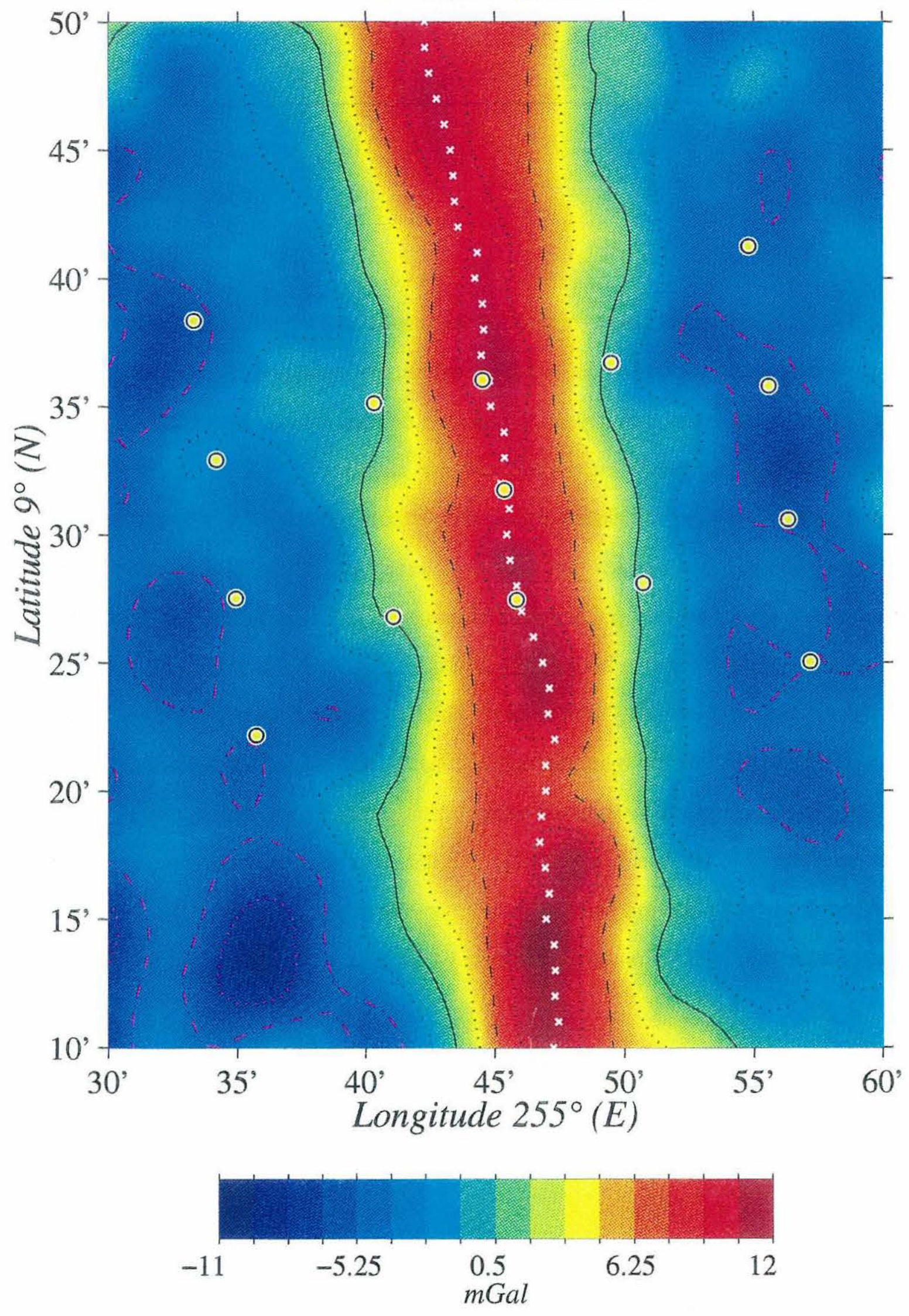
Figure 5.4. Initial model used to correct for the gravitational attraction of distinct crustal layers and the effects of plate cooling. As shown by the illustration on the left, the midocean ridge is modeled as four layers of differing density, that is, layers $2 \mathrm{~A}$ (extrusive section), 2B (dike complex), 3 (gabbro), and the mantle (Table 5.1). Each layer is assumed to have a constant thickness across-axis, except for layer $2 \mathrm{~A}$, whose thickness increases by almost a factor of 2 within 1-2 km of the rise axis [Harding et al., 1993]. The thermal model, shown on the right, is that of Wilson et al. [1988] at distances within $10 \mathrm{~km}$ of the axis. Their model is for a horizontal, uniform slab spreading at a constant rate from a narrow, continuously intruding vertical dike. Point sources and sinks of heat were used to simulate latent heat release, hydrothermal circulation, and convection within a magma chamber. The isotherms in their model were constrained to match multichannel seismic results from the EPR [Detrick et al., 1987]. For distances beyond $10 \mathrm{~km}$, we continued their thermal model by solving the steady-state two-dimensional heat flow problem with the temperature profile of Wilson et al. [1988] at $10 \mathrm{~km}$ distance as a boundary condition. 


\title{
Initial model used to correct contributions from a variety of sources
}

\author{
Lithological Model \\ Thermal Model
}

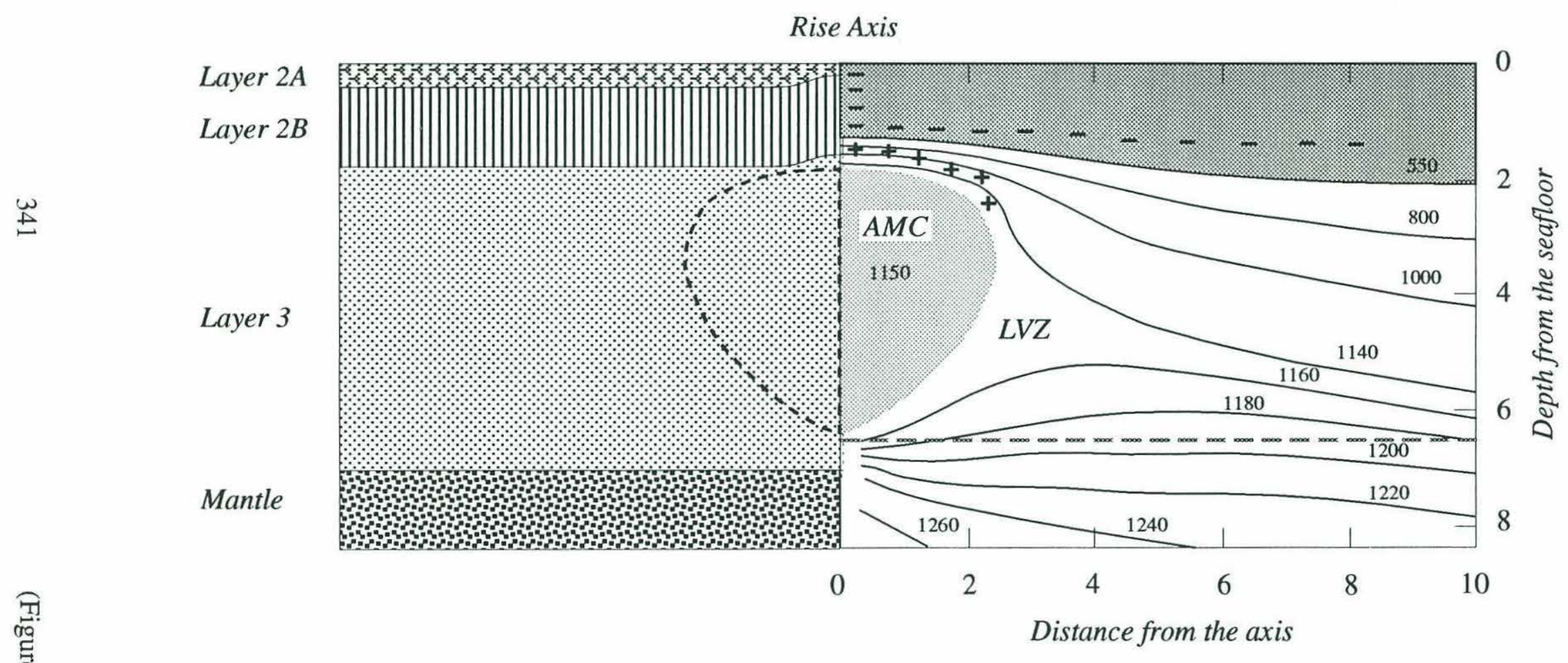


Figure 5.5. Migrated time section for CDP seismic reflection lines which cross the EPR at (a) $9^{\circ} 19^{\prime}$, (b) $9^{\circ} 24^{\prime}$, (c) $9^{\circ} 30^{\prime}$, (d) $9^{\circ} 35^{\prime}$, (e) $9^{\circ} 40^{\prime}$, (f) $9^{\circ} 45^{\prime}$, and (g) $9^{\circ} 50^{\prime} \mathrm{N}$ [after Barth, 1991]. The solid lines trace some of the notable reflections seen along the profiles. The relatively flat, high-amplitude event beneath the rise axis is believed to be a reflection from the top of an AMC and from the off-axis continuation of the frozen top. Along most of these profiles, Moho reflections can be traced to within $2-3 \mathrm{~km}$ of the rise axis. 

563
$3 \mathrm{~km}$
$9^{\circ} 19^{\prime} \mathrm{N}$

(a)

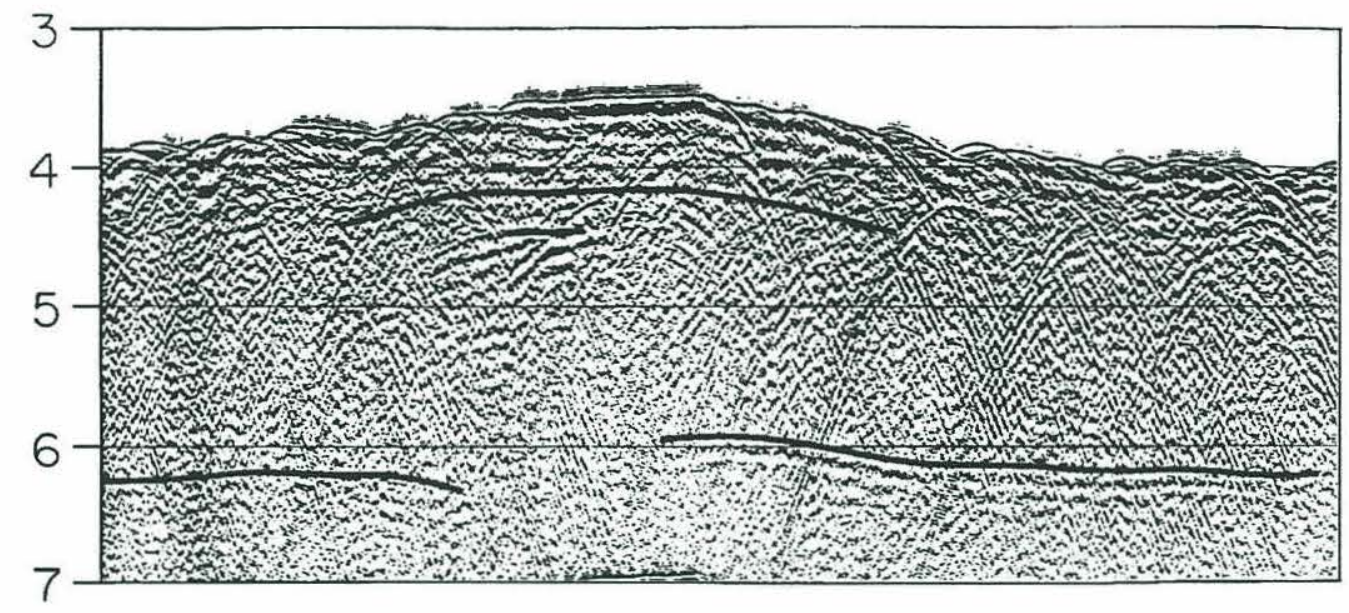

581

$9^{\circ} 24^{\prime} \mathrm{N}$

(b)

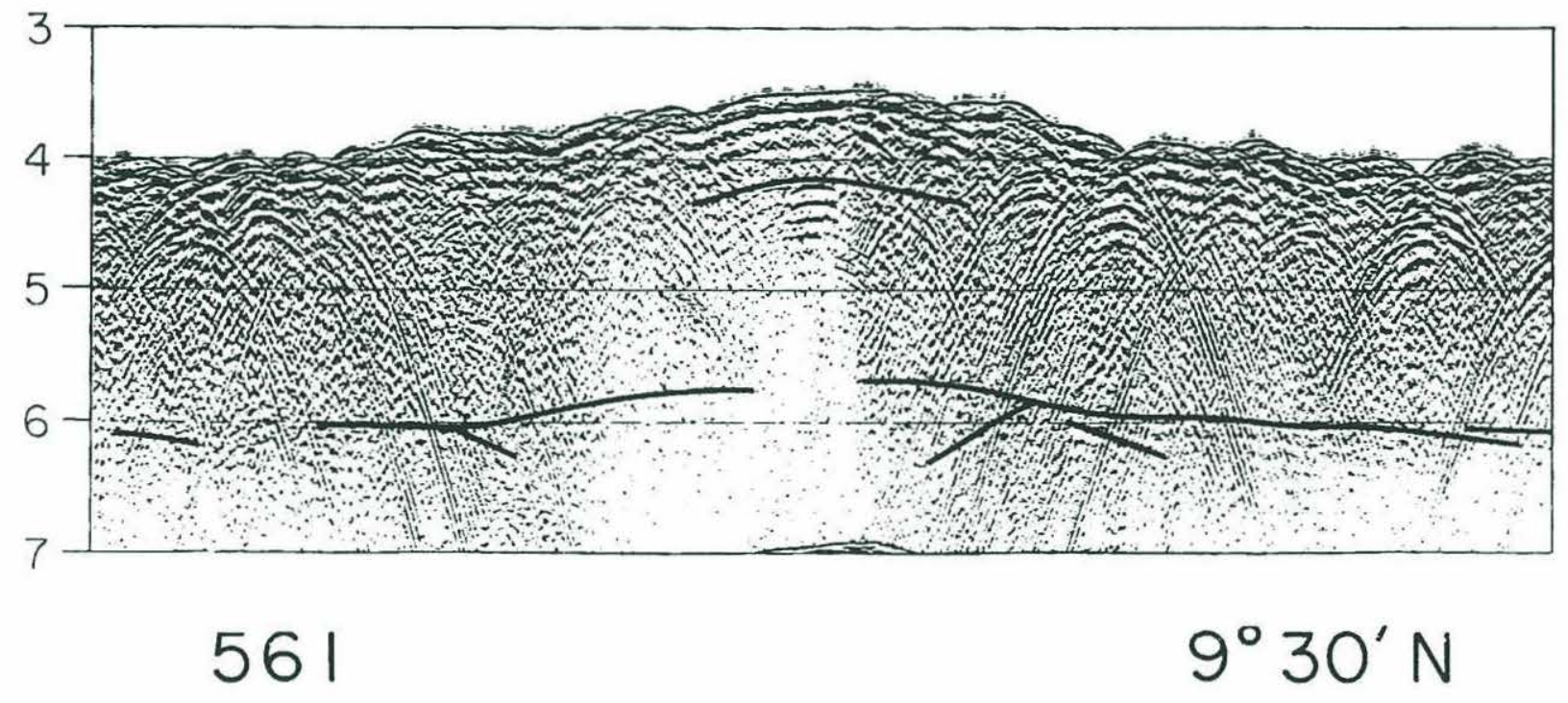

(c)

3

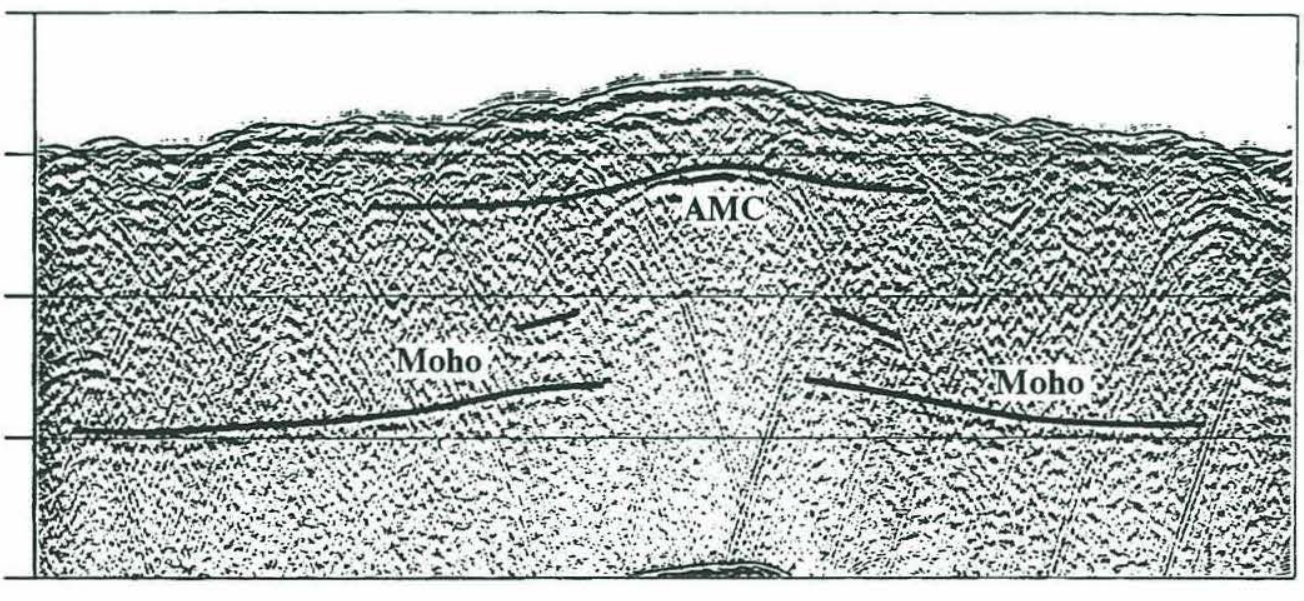




\section{7}

$9^{\circ} 35^{\prime} \mathrm{N}$

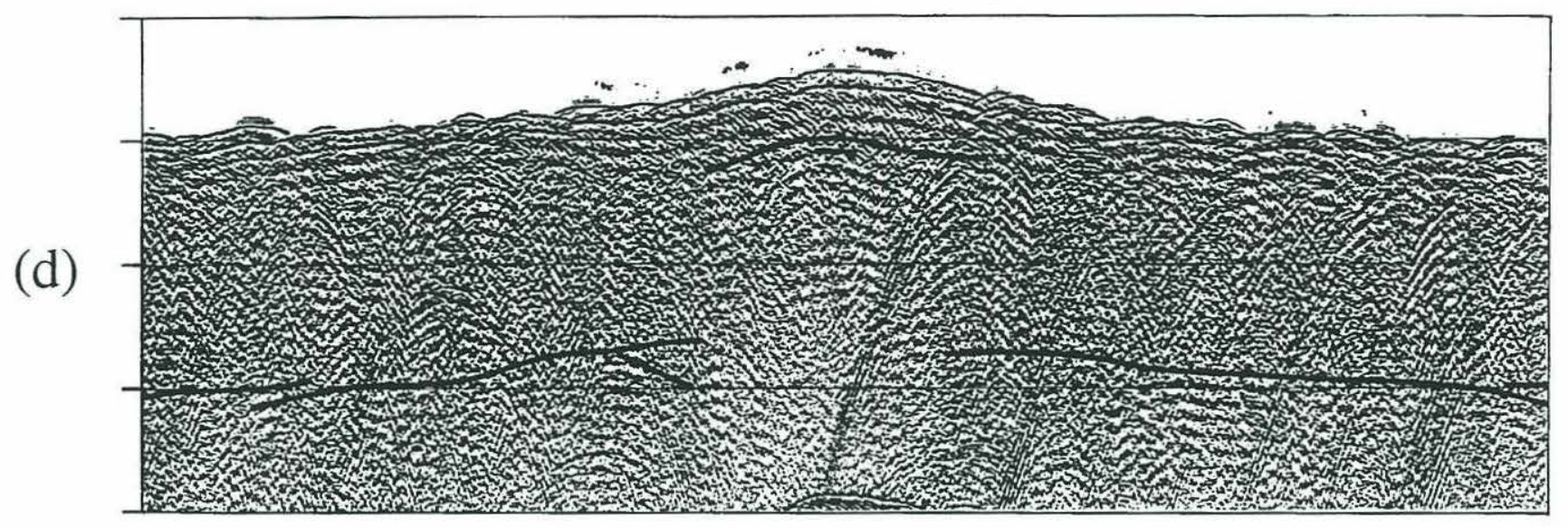

559
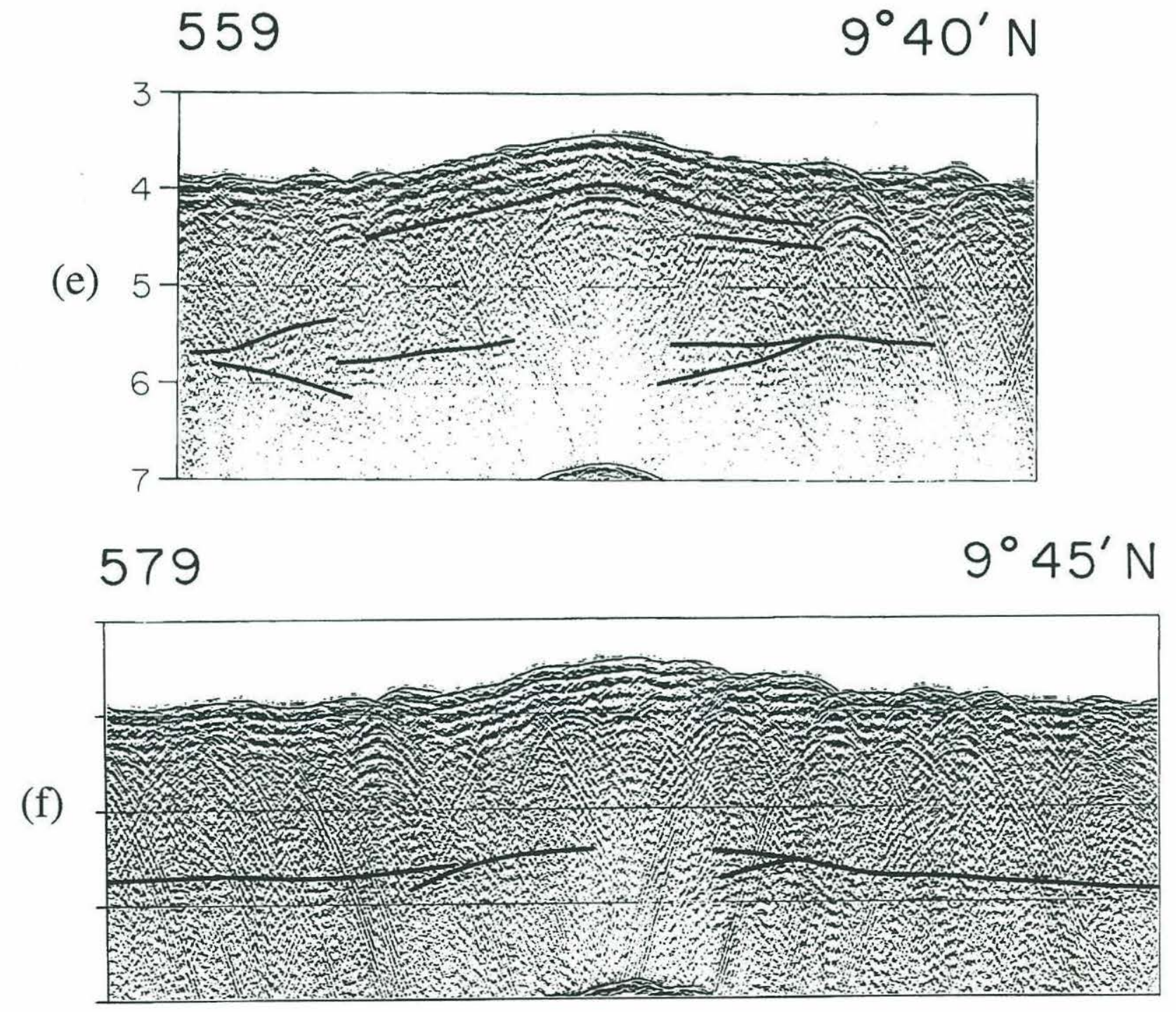


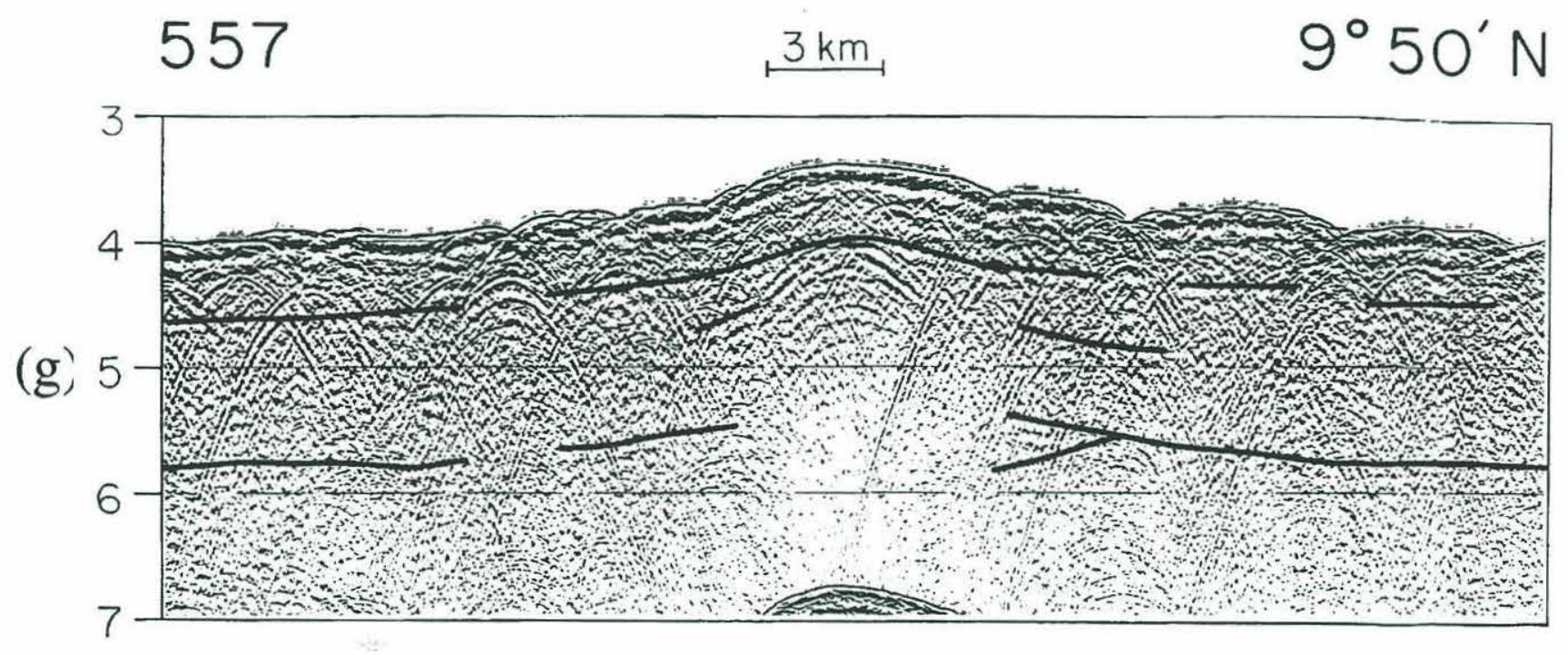

\section{Barth [1991]}


Figure 5.6. Gravitational attraction at the sea surface predicted from the geometry of the following interfaces: (a) the seafloor; (b) between layers 2A and 2B; (c) between layers 2B and 3; and (d) the Moho. The gravitational attraction of the seafloor dominates the summed gravitational attraction, because it is the interface with the largest density contrast and is the nearest to the observation datum. 


\section{Attraction from various layers}

(a) Water/Layer $2 \mathrm{~A}$

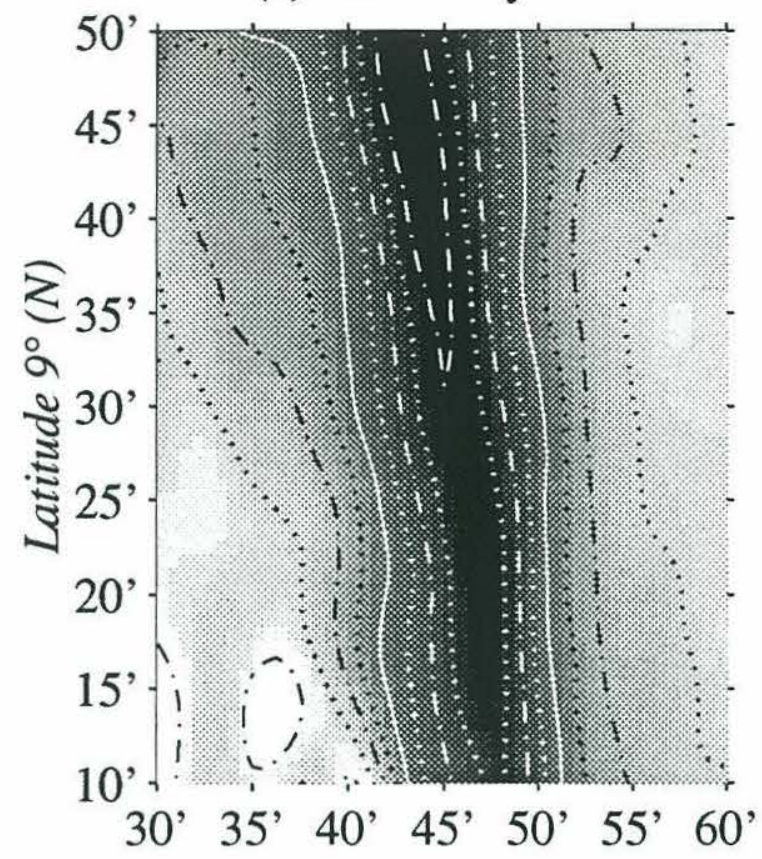

(c) Layer $2 \mathrm{~B} / 3$

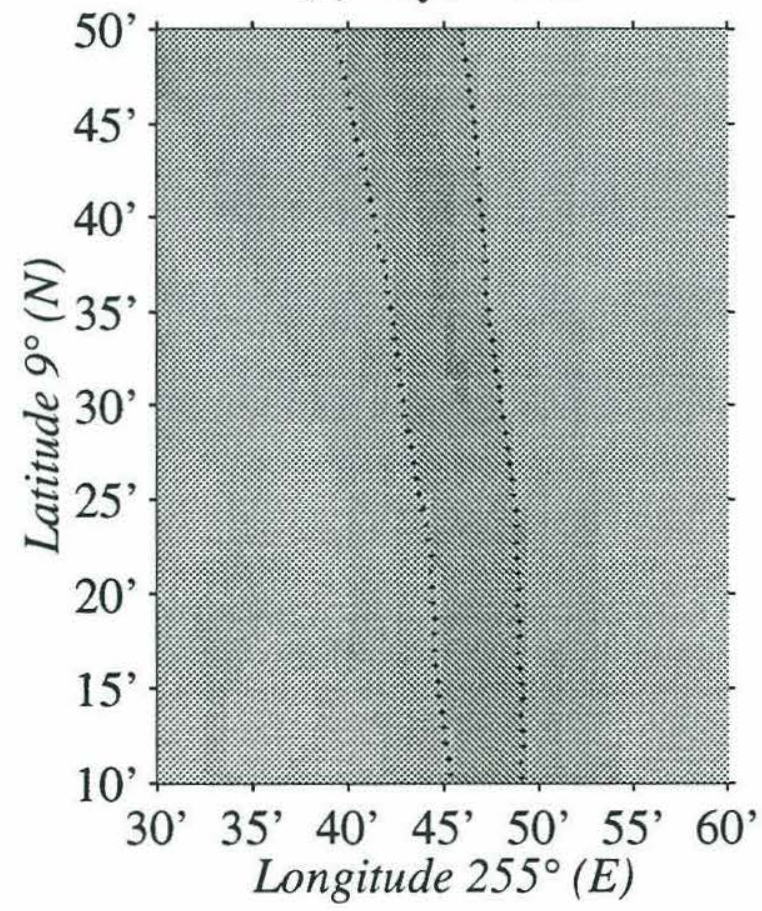

(b) Layer $2 \mathrm{~A} / 2 \mathrm{~B}$

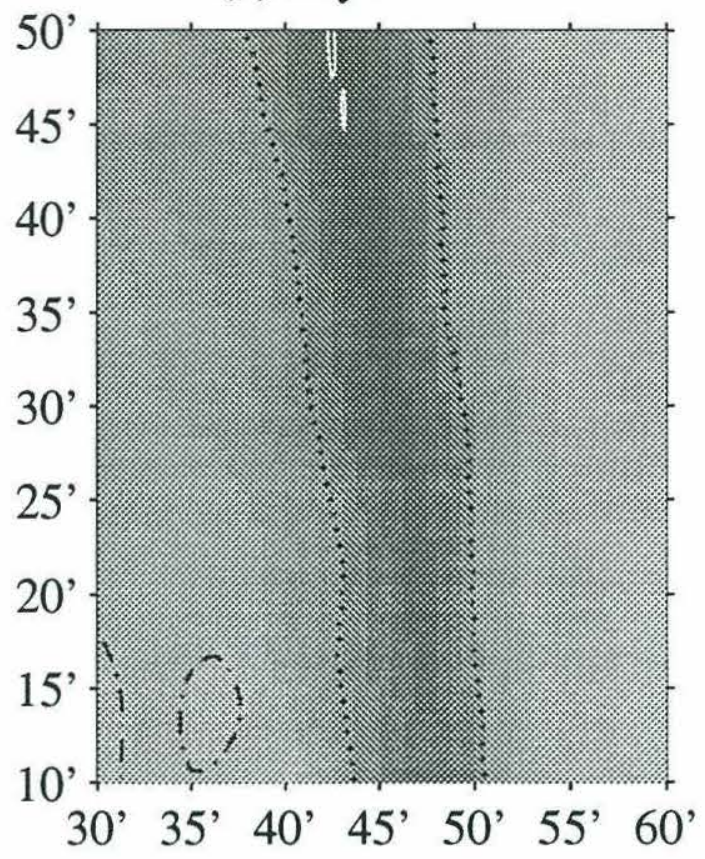

(d) Layer 3/Mantle

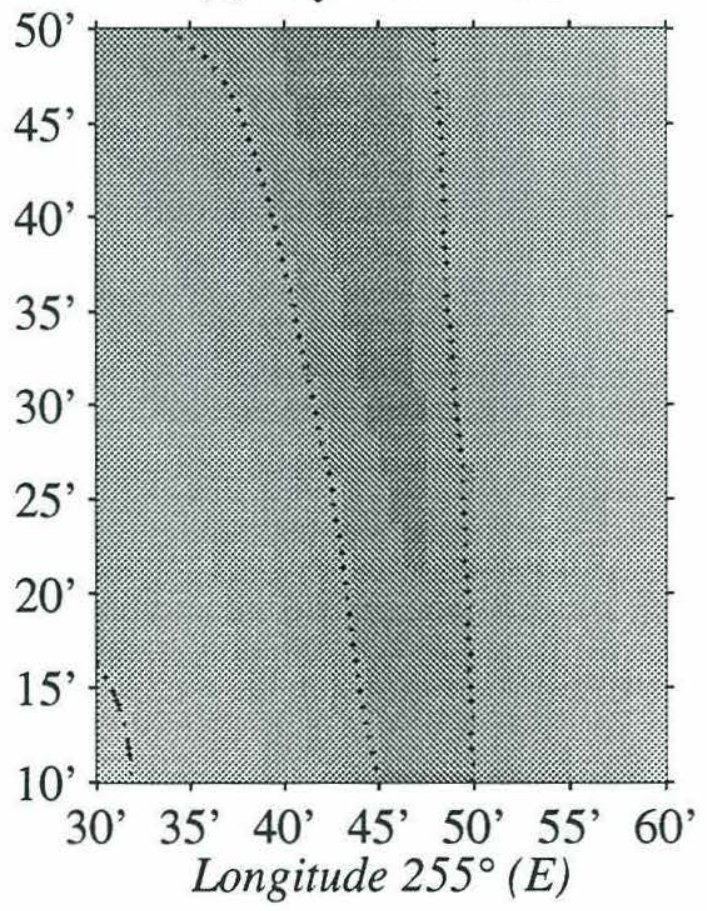

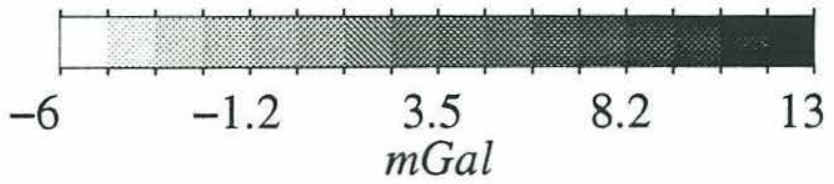


Figure 5.7. Mantle Bouguer anomaly map, obtained after correcting for the gravitational attraction of the various crustal layers of the rise. The white crosses represent the bathymetric axis of the rise. 


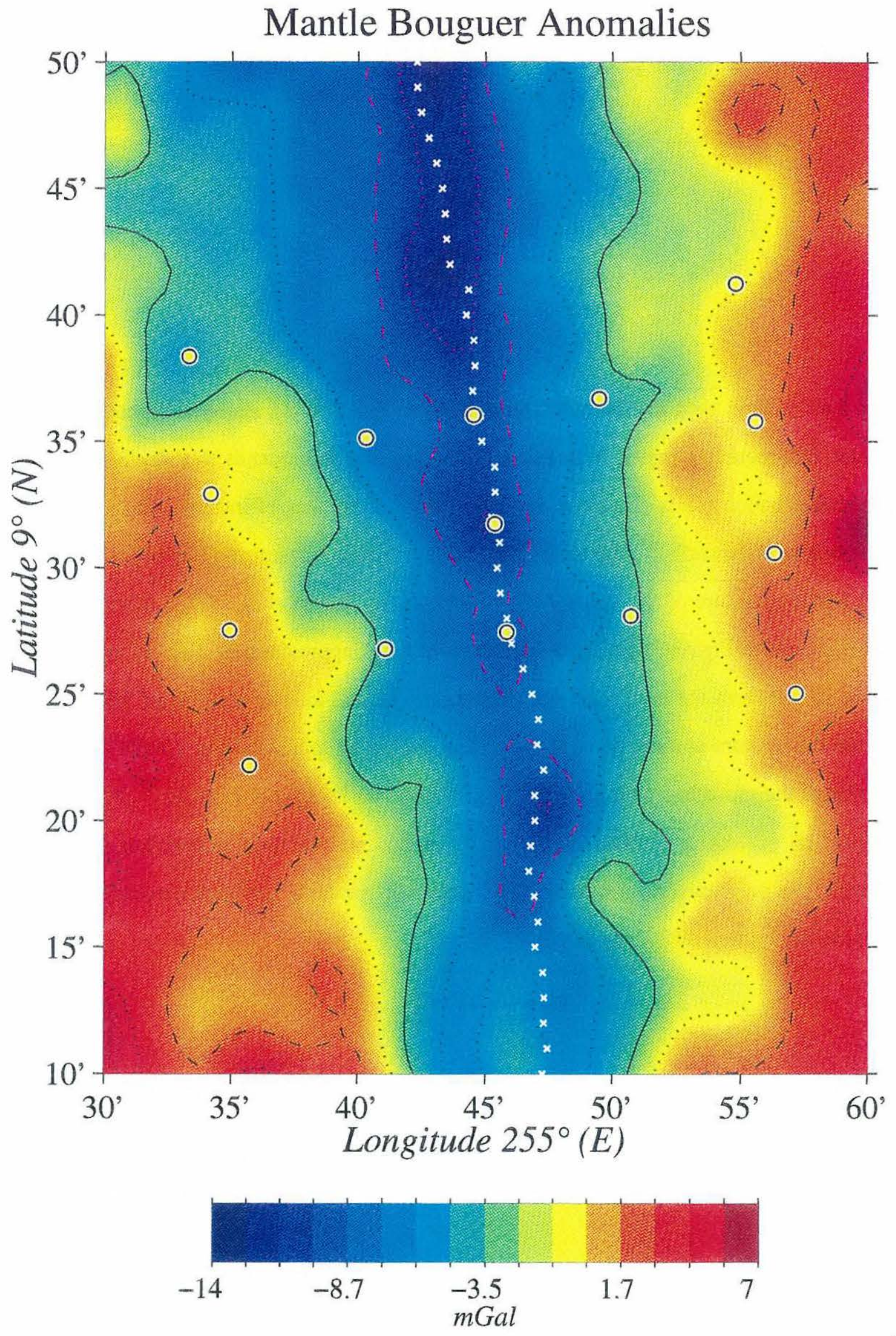


Figure 5.8. Grid used for finite difference analysis to solve the steady-state heat flow problem. Our modeling region begins $10 \mathrm{~km}$ from the axis and extends to a depth of 100 $\mathrm{km}$ from the seafloor. It is also more densely gridded in the area of interest, which is the axial region near the surface. The temperature at the seafloor is assumed to be $0^{\circ} \mathrm{C}$. At $x=$ $10 \mathrm{~km}$, the temperature of the upper $7 \mathrm{~km}$ is taken from Wilson et al. [1988] (illustration on the right side of Figure 5.4). The temperature, which is approximately $1220^{\circ} \mathrm{C}$ at $7 \mathrm{~km}$ depth at $10 \mathrm{~km}$ from the axis, increases adiabatically $\left(0.8^{\circ} \mathrm{C} / \mathrm{km}\right)$ to a depth of $100 \mathrm{~km}$. Thus the temperature at the base of the modeling region is approximately $1300^{\circ} \mathrm{C}$. The right side of the modeling region is assumed to have no horizontal heat flux. As with Wilson et al. [1988], a uniform slab moving away from the axis at constant rate is assumed. The only remaining variable that affects the resulting temperature distribution strongly is the thermal diffusivity ( $\mathrm{\kappa}$ ). 


\section{Configuration of FDM Model}

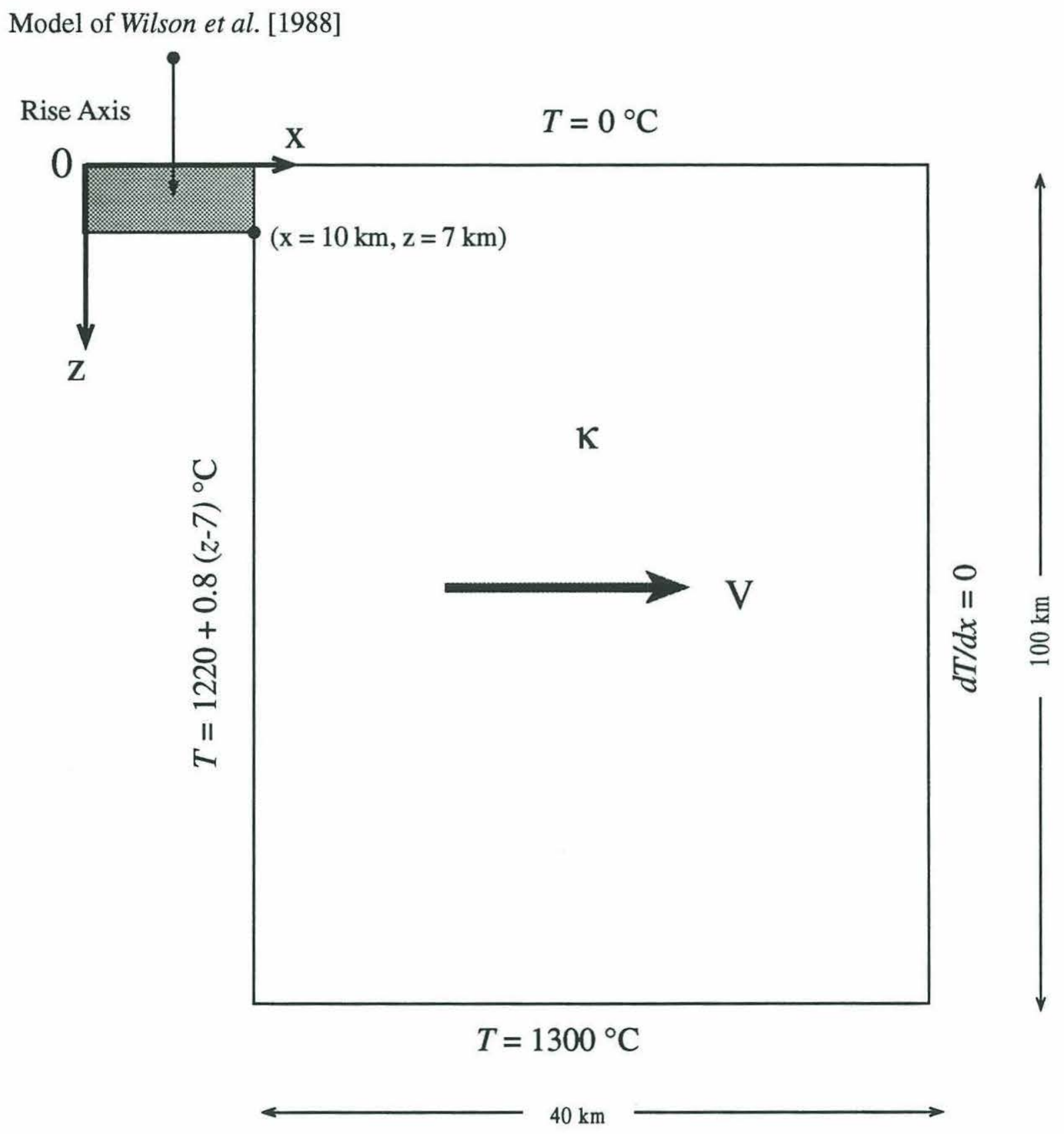


Figure 5.9. Thermal models obtained by prescribing four different values for thermal diffusivity $\mathrm{\kappa}$ : (a) 0.25 ; (b) 1 ; (c) 5 ; and (d) $10 \mathrm{~mm}^{2} / \mathrm{s}$. The dashed lines represent the contours of the 300 and $900^{\circ} \mathrm{C}$ isotherms, and the solid lines 500 and $1100^{\circ} \mathrm{C}$ isotherms. 


\section{Temperature structure as a function of thermal diffusivity}

(a) Therm. Diffusivity $=0.25 \mathrm{~mm}^{2} / \mathrm{s}$

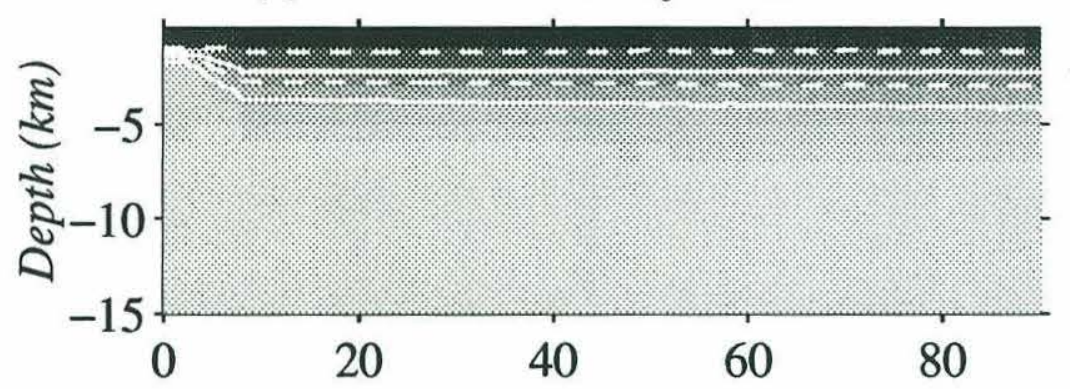

w

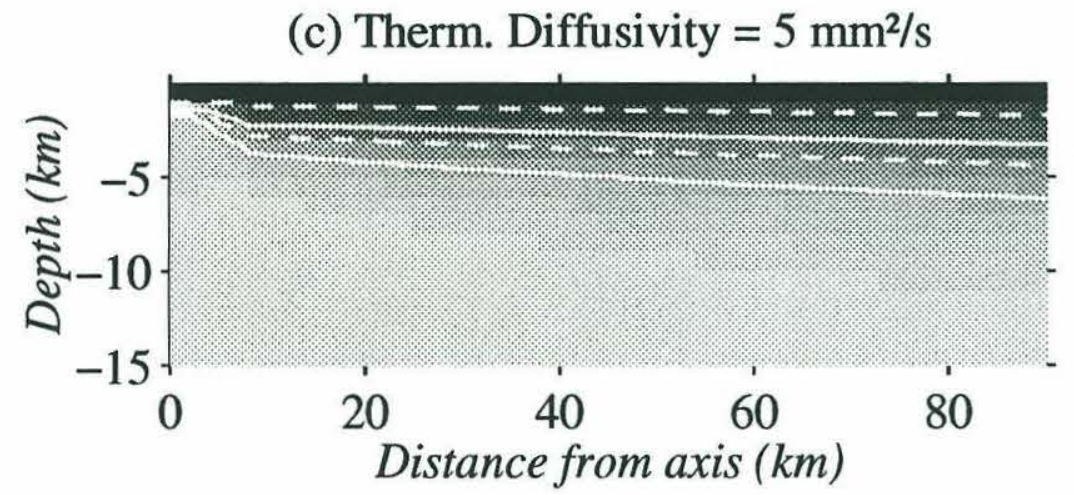

(b) Therm. Diffusivity $=1 \mathrm{~mm}^{2} / \mathrm{s}$

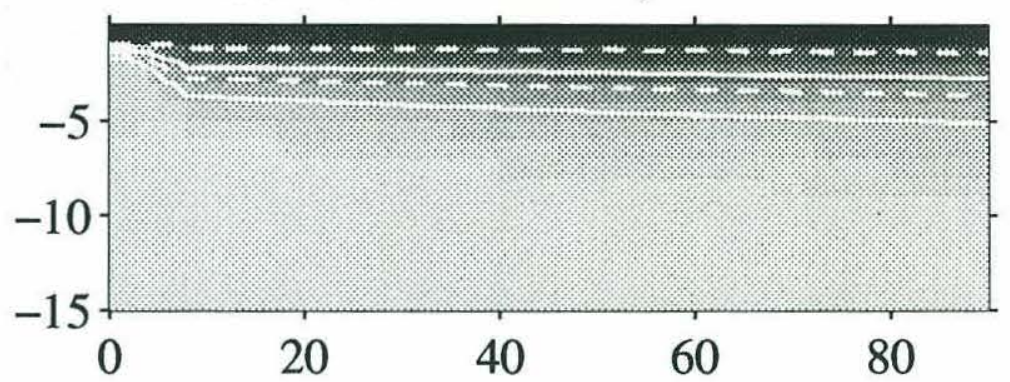

(d) Therm. Diffusivity $=10 \mathrm{~mm}^{2} / \mathrm{s}$

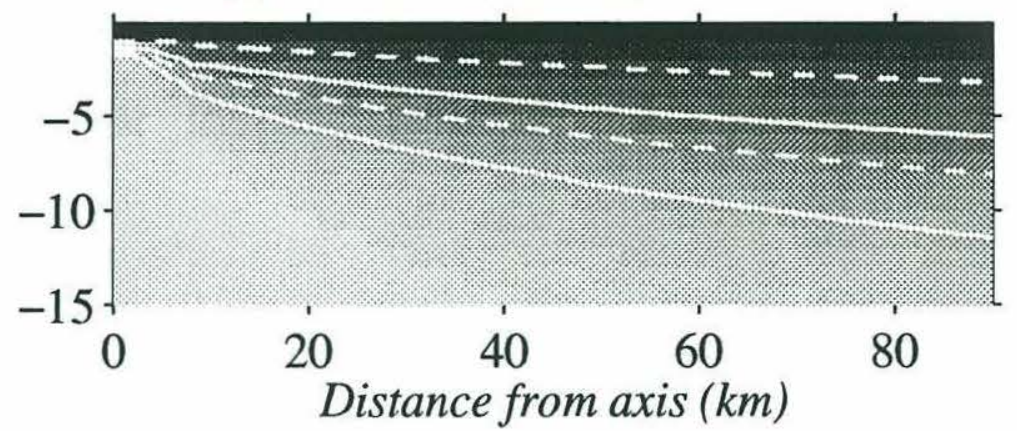

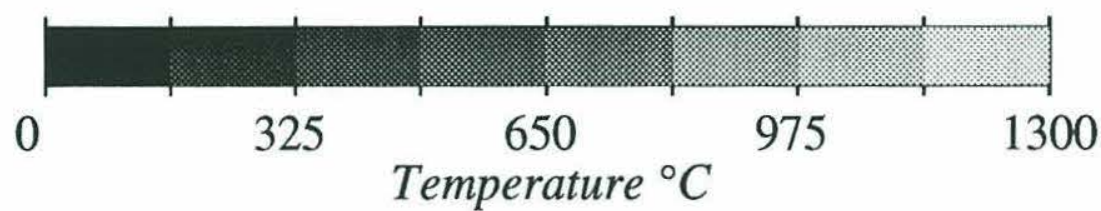


Figure 5.10. Residual gravity anomalies obtained after removing both the gravitational attraction of crustal layers (Figure 5.6) and the effect of plate cooling predicted by the thermal model with a thermal diffusivity $\mathrm{K}$ of $5 \mathrm{~mm}^{2} / \mathrm{s}$ (Figure 5.9 ). The white crosses represent the bathymetric axis of the rise. 

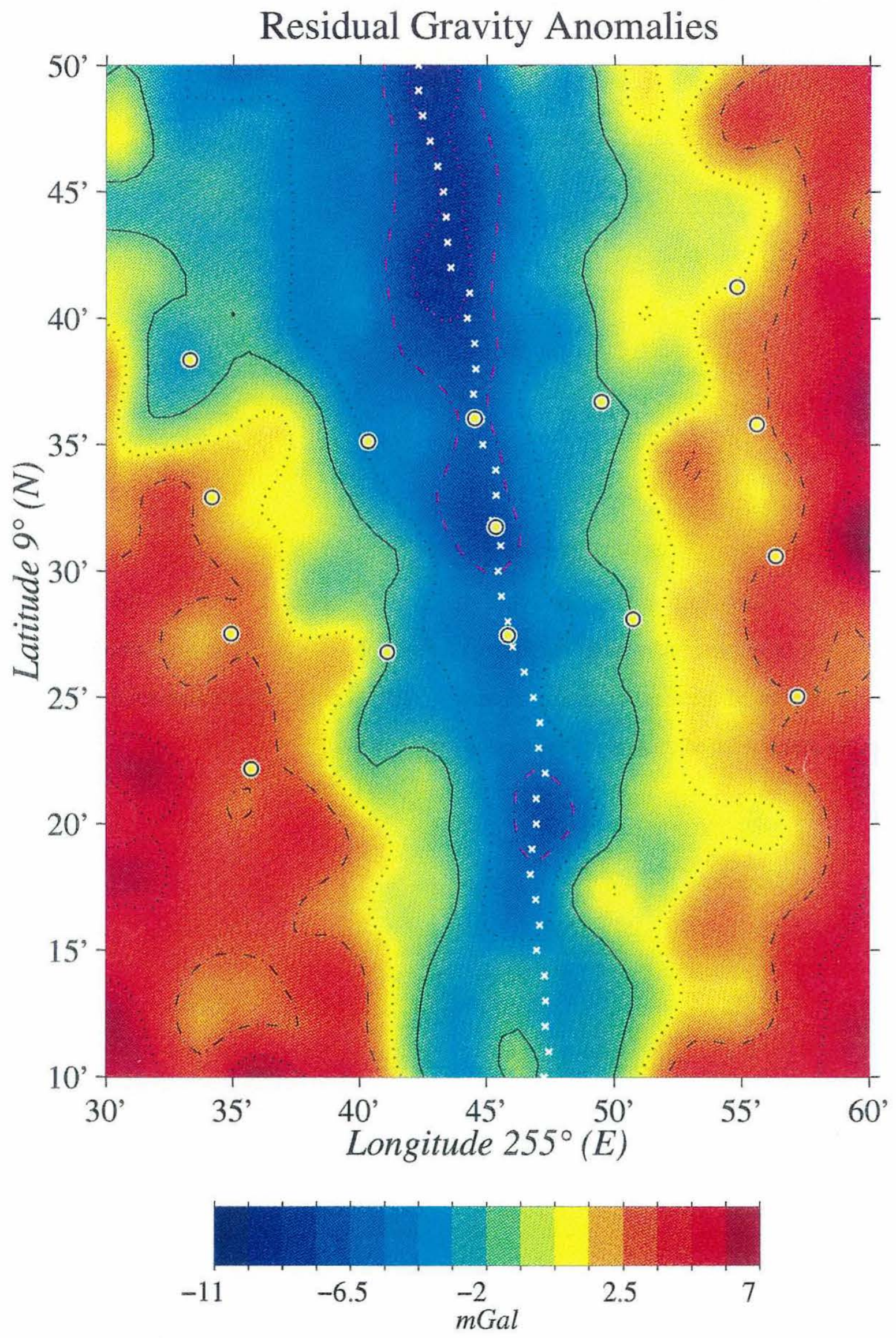
Figure 5.11. Variations in the thickness of layer 3 obtained from a downward continuation of the residual gravity anomalies of Figure 5.10. (a) Solution obtained after lowpass filtering of the residual gravity anomalies with an empirically determined cosine taper; (b) solution based on a maximum smoothness criterion. 


\section{Estimated variations in crustal thickness}

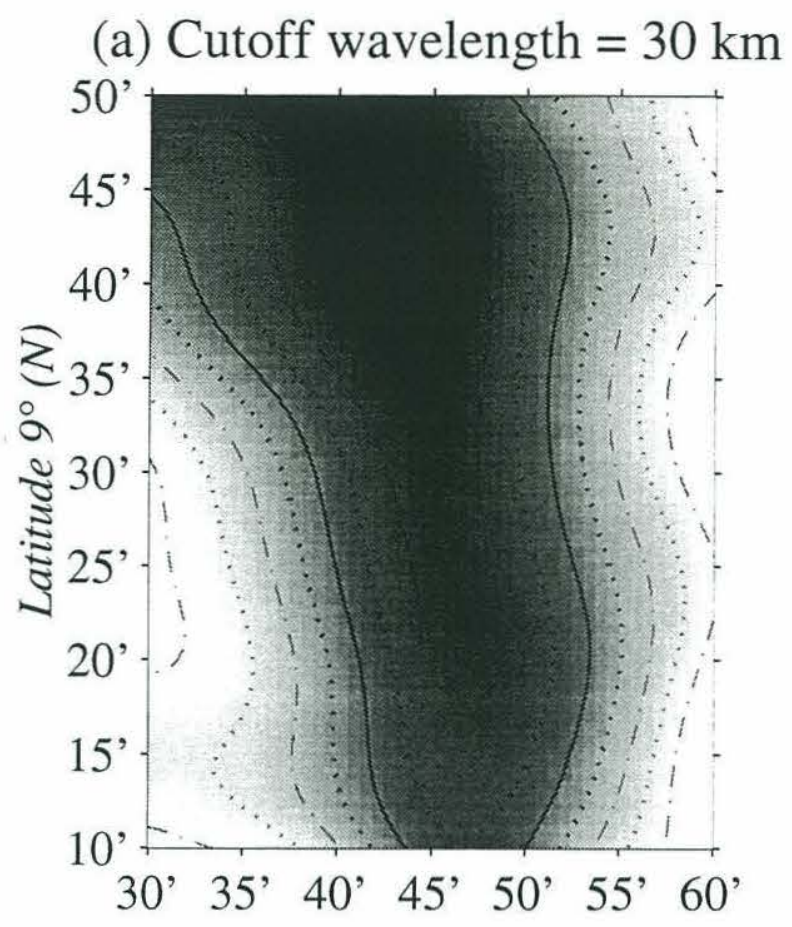

(b) Maximum smoothness criterion
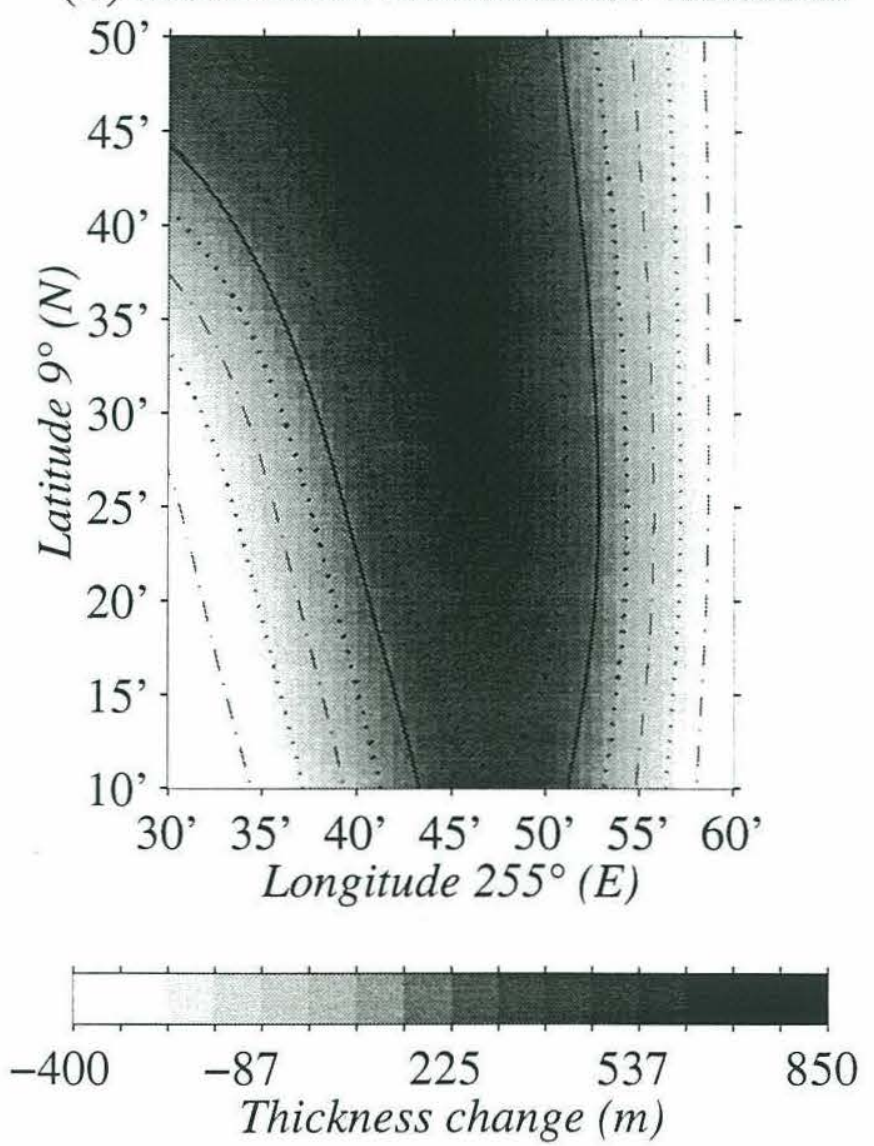
Figure 5.12. Local residual gravity anomaly, obtained after removing the residual anomaly map (Figure 5.10) a low-frequency contribution using a two-dimensional highpass filter with cosine tapering between a stopband cutoff wavenumber of $2 \pi / 40 \mathrm{~km}^{-1}$ and a passband cutoff wavenumber of $2 \pi / 20 \mathrm{~km}^{-1}$. The box represents the area where seismic tomography images where obtained [Toomey et al., 1990]. The white crosses represent the bathymetric axis. 


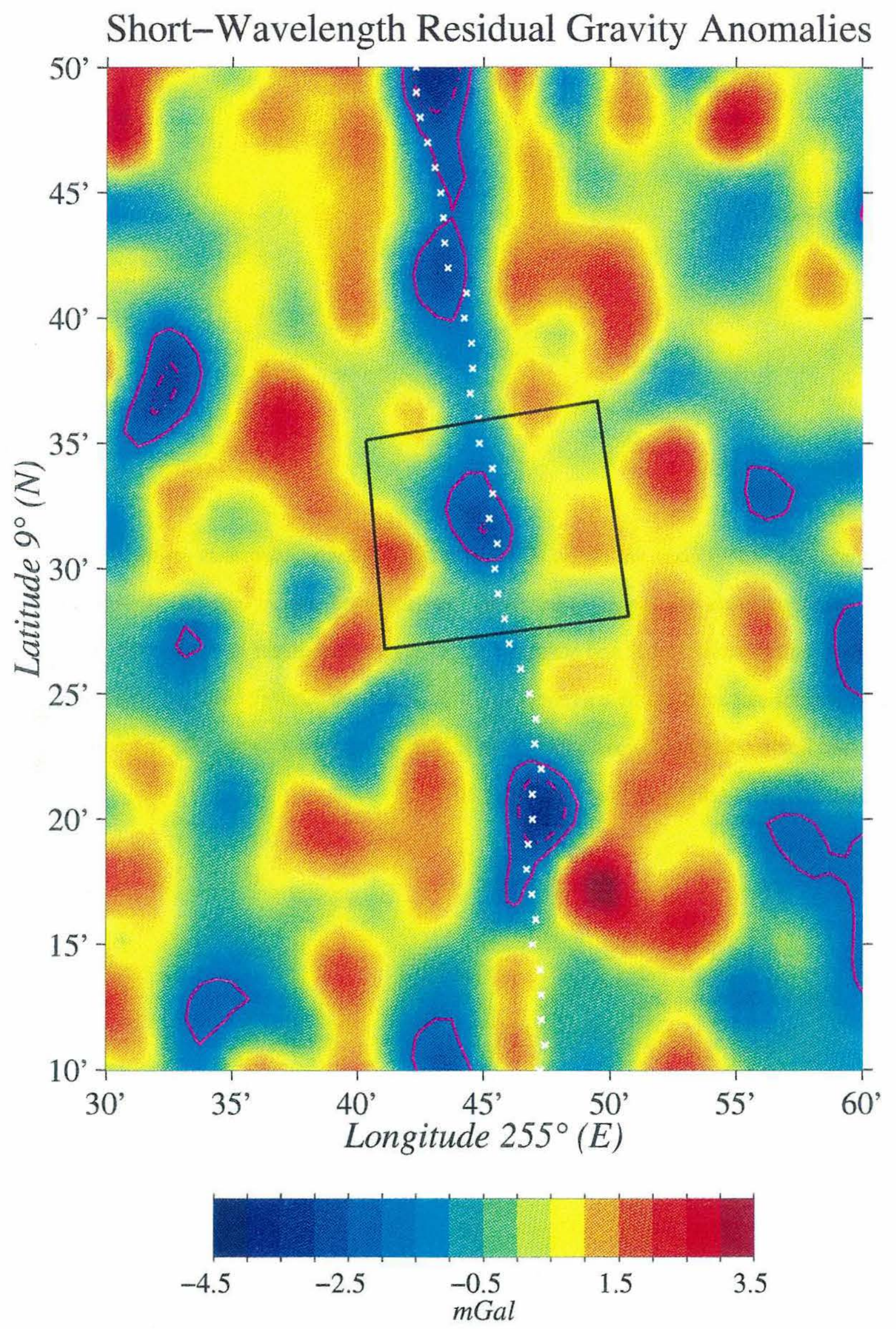


Figure 5.13. Along-axis variations of local residual gravity anomalies using different cutoff wavenumbers for the highpass filter. We assumed cosine tapering between the passband cutoff wavenumber and stopband cutoff wavenumber half as great. The results are shown for stopband cutoff wavenumber of (a) $2 \pi / 20$; (b) $2 \pi / 40$; and (c) $2 \pi / 60 \mathrm{~km}^{-1}$. The solid line represents the case where a linear trend along the axis was removed from the unfiltered residual gravity anomaly (Figure 5.10). 


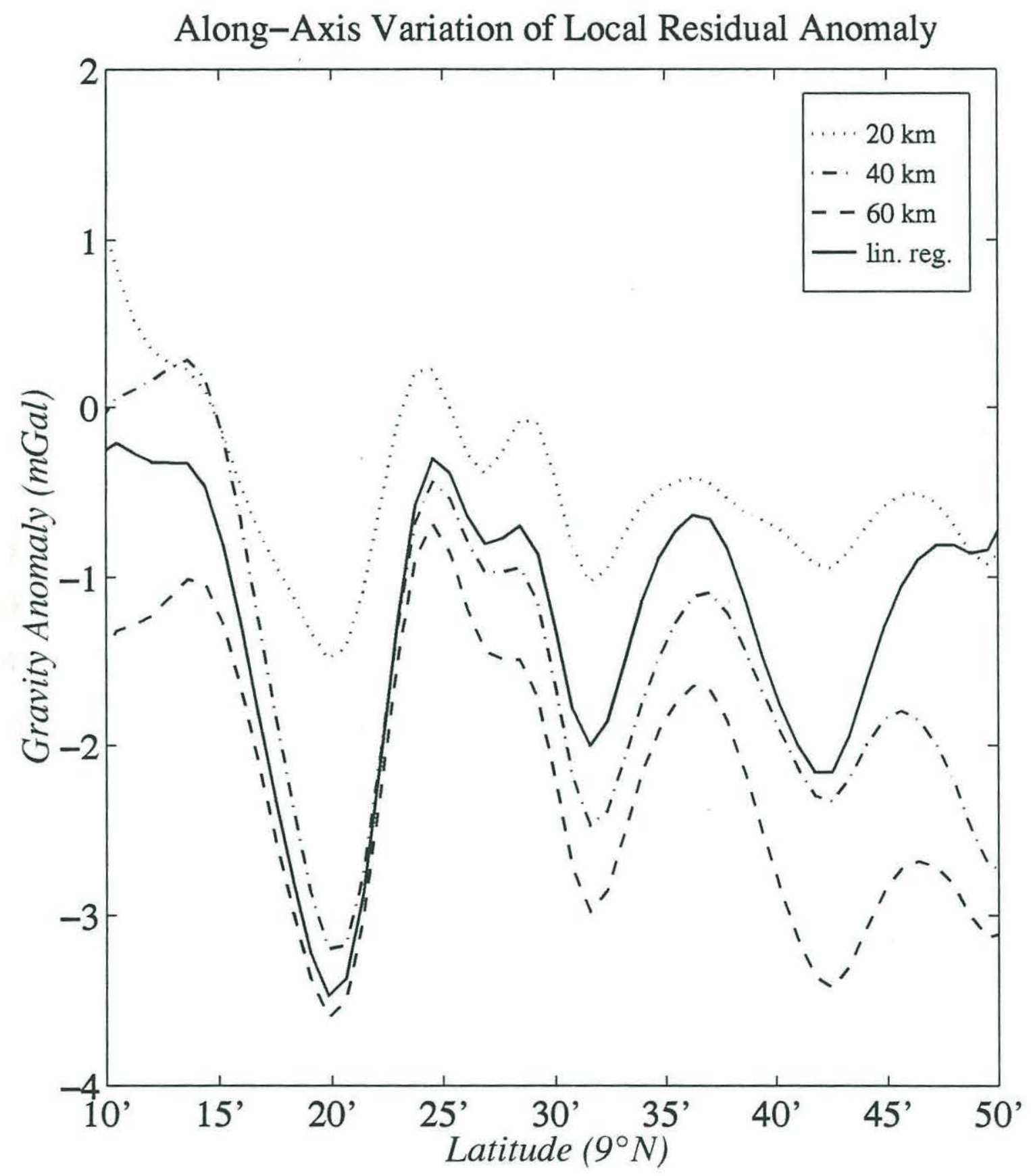

(Figure 5.13) 
Figure 5.14. Comparison of the observed variation of local residual gravity anomaly (Figure 5.12) and the modeled gravity anomaly (a) along and (b) across the axis. In calculating the modeled gravity anomaly, we assumed that there are three anomalous cylindrical bodies of circular cross-section beneath the seafloor. These anomalous bodies are equal in dimensions and depths beneath the seafloor and their centers coincide with the centers of the gravity lows (i.e., $9^{\circ} 21^{\prime}, 9^{\circ} 32^{\prime}$, and $9^{\circ} 42^{\prime} \mathrm{N}$ ). Also, we fixed the radius at 1 $\mathrm{km}$, the along-axis length at $10 \mathrm{~km}$, and the depth to the top of the anomalous body at 1.25 $\mathrm{km}$ beneath the seafloor. Density contrasts of 350,200 , and $200 \mathrm{~kg} / \mathrm{m}^{3}$ for the anomalous cylindrical bodies at $9^{\circ} 21^{\prime}, 9^{\circ} 32^{\prime}$, and $9^{\circ} 42^{\prime} \mathrm{N}$, respectively, provide the best match to the observed local residual gravity anomaly. As with the local residual gravity anomaly, the modeled gravity anomaly was highpass-filtered using a stopband cutoff wavenumber of $2 \pi / 40 \mathrm{~km}^{-1}$. In (b) the profiles were shifted vertically by a constant amount so that the troughs of the observed and modeled gravity anomaly profiles match at 0 and $-2 \mathrm{mGal}$, respectively. 
(a) Observed vs. Modeled Residual Anomalies Along Axis

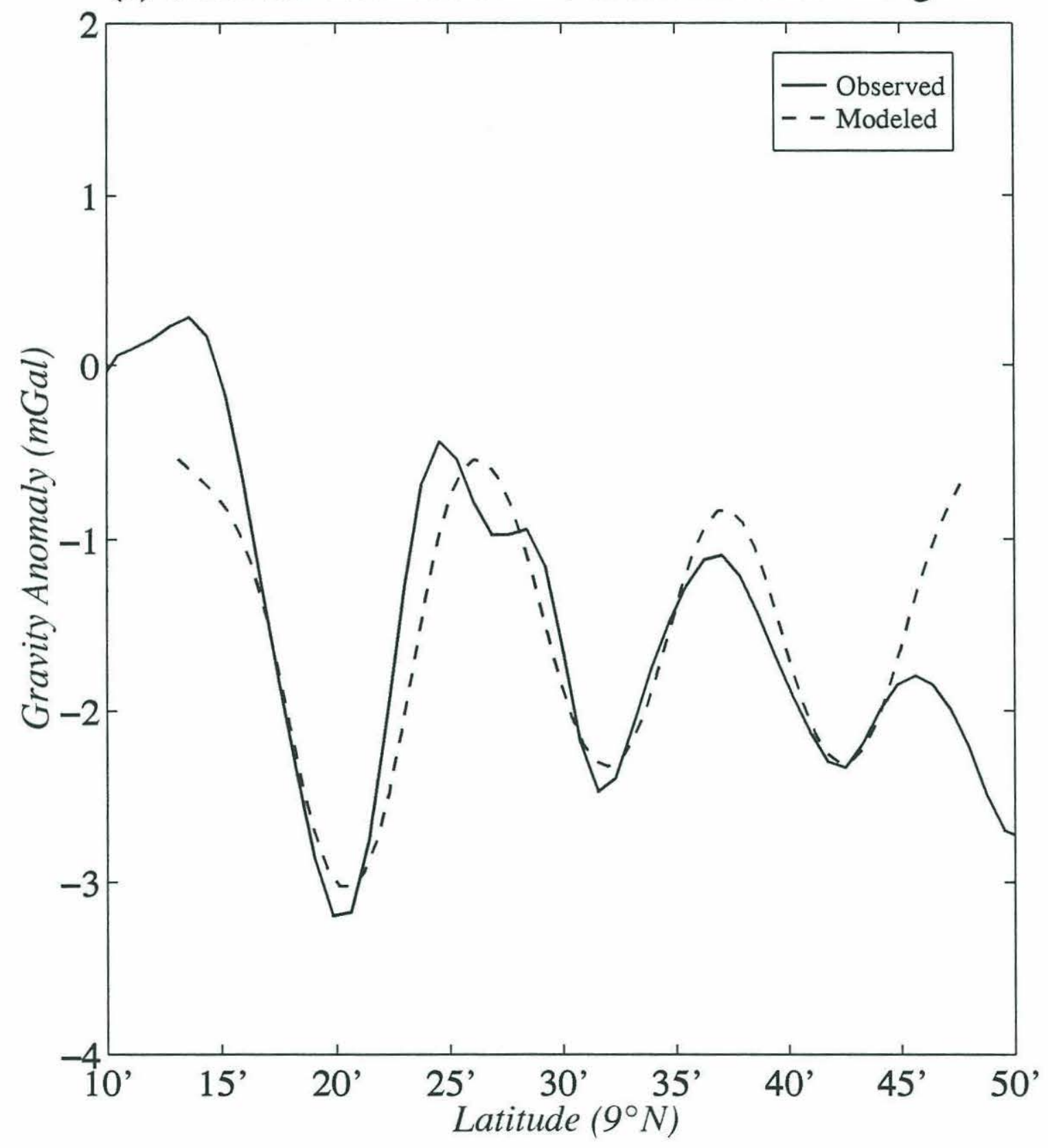


(b) Observed vs. Modeled Residual Anomalies Across Axis

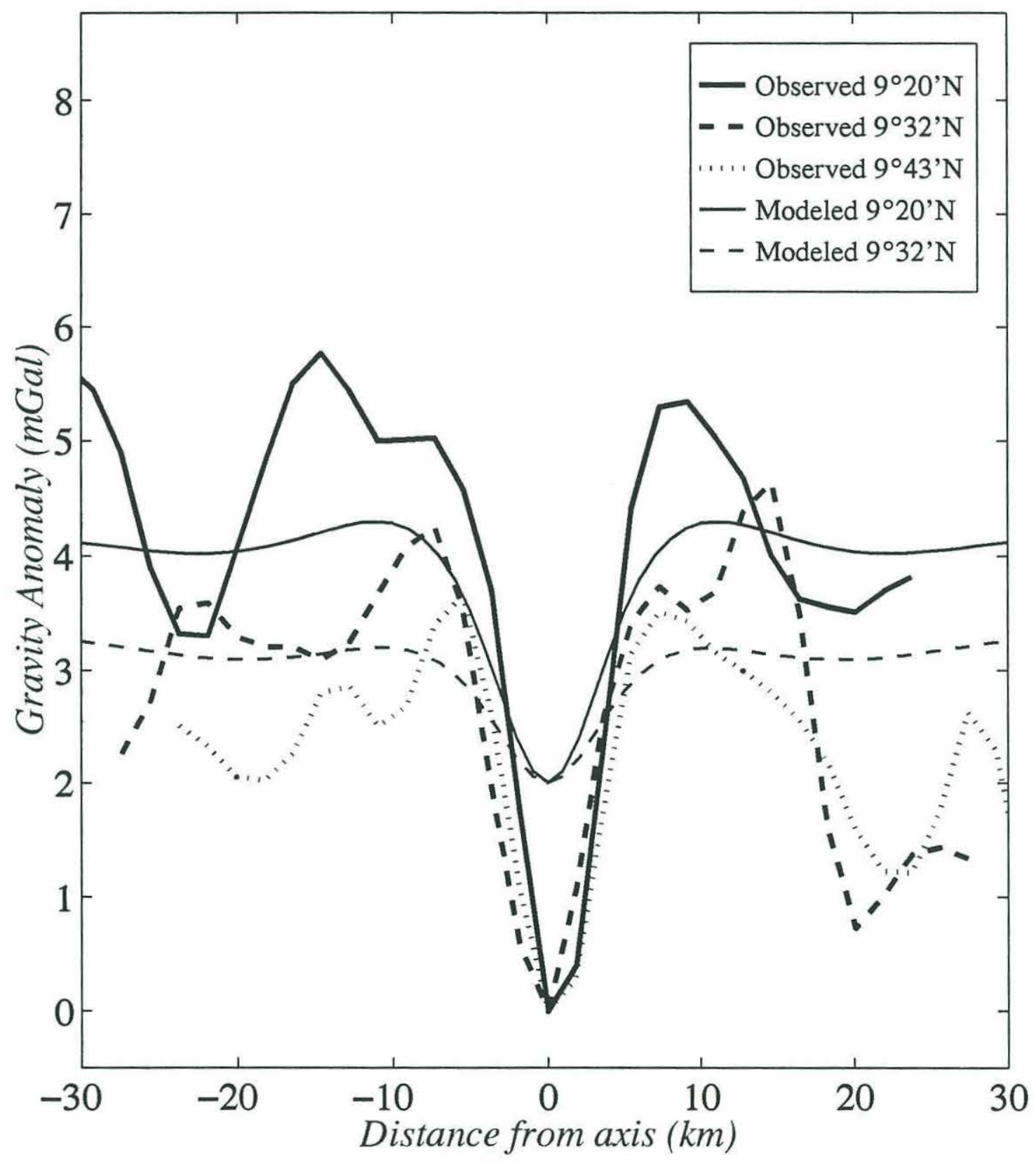


Figure 5.15. Horizontal cross-sections through a three-dimsional P-wave velocity (in $\mathrm{km} / \mathrm{s}$ ) structure obtained from delay-time tomography [after Toomey et al., 1990]. (a) At the seafloor, and (b) $2 \mathrm{~km}$ depth. 

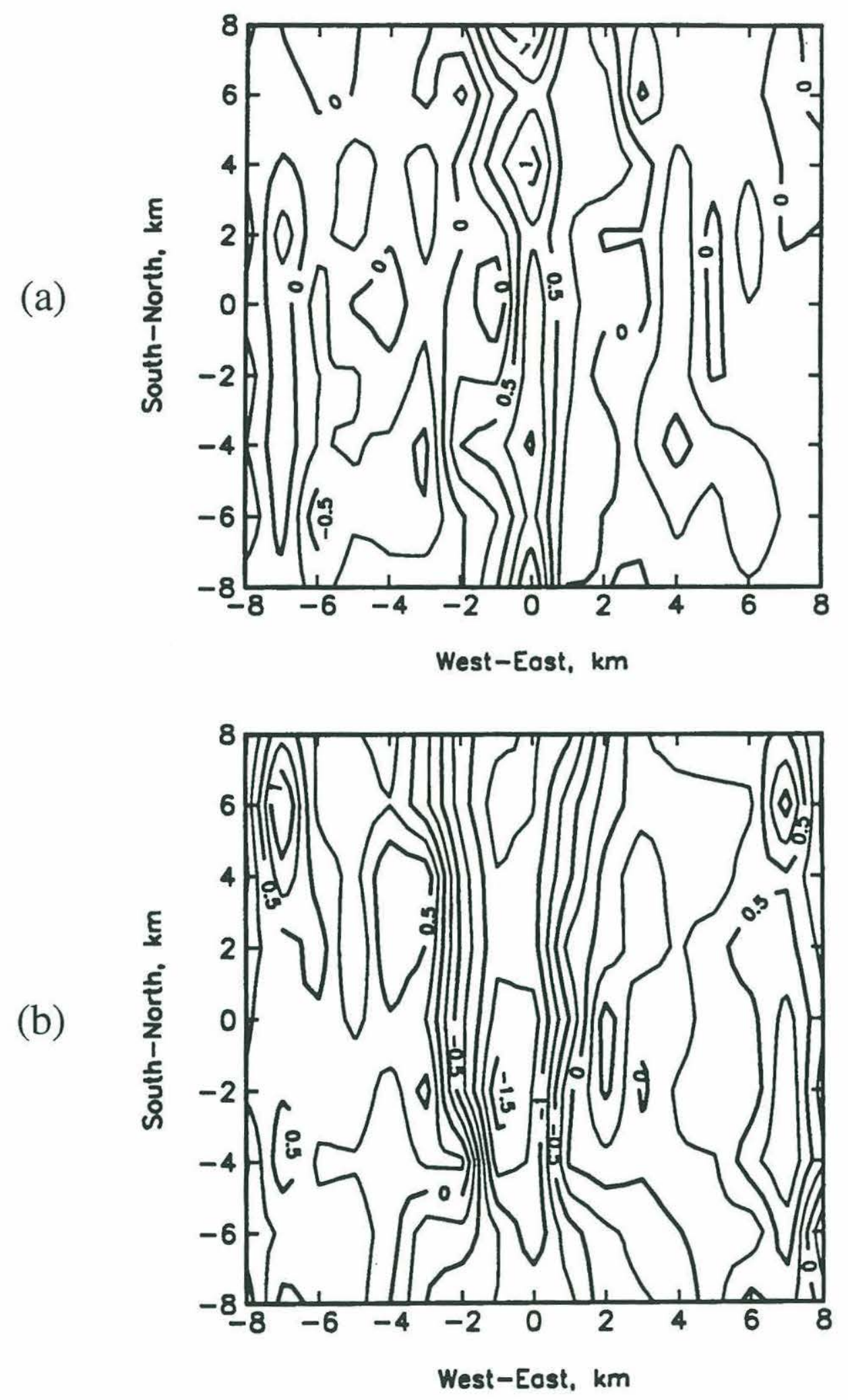
Figure 5.16. Estimates of crustal thickness beneath the EPR between $8^{\circ} 50^{\prime}$ and $9^{\circ} 50^{\prime} \mathrm{N}$, based on measurements of travel time between the seafloor and the Moho along CDP lines of the 1987 multichannel seismic reflection survey [Detrick et al., 1987], from Barth and Mutter [1994]. These results were obtained by assuming that all travel-time anomalies arise within layer 3 . 


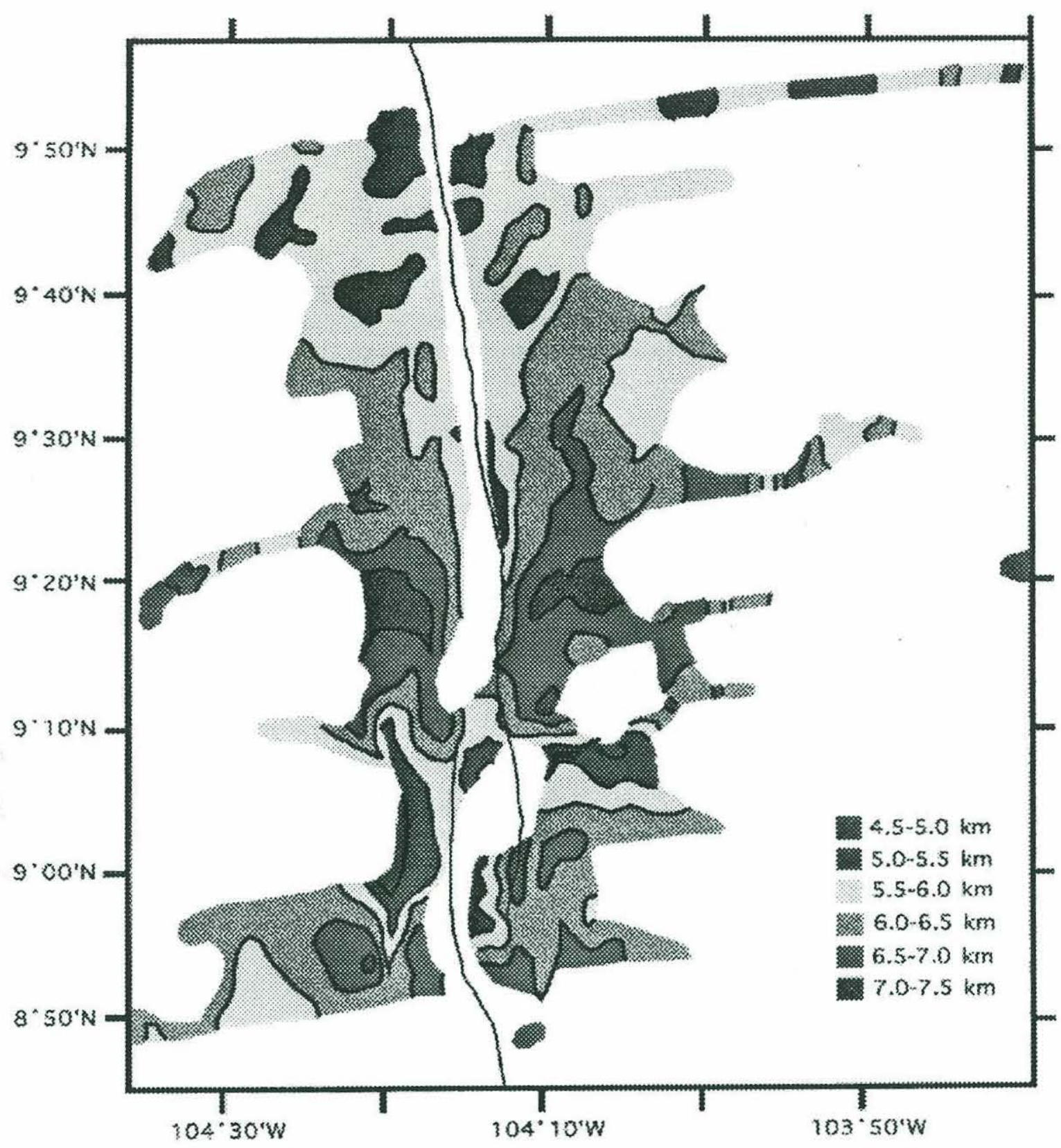

Barth and Mutter [1994] 
Figure 5.17. A schematic diagram illustrating the density structure of the EPR inferred from the analysis of gravity anomalies and from results of other investigations conducted over the same general area. The source of low-density beneath the axis may be divided into sources within and below the crust. The series of distinctive short wavelength gravity lows near the rise axis corresponds to regions of high melt concentrations within the crust. In our survey area, the local lows appear almost regularly-spaced along the rise axis and are surrounded by a region of lesser melt concentration but of greater along-axis continuity which probably corresponds to the LVV imaged with seismic tomography. As the OSC at $9^{\circ} 03^{\prime} \mathrm{N}$ is approached, the local gravity low may become offset and eventually divide into two anomalies. With increased magmatic activity beneath the Pacific plate, the magmatic axis (shown as a dashed line in the top figure) may also migrate to the west. These local gravity lows are replenished by sources in the upper mantle as indicated by upward arrows in the bottom figure. Shading in the lower figure represents the density structure of the upper mantle, with regions of lower density indicated by darker shades. The increase in the width of the residual gravity low to the north suggests that the region to the north is hotter and receiving a greater flux of magma than that to the south. 


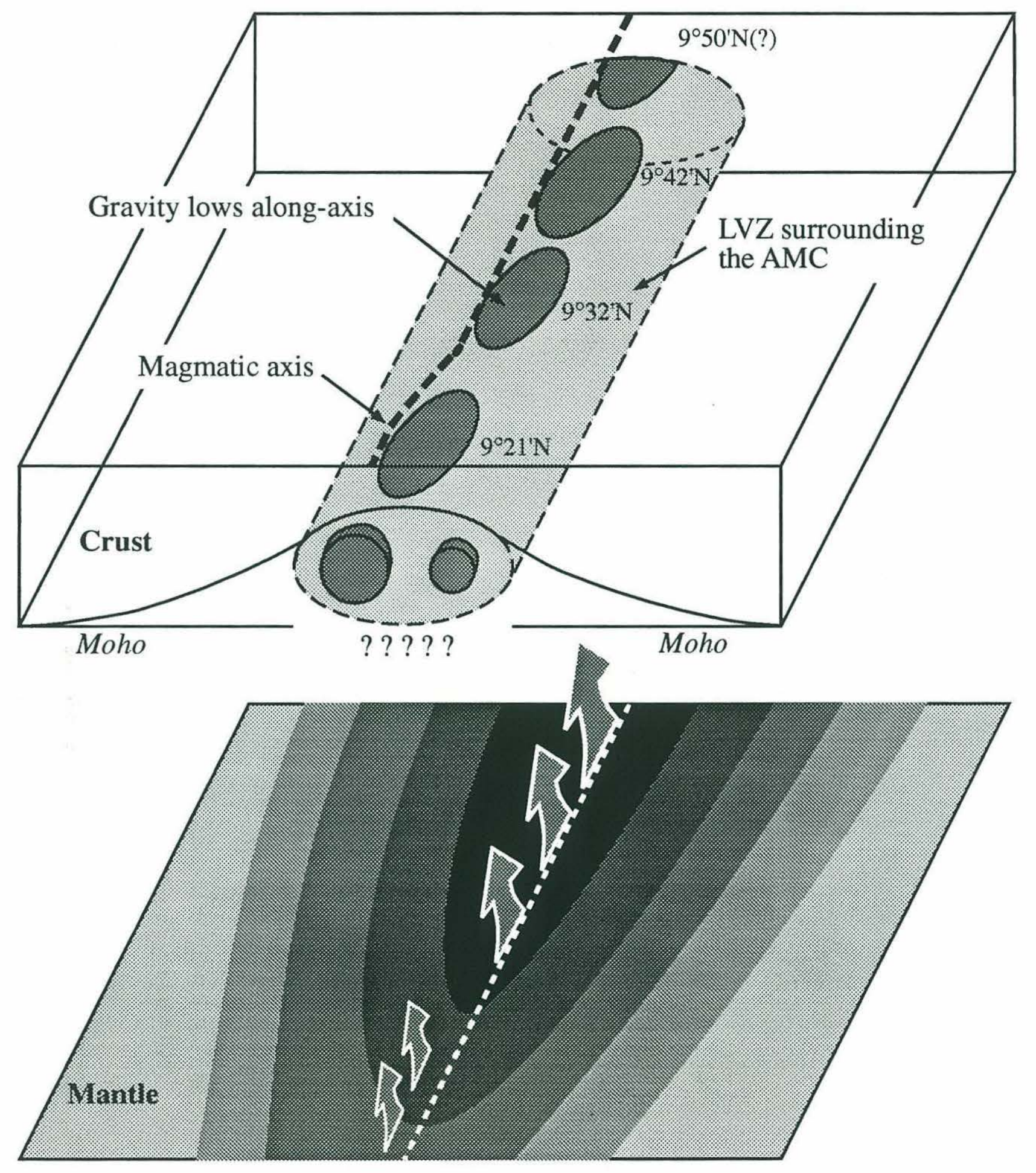

Density structure of the upper mantle 


\section{Chapter 6}

\section{Conclusions}

\section{Review of Primary Results}

A multidisciplinary approach is often the most beneficial way to gain insight into any geological structure or process. This is because, although each type of observation may be limited by spatial or temporal resolution or by inherent nonuniqueness, together these observations can provide important constraints on the detailed structure and processes. Through a diverse set of observations, we were able to document a number of important aspects of the East Pacific Rise (EPR), including the initiation and development of normal faults on the seafloor, the magnetization structure of the upper crust, and the density structure of the crust and upper mantle. This chapter attempts to integrate the different views arrived at through these diverse observations and analyses into a new tectonic model for fast-spreading ridges. We begin by reviewing the primary results of our investigations. Figure 6.1 summarizes some of the important results from our investigations as well as those from other researches pertinent to our interpretations.

Despite the general acknowledgment of normal faults as the basic tectonic element of the EPR, there has been considerable disagreement among investigators on some of the characteristics such as the distance from the ridge axis to which normal fault activity 
continues and the number of inward- versus outward-facing normal faults. Many of these disagreements can be attributed in part to the different types of instruments and the data processing schemes that were used to analyze normal faulting [Cowie et al., 1994]. In this study, we used a relatively simple scheme for estimating the abundance of normal fault scarps at a given distance from the axis; we gridded individual swaths of Sea Beam into fine-scale grids of equal area $(20 \mathrm{~m} \times 100 \mathrm{~m})$ and then counted those grid elements within which the dip angle exceeded a critical angle $\left(30^{\circ}\right)$. This analysis showed that the planview area of fault zones increases to a distance of at least $30 \mathrm{~km}$ from the axis. Since the plan-view area of fault zones can increase with off-axis distance simply because of mass wasting, however, we examined how fault zone throws vary with distance. Our analysis of fault zone throws not only confirmed previous observations that the axial region of the EPR is generally free of large-offset normal faults, but also provided new evidence for continued normal faulting to a distance of at least $30-40 \mathrm{~km}$ from the axis. We also found that, in our survey area, the midpoint between the nearest large-offset normal faults on either side of the axis does not always coincide with the bathymetric axis. According to a recent investigation of the distribution of the axial magma chamber (AMC) reflector [Kent et al., 1993a, b], there is evidence that the AMC reflector is offset to the west of the bathymetric axis to the south of $9^{\circ} 23^{\prime} \mathrm{N}$ (Figure 6.1g), which coincides with the offset in the midpoint between the nearest large-offset normal faults on either side of the axis in the same general area (Figure 6.1b).

An extensive modeling effort was performed to understand the two important characteristics of normal faulting on the EPR: the initiation of normal faults a few kilometers off-axis and the continued development of these faults farther off-axis. We examined stress and strain fields in the upper crust arising from two sources, the buoyancy that low-density regions in the lower crust, such as the AMC and the surrounding lowvelocity volume, exert on the upper crust, and gravitational spreading as a result of a mechanically strong upper crust trying to slide over a relatively weak lower crust. The 
stress and strain fields were modeled using the boundary element method and, to simplify our modeling effort, we assumed that the modeled regions, including those beneath the upper crust, are elastic media with variable moduli rather than low-viscosity fluids.

The results of both buoyancy and gravitational spreading modeling showed that the boundary condition of the rise axis, that is, the mechanical strength of the rise axis, can have a great effect on the near-axial stress field. If the rise axis is mechanically strong, the extensional stress due to buoyancy would be concentrated at the axis. On the other hand, if the rise axis is mechanically weak, the peak extensional stress occurs off-axis. While this occurrence of peak extensional stress off-axis may explain the initiation of normal faults, the extensional stresses resulting from buoyancy do not extend far enough from the axis (< $10-15 \mathrm{~km}$ ) to explain continued normal fault activity to distances of $30 \mathrm{~km}$ or more. The presence of partial melt below the upper crust may also be important since it can lower the magnitude of stress in the upper crust near the axis for cases with a mechanically weak rise axis.

It is difficult to predict the style of faulting from the results of gravitational spreading modeling other than to obtain a general understanding of the importance of several factors. This is because the details of the stress field depend largely on factors such as the ease at which the upper crust can slide over the lower crust and boundary conditions at the far end of the modeled region, which are presently not well constrained. An important characteristic of gravitational spreading models is that, as with the case of buoyancy, a mechanically strong rise axis would cause a zone of large horizontal extensional stress to develop on the rise axis. This is not consistent with off-axis initiation of normal faults. A weak rise axis with an extremely weak lower crust (e.g., an inviscid fluid) would also be inconsistent with the observation of normal faults because it predicts horizontal compressional stress within the upper crust whose magnitude increases with distance from the rise axis. 
Our treatment of buoyancy differs from previous investigations [e.g., Madsen et al., 1984; Wang and Cochran, 1993] in several ways. In the model of Madsen et al. [1984], the lithosphere was considered to be underlain by a region of inviscid fluid, and therefore no shear stress could be applied at its base. In that case, a buoyant force could not explain normal faulting at the seafloor, because it causes the lithosphere to bend in a concave upward manner, in which case the upper half of the lithosphere is compressed while the lower half is extended. However, we assumed the lower crust to have a finite strength, thus allowing shear stress to be transmitted across the interface between the upper and lower crust. We found that, if the strength of the lower crust is sufficiently large, the buoyant force will cause the crust to bend in a convex upward manner, in which case the upper crust will be extended. Therefore, our treatment of buoyancy is consistent with the presence of normal faults at the seafloor.

Besides buoyancy and gravitational spreading, there are other sources that are thought to be important contributors of tectonic stress at mid-ocean ridges, including shear stress exerted at the base of the plate by mantle flow and thermal stress due to differential plate cooling. However, previous models of these sources can not explain normal faulting at the seafloor. In previous models of differential cooling [Bratt et al., 1985; Haxby and Parmentier, 1988], for example, horizontal compressional tectonic stress is predicted in the direction parallel to plate spreading within the shallow crust. Mantle induced shear stress can give rise to extensional stress, but at fast-spreading ridges, because of a low-viscosity region in the upper asthenosphere, the extensional stress in the lithosphere is not large enough to cause brittle failure [Chen and Morgan, 1990a, b]. We believe that such predictions are the direct result of the boundary conditions at the rise axis assumed in these models. In previous models, for example, the rise axis was either treated as a stress-free surface [Bratt et al., 1985; Haxby and Parmentier, 1988] or as a surface which is constantly moving at the velocity of plate spreading [Chen and Morgan, 1990a, b], both of which are equivalent to treating the rise axis as a mechanically weak region. However, if 
one assumes the rise axis has a finite strength then, depending on the magnitude of this strength, these sources may produce extensional stress large enough to produce normal faulting. Further, unlike buoyancy, these sources would generally affect large areas of seafloor over a significant distance from the axis $(>30 \mathrm{~km})$ and thus may explain the continued development of normal faults. Although the assumption of a weak rise axis may be valid for regions of most recent volcanic eruptions, such regions may be localized, and therefore it may be valid to consider a substantial length of the mid-ocean ridge axis ( many tens of kilometers) as having a finite strength. Later in this section, we discuss the details of a new model of fault development at fast-spreading ridges which incorporates the weak axis assumption to explain the initiation of normal faulting off-axis, and the strong axis assumption to explain the continued development of normal faults farther off-axis.

Analysis of the scalar magnetic field often provides constraints that can improve our understanding of the structure and properties of the upper crust of the EPR. One of the most widely used methods for analyzing the sea-surface magnetic field is to assume a uniformly thick magnetic source layer and invert for the intensity of crustal magnetization. However, it is often difficult to determine the exact cause of the magnetic anomaly, because diverse processes can lead to similar anomalies. According to our map of magnetization anomalies (Figure 4.9), a considerable variation in the magnitude of axial magnetization high occurs along the axis, with the magnitude generally increasing to the south. We examined whether an increase in the thickness of the magnetic source layer to the south might explain the observed variation in the axial magnetization high. The results showed that, to explain the observed variation along-axis with a small change in layer thickness ( $50 \mathrm{~m})$, the magnetization intensity of the source had to be either extremely high $(>70 \mathrm{~A} / \mathrm{m})$ or, for a more reasonable estimate of magnetization intensity $(\sim 25 \mathrm{~A} / \mathrm{m})$, the thickness had to increase by approximately $200 \mathrm{~m}$ along axis. This is probably too large to be consistent with recent determinations of the amount of deepening of the AMC reflector to the south [Harding et al., 1993]. An alternative explanation of the axial magnetization anomaly is 
that it represents variations in the $\mathrm{FeO}$ and $\mathrm{TiO}_{2}$ contents of source rock. We found that, for a magnetic source layer that is $500 \mathrm{~m}$ thick, the variation in magnetization intensity predicted from the $\mathrm{FeO}$ and $\mathrm{TiO}_{2}$ contents of dredged rock samples [Batiza and Niu, 1991] explains less than half of the total variance of our observation. Hence, we conclude that a combination of variation in both magnetic layer thickness and in intensity of magnetization (by variation in the $\mathrm{FeO}$ and $\mathrm{TiO}_{2}$ contents of the source rock or by other mechanisms) is needed to explain the along-axis variation of axial magnetization.

In addition to an increase to the south, the axial magnetization high exhibits shortwavelength variability. In particular, the discontinuities between adjacent segments of the axial summit caldera (ASC) seem to correlate with breaks in the axial magnetization anomaly (e.g., $9^{\circ} 25^{\prime}, 9^{\circ} 37^{\prime}$ ', and $9^{\circ} 45^{\prime} \mathrm{N}$ ), i.e., so-called "magnetic devals" (Figure 4.15). The amplitudes of the axial magnetization anomalies are highest at the midpoints of the ASC segments. The midpoints of the ASCs appear to be the loci of most frequent lava eruptions, and thus the lava at the midpoints will tend to be younger and more magnetic.

A comparison of off-axis bands of short-wavelength $(\sim 5 \mathrm{~km})$ magnetization anomalies with the thicknesses of a seismically-defined layer 2A [Harding et al., 1993] does not show conclusively that the high magnetization features off-axis are caused by a thicker layer 2A. There are a number of other possible explanations for these off-axial anomalies including short geomagnetic reversal events, variations in the paleointensity of the Earth's field, variations in the magnetization intensity of the source rock due to variability in the magmatic supply, and variations in the degree of hydrothermal alteration at the rise axis. However, we found a convincing correlation between the off-axis magnetization anomalies and the short geomagnetic reversal events within the Brunhes epoch and so propose this as the most plausible explanation.

Analysis of sea surface measurements of the gravity field can provide information on the density structure of the crust and upper mantle, which is important for corroborating many of the models of shallow and surficial structure of the EPR. According to our 
analysis, a considerable variation in the residual gravity anomaly occurs along axis, with more negative anomalies occurring to the north. The magnitude and the extent of this variation are too large to be explained entirely by a variation in the thickness of the crust. The most plausible explanation of the long-wavelength components of the residual gravity anomaly is that they represent variations in the density structure of the upper mantle, presumably caused by higher temperatures and a greater presence of melt to the north of our survey area. At present, the depth extent of such a density anomaly is unclear; however, it is unlikely that the density anomaly is caused by a large temperature variation (e.g., $>100^{\circ} \mathrm{C}$ ) in the upper mantle. This is because a large increase in temperature in the upper mantle would lead to a significant increase in melt production rate, which in turn would produce a thicker crust. Despite having lower long-wavelength residual gravity anomalies to the north of our survey, there is no evidence from multichannel seismic reflection data [Detrick et al., 1987] that the crust is thicker to the north. Our calculation suggests that if the long-wavelength residual gravity anomaly represents a moderate temperature difference of $50^{\circ} \mathrm{C}$ along axis, then such an anomalous region may extend 40$50 \mathrm{~km}$ below the seafloor, which is consistent with the depth of the melting inferred by Wilson [1992] from geochemistry of seamount lavas near fast-spreading ridges.

In addition to the broad variations in the residual gravity anomalies, several local gravity lows appear along the axis (e.g., $9^{\circ} 21^{\prime}, 9^{\circ} 32^{\prime}, 9^{\circ} 42^{\prime}$ and $9^{\circ} 50^{\prime} \mathrm{N}$ ), whose positions correlate with documented variations in the crustal structure, including those shown by seismic tomographic images near $9^{\circ} 30^{\prime} \mathrm{N}$ [Toomey et al., 1990] and by the presence or absence of the AMC reflector along the axis [Kent et al., 1993a] (Figure 6.1g). The relation between the local gravity lows and the distribution of ASCs along the rise crest [Haymon et al., 1991] (Figure 6.1e) is, however, not clear. Although we interpret these local gravity lows as density anomalies arising primarily from crustal magma chambers of greater than average dimensions, the geometry and density of the anomalous sources are difficult to constrain. For one, we do not know how much of the residual gravity anomaly 
is caused by sources in the crust and how much is caused by those in the mantle. If we assume that only features with wavelengths less than $40 \mathrm{~km}$ or those that remain after removing a linear trend from the along-axis anomaly are caused by crustal sources, then the local gravity lows range from $1.5-3 \mathrm{mGal}$ in amplitude along the rise axis. Further, assuming that we know the dimensions of crustal density anomalies, we can examine the density contrast that these local lows represent. We represented the crustal density anomalies as a circular rod with a radius of $1 \mathrm{~km}$, an along-axis length of $10 \mathrm{~km}$, and a top at $1.25 \mathrm{~km}$ below the seafloor. We considered three such crustal density anomalies and assumed that their along-axis centers lie just below the peaks of local gravity lows $\left(9^{\circ} 21^{\prime}\right.$, $9^{\circ} 32^{\prime}$, and $\left.9^{\circ} 42^{\prime} \mathrm{N}\right)$. The results showed that local lows correspond to a density contrast of approximately $200-350 \mathrm{~kg} / \mathrm{m}^{3}$. Such contrasts are far too large to be due to unmodeled thermal anomalies, and they are also higher than can be plausibly be explained by melt fraction given that the density change associated with complete melting of typical crustal rock is less than $300 \mathrm{~kg} / \mathrm{m}^{3}$. Of course, lesser contrasts would be obtained for anomalous masses of greater volume.

\section{Discrete Emplacement Model}

It has long been thought that the melt which accumulates within the zone of melt production in the upper mantle forms a gravitationally unstable layer beneath a depleted mantle residuum and rises in the form of plumes to a level near the surface by buoyancy [Whitehead et al., 1984; Crane, 1985; Schouten et al., 1985]. According to this hypothesis, the observed variability and inferred episodicity of tectonic and magmatic processes along a mid-ocean ridge are explained by the characteristic spacing between mantle-derived melt-rich plumes and the timing of their ascent to the upper lithosphere [e.g., Macdonald et al., 1988]. Many of the results derived in this thesis, including the 
pattern of residual gravity anomalies and the along-axis variation of magnetization anomalies, can be explained by a model in which magmas derived from the upper mantle are injected or emplaced at discrete locations along the axis within the crust. The most convincing new piece of evidence is the short-wavelength residual gravity anomaly lows appearing at almost regularly-spaced (10-15 km) intervals along the axis. In addition, the axial segments defined by distinct magnetization values and delimited by magnetic devals (Figure 6.1c) show correlations with those defined by the short-wavelength residual gravity anomaly (Figure 6.1d). In particular, the midpoints of axial magnetization segments generally coincide with residual gravity anomaly lows, implying that some of the characteristics of crustal magma chambers, such as replenishment rate or the time it takes for magma to reach the surface, may differ among those segments.

Without knowing how much of the gravity anomaly is caused by sources in the mantle, it is difficult to determine from the residual gravity anomaly whether crustal magma chambers vary in size or density along the axis. If one simply attributes the longest wavelength component to the mantle source and removes it from our residual gravity anomaly, then the resulting anomaly shows local gravity anomalies which are almost equal in amplitude along the axis. However, since the axial long-wavelength gravity anomaly low becomes progressively broader and deeper to the north along the axis, one possibility is that the frequency at which the magma chambers are replenished may differ along axis with crustal magma chambers in the northern part of our survey area more frequently replenished than those to the south.

One corollary of discrete magmatic emplacement along-axis is that there will also be magmatically starved regions at the distal ends of magmatic segments. Although there are numerous small-scale offsets in the bathymetric axis in our survey area, this portion of the fast-spreading ridge exhibits considerable general continuity, which leads us to suggest that, over a period of time, as the older melt sources in the upper mantle become depleted, 
previously untapped regions become new sources and thus change the position of magmatic emplacement along the axis.

\section{Fault Development Model}

In constructing a model of fault development for fast-spreading ridges, one needs to consider several constraints. These constraints provide insight into the mechanical strength of the rise axis as viewed from several scales and in some cases may appear to be inconsistent.

First, we showed that, to explain the initiation of normal faults by buoyant forces arising from the crustal magma chamber, we need a weak axis condition. However, to explain continued slip on normal faults to distances of $30 \mathrm{~km}$ or more off axis, one must have a significant extensional stress at the surface that extends to comparable distances, which is possible only if the rise axis has a finite strength.

Another important constraint can be derived from the argument that the stress field that we infer from the observation of normal faults within $30-40 \mathrm{~km}$ of the axis must be consistent with the stress field derived from a more plate-scale consideration. According to investigations of near-ridge earthquakes in lithosphere 3-35 $\mathrm{My}$ in age, normal faulting mechanisms are common, but waveform inversion indicates that most such normal faulting events have centroid depths beneath the crust, whereas near-ridge events with centroid depths of less than $6 \mathrm{~km}$ typically have thrust or reverse faulting mechanisms [Bergman and Solomon, 1984; Wiens and Stein, 1984]. Therefore, the state of tectonic stress near the seafloor has to change from one that is predominantly extensional to distances of at least $30-40 \mathrm{~km}$ from the axis, to one that is compressional beyond approximately $160 \mathrm{~km}$ from the axis. 
The most plausible explanation of the occurrence of thrust faulting at shallow crustal levels, and normal faulting at deeper levels for lithosphere older than $3 \mathrm{My}$, is that such deformation is caused by cooling of the plate [Bratt et al., 1985]. For a plate that is cooling and underlain by a region of inviscid fluid, a characteristic pattern of extensional stresses develops as a function of depth, which can be divided into a thickness-averaged uniform extensional stress and a deviation from this thickness-averaged uniform extensional stress. The latter represents a bending moment and matches the stress field inferred from observations of near-ridge earthquakes. However, in order for the bending moment only to remain, the thickness-averaged uniform extensional stress has to be relieved, and such a condition can be achieved only if the plate has a weak rise axis.

Finally, according to a recent near-bottom seismic refraction study performed near the $9^{\circ} 30^{\prime} \mathrm{N}$ of the EPR [Christeson et al., 1992, 1994a, b] which overlaps the region of the seismic tomography experiment of Toomey et al. [1990], the rise axis appears to be underlain by solidified dikes in the upper crust. The argument that the rise axis is underlain by solidified dikes over a region that is considered as magmatically robust implies that the rise axis cools rapidly after a volcanic eruption through hydrothermal activity. Therefore, if the rise axis is underlain by solidified dikes for most of the time, then it is appropriate that it be considered as strong mechanically.

All the constraints mentioned above may be satisfied if we consider the following model of fault development (Figure 6.2). Here we divide the fault development into three stages: the initiation of normal faulting, continued normal fault activity, and the occurrence of thrust faulting in the upper crust.

An important element of the model is that at any given time only portions of the rise axis are mechanically weakened from volcanic activity. During the magmatically active phase, the crustal magma chamber will exert the greatest buoyant force to the upper crust, and together with a weak-axis condition, a zone of extensional stress may develop near the 
seafloor some distance from the axis. The initiation of normal faulting will probably occur during this stage.

Within a long segment of the mid-ocean ridge, such as that bounded by major transform faults, there may be regions where the rise axis is undergoing an active magmatic phase as well as those that have already solidified the axial injection zone. Therefore, it may be valid to consider a substantial length of the mid-ocean ridge axis ( many tens of kilometers) as having a finite strength. This seems a reasonable assumption if the portion of the rise axis weakened by dike intrusions and volcanic eruptions is short compared with the length of the transform-fault-bounded segment, and if the phase during which the rise axis remains weak is short-lived due to rapid hydrothermal cooling of the crust. With increasing distance from the axis, the local boundary conditions of the rise axis that initiated the faults will become less important, and instead the boundary condition of the rise axis as determined by the average strength of transform-fault-bounded segment will govern the further displacements along those faults. On the basis of an examination of a recent Sea MARC II side scan sonar data [Carbotte and Macdonald, 1994] in our survey area and our boundary element calculations, such a transition seems to occur at $10-15 \mathrm{~km}$ from the axis. Consequently, beyond $10-15 \mathrm{~km}$ from the axis the rise axis may be considered as having a finite-strength and able to support horizontal extensional stresses. Then in the presence of horizontal extensional streses induced by such sources as gravitational spreading, plate cooling, and mantle-convective tractions, normal fault zones can continue to be active.

The argument that the rise axis possesses some strength is not inconsistent with studies of near-ridge earthquakes [Bergman and Solomon, 1984; Bratt et al., 1985]. If there exists a finite width zone, in which most of the deformation takes place, then the plate outside this zone can still act in the same manner as if the axis were weak.

On the basis of this model, which argues that the initiation of normal faulting is caused by buoyancy during a weak-axis condition, one would expect to see a variation in the 
distance from the axis to the nearest fault zones. For instance, portions of rise axis that experienced active magmatism most recently should have fault zones appearing closer to the axis than those that previously experienced active magmatism. When we compared the short-wavelength residual gravity anomalies with the distribution of normal faults mapped by recent Sea MARC II side scan sonar survey [Carbotte and Macdonald, 1994], we found that the portions of rise axis with low residual gravity anomalies generally showed shorter distances from the axis to the nearest normal fault zone, which is consistent with our model.

\section{Future Work}

Through analysis of Sea Beam swaths, we found evidence which suggests that normal faulting continues to the boundary of our coverage, which is only $30 \mathrm{~km}$ from the axis. An extended investigation of Sea Beam bathymetry would allow the determination of the distal end of the zone of normal fault development. Through such an investigation, we may be able to determine the sources of continued fault development and the total width of the active tectonic zone at fast-spreading ridges. Also, by taking full advantage of a highly accurate navigation system such as GPS, which was only partially available during the time of our survey, we can construct a better high-resolution composite map of the seafloor. Such a map would allow us to estimate along-strike length of the normal faults, which was not measured during our analysis of individual swaths.

The linear elastic models that we used to calculate stress fields can provide at best only a qualitative understanding of the effect of various tectonic sources of stress. This is because material beneath mid-ocean ridges varies widely in physical state, from molten lava to brittle crust. Of course, the advantage of using linear elastic models is that the numerical results can be calculated relatively easily and accurately based on approaches 
such as the boundary element method. Despite the fact that we considered a wide range of lower moduli for regions underlying the upper crust, the assumption of linear elasticity for the entire modeling region still remains questionable. Now that the first-order effects of various parameters of our model are understood, we can treat the regions underlying the upper crust as viscoelastic materials, and consider effects such as time-dependent stressrelaxation and rheology that is temperature-dependent, as ways to improve the representation of mechanical behavior.

In interpreting the cause of our magnetic anomalies, the magnetization intensity of the source rock is a crucial piece of information. In this study, we used an indirect estimate based on an empirical relationship between $\mathrm{FeO}$ and $\mathrm{TiO}_{2}$ contents and magnetization intensity of surface rock samples obtained for other mid-ocean ridges [Vogt and de Boer, 1976]. However, a comparison of our estimate with other estimates taken near our survey area suggests that there may be a large uncertainty with this relationship. A significant improvement in our interpretation of magnetic data can be made if the magnetization intensity of the source rocks in our survey area can be accurately measured.

Although we were able to infer the loci of magmatically robust regions along the axis from residual gravity anomalies, we could only marginally resolve their density anomalies. Again, this is because in our survey area there is a significant along-axis variation in the long-wavelength component of the residual gravity anomaly and one can not tell from the gravity anomalies alone how much of it is due to sources in the crust and in the mantle. Recently, a new three-dimensional mantle flow model [Sparks et al., 1993], that incorporates both plate driven and buoyancy flows, has been developed. Using such a model, we may be able to constrain the long-wavelength component of our residual gravity anomaly. This, in turn, would provide us with a better chance, providing the model is valid, of resolving the densities or the sizes of crustal magma chambers in our area. 


\section{References}

Batiza, R., and Y. Niu, Petrology and magma chamber processes at the East Pacific Rise -9³0'N, J. Geophys. Res., 97, 6779-6797, 1992.

Bergman, E. A., and S. C. Solomon, Source mechanisms of earthquakes near mid-ocean ridges from body waveform inversion: Implications for the early evolution of oceanic lithosphere, J. Geophys. Res., 89, 11,415-11,441, 1984.

Bratt, S. R., E. A. Bergman, and S. C. Solomon, Thermoelastic stress: How important as a cause of earthquakes in young oceanic lithosphere?, J. Geophys. Res., 90, 10,24910,260, 1985.

Carbotte, S. M., and K. C. Macdonald, Comparison of seafloor tectonic fabrics at intermediate, fast, and superfast spreading ridges: Influence of spreading rate, plate motions, and ridge segmentation of fault patterns, J. Geophys. Res., 99, 13,60913,631, 1994.

Chen, Y., and W. J. Morgan, Rift valley/no rift valley transition at mid-ocean ridges, $J$. Geophys. Res., 95, 17,571-17,581, 1990a.

Chen, Y., and W. J. Morgan, A nonlinear rheology model for mid-ocean ridge axis topography, J. Geophys. Res., 95, 17,583-17,604, 1990b.

Christeson, G. L., G. M. Purdy, and G. J. Fryer, Structure of young upper crust at the East Pacific Rise near 9³0N, Geophys. Res. Lett., 19, 1045-1048, 1992.

Christeson, G. L., G. M. Purdy, and G. J. Fryer, Seismic constraints on shallow crustal emplacement processes at the fast spreading East Pacific Rise, J. Geophys. Res., 99, $17,957-17,973,1994 a$.

Christeson, G. L., G. M. Kent, G. M. Purdy, and R. S. Detrick, Extrusive thickness variability at the East Pacific Rise: Constraints from seismic techniques, J. Geophys. Res., submitted, 1994b. 
Cowie P. A., A. Malinverno, W. B. F. Ryan, and M. H. Edwards, Quantitative fault studies on the East Pacific Rise: A comparison of sonar imaging techniques, $J$. Geophys. Res., 99, 15,205-15,218, 1994.

Crane, K., The spacing of rift axis highs: Dependence upon diapiric processes in the underlying asthenosphere?, Earth Planet. Sci. Lett., 72, 405-414, 1985.

Detrick, R. S., P. Buhl, E. Vera, J. C. Mutter, J. Orcutt, J. Madsen, and T. Brocher, Multichannel seismic imaging of a crustal magma chamber along the East Pacific Rise, Nature, 326, 35-41, 1987.

Harding, A. J., G. M. Kent, and J. A. Orcutt, A multichannel seismic investigation of upper crustal structure at $9^{\circ} \mathrm{N}$ on the East Pacific Rise: Implications for crustal accretion, J. Geophys. Res., 98, 13,925-13,944, 1993.

Haxby, W. F., and E. M. Parmentier, Thermal contraction and the state of stress in the oceanic lithosphere, J. Geophys. Res., 93, 6419-6429, 1988.

Haymon, R. M., D. J. Fornari, M. H. Edward, S. Carbotte, D. Wright, and K. C. Macdonald, Hydrothermal vent distribution along the East Pacific Rise crest $\left(9^{\circ} 09^{\prime}-\right.$ 54 'N) and its relationship to magnetic and tectonic processes on fast-spreading midocean ridges, Earth Planet. Sci. Lett., 104, 513-534, 1991.

Kent, G. M., A. J. Harding, and J. A. Orcutt, Distribution of magma beneath the East Pacific Rise between the Clipperton transform and the $9^{\circ} 17^{\prime} \mathrm{N}$ deval from forward modeling of common depth point data, J. Geophys. Res., 98, 13,945-13,969, 1993a.

Kent, G. M., A. J. Harding, and J. A. Orcutt, Distribution of magma beneath the East Pacific Rise near the $9^{\circ} 03^{\prime} \mathrm{N}$ overlapping spreading center from forward modeling of common depth point data, J. Geophys. Res., 98, 13,971-13,995, 1993b.

Macdonald, K. C., P. J. Fox, L. J. Perram, M. F. Eisen, R. M. Haymon, S. P. Miller, S. M. Carbotte, M.-H. Cormier, and A. N. Shor, A new view of the mid-ocean ridge from the behavior of ridge-axis discontinuities, Nature, 335, 217-225, 1988. 
Madsen, J. A., D. W. Forsyth, and R. S. Detrick, A new isostatic model for the East Pacific Rise crest, J. Geophys. Res., 89, 9997-10,015, 1984.

Schouten, H., K. D. Klitgord, and J. A. Whitehead, Segmentation of mid-ocean ridges, Nature, 317, 225-229, 1985.

Sparks, D. W., E. M. Parmentier, and J. P. Morgan, Three-dimensional mantle convection beneath a segmented spreading center: Implication for along-axis variations in crustal thickness and gravity, J. Geophys. Res., 98, 21,977-21,995, 1993.

Toomey, D. R., G. M. Purdy, S. C. Solomon, and W. S. D. Wilcock, The threedimensional seismic velocity structure of the East Pacific Rise near latitude $9^{\circ} 30^{\prime} \mathrm{N}$, Nature, 347, 639-645, 1990.

Vogt, P. R. and J. de Boer, Morphology, magnetic anomalies and basalt magnetization at the ends of the Galapagos high-amplitude zone, Earth Planet. Sci. Lett., 33, 145-164, 1976.

Wang, X., and J. R. Cochran, Gravity anomalies, isostasy, and mantle flow at the East Pacific Rise crest, J. Geophys. Res., 98, 19,505-19,531, 1993.

Whitehead, J. A., H. J. B. Dick, and H. Schouten, A mechanism for magmatic accretion under spreading centres, Nature, 312, 146-148, 1984.

Wiens, D. A., and S. Stein, Intraplate seismicity and stresses in young oceanic lithosphere, J. Geophys. Res., 89, 11,442-11,464, 1984.

Wilson, D. S., Focused mantle upwelling beneath mid-ocean ridges: Evidence from seamount formation and isostatic compensation of topography, Earth Planet. Sci. Lett., 113, 41-45, 1992. 
Figure 6.1. Summary of observations made along the EPR between $9^{\circ} 10^{\prime}-9^{\circ} 50^{\prime} \mathrm{N}$. (a) The information on the location of the bathymetric devals is derived from various reports, including Toomey et al. [1990], Haymon et al. [1991], and Kent et al. [1993a]. While most of the bathymetric devals in this area appear to be quite distinct, one near $9^{\circ} 19^{\prime} \mathrm{N}$ appears sigmoidal in shape; its exact location is therefore difficult to define. (b) The distances to the nearest large-offset $(>50 \mathrm{~m}$ ) normal faults on either side of the plate. The uneven dashed line represents the highest point of the seafloor, i.e., the bathymetric axis. The midpoint between the two nearest normal faults is offset to the west of the bathymetric axis, especially to the south of $9^{\circ} 23^{\prime} \mathrm{N}$. (c) Three major changes in the magnitude of the axial magnetization high, each with an offset in the linearity of the magnetization anomaly (magnetic deval), occur in our survey area. A sharp change in the magnitude of axial magnetization anomaly with a small offset in the linearity of the magnetization anomaly occurs at $9^{\circ} 25^{\prime}$ and $9^{\circ} 37^{\prime} \mathrm{N}$, and a large offset in the linearity of the magnetization anomaly occurs at approximately $9^{\circ} 45^{\prime} \mathrm{N}$. (d) The distribution of local residual gravity lows along the axis. At least five local residual gravity lows are found along this portion of the EPR. The black dots represent the locations of local minima. The extent of local gravity lows that appear near the top and bottom of the survey area are unclear, and thus their local minima are not shown. Towards the bottom of the survey area, the local gravity low may bifurcate. (e) The distribution and the width of ASCs [from Haymon et al., 1991]. Here, we divided the rise axis into four segments by widths of ASCs (i.e., those less than $50 \mathrm{~m}$, between 50 and $100 \mathrm{~m}$, and greater than $100 \mathrm{~m}$ as represented by three different thickness of solid lines) and their offset. The first segment occurs to the south of $9^{\circ} 25^{\prime} \mathrm{N}$. Although an ASC exists between $9^{\circ} 21^{\prime}-9^{\circ} 25^{\prime} \mathrm{N}$ on this segment, it is quite narrow. No ASC is found in the remainder of this segment. On the second segment, between $9^{\circ} 25^{\prime}-9^{\circ} 37^{\prime} \mathrm{N}$, several ASCs defined by small discontinuies separating their distal ends can be seen. On average, the ASCs in this segment are wider than those in the other segments, with the widest ASC found between $9^{\circ} 32^{\prime}-9^{\circ} 37^{\prime} \mathrm{N}$. The third segment can be defined as a rise axis 
between $9^{\circ} 37^{\prime}-9^{\circ} 45^{\prime} \mathrm{N}$ by a large offset and overlap of ASCs at approximately $9^{\circ} 37^{\prime} \mathrm{N}$. The fourth segment can be defined to the north of $9^{\circ} 44^{\prime} \mathrm{N}$. Two ASCs appear in this segment, however, their widths are generally small. (f) The location of active hydrothermal vents and hydrothermal gaps [from Haymon et al., 1991]. Hydrothermal gaps (arrows) are defined as segments of the rise axis where no active hydrothermal vents, sulfide deposits, or vent biota were found. (g) The distribution of the AMC reflectors as mapped by Kent et al. [1993a] from a series of cross-axis CDP and wide aperture profile (WAP) lines as well as along-axis CDP lines. The locations of the AMC reflector are shown by the solid line. The uneven dashed line represents the bathymetric axis. The AMC reflector is absent between $9^{\circ} 23^{\prime}$ and $9^{\circ} 29^{\prime} \mathrm{N}$. The AMC reflector generally coincides with the bathymetric axis to the north of $9^{\circ} 29^{\prime} \mathrm{N}$, but starts to deviate to the west of the bathymetric axis south of $9^{\circ} 23^{\prime} \mathrm{N}$. 


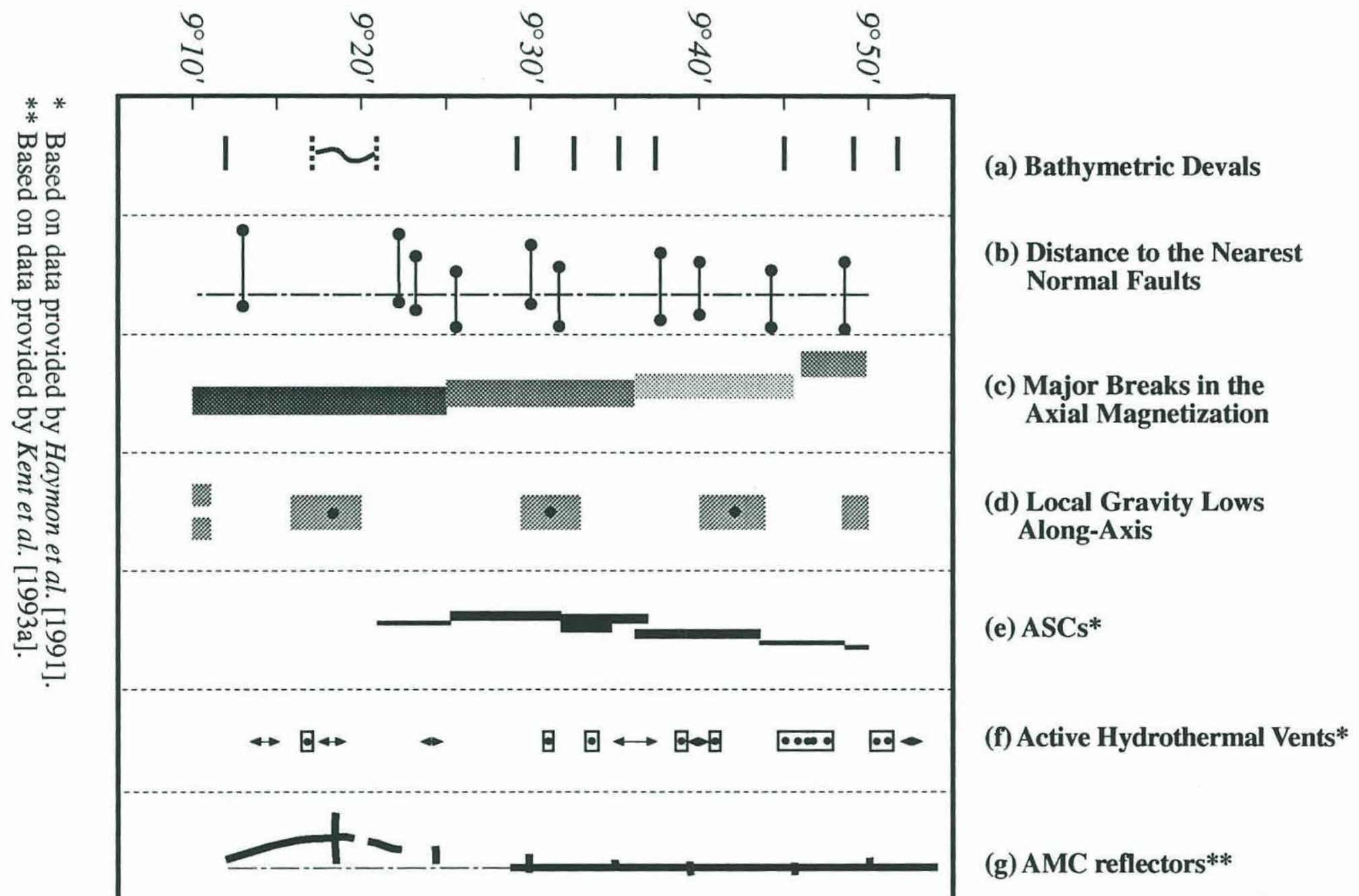


Figure 6.2. A schematic diagram illustrating the basic characteristics of faulting observed at fast-spreading mid-ocean ridges, which are described in three stages: the initiation of normal faulting, which generally occurs $2-12 \mathrm{~km}$ from the axis, continued activity on normal faults, and the transformation in the state of stress in the upper lithosphere such that thrust faulting occurs. Shown here is a segment of mid-ocean ridge bounded by major transform faults, which in turn is composed of smaller segments of mechanically weak axes. Pairs of parallel lines denote fault zones on the seafloor. The outward- and inward-facing pairs of arrows depict extensional and compressional states of stress, respectively. The probable causes of faulting at each stage are also depicted. 


\section{Stages of Fault Development at a Fast-Spreading Ridge}

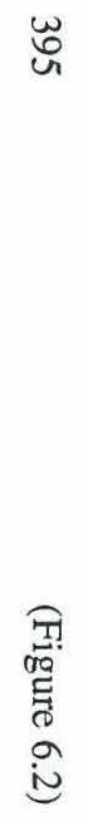

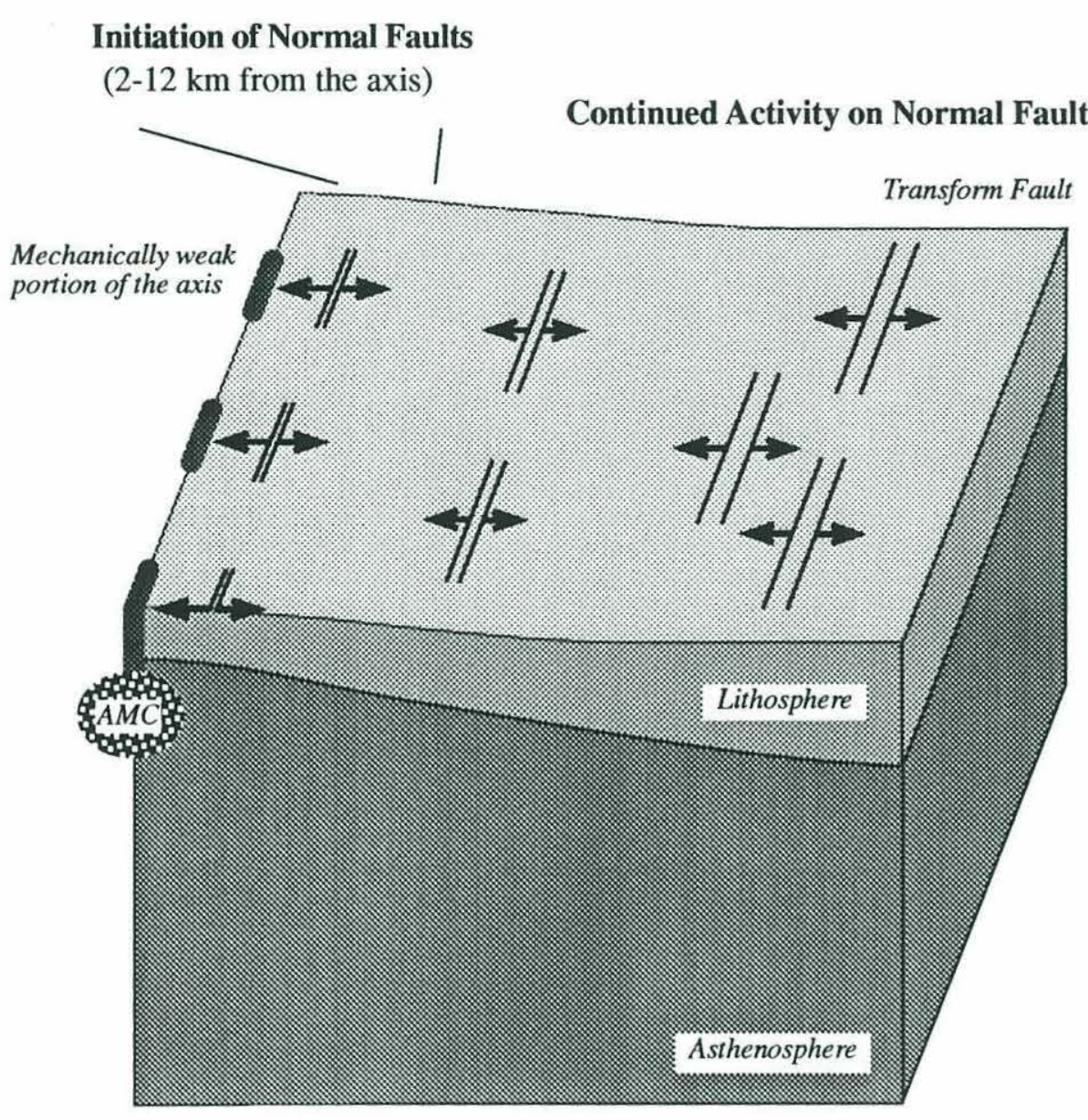

MOR < 0.7 My old
Thrust Faulting

in the Upper Lithosphere

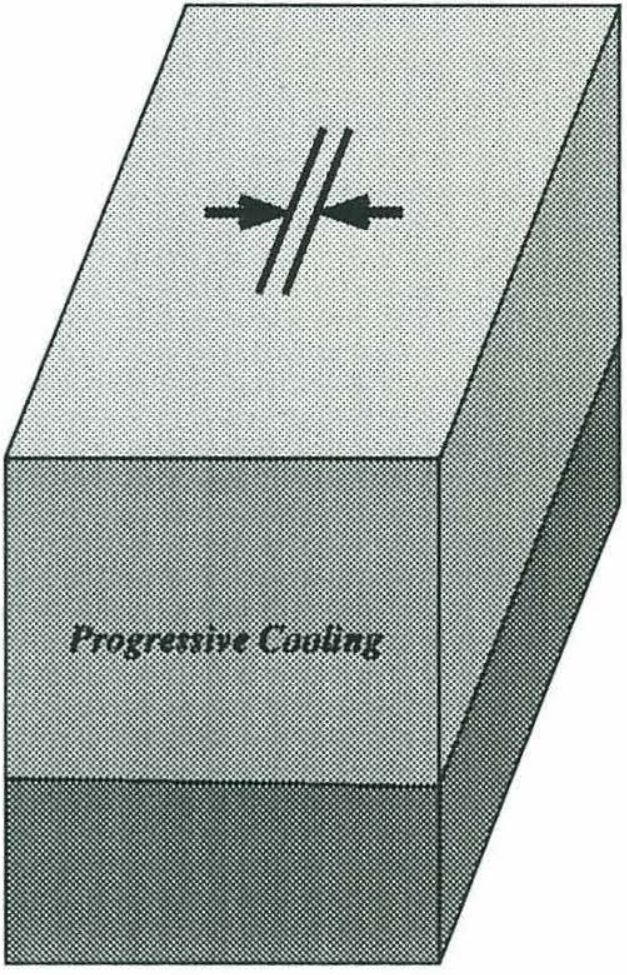

MOR > 3 My old 


\section{APPENDIX A}

\section{Overview of Numerical Methods}

Physical problems can often be defined by sets of differential or integral equations which are referred to as governing equations. Because the differential forms of governing equations merely express physical laws, boundary conditions are either prescribed separately or incorporated within differential equations to form integral equations. Solving a problem thus implies finding an expression or a set of expressions that satisfy the governing equations with conditions imposed either upon the boundary or within the domain of interest. Since analytical solutions are difficult to obtain except for very simple cases, numerical methods used in conjunction with computers have become widely used for solving many scientific and engineering problems.

The most widely used numerical schemes are the Finite Difference Method (FDM) and Finite Element Method (FEM). Numerical schemes such as these can be characterized by the choices of approximate solutions for the governing equations and the way errors due to such approximate solutions are handled. The FDM and FEM are referred to as 'domain methods' because their choice of approximate solutions satisfy the boundary conditions, as a whole or partially, but not necessarily the governing equation in the domain. Thus the final solution is determined based on a concept of the least amount of error within the domain. The FEM, in particular, has attracted the most attention largely because it divides the continuum into a series of elements that can be associated with physical parts.

In recent years, the Boundary Element Method (BEM) has emerged as a powerful alternative to the domain methods. Although the BEM began appearing in the literature in 1978, the fundamental concept of the BEM has been used by mathematicians and 
physicists for a long time under such names as 'boundary integral method' or 'boundary value problem.' BEM differs from domain methods because the approximate solution is chosen as the one that satisfies the governing equation in the domain, and thus matching the conditions is necessary only on the boundary. For this reason, it is categorized as a 'boundary method.'

The BEM offers several important advantages over the FDM and FEM. These advantages, listed below, are detailed in Appendices B and C as well.

- In BEM, the dimension of the problem is reduced by one; the volume integrations in three-dimensional problems are reduced to surface integrations and surface integrations in two-dimensional problems to contour integrations. Because one needs to define meshes only at the boundary rather than the whole domain, BEM takes far less time to set up a problem or modify it than FDM or FEM. In BEM the internal points within the domain are computed only if needed and are not required to solve the problem.

- $\quad$ BEM does not require conformal mapping like domain methods and can handle any type of well-posed boundary conditions, whether uniform or mixed. Mixed types of boundary conditions include cases where displacement and traction (or temperature and flux) are prescribed by the same boundary.

- $\quad$ BEM provides greater accuracy than domain methods especially in regions of high stress or flux, which makes it an appropriate tool for solving problems such as stress in the vicinity of cracks and other fracture mechanical applications. An example will be given later in this appendix in which FEM gives poor results when used to ascertain surface fluxes or tractions at a boundary.

- The approximate solution of BEM corresponds to the 'fundamental' solution of the governing equation (i.e., the solution due to a unit load or source in an infinite domain), whereas in FEM it is an arbitrary function that satisfies certain types of 
boundary conditions. As a result, a BEM formulation is mathematically succinct and elegant.

- Because it uses a fundamental solution and does not require the generation of a mesh within the domain, BEM is suitable for problems where the domain extends to infinity. Boundary elements can be easily extended to analyze half-space problems as well.

- The consideration of body forces is cumbersome in domain methods, since it requires an integration over the domain. However, in BEM, because the fundamental solution already exists, body forces can be considered accurately and effectively by taking the integration to the boundary. For example, various types of body forces in elastic problems can be reduced to boundary integration using the Galerkin vectors already defined as a part of the fundamental solution.

In summary, the BEM is advantageous over the domain methods in problems where there exists a fundamental solution for the governing equations. Such is the case for potential field and elastostatic problems. Because BEM is relatively new as a numerical method, many aspects of it remain to be developed and improved. For instance, drawbacks of the BEM are:

- it is not appropriate for solving problems involving complex material properties such as those of nonlinear materials. In BEM, the domain may be divided into several subregions but each subregion has to be homogeneous.

- $\quad$ it is not cost-effective for the analysis of thin bodies; BEM is most appropriate for bulky bodies with low surface to volume ratio.

This appendix investigates some of the fundamental properties of differential equations from which numerical method such as the FDM, FEM and BEM can be developed. A 
simple differential equation is used to illustrate fundamental concepts instead of relying on mathematical theorems and derivations. In addition, solutions to the same differential equation are provided using concepts of different numerical methods.

The boundary element formulation in this thesis is based on the so-called 'direct method' which, in a way, corresponds to Green's theorem in mathematics. The direct method is used to describe the fundamental concepts in Appendices B and $\mathrm{C}$ as well. In Appendix B, we will derive the boundary element formulations for Poisson's equation or its homogeneous form, Laplace's equation. The direct boundary element formulation of potential theory can be traced back to as early as the 1960s (e.g., Jaswon [1963] and Symm [1963]). In Appendix C, we will then derive boundary element formulations for two- and three-dimensional elastostatic problems.

As with many papers on the subject, we shall follow the notations and conventions of Brebbia et al. [1984]. Since our main goal is to show the important ingredients used by boundary element analyses in Chapter 3 of this thesis, the formulation is not complete. More complete derivations of the expressions that appear in these appendices and other related matters can be found in boundary element textbooks such as Brebbia et al. [1984] and Crouch and Starfield [1983].

Applications of boundary element analysis for geological problems has, thus far, been somewhat limited. Some of the recent examples are Phipps Morgan et al. [1987], who used it to solve a potential flow problem, and King and Ellis [1990], who solved a planestrain linear elastic problem. Recent developments in boundary element analysis have shown that the formulations can be extented to viscous flow [e.g., Kitagawa, 1990] and inelastic [e.g., Telles, 1983] problems. The boundary element method is expected to become a popular tool in the geological sciences. 


\section{SOLUTIONS TO DIFFERENTIAL EQUATIONS}

Many of the fundamental principles of numerical methods are derived from the analytical properties of differential equations. In this section, we explore some of the characteristics of differential equations using a simple one-dimensional, second-order differential equation as an example.

Let us consider the following equation defined over domain $x$ which is bounded by two boundaries at $x=0$ and $x=1$,

$$
\frac{d^{2} u}{d x^{2}}+\lambda^{2} u-b=0 \quad 0 \leq x \leq 1
$$

where $\lambda^{2}$ is a known positive constant and $b$ is a known function of $x$. The solution of the above problem $u(x)$ may be found analytically or numerically by approximating $u$ by a series of functions. Such an approximation is not only the foundation of many numerical techniques but also an important analytical concept.

We assume that there is an arbitrary function $w$, which is continuous and whose derivatives are continuous up to second-order over the domain, and multiply it by the above equation and integrate over $x$ :

$$
\int_{0}^{1}\left(\frac{d^{2} u}{d x^{2}}+\lambda^{2} u-b\right) w d x=0
$$

This operation is called an 'inner' product and although it does not imply any new concepts, it allows us to investigate the property of the differential equation. We then

perform an integration by parts of the terms with derivatives in the above expression, i.e., 


$$
\int_{0}^{1}\left\{-\frac{d u}{d x} \frac{d w}{d x}+\left(\lambda^{2} u-b\right) w\right\} d x+\left[\frac{d u}{d x} w\right]_{0}^{1}=0
$$

The first term in equation (A.2) produced two terms, one in the domain with first derivatives of $u$ and $w$, and the other on the boundaries, that is at $x=0$ and $x=1$. By integrating by parts the first term in equation (A.3), we obtain

$$
\int_{0}^{1}\left\{u \frac{d^{2} w}{d x^{2}}+\left(\lambda^{2} u-b\right) w\right\} d x+\left[\frac{d u}{d x} w\right]_{0}^{1}-\left[u \frac{d w}{d x}\right]_{0}^{1}=0
$$

In effect, through integration by parts, the derivatives of function $u$ have been transferred to an arbitrary function $w$. Also, we have introduced the boundary conditions into the problem. To solve the above equation, we need to know the values of

$$
u \text { or } \frac{d u}{d x} \quad \text { at } x=0 \text { and } x=1
$$

Boundary conditions are an essential part of a differential operator. They allow the transformation of the differential form of the governing equations into an integral form.

We shall assume the following boundary conditions for our problem:

$$
\begin{array}{ll}
u=\bar{u} & \text { at } x=0 \\
q=\frac{d u}{d x}=\bar{q} & \text { at } x=1
\end{array}
$$

where the derivative of $u$ is now defined as $q$. The bar indicates that the value of the quantity is known. The first type of condition is called an 'essential' (or kinematic or Dirichlet) boundary condition and the second type involving a derivative is called a 'natural' (or dynamic or Neumann) boundary condition. 
By substituting those defined boundary conditions into equation (A.4), we obtain,

$$
\begin{aligned}
& \int_{0}^{1}\left\{u \frac{d^{2} w}{d x^{2}}+\left(\lambda^{2} u-b\right) w\right\} d x+\left\{[\bar{q} w]_{x=1}-[q w]_{x=0}\right\} \\
& -\left\{\left[u \frac{d w}{d x}\right]_{x=1}-\left[\bar{u} \frac{d w}{d x}\right]_{x=0}\right\}=0
\end{aligned}
$$

Let us try to return to the original expression (A.2) by exchanging derivatives for $w$ to those for $u$ again by integrating by parts. However, this time we will not substitute values of the expressions on the boundary. Integrating by parts twice leads us to the following expression

$$
\int_{0}^{1}\left\{\frac{d^{2} u}{d x^{2}}+\left(\lambda^{2} u-b\right)\right\} w d x-[(q-\bar{q}) w]_{x=1}+\left[(u-\bar{u}) \frac{d w}{d x}\right]_{x=0}=0
$$

This integral equation provides an important concept which is the starting point of many numerical techniques. It implies that when one is solving a differential equation one is trying to satisfy not only the differential equation in the domain but also its boundary conditions. In this sense, both functions $w$ and $d w / d x$ can be seen as Lagrangian multipliers.

\section{APPROXIMATE SOLUTIONS}

Representing an unknown function by a series of known functions with weight coefficients and then solving for the coefficients is a common mathematical tool. Let us assume that the exact solution for $u$ is unknown. We can write an approximate solution for $u$ as 


$$
u=\alpha_{1} \phi_{1}+\alpha_{2} \phi_{2}+\cdots
$$

where $\alpha_{i}$ are unknown coefficients and the $\phi_{i}$ are a set of linearly independent functions which are known. In practice, one prefers to use nodal values as they have a clear physical meaning. In such a case, $u$ may be written as

$$
u=\sum_{i=1}^{N} u_{i} \phi_{i}
$$

where $\phi_{i}$ are now the interpolation functions and $u_{i}$ are the nodal values of the field variables or its derivative.

Because $u$ is an approximate solution, an error will occur when we substitute it instead of the exact solution. Error or residual functions can be defined to represent the errors occurring in the domain and on the boundary. For the governing equation in (A.1) and the boundary condition in (A.5), these residual functions may be written as

$$
\begin{aligned}
& R=\frac{d^{2} u}{d x^{2}}+\lambda^{2} u-b \neq 0 \\
& R_{1}=u-\bar{u} \neq 0 \\
& R_{2}=q-\bar{q} \neq 0
\end{aligned}
$$

There are several ways that residuals can be minimized or reduced in the domain. For example, one could perform the reduction by forcing the errors to be zero at certain points, regions or in a mean sense. The reduction of error in fact is similar to distributing the 
errors, and various distributions of errors in the domain and on the boundary have resulted in different numerical methods.

\section{WEIGHTED RESIDUAL METHODS}

This section describes various methods used to reduce error by using an approximate solution within the context of the weighted residual method.

We assume that $\phi_{i}$ in equation (A.8) is chosen such that $u$ satisfies all the boundary conditions but not the governing equation in the domain. The operation of distributing the error $R$ over the domain $\Omega$ can be expressed as

$$
\int_{\Omega} R \psi_{i} d \Omega=0 \quad \text { in } \Omega \quad i=1,2, \ldots, N
$$

where $\psi_{i}$ are the weighting functions, linearly independent from one another.

The above equation can be also written as

$$
\int_{\Omega} R w d \Omega=0 \quad \text { in } \Omega
$$

by defining a function $w$ such that

$$
w=\beta_{1} \psi_{1}+\beta_{2} \psi_{2}+\cdots+\beta_{N} \psi_{N}=\sum_{i=1}^{N} \beta_{i} \psi_{i}
$$

where $\beta_{i}$ are arbitrary coefficients. We now examine several well-known approximate techniques by employing these definitions. 


\section{Point Collocation Method}

In this method, $N$ points are chosen within the domain and the residuals at these points are set to zero. This process can be described as defining the weighting functions $\psi_{i}$ as Dirac delta functions, i.e.,

$$
\psi_{i}=\delta\left(x-x_{i}\right) \quad i=1,2, \ldots, N
$$

Dirac's delta has such property that

$$
\int_{-\infty}^{\infty} \delta\left(x-x_{i}\right) d x=\int_{x_{i}-\varepsilon}^{x_{i}+\varepsilon} \delta\left(x-x_{i}\right) d x=1
$$

where $\varepsilon$ is any positive number.

For a point collocation method, the domain integration in equation (A.12) can be expressed as

$$
\int_{\Omega} R \delta\left(x-x_{i}\right) d \Omega=0 \quad i=1,2, \ldots, N
$$

This is equivalent to the statement that

$$
R\left(x=x_{i}\right)=0 \quad i=1,2, \ldots, N
$$

Point collocation is essentially what one does when using the finite difference method. In the point collocation method the residuals are set to zero at as many points as there are unknown coefficients in the approximate solution. 


\section{Example 1. (Finite Difference Approach)}

To better understand the characteristics of the point collocation method and thus the finite difference method, let us consider the following example.

$$
\frac{d^{2} u}{d x^{2}}+u+x=0
$$

$$
0 \leq x \leq 1
$$

with the following boundary conditions

$$
\begin{array}{ll}
u=0 & \text { at } x=0 \\
u=0 & \text { at } x=1 .
\end{array}
$$

It can be shown easily that the exact solution for the above equation is

$$
u_{\text {exact }}=\frac{\sin x}{\sin 1}-x
$$

In the FDM, an approximate solution is chosen as one that satisfies the given boundary conditions. Therefore, we chose the following as our approximate solution,

$$
u=x(1-x)\left(\alpha_{1}+\alpha_{2} x\right)
$$

Substituting this approximate solution into the governing equation (a) we obtain the following residual function

$$
R=\frac{d^{2} u}{d x^{2}}+u+x=\left(-2+x-x^{2}\right) \alpha_{1}+\left(2-6 x+x^{2}-x^{3}\right) \alpha_{2}+x
$$


According to the point collocation method, we then set the residual function to zero at points within the domain $x$. We chose the following two points, $x=\frac{1}{4}$ and $x=\frac{1}{2}$. Thus the weighting function can be expressed in terms of Dirac delta functions applied at these two points as follows

$$
w=\beta_{1} \delta\left(x-\frac{1}{4}\right)+\beta_{2} \delta\left(x-\frac{1}{2}\right)
$$

The weighted residual integral is represented by

$$
\int_{0}^{1} R w d x=0
$$

or equivalently,

$$
R\left(x=\frac{1}{4}\right)=0 \quad R\left(x=\frac{1}{2}\right)=0
$$

We obtain two equations in $\alpha_{1}$ and $\alpha_{2}$, which can be expressed in matrix form as

$$
\left[\begin{array}{cc}
\frac{29}{16} & -\frac{35}{64} \\
\frac{7}{4} & \frac{7}{8}
\end{array}\right]\left[\begin{array}{l}
\alpha_{1} \\
\alpha_{2}
\end{array}\right]=\left[\begin{array}{c}
\frac{1}{3} \\
\frac{2}{3}
\end{array}\right]
$$

Solving the above linear system, we obtain $\alpha_{1}=\frac{6}{31}$ and $\alpha_{2}=\frac{40}{217}$. Therefore, the approximate solution can be written as

$$
u=\frac{x(1-x)}{217}(42+40 x)
$$

and the residual function as 


$$
R=\frac{1}{217}\left(-4+19 x-2 x^{2}-40 x^{3}\right)
$$

Notice that $R$ is identically zero at $x=\frac{1}{4}$ and $x=\frac{1}{2}$. However, this does not mean that the solution for $u$ is exact at those points.

\section{Subdomain Collocation Method}

In this method, the domain $\Omega$ is divided into $N$ subdomains and the integral of error in each of them is set to zero. This is equivalent to choosing the weight functions such that,

$$
\psi_{i}=\left\{\begin{array}{lll}
1 & \text { for } & x \in \Omega_{i} \\
0 & \text { for } & x \notin \Omega_{i}
\end{array}\right.
$$

Notice the weighting function is a step-type function in the subdomain collocation method. The weighted residual integral in equation (A.12) then becomes simply

$$
\int_{\Omega_{i}} R d x=0 \quad i=1,2, \ldots, N
$$

In most cases, the subdomain collocation method provides more accurate results than the point collocation method.

\section{Galerkin Method}

In this method, the weighting functions are chosen to be the same as the approximating functions, i.e.,

$$
\phi_{i}=\psi_{i}
$$


The weighted residual integral in equation (A.12) therefore becomes

$$
\int_{\Omega} R \phi_{i} d \Omega=0 \quad i=1,2, \ldots, N
$$

This is the method used in most finite element formulations for which the symmetry of $\phi_{i}=\psi_{i}$ coupled to inherently symmetric field equations leads to symmetric algebraic matrices.

In this section, we examined three methods of weighting the residual due to error in the approximate solution. As shown in equation (A.15), the FDM is equivalent to approximating the governing equations at points within the domain using local expansions for the variables, generally truncated Taylor series. The solution is then found by forcing it to be satisfied at a series of points. On the other hand, the solution of FEM is found using the concept of distributing error within the domain, which is analogous to a process of smoothing. Therefore, the FEM solutions tend to have less 'noise' than ones that are derived from the FDM.

\section{WEAK FORMULATIONS}

We showed that integration by parts of the governing equation reduces or 'weakens' the order of continuity required for the $u$ function by transferring it to an arbitrary function $w$. In other words, by chosing the right function for $w$, we can find $u$ that satisfies the governing equation with less requirements. For such a reason, the formulations derived from integration by parts of the original differential equation, such as equations (A.4), 
(A.6) and (A.7), are referred to as 'weak formulations.' Combined with weighted residual statements they provide the fundamental integral statements of the FEM and BEM.

\section{Finite Element Method}

Let us again consider the governing equation of (A.1). We showed that it can be written as

$$
\int_{0}^{1}\left\{\frac{d^{2} u}{d x^{2}}+\left(\lambda^{2} u-b\right)\right\} w d x-[(q-\bar{q}) w]_{x=1}+\left[(u-\bar{u}) \frac{d w}{d x}\right]_{x=0}=0
$$

This equation can be written in more compact form using residual functions as defined by equation (A.10) and (A.11), i.e.,

$$
\int_{0}^{1} R w d x-\left[R_{2} w\right]_{x=1}+\left[R_{1} \frac{d w}{d x}\right]_{x=0}=0
$$

We assume that the approximate solution $u$ satisfies exactly the 'essential' boundary condition $u=\bar{u}$ at $x=0$. The equations (A.21) and (A.22) then become

$$
\int_{0}^{1}\left[\frac{d^{2} u}{d x^{2}} w+\left(\lambda^{2} u-b\right) w\right] d x=[(q-\bar{q}) w]_{x=1}
$$

or equivalently

$$
\int_{0}^{1} R w d x=\left[R_{2} w\right]_{x=1}
$$

By integrating by parts equation (A.23), we obtain 


$$
\int_{0}^{1}\left\{-\frac{d u}{d x} \frac{d w}{d x}+\left(\lambda^{2} u-b\right) w\right\} d x=[q w]_{x=0}-[\bar{q} w]_{x=1}
$$

Further, if we force the weighting function $w$ to satisfy the homogeneous version of the essential boundary condition at $x=0$, the above equation becomes

$$
\int_{0}^{1}\left\{-\frac{d u}{d x} \frac{d w}{d x}+\left(\lambda^{2} u-b\right) w\right\} d x=-[\bar{q} w]_{x=1}
$$

This is the basic formulation of the FEM. We shall investigate the characteristics of the FEM using the following example.

Example 2. (Finite Element Approach)

Let us consider the following differential equation (for which we know the exact solution)

$$
\frac{d^{2} u}{d x^{2}}+u+x=0 \quad 0 \leq x \leq 1
$$

with the following boundary conditions

$$
\begin{array}{ll}
u=0 & \text { at } x=0 \\
q=\frac{d u}{d x}=\bar{q} & \text { at } x=1
\end{array}
$$

The approximate solution for $u$ can be expressed as

$$
u=a_{1}+a_{2} x+a_{3} x^{2}+\ldots
$$


However, since we assumed that our approximate solution satisfies the essential boundary condition exactly, we find that

$$
u(x=0)=a_{1}=0
$$

The approximate solution for $u$ and the residual function is now written as

$$
\begin{aligned}
& u=\alpha_{1} x+\alpha_{2} x^{2}+\ldots \\
& R=\frac{d^{2} u}{d x^{2}}+u+x=\alpha_{1} x+\alpha_{2}\left(2+x^{2}\right)+x
\end{aligned}
$$

The weighted residual integral statement can be written as

$$
\int_{0}^{1} R w d x=\left[R_{2} w\right]_{x=1}
$$

or equivalently

$$
\int_{0}^{1}\left(\frac{d^{2} u}{d x^{2}}+u+x\right) w d x=[(q-\bar{q}) w]_{x=1}
$$

In FEM the governing equation is solved by reducing the order of derivatives in the domain by integration by parts the $d^{2} u / d x^{2}$ term, i.e.,

$$
\int_{0}^{1}\left\{\frac{d u}{d x} \frac{d w}{d x}-(u+x) w\right\} d x=[\bar{q} w]_{x=1}-[q w]_{x=0}
$$


According to the Galerkin method, we set the weighting function $w$ to have the same shape as the approximate solution for $u$. Therefore, by using only the first two terms of the approximate solution (equation (A.8)) and the weighting function (equation (A.14)), we obtain,

$$
u=\alpha_{1} \phi_{1}+\alpha_{2} \phi_{2}
$$

and

$$
w=\beta_{1} \phi_{1}+\beta_{2} \phi_{2}
$$

where

$$
\phi_{1}=x \text { and } \phi_{2}=x^{2}
$$

Substituting these values into (i), we obtain

$$
\begin{aligned}
& \int_{0}^{1}\left\{\left(\alpha_{1} \frac{d \phi_{1}}{d x}+\alpha_{2} \frac{d \phi_{2}}{d x}\right)\left(\beta_{1} \frac{d \phi_{1}}{d x}+\beta_{2} \frac{d \phi_{2}}{d x}\right)-\left(\alpha_{1} \phi_{1}+\alpha_{2} \phi_{2}+x\right)\left(\beta_{1} \phi_{1}+\beta_{2} \phi_{2}\right)\right\} d x \\
& =\left[\bar{q}\left(\beta_{1} \phi_{1}+\beta_{2} \phi_{2}\right)\right]_{x=1}
\end{aligned}
$$

which can then be reduced to

$$
\begin{aligned}
& \int_{0}^{1}\left\{\left(\alpha_{1}+2 \alpha_{2} x\right)\left(\beta_{1}+2 \beta_{2} x\right)-\left(\alpha_{1} x+\alpha_{2} x^{2}+x\right)\left(\beta_{1} x+\beta_{2} x^{2}\right)\right\} d x \\
& =\left[\bar{q}\left(\beta_{1}+\beta_{2}\right)\right]
\end{aligned}
$$

As the quantities $\beta_{1}$ and $\beta_{2}$ are arbitrary, the satisfaction of the above equation implies satisfaction of the following two equations.

$$
\int_{0}^{1}\left\{\left(\alpha_{1}+2 \alpha_{2} x\right)-\left(\alpha_{1} x^{2}+\alpha_{2} x^{3}+x^{2}\right)\right\} d x=\bar{q}
$$




$$
\int_{0}^{1}\left\{2\left(\alpha_{1} x+2 \alpha_{2} x^{2}\right)-\left(\alpha_{1} x^{3}+\alpha_{2} x^{4}+x^{3}\right)\right\} d x=\bar{q}
$$

Integrating the above equations and expressing them in matrix form, we obtain

$$
\left[\begin{array}{ll}
\frac{2}{3} & \frac{3}{4} \\
\frac{3}{4} & \frac{17}{15}
\end{array}\right]\left[\begin{array}{l}
\alpha_{1} \\
\alpha_{2}
\end{array}\right]=\left[\begin{array}{l}
\bar{q}+\frac{1}{3} \\
\bar{q}+\frac{1}{4}
\end{array}\right]
$$

We now obtained the FEM solution. The values of $\alpha_{1}$ and $\alpha_{2}$ are,

$$
\begin{aligned}
& \alpha_{1}=0.9859+1.9864 \bar{q} \\
& \alpha_{2}=-0.4319-0.4322 \bar{q}
\end{aligned}
$$

Notice, however, that an error will now appear when we try to compute the value of $q$ at $x=1$.

$$
q=\left[\frac{d u}{d x}\right]=\alpha_{1}+2 \alpha_{2}=0.1221+1.122 \bar{q}
$$

In other words, $q \neq \bar{q}$. This peculiar result is characteristic of weak formulations such as those used in finite elements. Because of this approximate satisfaction of the natural boundary conditions, finite element solutions tend to give poor results for surface fluxes or tractions. 


\section{Boundary Element Method}

A boundary element method can be obtained by choosing a weighting function $w$ in either of the following two ways:

- By selecting a function $w$ which satisfies the homogeneous form of the differential equation.

- By using special types of functions which satisfy those equations in a way that is still possible to reduce the problem to the boundary only. The best examples are singular functions such as Dirac delta functions which simply give a value at the point when integrated over the domain.

\section{First Approach}

By performing an integration by parts again on equation (A.23), we obtain

$$
\int_{0}^{1}\left\{u\left(\frac{d^{2} w}{d x^{2}}+\lambda^{2} w\right)-b w\right\} d x+\left[\frac{d u}{d x} w\right]_{0}^{1}-\left[u \frac{d w}{d x}\right]_{0}^{1}=0
$$

The first approach assumes that we know a solution to the homogeneous version of the governing equation, i.e.,

$$
\frac{d^{2} w}{d x^{2}}+\lambda^{2} w \equiv 0
$$

regardless of the boundary conditions of the problem. By substituting the above expression, the statement (A.27) becomes 


$$
\int_{0}^{1} b w d x=\left[\frac{d u}{d x} w\right]_{0}^{1}-\left[u \frac{d w}{d x}\right]_{0}^{1}
$$

\section{Second Approach}

This approach is based on the assumption that there exists a function $w$ such that

$$
\frac{d^{2} w}{d x^{2}}+\lambda^{2} w \equiv-\delta\left(x-x_{i}\right)
$$

where $\delta\left(x-x_{i}\right)$ is the Dirac delta function. By substituting the above expression, the left side of the equation (A.27) becomes

$$
\int_{0}^{1}\left\{u\left(\frac{d^{2} w}{d x^{2}}+\lambda^{2} w\right)\right\} d x=-\int_{0}^{1} u \delta\left(x-x_{i}\right) d x=-u_{i}
$$

where $u_{i}$ represents the value of the function $u$ at point $x=x_{i}$. The equation (A.27) can then be written as

$$
u_{i}+\int_{0}^{1} b w d x=\left[\frac{d u}{d x} w\right]_{0}^{1}-\left[u \frac{d w}{d x}\right]_{0}^{1}
$$

When the point $x_{i}$ is chosen at the boundary, the equation (A.30) gives a relationship between boundary variables. This approach is applied in boundary elements where the function $w$, called the 'fundamental' solution or Green's function, is known.

Example 3. (Boundary Element Method Using the First Approach)

Let us consider the following differential equation. 


$$
\frac{d^{2} u}{d x^{2}}+u+x=0 \quad 0 \leq x \leq 1
$$

with the following boundary conditions

$$
u=0 \quad \text { at } x=0 \text { and } x=1
$$

The weight function is chosen as the one that satisfies the homogeneous form of equation (a), i.e.,

$$
\frac{d^{2} w}{d x^{2}}+w \equiv 0
$$

The general solution for (c) is

$$
w=\beta_{1} \cos x+\beta_{2} \sin x
$$

with $\frac{d w}{d x}=-\beta_{1} \sin x+\beta_{2} \cos x$

By substituting $w$ and $d w / d x$, the governing equation (a) becomes

$$
\begin{aligned}
& \int_{0}^{1} x w d x+[q w]_{1}-[q w]_{0}=0 \\
& \int_{0}^{1} x\left(\beta_{1} \cos x+\beta_{2} \sin x\right) d x+q_{1}\left(\beta_{1} \cos 1+\beta_{2} \sin 1\right)-q_{0} \beta_{1}=0
\end{aligned}
$$


Since the above equation has to hold for any arbitrary values of $\beta_{1}$ and $\beta_{2}$, we obtain the following two expressions

$$
\begin{aligned}
& \int_{0}^{1} x \cos x d x=-\left(q_{1} \cos 1-q_{0}\right) \\
& \int_{0}^{1} x \sin x d x=-q_{1} \sin 1
\end{aligned}
$$

Therefore,

$$
q_{1}=\frac{\cos 1}{\sin 1}-1 \quad q_{0}=\frac{1}{\sin 1}-1
$$

which are the exact boundary fluxes at $x=1$ and $x=0$.

Example 4. (Boundary Element Method Using the Second Approach)

The weighting function is chosen as the one that satisfies the following singular equation

$$
\frac{d^{2} w}{d x^{2}}+w \equiv \delta\left(x-x_{i}\right)
$$

A solution of $w$ is

$$
w=\frac{1}{2} \sin r
$$

where $r=|x-\zeta|$. Again, this is a solution to the singular problem regardless of the boundary conditions. 
By substituting the above expressions, the governing equation becomes

$$
u_{i}=-\int_{0}^{1} x w d x-q_{1} w_{1}+q_{0} w_{0}
$$

where

$$
q_{0}=\frac{1}{\sin 1}-1 \quad q_{1}=\frac{\cos 1}{\sin 1}-1
$$

Taking into consideration that $w \equiv 0$, and substituting other values of $w$, we obtain

$$
u\left(\frac{1}{2}\right)=-\frac{1}{2} \int_{0}^{1 / 2} x \sin \left(\frac{1}{2}-x\right) d x-\frac{1}{2} \int_{1 / 2}^{1} x \sin \left(x-\frac{1}{2}\right) d x-q_{1} \sin \frac{1}{2}+q_{0} \sin \frac{1}{2}
$$

where $r= \begin{cases}\frac{1}{2}-x & \text { for } 0<x<\frac{1}{2} \\ x-\frac{1}{2} & \text { for } \quad \frac{1}{2}<x<1\end{cases}$

Thus

$$
\begin{aligned}
& u\left(\frac{1}{2}\right)=-\frac{1}{2}\{(\cos 1-1) / \sin 1\} \sin \frac{1}{2}-\frac{1}{2}\left(\frac{1}{2}-\sin \frac{1}{2}\right)-\frac{1}{2}\left(\frac{1}{2}+\sin \frac{1}{2}-\cos \frac{1}{2}\right) \\
& =0.069746964
\end{aligned}
$$

This result is the same as the exact solution

$$
u_{\text {exact }}\left(\frac{1}{2}\right)=\frac{\sin \frac{1}{2}}{\sin 1}-\frac{1}{2}=0.069746964
$$

The fundamental solutions that satisfy the boundary conditions as well as the governing equations are called Green's functions. 


\section{REFERENCES}

Brebbia, C. A., J. C. F. Telles, and L. C. Wrobel, Boundary Element Techniques: Theory and Applications in Engineering, Springer-Verlag, Berlin, 464 pp., 1984.

Crouch, S. L., and A. M. Starfield, Boundary Element Methods in Solid Mechanics, Unwin Hyman, London, 322 pp., 1983.

Jaswon, M., Integral equation methods in potential theory, I, Proc. Roy. Soc. Ser. A., 275, 23-32, 1963.

King, G., and M. Ellis, The origin of large local uplift in extensional regions, Nature, 348, 689-692, 1990.

Kitagawa, K., Boundary Element Analysis of Viscous Flow, Lecture Notes in Engineering 55, edited by C. A. Brebbia and S. A. Orszag, Springer-Verlag, Berlin, 243 pp., 1990.

Phipps Morgan, J., E. M. Parmentier, and J. Lin, Mechanisms for the origin of mid-ocean ridge axial topography: Implications for the thermal and mechanical structure of accreting plate boundaries, J. Geophys. Res., 92, 12,823-12,836, 1987.

Symm, G. T., Integral equation methods in potential theory, II, Proc. Roy. Soc. Ser. A. 275, 33-46, 1963.

Telles, J. C. F., The Boundary Element Methods Applied to Inelastic Problems, Lecture Notes in Engineering 1, edited by C. A. Brebbia and S. A. Orszag, Springer-Verlag, Berlin, 243 pp., 1983. 


\section{APPENDIX B}

\section{Boundary Element Formulation for Potential Field Problems}

This appendix formulates boundary element methods for the two- and threedimensional Laplace's and Poisson's equations. These equations govern many physical problems including heat conduction, diffusion processes, torsion, fluid motion, and flow in porous media. In our case, because the boundary element formulation for the elastostatic problem is relatively complex, it is beneficial to understand the formulation for the potential field problem first. As in Appendix A, the notation and convention of Brebbia et al. [1984] are followed.

We begin with the Laplace's equation

$$
\nabla^{2} u=0 \quad \text { in domain } \Omega
$$

Implicit in the above expression are the conditions that $u$ is continuous in $\Omega$ and that $u$ is differentiable to at least the second order in $\Omega$.

We assume that $u$ satisfies the following boundary conditions.

$$
\begin{array}{lll}
u=\bar{u} & \text { on } \Gamma_{1} & \text { (essential) } \\
q=\frac{\partial u}{\partial \bar{n}}=\bar{q} & \text { on } \Gamma_{2} & \text { (natural) }
\end{array}
$$


where $n$ is normal to the boundary $\Gamma$. Figure B.1 illustrates the configuration for such a potential problem. For a thermal conduction problem, the boundary conditions of the first type represent temperature and the second type flux.

We assume that only the approximate solution for $u$ is known. Therefore, errors would occur if we substitute the approximate solution in place of the exact solution. Such errors can be represented by nonzero residual functions in the domain and on the boundaries, i.e.,

$$
\begin{aligned}
& R=\nabla^{2} u \neq 0 \\
& R_{1}=u-\bar{u} \neq 0 \\
& R_{2}=q-\bar{q} \neq 0
\end{aligned}
$$

Finding the solution to Laplace's equation with given boundary conditions is the same as finding an approximate solution $u$ which satisfies the following integral equation

$$
\int_{\Omega}\left(\nabla^{2} u\right) u^{*} d \Omega=\int_{\Gamma_{2}}(q-\bar{q}) u^{*} d \Gamma-\int_{\Gamma_{1}}(u-\bar{u}) q^{*} d \Gamma
$$

where $u^{*}$ is an arbitrary function that satisfies the same conditions as $u$. Based on the definitions in equation (B.2), the above equation can also be written as

$$
\int_{\Omega} R u^{*} d \Omega=\int_{\Gamma_{2}} R_{2} u^{*} d \Gamma-\int_{\Gamma_{1}} R_{1} q^{*} d \Gamma
$$

Integration by parts of the term on the left hand of equation (B.3) leads us to

$$
-\int_{\Omega}\left(\frac{\partial u}{\partial x_{k}} \frac{\partial u^{*}}{\partial x_{k}}\right) d \Omega=-\int_{\Gamma_{2}} \bar{q} u^{*} d \Gamma-\int_{\Gamma_{1}} q u^{*} d \Gamma-\int_{\Gamma_{1}} u q^{*} d \Gamma+\int_{\Gamma_{1}} \bar{u} q^{*} d \Gamma
$$


where $k=1,2,3$ and Einstein's summation convention is implied by repeated indices.

By integrating by parts the term on the left side of equation (B.4), we obtain

$$
\int_{\Omega}\left(\nabla^{2} u^{*}\right) u d \Omega=-\int_{\Gamma_{2}} \bar{q} u^{*} d \Gamma-\int_{\Gamma_{1}} q u^{*} d \Gamma+\int_{\Gamma_{2}} u q^{*} d \Gamma+\int_{\Gamma_{1}} \bar{u} q^{*} d \Gamma
$$

Notice that by integrating by parts, we have transferred the derivative on $u$ in our original equation to that of an arbitrary function $u^{*}$. In the boundary element method, $u^{*}$ is chosen as the fundamental solution of the governing equation.

\section{FUNDAMENTAL SOLUTION}

The fundamental solution $u^{*}$ of Laplace's equation represents the field generated by a concentrated unit charge or unit source acting at a point $i$. Physically, the effect of this source can be imagined as a field which propagates from $i$ to infinity without any consideration of boundary conditions. This property is in contrast to domain methods such as the finite element method where the approximate solution is required to satisfy the essential types of boundary conditions.

The fundamental solution of Laplace's equation must satisfy the following expression

$$
\nabla^{2} u^{*}+\delta\left(x-x_{i}\right)=0
$$

where $\delta\left(x-x_{i}\right)$ represents the Dirac delta function. By substituting equation (B.7) into (B.6), the left hand side can be reduced to

$$
\int_{\Omega}\left(\nabla^{2} u^{*}\right) u d \Omega=\int_{\Omega}\left\{-\delta\left(x-x_{i}\right)\right\} u d \Omega=-u^{i}
$$


Thus equation (B.6) can now be written

$$
u^{i}+\int_{\Gamma_{2}} u q^{*} d \Gamma+\int_{\Gamma_{1}} \bar{u} q^{*} d \Gamma=\int_{\Gamma_{2}} \bar{q} u^{*} d \Gamma+\int_{\Gamma_{1}} q u^{*} d \Gamma
$$

Note that in the above equation, the values of $u^{*}$ and $q^{*}$ are those corresponding to that of the charge at point $i$. For the sake of simplicity, unless mentioned otherwise, we shall assume that the charge is at point $i$.

For an isotropic medium, the fundamental solution of Laplace's equation is

$$
u^{*}=\frac{1}{4 \pi r} \quad \text { for a three-dimensional problem }
$$

and

$$
u^{*}=\frac{1}{2 \pi} \ln \left(\frac{1}{r}\right) \quad \text { for a two-dimensional problem }
$$

where $r$ is the distance measured from the position of the source charge, $\mathbf{x}^{i}$.

\section{BOUNDARY INTEGRAL EQUATION}

Now that the fundamental solutions are found, we formulate the boundary integration scheme. The formulation in this section is for a continuous case.

For the moment we shall not distinguish the two types of boundary conditions. The equation (B.9) can then be written as 


$$
u^{i}+\int_{\Gamma} u q^{*} d \Gamma=\int_{\Gamma} u^{*} q d \Gamma
$$

By definition the above equation applies to any point within the domain $\Omega$. A problem arises when we place the source charge (point $i$ ) on the boundary $\Gamma$. The evaluation of the above integrals can be done simply by considering a semicircle (for the two-dimensional problem) (Figure B.2) or a hemisphere (for the three-dimensional problem) around point $i$ and then taking the radius to zero.

Next, we examine how the integrations are carried along the boundary around the point source $\left(\Gamma_{\varepsilon}\right)$. The integral of the type shown on the right side of the above equation can be evaluated easily. For the three-dimensional case, it becomes

$$
\lim _{\varepsilon \rightarrow 0}\left(\int_{\Gamma_{\varepsilon}} q u^{*} d \Gamma\right)=\lim _{\varepsilon \rightarrow 0}\left(\int_{\Gamma_{\varepsilon}} q \frac{1}{4 \pi r} d \Gamma\right)=\lim _{\varepsilon \rightarrow 0}\left(q \frac{2 \pi \varepsilon^{2}}{4 \pi \varepsilon}\right) \equiv 0
$$

The right side of equation (B.12) is thus zero. The integral on the left side of equation (B.12), however, is different, i.e.,

$$
\lim _{\varepsilon \rightarrow 0}\left(\int_{\Gamma_{\varepsilon}} u q^{*} d \Gamma\right)=\lim _{\varepsilon \rightarrow 0}\left(-\int_{\Gamma_{\epsilon}} u \frac{1}{4 \pi \varepsilon^{2}} d \Gamma\right)=\lim _{\varepsilon \rightarrow 0}\left(-u \frac{2 \pi \varepsilon^{2}}{4 \pi \varepsilon^{2}}\right)=-\frac{1}{2} u^{i}
$$

In other words, a free term is produced. The same free term is produced for the twodimensional case, i.e.,

$$
\lim _{\varepsilon \rightarrow 0}\left(\int_{\Gamma_{\varepsilon}} u q^{*} d \Gamma\right)=\lim _{\varepsilon \rightarrow 0}\left(-\int_{\Gamma_{\epsilon}} u \frac{1}{2 \pi \varepsilon} d \Gamma\right)=\lim _{\varepsilon \rightarrow 0}\left(-\frac{\pi \varepsilon}{2 \pi \varepsilon}\right)=-\frac{1}{2} u^{i}
$$


Therefore, the governing equation for both two- and three-dimensional problems can be expressed as

$$
\frac{1}{2} u^{i}+\int_{\Gamma} u q^{*} d \Gamma=\int_{\Gamma} u^{*} q d \Gamma
$$

This boundary integral equation is generally regarded as a starting point for the boundary element formulation.

\section{THE BOUNDARY ELEMENT METHOD}

Thus far we have examined the boundary element formulation for continuous cases. To implement the boundary element method on a computer, we need to render the boundary into a finite number of discrete elements. In this section, the boundary element formulation for discrete cases is provided.

Depending on how the boundary is discretized, the boundary element method can be formulated for constant, linear and quadratic cases (Figure B.3). Although one can achieve a greater accuracy with higher-order boundary types such as linear or quadratic elements than with constant elements, the problem size becomes larger with such higher-order boundary types. In the previous section, a free term was produced when the integration was carried around a point source located on the boundary. Because the angle between two adjoining boundaries may be different for linear and quadratic elements, special considerations are needed in dealing with the free term in higher-order boundary types.

We begin by considering the simplest case, the constant element. The boundary is assumed to be divided into $N$ elements (Figure B.3a). The values of $u$ and $q$ are assumed to be constant over each element and equal to the value at the mid-element node. 
By discretizing, the boundary integral equation (equation (B.16)) which represents the relationship between boundary values can now be expressed as

$$
\frac{1}{2} u^{i}+\sum_{j=1}^{N} \int_{\Gamma_{j}} u q^{*} d \Gamma=\sum_{j=1}^{N} \int_{\Gamma_{j}} u^{*} q d \Gamma
$$

The point $i$ is one of the boundary nodes and is the location of the point source. $\Gamma_{j}$ is the boundary of the jth element. Notice that for this type of element (i.e., constant) the boundary is always as 'smooth' as the node is at the center of the element, and therefore the multiplier of $u^{i}$ is $\frac{1}{2}$.

The $u$ and $q$ values can be taken out of the integral because they are constant over each element. We shall call them $u_{j}$ and $q_{j}$ for element $j$.

$$
\frac{1}{2} u^{i}+\sum_{j=1}^{N}\left(\int_{\Gamma_{j}} q^{*} d \Gamma\right) u^{j}=\sum_{j=1}^{N}\left(\int_{\Gamma_{j}} u^{*} d \Gamma\right) q^{j}
$$

Notice that we now have two types of integrals that need to be carried out over the element. They are

$$
\int_{\Gamma_{j}} q^{*} d \Gamma \quad \text { and } \quad \int_{\Gamma_{j}} u^{*} d \Gamma
$$

These integrals relate the $i$ th node where the fundamental solution is acting to another node, the $j$ th node. For this reason, they are referred to as 'influence coefficients'

$$
\begin{aligned}
\hat{H}^{i j} & =\int_{\Gamma_{j}} q^{*} d \Gamma \\
G^{i j} & =\int_{\Gamma_{j}} u^{*} d \Gamma
\end{aligned}
$$


This effect of influence coefficients is illustrated in Figure B.4a. In general, a numerical method such as Gaussian quadrature is used to calculate these two terms. By substituting equation (B.19) and (B.20), equation (B.18) can now be expressed as

$$
\frac{1}{2} u^{i}+\sum_{j=1}^{N} \hat{H}^{i j} u^{j}=\sum_{j=1}^{N} G^{i j} q^{j}
$$

Furthermore, we can define $H$ such that

$$
H^{i j}= \begin{cases}\hat{H}^{i j} & \text { for } i \neq j \\ \hat{H}^{i j}+\frac{1}{2} & \text { for } i=j\end{cases}
$$

The governing equation thus reduces to the more compact form

$$
\sum_{j=1}^{N} H^{i j} u^{j}=\sum_{j=1}^{N} G^{i j} q^{j}
$$

This set of equations can be expressed in matrix form as

$$
\mathbf{H U}=\mathbf{G} \mathbf{Q}
$$

where $\mathbf{H}$ and $\mathbf{G}$ are two $N \times N$ matrices, and $\mathbf{U}$ and $\mathbf{Q}$ are two vectors of length $N$. We can rearrange the terms so that all the unknowns are passed to the left side, and thus the above equation can be expressed as

$$
\mathbf{A X}=\mathbf{F}
$$


where $\mathbf{X}$ is a vector of unknown $u$ and $q$ boundary values. Note that the unknowns are now a mixture of the potentials and their derivatives, rather than potentials only as in the finite element method. This is a result of the boundary element being a 'mixed' formulation, which gives it an important advantage over the finite element method.

Once equation (B.25) is solved, we know all the boundary values of $u$ and $q$. Unlike the finite element method no domain integration is neccessary.

Since we now know all the boundary values, it is possible to calculate any internal value of $u$ or its derivatives. The value of $u$ can be calculated at any internal point $i$ using equation (B.12) which can be written as

$$
u^{i}=\int_{\Gamma} q u^{*} d \Gamma-\int_{\Gamma} u q^{*} d \Gamma
$$

Because the fundamental solution is considered to be acting on an internal point $i$, there is no need to consider free terms. Since all values of $u$ and $q$ are already known, we only need to compute

$$
\int_{\Gamma_{j}} q^{*} d \Gamma \quad \text { and } \quad \int_{\Gamma_{j}} u^{*} d \Gamma
$$

which are due to a point source acting on an internal point $i$. The relationship between the internal point $i$ and the known values at boundary nodes is illustrated in Figure B.4b. Again, a numerical method such as Gaussian quadrature is used to calculate the above two terms. The same discretization is used for the boundary integrals, i.e.,

$$
u^{i}=\sum_{j=1}^{N} G^{i j} q^{j}-\sum_{j=1}^{N} \hat{H}^{i j} u^{j}
$$

The coefficients $G^{i j}$ and $\hat{H}^{i j}$ are calculated for each different internal point. 
Once the $u^{i}$ are known at internal points, the values of internal fluxes can be calculated as follows

$$
\begin{aligned}
& \left(q_{x_{1}}\right)^{i}=\left(\frac{\partial u}{\partial x_{1}}\right)^{i}=\int_{\Gamma} q\left(\frac{\partial u^{*}}{\partial x_{1}}\right)^{i} d \Gamma-\int_{\Gamma} u\left(\frac{\partial q^{*}}{\partial x_{1}}\right)^{i} d \Gamma \\
& \left(q_{x_{2}}\right)^{i}=\left(\frac{\partial u}{\partial x_{2}}\right)^{i}=\int_{\Gamma} q\left(\frac{\partial u^{*}}{\partial x_{2}}\right)^{i} d \Gamma-\int_{\Gamma} u\left(\frac{\partial q^{*}}{\partial x_{2}}\right)^{i} d \Gamma
\end{aligned}
$$

where $x_{1}$ and $x_{2}$ represent two coordinate directions. Note that the derivatives are carried out only on the fundamental solution function $u^{*}$ and $q^{*}$, which are exact solutions, as we are computing the variations of flux around the point $i$.

\section{Linear Elements}

In the case of a linear element, the free term is no longer $\frac{1}{2} u^{i}$ and we need special treatment of corners. This is because, in linear elements, the first node of the $j$ element is the same as the second node of the $j+1$ element (Figure B.5).

The boundary integral formulation can be written in general as

$$
c^{i} u^{i}+\int_{\Gamma} u q^{*} d \Gamma=\int_{\Gamma} u^{*} q d \Gamma
$$

The value of $c^{i}$ for any other boundary has proved to be

$$
c^{i}=\frac{\theta}{2 \pi}
$$


where $\theta$ is the internal angle of the corner in radians (Figure B.5, top). This result was also obtained by defining a small spherical or circular region around the corners and then taking the radius of the region to zero. The constant element represents a special case where $c^{i}$ is $\frac{1}{2}$.

After discretizing the boundary into a series of $N$ elements, equation (B.30) can be written as

$$
c^{i} u^{i}+\sum_{j=1}^{N} \int_{\Gamma_{j}} u q^{*} d \Gamma=\sum_{j=1}^{N} \int_{\Gamma_{j}} u^{*} q d \Gamma
$$

- Interpolation Functions

Higher-order element types can be considered systematically by introducing interpolation functions. For linear elements, $u$ and $q$ vary linearly over each $\Gamma_{j}$, and therefore by using interpolation functions they can simply be taken out of the integrals.

Specifically, we can write $u$ and $q$ as

$$
\begin{aligned}
& u(\xi)=\phi_{1} u^{1}+\phi_{2} u^{2}=\left[\begin{array}{ll}
\phi_{1} & \phi_{2}
\end{array}\right]\left[\begin{array}{l}
u^{1} \\
u^{2}
\end{array}\right] \\
& q(\xi)=\phi_{1} q^{1}+\phi_{2} q^{2}=\left[\begin{array}{ll}
\phi_{1} & \phi_{2}
\end{array}\right]\left[\begin{array}{l}
q^{1} \\
q^{2}
\end{array}\right]
\end{aligned}
$$

where $\xi$ is the dimensionless coordinate that varies from -1 to +1 , and the two interpolation functions are

$$
\begin{aligned}
& \phi_{1}=\frac{1}{2}(1-\xi) \\
& \phi_{2}=\frac{1}{2}(1+\xi)
\end{aligned}
$$


Let us consider the integrals over an element $j$. Those on the left side can be written as

$$
\int_{\Gamma_{j}} u q^{*} d \Gamma=\int_{\Gamma_{j}}\left[\begin{array}{ll}
\phi_{1} & \phi_{2}
\end{array}\right] q^{*} d \Gamma\left[\begin{array}{l}
u^{1} \\
u^{2}
\end{array}\right]=\left[\begin{array}{ll}
h_{1}^{i j} & h_{2}^{i j}
\end{array}\right]\left[\begin{array}{l}
u^{1} \\
u^{2}
\end{array}\right]
$$

where

$$
h_{1}^{i j}=\int_{\Gamma_{j}} \phi_{1} q^{*} d \Gamma \quad h_{2}^{i j}=\int_{\Gamma_{j}} \phi_{2} q^{*} d \Gamma
$$

Similarly, the integrals on the right side can be written as

$$
\int_{\Gamma_{j}} q u^{*} d \Gamma=\int_{\Gamma_{j}}\left[\begin{array}{ll}
\phi_{1} & \phi_{2}
\end{array}\right] u^{*} d \Gamma\left[\begin{array}{l}
q^{1} \\
q^{2}
\end{array}\right]=\left[\begin{array}{ll}
g_{1}^{i j} & g_{2}^{i j}
\end{array}\right]\left[\begin{array}{l}
q^{1} \\
q^{2}
\end{array}\right]
$$

where

$$
g_{1}^{i j}=\int_{\Gamma_{j}} \phi_{1} u^{*} d \Gamma \quad g_{2}^{i j}=\int_{\Gamma_{j}} \phi_{2} u^{*} d \Gamma
$$

- Treatment of Corners

Unlike constant elements, linear and quadratic elements have a common node between two elements (Figure B.5). A quantity such as potential $(u)$ is unique at any point on the boundary, and therefore the common node does not pose any problems. However, this is not the case for a quantity such as flux $(q)$ which is calculated in the direction normal to the boundary. The flux is not unique at the corner node because it has two normal directions. A similar situation arises if the flux prescribed along a smooth boundary is discontinuous. This dilemma can be circumvented by arranging the values of $q$ such that they are now a $2 \mathrm{~N}$ array for linear elements and $3 \mathrm{~N}$ for quadratic elements.

The boundary element formulation is thus expressed as 


$$
c^{i} u^{i}+\left[\begin{array}{llll}
\hat{H}^{i 1} & \hat{H}^{i 2} & \ldots & \hat{H}^{i N}
\end{array}\right]\left[\begin{array}{c}
u^{1} \\
u^{2} \\
\vdots \\
u^{N}
\end{array}\right]=\left[\begin{array}{llll}
G^{i 1} & G^{i 1} & \ldots & G^{i 2 N}
\end{array}\right]\left[\begin{array}{c}
q^{1} \\
q^{2} \\
\vdots \\
q^{2 N}
\end{array}\right]
$$

where $\mathbf{q}$ is a vector of length $2 N$ and $\mathbf{G}$ an array of $N$ by $2 N$. The above equation can also be expressed as

$$
c^{i} u^{i}+\sum_{j=1}^{N} \hat{H}^{i j} u^{j}=\sum_{j=1}^{2 N} G^{i j} q^{j}
$$

Similarly, as we showed for the constant-element case (equation (B.23)), this can be reduced to

$$
\sum_{j=1}^{N} H^{i j} u^{j}=\sum_{j=1}^{2 N} G^{i j} q^{j}
$$

where

$$
H^{i j}= \begin{cases}\hat{H}^{i j} & \text { for } i \neq j \\ \hat{H}^{i j}+c^{i} & \text { for } i=j\end{cases}
$$

The matrix form of equation (B.41) can be written as

$$
\mathbf{H U}=\mathbf{G Q}
$$

Again, by rearranging all the unknowns to the left side, we can express the above equation as

$$
\mathbf{A X}=\mathbf{F}
$$




\section{Quadratic Elements}

For a curved geometry, it is useful to implement curvilinear elements (Figure B.5b). The simplest of curvilinear elements are three-noded quadratic elements. However, quadratic elements are still much more complex than constant or linear elements because they require transformations. In this section, we provide some of the important steps of the formulations and omit detailed derivations.

In the same sense as with linear elements, the quantities $u$ and $q$ can be defined by using interpolation functions such as

$$
\begin{aligned}
& u(\xi)=\phi_{1} u^{1}+\phi_{2} u^{2}+\phi_{3} u^{3}=\left[\begin{array}{lll}
\phi_{1} & \phi_{2} & \phi_{3}
\end{array}\right]\left[\begin{array}{l}
u^{1} \\
u^{2} \\
u^{3}
\end{array}\right] \\
& q(\xi)=\phi_{1} q^{1}+\phi_{2} q^{2}+\phi_{3} q^{3}=\left[\begin{array}{lll}
\phi_{1} & \phi_{2} & \phi_{3}
\end{array}\right]\left[\begin{array}{l}
q^{1} \\
q^{2} \\
q^{3}
\end{array}\right]
\end{aligned}
$$

where interpolation functions are

$$
\begin{aligned}
& \phi_{1}=\frac{1}{2} \xi(\xi-1) \\
& \phi_{2}=(1-\xi)(1+\xi) \\
& \phi_{3}=\frac{1}{2} \xi(1+\xi)
\end{aligned}
$$


As in the case of linear elements, we consider $\xi$ as the dimensionless coordinate which varies from -1 to +1 . The interpolation function indices are referenced according to Figure B.5 (middle).

The integrals along any $j$ th element are similar to those computed for the linear element, but there are now three nodal unknowns and their integration requires the use of a Jacobian. For example, let us see how an integral for $H$ type terms is transformed. In the same sense as the linear element case, they can be expressed as

$$
\int_{\Gamma_{j}} u(\xi) q^{*} d \Gamma=\int_{\Gamma_{j}}\left[\begin{array}{lll}
\phi_{1} & \phi_{2} & \phi_{3}
\end{array}\right] q^{*} d \Gamma\left[\begin{array}{l}
u^{1} \\
u^{2} \\
u^{3}
\end{array}\right]=\left[\begin{array}{lll}
h_{1}^{i j} & h_{2}^{i j} & h_{3}^{i j}
\end{array}\right]\left[\begin{array}{l}
u^{1} \\
u^{2} \\
u^{3}
\end{array}\right]
$$

where

$$
h_{1}^{i j}=\int_{\Gamma_{j}} \phi_{1} q^{*} d \Gamma \quad h_{2}^{i j}=\int_{\Gamma_{j}} \phi_{2} q^{*} d \Gamma \quad h_{3}^{i j}=\int_{\Gamma_{j}} \phi_{3} q^{*} d \Gamma
$$

For a curve such as in Figure B.5b, the transformation is

$$
d \Gamma=\left\{\sqrt{\left(\frac{d x_{1}}{d \xi}\right)^{2}+\left(\frac{d x_{2}}{d \xi}\right)^{2}}\right\} d \xi=|G| d \xi
$$

where $|G|$ is the Jacobian. Therefore, we can write,

$$
h_{k}^{i j}=\int_{\Gamma_{j}} \phi_{k}(\xi) q^{*} d \Gamma=\int_{\text {node } 1}^{\text {node } 2} \phi_{k}(\xi) q^{*}|G| d \xi
$$


To calculate the Jacobian we need to know the variation of the $x_{1}$ and $x_{2}$ coordinates in terms of $\xi$. This can be done by defining the geometrical shape of the element in the same way as the $u$ and $q$ are defined, that is using quadratic interpolation functions so that

$$
\begin{aligned}
& x_{1}=\phi_{1} x_{1}^{1}+\phi_{2} x_{1}^{2}+\phi_{3} x_{1}^{3} \\
& x_{2}=\phi_{1} x_{2}^{1}+\phi_{2} x_{2}^{2}+\phi_{3} x_{2}^{3}
\end{aligned}
$$

where the superscripts indicate the node numbers.

\section{Subregions}

Many problems require treatments with variable material properties or body forces in the domain. In boundary element methods these problem can be considered by dividing the domain into piecewise homogeneous subdomains. The way that the boundary element method handles the heterogeneity is by formulating the problem for each subdomain and then combining them to solve for a final set of equations for the whole region using a compatibility rule along common interfaces between the subdomains.

Let us consider the case where the whole region is divided into two subregions, $\Omega^{1}$ and $\Omega^{2}$, with two boundaries $\Gamma^{1}$ and $\Gamma^{2}$ and an interface represented by $\Gamma_{1}$ (Figure B.6). We use the following definitions:

On the subregion $\Omega^{1}$

$$
\begin{aligned}
& \mathbf{U}^{1} \text { and } \mathbf{Q}^{1} \text { are nodal values of } u \text { and } q \text { on boundary } \Gamma^{1} \\
& \mathbf{U}_{\mathbf{i}}^{1} \text { and } \mathbf{Q}_{\mathbf{i}}^{1} \text { are nodal values of } u \text { and } q \text { on the interface } \Gamma^{1} \text { which belongs to } \Omega^{1}
\end{aligned}
$$

On the subregion $\Omega^{2}$ 


$$
\begin{aligned}
& \mathbf{U}^{2} \text { and } \mathbf{Q}^{2} \text { are nodal values of } u \text { and } q \text { on boundary } \Gamma^{2} \\
& \mathbf{U}_{\mathbf{i}}^{2} \text { and } \mathbf{Q}_{\mathbf{i}}^{2} \text { are nodal values of } u \text { and } q \text { on the interface } \Gamma^{2} \text { which belongs to } \Omega^{2}
\end{aligned}
$$

The system of equations in $\Omega^{1}$ can then be written as

$$
\left[\begin{array}{ll}
\mathbf{H}^{1} & \mathbf{H}_{\mathrm{i}}^{1}
\end{array}\right]\left[\begin{array}{l}
\mathbf{U}^{1} \\
\mathbf{U}_{\mathrm{i}}^{1}
\end{array}\right]=\left[\begin{array}{ll}
\mathbf{G}^{1} & \mathbf{G}_{\mathrm{i}}^{1}
\end{array}\right]\left[\begin{array}{l}
\mathbf{Q}^{1} \\
\mathbf{Q}_{\mathrm{i}}^{1}
\end{array}\right]
$$

and that in $\Omega^{2}$ as

$$
\left[\begin{array}{ll}
\mathbf{H}^{2} & \mathbf{H}_{\mathrm{i}}^{2}
\end{array}\right]\left[\begin{array}{l}
\mathbf{U}^{2} \\
\mathbf{U}_{\mathrm{i}}^{2}
\end{array}\right]=\left[\begin{array}{ll}
\mathbf{G}^{2} & \mathbf{G}_{\mathrm{i}}^{2}
\end{array}\right]\left[\begin{array}{l}
\mathbf{Q}^{2} \\
\mathbf{Q}_{\mathrm{i}}^{2}
\end{array}\right]
$$

If we assume that the displacements and the stresses are continuous across the interface, the compatibility and equilibrium conditions on the interface $\Gamma_{i}$ can be expressed as

$$
\mathbf{U}_{\mathbf{i}}^{1}=\mathbf{U}_{\mathbf{i}}^{2}
$$

and

$$
\mathbf{Q}_{\mathrm{i}}^{1}+\mathbf{Q}_{\mathrm{i}}^{2}=\mathbf{0}
$$

If we call the potential at the interface $\mathbf{U}^{1}$ and adopt on the same interface the fluxes of $\Omega^{1}$ as reference values, we obtain

$$
\mathbf{U}_{\mathrm{i}}=\mathbf{U}_{\mathrm{i}}^{1}=\mathbf{U}_{\mathrm{i}}^{2}
$$

and

$$
\mathbf{Q}_{\mathrm{i}}=\mathbf{Q}_{\mathrm{i}}^{1}=-\mathbf{Q}_{\mathrm{i}}^{2}
$$


The system of equations for the whole region can be written as

$$
\left[\begin{array}{ccc}
\mathbf{H}^{1} & \mathbf{H}_{\mathrm{i}}^{1} & \mathbf{0} \\
\mathbf{0} & \mathbf{H}_{\mathrm{i}}^{2} & \mathbf{H}^{2}
\end{array}\right]\left[\begin{array}{c}
\mathbf{U}^{1} \\
\mathbf{U}_{\mathrm{i}} \\
\mathbf{U}^{2}
\end{array}\right]=\left[\begin{array}{ccc}
\mathbf{G}^{1} & \mathbf{G}_{\mathrm{i}}^{1} & \mathbf{0} \\
\mathbf{0} & -\mathrm{G}_{\mathrm{i}}^{2} & \mathbf{G}^{2}
\end{array}\right]\left[\begin{array}{c}
\mathbf{Q}^{1} \\
\mathbf{Q}_{\mathrm{i}} \\
\mathbf{Q}^{2}
\end{array}\right]
$$

Since $\mathbf{U}_{\mathbf{i}}$ and $\mathbf{Q}_{\mathbf{i}}$ are unknowns, they can be transferred to the left side. In such a case, the system of equations becomes

$$
\left[\begin{array}{cccc}
H^{1} & H_{i}^{1} & -G_{i}^{1} & 0 \\
0 & H_{i}^{2} & G_{i}^{2} & H^{2}
\end{array}\right]\left[\begin{array}{c}
U^{1} \\
U_{i}^{1} \\
Q_{i} \\
U^{2}
\end{array}\right]=\left[\begin{array}{cc}
G^{1} & 0 \\
0 & G^{2}
\end{array}\right]\left[\begin{array}{l}
Q^{1} \\
Q^{2}
\end{array}\right]
$$

As more subdomains are defined, the system of equations will become banded and thus have a large number of zero submatrices. 


\section{POISSON'S EQUATION}

Laplace's equation is a special case of Poisson's equation in which the term that usually represents sources in the domain $b(\mathbf{x})$ is zero. The boundary element formulation for Poisson's equation is the same as that of Laplace's equation except for the term $b(\mathbf{x})$.

Let us consider the following equation.

$$
\nabla^{2} u=b \quad \text { in } \Omega
$$

where $b$ is a known function of position. The boundary integral formulation of the above equation can be written as

$$
\int_{\Omega}\left(\nabla^{2} u-b\right) u^{*} d \Omega=\int_{\Gamma_{2}}(q-\bar{q}) u^{*} d \Gamma-\int_{\Gamma_{1}}(u-\bar{u}) q^{*} d \Gamma
$$

Using the fundamental solution, the above expression can be then reduced to

$$
c^{i} u^{i}+\int_{\Gamma} u q^{*} d \Gamma+\int_{\Omega} b u^{*} d \Omega=\int_{\Gamma} u^{*} q d \Gamma
$$

The only difference from the boundary integral formulation of Laplace's equation is the third term on the left side of the above equation which involves a domain integration.

There are several ways in which this term can be evaluated instead of directly performing the domain integration. The most simple case is when function $b$ is harmonic, i.e.,

$$
\nabla^{2} b=0
$$


This case is analogous to the elastostatic case presented in Appendix C where body forces could be represented by a potential field.

Another way to evaluate the domain integral is to define regions of integration called 'cells' in the domain and compute the domain integral. In this case, for each position of singularity at a boundary point $i$, the domain integral can be expressed as

$$
B^{i}=\int_{\Omega} b u^{*} d \Omega=\sum_{e=1}^{M}\left\{\sum_{k=1}^{r} w_{k}\left(b u^{*}\right)_{k}\right\} \Omega_{e}
$$

where $e$ denotes the different cells, $M$ is the total number of cells describing the domain $\Omega$, $w_{k}$ is the integration weight, and $\Omega_{e}$ is the area of the cell $e$. The function $b u^{*}$ is evaluated at $r$ integration points on each cell.

Equation (B.64) then becomes

$$
c^{i} u^{i}+\sum_{j=1}^{N} \hat{H}^{i j} u^{j}+B^{i}=\sum_{j=1}^{N} G^{i j} q^{j}
$$

or in matrix form

$$
\mathbf{H U}+\mathbf{B}=\mathbf{G Q}
$$

The domain integrals need to be computed also when calculating the values of potentials or fluxes at internal points. For an internal point $i$, the boundary element formulation can be expressed as

$$
u^{i}=\sum_{j=1}^{N} G^{i j} q^{j}-\sum_{j=1}^{N} \hat{H}^{i j} u^{j}-B^{i}
$$




\section{REFERENCES}

Brebbia, C. A., J. C. F. Telles, and L. C. Wrobel, Boundary Element Techniques: Theory and Applications in Engineering, Springer-Verlag, Berlin, 464 pp., 1984. 
Figure B.1 Configuration of Laplace's equation. 

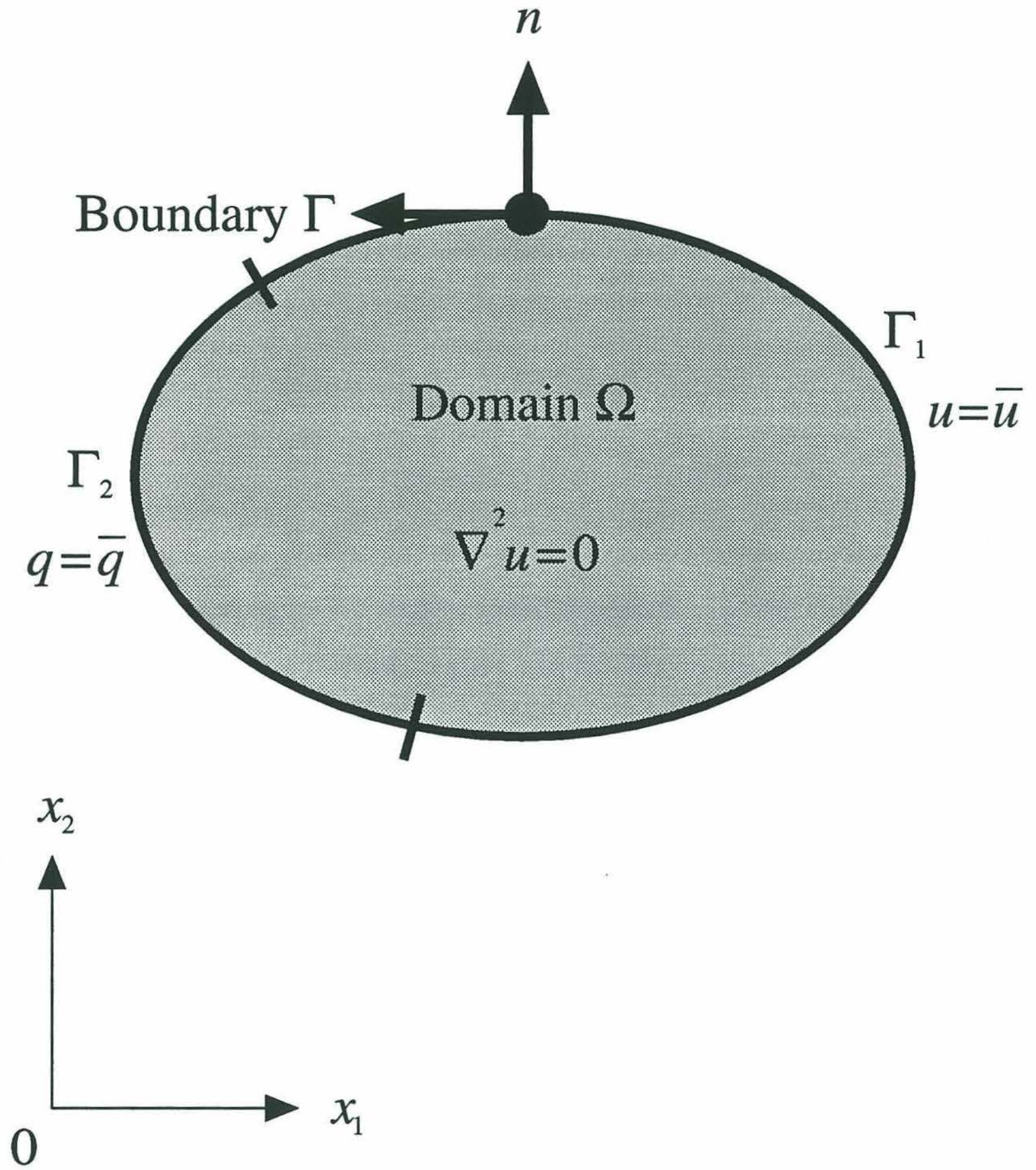
Figure B.2 Illustration of source point $i$ on the boundary for the two-dimensional case. In this case the boundary is modified to include a semicircle around source point $i$. 


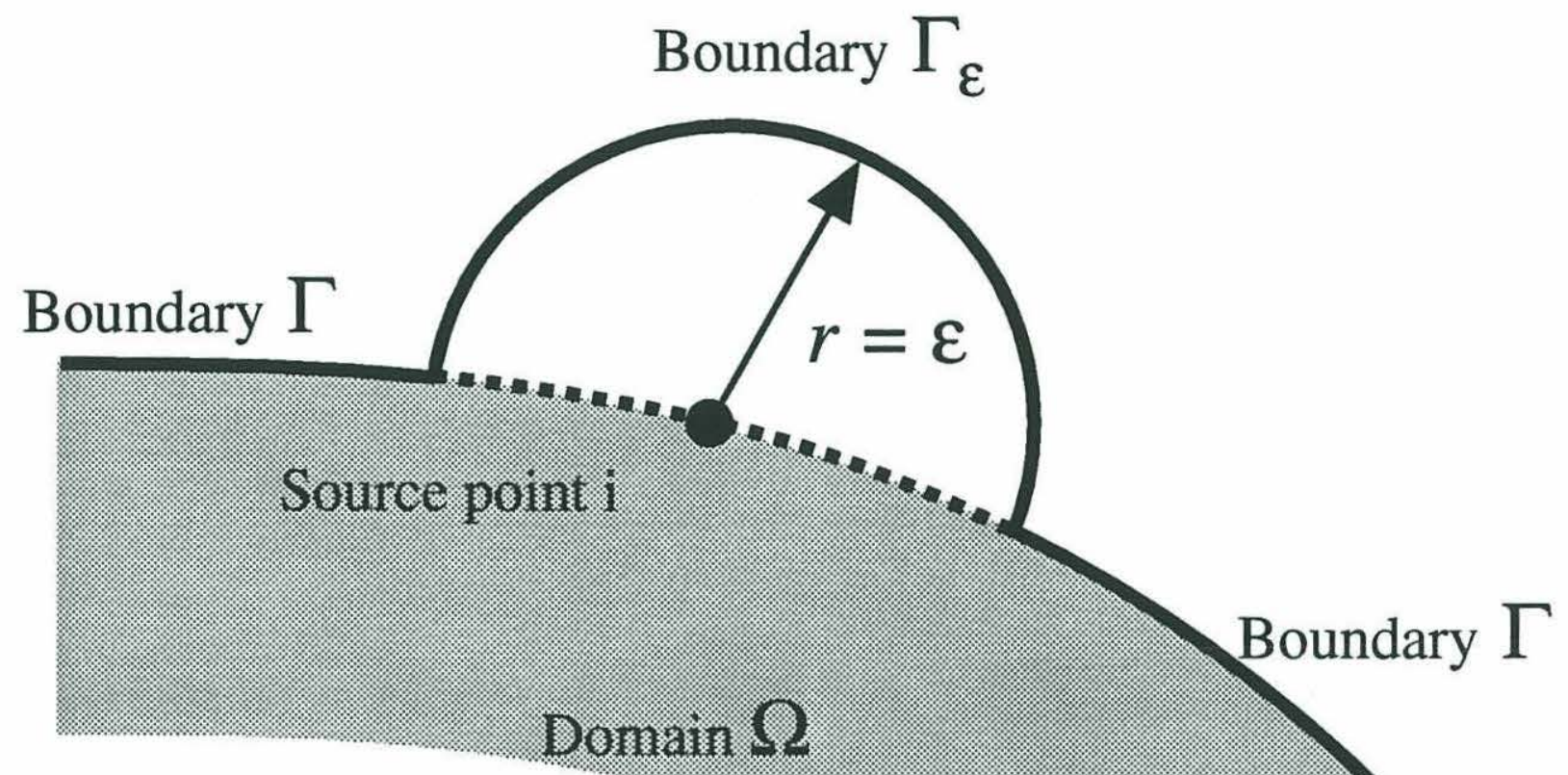


Figure B.3 Different types of boundary elements. (a) Constant, (b) linear, and (c) quadratic. 
(a) Constant Elements

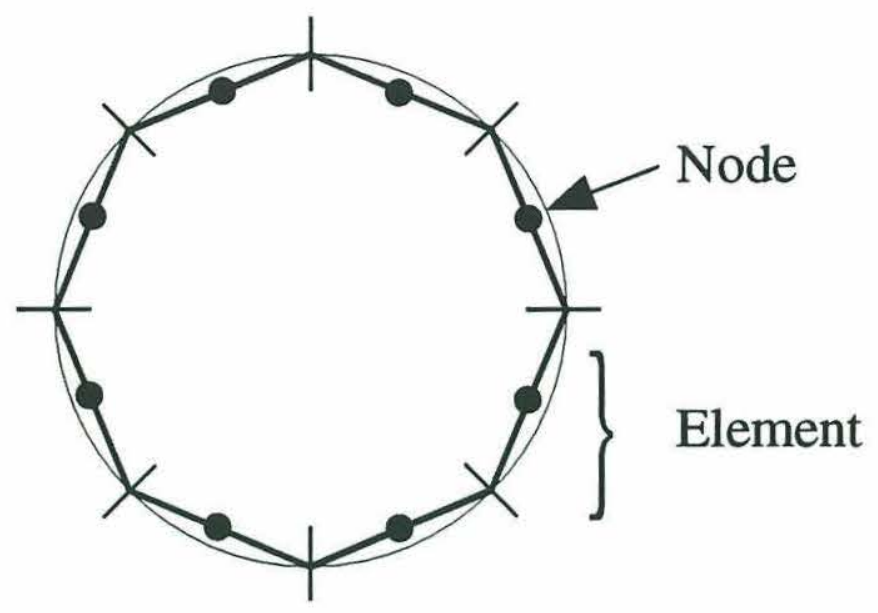

(b) Linear Elements

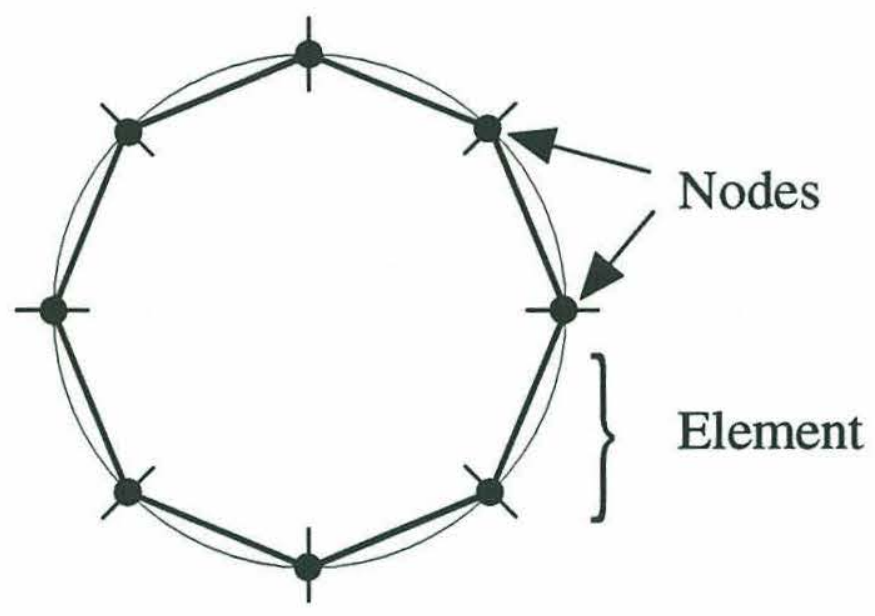

(c) Quadratic Elements

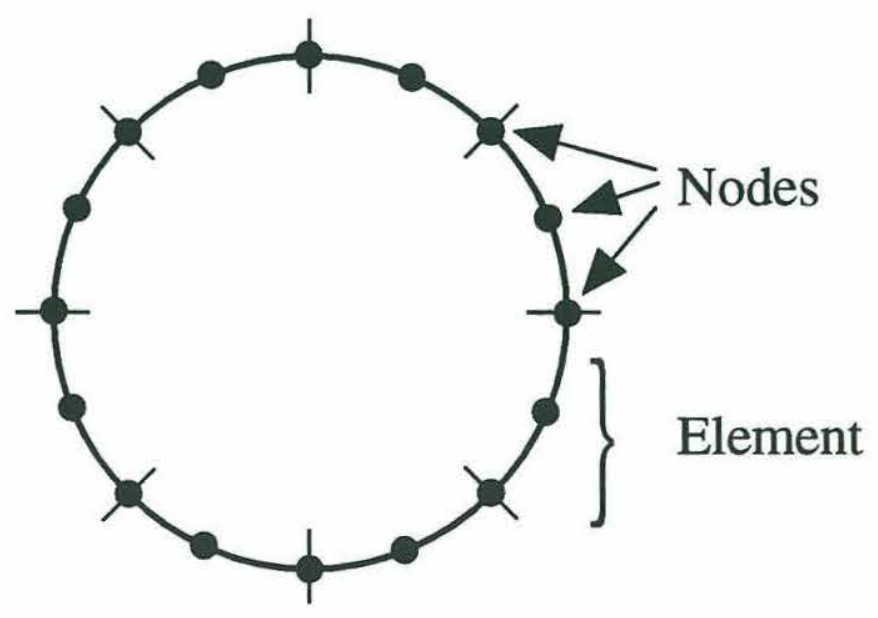


Figure B.4 (a) Relationship between the fundamental solution at the boundary node $i$ and other boundary nodes. (b) Relationship between the fundamental solution at the internal point $i$ and other boundary nodes. 

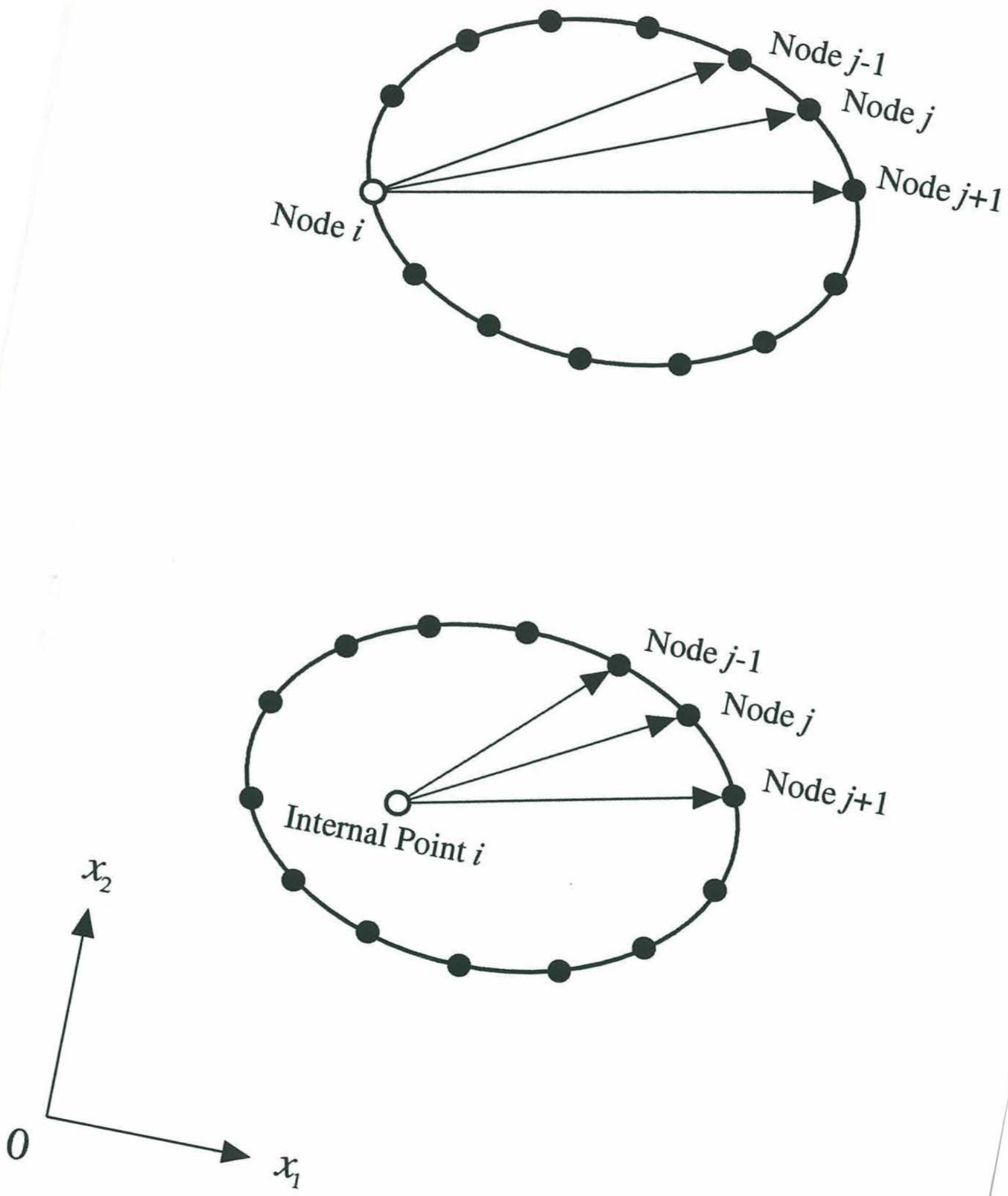

(Figure B.4) 
Figure B.5 An example of notation definition and corner treatments for (top) linear and (middle) quadratic elements. 

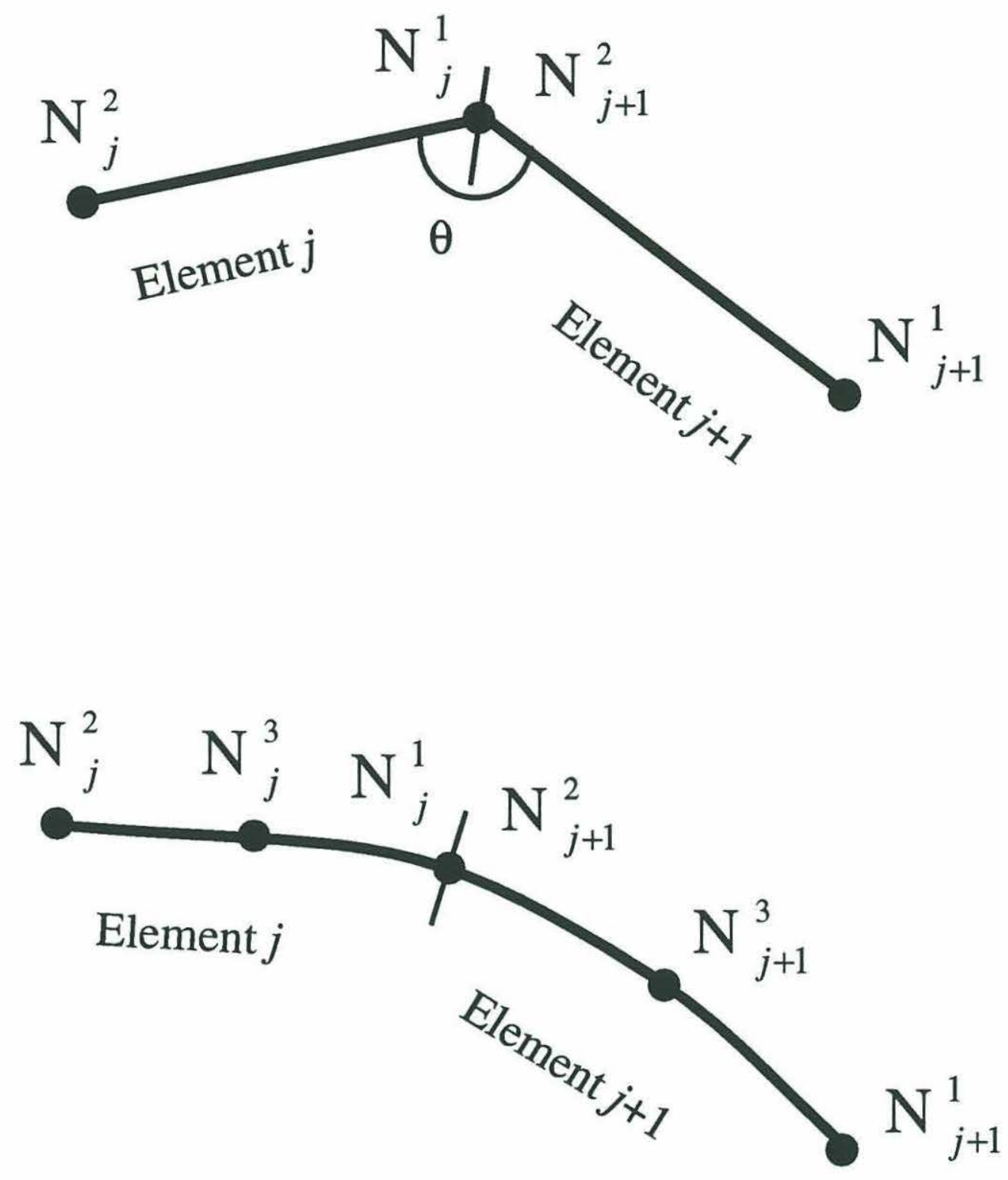

$x_{2}$

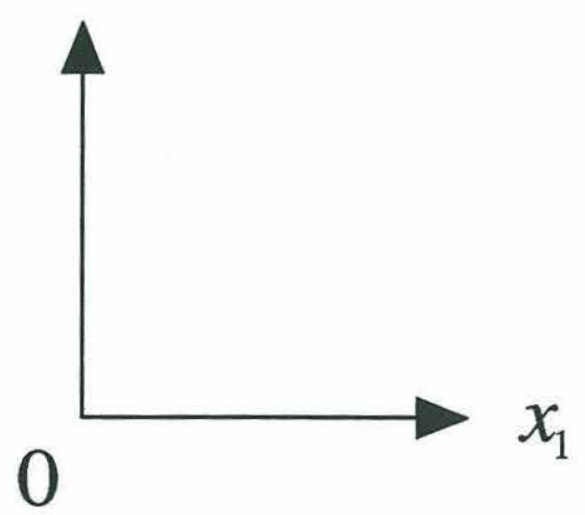


Figure B.6 Domain $\Omega$ divided into two piecewise homogeneous subdomains. 


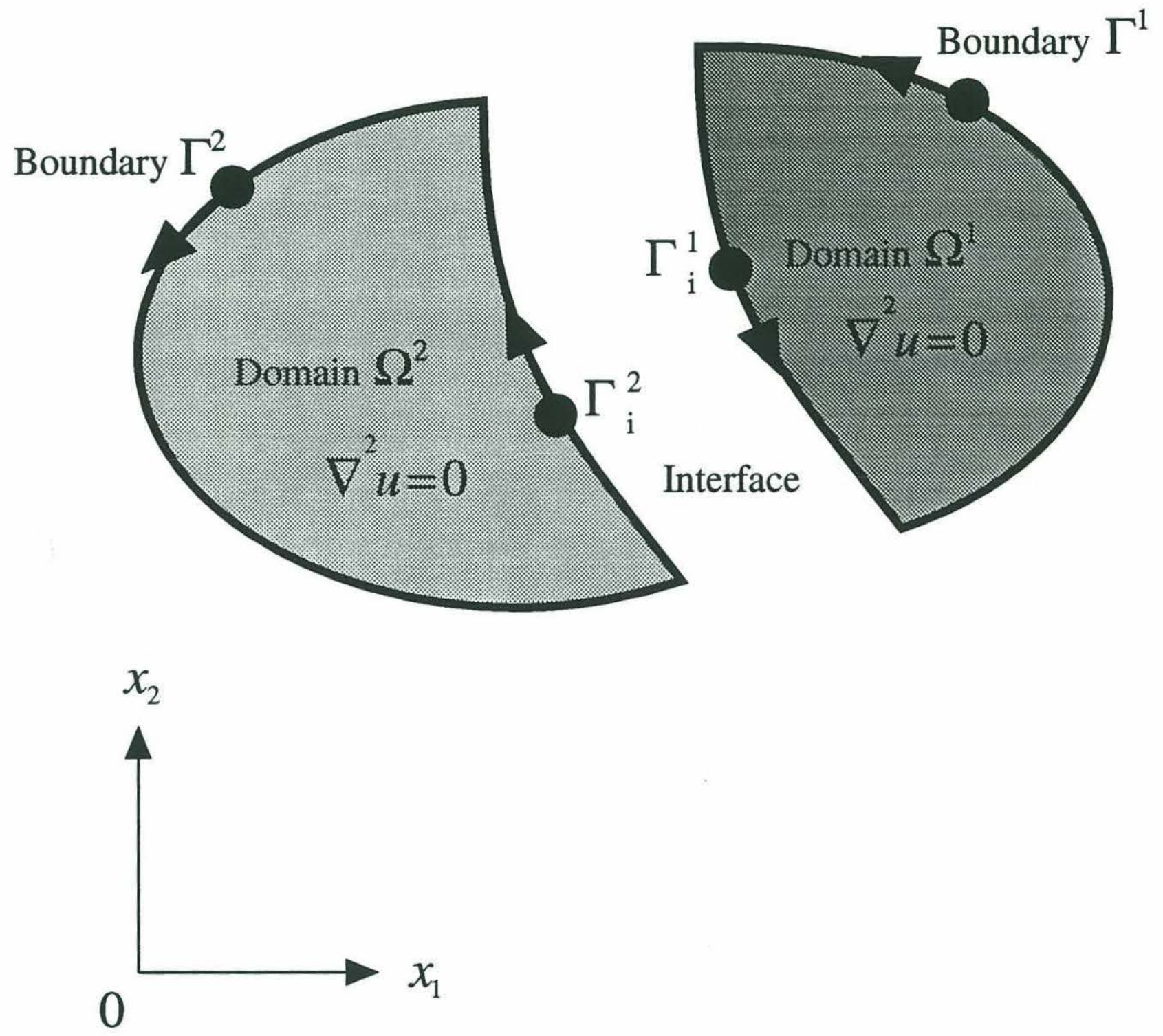




\section{APPENDIX C}

\section{Boundary Element Formulation for Elastostatic Problems}

\section{LINEAR ELASTICITY}

Under linear elasticity material behaves linearly, and changes in the orientation of a body in the deformed state are negligible. The latter assumption leads to linear relations between strain and displacement and allows the equilibrium equation to be referenced to the undeformed geometry. Due to the existence of the fundamental solution, linear elasticity is another important area where one can benefit from using the boundary element method over domain methods.

We begin by describing the basic theories of linear elasticity. Because they be can found in many textbooks [e.g., Timoshenko and Goodier, 1951], we shall state them without any proof.

The state of stress in the body can be described by the following second-order tensor

$$
\left[\begin{array}{lll}
\sigma_{11} & \sigma_{12} & \sigma_{13} \\
\sigma_{21} & \sigma_{22} & \sigma_{23} \\
\sigma_{31} & \sigma_{32} & \sigma_{33}
\end{array}\right]
$$

For static problems, the stress tensor is symmetric, i.e., $\sigma_{i j}=\sigma_{j i}$. As a result, we have only six independent components.

The infinitesimal strain of the body can also be defined as a second-order tensor 


$$
\left[\begin{array}{lll}
\varepsilon_{11} & \varepsilon_{12} & \varepsilon_{13} \\
\varepsilon_{21} & \varepsilon_{22} & \varepsilon_{23} \\
\varepsilon_{31} & \varepsilon_{32} & \varepsilon_{33}
\end{array}\right]
$$

The strain tensor is symmetric by definition, i.e., $\varepsilon_{i j}=\varepsilon_{j i}$. Therefore, the strain tensor also has only six independent components. All linear elastic problems can be fully described by a total of fifteen quantities. These fifteen quantities represent the unknowns.

There are a total of fifteen independent relations or equations that describe linear elastic laws. There are three equations from a consideration equilibrium

$$
\sigma_{i j, j}+b_{i}=0
$$

six equations from compatibility relations

$$
\varepsilon_{i j}=\frac{1}{2}\left(u_{i, j}+u_{j, i}\right)
$$

and six equations from the constitutive law

$$
\sigma_{i j}=2 \mu\left(\frac{v}{1-2 v} \delta_{i j} \varepsilon_{m m}+\varepsilon_{i j}\right)
$$

where $\delta_{i j}$ is the Kronecker delta, $b_{i}$ is the component of the body force, $\mu$ and $v$ are the shear modulus and Poisson's ratio, respectively, and repeated indices imply summation. Only two quantities are required to describe the material property in linear elastic cases if elastic isotropy is assumed. Since there are an equal number of unknowns and equations, one can always find a unique solution for a well-posed linear elastic problem. 


\section{FUNDAMENTAL SOLUTION}

The fundamental solution in elastostatics corresponds to an infinite domain loaded with a concentrated unit point load. This problem is also known as Kelvin's problem.

If the governing equation in equation (C.1) is expressed in terms of displacements, we obtain what is known as the Navier equation, i.e.,

$$
\left(\frac{1}{1-2 v}\right) u_{j, j i}+u_{i, j j}+\frac{1}{\mu} b_{i}=0
$$

Kelvin's problem is a special case when a unit load is applied at a point $i$ in the direction of the unit vector $e_{l}$, i.e.,

$$
b_{l}=\delta\left(x-x_{i}\right) e_{l}
$$

There are several methods of finding solutions to Kelvin's problem. One such method involves representation of the displacements in terms of Galerkin vectors, i.e.,

$$
u_{j}=G_{j, m m}-\frac{1}{2(1-v)} G_{m, j m}
$$

where

$$
G_{l}=G \cdot e_{l}
$$

The problem is thus reduced to finding the Galerkin vector $G$.

For the three-dimensional case, this is

$$
G=\frac{1}{8 \pi \mu} r
$$


and for the two-dimensional case

$$
G=\frac{1}{8 \pi \mu} r^{2} \ln \left(\frac{1}{r}\right)
$$

If we assume that each load is independent, we can define a new quantity $G_{l k}$ to represent the load, i.e.,

$$
G_{l k}=G \delta_{l k}
$$

where $G_{l k}$ is the $k$ th component of the Galerkin vector at any point when a load is applied at $i$ in the $l$ direction. We can also represent the displacement in the domain for the point load as

$$
u_{k}^{*}=u_{l k}^{*} e_{l}
$$

where $u_{l k}^{*}$ represents the displacement in the $k$ direction when the unit load is at point $i$ applying a force in the $l$ direction.

Substituting equation (C.8) and (C.10) into equation (C.6), we obtain

$$
u_{l k}^{*}=\frac{1}{16 \pi \mu(1-v) r}\left\{(3-4 v) \delta_{l k}+r_{, l} r_{, k}\right\}
$$

for three-dimensional problems, and for two-dimensional problems

$$
u_{l k}^{*}=\frac{1}{8 \pi \mu(1-v)}\left\{(3-4 v) \ln \left(\frac{1}{r}\right) \delta_{l k}+r_{, l} r_{, k}\right\}
$$


Stress at any internal point can be written using the compatibility equation (equation (C.2)) and the constitutive law (equation (C.3)) as

$$
\sigma_{k j}^{*}=S_{l k j}^{*} e_{l}
$$

The kernel $S_{l k j}$ will be shown later in this appendix.

The tractions or surface forces on the boundary $\Gamma$ whose normal direction is $\mathbf{n}$ can be expressed as

$$
p_{k}^{*}=p_{l k}^{*} e_{l}
$$

For a three-dimensional case, the traction components can be expressed as

$$
p_{l k}^{*}=-\frac{1}{8 \pi(1-v) r^{2}}\left[\frac{\partial r}{\partial n}\left\{(1-2 v) \delta_{l k}+3 r_{, l} r_{, k}\right\}+(1-2 v)\left(n_{l} r_{, k}-n_{k} r_{, l}\right)\right]
$$

where $n_{l}$ and $n_{k}$ are the direction cosines of the normal vector with respect to the $x_{l}$ and $x_{k}$ directions. $\partial r / \partial n$ is the derivative of the distance vector $r$ with respect to the normal vector.

For a two-dimensional plane strain problem, the traction components can be expressed as

$$
p_{l k}^{*}=-\frac{1}{4 \pi(1-v) r}\left[\frac{\partial r}{\partial n}\left\{(1-2 v) \delta_{l k}+2 r_{, l} r_{, k}\right\}+(1-2 v)\left(n_{l} r_{, k}-n_{k} r_{, l}\right)\right]
$$




\section{BOUNDARY INTEGRAL FORMULATIONS}

The boundary element formulation for linear elasticity can be obtained by minimizing the error arising from an approximate solution. For an elastostatic problem, the governing equation can be expressed as

$$
\sigma_{k j, j}+b_{k}=0
$$

We assume the following boundary conditions

$$
\begin{array}{ll}
u_{k}=\bar{u}_{k} & \text { on } \Gamma_{1} \\
p_{k}=\sigma_{k j} n_{j}=\bar{p}_{k} & \text { on } \Gamma_{2}
\end{array}
$$

The first type of boundary condition represents the essential or displacement boundary condition and the second type the natural or traction boundary condition.

The weighted residual integral for the above problem can be expressed as

$$
\int_{\Omega}\left(\sigma_{k j, j}+b_{k}\right) u_{k}^{*} d \Omega=0
$$

Integration by parts twice on the above equation leads to a familiar equation, i.e.,

$$
\int_{\Omega} \sigma_{k j, j}^{*} u_{k} d \Omega+\int_{\Omega} b_{k} u_{k}^{*} d \Omega=-\int_{\Gamma} p_{k} u_{k}^{*} d \Gamma+\int_{\Gamma} p_{k}^{*} u_{k} d \Gamma
$$

This equation corresponds to Betti's reciprocal theorem in elasticity. Applying the boundary conditions provided in equation (C.19) and (C.20) to (C.22), we obtain 


$$
\int_{\Omega} \sigma_{k j, j}^{*} u_{k} d \Omega+\int_{\Omega} b_{k} u_{k}^{*} d \Omega=-\int_{\Gamma_{1}} p_{k} u_{k}^{*} d \Gamma-\int_{\Gamma_{2}} \bar{p}_{k} u_{k}^{*} d \Gamma+\int_{\Gamma_{1}} \bar{u}_{k} p_{k}^{*} d \Gamma+\int_{\Gamma_{2}} u_{k} p_{k}^{*} d \Gamma
$$

In the boundary element method, the weight function corresponds to the fundamental solution. We assumed that the fundamental solution corresponds to a point load acting at the point $i$ in the direction of the unit vector $e_{l}$, i.e.,

$$
\sigma_{l j, j}^{*}+\delta\left(x-x_{i}\right) e_{l}=0
$$

Substituting equation (C.24) into the term on the left side of equation (C.23) leads to

$$
\int_{\Omega} \sigma_{k j, j}^{*} u_{k} d \Omega=\int_{\Omega} \sigma_{l j, j}^{*} u_{l} d \Omega=-\int_{\Omega} \delta\left(x-x_{i}\right) u_{l} e_{l} d \Omega=-u_{l}^{i} e_{l}
$$

The whole equation (C.23) can now be written as

$$
u_{l}^{i}+\int_{\Gamma_{1}} p_{l k}^{*} \bar{u}_{k} d \Gamma+\int_{\Gamma_{2}} p_{l k}^{*} u_{k} d \Gamma=\int_{\Gamma_{1}} u_{l k}^{*} p_{k} d \Gamma+\int_{\Gamma_{2}} u_{l k}^{*} \bar{p}_{k} d \Gamma+\int_{\Omega} u_{l k}^{*} b_{k} d \Omega
$$

For the moment we shall not distinguish the two boundaries, $\Gamma_{1}$ and $\Gamma_{2}$. The above equation can then be written as

$$
u_{l}^{i}+\int_{\Gamma} p_{l k}^{*} u_{k} d \Gamma=\int_{\Gamma} u_{l k}^{*} p_{k} d \Gamma+\int_{\Omega} u_{l k}^{*} b_{k} d \Omega
$$

This equation is known as Somigliana's identity in elasticity. 
Equation (C.27) describes the relationship between the boundary values for the point load within the domain. However, one needs to be careful how the boundary integration is carried out when the point load is located on the boundary $\Gamma$.

The first integral in equation (C.27) can be divided in two parts, i.e.,

$$
\int_{\Gamma} u_{l k}^{*} p_{k} d \Gamma=\lim _{\varepsilon \rightarrow 0}\left\{\int_{\Gamma-\Gamma_{\epsilon}} u_{l k}^{*} p_{k} d \Gamma\right\}+\lim _{\varepsilon \rightarrow 0}\left\{\int_{\Gamma_{\epsilon}} u_{l k}^{*} p_{k} d \Gamma\right\}
$$

The first integral on the right side of the above equation will simply become an integral on the whole boundary $\Gamma$ when $\varepsilon \rightarrow 0$. The second integral becomes

$$
p_{k}^{i} \lim _{\varepsilon \rightarrow 0}\left\{\int_{\Gamma_{\varepsilon}} u_{l k}^{*} d \Gamma\right\} \equiv 0
$$

A special consideration is required for the integral on the left side of equation (C.27), which also can be divided into two terms

$$
\int_{\Gamma} p_{l k}^{*} u_{k} d \Gamma=\lim _{\varepsilon \rightarrow 0}\left\{\int_{\Gamma-\Gamma_{\epsilon}} p_{l k}^{*} u_{k} d \Gamma\right\}+\lim _{\varepsilon \rightarrow 0}\left\{\int_{\Gamma_{\varepsilon}} p_{l k}^{*} u_{k} d \Gamma\right\}
$$

The second term on the right side of the above equation produces a free term. For a smooth boundary such as a constant element, this is

$$
\lim _{\varepsilon \rightarrow 0}\left\{\int_{\Gamma_{\varepsilon}} p_{l k}^{*} u_{k} d \Gamma\right\}=u_{k}^{i} \lim _{\varepsilon \rightarrow 0}\left\{\int_{\Gamma_{\epsilon}} p_{l k}^{*} d \Gamma\right\}=-\frac{1}{2} u_{l}^{i}
$$


As a result, we can write equation (C.28) as

$$
c_{l k}^{i} u_{k}^{i}+\int_{\Gamma} p_{l k}^{*} u_{k} d \Gamma=\int_{\Gamma} u_{l k}^{*} p_{k} d \Gamma+\int_{\Omega} \dot{u_{l k}^{*}} b_{k} d \Omega
$$

where $c_{l k}^{i}$ represents the coefficient of the free term, which for a smooth boundary is $\frac{1}{2} \delta_{l k}$.

\section{BOUNDARY ELEMENT FORMULATION}

We can now formulate the boundary element method for the discrete case. First, we need to define the following functions

$$
\mathbf{u}=\Phi \mathbf{u}^{j}
$$

and

$$
\mathbf{p}=\Phi \mathbf{p}^{j}
$$

where $\mathbf{u}^{j}$ and $\mathbf{p}^{j}$ are the displacements and tractions at the nodal points, respectively. The dimension of matrices $\mathbf{u}^{j}$ and $\mathbf{p}^{j}$ is $3 \times Q$ and $2 \times Q$ for three- and two-dimensional problems, respectively, where $Q$ is the number of nodes on the element. Using the above definition, displacement and traction may be represented at any point on the boundary as $\mathbf{u}$ and $\mathbf{p}$, respectively.

$\Phi$ represents the interpolation function matrix, whose dimension is $3 \times 3 Q$ and $2 \times 2 Q$ for three- and two-dimensional problems, respectively. For the three-dimensional case $\Phi$ can be written as

$$
\Phi=\left[\begin{array}{llll}
\Phi_{1} & \Phi_{2} & \ldots & \Phi_{Q}
\end{array}\right]
$$


where

$$
\Phi_{i}=\left[\begin{array}{ccc}
\phi_{i} & 0 & 0 \\
0 & \phi_{i} & 0 \\
0 & 0 & \phi_{i}
\end{array}\right]
$$

Using the notations defined above, we can now write equation (C.32) as

$$
\mathbf{c}^{i} \mathbf{u}^{i}+\int_{\Gamma} \mathbf{p}^{*} \mathbf{u} d \Gamma=\int_{\Gamma} \mathbf{u}^{*} \mathbf{p} d \Gamma+\int_{\Omega} \mathbf{u}^{*} \mathbf{b} d \Omega
$$

where $c^{i}=\frac{1}{2}$ for a smooth boundary. Otherwise it will be a $3 \times 3$ or $2 \times 2$ array.

By discretizing the boundary, the above equation can be then be written as

$$
\mathbf{c}^{i} \mathbf{u}^{i}+\sum_{j=1}^{R}\left(\int_{\Gamma_{j}} \mathbf{p}^{*} \Phi d \Gamma\right) \mathbf{u}^{j}=\sum_{j=1}^{R}\left(\int_{\Gamma_{j}} \mathbf{u}^{*} \Phi d \Gamma\right) \mathbf{p}^{j}+\sum_{s=1}^{M}\left(\int_{\Omega_{s}} \mathbf{u}^{*} \mathbf{b} d \Omega\right)
$$

where $R$ represents the number of elements on the surface, and $\mathbf{u}^{j}$ and $\mathbf{p}^{j}$ are the nodal displacement and traction on element $j$, respectively.

\section{System of Equations}

Equation (C.38) can be expressed in a more compact form as

$$
\mathbf{c}^{i} \mathbf{u}^{i}+\sum_{j=1}^{N} \hat{\mathbf{H}}^{i j} \mathbf{u}^{j}=\sum_{j=1}^{N} \mathbf{G}^{i j} \mathbf{p}^{j}+\sum_{s=1}^{M} \mathbf{B}^{i j}
$$

where $N$ is the number of nodes. The influence coefficients $\hat{\mathbf{H}}$ and $\mathbf{G}$ can be written as

$$
\hat{\mathbf{H}}^{i j}=\sum_{t} \int_{\Gamma_{t}} \mathbf{p}^{*} \Phi_{q} d \Gamma
$$




$$
\mathbf{G}^{i j}=\sum_{t} \int_{\Gamma_{t}} \mathbf{u}^{*} \Phi_{q} d \Gamma
$$

where the summation extends to all the elements to which node $j$ belongs and $q$ is the number of the order of the node $j$ within element $t$. For constant elements, the summation extends only to one element, $t=j$, and $\Phi_{q}$ is the identity matrix.

The body force integration can also be expressed as

$$
\mathbf{B}^{i s}=\int_{\Omega_{s}} \mathbf{u}^{*} \mathbf{b} d \Omega
$$

Equation (C.39) can be written in a more compact form by defining $\mathbf{H}$ such that

$$
\mathbf{H}^{i j}= \begin{cases}\hat{\mathbf{H}}^{i j} & \text { if } i \neq j \\ \hat{\mathbf{H}}^{i j}+\mathbf{c}^{i} & \text { if } i=j\end{cases}
$$

Equation (C.39) is now

$$
\sum_{j=1}^{N} \mathbf{H}^{i j} \mathbf{u}^{j}=\sum_{j=1}^{N} \mathbf{G}^{i j} \mathbf{p}^{j}+\sum_{s=1}^{M} \mathbf{B}^{i j}
$$

This can be written in matrix form as

$$
\mathbf{H U}=\mathbf{G P}+\mathbf{B}
$$

Rearrangement of the terms such that unknowns are gathered into $\mathbf{X}$ leads from the above equation to 


$$
\mathbf{A X}=\mathbf{F}
$$

Once this linear equation is solved, we know all the quantities on the boundary.

\section{Internal Points}

For internal points, the boundary element formulation can be expressed as

$$
\mathbf{u}^{i}=\sum_{j=1}^{R}\left(\int_{\Gamma_{j}} \mathbf{u}^{*} \Phi d \Gamma\right) \mathbf{p}^{j}-\sum_{j=1}^{R}\left(\int_{\Gamma_{j}} \mathbf{p}^{*} \Phi d \Gamma\right) \mathbf{u}^{j}+\sum_{s=1}^{M}\left(\int_{\Omega_{s}} \mathbf{u}^{*} \mathbf{b} d \Omega\right)
$$

where $i$ is now an internal point.

Displacement at an internal point can be found directly in terms of the nodal displacements and tractions using the following expression

$$
\mathbf{u}^{i}=\sum_{j=1}^{N} \mathbf{G}^{i j} \mathbf{p}^{j}-\sum_{j=1}^{N} \hat{\mathbf{H}}^{i j} \mathbf{u}^{j}+\sum_{s=1}^{M} \mathbf{B}^{i j}
$$

On the other hand, internal stresses can be computed indirectly using the following relationship for an isotropic medium

$$
\sigma_{i j}=\frac{2 \mu \nu}{1-2 v} \delta_{i j} \frac{\partial u_{l}}{\partial x_{l}}+\mu\left(\frac{\partial u_{i}}{\partial x_{j}}+\frac{\partial u_{j}}{\partial x_{i}}\right)
$$

Equation (C.49) can also be written as

$$
\sigma_{i j}=\int_{\Gamma}\left\{\frac{2 \mu v}{1-2 v} \delta_{i j} \frac{\partial u_{l k}^{*}}{\partial x_{l}}+\mu\left(\frac{\partial u_{i k}^{*}}{\partial x_{j}}+\frac{\partial u_{j k}^{*}}{\partial x_{i}}\right)\right\} p_{k} d \Gamma
$$




$$
\begin{aligned}
& -\int_{\Gamma}\left\{\frac{2 \mu \nu}{1-2 v} \delta_{i j} \frac{\partial p_{l k}^{*}}{\partial x_{l}}+\mu\left(\frac{\partial p_{i k}^{*}}{\partial x_{j}}+\frac{\partial p_{j k}^{*}}{\partial x_{i}}\right)\right\} u_{k} d \Gamma \\
& +\int_{\Omega}\left\{\frac{2 \mu \nu}{1-2 v} \delta_{i j} \frac{\partial u_{l k}^{*}}{\partial x_{l}}+\mu\left(\frac{\partial u_{i k}^{*}}{\partial x_{j}}+\frac{\partial u_{j k}^{*}}{\partial x_{i}}\right)\right\} b_{k} d \Omega
\end{aligned}
$$

This equation in turn can be expressed as

$$
\sigma_{i j}=\int_{\Gamma} D_{k i j} p_{k} d \Gamma-\int_{\Gamma} S_{k i j} u_{k} d \Gamma+\int_{\Omega} D_{k i j} b_{k} d \Omega
$$

where

$$
D_{k i j}=\frac{1}{r^{\alpha}}\left\{(1-2 v)\left(\delta_{k i} r_{, j}+\delta_{k j} r_{, i}-\delta_{i j} r_{, k}\right)+\beta r_{, i} r_{, j} r_{, k}\right\} \frac{1}{4 \alpha \pi(1-v)}
$$

and

$$
\begin{aligned}
& S_{k i j}=\frac{2 \mu}{r^{\beta}}\left[\beta \frac{\partial r}{\partial n}\left\{(1-2 v) \delta_{i j} r_{, k}+v\left(\delta_{i j} r_{, j}+\delta_{j k} r_{, i}\right)-\gamma r_{, i} r_{, j} r_{, k}\right\}\right. \\
& +\beta \gamma\left(n_{i} r_{, j} r_{, k}+n_{j} r_{, i} r_{, k}\right)+(1-2 v)\left(\beta n_{k} r_{, i} r_{, j}+n_{j} \delta_{i k}+n_{i} \delta_{j k}\right) \\
& \left.-(1-4 v) n_{k} \delta_{i j}\right] \frac{1}{4 \alpha \pi(1-v)}
\end{aligned}
$$

where, for the two-dimensional case $\alpha=1, \beta=1$ and $\gamma=4$, and for the threedimensional case $\alpha=2, \beta=3$ and $\gamma=5$. 
Treatment of Domain Integrals and Body Force Terms

The body force term requires a special consideration because it involves an integration over the domain. As we saw in Appendix B, one way to evaluate the body force term is to divide the domain into $M$ internal cells and compute body force integrals over them. In some cases, such domain integrations can be avoided by taking the body force integrals to the boundary.

(i) Body Forces

The domain integrals can be avoided in many cases by reducing them to the boundary. Consider in this case that body force components $b_{k}$ can be obtained from a potential function $\psi$ such that

$$
b_{k}=\frac{\partial \psi}{\partial x_{k}}
$$

where the potential $\psi$ is assumed to satisfy the following harmonic relationship

$$
\nabla^{2} \psi=K_{0}=\text { constant }
$$

The body force integral can then be written as

$$
\int_{\Omega} b_{k} u_{l k}^{*} d \Omega=\int_{\Omega} u_{l k}^{*}\left(\frac{\partial \psi}{\partial x_{k}}\right) d \Omega=\int_{\Omega} \frac{\partial}{\partial x_{k}}\left(u_{l k}^{*} \psi\right) d \Omega-\int_{\Omega} \frac{\partial u_{l k}^{*}}{\partial x_{k}} \psi d \Omega
$$

Furthermore, if we use the divergence theorem, the above equation can be written as 


$$
\int_{\Omega} b_{k} u_{l k}^{*} d \Omega=\int_{\Omega} u_{l k}^{*} \psi n_{k} d \Omega-\int_{\Omega} \frac{\partial u_{l k}^{*}}{\partial x_{k}} \psi d \Omega
$$

where $n_{k}$ is the direction cosine normal to $\Gamma$ with respect to the $x_{k}$ axis. To take the last integral of the above equation to the boundary, we can write $u_{l k}^{*}$ in terms of the Galerkin vector $G_{l k}$, i.e.,

$$
u_{l k}^{*}=G_{l k, j j}-\frac{1}{2(1-v)} G_{l j, k j}=\nabla^{2}\left(G_{l k}\right)-\frac{1}{2(1-v)} G_{l j, k j}
$$

For three-dimensional problems, the solution is when

$$
G_{k l}=\frac{1}{8 \pi \mu} r \delta_{k l}
$$

and for two-dimensional problems it is when

$$
G_{k l}=\frac{1}{8 \pi \mu} r^{2} \ln \left(\frac{1}{r}\right) \delta_{k l}
$$

For two-dimensional problems the solution can be written as

$$
u_{l k}^{*}=\frac{1}{8 \pi \mu(1-v)}\left\{(3-4 v) \ln \left(\frac{1}{r}\right) \delta_{k l}-\left(\frac{7-8 v}{2}\right) \delta_{k l}+r_{, k} r_{, l}\right\}
$$

This solution differs from the fundamental solution in equation (C.13) by constant term, which was dropped because rigid body motion does not change the solution of the systems of equations. 
The last integral in equation (C.57) thus becomes

$$
\int_{\Omega} u_{l k, k}^{*} \psi d \Omega=\frac{1-2 v}{2(1-v)} \int_{\Omega} \nabla^{2}\left(G_{l k, k}\right) \psi d \Omega
$$

The Green's theorem can be applied between the field $G_{l k, k}$ and $\psi$, i.e.,

$$
\int_{\Omega}\left\{G_{l k, k} \nabla^{2} \psi-\nabla^{2}\left(G_{l k, k}\right) \psi\right\} d \Omega=\int_{\Gamma}\left(G_{l k, k} \psi, n_{j}\right) d \Gamma-\int_{\Gamma}\left(G_{l k, k j} \psi n_{j}\right) d \Gamma
$$

The first integral on the left side is

$$
\int_{\Omega} G_{l k, k} \nabla^{2} \psi d \Omega=K_{0} \int_{\Omega} G_{l k, k} d \Omega=K_{0} \int_{\Gamma} G_{l k} n_{k} d \Omega
$$

Therefore, equation (C.63) is now

$$
-\int_{\Omega} \nabla^{2}\left(G_{l k, k}\right) \psi d \Omega=\int_{\Gamma}\left(G_{l k, k} \psi, n_{j}\right) d \Gamma-\int_{\Gamma}\left(G_{l k, k j} \psi n_{j}\right) d \Gamma-K_{0} \int_{\Gamma} G_{l k} n_{k} d \Gamma
$$

Finally, the body force integral can be expressed in terms of boundary integrals as

$$
\begin{aligned}
& \int_{\Omega} u_{l k}^{*} b_{k} d \Omega= \\
& \int_{\Gamma} u_{l k}^{*} \psi n_{k} d \Gamma+\frac{1-2 v}{2(1-v)}\left\{\int_{\Gamma}\left(G_{l k, k} \psi_{, j} n_{j}\right) d \Gamma-\int_{\Gamma}\left(G_{l k, k j} \psi n_{j}\right) d \Gamma-K_{0} \int_{\Gamma} G_{l k} n_{k} d \Gamma\right\}
\end{aligned}
$$


(ii) Gravitational Loads

A gravitational load represents a special case in which the body force takes the form

$$
\psi=-\rho g x_{3}
$$

and

$$
\mathbf{b}=\left[\begin{array}{c}
0 \\
0 \\
-\rho g
\end{array}\right]
$$

The potential arising from such a body force satisfies the harmonic equation, i.e.,

$$
\nabla^{2} \psi=0
$$

Substituting these terms into equation (C.66), the body force integral can be reduced to

$$
\int_{\Omega} u_{l k}^{*} b_{k} d \Omega=-\int_{\Gamma} u_{l k}^{*} \rho g x_{3} n_{k} d \Gamma-\frac{(1-2 v)}{16 \pi \mu(1-v)} \int_{\Gamma}\left(r_{, l} n_{3}-x_{3} r_{, l j} n_{j}\right) d \Gamma
$$

(iii) Thermoelastic Problems

Temperature changes $\theta$ in an elastic body are equivalent to adding a body force equal to $-\gamma \theta_{, k}$ at each point and increasing the traction by $\gamma \theta n_{k}$ where

$$
\gamma=\frac{2 \mu \alpha(1+v)}{(1-2 v)}
$$

and $\alpha$ is the volumetric thermal expansion coefficient. Therefore, the thermoelastic problem is a special case of the elastostatic problem with body forces. 
If only thermoelastic body forces exist, the boundary integral equation can be written as

$$
c_{l k}^{i} u_{k}^{i}+\int_{\Gamma} p_{l k}^{*} u_{k} d \Gamma=\int_{\Gamma} u_{l k}^{*} p_{k} d \Gamma+\int_{\Gamma} u_{l k}^{*}(\gamma \theta) n_{k} d \Gamma-\int_{\Omega} u_{l k}^{*} \gamma \theta_{, k} d \Omega
$$

We can write the potential of the equivalent body force as

$$
\psi=-\gamma \theta
$$

For steady state conduction, the potential satisfies the harmonic equation, i.e.,

$$
\nabla^{2} \theta=0
$$

As a result, the boundary integral equation can now be written as

$$
c_{l k}^{i} u_{k}^{i}+\int_{\Gamma} p_{l k}^{*} u_{k} d \Gamma=\int_{\Gamma} u_{l k}^{*} p_{k} d \Gamma+\frac{(1-2 v)}{2(1-v)} \int_{\Gamma}\left(G_{l k, k j} \theta n_{j}-G_{l k, k} \theta_{, j} n_{j}\right) d \Gamma
$$




\section{REFERENCES}

Timoshenko, S., and J. N. Goodier, Theory of Elasticity, 2nd ed., McGraw-Hill, New York, 506 pp., 1951. 


\section{APPENDIX D \\ Comparison Between Subregion and Spring Models of the Axial Dike Region}

The axial dike region at the rise axis can be modeled either as a separate subregion or as internal springs connecting two imaginary walls of a slit (Figure D.1). In the former case, the strength of the axial dike region can be defined by the Young's modulus and the width of the subregion, whereas in the latter case, it can be defined by the spring stiffness.

For a subregion model, we can consider a region of dikes as being embedded within a semi-infinite half-space that is being stretched by a far-field horizontal extensional stress $\left(\sigma_{\infty}\right)$ (Figure D.1a). For the sake of simplicity, let us assume that there is only horizontal strain as a result of the far-field horizontal extensional stress. The stress $\sigma$ along the vertical interface between the dike zone and the surrounding medium may be expressed as

$$
\sigma=E_{d} \varepsilon=E_{d} \frac{W-W_{o}}{W_{o}}
$$

where $E_{d}$ is the Young's modulus of the dike region, $\varepsilon$ is the strain, and $W$ and $W_{o}$ are the widths of the axial dike region before and after the application of far-field stress, respectively. Correspondingly, the amount of traction $\left(T_{1}\right)$ applied along the vertical interface between the axial dike zone and the surrounding medium is

$$
T_{1}=E_{d} \frac{W-W_{o}}{W_{o}}
$$


Note that the traction here is applied on an area along the vertical interface of unit thickness between the axial dike zone and the surrounding medium.

For a spring model, we shall consider the same axial dike region as a slit where a series of springs connect the two opposing walls with unit thickness (Figure D.1b). The force $F$ applied along the walls can be expressed as

$$
F=k_{T} x=k_{T}\left(W-W_{o}\right)
$$

where $k_{T}$ is the total spring stiffness of the springs, and $x$ is the displacement resulting from far-field extension, and is thus equivalent to the difference in the width of the slit before and after the application of far-field stress. If we use $k$, the spring stiffness per unit length, then the total spring stiffness can be written as

$$
k_{T}=k \cdot L
$$

where $L$ is the vertical extent of the dike zone. The amount of traction applied along the walls of the slit $\left(T_{2}\right)$ can be expressed as

$$
T_{2}=\frac{k_{T}\left(W-W_{o}\right)}{L}=k\left(W-W_{o}\right)
$$

Finally, by assuming that the tractions derived in the subregion and spring models are equal,

$$
T_{1}=T_{2}
$$

we obtain the following relationship 


$$
k \approx \frac{E_{d}}{W_{o}}
$$

The reason that the above relationship is an approximate one is because we have only considered the horizontal strain in our models, thus ignoring the Poisson effect of the material.

To test the above relationship, we used the boundary element method to compare the predictions of a model of the axial dike zone as a subregion with a model in which the dike zone is a slit with springs (Figure D.2). First, we considered an axial dike $2 \mathrm{~m}$ wide and with a Young's modulus of $0.01 \mathrm{MPa}$. Next, we considered it as a slit with a spring stiffness per unit area of $0.005 \mathrm{MPa} / \mathrm{m}$. In this particular example, we assumed $1 \mathrm{MPa}$ as the magnitude of the far-field horizontal extensional stress and $10 \mathrm{~m}$ as the vertical length of the axial dike region. The comparison of resulting differential stress fields from both approaches shows good agreement. 
Figure D.1. Two different ways to model the axial dike zone. (a) The dike zone is modeled as a separate subregion which is embedded in a surrounding medium; (b) the dike zone is modeled as a slit with springs connecting the two opposing walls. 
(a) Dike modeled as elastic subregion

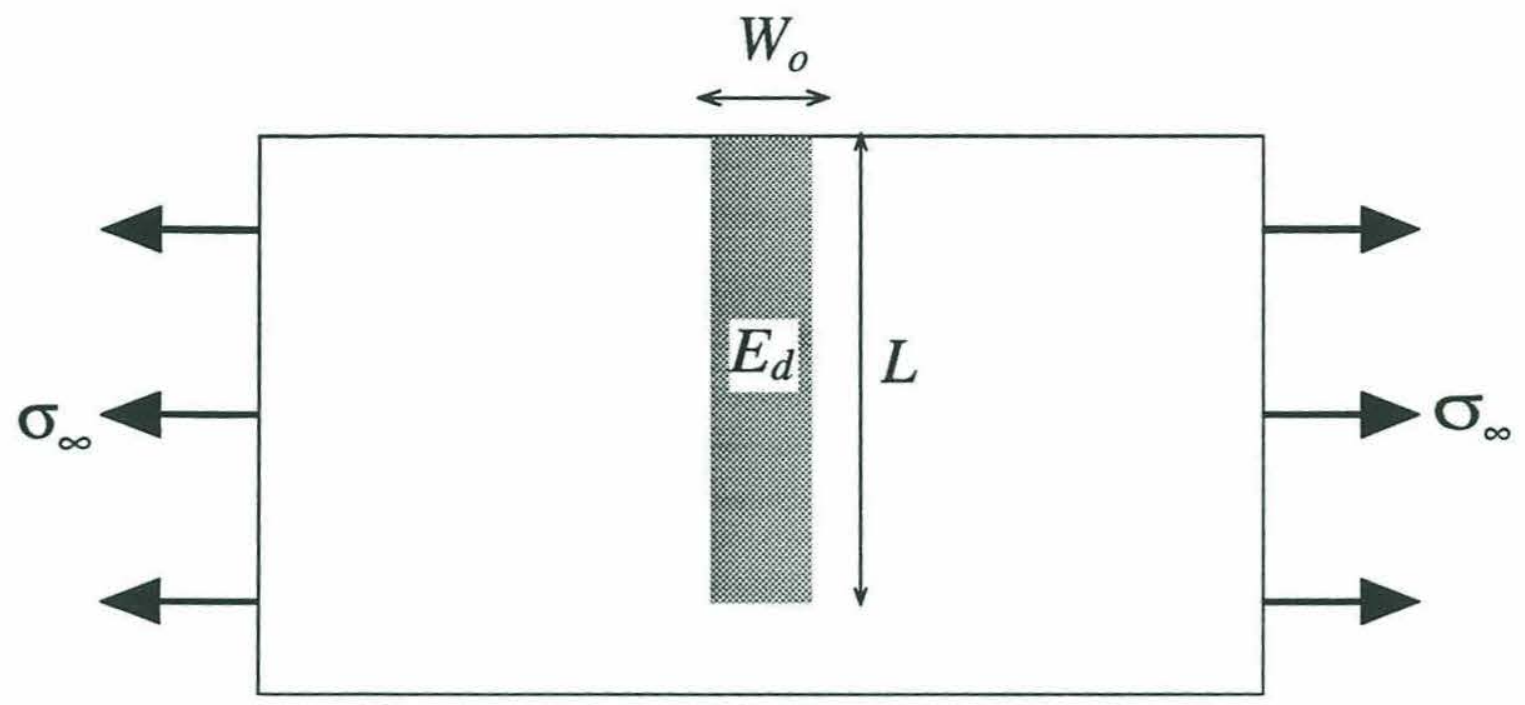

(b) Dike modeled as an interface with springs

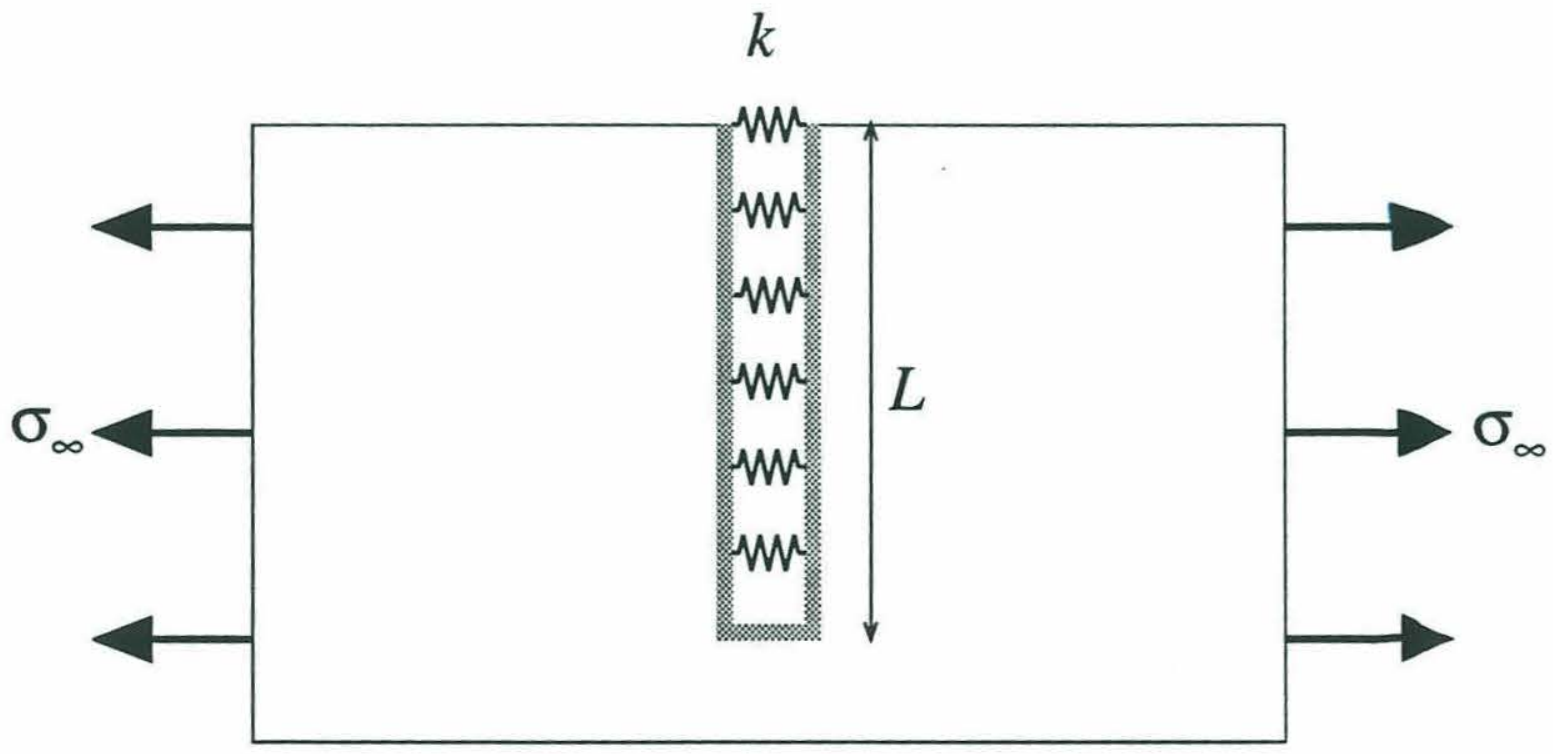


Figure D.2. Differential stress fields resulting from cases where the axial dike zone was modeled (a) as a separate subregion and (b) as an internal spring connecting the two opposing walls of a slit. 


\section{Comparison of two different dike models}

(a) Subregion with $\mathrm{E}=0.01$

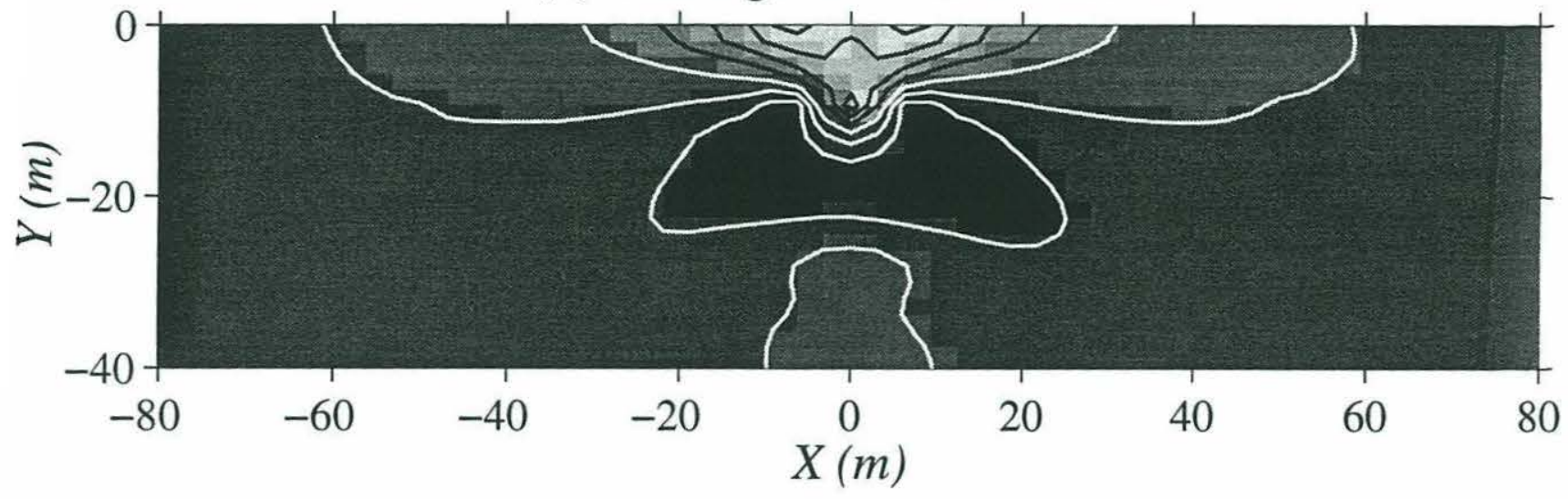

(b) Interface with $\mathrm{k}=0.005$
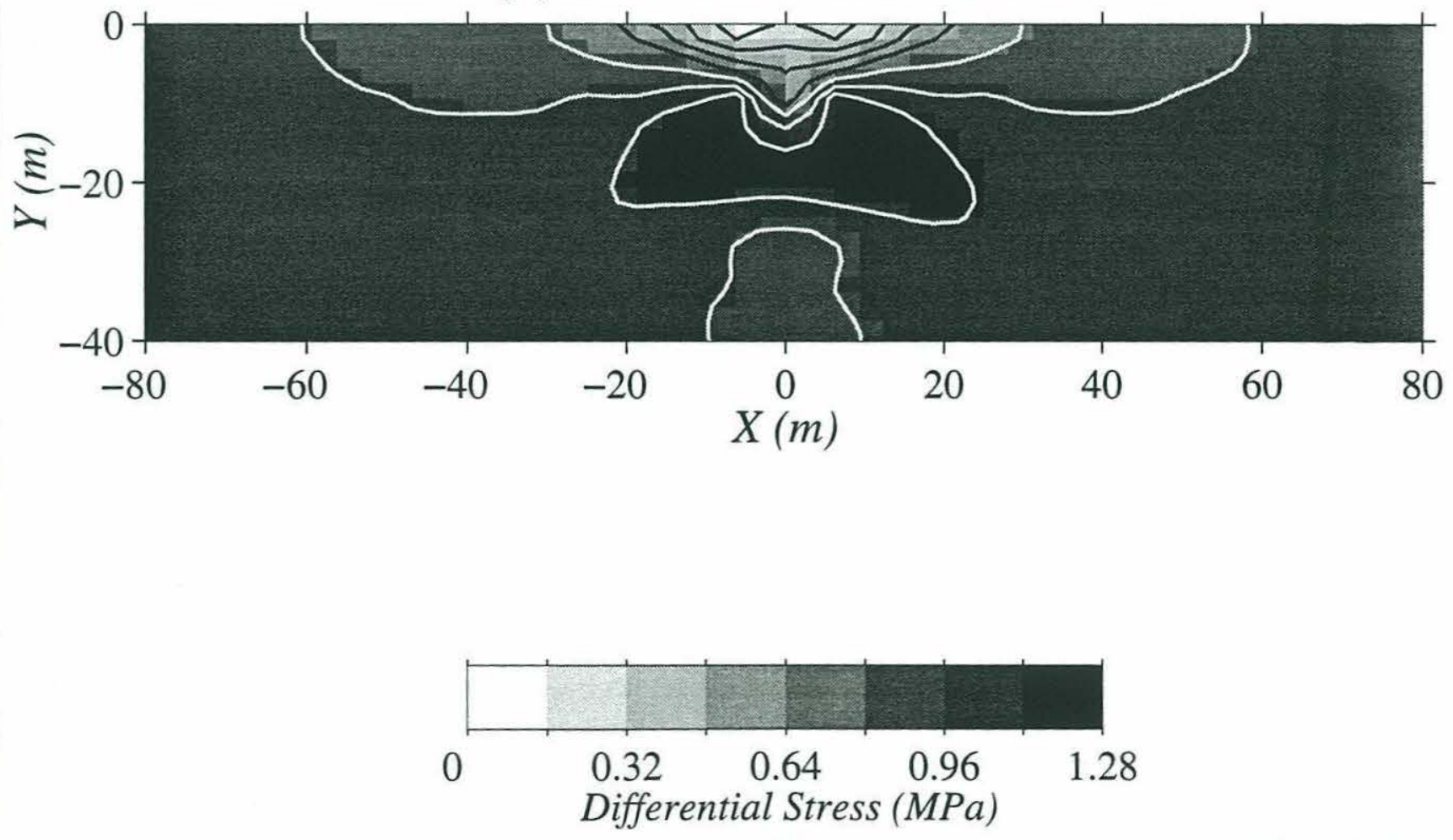


\section{APPENDIX E}

\section{A Method for Improving Navigation Based on Sea Beam and Free-Air Gravity Anomaly at Crossovers}

Navigational information is used to reduce measurements and generate maps for subsequent analyses, and thus estimating a ship's position accurately during a survey is an important task. Unlike determining position on land, obtaining an accurate estimate of position is difficult at sea, especially if the survey is conducted distant from the shore where there are few well-established positional references. Given these difficulties, a number of systems of satellite-positioning have been used throughout marine geophysical surveys.

Prior to the introduction of the Global Positioning System (GPS) in recent years, navigation was based on positional fixes given by Transit satellites and interpolation between the positional fixes, a procedure known as dead-reckoning. This type of navigation, however, was unsuitable for detailed investigation, because the accuracy of some of the positional fixes on conventional satellites was poor and the positional fixes were given only at intervals of tens of minutes to hours; past surveys have shown that error could amount to several kilometers between positional fixes. For a survey conducted by interlacing ship tracks, the inaccuracy of navigation becomes evident as measurements such as bathymetry, free-air gravity anomaly, and magnetic field taken along the tracks do not necessarily match at the expected crossover points of two ship's tracks.

Several techniques have been devised to reconcile the misfit of measurements at the crossovers. Prince and Forsyth [1984], for example, used an inversion method based on a least squares criterion to determine the amount of constant shifts that need to be applied 
along each track as a way to minimize the overall misfit. However, this technique, apart from being ad hoc, did little to reduce the uncertainty of navigation.

For a survey conducted with a high-resolution, swath-mapping bathymetric survey system such as Sea Beam, an additional set of constraints can be placed on navigation by requiring the features of two swaths to match at a crossover. If the number of tracks involved and thus the number of crossovers is small, ship track adjustments can, to some extent, be made by fixing one or more reliable tracks such as those navigated by GPS while shifting the other tracks manually; however, as the number of tracks involved and thus the number of crossovers become large, it becomes difficult to make consistent adjustments to the tracks manually.

For an extensive survey, the navigation and the constraints, including the positional fixes provided by satellites and the shifts required to match Sea Beam swaths at crossovers, can be represented as random variables, and then a generalized inversion technique can be applied to update navigation [Nishimura and Forsyth, 1988]. However, to increase numerical efficiency, instead of representing a misfit as differences between positional parameters of each track, Nishimura and Forsyth attributed half of the positional difference to each of the tracks at a crossover. Making this assumption allowed them to avoid placing off-diagonal elements in the matrices and thus having to store and invert full matrices. Although this approach reduced the overall Sea Beam misfit, since matching Sea Beam swaths at crossovers was built into the inverse problem as a constraint, the overall reduction of misfit cannot be an objective measure of whether navigation was improved. In fact, when independent measurements such as free-air gravity anomalies were compared at crossovers, the crossover errors increased as a result of renavigation [C. E. Nishimura, personal communication, 1988; Wilcock et al., 1993].

Another problem with the approach taken by Nishimura and Forsyth [1988] is that their code can not handle large matrices efficiently. As a result, it is difficult to explore a large range of possible inversion parameters. Nonetheless, to represent the functional form 
of navigation generally requires a large number of parameters. A survey conducted over a period of 21 days, for example, would require at least $10^{5}$ pairs of latitudinal and longitudinal parameters to represent navigation at every 3 minutes. A model with $m$ parameters involves an $m$ by $m$ matrix. Such a matrix requires $m^{2}$ words of computer storage and computational time proportional to $\mathrm{m}^{3}$ to solve a system of simultaneous equations. Even on contemporary workstations, a model becomes inconvenient or intractable when the number of parameters reaches several hundred or a thousand. Fortunately, as with many large models, the matrices involved in navigation are sparse; specifically, each parameter is directly related to only a few other parameters. If the number of nonzero elements in a matrix comprise only a few percent of the total number of elements, a significant reduction in the amount of storage and computation time can be gained by using algorithms for solving sparse linear systems such as SPARSPAK [George and Liu, 1981], the Yale Sparse Matrix Package [Eisenstat et al., 1981], the Harwell Subroutine Library [United Kingdom Atomic Authority, 1988], and MATLAB [Gilbert et al., 1992].

Instead of relying only on the reduction of Sea Beam misfit at crossovers as a measure of the quality of inversion solutions, we use the free-air gravity anomaly misfit at crossovers as a criterion for selecting among a family of inversion solutions. Unlike Nishimura and Forsyth, we represent the Sea Beam crossovers as positional differences between two tracks, and we employ sparse matrix algorithms. The sparse matrix algorithms allow us to examine the renavigation solutions over a wide of range of inversion parameters efficiently. This Appendix outlines the theory and approach we have taken to this problem. 


\section{THEORY}

Our knowledge of navigation can be represented by a set of discrete quantities, referred to as model parameters. In general, for any physical problem, there exists a law to describe how model parameters relate among themselves and to observations. As a new set of observations is made, we are required to modify our model parameters on the basis of inferences drawn from these so-called data parameters. One important use of an inverse theory is that it provides a formal procedure for updating model parameters.

Because observations contain noise or the law itself may be probabilistic, the model and data parameters can be described by random variables with certain probability distributions. In particular, if the probability distributions are Gaussian, the problem reduces to a compact form of linear inverse theory. This section describes the formulation of a renavigation problem within such a framework.

If we neglect the curvature of the Earth's surface over our survey area, the navigation can be represented by a pair of Cartesian coordinates as a function of time; in particular, the navigation can be represented by pairs of latitude and longitude estimates. Further, we can assume that the latitudinal and the longitudinal parameters are uncorrelated; this assumption allows us to divide the problem of renavigation into two problems that are similar in formulation, one for estimating latitude and the other for longitude. The formulation in this section applies to estimation of both latitude and longitude.

In discrete form, navigation can be represented by a set of model parameters 


$$
\mathbf{m}=\left[\begin{array}{c}
\mathrm{m}_{1} \\
\mathrm{~m}_{2} \\
\vdots \\
\mathrm{m}_{m-1} \\
\mathrm{~m}_{m}
\end{array}\right]
$$

where $\mathbf{m}$ is the vector that represents model parameters, $m$ the number of discrete points, and $\mathrm{m}_{\mathrm{i}}$ the value of the navigational function at time $\mathrm{t}_{\mathrm{i}}$. We can also define $\mathbf{C}_{\mathrm{m}}$, an $m$ by $m$ matrix, which represents covariance among model parameters.

$$
\mathbf{C}_{\mathbf{m}}=\left[\begin{array}{ccc}
\mathrm{C}_{11} & \ldots & \mathrm{C}_{1 m} \\
\vdots & & \vdots \\
\mathrm{C}_{m 1} & \cdots & \mathrm{C}_{m m}
\end{array}\right]
$$

One important condition which we can impose on the navigation model is smoothness. Smoothness can be prescibed in the functional form of the a priori model covariance matrix, $\mathbf{C}_{\mathrm{m}}$. We use the Gaussian weighting function in which

$$
\mathrm{C}_{\mathrm{ij}}\left(\mathrm{t}_{\mathrm{i}}, \mathrm{t}_{\mathrm{j}}\right)=\sigma \exp \left[-\frac{\left(\mathrm{t}_{\mathrm{i}}-\mathrm{t}_{\mathrm{j}}\right)^{2}}{2 \Delta^{2}}\right]
$$

where $\Delta$ is the characteristic correlation interval and $\sigma^{2}$ the a priori model variance. The model covariance matrix, $\mathbf{C}_{\mathbf{m}}$, is always positive, and the magnitude of the correlation coefficient decreases with increasing time difference, $t_{i}-t_{j}$.

Next, we can construct a vector $\mathbf{d}$ which consists of $n$ observations 


$$
\mathbf{d}=\left[\begin{array}{c}
\mathrm{d}_{1} \\
\mathrm{~d}_{2} \\
\vdots \\
\mathrm{d}_{n-1} \\
\mathrm{~d}_{n}
\end{array}\right]
$$

The uncertainty associated with these observations can also be represented by an $n$ by $n$ data covariance matrix $\mathbf{C}_{\mathrm{d}}$. Since we assume each observation to be independent, the matrix $\mathbf{C}_{\mathbf{d}}$ is a diagonal matrix

$$
\mathbf{C}_{\mathbf{d}}=\left[\begin{array}{ccc}
\sigma_{11} & \cdots & 0 \\
\vdots & \ddots & \vdots \\
0 & \cdots & \sigma_{n n}
\end{array}\right]
$$

The data parameters and the model parameters are related by linear equation:

$$
\mathbf{G} \mathbf{m}=\mathbf{d}
$$

where $\mathbf{G}$ is an $n$ by $m$ matrix.

The form of $\mathbf{G}$ depends on the type of problem. In a case where positional differences are used to update the model parameter, each crossover point can be expressed as

$$
\mathrm{m}_{\mathrm{i}}=\mathrm{m}_{\mathrm{j}}
$$

where $\mathrm{m}_{\mathrm{i}}$ and $\mathrm{m}_{\mathrm{j}}$ are two model parameters that correspond to the time of crossover according to the updated observations. Therefore, each row of $\mathbf{G}$ should have two nonzero elements whose values are 1 and -1 . 
The solution to equation (E.6) can be found by searching for a set of model parameters that produces zero predicted error $E_{\mathrm{d}}$, where

$$
E_{\mathrm{d}}(\mathbf{m})=(\mathbf{d}-\mathbf{G} \mathbf{m})^{\mathrm{T}} \mathbf{C}_{\mathbf{d}}^{-1}(\mathbf{d}-\mathbf{G} \mathbf{m})
$$

However, if the number of equations $n$ is less than that of model parameters $m$, it is possible to find more than one solution for which the predicted error $E_{\mathrm{d}}$ is zero. In fact, there exists an infinite number of solutions that satisfy such a criterion since the system of linear equations is underdetermined. To single out one of the infinite number of solutions, we must add to the problem additional information not contained in equation (E.6). This extra information is referred to as a priori information [Jackson, 1979]. We shall assume that the best solution is the one that deviates as little as possible from our initial model. Deviation from the initial model $\mathbf{m}_{\mathrm{o}}$, or the length of estimated perturbational model parameters $\mathbf{m}-\mathbf{m}_{\mathrm{o}}$, can be expressed as

$$
E_{\mathrm{m}}(\mathbf{m})=\left(\mathbf{m}-\mathbf{m}_{\mathbf{o}}\right)^{\mathrm{T}} \mathbf{C}_{\mathbf{m}}^{-1}\left(\mathbf{m}-\mathbf{m}_{\mathbf{o}}\right)
$$

The solution of linear equations can be found by minimizing a weighted sum of the data misfit and the length of estimated perturbational model parameters

$$
E_{\mathrm{t}}(\mathbf{m})=E_{\mathrm{d}}(\mathbf{m})+\lambda E_{\mathrm{m}}(\mathbf{m})
$$

where $\lambda$ is a coefficient that represents the trade-off between fitting the data and staying close to the initial model. In a case when $\lambda$ is zero we are fitting the data only, whereas when $\lambda$ is infinite we are fitting the initial model only.

The problem can be reduced to finding that $\mathbf{m}$ which yields a minimum $E_{\mathrm{t}}$. Mathematically, 


$$
\frac{d E_{\mathrm{t}}}{d \mathbf{m}}=\frac{d E_{\mathrm{d}}}{d \mathbf{m}}+\lambda \frac{d E_{\mathrm{m}}}{d \mathbf{m}}=0
$$

Using equations (E.9) and (E.10), equation (E.12) becomes

$$
\mathbf{G}^{\mathrm{T}} \mathbf{C}_{\mathbf{d}}^{-1}(\mathbf{d}-\mathbf{G} \mathbf{m})-\lambda \mathbf{C}_{\mathbf{m}}^{-1}\left(\mathbf{m}-\mathbf{m}_{\mathbf{o}}\right)=0
$$

By rearranging the terms in equation (E.13), the model parameter $\mathbf{m}$ can be written as

$$
\mathbf{m}=\left(\mathbf{G}^{\mathrm{T}} \mathbf{C}_{\mathbf{d}}^{-1} \mathbf{G}+\lambda \mathbf{C}_{\mathbf{m}}^{-1}\right)^{-1}\left(\mathbf{G}^{\mathrm{T}} \mathbf{C}_{\mathbf{d}}^{-1} \mathbf{d}+\lambda \mathbf{C}_{\mathbf{m}}^{-1} \mathbf{m}_{\mathrm{o}}\right)
$$

However, finding the model parameter $\mathbf{m}$ in the form of equation (E.14) can be time consuming, since one needs to calculate the inverses of three matrices: $\mathbf{C}_{d}, \mathbf{C}_{m}$ and $\left(\mathbf{G}^{\mathrm{T}} \mathbf{C}_{\mathrm{d}}^{-1} \mathbf{G}+\lambda \mathbf{C}_{\mathrm{m}}^{-1}\right)$. The above equation can be simplified to a more numerically efficient form by using a matrix identity as described in Appendix F

$$
\mathbf{m}=\left(\mathbf{C}_{\mathbf{m}}-\mathbf{C}_{\mathbf{m}} \mathbf{G}^{\mathrm{T}} \mathbf{S}^{-1} \mathbf{G} \mathbf{C}_{\mathbf{m}}\right)\left(\lambda^{-1} \mathbf{G}^{\mathrm{T}} \mathbf{C}_{\mathbf{d}}^{-1} \mathbf{d}+\mathbf{C}_{\mathbf{m}}^{-1} \mathbf{m}_{\mathbf{o}}\right)
$$

where

$$
\mathbf{S}=\mathbf{C}_{\mathrm{d}}+\lambda \mathbf{G} \mathbf{C}_{\mathrm{m}} \mathbf{G}^{\mathrm{T}}
$$

By rearranging the terms in equation (E.15), we obtain

$$
\mathbf{m}=\mathbf{m}_{\mathrm{o}}+\lambda^{-1} \mathbf{C}_{\mathrm{m}} \mathbf{G}^{\mathrm{T}}\left(\mathbf{I}-\mathbf{S}^{-1} \mathbf{G} \mathbf{C}_{\mathrm{m}} \mathbf{G}^{\mathrm{T}}\right) \mathbf{C}_{\mathrm{d}}^{-1} \mathbf{d}-\mathbf{C}_{\mathrm{m}} \mathbf{G}^{\mathrm{T}} \mathbf{S}^{-1} \mathbf{G} \mathbf{m}_{\mathrm{o}}
$$

Equation (E.17) can be further simplied to 


$$
\mathbf{m}=\mathbf{m}_{\mathrm{o}}+\lambda^{-1} \mathbf{C}_{\mathbf{m}} \mathbf{G}^{\mathrm{T}} \mathbf{S}^{-1}\left(\mathbf{d}-\mathbf{G} \mathbf{m}_{\mathrm{o}}\right)
$$

The above equation (E.18) requires the inversion of an $n$ by $n$ matrix only once and is thus far less time consuming than equation (E.14). A set of new model parameters was found using equation (E.18) combined with sparse matrix algorithms.

\section{DATA}

The navigation and gravity data used in this study were obtained during a survey of the EPR near $9^{\circ} 30^{\prime} \mathrm{N}$ over a period of 21 days. The survey was conducted on board $R / N$ Thomas Washington operated by the Scripps Institution of Oceanography and had two primary objectives: to conduct a seismic tomography experiment near the axis in the central portion of the survey area $\left(9^{\circ} 30^{\prime}-9^{\circ} 40^{\prime} \mathrm{N}\right.$ and $\left.255^{\circ} 35^{\prime}-255^{\circ} 45^{\prime} \mathrm{E}\right)$, and to map the seafloor using Sea Beam and to measure gravity and total magnetic fields at the sea surface over the entire survey area $\left(9^{\circ} 08^{\prime}-9^{\circ} 50^{\prime} \mathrm{N}\right.$ and $\left.255^{\circ} 20^{\prime}-256^{\circ} 05^{\prime} \mathrm{E}\right)$.

The navigation during this survey was performed by Transit satellites and GPS. At the time of this survey, however, GPS satellites were not fully deployed and, as a result, GPS navigation was available for only 6-8 hours a day. Since seismic tomography experiments demand more precise information on a ship's position than gravity and magnetic surveys, most of the GPS navigation was used to conduct seismic tomography experiments.

The most up-to-date navigational information that we had was NAVLIST, processed onboard from information gathered from a variety of sources, including satellite fixes and doppler speed readings. NAVLIST served as the starting or a priori model in our

inversion and thus was sampled at 3-minute intervals to produce discrete model parameters consisting of pairs of latitude and longitude estimates. It is important to reduce the number of model parameters if possible. We excluded from the starting model the times when 
seismic tomography experiments were conducted because the GPS-based navigation was sufficiently accurate. Parts of the tracks where speed or course changes were made were also removed from the starting model. Figure E.1 shows a plot of remaining ship tracks that we used for the inversion. The cumulative time span of the data in the starting model is 240 hours, comprising $70 \%$ of the entire survey period.

Next, we determined a set of observations that the starting model must satisfy, as follows. First, we estimated crossover points on the basis of navigational information provided by NAVLIST and gridded each track in the vicinity of each point (Figure E.2). In this study, we used a grid of $5 \mathrm{~km}$ by $5 \mathrm{~km}$ with grid spacings of $100 \mathrm{~m}$ in both the latitudinal and longitudinal directions. Then by systematically shifting one of the gridded tracks relative to the other, we calculated the average misfit between the two tracks for each shift. The results can be represented on a two dimensional misfit distribution diagram as shown in Figure E.3; the minimum represents the best fit between the two tracks, and the vector from the center of the error surface to the minimum gives the amount of optimal shift for track 1 to match track 2 .

Assuming that a two-dimensional Gaussian error distribution $\left(\chi^{2}\right)$ is the proper measure for misfit distribution, we inverted for the best fitting ellipsoid. For a $\chi^{2}$ error distribution, the two dimensional parabolic error surface is [Hald, 1960],

$$
\chi^{2}=\frac{1}{1-\rho^{2}}\left[\frac{\left(\theta-\theta_{0}\right)^{2}}{\sigma_{\theta}^{2}}+\frac{\left(\phi-\phi_{0}\right)^{2}}{\sigma_{\phi}^{2}}-2 \rho \frac{\left(\theta-\theta_{0}\right)\left(\phi-\phi_{0}\right)}{\sigma_{\theta} \sigma_{\phi}}\right]+\sigma_{0}^{2}
$$

where

$$
\chi^{2}=\text { chi-squared error distribution }
$$

and the six parameters that describe the errors are

$$
\theta_{o}=\text { optimal shift in latitude }
$$$$
\phi_{o}=\text { optimal shift in longitude }
$$ 


$$
\begin{aligned}
& \sigma_{\theta}^{2}=\text { variance of error in latitude } \\
& \sigma_{\varphi}^{2}=\text { variance of error in longitude } \\
& \rho=\text { correlation coefficient of the errors in latitude and longitude } \\
& \sigma_{o}^{2}=\text { minimum variance of misfit. }
\end{aligned}
$$

The optimal shift point in latitude and longitude and the minimum variance, $\theta_{o}, \phi_{o}$ and $\sigma_{o}^{2}$, can be found directly from the error distribution. One must make sure, however, that they are not from local minima. The three remaining parameters, $\sigma_{\theta}^{2}, \sigma_{\phi}^{2}$ and $\rho$, can be estimated through a least square inversion of values of the error surface. Because most of the bathymetric features in our survey area strike parallel to the mid-ocean ridge axis, the variance of error tends to be greater in the latitudinal direction than in the longitudinal direction.

Once the parameters for the best fitting ellipsoid are found, it is possible to calcuate the new crossover times for both tracks, $\mathrm{t}_{1}{ }^{*}$ and $\mathrm{t}_{2}{ }^{*}$. The new times are when crossover occurred according to the comparison of Sea Beam swaths as opposed to the crossover times of starting model, $\mathrm{t}_{1}$ and $\mathrm{t}_{2}$. Therefore, the latitude and longitude of two tracks must be equal at times $\mathrm{t}_{1}{ }^{*}$ and $\mathrm{t}_{2}{ }^{*}$ (see equation E.7). The data covariance matrix $\mathbf{C}_{\mathrm{d}}$ can be constructed by using the standard deviation of the latitude misfit error $\left(\sigma_{\theta}\right)$ or the longitude misfit error $\left(\sigma_{\phi}\right)$ as its diagonal element.

The new crossover times should not necessarily match with the times that we used to sample the model parameters. With the addition of model parameters that correspond to the new crossover times, the total number of model parameter pairs became 5900. From 700 crossovers initially, we removed bad error surfaces, including those that contained multiple minima, poorly constrained error ellipsoids, and too large a minimum variance of misfits. A total 500 valid crossovers remained. 


\section{INVERSION RESULTS}

The inversion of navigation as formulated contains three free parameters: the a priori model variance $\sigma^{2}$, the correlation interval $\Delta$, and the trade-off coefficient $\lambda$ between fitting the data and remaining close to the initial model. Since reduction of Sea Beam misfit at crossovers is already imposed as a constraint in the inversion, we searched for the set of these parameters that best reduces free-air gravity misfit at crossovers. To do so, we performed a number of inversions of Sea Beam misfit by changing these parameters systematically. For each inversion, we estimated the ship's velocity and position and used them to calculate the misfits of free-air gravity anomaly at the points of crossover.

We assigned the same importance to fitting the data and remaining close to the starting model $(\lambda=1)$ and varied the a priori model variance $\sigma^{2}$ and the correlation interval $\Delta$. The results are summarized in Figure E. 4 in terms of the rms free-air gravity anomaly misfit. The figure shows that the minimum rms gravity misfit is obtained when $\Delta=4500 \mathrm{~s}$ and $\sigma$ $=3000 \mathrm{~m}$. The rms free-air gravity anomaly misfit in this case is $1.9 \mathrm{mGal}$. Since the rms free-air gravity anomaly misfit prior to the inversion was approximately $3.9 \mathrm{mGal}$, the navigation solution corresponds to a $75 \%$ reduction in the variance of gravity misfit. Considering that the accuracy of the gravimeter used in this study, BGM-3, is no better than 1-2 mGal [Bell and Watts, 1986], this reduction represents a reasonable improvement.

In addition to reducing the misfit of free-air gravity anomalies, a significant improvement in numerical efficiency was achieved by utilizing sparse forms of matrices for storage and calculation. In our case, where the number of model and data parameters are 5900 and 500, respectively, the amount of memory required to store the $\mathbf{C}_{m}, \mathbf{C}_{\mathrm{d}}$ and $\mathbf{S}$ matrices in full form would have been 280, 2 and 27 Mbyte in double precision, respectively. However, by using the sparse form, the sizes of these matrices were reduced to 8, 0.1 and 3 Mbyte, respectively. The computation time was also significantly reduced: 
for example, the right side of equation (E.18) took 170 hours in full form but took only 12 minutes in sparse form. 


\section{REFERENCES}

Bell, R. E., and A. B. Watts, Evaluation of the BGM-3 sea gravity meter system onboard R/V Conrad, Geophysics, 51, 1480-1493, 1986.

Eisenstat, S. C., M. H. Schultz, and A. H. Sherman, Algorithms and data structures for sparse symmetric Gaussian elimination, SIAM J. Sci. Statist. Comput., 2, 225-237, 1981.

George, A., and J. Liu, Computer Solution of Large Sparse Positive Definite Systems, Prentice-Hall, Englewood Cliffs, N.J., 1981.

Gilbert, J. R., C. Moler, and R. Schreiber, Sparse matrices in MATLAB: Design and implementation, SIAM J. Matrix Anal. Appl., 13, 333-356, 1992.

Hald, A., Statistical Theory with Engineering Applications, Wiley, New York, 1960.

Jackson, D. D., The use of a priori data to resolve non-uniqueness in linear inversion, Geophys. J. R. Astron. Soc., 57, 137-157, 1979.

Nishimura, C. E., and D. W. Forsyth, Improvements in navigation using SeaBeam crossing errors, Mar. Geophys. Res., 9, 333-352, 1988.

Prince, R. A., and D. W. Forsyth, A simple objective method for minimizing crossover errors in marine gravity data, Geophysics, 49, 1070-1083, 1984.

United Kingdom Atomic Energy Authority, Harwell Subroutine Library: A Catalogue of Subroutines, Tech. Report AERE R 9185, Harwell Laboratory, Oxfordshire, Great Britain, 1988.

Wilcock, W. S. D., D. R. Toomey, G. M. Purdy, and S. C. Solomon, The renavigation of Sea Beam bathymetric data between $9^{\circ} \mathrm{N}$ and $10^{\circ} \mathrm{N}$ on the East Pacific Rise, Mar. Geophys. Res., 15, 1-12, 1993. 
Figure E.1. Plot of ship tracks used in the inversion. These tracks represent our starting model and were cast in discrete form from the most up-to-date navigational information prior to the inversion. Most of the tracks shown here were navigated by Transit satellites. The Sea Beam swaths were gridded around the crossovers and then compared to find a better match. 


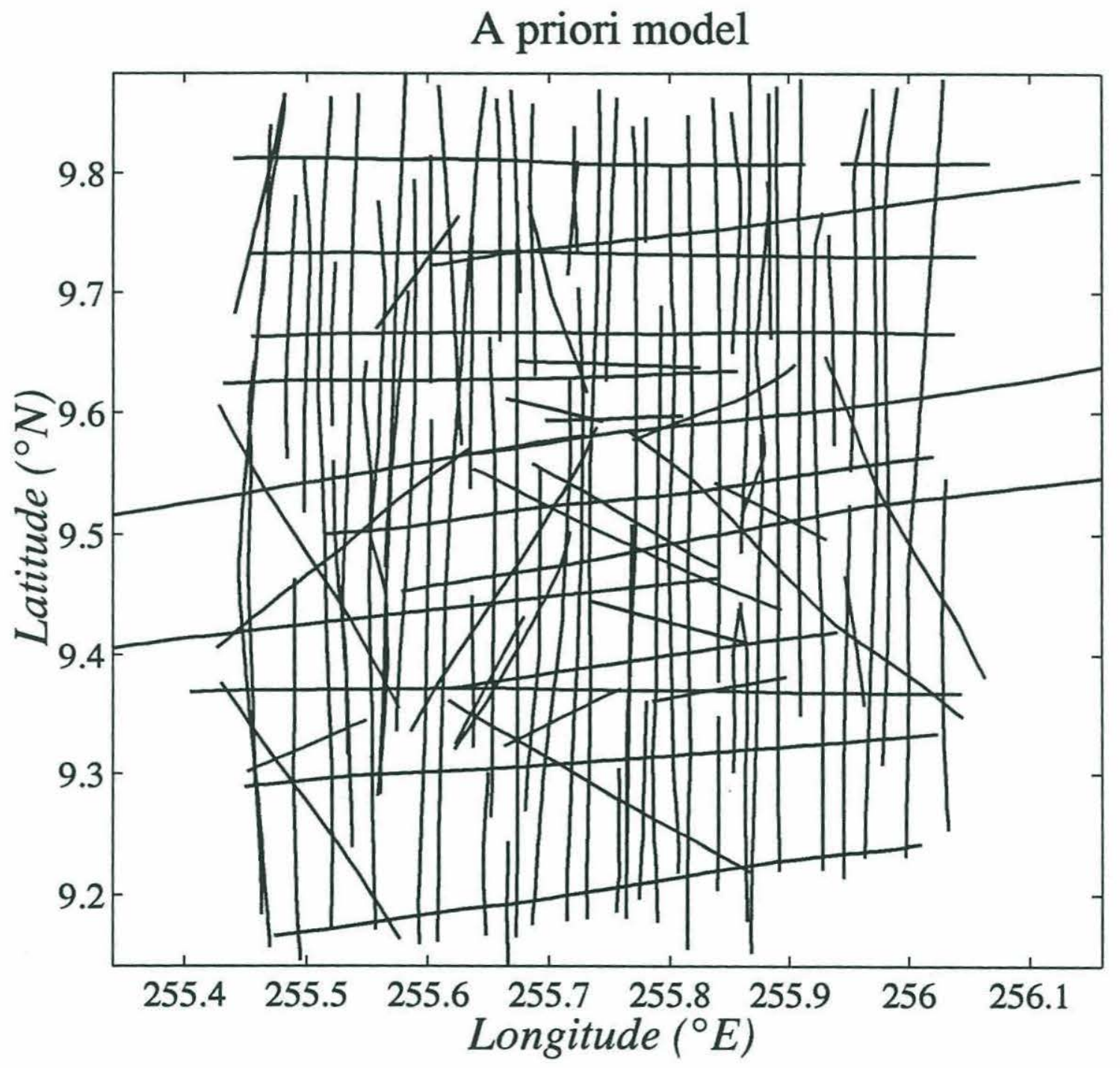


Figure E.2. Schematic illustration of two tracks at a crossover point. The shaded area represents the portions of the seafloor insonified by Sea Beam. The plus symbol represents the crossover point according to our starting model of navigation. To find a new crossover point, bathymetric data for each track are gridded around the crossover; the box represents the area of the gridded swaths. The gridded swaths are then compared against each other to find a better fit. The circle in this plot marks the place where a new crossover point was successfully identified. 
Sea Beam swaths at a crossover
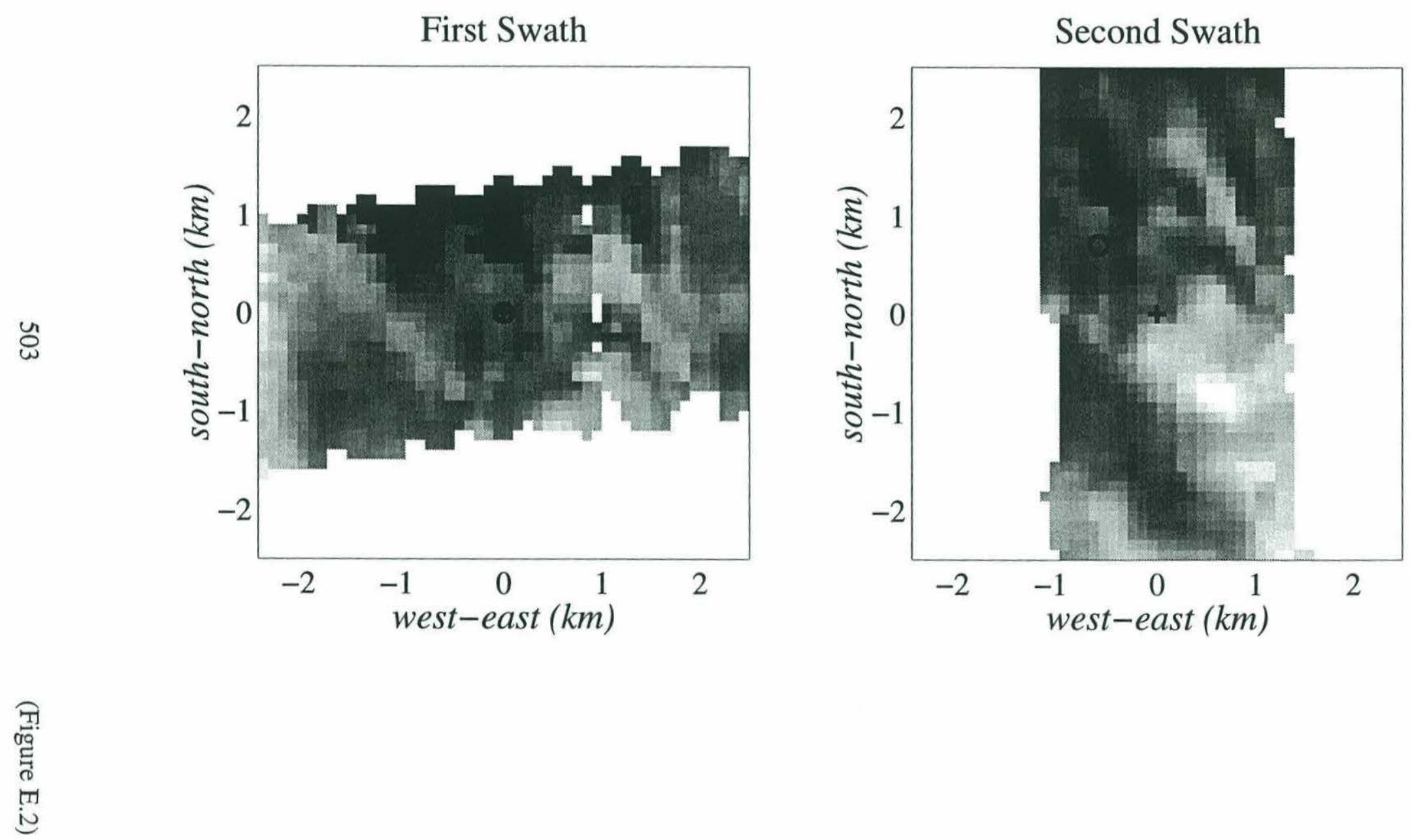
Figure E.3. Plot of a two dimensional misfit distribution map and an ellipsoid fit to it. The vertical and horizontal axes correspond to the amount of shift made by track 1 against track 2 in latitudinal and longitudinal directions, respectively. The vector corresponds to optimal shift to match the bathymetric features of tracks 1 and 2 . 

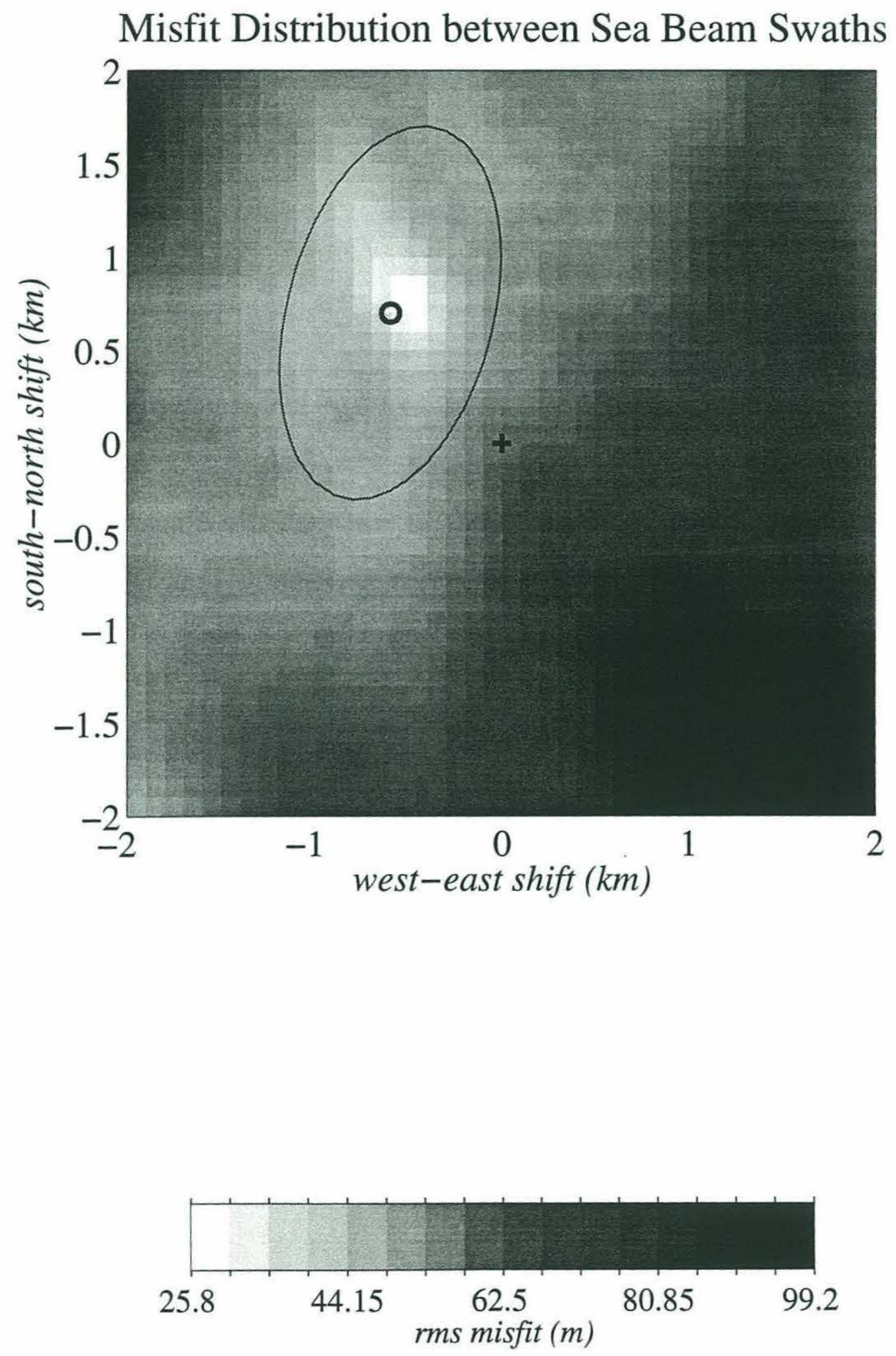
Figure E.4. Variation in the rms free-air gravity anomaly misfit as a function of a priori model uncertainty $\sigma$ and correlation interval $\Delta$. The same weight is given to fitting data and remaining close to the starting model $(\lambda=1)$. 

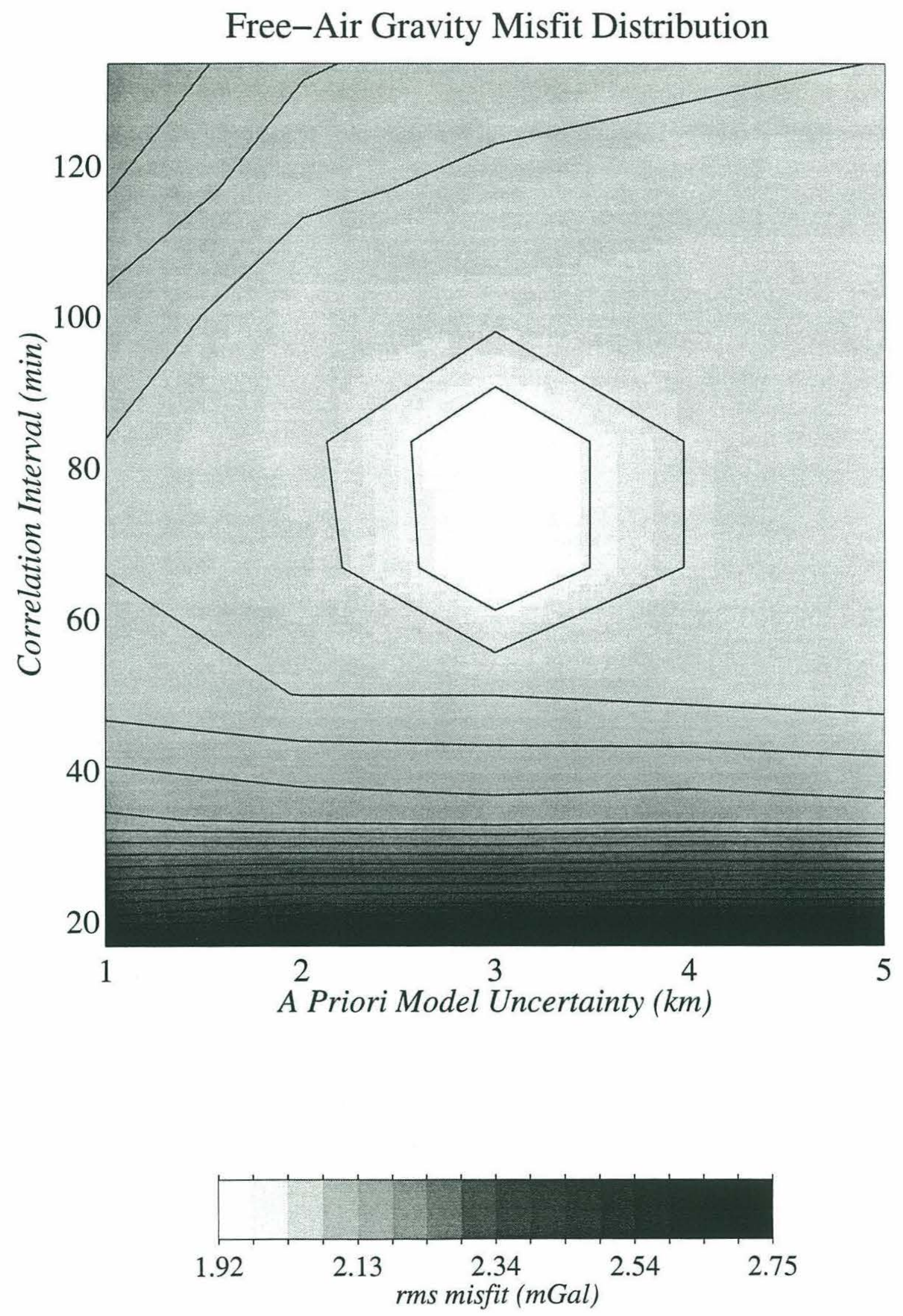


\section{APPENDIX F \\ Derivation of Matrices in Appendix E}

Assume that $\mathbf{C}_{1}$ and $\mathbf{C}_{2}$ are symmetric matrices whose inverses exist, $\mathbf{M}$ is a third matrix, and $\lambda$ is an arbitrary scalar. Let us consider the following expression:

$$
\lambda \mathbf{M}^{\mathrm{T}}+\mathbf{M}^{\mathrm{T}} \mathbf{C}_{1}^{-1} \mathbf{M ~ C}_{2} \mathbf{M}^{\mathrm{T}}
$$

A special case where $\lambda=1$ is given by Menke [1984, pp. 98]. However, the derivations for a general case where $\lambda$ is arbitrary are not so obvious and thus will be examined.

By grouping terms in the above expression in two different ways, we can establish the following relationship:

$$
\mathbf{M}^{\mathrm{T}} \mathbf{C}_{1}^{-1}\left(\lambda \mathbf{C}_{1}+\mathbf{M} \mathbf{C}_{2} \mathbf{M}^{\mathrm{T}}\right)=\left(\lambda \mathbf{C}_{2}^{-1}+\mathbf{M}^{\mathrm{T}} \mathbf{C}_{1}^{-1} \mathbf{M}\right) \mathbf{C}_{2} \mathbf{M}^{\mathrm{T}}
$$

By multiplying by the appropriate matrix inverses, (F.1) can also be written as:

$$
\mathbf{C}_{2} \mathbf{M}^{\mathrm{T}}\left(\lambda \mathbf{C}_{1}+\mathbf{M ~ C}_{2} \mathbf{M}^{\mathrm{T}}\right)^{-1}=\left(\lambda \mathbf{C}_{2}^{-1}+\mathbf{M}^{\mathrm{T}} \mathbf{C}_{1}^{-1} \mathbf{M}\right)^{-1} \mathbf{M}^{\mathrm{T}} \mathbf{C}_{1}^{-1}
$$

Now let us consider another matrix expression:

$$
\mathrm{C}_{2}-\mathrm{C}_{2} \mathbf{M}^{\mathrm{T}}\left(\lambda \mathrm{C}_{1}+\mathbf{M C}_{2} \mathbf{M}^{\mathrm{T}}\right)^{-1} \mathbf{M C}_{2}
$$


By using the matrix identity that we derived in (F.2), the above expression is equal to the following expressions:

$$
\begin{aligned}
& \mathbf{C}_{2}-\left(\lambda \mathbf{C}_{2}^{-1}+\mathbf{M}^{\mathrm{T}} \mathbf{C}_{1}^{-1} \mathbf{M}\right)^{-1} \mathbf{M}^{\mathrm{T}} \mathbf{C}_{1}^{-1} \mathbf{M} \mathbf{C}_{2} \\
= & \left(\lambda \mathbf{C}_{2}^{-1}+\mathbf{M}^{\mathrm{T}} \mathbf{C}_{1}^{-1} \mathbf{M}\right)^{-1}\left\{\left(\lambda \mathbf{C}_{2}^{-1}+\mathbf{M}^{\mathrm{T}} \mathbf{C}_{1}^{-1} \mathbf{M}\right) \mathbf{C}_{2}-\mathbf{M}^{\mathrm{T}} \mathbf{C}_{1}^{-1} \mathbf{M} \mathbf{C}_{2}\right\} \\
= & \lambda\left(\lambda \mathbf{C}_{2}^{-1}+\mathbf{M}^{\mathrm{T}} \mathbf{C}_{1}^{-1} \mathbf{M}\right)^{-1}
\end{aligned}
$$

Therefore, we conclude

$$
\left(\lambda \mathbf{C}_{2}^{-1}+\mathbf{M}^{\mathrm{T}} \mathbf{C}_{1}^{-1} \mathbf{M}\right)^{-1}=\lambda^{-1}\left\{\mathbf{C}_{2}+\mathbf{C}_{2} \mathbf{M}^{\mathrm{T}}\left(\lambda \mathbf{C}_{1}+\mathbf{M C}_{2} \mathbf{M}^{\mathrm{T}}\right)^{-1} \mathbf{M C}_{2}\right\} \text { (F.4) }
$$




\section{REFERENCES}

Menke, W., Geophysical Data Analysis: Discrete Inverse Theory, 260 pp., Academic Press, San Diego, 1984. 
